Irene Poczka

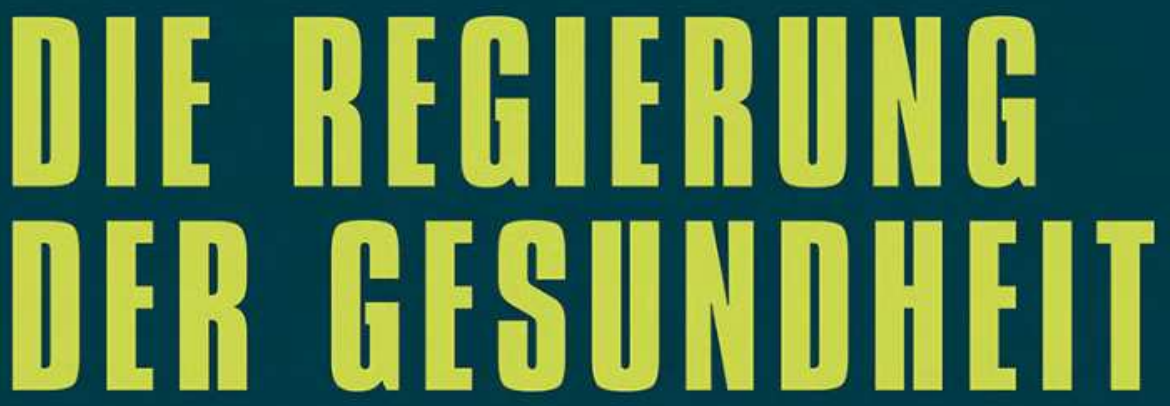

Fragmente einer Genealogie liberaler Gouvernementalität

[transcript] Edition Politik 
Irene Poczka

Die Regierung der Gesundheit

Edition Politik | Band 37 
Irene Poczka (Dr. phil.), geb. I98I, ist wissenschaftliche Mitarbeiterin an der Universität Tübingen und an einem Forschungsprojekt zu Präventions- und Bedrohungsdiskursen beteiligt. Ihre Forschungsschwerpunkte sind die europäische Gesundheitspolitik und Public Health in der Wissensgeschichte des I9. Jahrhundert und in der Zeitgeschichte sowie Michel Foucaults Diskurstheorie und -analyse. 
IRENE POCZKA

\section{Die Regierung der Gesundheit}

Fragmente einer Genealogie liberaler Gouvernementalität

[transcript] 
Dissertationsschrift der Freien Universität Berlin; Gutachter_innen: Frau Prof. Dr. Brigitte Kerchner (Berlin) und Prof. Dr. Matthias Bohlender (Osnabrück)

\section{Hans Böckler \\ Stiftung}

\section{(c) $\frac{1}{\mathrm{BY}}(\mathrm{NC}) \mathrm{ND}$}

Dieses Werk ist lizenziert unter der Creative Commons Attribution-NonCommercial-NoDerivs 4.० Lizenz (BY-NC-ND). Diese Lizenz erlaubt die private Nutzung, gestattet aber keine Bearbeitung und keine kommerzielle Nutzung. Weitere Informationen finden Sie unter https://creativecommons.org/licenses/by-nc-nd/4.o/deed.de/.

Um Genehmigungen für Adaptionen, Übersetzungen, Derivate oder Wiederverwendung zu kommerziellen Zwecken einzuholen, wenden Sie sich bitte an rights@ transcript-verlag.de

\section{(C) 2017 transcript Verlag, Bielefeld}

Die Verwertung der Texte und Bilder ist ohne Zustimmung des Verlages urheberrechtswidrig und strafbar. Das gilt auch für Vervielfältigungen, Übersetzungen, Mikroverfilmungen und für die Verarbeitung mit elektronischen Systemen.

\section{Bibliografische Information der Deutschen Nationalbibliothek}

Die Deutsche Nationalbibliothek verzeichnet diese Publikation in der Deutschen Nationalbibliografie; detaillierte bibliografische Daten sind im Internet über http:// dnb.d-nb.de abrufbar.

Umschlagkonzept: Kordula Röckenhaus, Bielefeld

Korrektorat \& Satz: Angelika Wulff, Witten

Druck: Majuskel Medienproduktion $\mathrm{GmbH}$, Wetzlar

Print-ISBN 978-3-8376-3695-6

PDF-ISBN 978-3-8394-3695-0

Gedruckt auf alterungsbeständigem Papier mit chlorfrei gebleichtem Zellstoff.

Besuchen Sie uns im Internet: http://www.transcript-verlag.de

Bitte fordern Sie unser Gesamtverzeichnis und andere Broschüren an unter: info@ transcript-verlag.de 


\section{Inhalt}

Vorwort | 7

Danksagung $\mid 8$

Einleitung | 9

Forschungsgeschichte | 14

Fragestellung | 17

Genealogie der Gouvernementalität | 18

Quellenauswahl | 26

Die Regierung von Gesundheit | 27

Regierungsrationalitäten der Gesundheit um 1800 | 33

Deutsche Staaten | 35

Frankreich | 96

Großbritannien | 152

Die Cholera als diskursives Ereignis 1829 - 1892 | 217

Das Wissen über die Cholera vor 1829 | 218

Die Cholera in Deutschland | 225

Die Cholera in Frankreich | 259

Die Cholera in Großbritannien | 304

Die Internationalen Gesundheitskonferenzen 1851 - 1903 | 359

Das Verhältnis von Wissen, Wissenschaft und Regierung | 362

Die Rationalisierung der Quarantäne | 379

Von der Abgrenzung zur Regierung des >Orients < | 394

Verallgemeinerung liberaler Gouvernementalität und Rationalität | 405

Schluss | 421

Gouvernementalisierung und liberale Regierung | 422

Ausblick | 434

Quellen und Literatur | 437

Quellen | 437

Literatur | 452 



\section{Vorwort}

Bei dem vorliegenden Buch handelt es sich um die stark gekürzte Fassung meiner mit magna cum laude abgeschlossenen Dissertation, die mit dem Titel: »Liberale Rationalitäten des Regierens in der Gesundheitspolitik - Geschichte und transnationale Zirkulation« am Fachbereich Politikwissenschaft der Freien Universität Berlin 2013 eingereicht wurde. Prof. Dr. Brigitte Kerchner (FU Berlin) und Prof. Dr. Matthias Bohlender (Universität Osnabrück) haben die Dissertation betreut und begutachtet.

Für die Politikwissenschaft bleiben historische Analysen in der Regel auf das Zeithistorische begrenzt. Tatsächlich zählten geschichtswissenschaftliche Methoden nicht zum Curriculum des Politik-Studiums am Otto-Suhr-Institut. Mein erstes Interesse an Genealogie und Diskursanalyse und damit schließlich auch mein Interesse an einem historischen Forschungsansatz habe ich Brigitte Kerchners und Silke Schneiders Seminaren über die Diskursanalyse Foucaults für die Politikwissenschaft zu verdanken.

Daran anschließend führte ich in meiner Abschlussarbeit eine Analyse von WHO-Jahresberichten zwischen 1948 und 2006 durch. Ein halbes Jahr nach Abschluss meines Politikstudiums im Dezember 2007 entschloss ich mich, einen Antrag auf ein Promotionsstipendium bei der Hans-Böckler-Stiftung einzureichen. Im Rahmen einer Dissertation wollte ich weiter nach den historischen Entstehungsbedingungen der von mir für das 20. Jahrhundert herausgearbeiteten Rationalitäten in der Gesundheitspolitik forschen. Ab April 2009 konnte ich schließlich nach der Bewilligung des Stipendiums mit der intensiveren Arbeit an der Dissertation beginnen.

Leider haben eine Reihe von Gründen die Veröffentlichung der Arbeit verzögert, so dass sie nun erst vier Jahre nach der Disputation erscheint. Zu den guten Gründen zählt, dass ich direkt im Anschluss an meine Disputation begann, als wissenschaftliche Mitarbeiterin an einem Forschungsprojekt am Institut für Ethik und Geschichte der Medizin an der Eberhard-Karls-Universität in Tübingen zu arbeiten. Dort bin ich bis heute tätig. Des Weiteren habe ich seit 2006 die Mitelternschaft für die Tochter einer Freundin übernommen. Und schließlich hat mich die Geburt meiner (2.) Tochter im Oktober 2014 und das Leben mit ihr täglich auf wunderbarste Weise vom Arbeiten abgehalten und damit auch zu der weiteren Verzögerung der Veröffentlichung beigetragen. 


\section{DANKSAGUNG}

Ich möchte an dieser Stelle allen meinen Freund_innen, Mitstreiter_innen und meiner Familie danken, die mich während meiner Arbeit an der Dissertation und während der langen und zähen Phase der Kürzung, Überarbeitung und Publikation durch ihre Zuneigung, Sorgearbeit und Diskussionen inspiriert und unterstützt haben. Sie haben mich daran erinnert, dass Wissenschaft ein kollektiver Prozess sein sollte und mich immer wieder aus meinem vereinzelten Autorinnendasein herausgeholt. Insbesondere danken möchte ich Florian, Johanna, Cornelia, Anna, Rosa und meiner Lektorin Angelika Wulff, die den Text in den verschiedenen Fassungen Korrektur gelesen und mit meiner chaotischen Arbeitsweise Nachsicht gezeigt haben.

Ich danke auch der Hans-Böckler-Stiftung für die Finanzierung meiner Promotion im Rahmen des Stipendiums und meinen Betreuer_innen für den wissenschaftlichen Austausch. Besonders aber danke ich Brigitte Kerchner dafür, mein Interesse an Foucault geweckt und mich die Diskursanalyse gelehrt zu haben.

Ich danke meinen Kindern Lia und Laura dafür, dass sie mich daran erinnert haben, was wirklich wichtig ist.

Berlin, 2017 


\section{Einleitung}

»Ich wollte die Regierung studieren, d.h. die reflektierte Weise, wie man am besten regiert, und zugleich auch das Nachdenken über die bestmögliche Regierungsweise. [...] Kurz gesagt, es handelt sich um die Untersuchung der Rationalisierung der Regierungspraxis bei der Ausübung der politischen Souveränität.«1

»Die Rationalität zu überprüfen, die unseren Wahlentscheidungen in Sachen Gesundheit zugrunde liegt, ist in der Tat eine Aufgabe, der man sich entschieden zuwenden müsste. $\ll^{2}$

Die Politikwissenschaft, aus der ich komme, ist eine Wissenschaft der Gegenwart. In ihren Versuchen, zukünftige Entwicklungen zu prognostizieren, ist sie weitestgehend gescheitert. Bestenfalls kann sie zeitgeschichtliche Ereignisse der jüngeren Vergangenheit berücksichtigen. Selbstverständlich hat auch die verhältnismäßig junge Politikwissenschaft eine Geschichte ihrer Ideen, eine Tradition bereitgestellt, die sie selbst legitimiert. Doch für die meisten Gegenstände, mit denen sie sich befasst, scheint eine Geschichte nicht zu existieren. Dies gilt auch für den Gegenstand der Gesundheitspolitik.

Dagegen hat besonders die jüngste Geschichte verdeutlicht, dass Medizin und Gesundheitsversorgung sehr wandelbare Bereiche sozialer Praxis sind. In den vergangenen zwanzig Jahren haben eine Reihe von Zeithistorikern und Sozialwissenschaftlern den Wandel in der Gesundheitsversorgung und der gesellschaftlichen Perspektive im Zusammenhang mit einem umfassenden neoliberalen Wandel in Verbindung gebracht. Diese Entwicklung ist von dem Widerspruch gekennzeichnet, dass sich der Staat aus immer weiteren Teilen der Gesundheitsversorgung zurückzieht, während das Problem der Gesundheit und medizinisches Denken immer tiefer und in alle möglichen Bereiche unseres alltäglichen Lebens hineindiffundiert.

1 Foucault: Geschichte der Gouvernementalität II, 2004 [1978 - 1979]: S. 14.

2 Foucault: Ein endliches System angesichts einer unendlichen Nachfrage, 2005 [1983]: S. 456 . 
Diese paradoxe Situation hat mich dazu bewogen, nach der historischen Entstehung von Rationalitäten und Universalien zu fragen, die uns heute in der Gesundheitspolitik aber auch in unserem persönlichen Umgang mit Gesundheit selbstverständlich, veraltet oder völlig neu erscheinen. Aus der Politikwissenschaft kommend schien es mir unüblich, aber vielleicht gerade deshalb an der Zeit, einen anderen als den klassischen ideengeschichtlichen oder zeithistorisch begrenzten Zugang für die Untersuchung der Geschichte politischer und sozialer Rationalität im Umgang mit Gesundheit zu wählen.

Das vorliegende Buch ist also der Versuch, historische Zeiträume und Fragmente, die unsere aktuellen Rationalitäten im Umgang mit Gesundheit seit dem ausgehenden 19. Jahrhundert geprägt haben, diskursgeschichtlich und am Beispiel dreier Länder die deutschen Staaten, Frankreich und Großbritannien, zu untersuchen. Wer daher eine Geschichte der Gesundheitspolitik im eher klassischen Sinne sucht, die sich ausgehend von den Gesetzen, Institutionen und bekannten Personen entfaltet, wird hier nicht fündig werden. Ausgehend von Michel Foucault ist das Ziel der von mir nachgezeichneten Herkunftsgeschichte aufzuzeigen, dass verstreute Kämpfe und Konflikte, Initiativen und Strategien verschiedener Akteure und Gruppen die Idee und die Praxis der Regierung der Gesundheit von Menschen geformt haben. Schließlich soll diese Perspektive die moderne Regierung der Gesundheit - auch in ihren aktuellen Neuerungen - als Erbin vergangener Diskurse in ein neues Licht rücken.

Möglicherweise können aktuelle Entwicklungen hierdurch einer alternativen Bewertung unterzogen werden. Der jüngste Wandel im Bereich der Gesundheitspolitik und der Organisation der Versorgung von Kranken und Pflegebedürftigen wird derzeit als Folge eines umfassenden sozialen Strukturwandels der vergangenen 40 Jahre gewertet. Zeithistoriker wie Doering-Manteuffel und Raphael sprechen diesem sogar eine revolutionäre Qualität zu. ${ }^{3}$ Gegenüber staatlichen Steuerungsformen des Fordismus rücken Wettbewerbselemente und marktorientierte Regulierungsmechanismen in den Vordergrund. Dies zeigt sich nicht zuletzt in der Sprache: Es geht um Management, Effizienz, Rationalisierung, Profit, Ärzte als Dienstleister und Patienten als Kunden. ${ }^{4}$ Angebotsorientierte Konzepte in der Wirtschaftspolitik und Sparprogramme bilden das Pendant zu einer krisenhaften und immer stärker finanzialisierten globalen kapitalistischen Ökonomie. Ihre Auswirkungen auf die Organisations- und Finanzierungskonzepte in der Gesundheitsversorgung sind vor allem nach der Krise von 2008 noch deutlicher zu spüren und sowohl medial als auch wissenschaftlich aufbereitet worden. Mit dem Verweis auf die Kostenexplosion im Gesundheitswesen, die in der Regel ohne besondere Nachweispflicht schlicht auf einen demografischen Wandel und den unaufhaltsamen medizinisch-technischen Fortschritt zurückgeführt werden darf, wurden in den letzten Jahrzehnten tatsächlich in vielen europäischen Staaten, u.a. in Frankreich, Großbritannien, den Niederlanden, Österreich und Deutschland Reformen der Gesundheitssysteme eingeleitet.

3 Vgl. Doering-Manteuffel/Raphael: Nach dem Boom, 2008: S. 13.

4 Vgl. Stuckler/Basu: Sparprogramme töten, 2014: S. 9. Vgl. Sablowski: Die jüngste Weltwirtschaftskrise und die Krisentheorien, 2011: S. 39ff. Vgl. Vereinigung zur Kritik der Politischen Ökonomie/Altvater: Editorial: Gesundheit im Neoliberalismus, 2003: S. 361. 
Jenseits dieser Entwicklung der Ökonomisierung der Medizin stellen einige Autoren einen seit Jahrzehnten sich allmählich vollziehenden kulturellen und WerteWandel fest. ${ }^{5} \mathrm{Ob}$ in der alltäglichen Selbstsorge oder hinsichtlich der Familien-, Lebens- und Karriereplanungen: Es dominieren zunehmend ökonomische Denkmuster, lautet hier die Feststellung. Auch sie werden als Merkmal eines Strukturbruchs oder zumindest eines qualitativen Wandels hin zu einer modernen Risikogesellschaft interpretiert, deren Mitglieder, wie Ulrich Beck und Zygmunt Baumann diagnostizieren, mit neuen Freiheiten, aber auch mit Individualisierungs- und Verunsicherungstendenzen umgehen müssen: ${ }^{6} \gg$ Healthy choices are complex within a >risk society< where unknown and unexpected risks emerge . $^{7}$

Im Zuge dieses konstatierten Wandels - erkennbar auch an der Verschiebung hin zur Gesundheitsförderung -, scheint sich der Gegenstand der Gesundheitsregierung (im foucaultschen Sinne) und das Spektrum von Techniken sichtbar verändert und vor allem auch enorm erweitert zu haben. ${ }^{8}$ Nahezu alles, was man tut oder nicht tut, oder was eine Regierung tut oder nicht tut, hat Auswirkungen auf die Gesundheit dies gilt sowohl für den Bereich der >Selbstregierung < als auch für die Ebene der Politik. $^{9}$

Trotz der konstatierten Wiedererstarkung liberaler Paradigmen in der Politik ist die Regierung der Gesundheit, die beim Kranken ebenso wie beim Gesunden ihre Ansatzpunkte findet, heute umfassender als je zuvor. Es stellt sich die Frage, wie ein solches $>$ Mehr $<$ an Regierung bei gleichzeitigem Rückzug staatlicher Eingriffe und Verantwortlichkeiten im Bereich der Gesundheitsversorgung und angesichts der betonten Wichtigkeit von Autonomie und Selbstbestimmung ${ }^{10}$ hinsichtlich der eigenen Gesundheit erklärt werden kann. Neben den jüngsten Debatten um eine neoliberale Neukonfiguration der Regierung von Gesundheit hat mich diese Frage motiviert, nach den historischen Entstehungs- und Existenzbedingungen der wirkenden liberalen Rationalität zu suchen.

Mit der Gouvernementalität stellt uns Foucault einen Begriff von Regierung vor, der sich vielen klassischen und in der Politikwissenschaft etablierten Bestimmungen von z.B. staatsbezogener politischer Herrschaft, von Staatlichkeit und Öffentlichkeit

5 Vgl. Doering-Manteuffel/Raphael: Nach dem Boom, 2008: S. 78ff. Vgl. auch die Beiträge in Dietz/Neumaier/Rödder: Gab es den Wertewandel?, 2014.

6 Vgl. Beck/Beck-Gernsheim, Riskante Freiheiten, 1994: S. 115ff. Vgl. Bauman, Flüchtige Moderne, 2003.

7 Kickbusch, Health Governance: The Health Society, 2007: S. 161.

8 Vgl. McQueen/Kickbusch, Introduction. Health Promotion: The Origins of the Third Public Health Revolution Leading to a New Public Health, 2007: S. 4. Vgl. Schmidt-Semisch/ Paul: Risiko Gesundheit. Eine Einführung, 2010: S. 7. Vgl. Koppelin/Müller: Gesundheit und Krankheit in »biopolitischen Zeiten«, 2010: S. 78f. Vgl. Baumann: Flüchtige Moderne, 2003: S. $95 f$.

9 Vgl. Beck-Gernsheim, Gesundheit und Verantwortung im Zeitalter der Gentechnologie, 1994: S. 322.

10 Vgl. Ottawa Charta zur Gesundheitsförderung, 1986. 
entzieht. ${ }^{11}$ Foucault wollte mit dieser Wortneuschöpfung keinen neuen theoretischen Begriff einführen. Er suchte ein Analyseraster. Regierung sollte einen erweiterten Bereich von Macht-Beziehungen, Institutionen, Reflexionen und Techniken bezeichnen, durch welchen Menschen unter Bezug auf eine spezifische, historisch oft umkämpfte Rationalität in ihrem Verhalten geführt oder geleitet werden. ${ }^{12}$ Foucault kam $\mathrm{zu}$ dem Ergebnis, dass sich historische Formen der Regierung voneinander unterschieden. Im 18. Jahrhundert bildete sich eine neue Form der Regierung heraus, die Foucault in verschiedenen Abschnitten seiner Forschung als Biomacht, als moderne Regierung und Gouvernementalität oder schließlich als liberale Gouvernementalität bezeichnet hat. Mit dem Aufkommen dieses neuen Regierungstyps ging ein umfassender sozialer Wandel einher. Die Aufgabe der Regierung, den Staat als ganzes zu erhalten und zu stärken, bezog sich nicht mehr vorrangig auf den Staat und seine politisch-rechtliche Existenz. Ziel jeden Regierens sollte es nun sein, die Bevölkerung, die Ökonomie, das Leben, also die inneren und biologisch-materiellen Bedingungen der Existenz eines Staates, oder einer Gesellschaft zu regulieren. ${ }^{13}$ Gleichzeitig wurden die auf das Individuum bezogenen Techniken der Regierung, die im Bereich der ärztlichen, religiösen oder pädagogischen Führung schon lange eine Rolle gespielt hatten, in diese neue Regierungsform integriert.

Foucaults Thesen zur Gouvernementalität eröffnen die Möglichkeit, aktuelle Machtwirkungen moderner Regierungsformen unter einer erweiterten Perspektive vertiefend zu betrachten. ${ }^{14}$ Die vornehmlich »soziologisch interessierten $«{ }^{15}$ Governmentality Studies und die deutsche Gouvernementalitätsforschung ${ }^{16}$ greifen den Ansatz Michel Foucaults für die Analyse und auch Kritik aktueller neoliberaler Transformationen und Zusammenhänge zwischen neoliberaler Umstrukturierung, Subjektivierung von sozialen und ökonomischen Risiken auch im Bereich der Medizin und Gesundheitsvorstellungen auf. ${ }^{17}$ Einzelne Teilbereiche, wie Biotechnologie, Gentechnik, Hirnforschung und Fortpflanzungsmedizin gehören $\mathrm{zu}$ den thematischen

11 Vgl. Kerchner: Wirklich Gegendenken. Politik analysieren mit Michel Foucault, 2006: S. 152.

12 Vgl. Foucault: Geschichte der Gouvernementalität II, 2004 [1978 - 1979]: S. 261.

13 Foucault: Die Maschen der Macht, 2005 [1981]: S. 236.

14 Vgl. ebd.: S. 159.

15 Kerchner: Wirklich Gegendenken. Politik analysieren mit Michel Foucault, 2006: S. 153.

16 Vgl. Bröckling/Lemke/Krasmann: Gouvernementalität, Neoliberalismus und Selbsttechnologien, 2000: S. 7. Dieser hier zuerst auf deutsch veröffentlichte Aufsatz von Michel Foucault stellte vor Übersetzung und Veröffentlichung seiner Vorlesungen zur Geschichte der Gouvernementalität den wichtigsten Bezugspunkt der größtenteils erst zu Beginn der 90er Jahre entstandene Forschungszusammenhangs dar. Vgl. auch Ziai: Gouvernementalität, 2003: S. 409.

17 Siehe z.B.: Gehring: Was ist Biomacht?, 2006; Greco: Homo Vacuus. Alexithymie und das neoliberale Gebot des Selbstseins, 2000; Schmidt-Semisch: Selber schuld - Skizzen versicherungsmathematischer Gerechtigkeit, 2000; und Vgl. Lemke: Die Regierung von Risiken, 2000. 
Schwerpunkten. ${ }^{18}$ Bei der starken Konzentration auf die Gouvernementalität der Gegenwart bleiben Fragen über die Dimensionen der historischen und diskursiven Herausbildung der auch heute noch wirksamen Regierungsrationalitäten allerdings kaum genauer berücksichtigt. ${ }^{19}$

Die historische Analyse der Gouvernementalität mithilfe der von Foucault entwickelten genealogischen Methode hingegen erlaubt es, Technologien und Rationalitäten des Regierens, die heute noch - oder wieder - wirkungsmächtig sind, zu historisieren und von ihrem Auftauchen und ihrer Ausbreitung aus kritisch zu untersuchen. Die Genealogie untersucht historische Diskurse nach den Bedingungen und Konflikten, die das Auftauchen eines neuen Gegenstands oder Problems bedingt haben. Die Genealogie unterscheidet sich aber von einer Suche nach dem Ursprung. Denn der Begriff des Ursprungs legt die Entstehung aus einer einzigen Quelle nahe, die selbst außerhalb der Geschichte oder ihr vorgeordnet liegen kann. Der Ursprung passt zu einem essentialistischen Modell, dass versucht, die Existenz eines Gegenstands oder ein Phänomen aus ihm abzuleiten. Der Ursprung unterstellt eine Kontinuität. Dagegen fragt die Genealogie nach dem komplexen Zusammenwirken einer Vielzahl von alten und neuen Bedingungen und wenig planvollen Ereignissen, die zu der Entstehung eines neuen Gegenstandes führen. Anstatt zu fragen, wo der Fluss entspringt, forscht sie eher nach dem Klima und der ganzen Landschaft, die eine Vielzahl kleinerer Flüsschen durchflossen hat, um sich schließlich zu verbinden und wieder zu trennen, und die zu einem Zeitpunkt an einem Ort den Fluss ausmachen. Damit unterscheidet sich die Genealogie auch von aktuellen Vorschlägen, eine Geschichte der Gesundheitspolitik oder der öffentlichen Gesundheit zu schreiben.

Dass in der Politikwissenschaft und vor allem in der Governanceforschung seit einigen Jahrzehnten wieder verstärkt Interesse an der Geschichte der öffentlichen Gesundheit besteht, zeigt sich etwa an der Wiederentdeckung der sog. (old) public health als interdisziplinäres wissenschaftliches Forschungs-, Praxis- und Politikfeld. Im Unterschied zur genealogischen Perspektive scheint mir dieser Forschungszweig allerdings in erster Linie auf die Funktion erpicht zu sein, Wissen für ein >besseres Regieren $<\mathrm{zu}$ generieren. ${ }^{20}$

18 Vgl. Bröckling/Lemke/Krasmann: Gouvernementalität, Neoliberalismus und Selbsttechnologien, 2000: S. 7f. Siehe auch Krasmann: Die Kriminalität der Gesellschaft, 2003. Beispiele aus dem deutschen Forschungskontext liefern außerdem die Arbeiten von Henning Schmidt-Semisch, Monika Greko, Susanne Krasmann und Thomas Lemke: in: Bröckling/ Lemke/Krasmann (Hrsg.): Gouvernementalität der Gegenwart, 2000.

19 Vgl. hierzu die Kritik von Sarasin: Michel Foucault zur Einführung, 2005: S. 180f. Vgl. Kerchner: Wirklich Gegendenken. Politik analysieren mit Michel Foucault, 2006: S. 153; Vgl. Bröckling/Lemke/Krasmann: Gouvernementalität, Neoliberalismus und Selbsttechnologien, 2000: S. 17ff.

20 Vgl. Hurrelmann/Razum, Handbuch Gesundheitswissenschaften, 2012: S. 7. 


\section{FORSCHUNGSGESCHICHTE}

Nachdem George Rosens 1958 erschienene History of Public Health lange Zeit als einziges vergleichbares Standardwerk einer länder- und epochenübergreifenden Geschichte der Medizin und der öffentlichen Gesundheit in Europa und den USA galt ${ }^{21}$, hatten, nach Aussage von Elizabeth Fee und Theodore Brown, in den 1990er Jahren eine Reihe von Erkenntnissen und Lernprozessen dazu beigetragen, die Betrachtung der jüngeren Geschichte der internationalen öffentlichen Gesundheit in den Fokus aktueller wirtschafts- und sozialwissenschaftlicher Fragestellungen zu rücken. ${ }^{22}$ Die Geschichte wurde mit anderen Worten wieder entdeckt, als ein Instrument, um den historischen sozio-ökonomischen Wandel und dessen Auswirkungen auf die Gesundheitspolitik, der seit den 1970er Jahren deutlich geworden war, historisch zu legitimieren. ${ }^{23}$ Als Rosen seine History of Public Health Ende der 1950er Jahre veröffentlichte, läutete er gemeinsam mit anderen Autoren seiner Zeit einen zähen Wandel in der Interpretation der Geschichte der Medizin und öffentlichen Gesundheit ein. Bis in die 1950er Jahre hatte die eher administrative Dokumentation der Geschichte der öffentlichen Gesundheit noch relativ ungebrochen an das 19. Jahrhundert angeknüpft. ${ }^{24}$ Rosen wies die traditionelle positivistische Darstellung der Geschichte des wissenschaftlichen Fortschritts medizinischer Methoden, Erkenntnisse und Praktiken zurück und stärkte eine breiter gefasste soziale Auffassung von öffentlicher Gesundheit. ${ }^{25}$ Nichtsdestotrotz erzählt auch er eine Fortschrittsgeschichte, zwar nicht der Medizin, sondern der Public Health. ${ }^{26}$ Rosens >Hinwendung « zur Geschichte der Gesundheit der Bevölkerungen und Gesellschaften ${ }^{27}$ zeugen von den klassischen Mythen der Public Health als Gegenmodell zu staatlichen und repressiven Gesundheitspolitiken. Während die historischen Bedingungen der Verwirklichung der öffentlichen Gesundheit variierten, sah Rosen ihre Ziele weiterhin als universell und jenseits dieser historischen Bedingungen. Elizabeth Fee nahm 1993 Rosens Perspektive auf. ${ }^{28}$ Einige Jahre später machten Michael H. Merson et al., Whaley et al. und andere Autoren Rosens Arbeit für das aktuelle Konzept der International Public Health fruchtbar. ${ }^{29}$

Der kritische Gehalt ihrer Formulierung der Public Health als Gegenmodell zur Macht der Medizin lässt sich heute aber bezweifeln. Denn mit dem neuen Bezug auf das Public-Health-Konzept werden die aktuellen Auseinandersetzungen um globales

21 Vgl. Rosen: A History of Public Health, 1993 [1958]: S. 4.

22 Vgl. Brown/Fee: Editorials, American Journal of Public Health, 2004: S. 1852f.

23 Vgl. Trojan/Legewie: Nachhaltige Gesundheit und Entwicklung, 2000: S. 28.

24 Vgl. Porter, Health, Civilization, and the State, 1999: S. 1f.

25 Vgl. Fee: Introduction - Public Health, Past and Present, 1993: S. x.

26 Vgl. Porter, Health, Civilization, and the State, 1999: S. 1f.

27 Vgl. ebd.: S. xxxviii.

28 Vgl. ebd.: S. xi.

29 Vgl. Fee: Introduction - Public Health, Past and Present, 1993: S. xxxviii. Vgl. Merson/ Black/Mills: International Public Health - Diseases, Programs, Systems, and Policies, 2001: S. xvii. Vgl. Whaley/Hashim: Textbook on world health, 1995: S. 187f; 190. Vgl. Rosen: A History of Public Health, 1993 [1958]: S. 4. 
Regieren von Gesundheit weiterhin in eine angeblich bestehende jahrhundertealte Tradition liberaler, demokratischer Bestrebungen und sozialer Kämpfe gegen die staatliche Reglementierung bzw. polizeiliche Kontrolle von Gesundheit gestellt. Eine solche Darstellung schließt eine kritische Reflexion liberaler Regierungslogik von vornherein aus. ${ }^{30}$ Das Problem eines tatsächlichen $>$ Mehr $<$ an Regierung wird hier nicht reflektiert.

Dabei gibt es Hinweise dafür, dass es gerade die Entstehung und transnationale Ausweitung der liberalen Rationalität ist, die erst zu einer so enormen Dehnung des Zugriffsrahmens und der Macht der Regierung von Gesundheit geführt hat.

Indem ich dies analysiere, knüpfe ich an aktuellere kritische und dezidiert historisch-rekonstruierende Arbeiten zur Geschichte öffentlicher Gesundheit an. Viele dieser historiographischen Untersuchungen befassen sich mit einzelnen Teilbereichen der öffentlichen Gesundheit oder konzentrieren sich eher auf die Geschichte der Berufsgruppe der Ärzte oder die Rolle der Medizin. Meist ist Gesundheitspolitik in enger gesetzten historischen Zeitrahmen nur auf einzelne Länder bezogen oder speziell in seiner globalen Dimension Forschungsgegenstand. Dabei nehmen Autoren auch Bezug auf den staatswissenschaftlichen und politisch-philosophischen Kontext in den einzelnen Ländern.

Für meinen ersten Untersuchungszeitraum um 1800 waren die Arbeiten von Matthew Ramsey, Gérard Jorland, Roy und Dorothy Porter, Mark Harrison und Andrew Aisenberg besonders hilfreich. ${ }^{31}$ Alle diese Autoren haben ihre besondere Aufmerksamkeit auf den Wandel der Machtbeziehungen zwischen Ärzten, Patienten unterschiedlichen sozialer Gruppen und dem Staat gelegt. Damit haben sie aus meiner Perspektive auch die Neuverteilung der auf die Gesundheit gerichteten Regierungsmacht mit beobachtet. Ihre Forschungen stellen daher auch immer wieder Verknüpfungen zwischen dem Wandel der Medizin und der Gesundheitspolitik und größeren politischen und philosophischen Diskursen in ihren Untersuchungszeiträumen her. Zusätzlich existiert eine Reihe von Forschungen, die sich mit dieser auf Macht und Diskurse gerichteten Perspektive speziell mit dem Umgang mit der Cholera in Deutschland, Frankreich und Großbritannien beschäftigt haben. Peter Baldwin, Barbara Dettke und Catherine Kudlick ${ }^{32}$ waren an dieser Stelle eine große Hilfe. Die weniger umfangreiche Literatur zu den Internationalen Gesundheitskonferenzen, den Conférences Sanitaire International (CSI) des 19. Jahrhunderts lässt sich im Wesentlichen zwei verschiedenen Forschungsperspektiven zuordnen, einer eher wissenschaftshistorischen und einer politikwissenschaftlichen. Dennoch interessieren sich so gut wie alle Autoren für die Frage, warum die CSIs im 19. Jahrhundert so lange >erfolglos< blieben. Die eher medizinhistorische Perspektive richtet sich auf die divergierenden wissenschaftlichen Strömungen und Positionen bezüglich der Über-

30 Vgl. Fee: Introduction - Public Health, Past and Present, 1993: S. xxxviii.

31 Vgl. Aisenberg: Contagion. Disease, Government, 1999. Vgl. Harrison: Disease and Modern World, 2004. Vgl. Jorland: Une société à soigner, 2010. Vgl. Porter, D.: The History of Public Health and the Modern State, 1994. Vgl. Porter, R.: The patient in England, 1992. Vgl. Ramsey: Professional and popular medicine in France, 1988.

32 Vgl. Baldwin: Contagion and the State in Europe 1830 - 1930, 1999. Vgl. Dettke: Die asiatische Hydra, 1995. Vgl. Kudlick: Cholera in Post-Revolutionary Paris, 1996. 
tragbarkeit epidemischer Krankheiten, wie Pest, Gelbfieber und vor allem Cholera. ${ }^{33}$ Aus einer eher politikwissenschaftlichen, sozialhistorischen Sicht lassen sich die CSIs unter dem Gesichtspunkt der im 19. Jahrhundert noch sehr neuen Praxis zwischenstaatlicher Verhandlungen mit dem Ziel des Abschlusses multilateraler Verträge betrachten. Es existierte weder eine effiziente Praxis der Verhandlung und Erstellung von Verträgen noch hatten die Regierungen einen geübten Umgang oder Erfahrungen mit internationalen Verträgen zu solchen Themen. Diese Hindernisse werden von politikwissenschaftlicher Seite als Gründe für die Ergebnislosigkeit der Konferenzen angesehen. ${ }^{34}$ Nur wenige Forschungen haben versucht, empirisch anhand der Verhandlungsprotokolle zu erforschen, welche Gründe für die Schwierigkeiten und welche Motivation der Staaten im Laufe der Verhandlungen sichtbar wurden. Die Beiträge von Erwin Ackerknecht, Mark Harrison und Peter Baldwin haben dabei noch am ehesten vermocht, die Verflechtungen zwischen den Anhängern wissenschaftlicher Theorien und diversen Machtstrategien der Konferenzteilnehmer aufzuzeigen, auch wenn diese sich nur sehr am Rande und kaum mit den Details und Abläufen der Konferenzen beschäftigt haben. ${ }^{35}$

Grundlegend für meine Untersuchung der »Regierung der Gesundheit« sind Michel Foucaults Texte zur Herausbildung und Geschichte der modernen Medizin und Gesundheitspolitik. Diese sind überaus zahlreich, sind aber bisher noch wenig rezipiert worden. ${ }^{36}$ Seine wohl bekannteste Arbeit stellt Die Geburt der Klinik ${ }^{37}$ dar. Darin analysiert Foucault die Geschichte des ärztlichen Blicks, nimmt also vor allem die Verschiebungen hinsichtlich der Betrachtung und Behandlung von Körpern und Krankheiten in der ärztlichen, klinischen Praxis in Augenschein. Nur am Rande geht es dort auch um die Herausbildung eines politischen Interesses an Gesundheit. Dem gegenüber hat sich Foucault in einem Aufsatz zur Entstehung der »médecine sociale « in Europa auf die verschiedenen Regierungsweisen in Deutschland, Frankreich, England konzentriert. Er versuchte in diesem kurzen Text, ohne viel Materialbezüge, zu zeigen, dass die interessanten Veränderungen gesundheitspolitischer Strategie nicht

33 Vgl. Huber: The unification of the globe by disease?, 2006: S. 459. Vgl. Howard-Jones: The scientific background of the International Sanitary Conferences $1851-1938$, 1975: S. 9, 458. Vgl. Open Collections Program: Contagion, International Sanitary Conferences: http://ocp.hul.harvard.edu/contagion/sanitaryconferences.html (03. Februar 2016).

34 Vgl. Huber: The unification of the globe by disease?, 2006: S. 459. Vgl. Bynum: Policing Hearts of Darkness, 1993: S. 433.

35 Vgl. Stern/Markel: Disease etiology and political ideology: revisiting Erwin H. Ackerknecht's Classic 1948 Essay, 2009: S. 31f. Vgl. Harrison: Disease and Modern World, 2004: S. 102. Vgl. Baldwin: Contagion and the State in Europe 1830 - 1930, 1999: S. 242f; 550. Vgl. Harrison: Disease, diplomacy and international commerce, 2006: S. 213.

36 Vgl. z.B. Foucault, Michel: Religiöse Abweichung und medizinisches Wissen, 2001 [1968]; ders.: Ärzte, Richter und Hexer im 17. Jahrhundert, 2001 [1968]. Vgl. außerdem: Foucault, Michel: Die wesentlichen Funktionen der Medizin in unserer Gesellschaft, 2002 [1972]; ders.: Krise der Medizin oder Krise der Antimedizin?, 2003 [1979].

37 Im Original, La Naissance de la clinique: une archéologie du regard médical, 1963 veröffentlicht bei P.U.F. 
in einer Umwandlung der staatlichen in eine private oder liberale Organisation des Gesundheitswesens bestanden hätten. Mit der Entstehung kapitalistischer, bürgerlicher Gesellschaften in Europa, so Foucaults Hypothese, seien die Veränderungen des öffentlichen Gesundheitswesens vor allem durch die Konzentration der Regierungspraktiken auf den menschlichen Körper als Körper von Arbeitskräften festzustellen. ${ }^{38}$ Ein Körper, den diese Regierung selbst im Rahmen einer biopolitischen Strategie hervorbringe und sozialisiere. ${ }^{39}$

Foucaults Thesen, die einen komplexeren Zusammenhang von historischen Ereignissen, Diskursen und Regierungsstrategien einbeziehen, deuten auf eine engere Verbindung der Veränderungen von Regierungstechniken im Bereich der öffentlichen Gesundheit, der Entwicklungen innerhalb der medizinischen Disziplin und der Perspektive auf die menschlichen Körper zu einem bestimmten historischen Zeitpunkt hin. An vielen anderen Stellen in seinen Vorlesungen, Büchern und unzähligen Artikeln und Interviews unternimmt Foucault historische Analysen sowohl zu Selbstund Körperpraxen, als auch zu der Entstehung und Entwicklung von Institutionen und Einrichtungen, die für die Geschichte der Regierung von Gesundheit eine Rolle spielen. Diese vielen Texte und Thesen Foucaults bilden einen wichtigen Hintergrund für meine eigene Analyse, die, anschließend an seine historischen Rekonstruktionen, versucht, diese Arbeit im Rahmen einer Genealogie der Regierung von Gesundheit in Fragmenten fortzuführen.

\section{FragestelLung}

Der Wahnsinn, die Krankheit, die Kriminalität und die Sexualität sind, äußerte Foucault in einer seiner letzten Vorlesungen, »Brennpunkte von Erfahrungen « von denen unsere Kultur stark geprägt ist. Er gab zu, nie eine Geschichte des Wahnsinns, sondern vielmehr eine Geschichte der Erfahrung des Wahnsinns in dieser Kultur geschrieben zu haben.

Hieran anschließend möchte ich Krankheit und Gesundheit im Sinne solcher Brennpunkte der Erfahrung als soziale und zugleich diskursive Konfliktfelder analysieren. Wie wurden historisch die Grenzen und Bedingungen der wissenschaftlichen, religiösen, sozialen und politischen Deutung und Klassifizierung von Krankheit und Gesundheit ausgehandelt? Wie haben sich diese jeweiligen Deutungen und Bewertungen von Krankheit und Gesundheit in einer Gesellschaft mit Regeln und Rechten ihres Gebrauchs bzw. ihrer Regierung verbunden? Welche Rationalitäten des Regierens von Gesundheit haben sich historisch mit dem Übergang zur Moderne im westlichen Europa herausgebildet? Wie haben sich auf dem Feld von Krankheit und Gesundheit liberale Logiken des Regierens historisch entfaltet und auf welche Weise

38 Auch in Sexualität und Wahrheit I schrieb Foucault »Diese Biomacht war gewiß ein unerläßliches Element bei der Entwicklung des Kapitalismus, der ohne kontrollierte Einschaltung der Körper in die Produktionsapparate und ohne Anpassung der BevölkerungsPhänomene in die ökonomischen Prozesse nicht möglich geworden wäre.« Ebd., 1997 [1976]: S. 136.

39 Vgl. Foucault, Michel: La naissance de la médecine social, 1994 [1974]: S. $209 f$. 
wurde eine transnationale Ausweitung dieser modernen Regierungsformen von Gesundheit und auch liberaler Ideen und Programme in Gang gesetzt?

Aus diesen Fragen heraus ist das vorliegende Buch und die darin enthaltene selbstverständlich unvollständige und fragmentierte - Genealogie moderner europäischer Regierung von Gesundheit am Beispiel der deutschen Staaten, Frankreichs und Großbritanniens entstanden.

\section{Genealogie der Gouvernementalität}

Foucault hat leider nie systematisch dargelegt, wie er bei seiner Forschung genau vorgegangen ist. Dies gilt vor allem für die Genealogie. Nach Auffassung von Petra Gehring setzt Foucault die Genealogie methodisch um, indem er in vertikaler Richtung eine Herkunftsgeschichte aufzuspüren sucht. ${ }^{40}$ Doch was unterscheidet die Genealogie von der traditionellen Auffassung von Geschichte?

Zunächst einmal bedeutet der Ansatz der Genealogie, wie schon erwähnt, den Gedanken des Ursprungs und der Kontinuität in der Geschichte radikal abzulehnen und damit auch das Problem der Identität anders zu stellen. Die Genealogie geht von einer Geschichte der Brüche, vom Zufall und von Diskontinuität aus. Foucault betrachtete, interessiert an einer historischen Analyse, Körper und Subjektivitäten als Bereiche, an denen sich Geschichte vollzieht und an denen die Historie demnach abgelesen werden kann. Ihn interessierte die Erfahrung als Ausgangspunkt historischer Transformationen von Verfahren und Praktiken des Selbst, der Macht (Gouvernementalität) und der Kriterien für Wahrheit. ${ }^{41}$ Dabei ist wichtig zu berücksichtigen, dass Foucault Erfahrung nicht als einen deterministischen und rein gewalttätigen Vorgang beschrieben hat, den die passiven Subjekte nur erleiden bzw. aus denen sie schlicht resultieren. Auch geht er nicht davon aus, dass ein bestimmtes Subjekt der Möglichkeit der Erfahrung vorausgehen muss. ${ }^{42}$

In Anlehnung an Nietzsches Begriff lehnte Foucault die Suche nach dem Ursprung als Aufgabenstellung historischer Forschung ab.

»Weil es bei einer solchen Suche [nach dem Ursprung] in erster Linie darum geht, das Wesen der Sache zu erfassen, ihre reinste Möglichkeit, ihre in sich gekehrte Identität, ihre unveränderliche, allem Äußerlichen, Zufälligen, Späteren vorausgehende Form. Wer einen solchen Ursprung sucht, der wird finden, > was bereits war<, das `Eigentliche < eines mit sich selbst übereinstimmenden Bildes. ${ }^{43}$

40 Vgl. Gehring: Die Philosophie im Archiv, 2004: S. 132.

41 Vgl. Foucault: Die Rückkehr der Moral, 2005 [1984]: S. 871. Vgl. außerdem Foucault: Die Regierung des Selbst und der anderen I, 2009 [1982 - 1983]: S. 18.

42 Vgl. Foucault: Die Rückkehr der Moral, 2005 [1984]: S. 871.

43 Foucault: Nietzsche, die Genealogie, die Historie, 2002 [1971]: S. 168. 
Foucault führte den Körper ${ }^{44}$ als Beispiel an, um zu demonstrieren, was die Genealogie für alles >Existierende< bedeuten müsse. ${ }^{45}$ Es gäbe demnach keinen ursprünglichen Körper und kein ursprüngliches Subjekt mehr, auf das die Erfahrungen und alles in der Geschichte rückbezogen werden könnte. ${ }^{46}$ Ihr Auftauchen und ihre Existenz lassen sich eher aus einem Ensemble von historischen Bedingungen verstehen. Dem entsprechend fragte er also nicht nach dem Ursprung, sondern nach dem Auftauchen eines Gegenstandes oder eines Problems in der Geschichte, genauer gesagt in den Diskursen.

\section{Diskursanalyse und Machtanalyse}

Nachdem einige Zweifel diskutiert wurden, ob die archäologische und vor allem genealogische Methoden Foucaults überhaupt erlernbar sind, ${ }^{47}$ ja, lange Zeit kaum ein Diskursforscher behaupten wollte, methodisch eng an Foucault anzuknüpfen, gibt es mittlerweile einige konkretere Vorschläge, wie etwa der Begriff der >Aussage< als Werkzeug einzusetzen wäre. ${ }^{48}$

Wie in der Archäologie des Wissens erläutert, betreibt Foucault bei seiner Diskursanalyse zunächst eine Untersuchung von sich wiederholenden Aussagen, die zu einem bestimmten Zeitpunkt und auf einen Gegenstand bezogen als Diskurse zu verstehen sind.

Weil Foucault den Diskurs als Gegenstand der Untersuchung wählt, bedeutete dies aber nicht, dass er nur einen Bereich der Repräsentation von Wirklichkeit analysiert. Foucaultkritiker haben oft behauptet, er würde nur >das Reden über < die tatsächlichen Ereignisse in der Sprache oder im Diskurs berücksichtigen, nicht aber die Ereignisse selbst. Philipp Sarasin hat als Historiker die Diskursanalyse Foucaults verteidigt und bekräftigt, dass sie als ein Werkzeug der Erkenntnis zu sehen sei, bei der

44 In der deutschen Übersetzung des Textes wird das französische »corps« mit »Leib« übersetzt. In der deutschsprachigen Literatur zu Körpergeschichte wird Leib allerdings eher verwendet, um den Körper ohne, oder vor, den Prozessen sozialer Einschreibung zu bezeichnen. (Vgl. Duden, Körpergeschichte, 1990 und Lindemann, Das paradoxe Geschlecht, 1993). Das Wort »Körper«, vermag die Verstrickung sozialer und physiologischer Funktionen besser zu fassen und entspricht daher eher der inhaltlichen Bestimmung Foucaults, der hier ja gerade den historisch gewordenen Körper bezeichnet und nicht dessen primordiale Substanz oder Wesenhaftigkeit.

45 Sarasin: Geschichtswissenschaft und Diskursanalyse, 2003: S. 105.

46 Vgl. Sarasin: Darwin und Foucault, 2009: S. 226f.

47 Folgt man Philipp Sarasin, dann handelt es sich bei Foucaults Diskursanalyse und Diskurstheorie eher um eine »theoretische, vielleicht sogar philosophische Haltung « zur Wirklichkeit. Sarasin spekulierte sogar, man könne die Diskursanalyse nicht wie andere Methoden einfach lernen: Sarasin: Geschichtswissenschaft und Diskursanalyse, 2003: S. 8. Landwehr warf Sarasin dagegen eine Verklärung des diskurstheoretischen Ansatzes von Foucault vor und bestand darauf, dass es möglich sei, auch aus einer philosophisch-theoretischen Haltung eine Methode abzuleiten: Vgl. Landwehr: Rezension zu: Sarasin, Philipp: Geschichtswissenschaft und Diskursanalyse, 2003.

48 Vgl. Palfner: Werkzeug Aussage - Ein politikwissenschaftlicher Versuch, 2006. 
es selbstverständlich darum ginge, etwas über die Wirklichkeit und Wahrheit zu erfahren und nicht nur deren Darstellung. ${ }^{49}$ Diskurse bedeuten einen Bereich von Existenzbedingungen, für mögliche Aussagen, Praktiken und Identitäten. Sie sind selbst Ort der Bedingungen von Machtausübung, für wahre Aussagen und moralische Subjektivität. Diskurse sind auch Schauplatz der Auseinandersetzung drüber, wer als Subjekt eines Diskurses an dieser Auseinandersetzung überhaupt teilnimmt. Akteure bringen neue Gegenstände und Probleme in die Diskurse ein, um Grundlagen für ihr Handeln zu schaffen, oder das Anderer zu de-legitimieren. Sie reproduzieren und modifizieren Diskurse - bewusst oder unbewusst. In diesem Sinne kann die Aneignung von Diskursen selbst als Machtstrategie gelesen werden.

»Er [der Diskurs] erscheint als ein endliches, begrenztes wünschenswertes Gut, das seine Erscheinungsregeln, aber auch seine Aneignungs- und Anwendungsbedingungen hat. Ein Gut, das infolgedessen mit seiner Existenz (und nicht nur in seiner >praktischen Anwendung $<$ ) die Frage nach der Macht stellt. Ein Gut, das von Natur aus der Gegenstand des Kampfes und eines politischen Kampfes ist. « ${ }^{50}$

Dabei lässt sich eine solche Aneignung von Diskursen nicht schlicht aus den Intentionen der Akteure erklären. Sie findet immer auch auf der Grundlage bestehender diskursiver Regeln (dieser Aneignung) aber auch nicht-diskursiver historischer Bedingungen statt.

Bei der genealogischen Analyse der Gouvernementalität hat Foucault sich weniger auf einzelne bestimmte Diskurse konzentriert, als vielmehr ein ganzes Feld von Aussagen verschiedener Teildiskurse einbezogen. ${ }^{51}$ Die Genealogie funktioniert in dieser Weise als eine Art »Rückfrageverfahren ${ }^{52}$, weil sie im Gegensatz zur Archäologie ihr Augenmerk auf einen breiteren Rahmen historischer Veränderungen richtet: »[D]er Gegenstand der Genealogie sind Funktionsgefüge, ihr aus sich heraus aktives Fortwirken und ihr Wandel. $\ll^{53}$

Für meine Analyse bedeutete dies, anhand konkreter sprachlicher Praktiken - den Aussagen -, die in Quellentexten vertretenen Rationalitäten der Regierung von Gesundheit herauszuarbeiten. Mittels eines temporalen Durchgangs durch einen zu diesem Zweck präparierten Textkorpus habe ich so Fragmente einer Geschichte der Herkunft und der Bedingungen des Entstehens und der Veränderung der in ihnen wirkenden Bereiche von Wissen und Techniken bzw. möglicher Subjekte freigelegt. Dabei ist es wichtig zu sehen, dass die verschiedenen Aussagen, die diese Referenzen beinhalten, hierdurch als zugehörig zu einem Aussagefeld erkannt werden können, aber keineswegs gleich oder in gleicher Absicht z.B. positiv oder nur negativ referieren. Die Analyse der Aussagen ist vor allem da interessant und ertragreich, wo diese

49 Vgl. Sarasin: Geschichtswissenschaft und Diskursanalyse, 2003: S. 8f.

50 Foucault: Archäologie des Wissens, 1988 [1976]: S. 96ff. Vgl. auch Foucault: Die Ordnung des Diskurses, 2001 [1970]: S. 11; und Maset: Diskurs, Macht und Geschichte, 2002:

S. 175 .

51 Vgl. Gehring: Die Philosophie im Archiv, 2004: S. 132.

52 Ebd.

53 Ebd. 
als antagonistische Praxisformen auftreten. Die so erkennbaren Konflikte deuten auf den historisch unterschiedlichen $>$ Gebrauch $<$ in den verschiedenen $»$ Episoden [...] einer Serie von Nutzungsweisen ${ }^{54}$ des untersuchten Gegenstands hin. Die strategische Perspektive, die in den >Nutzungsweisen $<$ zu erkennen ist, ist allerdings nicht einzig auf Praktiken beschränkt, die direkt auf dem Feld von Diskursen liegen. Auch >nichtdiskursive< gesellschaftliche Praxis kann sich in dieser Strategie artikulieren und rekonstruierbar werden. Die antagonistischen Praktiken verweisen für Foucault auf vorausgehende historische Konflikte verschiedener Nutzungsweisen, auf die Momente des Entstehens neuer und auf den Beginn des Verschwindens anderer Nutzungsweisen, deren Überreste dem Gegenstand gegenüber später als fremd oder als bedeutungslos erscheinen werden.

»Es sind nicht nur einfach die $>$ Kämpfe , sondern, genauer noch, längst vergessene Verhältnisse und Konflikte, die zum einen dem prätendierten >Wesen<, der angeblichen >Identität< der gegenwärtigen Sache, fremd sind, und es sind, zum anderen, auch sich widersprechende, diskordante Elemente, die im Verlaufe der Zeit gleichsam unter Druck, ja mit Gewalt zu einer Einheit zusammengefügt wurden. $\ll^{55}$

Die Momente des Auftretens neuer Gegenstände und des >Konflikts $<$, aber auch die Existenz von fremd wirkenden Diskurselementen bilden die sinnvollen Ansatzpunkte für eine genealogische Analyse. ${ }^{56}$ Unter Bezug auf welche Umstände, auf welche Wahrheiten, welchen Plan von der Wirklichkeit deuten die Aussagen hin und wie entstehen daraus (neue) Existenzbedingungen? Welche Regularien bestimmen das Auftauchen und die Wiederholbarkeit von Aussagen? Was lässt sich im Rückschluss von dieser diskursiven Ordnung über die sozialen Machtbeziehungen sagen? Welche Subjektposition sind zugelassen? Wer sprich für wen? Bedeutet die Veränderung im Gebrauch eines umkämpften Phänomens eine Verbesserung, Stabilisierung der Machtposition einer sozialen Gruppe oder ein neues Feld der Ausübung von Macht?

Foucault rekonstruiert mit der Genealogie die Veränderungen, Verschiebungen und das Verschwinden von Aussagen, die Etablierung neuer Themen, Probleme und Begriffe. Auf diese Weise kann deutlich gemacht werden, dass sich Denkweisen und Disziplinen, Gegenstände und Praktiken, denen heute eine universelle Bedeutung zugeordnet wird, historisch im Rahmen solcher Auseinandersetzungen um soziale Machtpositionen herausgebildet haben ${ }^{57}$. Die Modalitäten des jeweiligen Gebrauchs der Phänomene sind Artikulationen eines bestimmten historischen politischen Kräfteverhältnisses. Dieser Zusammenhang hat die Nähe der Diskurs- und Machtanalyse bei Foucault bedingt, was ihm zum Teil auch erst rückblickend auf seine frühen Arbeiten klar wurde: »Im Grunde habe ich nichts anderes geschrieben als eine Ge-

54 Foucault: Nietzsche, die Genealogie, die Historie, 2002 [1971]: S. 174.

55 Sarasin: Darwin und Foucault, 2009: S. 228.

56 Foucault schreibt tatsächlich von einem »Kampfplatz«, wo eine jeweilige Praxismodalität entsteht und der Konflikt um den zukünftigen Gebrauch eines Phänomens ausgetragen wird: Foucault: Nietzsche, die Genealogie, die Historie, 2002 [1971]: S. 174.

57 Vgl. Gehring: Die Philosophie im Archiv, 2004: S. 132. 
schichte der Macht. $«{ }^{58}$ Foucault spricht daraufhin häufiger von $>$ Macht $<$ (aber nicht mit einem großen $>\mathbf{M}<$ ) und verfolgt dabei ein ähnliches Interesse, wie es sich bereits bei seiner Bestimmung von >Diskurs < gezeigt hat. Foucault hat weder einen monistischen noch einen metaphysischen Machtbegriff, sondern er schafft ein Analyseraster für einen Bereich sozialer und historischer Realität, der von Begriffen der Macht und Herrschaft, wie sie bisher diskutiert wurden, seiner Auffassung nach, nicht oder unzureichend erfasst wird. ${ }^{59}$ Für Foucault stellt sich das Problem der Regierung in dem Moment, wo er beginnt, das, was er zuvor als Macht bezeichnet hatte, in einer weiteren gesellschaftlichen Ebene historisch-spezifisch zu fassen.

»Die Macht ist nichts anderes als eine bestimmte Art von Beziehungen zwischen Individuen. [...] Das unterscheidende Merkmal der Macht besteht darin, dass bestimmte Menschen mehr oder weniger das Verhalten anderer Menschen völlig bestimmen können - jedoch niemals erschöpfend oder zwingend. ${ }^{60}$

Foucault stößt bei der Untersuchung verschiedener Veränderungen im 18. und 19. Jahrhundert auf neue Ordnungen und Rationalitäten von Regierungsmacht, die er zunächst als Biomacht bezeichnet. Petra Gehring fasste diese Entdeckung Foucaults so zusammen:

»Biomacht ist also eine beschreibende Kategorie. Als epochenspezifische Form der Ordnung der Wirklichkeit, des Einsatzes von Wissen, der Menschenregierung datiert Foucault ihr Heraufkommen auf das 19. Jahrhundert. [...] Bestimmte wohlfahrtliche Maßnahmen einer Politik des Lebens beginnen sich in Europa und Nordamerika flächendeckend zu verbreiten: Man betrachtet das, was vormals einfach Untertanen waren, in seiner physischen Substanz, und man beginnt, das physische Leben nicht nur einzelner Menschen, sondern der ganzen $>$ Bevölkerungen $<$, als Bedingung für das Wohl des Staates und somit als Ziel von Politik zu erkennen und zum Gegenstand von politischen Maßnahmen zu machen. Physisches Leben - das sind Gesundheit, aber auch Ernährungszustand Arbeitskraft, Fruchtbarkeit. ${ }^{61}$

In Korrespondenz mit einer Reihe von historischen Bedingungen in Europa, zu denen Foucault explizit die Durchsetzung kapitalistischer Produktion zählt, rationalisieren sich, seiner Meinung nach, die Machtverhältnisse in einer spezifischen Weise. Die Macht wird selbst materialistisch, weil die sozialen und ökonomischen Bedingungen auch die Bedingungen für das Regieren von Menschen und damit die Existenz der Regierungsmacht selbst verändern. Im Gegensatz zu vorangegangenen Machttypen konzentriert sich die Biomacht auf ihre Möglichkeiten, das >Leben< der Bevölkerung aktiv herzustellen. ${ }^{62}$ Der Terminus Bevölkerung hat bei Foucault eine umfassendere Bedeutung als im allgemeinen Gebrauch des Begriffs üblich ist. Foucault nimmt eine

58 Vgl. Foucault: Gespräch mit Ducio Trombadori, 2005 [1978]: S. 103.

59 Foucault: Sexualität und Wahrheit I, 1997 [1976]: S. 94.

60 Foucault: »Omnes et singulatim« Zu einer Kritik der politischen Vernunft, 2005 [1979]: S. 197.

61 Gehring: Was ist Biomacht?, 2006: S. 11.

62 Vgl. Foucault: In Verteidigung der Gesellschaft, 2001 [1975 - 76]: S. 284f. 
Abgrenzung $\mathrm{zu}$ vorangegangenen historisch entstandenen Vorstellungen und Bezeichnungen z.B. der Personen, die das Territorium eines feudalen Herrschers bewohnten, vor. Ab dem Moment, wo es um die Bevölkerung geht, hören die Menschen auf, das peuple (franz. Volk) zu sein.

»Mit dem 18. Jahrhundert wird das Leben zu einem Objekt der Macht. Das Leben und der Körper. Bis dahin gab es nur Untertanen, nur Rechtssubjekte, denen man Güter und auch das Leben wegnehmen konnte. Nun gibt es Körper und Bevölkerungen. Die Macht ist materialistisch geworden. Sie beschränkt sich nicht mehr im Wesentlichen auf den rechtlichen Aspekt. Nun muss sie mit realen Dingen umgehen, mit dem Körper und dem Leben. « ${ }^{63}$

Das Analyseraster der Biomacht stößt dort an seine Grenzen, wo es nicht nur zur Herausarbeitung der Unterschiede zu früheren Machtformen angesetzt wird, sondern positiv inhaltlich bestimmt werden soll, welche Rationalitäten diese moderne Gouvernementalität auszeichnen und welche Veränderungen mit ihr in Gang gesetzt werden. Eine solche Definition hat Foucault erst Ende der 70er Jahre zum ersten Mal formuliert:

»Unter Gouvernementalität verstehe ich die Gesamtheit, gebildet aus den Institutionen, den Verfahren, Analysen und Reflexionen, den Berechnungen und den Taktiken, die es gestatten, diese recht spezifische und doch komplexe Form der Macht auszuüben, die als Hauptzielscheibe die Bevölkerung, Hauptwissensform die politische Ökonomie als wesentliches technisches Instrument die Sicherheitsdispositive hat. [...] Zweitens verstehe ich unter >Gouvernementalität< die Tendenz oder die Kraftlinie, die im gesamten Abendland unablässig und seit sehr langer Zeit zur Vorrangstellung dieses bestimmten Machttypus, den man als >Regierung< bezeichnen kann, gegenüber allen anderen - Souveränität, Disziplin - geführt und zweitens die Entwicklung einer ganzen Reihe von Wissensformen zur Folge gehabt hat.« ${ }^{64}$

Eine Analyse von Gouvernementalität zu unternehmen, bedeutet, zu schauen, wo welche Aussagen über Wahrheit, Moral und Subjekt zum Ausgangspunkt und Bezugsrahmen der politischen Regierung und Praxis ihrer Machtausübung oder generell der Führung von Menschen geworden sind. Es bedeutet, darauf zu achten, welches Wissen und welche Technologien die Regierung (weiter)entwickelt und erfindet, die mal individualisierende, mal totalisierende Wirkung entfalteten. Hieraus setzt sich die Geschichte der Herausbildung und Rationalisierung der Regierung von Gesundheit seit dem 18. und 19. Jahrhundert zusammen.

Foucault konstatierte im Rückblick auf seine gesamten Untersuchungen und speziell seine Analyse der Gouvernementalität, es wäre ihm um eine Verschiebung gegangen: Statt einer Analyse der Machtausübung wollte er eine Analyse der Verfahren der Gouvernementalität durchführen. ${ }^{65}$ Es ging ihm darum, die Geschichte der Herrschaft durch die historische Analyse der Verfahren der Gouvernementalität zu erset-

63 Foucault: Die Maschen der Macht, 2005 [1981]: S. 236.

64 Foucault: Die »Gouvernementalität«, 2000 [1978]: S. 64f.

65 Vgl. ebd.: S. 188. 
zen. ${ }^{66}$ Ebenso, gab Foucault zu, sei es ihm auch darum gegangen, die Geschichte der Wissensformen durch eine historische Analyse der Veridiktion zu ersetzen, oder die Geschichte der Subjektivität durch eine historische Analyse der Praktiken des Selbst: Indem er die »Universalien, wie den Wahnsinn, das Verbrechen und die Sexualität durch die Analyse von Erfahrungen« und deren »singuläre historische Formen« ersetzen wollte. ${ }^{67}$

»Die Ersetzung der Geschichte der Wissensformen durch die historische Analyse der Formen der Veridiktion, die Ersetzung der Geschichte der Herrschaft durch die historische Analyse der Verfahren der Gouvernementalität, die Ersetzung der Theorie des Subjekts oder die Geschichte der Subjektivität durch die historische Analyse der Pragmatik des Selbst und der Formen, die diese angenommen hat, das sind die verschiedenen Zugangswege, auf denen ich versucht habe, die Möglichkeit einer Geschichte dessen näher zu bestimmen, was man `Erfahrungen $<$ nennen könnte. «68

An diese Überlegungen anschließend will ich bei dem Versuch, eine Diskursgeschichte der Gouvernementalität von Gesundheit zu schreiben, zeigen, dass sich gesundheitspolitische Techniken und Verfahren dieser Macht nicht auf gegebene Körper und Subjekte richteten oder sie als konstanten Ausgangspunkt nahmen, sondern dass die jeweiligen Praxen und Rationalitäten sich entlang einer Geschichte der Erfahrungen veränderten, die die Herstellung, Formung und vor allem die Differenzierung von Körpern und Subjekten und ihres Gebrauchs bei der Ausübung und Verteilung von Gouvernementalität verlangte. Durch diese Erweiterung wird eine andere Kritik der Macht möglich.

Die klassische Kritik an staatlicher und meist im nationalen Rahmen gedachte Regierung verfolgt das Ziel der Begrenzung oder gerechteren Verteilung ihrer Macht oder richtet sich gegen den Missbrauch der Macht einer solchen Regierung. Für derartige Kritik bietet die Gouvernementalität kaum eine Angriffsfläche. Wie etwa die Arbeit von Matthias Bohlender zur liberalen Regierung gezeigt hat, ist die Annahme abwegig, dass politische Technologien immer direkt gegen die Individuen wirken und grundsätzlich antiliberalen Charakters sein müssen. ${ }^{69}$

Das Problem, das die Bezeichnung einer liberalen Regierung mit sich bringt, liegt in ihrem scheinbaren inneren Widerspruch. Das liberale Prinzip, gedacht als Freiheit und Selbstbestimmung, stehen dem Prinzip der Regierung, also der Führung und Unterwerfung unter Regeln, welche die Abwesenheit oder das Gegenteil von Freiheit darstellen, gegenüber. Dieser innere Gegensatz taucht in den Argumentationen von u.a. liberalen Ökonomen, bei Verteidigern des Sozialstaates, vor allem aber im Alltagsverständnis der Begriffe >Regierung< und >Freiheit< auf. Für dieses Verständnis sind zwei Annahmen verantwortlich, die einmal von einer bestimmten Definition von Freiheit ausgehen und die zum anderen in einer nahezu Gleichsetzung der Bedeutung von Regierung und Staat liegen. Hinzu kommt außerdem die Annahme eines grund-

66 Vgl. Foucault: Die Regierung des Selbst und der anderen I, 2009 [1982 - 1983]: S. 18.

67 Ebd.: S. 19. Vgl. auch Foucault: Sexualität und Wahrheit II, 1998 [1984]: S. 10.

68 Foucault: Die Regierung des Selbst und der anderen I, 2009 [1982 - 1983]: S. 18.

69 Vgl. Bohlender: Metamorphosen des liberalen Regierungsdenkens, 2007: S. $18 \mathrm{f}$. 
sätzlichen Antagonismus von Staat (oft gleichbedeutend genannt mit Regierung) und Ökonomie.

Foucault beschrieb die liberale Gouvernementalität jedoch als eine Regierungspraxis, die »sich nicht damit begnügt die Freiheit zu respektieren oder zu garantieren. $\ll^{70}$

»In einem tieferen Sinne vollzieht sie die Freiheit. Sie vollzieht die Freiheit insofern, als sie nur in dem Maße möglich ist, in dem es tatsächlich eine bestimmte Anzahl von Freiheiten gibt: Freiheit des Marktes, Freiheit des Verkäufers und des Käufers, freie Ausübung des Eigentumsrechts, Diskussionsfreiheit evtl. Ausdrucksfreiheit usw. Die neue gouvernementale Vernunft braucht also die Freiheit. Sie vollzieht Freiheit, d.h., sie ist verpflichtet, Freiheit zu schaffen. Sie ist verpflichtet sie zu schaffen und sie zu organisieren. Die neue Regierungskunst stellt sich als Manager der Freiheit dar $[\ldots] . \ll^{71}$

Liberal ist die Regierung, wie Foucault schrieb, nicht, weil Freiheit das Ziel der liberalen Gouvernementalität darstellt, sondern weil sie Freiheit zu ihrem Organisationsund Regierungsprinzip macht. »[D]ie Einrichtung und Organisation der Bedingungen [...] unter denen man frei sein kann« würde aber, das betonte Foucault gleichermaBen, bedeuten »im Zentrum dieser liberalen Praxis ein problematisches, ständig wechselndes Verhältnis zwischen der Produktion von Freiheit und dem « herzustellen, »was sie zu begrenzen und zu zerstören droht $\ll^{72}$. »Die Befreiung [von Herrschaftsbeziehungen] eröffnet ein Feld neuer Machtbeziehungen, die es durch Praktiken der Freiheit zu kontrollieren gilt $\ll^{73}$.

Ich möchte mithilfe einiger Thesen u.a. von Foucault und durch meine Analyse belegen, warum vielleicht gerade das, was das >liberale< der modernen Regierung auszeichnet, eine sehr viel umfassender und sehr viel effizientere Regierung von Menschen ermöglicht hat.

Damit ist aber auch nicht gemeint, dass Regierung verstanden als moderne oder liberale Gouvernementalität heute nur über subtilere oder geschickt verschleierte Techniken funktioniert, sondern, dass sie sich auf andere Probleme richtet und in schwerer abzugrenzenden Bereichen, unter Einbeziehung von Praktiken und dem Wissen der Regierten, strategisch >herrscht<. Und weil sie sich auf das Leben konzentriert, ist ihre Wirkung, ganz im Sinne der Biomacht, nicht vorrangig destruktiv und ihre Mittel nicht vorrangig repressiv. Ihre Herrschaft besteht in der Rationalität und der Technologie, in der sie Normen und Bedingungen für die Existenz und Freiheit installiert. Erst nachgeordnet und dem Charakter nach korrigierend kann aber auch die liberale Regierung dabei ebenso effizient die Existenz und Freiheiten aktiv beschränken.

70 Vgl. Foucault, Michel: Geschichte der Gouvernementalität II, 2004 [1978 - 1979]: S. 97.

71 Ebd.

72 Ebd.: S. 97f.

73 Ebd.: S. 878. 


\section{QuellenauswaHL}

Aus dem methodischen Ansatz der genalogischen Diskursanalyse ergeben sich eine Vielzahl von Problemen für die Auswahl und Zusammenstellung eines Quellenkorpus. Der Methode selbst ist die Kritik an den hermeneutischen Vorgehen der traditionellen Geschichtswissenschaft inhärent. ${ }^{74}$ Foucault empfahl, die Quellenaussagen zuerst zu beschreiben und nach ihrer eigenen Logik, Materialität und Medialität zu fragen, statt sie reflexartig auf einen ihnen äußerlichen Sinn oder eine angeblich selbstverständlich gegebene Realität zu beziehen. ${ }^{75}$ Statt Quellen als ein durchsichtiges Objektiv, als dokumentarische Zeugnisse vergangener Ereignisses oder zum schweigen gebrachter »Stimmen« zu verstehen, plädierte Michel Foucault in der Archäologie des Wissens für die Behandlung der Quellen nicht als Dokumente, sondern als Monumente. ${ }^{76}$ Sie sind keine Dokumente, deren Wahrheit und Aussagekraft über ein »wirkliches« historisches Ereignis kritisch geprüft gehören. Die Quellen, oder eher die Aussagen, sind die wirklichen Ereignisse, die es zu untersuchen gilt. Damit ist die Durchführung einer klassischen Quellenkritik obsolet. Der Diskurs ist das Objekt der Untersuchung, nicht die >wirkliche Geschichte $<$, die sich in den Quellen besser oder schlechter repräsentiert findet.

Weiter setzt die Diskursanalyse die Einsicht voraus, dass ein Diskurs weder auf ein Werk, noch auf bestimmte Textgattungen, überhaupt auf Sprache oder gar auf ein Thema beschränkt werden kann. Der Diskurs lässt sich nur über das Gefüge von Aussagen in einer Zeit und auch in einer gewissen räumlichen Begrenzung identifizieren, die eine Regelmäßigkeit aufweisen und einen bestimmten Sinnzusammenhang bilden. Diese Aussagen sind verstreut, können sich verschiedener Symbole, Sprachen und Medien bedienen, aber auch ihre Spuren in der privaten Reflexion einer einzelnen Person hinterlassen. Dabei ist der spezielle Autor von geringerer Bedeutung als die Regeln des Subjekts eines Diskurses denen er entsprechen kann. ${ }^{77}$

Vor diesem Hintergrund stellt sich die Aufgabe, aus einem quasi unbegrenzten Fundus an Quellen eine Auswahl zu treffen. Diese erste Auswahl meiner Quellen basierte daher zunächst auf drei Kriterien:

1. Es sollte eine gewisse Wahrscheinlichkeit bestehen, dass die ausgewählten Texte, eine relevante Schnittmenge der für mich interessanten Diskurse beinhalten.

2. Es sollte die Möglichkeit bestehen, dass Konflikte um die Gegenstände oder die Regeln ihres Gebrauchs sichtbar werden.

3. Sollten die Textmenge groß genug und kontinuierlich in meinem Untersuchungszeitraum vorhanden sein, um die Regelmäßigkeit und die Wiederholbarkeit von Aussagen erkennbar zu machen.

Die erste Textsorte stellten für meine Forschung die medizinischen-philosophischen oder medizinischen- bzw. gesundheitsbezogenen populärwissenschaftlichen Journale

74 Sarasin: Geschichtswissenschaft und Diskursanalyse, 2003: S. $32 f$.

75 Foucault: Archäologie des Wissens, 1988 [1976]: S. 144f.

76 Foucault: Archäologie des Wissens, 1988 [1976]: S. 14f.

77 Ebd.: S. 139. 
dar. Von hier ausgehend bin ich weiteren Hinweisen auf andere Autoren und gedruckte Quellen wie Monographien einzelner Ärzte, Ratgeberliteratur, Gesetzestexte, Regierungsberichte und -erklärungen, Publikationen von Fachgesellschaften und Flugblätter gefolgt und habe diese ebenfalls einbezogen. Die gedruckten Quellen haben außerdem den Vorteil, sich für einen intertemporalen und internationalen Vergleich besser zu eignen als Archivalien. ${ }^{78}$

Diese Auswahl mag auf den ersten Blick recht willkürlich erscheinen, doch die Diskursanalyse verlangt es, über die Grenzen von Werken, Textgattungen und Sprachen hinwegzugehen und den Verweisen zu folgen, durch welche sich die Aussagen gegenseitig stützen und eine diskursive Formation bilden können.

»Was so in den Blick gerät, ist dennoch kein beliebiges, angeblich >postmodernes< Spiel von Texten, die ohne Wirklichkeitsbezug nur noch wechselseitig auf sich selbst verweisen, sondern konkrete, gesellschaftlich verortbare Formen und Verhältnisse von Medien und Kommunikation, Informationsverarbeitung und Sinnproduktion. $\ll^{79}$

Meine Auswahl deutscher, französischer und britischer Quellen begründet sich aus der Identifikation verschiedener Diskurse und diskursiver Elemente, die sich um die generelle Problemstellung der Regierung der Bevölkerung oder genauer, von Gesundheit, gruppieren. Der letzte Abschnitt zu den CSIs basiert vor allem auf der Analyse der sehr detailreichen Protokolle der Konferenzen.

Die engere Wahl dieser drei Länder stützt sich auf die Ergebnisse meiner bisherigen Forschung und der relativ durchgängigen Bezugnahme auf die Länder in verschiedenen anderen Arbeiten zur Geschichte von Gesundheitspolitik in Europa. ${ }^{80}$

\section{Die Regierung von Gesundheit}

Meine Entscheidung, die deutschen Staaten/Deutsches Reich, Frankreich und Großbritannien für die Untersuchung dieser Entstehungsgeschichte heranzuziehen, hatte im Wesentlichen zwei Gründe: Erstens existieren über diese drei Länder bereits eine relativ umfangreiche Literatur, die die Geschichte der Gesundheitspolitik, der Medizinischen Profession oder der Entwicklung ihrer Wissenschaften erforscht haben. Da ich keine klassische historiographische Rekonstruktion der mit dieser Geschichte in Verbindung gebrachten Ereignisse schreiben wollte, schien es mir sinnvoll, diese Literatur als Referenz im Hintergrund zu wissen und ihr gewissermaßen eine andere Perspektive hinzufügen zu können. Wer in der vorliegenden Arbeit viele sonst als

78 Vgl. Kerchner: Wirklich Gegendenken. Politik analysieren mit Michel Foucault, 2006: S. 155.

79 Sarasin: Geschichtswissenschaft und Diskursanalyse, 2003: S. 58.

80 Rosen: A History of Public Health, 1993 [1958]; Porter: The History of Public Health and the Modern State, 1994; Weindling: Public Health in Germany, 1994: S. 119 - 131; ders.: Introduction: constructing international health between the wars, 1995: S. 1 - 3; Weiner: The Citizen-Patient in Revolutionary and Imperial Paris, 1993; Carroll: Medical Police and the History of Public Health, 2002: S. 461 - 494. 
zentral bewertete Personen, Daten und Ereignisse vermisst, den kann ich getrost auf die bestehende Literatur verweisen.

Zweitens knüpfe ich mit dem Forschungsansatz der Genealogie und der Untersuchung von Gouvernementalität an Foucaults historischer Forschung an. Auch Foucault hat in seinen Arbeiten und Vorlesungen die Diskursgeschichte ab dem 18. Jahrhundert vorwiegend am Beispiel der deutschen Staaten, Frankreich und Großbritannien verdeutlicht. Die drei Ländern als Untersuchungsraum zu wählen, ermöglichte mir, an die von Foucault beschriebenen, meinem Untersuchungszeitraum vorgelagerten oder parallelen Entwicklungen anzuknüpfen.

Foucault problematisierte in einer der ersten Vorlesungen, die er zwischen 1975 und 1976 am Collège de France hielt, den historische Ansatz, bei welchem »aus dem allgemeinen Phänomen der Herrschaft der bürgerlichen Klasse alles nur Erdenkliche « abgeleitet würde. Anstelle aber von dieser Herrschaft - als gegebene - auszugehen, plädierte er dafür, zu untersuchen wie bestimmte Praktiken des Ausschlusses, der Unterdrückung und des Verbots sich historisch »von unten ausgehend « entwickeln und $»$ funktionieren konnten $\ll .{ }^{81}$

»[W]ie diese Phänomene der Unterdrückung und des Ausschlusses auf der Ebene der Familie, der unmittelbaren Umgebung, der Zellen oder der untersten Schichten einer Gesellschaft ihre eigenen Werkzeuge und ihre eigene Logik hatten und einer bestimmten Zahl von Bedürfnissen entgegenkamen. Man müsste zeigen, wer die Träger waren, und diese nicht auf Seiten des Bürgertums allgemein, sondern der realen Akteure suchen, in der unmittelbaren Umgebung von Familien, Eltern, Ärzten oder der auf der untersten Ebene der Polizei, und schließlich nachweisen, wie diese Machtmechanismen zum gegebenen Zeitpunkt, in einer präzisen Konstellation und dank einer gewissen Zahl von Transformationen ökonomisch vorteilhaft und politisch nützlich zu werden begannen. $\ll^{82}$

Foucault vermutete, dass der Gründung von Institutionen und der Verabschiedung von Gesetzen, eine Geschichte der Transformation und Herausbildung von kleinen alltäglichen Praxen und Verhaltensänderungen vorausgegangen sein musste, die »ab einem bestimmten Zeitpunkt, und aus Gründen, die noch zu untersuchen wären, einen gewissen ökonomischen Vorteil und politischen Nutzen deutlich werden ließen $\ll^{83}$ und erst dann »von globaleren Mechanismen und schließlich vom gesamten Staatssystem ganz natürlich kolonialisiert und mitgetragen ${ }^{84}$ wurden.

»Das Bürgertum interessiert sich nicht für die Irren, sondern für die Macht über die Irren; es interessiert sich nicht für die kindliche Sexualität, sondern für das Machtsystem, welches die Sexualität des Kindes kontrolliert. « ${ }^{85}$

81 Foucault: In Verteidigung der Gesellschaft, 2001 [1975 - 76]: S. 47.

82 Ebd.: S. 47f.

83 Ebd.: S. 48.

84 Ebd.

85 Ebd.: S. 48f. 
Ebenso könnte man sagen, das Bürgertum interessierte sich nicht für die Gesundheit und die Hygiene, sondern für die Macht-Alternativen, die die Hygiene ihm hinsichtlich der Krise der politischen Souveränität im 17. und 18. Jahrhundert zu bieten hatte. Oder man könnte sagen, die Ärzte interessierten sich nicht für die hippokratische Lehre, sondern für die Macht ihren Patienten oder sogar dem Staat gegenüber, denen sie auf Grundlage dieser Lehre erklärten, was eine gesunde, rationale und >gute< (Selbst-)Regierung sein müsse.

Foucault legte in seinen Vorlesungen zur Geschichte der Gouvernementalität überzeugend dar, wie sich im 16. Jahrhundert mit dem Übergang »von dem Pastoral der Seelen zur politischen Regierung der Menschen $~^{86}$, ein umfangreiches und heterogenes Gefüge um die Frage der Regierung entfaltete, das eine allgemeine Veränderung oder vielleicht sogar Vereinheitlichung der Regierungsrationalität hervorbrachte. Die von Foucault als Krise der pastoralen Seelenführung im 16. und v.a. im 17. Jahrhundert beschriebenen Auseinandersetzungen bilden einen wichtigen Hintergrund für meine eigene Untersuchung. Ich werde zeigen, dass es ab dem ausgehenden 18. Jahrhundert auch hinsichtlich des Umgangs mit Krankheit und Gesundheit zu einer »Intensivierung, eine[r] Übersetzung, eine[r] allgemeine Ausweitung dieser Frage und dieser Techniken der Verhaltensführung « auf die staatliche Regierung kam. Es kam zu einer Übertragung der zuvor zu einer pastoralen und auch >privaten< unpolitischen »Ökonomie der Seelen ${ }^{87}{ }^{8}$ gehörenden Form der Verhaltensführung.

Diese Übertragungen bildeten eine erste Bedingung für die Entstehung der Techniken der modernen und liberalen Gouvernementalität von Gesundheit. Dies ist auch der Grund dafür, dass ich mit der Analyse der Gouvernementalität gegen Ende des 18. Jahrhunderts ansetze. Nach Sichtung der Quellen stellte sich heraus, dass es in den drei Ländern in einem weiten Zeitraum von ca. 50 Jahren um 1800 zeitlich versetzt, zu einem ersten Schwerpunkt in der Problematisierung der Regierung von Gesundheit kam. Dieser erste Zeitrahmen, der möglicherweise als eine erste Verdichtung der Diskurse um die Idee einer modernen Regieren der Gesundheit darstellen, habe ich im ersten Kapitel fragmentarisch für die deutschen Staaten, Frankreich und Großbritannien bis Mitte des 19. Jahrhunderts nachgezeichnet. Selbstverständlich hörten die Diskurse mit dem Ende dieses Untersuchungszeitraums nicht auf. Im Gegenteil, es kam von da an zu einer immer weiteren Ausdifferenzierung der Gegenstände und Bereiche von Praxis, zu einer stetigen Erweiterung des Repertoires an Techniken der Regierung und der Spezialisierung ihrer Funktionen.

Das erste Kapitel ist auf diese erste Verdichtung von Aussagen begrenzt und soll ein Schlaglicht auf die Kontexte werfen, in welchen das Problem einer modernen Regierung von Gesundheit, zum ersten Mal so explizit gestellt wurde. Es fragt danach, wie die Idee, die Gesundheit der Bevölkerung zu regieren aufkam. Es will Antworten auf die Frage geben, wie die Regierung der Gesundheit sich als Teil der

86 Foucault: Geschichte der Gouvernementalität I, 2004 [1977 - 1978]: S. 331.

87 Ebd. Foucault fügt wenig später hinzu, diese Übertragungen wären im Zusammenhang mit einem »großen Klima der Widerstände, Revolten Aufstände des Verhaltens« voll_zogen worden. Ebd.: S. 333. Zu diesen zählte Foucault übrigens auch die Ablehnung der »Medizin[,] eine der größten Erbmächte des Pastorats« und ihrer »bestimmten Typs medizinischer Rationalität«. Ebd.: S. 298. 
Gouvernementalität in den drei Ländern unter unterschiedlichen Bedingungen und zeitlich versetzt in einem dennoch ähnlichen Konfliktfeld zwischen Ärzten, Bürgertum und Staat herausbildete. Teile bürgerlicher Pragmatiken des Selbst, die der Konstruktion von bürgerlichem Subjekt, bürgerlicher Moral und Lebensweise gedient hatten, wurden unter den spezifischen Bedingungen der Länder rationalisiert und zunehmend auch in staatliche Politiken übertragen. Alte Praxen staatlicher Regierung, die Bereiche von Gesundheit berührten, wurden durch die Rationalität dieser zunächst bürgerlichen Praxis der (Selbst-)Regierung konfrontiert, herausgefordert und verändert. Ehemals klassenspezifische und den bürgerlich-subkulturellen Lebensweisen eigene gesundheitliche und hygienische Wissensbezüge beanspruchten über die Verknüpfung mit moderner wissenschaftlicher Rationalität eine universelle Gültigkeit. Während diese zuvor private Regierung von Gesundheit einerseits selbst einer Medikalisierung unterzogen wurde, unterstützte sie andererseits die auf Bevölkerung gerichtete moderne Regierung bei der Entdeckung und Ausweitung ihres Wissensund Machtbereichs.

Diese Entwicklungen verliefen in den einzelnen Ländern, die mit unterschiedlichen Vorbedingungen zu kämpfen hatten, weder absolut parallel noch wurden sie in gleicher Weise vollzogen. Unter anderem aus diesem Grund ging ich bei der Analyse nicht nach einem vorgefertigten Schema vor, sondern orientierte mich an den Aussage-Formationen und relevanten Debatten in einigen repräsentativen verwaltungs- und staatswissenschaftlichen, medizinisch-philosophischen, medizinisch-praktischen und an Hygiene orientierten Zeitschriften und Veröffentlichungen im genannten Zeitraum. Unterschiedliche Themen und Probleme sind von mir hervorgehoben, um anhand von ihnen die Entstehung bestimmter Abgrenzungen und Formierungen im Bereich der Regierung von Gesundheit zu analysieren. Ich erhebe daher keinen Anspruch auf Vollständigkeit. Die Schwerpunktlegung ist weitestgehend durch die Dichte der Aussagenbereiche selbst und die Präsenz eines Problems zum historischen Zeitpunkt der Debatte bestimmt.

$\mathrm{Ab}$ dem Ende der 1820er Jahre war die Problematisierung der Cholera in den von mir untersuchten Diskursen derartig präsent, dass ich beschlossen habe, die Cholera als diskursives Ereignis zu bezeichnen und mich im zweiten Kapitel ausschließlich mit dem Teil der Aussagen zu beschäftigen, die sich um die Problematisierung der Cholera gruppierten.

Vier große Cholerapandemien haben im 19. Jahrhundert auch Europa einbezogen und betrafen die von mir berücksichtigten Länder in mehreren Wellen. Daraus ergab sich aus Sicht der Länder eine eigene Zählung der Epidemien, die sich von der der Pandemien im 19. Jahrhundert unterscheidet. Der Schwerpunkt der Problematisierung der Cholera als ein Problem der Regierung von Gesundheit in den deutschen Staaten, Frankreich und Großbritannien steht im zeitlichen Zusammenhang mit den Epidemien Anfang der 1830er, Ende der 1840er, Mitte der 1850er und schließlich Mitte der 1860er Jahre. In Deutschland und Frankreich kam es dann auch noch in den 1870 bis 1890 er Jahren zu weiteren Epidemien, die ich auch nicht völlig unbeachtet gelassen habe. Doch obwohl ich nicht behaupten will, dass sich Diskurse um Regierung von Gesundheit ab den 1870er Jahren nicht mehr auf die Cholera bezogen, würde ich dennoch sagen, dass ab den 1860ern eine erste Phase der Problematisierung zu Ende ging. 
Es ist weniger die Entwicklung des Wissens über die Cholera, deren medizinische Betrachtung und Kategorisierung, die mich interessierte. Tatsächlich gibt es gute Gründe davon auszugehen, dass die zahlreichen Beschreibungen der Cholera aus dieser Zeit und in älteren Quellen, die herangezogen wurden, unterschiedliche Krankheiten vor sich hatten. Denn in den allermeisten Fällen bestehen keine Möglichkeiten mittels einer Genomanalyse nachzuweisen, dass bei den beschriebenen Krankheitsfällen tatsächlich eine Infektion mit dem Mikroorganismus vibrio cholerae vorlag. Da es mir aber um die Geschichte eins bestimmten Bereichs von Erfahrung mit der Cholera, und nicht um die Cholera als Krankheit geht, spielt dies keine Rolle.

Die Erfahrung mit den Choleraepidemien zog eine große Anzahl von verschiedenen Publikationen nach sich, die in neuartiger Weise das Wissen über Krankheiten, Techniken der Regierung und die Frage nach einem Umgang mit der Cholera mobilisierten und miteinander konfrontieren. Die Erfahrungen veränderten den Gebrauch von Wissen und Technologien der Regierung, produzierten neue Ansatzpunkte und Gegenstände, setzten Kräfte frei und spannten neue Subjekte und Gruppen in die Regierung ein. Die Cholera wirkte wie ein Katalysator auf den Prozess der Rationalisierung und Anpassung auch der staatlichen Regierung an ihre neuen Anforderungen bei der Regierung des Lebens. Diese neue Anforderung war es, die die Staaten in ihren Versuchen, mit der Cholera umzugehen, dazu brachte, in eine Auseinandersetzung mit anderen Staaten zu treten. Berichte über die Choleraepidemien in einzelnen Städten und Ländern zirkulierten regelrecht unter den Fachgesellschaften und wissenschaftlichen Beratungsgremien von Regierungen. Es entstand hier ein Diskurs, der die verschiedenen Regierungspraxen von staatlicher Seite, aber auch die eher privaten oder ärztlichen Techniken der Vermeidung und Behandlung der Krankheit in einen direkten Vergleich setzte. Das dritte Kapitel habe ich daher der Analyse der Konferenzprotokolle der ersten elf von vierzehn Gesundheitskonferenzen im 19. Jahrhundert und bis Anfang des 20. Jahrhunderts gewidmet, da hier die Cholera im Zentrum der Analyse stand ${ }^{88}$. Die Choleraepidemien gaben Anlass zu der ersten durch den französischen Staat 1851 einberufenen Conférence Sanitaire International in Paris. Auch die weiteren Konferenzen beschäftigten sich schwerpunktmäßig mit dem Problem der Cholera. Das Kapitel zu den Konferenzen sollte dazu dienen, das direkte Zusammenprallen dieser unterschiedlichen und die in den einzelnen Ländern ja auch weiterhin heterogen und wechselhaft artikulierten Strategien mit Blick auf das gemeinsame Problem der Cholera zu beleuchte. Interessant sind die Konferenzen aber auch deshalb, weil sie direkter Ausdruck der neuen Gouvernementalität waren. Diese neue Regierungsform stellte mit dem Problem der Cholera noch deutlicher als zuvor fest, dass der neue Gegenstand, den sie zu regieren hatte - das Leben und seine biologischen und sozialen Erfordernisse - kaum auf ein Territorium einzugrenzen war. Bis zu diesem Zeitpunkt waren multilaterale Konferenzen allein für außenpolitische Themen reserviert gewesen. Mit der biopolitischen Umstülpung der Regierungsaufgabe ab dem 18. Jahrhundert von der äußerlichen auf die innere Existenz des Staates, wurde ein sonst völlig innenpolitisches Problem - die Gesundheit der Bevölkerung - zu einem Thema bilateraler und multilateraler Abkommen. Anstatt Innenpolitik zu betreiben, um die Existenz des Staates nach außen und als eine Macht unter 
anderen Mächten zu erhalten, ging es nun darum, Außenpolitik zu betreiben, um die materielle und biologische Existenz des Staates, einer Nation oder einer Gesellschaft zu gewährleisten.

In diesem Kapitel stehen daher die Konflikte und Diskurse im Zentrum, die zu einer Ausdehnung und Universalisierung der in Europa zu dieser Zeit gerade erst entstandenen Rationalitäten und Praxen des Regierens von Gesundheit geführt haben. Ich werde zeigen, dass es unter dem Einfluss eines auf den Konferenzen entfaltete Diskurses um gutes Regieren, zu einer Optimierung und Angleichung von Regierungsrationalitäten unter den europäischen Mächten kam. Ich werde außerdem nachzeichnen, wie diese Entwicklung mit einem Prozess der Abgrenzung und des Ausschlusses alter und anderer Regierungsweisen einherging.

Im Schlusskapitel werde ich die Ergebnisse meiner Forschung noch einmal zusammenfassen und auf den Kontext der aktuellen Diskussion um neoliberale Logiken in der Gesundheitspolitik rückbeziehen. 


\section{Regierungsrationalitäten der Gesundheit um 1800}

Im 18. Jahrhundert kam es zu einer erneuten Rezeption, Übersetzung und Interpretation der Schriften von Hippokrates und Galen durch Gelehrte und Ärzte. Diese bürgerlich geprägte neohippokratische Bewegung machten ihre Interpretationen der antiken Texte und die von ihr abgeleitete Diätetik, unter dem starken Einfluss einer sich professionalisierenden Medizin, zum zentralen Element eines bürgerlichen Diskurses um moralische und gesunde Lebensführung. Es entstanden im Rahmen subkultureller und klassenbezogener Verfahren der Subjektivierung Praktiken der Regierung des Selbst, die auf Gesundheit in einem sehr umfassenden Sinne, als Sorge um sich und auf gesunde Lebensweise, abzielten. Hieraus ergaben sich gleich mehrere vorteilhafte Positionen. Zum einen bildete der Diskurs und die damit einhergehende Praxis eine dem Pastorat entgegengesetzte >wissenschaftliche<, also aus Sicht des >aufgeklärten< Bürgers >rationale< Grundlage der Selbstführung. Es entwickelte sich, grob gesagt, vom gelehrten Bürgertum ausgehend, neue Praxen der diätetischen Selbstführung und besetzten die zuvor hauptsächlich von der Kirche monopolisierten und weitestgehend als privat angesehenen Bereiche der auf das Selbst und seine Regierung gerichteten Techniken.

»Aus der Sorge um das Heil der Menschen im Jenseits wurde die Sorge um ihr Heil im Diesseits. In diesem Kontext erhält das Wort >Heil<mehrere Bedeutungen; es meint nun Gesundheit, Wohlergehen (im Sinne eines angemessenen Lebensstandards und ausreichend Ressourcen), Sicherheit und Schutz vor Unfällen aller Art. «1

Zum anderen diente die spezifisch bürgerliche Pragmatik des Selbst dazu, sich gegenüber Adel und arbeitender Bevölkerung abzugrenzen und mit Blick auf die moralische Überlegenheit und >rationalere< Lebensweise einen Machtanspruch zu formulieren. Dieser bürgerliche Diskurs der Selbstregierung und seine von der Kirche unabhängig funktionierenden moralischen Praxen waren mit einem Begehren des Bürgertums nach politischer Herrschaftsbeteiligung ebenso wie mit dem Begehren nach der Befreiung von einer herrschenden Form der Regierung und Seelenführung verbunden. Der Verweis auf die bessere Lebensweise und damit bewiesene moralische Überlegenheit diente hier indirekt zur Rechtfertigung des wachsenden Einflusses auf

1 Foucault, Michel: Subjekt und Macht, 2005 [1982]: S. 278. 
die bestehenden staatlichen Institutionen und auf die Öffentlichkeit, wo die Kritik der Rationalität der Regierung ansetzte.

Darüber hinaus veränderte sich das Verhältnis von Regierung und Wissenschaft. Neue Anforderungen für moderne Wissenschaften und der wissenschaftlichen Begründung von Regierung im 18. und 19. Jahrhundert bewirkten eine Transformation der Medizin. Diese schwankte zwischen dem Anspruch einer exakten Wissenschaft, einer Annäherung ihrer Methoden und Wissensformen an die Naturwissenschaften und den an sie gerichteten Anforderungen, sich der neuen Rationalität der Regierung von Gesundheit zu unterwerfen. Die Auseinandersetzungen um das Verhältnis von Hygiene und Medizin wie auch um die Rationalisierung eines moralischen ärztlichen Berufsethos, die in den drei Ländern eine unterschiedliche Rolle spielten, zeugen von diesen Konflikten. Die neuen Anforderungen an Regierung sorgten auch für eine Rationalisierung und Kolonialisierung alter soziale Strukturen und der als Teil der Selbstsorge entstanden Praktiken des Heilens und der Pflege durch medizinisches Wissen. So wurde die Verpflichtung zur >rationalen< Selbstregierung, zur Erhaltung der Gesundheit bzw. Vorbeugung von Krankheit, die unter Einsatz verschiedener Regierungstechnologien an die Individuen herangetragen wurde, zu einem wichtigen Element der Gouvernementalität. Die Professionalisierung, wissenschaftliche Rationalisierung und Vereinheitlichung der Medizin ab ca. 1800 führte nicht automatisch zu einer Verdrängung der alten Praxis der Heilkunst und anderer gesundheitsbezogener sozialer Versorgungsstrukturen. Hierzu war zunächst die Anerkennung der Medizin und der Ärzte durch den Staat und staatliche Regularien erforderlich, die die wissenschaftliche Medizin unter Einbeziehung einer gemeinsamen gesundheitspolitischen Zielsetzung zur allgemeinen Grundlage gesundheitsbezogener Praxis und die Ärzte zur privilegierten Berufsgruppe kürten. Die staatliche Anerkennung und Vereinnahmung bestimmte die weitere Richtung der Rationalisierung der Medizin mit, indem sie die Vereinheitlichung und Verallgemeinerung der medizinischen Episteme beförderte und die Medizin institutionell organisierte. Die Praxis der >rationellen< Regierung der Gesundheit wurde in diesem Prozess nicht einfach durch >den Staat< übernommen. Es fand unter dem Druck des zunehmend gouvernementalen Regierungsdenkens und hinsichtlich der Aufgabe der Regierung der Bevölkerung eine Aufteilung der Macht und der Zuständigkeiten statt.

Die Verknüpfung von medizinischer Wissenschaft und Regierung von Gesundheit, die sich zunächst aus der Praxis der Diätetik, der Lebensführung und privaten Hygiene einer bürgerlichen Schicht herausgebildet hatte, war, wie ich zeigen werde, in den drei Ländern nicht einheitlich. Die anfänglich noch verschiedenen Ausprägungen der Regierung von Gesundheit können im Rückblick aber als Teil einer Reihe von Versuchen und Strategien der Rationalisierung politischer Herrschaft gesehen werden, welche mit »neuen Systemanforderungen $\aleph^{2}$ und Ansprüchen konfrontiert wurde. Dennoch ist diese Entwicklung keinem Plan gefolgt, sondern hat sich über unzählige lokale Konflikte, praktische »Aufstände des Verhaltens « ${ }^{3}$, Widerstände und Begehren nach Macht sowie nach Freiheit von Regierung bis zur Ebene der

2 Kuhn [1973] zitiert nach: Sarasin/Berger/Hänseler/Spörri: Bakteriologie und Moderne: Studien zur Politik des Unsichtbaren, 2007: S. 9.

3 Foucault: Geschichte der Gouvernementalität I, 2004 [1977 - 1978]: S. 333. 
transnationalen Politik entfaltet. Im Laufe dieser Veränderungen wurde der Gegenstand der Gesundheit, die Körper und Bevölkerungen, auf die sich die Regierungen richteten, ihre Techniken, das Subjekt der Regierung und des Regierten, unzähligen Verfahren der Differenzierung und Mechanismen des Ausschlusses unterzogen. Sie durchziehen bis heute die Gesundheit als Gegenstand der Politik und ihren ganz alltäglichen Gebrauch.

Ich werde nun im Folgenden auf die Entwicklungen in den drei Ländern etwa in der Zeit zwischen 1770 und 1850 eingehen. Die Darstellung entspricht keiner lückenlosen Geschichte, wie man sie vorgeblich in Form einer Geschichte entlang der Entstehung der auf Gesundheit gerichteten Institutionen und Gesetze schreiben könnte. Es sind also Fragmente einer Genealogie oder Teile eines unvollständigen Puzzles, in welchen die Veränderungen von Praxen und Diskursen der Regierung von Gesundheit infolge von Krisen und Konflikte deutlich werden. Diese Konflikte und Krisen mündeten ab einem bestimmten Punkt, möglicherweise auch erst nach Beendigung ihrer schärfsten und interessantesten Auseinandersetzungen, in der Bildung einer Institution oder der Verabschiedung eins Gesetzes.

\section{Deutsche StaAten}

Meine Untersuchung der Regierung von Gesundheit anhand deutscher Quellentexte setzt im letzten Drittel des 18. Jahrhunderts an. In dieser Zeit be- und entstanden in den meisten deutschen Staaten Institutionen, die sich mehr oder weniger der Aufgabe der staatlichen Regierung von Gesundheit annahmen. Diese waren zum einen die Medizinalverfassungen und zum anderen die medizinischen Polizeien. In die staatswissenschaftliche Auseinandersetzung darum, was eine gute Polizei oder eine gute medizinische Polizei sei und wie eine dem Staatszweck dienliche Medizinalverfassung eingerichtet werden könnte, mischten sich Kritiken und Einwände, hauptsächlich von Ärzten. Diese stellten die Frage, welche Rolle ihre Gruppe im Geflecht der Regierung von Gesundheit einnehmen sollten. Noch expliziter wurde diese Frage im Rahmen der Problematisierung des Verhältnisses von Arzneikunde und Staat, zum Volk oder zur gesamten Menschheit gestellt.

Die von mir analysierten Texte deuten an, dass die Arzneikunde oder die Ärzteschaft eine nicht zu unterschätzende Rolle bei der Entstehung einer modernen Gouvernementalität von Gesundheit gespielt haben. Sie geben aber auch relativ unabhängig von der Gruppe der Ärzte die Konstellationen der diskursiven Bedingungen und der Rationalitäten wieder, die von unterschiedlichen Seiten ins Spiel gebracht wurden. Es waren Rationalitäten und Bedingungen, die dauerhaft auf das Verhältnis des Souveräns zu den Regierten und auf den Inhalt und die Ziele der Regierung, hinsichtlich der Gesundheit der Untertanen oder der Bevölkerung einwirkten.

Einerseits ging es in diesen Auseinandersetzungen um eine Art Korrespondenz, bei der wechselseitig eine allgemeine Regierungsrationalität und später auch das Selbstverhältnis des Arztes oder des Souveräns modifiziert oder bestätigt wurde. Andererseits ging es darum, dass das Verhältnis zwischen Staat, Medizin bzw. zu den Ärzten und den Menschen einer Neuordnung unterworfen wurde, die schließlich auf eine Neuverteilung und allgemeine Ausweitung von Macht im Bereich der Regierung von Gesundheit zielte. Nicht einfach eine Umverteilung bestehender Macht, sondern 
eine Auseinandersetzung um die Aneignung und Erweiterung sowie den Ausschluss von der Regierung dokumentiert sich in diesen Quellen.

Gegen Ende des 18. Jahrhunderts war man damit beschäftigt, diese Einrichtungen wie die Polizei zu verbessern und zu kritisieren, obwohl ihre grundsätzliche Wichtigkeit im Prinzip kaum in Frage gestellt wurde. Die institutionalisierten Regierungsaufgaben der Ärzte, sofern ihnen zu diesem Zeitpunkt bereits welche zugeschrieben waren (z.B. innerhalb der gerichtlichen Arzneikunde) und die Rationalität, mit welcher sich der Staat auf die Regierung konzentrierte, wurde im Zuge dieser Veränderungen umgeordnet. Zuvor findet sich im 18. Jahrhundert noch die Idee einer systematischen, wissenschaftlichen Begründung von Regierungsaufgaben und Regierungsklugheit.

Bei den hier dargestellten Veränderungen und Umverteilungen von Regierungsmacht ist es wichtig zu bedenken, dass diese Diskussion bereits die Folge von verschiedenen Veränderungen waren, die zunächst, wie Foucault sagen würde, in ganz praktischen Verhaltensänderungen bestand. ${ }^{4}$ Foucault legte überzeugend dar, dass mit dem Übergang von der pastoralen Seelenführung zur >Regierung der Menschen< ab dem 16. Jahrhundert ein umfangreiches und heterogenes Gefüge um die Frage der Regierung entfaltet wird, die eine allgemeine Veränderung oder vielleicht sogar Vereinheitlichung der Regierungsrationalität hervorbrachten. Foucault hat in seinen Vorlesungen zur Geschichte der Gouvernementalität die These aufgestellt, dass es im 16. Jahrhundert einen Übergang »von dem Pastoral der Seelen zur politischen Regierung der Menschen « gegeben hat. ${ }^{5}$ Die Krise der pastoralen Seelenführung im 16. und v.a. 17. Jahrhundert, von der Foucault gesprochen hat, wird im Folgenden einen wichtigen Hintergrund für meine eigene Analyse der Veränderungen auf diesen unterschiedlichen Ebenen der staatlichen Regierung, im Verhalten der Ärzte und im Bürgertum, darstellen. Foucault rekonstruierte eine Reihe von »Umverteilungen«, die »diesen Übergang sanktioniert haben $\aleph^{6}$, und versuchte, einen Moment auszumachen, an dem die eher >private moralische Praxis der Führung und Selbstführung wieder zu einem öffentlichen und politischen Problem wurde. Dabei beobachtete er eine $» I n-$ tensivierung, eine Übersetzung, eine allgemeine Ausweitung dieser Techniken der Verhaltensführung «, ${ }^{7}$ die zuvor zu einer pastoralen privaten Form der gehörten. Wobei diese Differenzierung und das Problem dieser Aufteilung hier überhaupt erst entstanden.

»Diese Leitung [conduction] kommt ebenfalls auf in diesem Bereich, den ich öffentlich nennen werde. Dieser Gegensatz von Privatem und Öffentlichen ist noch nicht sehr relevant, obgleich sich der Gegensatz von Privatem und Öffentlichem zweifellos in der Problematisierung der Verhaltensführung und in der Spezifizierung der verschiedenen Formen der Verhaltensführung zu jener Zeit konstituieren wird. Auf jeden Fall stellt sich auch im öffentlichen Bereich, den man später politisch nennen wird, das Problem: Wie, in welchem Maße kann sich und darf sich

4 »Aufstände des Verhaltens «: Foucault: Geschichte der Gouvernementalität I, 2004 [1977 1978]: S. 333.

5 Ebd.

6 Ebd.

7 Ebd. 
die Machtausübung des Souveräns mit einer bestimmten Anzahl von Aufgaben belasten, die ihr bis dahin nicht bekannt waren und die eben Leistungsaufgaben sind? Der Souverän, der herrscht, der Souverän, der seine Souveränität ausübt, sieht sich von diesem Moment an mit neuen Aufgaben belastet, betraut, konfrontiert, und diese neuen Aufgaben sind gerade diejenigen der Seelenleitung. $\ll^{8}$

Es bestand zu dieser von Foucault beschriebenen Zeit der Transformation der Regierung, innerhalb der ärztlichen Praxis, bereits eine Technik der >Verhaltensführung und eine bestimmte Rationalität des Regierens, die sich auf das Verhältnis zu den $>$ Kranken< bezog. Diese Führungstechnik verfolgte das Ziel, ähnlich wie bei der pastoralen Führung, zu einem >Heil< zu verhelfen. Ein Heil, das sich zwar zunächst auf den Körper, aber im Prinzip auch auf die Seele der einzelnen Menschen richtete. Bis ins 18. Jahrhundert hinein bestand diese nicht-diskursive Regierungspraxis darin, dass Ärzte legitimerweise ihren Patienten sagen konnten, wie diese sich zum Wohle ihrer Gesundheit ernähren und kleiden sollten, welches Pensum von Schlaf und Arbeit, Sexualität usw. angemessen war. Das Ziel dieser ärztlichen Führung war die Erhaltung der Gesundheit, sowohl der seelischen als auch der körperlichen. Körper und Seele, ebenso wie die Glieder, Säfte und Organe des Körpers wurden im Zustand der Gesundheit als Einheit und als Gleichgewicht vorgestellt. ${ }^{9}$ Die Idee des Gleichgewichts oder der Harmonie von Säften und die Vorstellung von Krankheit als ein aus dem Gleichgewicht Geraten der Kräfte innerhalb des Körpers sowie die daran gebundene Konstruktion der Aufgabe der Ärzte wurde 17. und 18. Jahrhundert aus antiken Schriften abgeleitet und in medizinische Lehren und Praktiken eingebaut.

Wenn die Erneuerung der politischen Macht sich ab dem 16. Jahrhundert durch die Übersetzung und Erweiterung der Praxis des Pastorats, der Führung der Seelen vollzog, so meine ich, war die in diesen Texten häufig hergestellte Analogie zur Praxis der Ärzte für diese sehr nützlich, um sich zunehmend selbst als Regierende zu betrachten. Diese >Klugheit $<$ und das >Geschick<, welche die Kunst der Ärzte ausmachte, bot eine Analogie zu einer Regierungskunst im Sinne der Staatsräson. Foucault hat in seinen Vorlesungen u.a. einen Text von Chemnitz von 1647 zitiert, in dem es heißt:

»Was ist die Staatsraison? Sie ist >eine gewisse politische Aufmerksamkeit, die man in allen öffentlichen Angelegenheiten haben muß, in all den Ratschlägen und Plänen, und die einzige nach der Erhaltung, nach der Vergrößerung, nach der Glückseligkeit des Staates streben muß und für die man die verträglichsten und geeignetsten Mittel anwenden muß<.«10

Die Heilkunst versuchte im Grunde genommen auf den Körper bezogen das gleiche: Ihr Ziel war es, den Körper als Einheit und Gleichgewicht zu bewahren oder wiederherzustellen. Die Untersuchung und Behandlung konzentrierte sich auf das Verhältnis der Säfte und Kräfte im Körper mit einem allein auf diesen Körper bezogenes Ziel. Zu dieser Zeit versuchte die Heilkunst sich noch nicht auf Naturgesetze oder auf

8 Ebd.: S. 335f.

9 Vgl. Foucault, Michel: Die Geburt der Klinik, 2008 [1963]: S. 52.

10 Foucault: Geschichte der Gouvernementalität I, 2004 [1977 - 1978]: S. 372. 
universelle wissenschaftlichen Wahrheiten zu stützen. Ähnliches gilt auch für die Staatsräson:

»Sie haben keinerlei Bezugnahme auf eine natürliche Ordnung, auf eine Weltordnung, auf grundlegende Naturgesetze, oder gar auf eine göttliche Ordnung. [...] Das Ziel der Staatsräson ist der Staat selbst, und wenn es etwas wie eine Vollkommenheit, wie ein Glück, wie eine Glückseligkeit gibt, wird es immer nur die - oder dasjenige des Staates sein. $\ll^{11}$

Das bedeutet, dass sich die Staatsräson nicht auf einen Vergleich oder Konflikt um $>$ Universalität< mit einer anderen Souveränität einlassen wollte. Sie versuchte diesem Konflikt geradezu auszuweichen, indem sie ihre Rationalität aus nichts als dem Staat selbst bestimmte. ${ }^{12}$ Damit ist bereits der zweite Aspekt angesprochen, der den bewahrenden Charakter der Regierung betrifft. Das Regieren ist verbunden mit der Praxis der Erhaltung eines Zustandes des Ausgeglichenseins, sie ist eine Praxis des Maßhaltens.

Das Maßhalten hält Foucault für einen besonders charakteristischen Zug der Staatsräson. ${ }^{13}$ Die Staatsräson stellt ein Prinzip dar, dass die Beziehung der Regierung zu ihrem Gegenstand bzw. zu den Kenntnissen und der Kunst, die für eine Regierung notwendig ist, charakterisiert:

»Im Fall der Staatsräson und dieser neuen Art, die Menschen zu regieren, wird man auch ein ganzes Wahrheitsfeld haben, das jedoch offenkundig einem völlig andersartigen Typus angehört [als das des Pastorats.] [...] Ich denke, daß vom 17. Jahrhundert an das notwendige Wissen desjenigen, der regiert, auf ganz andere Weise charakterisiert ist. Was der Souverän oder derjenige, der regiert [...], kennen muß, [sind jene Elemente,] die den Staat ausmachen [...] welche die Aufrechterhaltung des Staates ermöglichen, [...] in seiner Stärke, oder die notwendige Entwicklung der Stärke des Staates, damit er nicht von den anderen beherrscht wird und nicht seine Existenz einbüßt. $\ll^{14}$

Ebenso wie die Staatsräson sich auf das Wissen über den Staat konzentrierte, bezog sich das Wissen der Ärzte auf den Körper und beanspruchte keinen darüberhinausgehenden Bezug zu einer Ordnung. Die Medizin war in dieser Hinsicht eher eine Art Praxiswissen, ein Handwerk oder eine Kunst, wie die Staatsräson: »Mit ihrer praktischen Seite und ihrer Seite der Kenntnis stellt sie eine Kunst dar. ${ }^{15}$ Diese Analogie zeigt nur, dass man die ärztliche Praxis als eine Form der Leitung und Führung ansehen konnte und sich deshalb die Herstellung einer Analogie zum jeweiligen Regierungsdiskurs anbot.

11 Ebd.: S. 373.

$12 »$ Das bedeutet, daß derjenige, der nach der Staatsräson regiert, als unabhängige Macht gegenüber anderen Mächten begrenzte Ziele hat«: Foucault: Geschichte der Gouvernementalität II, 2004 [1978 - 1979]: S. 21.

13 Vgl. Foucault: Geschichte der Gouvernementalität I, 2004 [1977 - 1978]: S. 372.

14 Ebd.: S. 395f.

15 Vgl. ebd.: S. 372. Vgl. Foucault: Die politische Technologie der Individuen, 2005 [1982]: S. 1002. 
In den deutschen Staaten gab es im 17. und 18 Jahrhundert, vor allem nach dem Ende des Dreißigjährigen Krieges und nach Abschluss des Westfälischen Friedens (1648), verschiedene Gründe dafür, dass diese Beschränkung des Regierungsdenkens auf den einzelnen Staat als mangelhaft angesehen wurde. Zum einen führte gerade die Existenz einer Vielzahl deutscher Staaten dazu, dass die Entwicklungen im Bereich der Regierungspraktiken und Gesetze und des Umgangs der jeweiligen >Landesväter mit bestimmten Problemen in einen direkten Vergleich zueinander gestellt werden konnten. Foucault sprach sogar von »kleinstaatlichen Labors«, die zu regelrechten »Experimentierstätten « des Staates und der Regierung wurden ${ }^{16}$. Hierdurch konnte die Form der Kritik der Regierung leichter auf das Mittel des Vergleichs zurückgreifen. ${ }^{17}$ Auch für den Vergleich der Medizinalverfassungen und die medizinische Polizei bestand im letzten Drittel des 18. Jahrhunderts eine eingespielte Praxis. Übrigens finden die Vergleiche hier nicht nur zwischen den deutschen Staaten statt, sondern durchaus auch zwischen den Staaten Europas. Über diese besondere Situation Deutschlands war sich u.a. August Friedrich Hecker sehr bewusst.

»Deutschlands Staatsverfassung, erleichterte und beförderte, vor ieder anderen, die Einführung eines guten Medizinalwesens, theils weil bei so vielen kleinen Ländern, eine genauere Uebersicht desselben, und eine strengere Beobachtung der Medizinalgesetze möglich war, theils weil unter so vielen Fürsten und Obrigkeiten, eine Nacheiferung entstehen musste, iene Quelle des allgemeinen Staatswohls in ieder Stadt, und iedem Lande, so gut als möglich zu besorgen. Dazu kam noch das ungleich festere Band, das die deutschen Fürsten mit ihren Unterthanen inniger vereinigte, als in iedem anderen Reiche, und das ihnen Gelegenheit gab, sich selbst von iedem Mangel, von ieder nötigen Verbesserung zu überzeugen. $\ll^{18}$

Die Frage, welche Medizinalverfassung die beste, die fortschrittlichste sei, ging einher mit der Notwendigkeit, ihren Zweck unabhängig von dem Zweck des einzelnen Staates, also allgemein und universell zu bestimmen. Das Problem der medizinischen Polizei und das der Medizinalverfassungen ist ein quasi grenzenloses - es ist im Verhältnis zur Beschränktheit der Staatsräson ein >endloses< Problem. Dieser Widerspruch prägte, laut Foucault, auch die Diskussionen um die Polizei im 17. und 18. Jahrhundert. ${ }^{19}$ In dieser Situation, die mit der Existenz der vielen kleinen Staaten und der Heterogenität dieser Staaten verbunden war, entstand im Laufe des 18. Jahrhunderts das Bedürfnis nach einer universelleren Grundlage für das, was man zuvor als Regierungskunst im Sinne der Staatsräson nur für den einzelnen Staat gemeint hatte. In Deutschland geschah dies auch unter dem Einfluss mehr oder weniger bürgerlicher, reformerischer und aufklärerischer Kritik der Rationalität der Regierung. ${ }^{20}$ Der Ort, an dem man u.a. versuchte, diese Universalität hervorzubringen, war die Universität.

16 Foucault: Geschichte der Gouvernementalität I, 2004 [1977 - 1978]: S. 457.

17 Ebd.

18 Hecker: Allgemeine Geschichte der Arzneikunde, 1793: S. 272.

19 Foucault: Geschichte der Gouvernementalität II, 2004 [1978 - 1979]: S. 21.

20 Vgl. Foucault: In Verteidigung der Gesellschaft, 2001 [1975 - 76]: S. 279f. 
»[D]ie Universalitäten [wurden] zugleich zu Orten der Reflexion auf die Techniken, die eingesetzt werden sollten, um die Kräfte des Staates zu steigern. Daher rührt die Tatsache, daß in den deutschen Universitäten sich etwas entwickelte, das in Europa praktisch kein Gegenstück hat, nämlich die Polizeiwissenschaft, die Wissenschaft von der Polizei. Diese Polizeiwissenschaft, die von der Mitte, d.h. von Ende des 17. Jahrhunderts bis zum Ende des 18. Jahrhunderts ausschließlich eine deutsche Besonderheit sein wird, [...] die sich über Europa ausbreiten und die einen wesentlichen Einfluß haben wird. $\ll^{21}$

Aber nicht nur die Polizeiwissenschaft, auch die Arzneiwissenschaft, Arzneikunde oder Medizin suchte in Deutschland in besonderer Weise nach einer universellen wissenschaftlichen und theoretischen Grundlage. Ähnlich so, wie man in den deutschen Staaten versuchte, anders als in anderen europäischen Ländern, die Idee der Polizei als Instrument der Steigerung der Kräfte des Staates ganz theoretisch und spekulativ zu problematisieren. Es gab auch eine ausgesprochen >idealistische< Suche nach der theoretischen Grundlage der Arzneiwissenschaft. ${ }^{22}$

So glaubte etwa der Arzt A.F. Marcus, der zwischen 1805 und 1808 gemeinsam mit Schelling die Jahrbücher der Medicin herausgab, angesichts des sich in Südeuropa ausbreitenden Gelbfiebers zu Beginn des 19. Jahrhunderts, dass ohne eine universelle medizinische Theorie auch kein >rationales< Heilmittel gegen die Krankheit gefunden werden könnte:

"So lange es noch an einer richtigen Theorie und besseren Ansichten in der Medizin fehlt, werden uns diese Selbstbeobachter wenig Haltbares und Nachahmungswerthes lifern. Ein jeder sieht aus seiner eigenen Brille, und verkauft uns seine Täuschungen für reine Beobachtung, oder gar für Erfahrung. $\ll^{23}$

21 Foucault: Geschichte der Gouvernementalität I, 2004 [1977 - 1978]: S. 458.

22 Der berühmteste Vertreter dieser Strömung war kein anderer als Friedrich Schelling. Er war, wie die anderen Anhänger dieser $>$ spekulativen $<$ Medizin, maßgeblich durch die $>$ Erregungstheorie< des schottischen Arztes John Brown, dessen Erfolg in Großbritannien scheinbar nur mäßig war, beeinflusst. Die Anhänger Schellings und der Naturphilosophie wendeten sich aber bald von dem zu sehr an >empirischen< Methoden ausgerichteten brownschen System ab. Schelling war der Meinung, man müsse die »Heilkunde auch auf sichre Principien, ihre Ausübung aber auf unfehlbare Regeln« stützen und schimpfte auf die Empiriker und die praktischen Ärzte, die nur die oberflächlichen Phänomene und Veränderungen in Augenschein nähmen. Vgl. Schelling: Entwurf eines Systems der Naturphilosophie, 1799: S. 274f.

23 Vgl. Marcus, A.F.: Beyträge zur Erkenntniß und Behandlung des gelben Fiebers, 1805: S. x. 


\section{Regierung der Arzneiwissenschaft und des Staates}

»Die Heilkunst ist ein Gemeingut der Menschheit. Sie gehört nicht einer Zeit, nicht einem Volk, sondern allen Zeiten und allen Völkern an. ${ }^{24}$

Der folgende Abschnitt soll zeigen, wie sich die Hinwendung zu einer universelleren Rationalität und Praxis der Regierung der Gesundheit der Menschen um 1800 in den deutschen Staaten auf der Diskursebene gestaltete. Der Ausgangspunkt im Denken und in der Praxis, der eine neue Verteilung der Regierung von Gesundheit zwischen Ärzten und Staat bewirken sollte, war eine auf Wissenschaft und Ethik begründete Universalisierung und Ausdehnung der Arzneiwissenschaft. Zwecke und Machtraum einer Regierung von Gesundheit und ihre ganze Existenzbedingung wurde aus dem Gegenstand der Regierung - dem Leben selbst - naturwissenschaftlich und philosophisch formuliert. Damit erfanden und entdeckten die bürgerlichen Ärzte und Arzneiwissenschaftler eine Rationalität der Regierung von Gesundheit wieder, indem sie sich auf antike Schriften griechischer und römischer Ärzte und deren medizinische und diätetische Lehren bezogen. Sie positionierte sich kritisch zu der zu dieser Zeit in vielen deutschen Staaten bereits existierenden staatlichen Medizinalverfassung und medizinischen Polizei. Im Zuge dessen artikulierten sie neue Kriterien für eine >vernünftige < und >moralische< Regierung der Gesundheit, die sie aus ihrer eigenen ärztlichen Regierungspraxis und ärztlichen Moral ableiteten. So nahmen sie schließlich Einfluss darauf, die Polizei und die Medizinalverfassungen zu reformieren. Dabei griffen die Ärzte erstens auf Elemente der ärztlich-philosophischen Auseinandersetzungen um eine Rationalisierung der Arzneiwissenschaft zurück. Zweitens integrierten sie Elemente der bürgerlich-hygienischen Idee einer (Selbst-)Regierung von Gesundheit, die aus der Kritik und teilweise Neubesetzung des Bereichs der pastoralen Führung erwachsen war.

\section{Die ärztliche Regierungspraxis}

Ende des 18. und Anfang des 19. Jahrhunderts geriet die deutsche Arzneiwissenschaft auch unter dem Druck veränderter Anforderungen an die Wissenschaft und Heilkunst in eine schwere Krise. Zu diesen neuen Anforderungen gehörte auch, die Arzneiwissenschaft auf Basis eines breiteren und auch naturwissenschaftlichen Wissens auszubauen. Die Bedingungen für Wahrheit knüpfte sich an naturwissenschaftliche Erkenntnistheorien und Methoden und schließlich auch an das Verhältnis des Wissens zur Aufgabe der Führung der Ärzte. Aus dieser Bewegung der Neubegründung der Arzneiwissenschaft und der ärztlichen Praxis resultierte der Anspruch, aus der Wissenschaft und Praxis der Ärzte eine moderne Regierungswissenschaft und Kritik der Regierung von Gesundheit entstehen zu lassen. Die Arzneiwissenschaft in Deutschland beanspruchte tatsächlich - zumindest eine Zeit lang - nicht nur das

24 Hufeland, C.W.: Aufforderung an alle Ärzte Teutschlands und des Auslands zu einer Verbindung für die Beibehaltung der officiellen Namen der Heilmittel: in: JPA, 1.33=40, 1815, S. 1 - 14: S. 8. 
Wissen, sondern auch eine bestimmte Rationalität der Regierung, eine Auffassung von dem Gegenstand - dem Leben oder der Gesundheit - und einem aus ihm hervorgehenden Existenzgrund einer allgemeinen Regierung von Gesundheit zu liefern. Dem ging eine Auseinandersetzung der Ärzte, die um die Bedeutung und Veränderung eines ganz bestimmten Teiles ärztlicher Praxis wussten, voraus. Im Fokus dieser Debatte stand weniger der eher als >handwerklich< bezeichnete Bereich ärztlichen Könnens und Wissens. Eher ging es um eine ganz bestimmte Funktion und moralische Position des Arztes, die es ihm ermöglichen sollte, das Vertrauen des Patienten zu gewinnen, ihn dazu zu bringen, die Medikamente, die man ihm verschreibt, einzunehmen und die Lebensweise, die man ihm für seine Heilung vorschreibt, anzunehmen. Sowohl die handwerkliche, wie auch die moralische Praxis sind auf das Ziel der Heilung von Krankheiten ausgerichtet. Aber die Bedeutung dieser moralischen Position des Arztes geht über den Moment der Heilung hinaus. Dieser ganze Bereich der Leitung des Verhaltens ist ein Bereich der Regierung, durch welchen die Ärzte versuchen können oder die Aufgabe haben, die Lebensweise und das Verhalten einer Person grundlegender zu ändern. Es ist eine Regierung unter den neuen Bedingungen der Gouvernementalität. Gerade weil die ärztliche Praxis über die Kluft der Jahrhunderte zwischen Antike und Modere, Elemente dieser Praktiken des »gouverner ${ }^{25}$ im Sinne einer moralischen Führung in sich aufgenommen hat, so wie im übrigen die Führung der Seelen als Bereich der Geistlichen Regierung begriffen wurde, ist die Heilkunst von den Transformationen der Verfahren der Gouvernementalität ${ }^{26}$ selbst betroffen, ohne zu diesem Zeitpunkt zu wissen, welche Rolle sie und welche Rolle die Ärzte bei diesen Übertragungen und Neuverteilungen der Macht spielen werden. »Alle [der Lehrer, der Erzieher, der Arzt etc.] « meinte Foucault, »können beanspruchen Pastoren zu sein und stellen demnach ausnahmslos Rivalen des Politikers dar $\ll^{27}$. Die Krise der Heilkunst bestand darin, dass sich die Bedingungen für diese Regierung änderten und die Ärzte, wenn sie diesen Anforderungen nicht entsprechen konnten, nichts weiter gewesen wären als Handwerker.

Das folgende Beispiel ist ein Artikel aus dem Journal der practischen Arzneikunde von 1795 und beschäftigt sich mit dem sog. Sçavoir faire ${ }^{28}$ der praktizierenden Ärzte. ${ }^{29}$ Den Ausdruck »Sçavoir faire« definiert der Herausgeber des Journals, Arzt und Autor, Christoph Wilhelm Hufeland, in dem Artikel als »Geschicklichkeit, etwas so zu machen, daß es so gut als möglich gelingt. $\ll^{30}$

25 Foucault: Geschichte der Gouvernementalität I, 2004 [1977 - 1978]: S. 182.

26 Denn mit Gouvernementalität meint Foucault alle Verfahren der Verhaltensführung, egal ob sie durch einen Arzt, Lehrer oder Prieser ausgeübt werden. Vgl. ebd.: S. $288 f$.

27 Ebd.: S. 212.

28 Es gibt Ende des 18. Jahrhunderts einen nicht unerheblichen Korpus von Veröffentlichung verschiedener Ärzte zum »Sçavoir faire in der ärztlichen Praxis«, »über die moralische Wirksamkeit des Arztes« und »Praktische Lehren und Regeln für angehende Ärzte«, von denen ich hier nur eine herausgegriffen habe.

29 Vgl. Vogel, S.G.: Einige allgemeine Bemerkungen über das Sçavoir faire in der medicinischen Praxis: in: JPA, 3.1, 1795, S. 295 - 324.

30 Ebd.: S. 295. 
»Sehr viel wichtiges Sçavoir faire liegt vor allen Dingen in der Kunst des Arztes, das Zutrauen seiner Kranken zu gewinnen, und zu erhalten. Dazu treten Weltklugheit, Menschenkenntniß, liberale Erziehung, Humanität, äussere Cultur, im Ganzen sehr viel bey. Solche Eigenschaften verschaffen dem Arzte überall leichten Eingang, nehmen für seine Kenntnisse sofort ein, und machen den Kranken geneigt, seine Verordnungen zu folgen, und alles Gute davon zu hoffen. [...] Was läßt sich dadurch nicht bei den Menschen erreichen! «11

Hufeland beschreibt hier über Seiten hinweg, was das Geschick und das Gespür eines Arztes sein müsse, um genau für jeden Patienten die richtigen Methoden anzuwenden - um diesen »gehörig zu leiten«. Er macht Unterschiede zwischen verschieden Patienten auf, die auf unterschiedliche Weise dazu gebracht werden müssten, sich an die Anleitung der Ärzte zu halten.

»Einzelne Kranke können darum nur gewisse Aerzte curieren. Mit manchen Aerzten ist es gleich oder bald vorbey, wenn die Cur nicht bald anschlägt, der Kranke verliert schnell die Neigung, ihnen weiter zu folgen. $\ll^{32}$

»Es gehört warlich zuweilen ein eher erfinderischer Kopf dazu, sich hierbey mahl so zu helfen, daß alles beseitigt oder verhütet wird, was die Ausführung des Plans behindert « ${ }^{33}$

Hufeland unterscheidet zwischen den Menschen, über die despotisch zu herrschen sei, und denen, die gebildet und in der Lage seien, auf Grundlage der Vernunft die Vorschläge der Behandlung des Arztes einzusehen:

»Es gehört vielmehr zum Sçavoir faire, zuweilen den Kranken nicht nachzugeben, sich nicht nach seinen Launen, nach seinem Eigensinne zu bequemen, nicht erst mit ihm gleichsam in Unterhandlungen sich einzulassen, u.s.w. sondern durchzugreifen und beharrlich zu insistieren. Manche Kranke sind nicht anders gut zu behandeln, als daß der Arzt mehr oder weniger anordnet und veranstaltet, was nötig ist. Er muß selbst zuweilen mit despotischer Autorität seine Plane ausführen. Aber wie, wo, wenn und unter welchen Umständen dies Statt finde, das muß er zu machen und zu treffen wissen. ${ }^{34}$

In Bezug auf den gebildeten einsichtigen Patienten schrieb Hufeland hingegen:

»Für den Arzt, der immer nach richtigen Gründen und mit Ueberlegung handelt, und zugleich seiner Sache, soviel es seyn kann, gewiß ist, sind solche Kranke sehr angenehm. Man kann mit ihnen ohne Bedenken überlegen, was zu ihrem Heile dient und anzuwenden ist, und darf auch nicht fürchten, ihr Zutrauen sey auf einmahl verlohren, wenn ihrgend eine widrige Wirkung erfolgt, weil sie sich von den Ursachen überzeugen lassen, welche möglicherweise daran Schuld sind. $\ll^{35}$

31 Ebd.: S. 297f.

32 Ebd.: S. 301.

33 Ebd.: S. 202.

34 Ebd.: S. 306f.

35 Ebd.: S. 310. 
Der Regierungsanspruch, der Anspruch der Ärzte, die Menschen zu leiten und ihnen vorschreiben zu können, wie sie sich führen sollten, wie sie leben sollen, um gesund zu bleiben oder um wieder gesund zu werden, dieser Anspruch wurde im 18. Jahrhundert von den Ärzten neu begründet. Das alte Sçavoir faire der ärztlichen Praxis, die Kunst der ärztlichen Regierung existierte im Wesentlichen getrennt von der (universellen) Wahrheit einer medizinischen Theorie oder medizinischen Kenntnissen. Sie hatte sich auf einen ganz anderen Bereich von Kenntnissen bezogen, die der Arzt für sich erworben hatte und sie bestanden in einer Art Geschick und Kunst. In dem Artikel von Hufeland taucht neben dem Sçavoir faire eine ganz andere Form der Regierung auf, die abhängig von der $>$ Wahrheit $<$ und $>$ Rationalität $<$ der Behandlung ist. Gleichzeitig ist sie eine Art Indikator, ein Beweisverfahren für die Subjektivität des Arztes. Lässt dieser sich darauf ein, die Gründe für seine Behandlung offenzulegen, zeichnet es ihn als Subjekt, als moralischen und rationalen Arzt aus. Die Methode setzt aber voraus, dass das Subjekt, auf welches die Behandlung angewendet wird, in der Lage ist, die Rationalität zu erkennen und sie zu akzeptieren. In diesem Fall, den Hufeland der gelungenen Ausübung der Sçavoir faire vorzieht, ist kein »Geschmeichel«, sind keine Tricks und keine Kunst der Überredung und Rhetorik mehr erforderlich. Es ist die Anerkennung der Regierung auf der Grundlage der Vernunft. Die Bewertungen, die Hufeland vornimmt, stehen im Zusammenhang mit einem an Hippokrates anknüpfenden bürgerlich-humanistischen moralischen Selbstbild der Ärzte und dem Anspruch der Arzneiwissenschaft, eine >objektive< (Natur-)Wissenschaft zu sein. Es ist aber auch die Reaktion auf eine Kritik an der ärztlichen Praxis, die sich auf die Begrenzung der Macht der Ärzte gegenüber der Selbstregierung der Subjekte bezieht. Das bedeutet, wenn eine Person sich selbst >rational< regiert, dann wird der Arzt zu einer Art Berater. ${ }^{36}$ Er darf nicht mehr sein als ein Berater der SelbstRegierung. Die Rationalisierung der hier entstehenden Gouvernementalität (der Gesundheit) wird auf eine Praxis der Reinigung und Trennung des Wissens von der Macht der Regierung aufbauen, während sie gleichzeitig eine neue Abhängigkeit zwischen den beiden Bereichen festlegt.

\section{Die Verteidigung der Arzneikunde}

Ich will mich im Folgenden mit einem Buch beschäftigen, dass der Arzt Christian Gottfried Gruner 1772 veröffentlicht hat. Gruner scheint mir besonders deswegen ein interessantes Beispiel zu sein, weil er neben Grimm und Ackermann ${ }^{37}$ zu einem im 18. Jahrhundert sehr einflussreichen neo-hippokratischen Schule von Medizinern gehörte, die ihre Lehre auf die Interpretation der Schriften von Galen und anderer anti-

36 Das ist übrigens die gleiche Konsequenz, die Platon aus dem Verhältnis eines Arztes der freien Medizin zu einem freien Mann zieht, um sie dann auf das Verhältnis zwischen einem politischen Berater und einem Herrscher rückzuübertragen. Vgl. Foucault: Die Regierung des Selbst und der anderen I, 2009 [1982 - 1883]: S. 292; S. 333.

37 Johann Christian Gottlieb Ackermann (1756 - 1801). Die deutsche Übersetzung der »Hippocratischen Sammlung« von Johann Friedrich Karl Grimm (1737 - 1821), die zwischen 1781 und 1792 erschien, wird noch heute verwendet. 
ker Texte über diätetische Praxen begründeten. ${ }^{38}$ Der Titel des Buches von Gruner lautet Gedanken von der Arzneiwissenschaft und den Aerzten. Das Buch beginnt mit dem Verhältnis von Arzneiwissenschaft und Staat. Gruner verteidigt die Arzneiwissenschaft und kritisiert die Regierung und die Obrigkeit. Das Buch beginnt damit, dass der Autor bemerkt, dass die Arzneiwissenschaft mehr als andere Wissenschaften einer besonderen Kritik ausgesetzt sei. »Keiner Wissenschaft hat man wohl jemals die Ungewißheit ihrer Sätze so sehr zum Vorwurf gemacht, als es der Arzneikunde widerfahren ist. $\ll^{39}$

In dem Journal der Erfindungen, Theorien und Widersprüche in der Natur und Arzneiwissenschaft findet sich 1796 ein Artikel, der vom Wortlaut dem Buch von Gruner sehr ähnelt. Der Artikel ist die Antwort auf einen Angriff auf die Arzneiwissenschaft in einem Artikel im Neuen teutschen Merkur ${ }^{40}$ und setzt zur $»$ Verteidigung der rationellen Arzneiwissenschaft« an, gegen den Vorwurf, die Medizin entbehre jeglicher Gewissheit und ihr Wissen sei nichts weiter als »ein verwirrtes Chaos « ${ }^{41}$.

Was lässt sich über die Gründe für die besonders harte Kritik an der Arzneikunde und der Medizin sagen? Ich denke, dass sich diese Kritik nicht so sehr auf die Medizin als Wissenschaft richtete, sondern, dass sie sich gerade auf die Tendenz der Arzneiwissenschaft bezog, sich als eine Regierungswissenschaft zu verstehen. Kritisiert wurde also ihre Tendenz, durch das, was sie an Wissen hervorbrachte, gleichzeitig Machtbereiche zu erschließen und sich die Aufgabe der Führung der Menschen anzueignen. Aus diesem Grund handelt Gruners Buch auch von der Verteidigung der Arzneikunde im Sinne ihrer Nützlichkeit für die Regierung. ${ }^{42}$ Der Text von Gruner, ebenso wie der aus dem Journal, will deshalb durch eine Reihe von Aussagen auf die Frage, warum und unter welchen Bedingungen Gesundheit Gegenstand einer Regierung sein kann oder sein muss, Antwort geben. Gruner legte besondere Betonung auf den konkreten Anteil, den Ärzte an diesen Aufgaben der Regierung des Lebens haben. Er betonte, welche Verantwortung sich aus dem Wissen der Arzneiwissenschaft auch für die Obrigkeit, die Eltern und andere Personen ergebe, die auf irgendeine Weise die Rolle der Führung von Menschen einnehmen würden und deshalb Macht über das Leben und die Gesundheit anderer Menschen hätten.

Ich werde versuchen, diese Konstellation von Wissen, Subjekt und Regierungsmacht und die Rationalität, die sie zusammenhält, ein wenig nachzuzeichnen. Eine Kernaussage des Buches von Gruner ist, dass die Arzneiwissenschaft nicht allein das Wissen der Ärzte ist, sondern, dass sie ebenso gut das Wissen des Staates ausmacht,

38 H. [Hecker, A.F.] Ueber die Lebenskraft, Heilkraft der Natur Rohheit der Krankheitsmaterie, Kochung, Krisen und kritische Tage; mit Hinsicht auf die neusten Behandlungen über diese Gegenstände überhaupt, besonders aber auf die Göttingsche Preisfrage vom Jahre 1803 [...]: in: JNA, 34.10, 1803, S. 3 - 83: S. 4f; $10 \mathrm{ff}$.

39 Gruner: Gedanken von der Arzneiwissenschaft und den Ärzten, 1772: S. 21.

40 Der Artikel richtete sich an den Herausgeber von Der neue teutsche Merkur, Christoph Martin Wieland.

41 [Anonym]: Verteidigung der rationellen Arzneiwissenschaft, gegen die Angriffe auf dieselbe im Neuen teutschen Merkur 8 Stück 1795 und 1 Stück 1796: in: JNA, 18.5, 1796, S. 70 - 125: S. 73.

42 Vgl. ebd.: S. 76. 
der sich um die Gesundheit seiner Bürger sorgt und sogar sorgen muss. Die Arzneikunde ist ein unentbehrlicher Bereich des Staatswissens, so die Behauptung Gruners. Dies gelte natürlich nur dann, wenn eine Regierung akzeptiert habe, dass sie als gute Regierung das Ziel haben müsse, die Gesundheit ihrer Bevölkerung durch den Rückgriff auf wissenschaftliche Wahrheiten zu erhalten und zu schützen. »Nichts muß dem Regenten mehr am Herzen liegen, als die Ursachen der Entvölkerung zu dämpfen, die fast in allen Theilen Europas mit aller Gewalt einzureißen scheint. « ${ }^{43}$

Immer wieder wird auch Bezug genommen auf den Zusammenhang von Bevölkerungszuwachs ${ }^{44}$ bzw. >Entvölkerung< und die Notwendigkeit der Förderung der Arzneiwissenschaft, die »so viel Glück über das Leben und die Gesundheit der Bürger verbreitet $\varkappa^{45}$ und guter Ärzte im Staat.

»Und wie notwendig und beinahe unentbehrlich muß es werden, in einer so wichtigen Sache, als Leben und Gesundheit ist, und wo der geringste Fehler nachtheilig werden kann, die Kennzeichen der guten und schlechten Aerzte, der Charlatans, Afterärzte und Aerztinnen, die, wie verderbliche Insekten das Land von seinen Einwohnern entblößen, genau und in ihrem ganzen Umfange zu kennen. $\ll^{46}$

Die Sorge einer guten Staatsregierung muss sich auf die Gesundheit und das Leben der Bevölkerung als auch ihre Vergrößerung richten. Die Arzneiwissenschaft ist die Wissenschaft, die am meisten der Erhaltung der Gesundheit und der Förderung des Lebens im Allgemeinen dient. Das sind die zwei Aussagen, die sich in sehr unterschiedlichen Texten wiederfinden. Über die Universalität des Gegenstandes der Gesundheit und des Lebens beansprucht die Arzneiwissenschaft mehr zu sein als eine Disziplin oder eine Kunst. Sie will sich von dem Vorwurf freimachen, sich selbst die Regierungsmacht anzumaßen, aber sie will wenigstens darauf bestehen, die unabkömmliche Beraterin einer rationellen Regierung zu sein.

Praktische Kenntnis und Geschick verbanden sich in der Kunst, die zugleich eine Fähigkeit und Macht darstellte, die eine Person besitzen konnte. Eine Macht, die z.B. ein Arzt oder ein Regent besitzen konnte, um seinen Staat zu leiten bzw. um eine Krankheit zu heilen. Kenntnis und Macht fallen ganz unproblematisch zusammen, oder haben zumindest eine direkte Verbindung. Macht und Kenntnis unterschiedlicher Ärzte wurde quantitativ gedacht. Nun ergab sich eine Situation, in der das Wissen, wie es die Ärzte hier charakterisieren, für das moralische Subjekt ein Gebot oder eine Pflicht nach sich zog, sich auf eine bestimmte Weise zu verhalten oder zu regieren, wobei dieses Wissen aber nicht notwendig eine Macht mit sich brachte, dies auch tun zu können. Das, was den Ärzten vom Regieren blieb, war nicht die Macht oder Fähigkeit, sondern eine Vernunft-Pflicht und ein moralisches Gebot. >Wer dem Imperativ seiner Vernunft nicht Folge leistet, ist entweder unmoralisch oder unglücklich oder vermutlich beides $<$ Genau in dieser »traurigen Lage « befanden sich nach Ansicht Gruners die Ärzte, da sie das Wissen besaßen und aufgrund ihrer Moralität

43 Gruner: Gedanken von der Arzneiwissenschaft und den Ärzten, 1772: S. 620.

44 Ebd.: S. 593.

45 Ebd.: Vorrede: S. 1.

46 Ebd.: Vorrede: S. 7. 
auch die Pflicht verspürten, die unwissenden $-» B \operatorname{Binden} \aleph^{47}-$ zu führen, aber die Mittel und Rechte nicht besaßen, um die Regierung der Gesundheit in ihre Hände zu nehmen. Auch Johann Christian Gottlieb Ackermann verwies auf diese Rolle des unglücklich Wissenden, der nur hoffen könne (und dessen Hoffnung sich teilweise bestätigt habe), dass der Regent seine »Winke« wahrnehmen und anerkennen würde. ${ }^{48}$ Wie ich bereits erwähnt habe, gehörte Johann Christian Gottlieb Ackermann wie Gruner zur »hippocratische[n] Zunft« oder stand sogar »an der Spitze der hippokratischen Aerzte ${ }^{49}$. Er veröffentlichte eine Reihe von direkten Empfehlungen für die Regierungen. Diese bezogen sich etwa auf das Problem der Brunnen und Bäder und auf das Problem der Ausbildung der Ärzte, wie seine erst 1806 durch Johann Friedrich Kühn veröffentlichten Polizeylich-medizinische Miszellen zeigen. ${ }^{50}$ Ackermann beschrieb wie Gruner das Dilemma, welches die Ärzte und die Regierung des Staates zusammenschweißen sollte: >Wir haben das Wissen $<$, sagen die Ärzte, >und dieses Wissen, um das, was wahr und richtig wäre, ist wie eine moralische Pflicht gegenüber uns selbst, sie ist eine Last unter der wir leiden. Aber wir, die Ärzte, haben keine Macht, die Dinge in eine gute Ordnung zu bringen. Diese Macht hat nur die Regierung, der aber das Wissen fehlt<.

»Die Menschlichkeit seufzt schon lange über das Elend, dem viele Armen bei ihren Krankheiten ausgesetzt sind. Hier, wo Kummer, Noth und Plagen die Bewohner schlechter Hütten folterten, mähte die unbarmherzige Hand des Todes, in großen Epidemien oft ganze Herden hin, ohne daß die Obern auf die vornehmste Ursache der Entvölkerung ihr Augenmerk richteten. Der Menschenfreund und Patriot vergoß oft im Stillen eine Zähre, die seinem guten Herzen Ehre machten, und trug alles mögliche bei, um das Elend der Armen zu mildern, ohne eine bessere Aussicht in die Zukunft zu haben [...]. $\ll^{51}$

Nur die Regierung, die Obrigkeit, sie hat die Mittel, sie muss regieren, indem sie sich auf das Wissen der Medizin und der Ärzte stützt. ${ }^{52}$

»Die Obrigkeiten sind die Aufseher und Richter der Nationen, und die Wichtigkeit ihres Postens verbindet sie, nicht allein alle Hindernisse des Lebens und der Gesundheit ihrer Untergebenen zu zernichten, sondern auch alle Vorschläge und Mittel, welche das Ihrige zur Erhaltung dieser Güter beitragen, durch ihr Ansehen und Gewalt wirklich zu machen. $\ll^{53}$

47 Ebd.: Vorrede: S. 6f.

48 Vgl. Vorwort von Johann Friedrich Kühn: in: Ackermann, Johann Christian Gottlieb: Polizeylich-medizinische Miszellen, 1806: S. Xf.

49 H. [Hecker, A.F.] Ueber die Lebenskraft, Heilkraft der Natur Rohheit der Krankheitsmaterie, Kochung, Krisen und kritische Tage; mit Hinsicht auf die neusten Behandlungen über diese Gegenstände überhaupt, besonders aber auf die Göttingsche Preisfrage vom Jahre 1803 [...]: in: JNA, 34.10, 1803, S. 3 - 83: S. 4.

50 Vgl. Kühn: Vorwort: in: Ackermann: Polizeylich-medizinische Miszellen, 1806: S. VII.

51 Vgl. Gruner: Gedanken von der Arzneiwissenschaft und den Ärzten, 1772: S. 584.

52 Vgl. ebd.: S. 610.

53 Ebd.: S. 590. 
»Der Regent hat stets die sichersten Mittel in seiner Gewalt, wenn er groß genug ist, uneigennützig zu seyn, und ihm eine große Anzahl gesunder und starker Bürger mehr Vergnügen macht, als eine kleine Vermehrung der Einkünfte. ${ }^{54}$

Dem Ansatz der Ärzte steht von Seiten der Regenten noch durchaus eine andere Rationalität entgegen. Die Regenten der Staaten interessierten sich für die Bevölkerung nur in einer sehr klar auf die Ziele des Staates gerichteten Weise. Ihr Ziel, die Stärke des Staates zu steigern, war begrenzt durch einen allein auf den Staat und seine Existenz bezogenen Zweck. Für alle Maßnahmen und Gesetzte, mit der eine StaatsRegierung diesen Zweck verfolgte, benötigte sie keiner weiteren Legitimation. Das galt auch für Maßnahmen, mit der sich die Obrigkeit auf die Bevölkerung richtete. In dem Handbuch der Staatsarzeneykunde, medicinische Policey und gerichtliche Arzneywissenschaft von 1787 hieß es unter $\$ 28 \mathrm{zu}$ den »Pflichten der Landes-Obrigkeit .

»So wie der Landes-Obrigkeit daß Recht zukommt, auf eine Med. Polizey mit Ernst und Nachdruck zu halten, so ist es auch ihre Pflicht durch zweckmäßige Gesetze und Verordnungen für eine gesunde Population zu sorgen und ihrer Unterthanen Gesundheit und Leben gegen alle Angriffe in Schutz zu nehmen; auch den Viehseuchen, so viel möglich, zu steuern. «55

Im folgenden Paragraphen wird die Sorge für die Population als erste Aufgabe der Obrigkeit folgendermaßen formuliert:

»Jeder Landes-Obrigkeit ist daran gelegen, daß die ihr untergebenen Provinzen bevölkert seyn. Doch ist nicht jede Bevölkerung dem Lande vortheilhaft, sondern nur diejenige, welche eine hinlängliche und der Beschaffenheit des Bodens angemessene Anzahl arbeitsamer und gesunder Einwohner voraussetzt. $\ll^{56}$

Diese Grundausrichtung, auf der die im 18. Jahrhundert eingerichteten Medizinalordnungen in den deutschen Ländern maßgeblich aufgebaut waren, enthielt keine besondere moralische Komponente. Das Leben und die Gesundheit der Bürger wurden nicht mit Verweis auf ein universelles moralisches Gebot begründet, sondern selbstverständlicher Selbstzweck der Staatsregierung. Leben und Gesundheit, ebenso wie Sittlichkeit und Moral, waren höchstens in dem Maße für die Regierung Thema, wie sie sich für den Staatszweck als relevant erwiesen.

In dem Paragraphen zur »Beförderung der Ehen« wird zum Beispiel angeführt, dass Sittlichkeit dazu diene, die Fortpflanzung innerhalb legaler und finanziell abgesicherter Ehen stattfinden zu lassen. Die Regierung, die hier der Obrigkeit zugeordnet ist, hat nicht den Auftrag, die einzelnen Menschen im Hinblick auf ihr Selbst oder ihre Seele zu regieren und darüber ihr Verhalten zu verändern. Die ganze aufwändige Aussagen-Formation, die später die Anforderungen für eine gute, das heißt morali-

54 Ebd.: S. 619.

55 Metzger: Handbuch der Staatsarzeneykunde enthaltend die medicinische Policey und die gerichtliche Arzneywissenschaft, 1787: S. 10.

56 Ebd. 
sche Regierung hervorbringen wird, ist hier nicht zu erkennen. ${ }^{57}$ An diesem Beispiel lässt sich zeigen, dass die Ärzte daran beteiligt waren, der Regierung der Gesundheit und der Bevölkerung ein ganz neues Kriterium der moralischen Seelenführung aufzuerlegen. Die strategische Konstruktion der ärztlichen Kritik an der Regierung ergibt sich aus einer Situation, in welcher die Ärzte aufgrund ihres traditionellen Anspruchs auf Regierung angefeindet werden und dabei mehr oder weniger bewusst eine neue Rationalität ins Spiel bringen. Diese Rationalität wird sich aber gerade deshalb durchsetzen, weil sie entgegen der Behauptung ihrer Distanz zur Macht gerade dazu führen wird, dass sich die Regierung von allen möglichen Beschränkungen der Regierung des Staates befreien können wird. Nämlich, indem sie nun einen quasi unendlichen und grenzenlosen Gegenstand, das Leben und die Gesundheit der Bevölkerung bzw. der Individuen, akzeptierbar macht.

Es ist zu diesem Zeitpunkt, im letzten Drittel des 18. Jahrhunderts, für den Regenten eines Staates noch völlig unproblematisch, ein rein auf den Staat gerichtetes Interesse zu vertreten und dieses zum Ausgangspunkt seiner Regierung zu machen. Es ist legitim, aus dem reinen Interesse, den Staat zu erhalten, ein Interesse an der Gesundheit seiner Bevölkerung zu haben. Der Anspruch der Ärzte, den einzelnen Menschen zum Wohl aller zu regieren und damit allgemein menschliche oder sogar göttliche Ziele zu verfolgen, wirkte dagegen anmaßend. Die Ärzte erlaubten sich sogar, der Obrigkeit zu sagen, wie sie regieren sollte, wenn es um die Regierung des Lebens ging. Denn die Regierung des Lebens und der Bevölkerung war längst nicht mehr Sache des Staates, sondern so allgemein, dass sie jeden Bürger etwas anging. Warum sollte aber jeder Bürger ein Recht haben, sich für diesen Gegenstand zu interessieren und ihn sogar zu regieren? Weil er laut den Ärzten ansonsten gezwungen würde, gegen seine eigenen moralischen Pflichten, die er seinem Selbst und seiner Seele schuldig war, zu verstoßen. Der Regent, der seine Pflicht vernachlässigte, verstieß gegen ein Gesetz, dass größer war als er selbst und das zuvor eben nur das göttliche war. Genau diese Argumentation diente den Ärzten. Sie konnten hierdurch begründen, warum sie, die formal weder Macht noch Mittel hatten, durch ihr Wissen und vor allem durch ihre moralische Position dazu berechtigt waren, allgemein über die Regierung zu urteilen. Gerade weil sie weder Macht noch Mittel hatten so umfangreich zu regieren, wie es der Gegenstand erforderte, konnten sie wahre Urteile über die Regierung aussprechen.

Was geschah, wenn die Ärzte dennoch versuchten, die Übel selbst zu bekämpfen, die sie sahen und zu ihrem Leidwesen so gut durchblickten, dass sie auch wussten, wie dem abgeholfen werden konnte? Gruner gab auch darauf eine Antwort. Er nannte ein Beispiel, dass eine Zeit lang relativ populär gewesen zu sein scheint, auch weil es vermutlich außergewöhnlich war. Zumindest habe ich in einer Ausgabe der Zeitschrift Berlinische Sammlungen von 1768 ebenfalls einen Artikel gefunden, der sich diesem Ereignis sehr ausführlich gewidmet hatte. Es ging um eine Vereinigung von Hamburger Ärzten, die es sich zum Ziel ihres Verbandes setzten, den kranken Armen in Hamburg zu helfen. Der Artikel über den »Vereinigungsplan verschiedener Aerzte und Wundärzte zum Vortheil der hamburgischen kranken Hausarmen« wurde ausdrücklich mit dem Ziel abgedruckt »in allen großen Städten eine löbliche Nachah- 
mung « zu fördern. In der Satzung der Vereinigung, die in der Zeitschrift abgedruckt ist, heißt es:

$» \S 2$. Weil einestheils die reine Menschenliebe, anderntheils aber auch die Erweiterung der medicinischen Kenntniß und Erfahrung unser einziger Bewegungsgrund ist, so versprechen wir gemeinschaftlich an der Erlangung dieses Zwecks zu arbeiten, und alles dasjenige, das den Gesundheits-Zustand der kranken Hausarmen betrifft, in gemeinschaftliche Erwägung zu ziehen, um nach Möglichkeit die hierzu dienlichsten Mittel ausfündig zu machen, und ihnen von dato des Anfangs der wirklichen Erfüllung dieses Instituti zwey ganzer Jahre lang unentgeltlich mit unserer Erkenntniß und deren bestmögliche Anwendung zu dienen, ohne daß wir deswegen eine besondere Belohnung verlangen. Sollte aber jemand sich erdreisten, durch eine fälschlich vorgegebene Dürftigkeit, unsers, nur zum Vortheil wirtschaftlich Armen errichteten Instituti, zu misbrauchen, so werden wir uns unseres Rechts, in Absicht der Bezahlung, zu gebrauchen wissen. $\ll^{58}$

Die Hamburger Ärzte nahmen sich einer Regierungsaufgabe an, die im Interesse des Staates formuliert wurde und die aus dem Interesse einer auf Handel und Produktion ausgerichteten Gesellschaft, für die die »kranken Hausarmen« ein Problem darstellte, heraus entstanden war. Dennoch stehen >humanistische< Ideale als Begründung im Vordergrund, die sich mit der ganzen Idee nicht auf eine Vergrößerung oder Stärkung des Staates, sondern seine moralische und rationelle Verbesserung der Menschen richtete. »Erreichen wollen wir alle Gefühl habenden Menschen, ihren Mitbürgern aus nachdrücklichste vorzuhalten, wie schwer sie es an jenen Tagen zu verantworten haben« wenn sich die Armen »Zeit ihres Lebens unglücklich machen, oder gar [durch Quacksalber] morden und umbringen lassen. ${ }^{59}$ Aber Ziel sei es auch, die Armen selbst davon zu überzeugen, dass es eine Pflicht sei, Leben und Gesundheit zu erhalten, selbst angesichts von Kosten und Mühen, die damit verbunden seien. Es sei eine Pflicht, die die Armen gegenüber sich selbst haben. Auf jeden Fall bestand hier tatsächlich die Idee der Verbreitung eines bestimmten Selbstverhältnisses in Verbindung mit der Sorge um Gesundheit, die als moralisches Vorbild auch den Bürgern diente, die an der Regierung beteiligt waren.

»Wir glauben, daß die Menschen von diesem ihnen so sehr verderblichen Irrthume auf vernünftigere Gedanken werden zu leiten seyn, wenn man ihnen deutlich vorstellet, daß kein Mensch mit seinen Haustieren so unbarmherzig, als sie mit sich selbst, umgehe, wie auch, daß die Pflicht, sein eigenes Leben und seine Gesundheit zu erhalten, die oberste und erste Pflicht sey, die man sich zu leisten habe, und daß solche bloß deswegen versäumet werde, weil der Mensch hierinnen als das dummste und einfältigste Thier handelt. $\ll^{60}$

Ich komme nun zurück zu Gruners Buch, dass vier Jahre später erschienen ist und in welchem er sich zu dieser Vereinigung der Hamburger Ärzte äußerte. Gruner sah of-

58 [Anonym]: Vereinigungs-Plan verschiedener Aerzte und Wundärzte zum Vortheil der hamburgischen kranken Hausarmen: in: BS, 2.1, 1768, S. 162 - 173: S. $136 f$.

59 Ebd.: S. 167.

60 Ebd. 
fensichtlich eine Gefahr darin, wenn die Ärzte oder die Bürger auf private Initiative versuchen, ein Problem zu bewältigen, dass, wie er meinte, außerhalb ihrer Kompetenz und Verantwortung lag. Gruner sah vor allem die negativen Auswirkungen, die ein solches Unternehmen für den Staat haben könnte. Diese nachteiligen Effekte seien vor allem die Unzufriedenheit mit dem Regenten, eine mangelnde Anerkennung und Loyalität und damit auch die Gefahr, dass seine Herrschaft generell in Frage gestellt werden könnte. Gruners Argumentation läuft darauf hinaus, dass er den Fürsten darauf aufmerksam macht, dass die neue Aufgabe der moralischen und rationellen Regierung mit der Anerkennung eines bestimmten Selbstbewusstseins, einer bestimmten Subjektivität der Regierung zusammenhängt. Gruner schreibt zunächst, dass die aufopfernde und menschliche Geste dieser Hamburger Bürger, die auch im »Sinne des Vaterlandes« sei, sie mit Recht die öffentliche Hilfe einfordern lässt. Denn sonst würden sie schließlich durch ihre Aufopferung selbst in Not geraten:

»Scham, Reue, Vorwürfe, und ein schwarzes Heer von Leidenschaften, ihre empfindliche Seele bestürmen, und eine stoische Unempfindlichkeit vor der Zukunft ist sodann die Frucht dieser Härte und Sorglosigkeit der Obern. Der Fürst verdient vor allen andern den Namen des Großen, der das Leben und die Gesundheit seiner Unterhanen auf alle nur mögliche Art zu erhalten sucht, und die öffentlichen Nachrichten, machen diesem Prinzen, von dem der Befehl herkam [Opfer eines Brandes in der Stadt zu versorgen], mehr Ehre, als wenn er Millionen Menschen getötet, Städte verwüstet, und, wie Alexander, die halbe Welt besieget hätte. Die Nachwelt wird sein Andenken noch segnen, wenn die vielleicht längst den Namen des stolzen Eroberers vergessen hat. $\ll^{61}$

Diese Aussage, dass jemand, der das Leben und die Gesundheit zum Gegenstand seiner Regierung und zum Ziel seiner Machtausübung macht, ehrenwerter ist als jemand, der, man könnte sagen, im >alten Sinneく seine Macht nur über Feldzüge und Eroberungen, also über das Töten, demonstriert und demonstrieren kann, lässt sich leicht mit Foucaults Thesen über das Eintreten des Zeitalters der Biomacht Ende des 18. Jahrhunderts zusammenbringen. Oder, wie er es auch ausdrückte, »die Vereinnahmung des Lebens durch die Macht « ab dem 19. Jahrhundert. ${ }^{62}$

»Eines der Hauptziele der klassischen Theorie der Souveränität war, wie Sie wissen, das Recht über Leben und Tod. [...] [Es] bedeutete im Grunde, dass er sterben machen und Leben lassen kann. [I]ch denke, daß eine der nachhaltigsten Transformationen des politischen Rechts im 19. Jahrhundert darin bestand, dieses alte Recht der Souveränität [...] zwar nicht unbedingt zu ersetzen, aber durch ein anderes zu ergänzen, durch ein Recht, das ersteres nicht beseitigt, sondern in es eindringt, es durchdringt, verändert und das ein Recht oder vielmehr eine genau umgekehrte Macht ist: Die Macht, leben zu >machen< und sterben zu >lassen «.«33

Foucault hat sich an dieser Stelle nicht mit dem Selbstverhältnis und der Veränderung der Subjektivität des Regierenden auseinandergesetzt. Das war ein späteres Pro-

61 Gruner: Gedanken von der Arzneiwissenschaft und den Ärzten, 1772: S. 585f.

62 Vgl. Foucault: In Verteidigung der Gesellschaft, 2001 [1975 - 76]: S. 282.

63 Ebd.: S. 283f. 
jekt von ihm. ${ }^{64}$ Aber ich denke, dass man diese Schwelle, diesen Übergang zur Regierung, die sich auf das Leben richtet, sofern man begreift, dass sich die Technologien des Staates auch auf die Individuen richteten, in Verbindung mit einer bürgerlichen Praxis sehen kann. Es handelt sich um den Übergang zu einer Regierung, die die physische und seelische Existenz ins Zentrum ihrer moralischen Selbsttechniken wie auch der Leitung und Führung anderer Menschen und vielleicht sogar der Regenten selbst gesetzt hat.

Gruner schrieb:

»[D]er geringste Mann im Kittel, der diese heilige Pflicht [Menschenleben zu retten] erfüllt, wird in meinen Augen und in den Augen der Patrioten und Menschenfreunde, weit größer, als ein Held, der tausenden den Hals gebrochen und mit Blut befleckten Händen von dem Schlachtfelde zurück kommt, um von einer Unmenschlichkeit zur anderen überzugehen, und über seine Untergebenen unbarmherzig zu tyrannisieren. ${ }^{65}$

Die Aussage hier ist: Der einfache Mann, der nach üblichen Maßstäben keinen hohen gesellschaftlichen Rang einnimmt, bezeugt seinen wirklichen Wert und seine moralische Höhe, indem er seinen Willen und seine Fähigkeit, das Leben zu schützen oder zu retten, beweist. Dieses Selbst ist aber kein privates, keins, dass sich einfach z.B. auf das Ziel des eigenen Seelenheils und auf die Zeit nach dem Tod richtet. Die moralische Existenz ist irdisch und ist auf die Zeit des Lebens und die Führung des Lebens gerichtet. Sie ist darüber hinaus aber auch noch eine politische und öffentliche Existenz. Deshalb ist dieses Selbstverhältnis auch in besonderem Maße für die wichtig, die im Bereich des Öffentlichen und Politischen jene Rolle der Leitung innehaben. Gruner macht diesen Zusammenhang zwischen der Subjektivität des Regenten und der Rationalität seiner Regierung deutlich:

»Das Leben und die Gesundheit sind keine Güter, womit der Unterthan ohne allen Einfluß der Obrigkeit thun kann, was er will, und dieß gebe ich gerne zu; allein die kräftigsten Gesetze werden ungültig, sobald ihnen der Wille der Bürger nicht den wahren Werth giebt, und ein weiser Regent gewinnt durch Liebe und Belohnung mehr, als der Tyrann durch Drohen und Folter. Der Geringste im Volk hat ein Gefühl der Freiheit, und läßt sich durch Gründe eines wahren Vaters des Vaterlandes leicht gewinnen [...]. Der Fürst steht auf einem erhabenen Posten, wo aller Augen auf ihn gerichtet sind, und sein Beispiel macht die Nachahmung seiner Unterthanen gewiß. Sobald also die Großen sich selbst die Blattern einimpfen lassen, wie man aus Paris, Berlin, Petersburg [...] Beispiele hat; [...] sobald kann man die glücklichen Zeiten hoffen, wo diese Seuche weniger wüten, und sich vielleicht nach und nach $[\ldots]$ verlieren wird. $\ll^{66}$

»Ausschweifung und Schwelgerei sind die gefährlichsten Feinde der Gesundheit, und obrigkeitliche Personen, die von den Regenten, als Aufseher des Volkes, angesetzt sind, müssen es

64 Z.B. Foucaults Reflexion über die Führung der Seele des Fürsten. Vgl. Foucault: Die Regierung des Selbst und der anderen I, 2009 [1982 - 1883]: S. 307, 368, 373ff. Und vgl. ders.: Die Regierung des Selbst und der anderen II, 2010 [1983 - 1984]: S. 356.

65 Gruner: Gedanken von der Arzneiwissenschaft und den Ärzten, 1772: S. 589.

66 Ebd.: S. 595. 
sich zur Pflicht machen, denselben Einhalt zu thun. Das Wohl der Bürger ist verloren, so bald eine närrische Nachahmung, in der Verschwendung groß zu seyn, ihre Gemüther ergreift, und der Monarch hat zuletzt das elende Glück über prächtige und ungesunde Bettler zu herrschen. $\ll{ }^{67}$

Die Techniken der Selbstregierung, die sich das Bürgertum aneignete und zur Formung einer Subjektivität beförderte, waren mit dem Verlangen verbunden, sich zunächst aus der von Kirche und Obrigkeit vorgeschriebenen Lebensweise zu befreien. Die Techniken enthielten aber auch den Anspruch, über den Bereich des Privaten hinaus zu gehen. In dem Maße, wie sie sich politisierten, formulierten sie auch einen neuen Machtanspruch, den das Bürgertum im 18. und 19. Jahrhundert erhob. In den deutschen Staaten Ende des 18. Jahrhunderts wirkte dieser moralische Diskurs um die gute Lebensführung auch auf einen aus der Staats- und der Polizeiwissenschaft entsprungenen staatlichen Regierungsanspruch der Gesundheit der Bevölkerung. Die Ärzte formulierten, wie auch Gruner, eine universellere philosophische Grundlage der Regierung des Lebens und der Gesundheit und gaben diese als Kritik an die bestehenden Institutionen und Einrichtungen der Medizinalordnungen und der medizinischen Polizei weiter. Die medizinische Polizei sollte sich aber nicht einfach nur des Wissens der Ärzte und ihrer Kompetenz, z.B. innerhalb der Gerichtsmedizin bedienen. Stattdessen sollte sie begreifen, dass sie einen ganz anderen Gegenstand regierte als den Staat und - als dessen Bestandteil - die Bevölkerung. Das menschliche Leben und seine Gesundheit sollte als ein viel umfangreicherer und sensiblerer Gegenstand erkannt und akzeptiert werden.

Als nächstes möchte ich anhand eines Beispiels zeigen, dass die Wissenschaft der medizinischen Polizei erst in Folge dieser Kritik mit der Diätetik verglichen wurde. In dem Handbuch der Staatsarzneykunde von 1787 hieß es mit Verweis auf Johann Peter Frank im Abschnitt zur medizinischen Polizei:

»Die medicinische Polizei ist die Wissenschaft, das Gesundheitswohl der in Gesellschaft lebenden Menschen und derjenigen Thiere, deren sie zu ihren Arbeiten und Unterhalt bedürfen, nach gewissen Grundsätzen zu handhaben. Sie ist die Diätetik des Staates. (Frank) ${ }^{68}$

Johann Peter Frank verfasste zwischen 1779 und 1817 sein Hauptwerk, das System einer vollständigen Medicinischen Polizey in sechs Bänden. In den Büchern widmete sich Frank der umfassenden Konzipierung eines politisch-polizeilichen Programms, das sich von Fortpflanzung, Bevölkerungskontrolle, Mütter-, Kinder- und Jugendpflege über Ernährung und Landwirtschaft bis hin zu Maßnahmen zur Verhinderung von Verkehrsunfällen und der Einrichtung von Schulen erstreckt. ${ }^{69}$ Der umfassende

67 Ebd.: S. 601.

68 Vgl. Metzger: Handbuch der Staatsarzeneykunde enthaltend die medicinische Polizei und die gerichtliche Arzneywissenschaft, 1787: S. 5.

$69 \mathrm{Im}$ ersten Band schrieb Frank »[v]on Fortpflanzung der Menschen und Eheanstalten, von Erhaltung und Pflege schwangerer Mütter, ihrer Leibesfrucht und der Kind-Bettnerinnen in jedem Gemeinwesen« und im zweiten Band »[v]on der außereheligen Zeugung, dem geflissentlichen Mißgebähren und andern Mißhandlungen der uneheligen Kinder, von der 
Charakter von Franks medizinischer Polizei wird auch von Foucault bemerkt. Er hob hervor, dass es sich bei der medizinischen Polizei, wie sie Frank entwarf, um eine positive, also eine biopolitische Technologie der Regierung handelte, die sich auf das Leben richtet, da sie aber genau auf das Leben der Einzelnen zielt, eine individualisierende Technik der Regierung darstellte.

»Franks Werk enthält das erste große Programm eines öffentlichen Gesundheitswesens für den modernen Staat. Es erläutert an und mit einer Vielzahl von Details, was eine Regierung tun muss, um für die Bevölkerung ausreichend Ernährung, ordentliche Wohnverhältnisse, verlässliche ärztliche Versorgung und solide medizinische Einrichtungen zu gewährleisten, kurz, was eine Regierung bewerkstelligen muss, um das Leben des Einzelnen zu fördern. Das Buch von Frank hilft uns zu erkennen, dass die Sorge für das Leben des Einzelnen um diese Zeit zu einer Aufgabe des Staates wurde. $\ll^{70}$

Franks Bände werden häufig erwähnt, um eine allgemeine Erscheinung zu veranschaulichen, sei es nun, um diese frühe Aufmerksamkeit für die Öffentliche Gesundheit zu bewundern, oder um mit dem Begriff der medizinischen Polizei den Schrecken dieser ersten Praktiken der Gesundheitspolitik hervorzurufen. ${ }^{71}$ Mir geht es mit dem Bezug auf Frank um etwas Anderes. Ich möchte argumentieren, dass Frank hier in erster Linie eine Kritik der medizinischen Polizei formuliert hat. Sein Text ist weder eine Schilderung der realen Aufgaben der medizinischen Polizei, wie sie diese zu diesem Zeitpunkt erfüllte oder von sich aus als ihren Aufgabenbereich anerkannte, noch ist es eine Ausarbeitung eines bestehenden oder tatsächlich von der Regierung beabsichtigten staatlichen Programms. Es handelt sich gewissermaßen um den Versuch, die Polizeywissenschaft dem Diktat der Staatszwecke ein Stück weit zu entziehen. Dies geschieht, indem man sie mit den allgemeinen und auf den bisher vorrangig auf den einzelnen Menschen bezogenen ethisch-medizinischen und von Bürgern und Ärzten angeregten hippokratischen und diätetischen Diskurs belädt, also indem man ihr gewissermaßen allgemeinere und neuerdings Aufgaben mit einem >morali-

physischen Erziehung des Neugebohrnen bis zum erwachsenen Bürger«, der dritte Band handelt »[v]on Speise, Trank und Gefäßen. Von Mäßigkeitsgesetzen, ungesunder Kleidertracht, Volksergözlichkeiten. Von bester Anlage, Bauart und nöthigen Reinlichkeit menschlicher Wohnungen und der vierte und fünfte Band »[v]on Sicherheits-Anstalten, in so weit sie das Gesundheitswesen angehen« bzw. »von Beerdigung der Todten«. Der sechste Band, der in drei Teilen veröffentlicht wurde, handelt $»[v]$ on den medicinischen Lehranstalten« bzw. der »Vieharzneykunde« und »der Prüfung und Bestätigung der Heilkünstler«. Vgl. Frank: System einer vollständigen medicinischen Polizey, Erster Band, 1791; Zweiter Band; 1804, Dritter Band, 1783; Vierter Band, 1790; Fünfter Band, 1813; Sechster Band, Teil I und Teil II, 1817; Teil III, 1819.

70 Foucault: Die politische Technologie der Individuen, 2005 [1982]: S. 1001.

71 Eine durch solche direkten staatlichen Techniken vollzogene Regierung der Gesundheit der Einzelnen ist, meiner Ansicht nach, seit dem Siegeszug der liberalen Gouvernementalität marginalisiert worden - zum Glück möchte man meinen. Aber die aktuellen Techniken zur Regierung der Einzelnen, zu den ich später kommen werde, sind auch nicht gerade erfreulich. Vor allem weil behauptet wird, es gäbe sie nicht. 
schen < Gewicht zurechnet. Zacharias Gottlieb Huszty, der, wie er schrieb, »nie Willens [war], ein System oder ein Handbuch der medicinischen Polizeiwissenschaft zu schreiben $~^{72}$, da er die Polizeigesetze für die besten Handbücher hielte, sah sich, noch bevor Franks System vollständig erschienen war, zu einer Kritik genötigt. Huszty schrieb: »Je nachdem die Bedürfnisse der Gesellschaft verschieden sind, so ist auch die Gründung der Maßßregeln und der Gesetze jene zu befriedigen, folglich die Polizeiwissenschaft überhaupt, verschieden. ${ }^{73}$ Für Huszty blieb die medicinische Polizey, ganz im Sinne der Staatsräson und der alten Definition von Johann Heinrich Gottlobs Justi, auf den ich später noch eingehen werde, dem Zweck des Staates untergeordnet. ${ }^{74}$ Auch wenn Huszty die Polizeiwissenschaft als >Bevölkerungswissenschaft ${ }^{75}$ bezeichnete, bedeutete es bei ihm nicht, dass diese für den Erhalt des Staates essentielle Aufgabe - die Regierung dieser Bevölkerung - wie bei Frank mit einem allgemeinen Zweck auf den einzelnen Menschen bezogen wurde.

»Die Staatslehre ist eine Wissenschaft, die Wohlfahrt des Staats überhaupt handzuhaben. [...] So wenig nun die allgemeine Wohlfahrt des Staats ohne innerer Sicherheit bestehen kann, eben so wenig kann auch diese innere Sicherheit ohne Sorge für die Erhaltung der Gesundheit und des Lebens und für die Fortpflanzung der Unterthanen als des Zweks der medicinischen Polizeiwissenschaft, gegründet werden. [...] Sie ist folglich ein Zweig eines Theils [der Teil Innere Sicherheit] der leztern [Staatswissenschaft]. Der Hauptgrundsatz aller dieser Wissenschaften ist eben derselbe, die Bevölkerung: nur die Mittel und Wege, ihn zu erfüllen, sind verschieden. $\ll^{76}$

Im Vorbericht zu seinem Werk legte Frank dar, warum er sich zu dieser Arbeit entschieden hatte, worin seine Kritik an der Regierung der Gesundheit durch den Staat und auch die Auseinandersetzung der Ärzte mit dieser Kritik bestand. Frank begann damit, zu bemängeln, dass es sehr viel Literatur zur medizinischen Polizei gäbe, die sich auf den Vergleich der Polizeiverfassungen und Medizinalordnungen unter den Ländern konzentriere und daraus versuchte er abzuleiten, was das allgemein Richtige und Gute einer solchen Verfassung und Polizei sei. Es handelt sich also um den weiter oben angesprochenen Diskurs des 18. Jahrhunderts, das Problem des europäischen Gleichgewichts, dass durch gute Polizeien in allen Staaten herzustellen sei. Dies mache allerdings, laut Frank, wenig Sinn. Dieser Vergleich der Staaten, um herauszufinden, wer die besten Gesetze hat, sei unwichtig. ${ }^{77}$ Wichtiger sei, dass man von dem Gegenstand und dessen Natur und Universalität ausgehe, um ein allgemeines System der medizinischen Polizei zu entwickeln, was dann, wohlgemerkt für alle Staaten gelte.

72 Huszty: Diskurs über die medizinische Polizei (I), 1786: Prolog [ohne Seitenzählung des Buches, S. 4f].

73 Ebd.: Prolog [ohne Seitenzählung des Buches, S. 7].

74 Justi: Grundsätze der Policey-Wissenschaft, 1756: Vorrede [Ohne Seitennummerierung, S. 3f].

75 Ebd.: S. 20.

76 Ebd.: S. 21f.

77 Frank: System einer vollständigen medicinischen Polizey (1. Bd.), 1791: S. 10f. 
»Ich dachte nemlich selbst, daß ein Werk, wie das gegenwärtige ist, entweder ganz unbedeutend, oder für das ganze Menschengeschlecht auf allezeit von Wichtigkeit seyn müßte: ich bildete mir ein, daß zwar das Interesse der Staaten, von Jahrhundert zu Jahrhundert, nach dem verschiedenen Verhältniß ihrer Nachbaren und der Zeitläuften, wechselte; daß aber nie jenes einer Veränderung unterworfen seyn würde, welches sich auf die gesunde und dauerhafte Beschaffenheit der Bürger, Fristung ihrer Lebensjahre, und auf ihre gesunde Vermehrung gründete; und, daß hier Wahrheiten zu sagen wären, die ihrem bestimmenden Grund, in dem entferntesten Zeitalter ebenso, wie zu unseren Tagen, aufweisen könnten. $\ll^{78}$

Weiter macht Frank sein Anliegen, die Anerkennung der Arzneiwissenschaft und der Ärzte zu verbessern deutlich:

»Ich war daher stolz genug, zu denken: daß die weitschichtige Bahn, welche ich mir öfnete, ein Feld seye, worin, wenn mein Eifer gesegnet würd, der Einfluß, den die Arzneiwissenschaft auf das Wohl der Staaten haben kann, einen neuen Glanz gewinnen, und der Arzt nicht mehr blos für den Mann, der sich in der Republik nur mit Gesundmachern anderer, mit mehr oder weniger auffallendem Erfolge, abzugeben hat, angesehen werden würde. « ${ }^{79}$

Um zu verstehen, schrieb Frank weiter, welches Anliegen er mit seinem Werk vertritt, reicht es nicht aus, Interesse an der Verbesserung der Medizinalordnung zu haben: »denn, man muß allerdings einen gewissen Grad der Wärme von Menschenliebe besitzen ${ }^{80}$. Franks Kritik der medizinischen Polizei bestand darin, zu sagen, dass der Staat und die Polizei ein falsches Ziel verfolgten:

»Man bemühet sich in unseren Tagen manche gute Verbesserung im ökonomischen und anderen Dingen zu treffen: sie beziehen sich aber nur auf den Reichtum eines Landes, und seiner Beherrscher: gesetzt, man brächte es hiermit, wie es doch das Ansehen nicht hat, so weit, daß in einer Provinz Ueberfluß herrschte: dürfte man wohl deswegen sagen, daß man eine einzige Gegend glücklich gemacht habe? Gewiß nein! Eine goldene Weste mache einen kranken Körper nicht glücklich, und eine silberne Todtenbare bezahlt einen dem gemeinen Wesen in seiner Blüte eintrissenen guten Bürger nicht. Was ist über die Gesundheit? Rufen alle Menschen, und die Erfahrung lehrt, daß mit nichts so verschwenderisch umgegangen werde, als mit der Gesundheit: und dennoch ist bisher, in den mehrsten Ländern, noch wenig Vorkehr gemacht worden, so sehr solche auch von den Pflichten der Vorsteher des gemeinen Wesen erwartet werden konnte. $\ll^{81}$

Wer hingegen kümmere sich, laut Frank, bereits um dieses universelle und allgemeine Gut der Gesundheit? Natürlich die Ärzte! Wohingegen die Polizei das Problem, das durch das Versäumnis der Regierung der Obrigkeit, dieses Gut zu schützen, entstehe, immer erst dann sehe, wenn es bereits zu spät sei. ${ }^{82}$ Aber wie auch Gruner

78 Ebd.: S. 9f.

79 Ebd.: S. 10.

80 Ebd.: S. 10.

81 Ebd.: S. $18 f$.

82 Vgl. ebd.: S. 19. 
stellte Frank fest, dass die Ärzte relativ hilflos waren. Ihr Bemühen, dass sich ihnen aus ihrer Menschlichkeit heraus als Pflicht aufdrängt, ist vergebens, weil das Ziel, die Menschen hinsichtlich ihrer Gesundheit zu regieren, ihre Fähigkeiten und Möglichkeiten bei weitem überschreitet. Frank äußert sich zu diesem Problem allerdings, indem er eine Kritik an den Ärzten formulierte. Diese hätten sich in allen möglichen Publikationen und Schriften, die nur von Ärzten gelesen werden, über die schlechten Medizinalordnungen und den Mangel und das Leid, was dadurch verursacht werde, ausgelassen. Stattdessen müsste diese Kritik der Ärzte endlich an die gerichtet werden, die im Gegensatz zu den Ärzten die Macht in ihren Händen hätten - also, die Mittel besitzen, die medizinische Polizei zu verbessern. Frank gab an dieser Stelle auch an, ganz bewusst einen nicht medizinischen Titel für sein Buch bestimmt zu haben: nämlich, um auch Nicht-Ärzte dazu zu bringen, es zu lesen. ${ }^{83}$

Einige Seiten später bekräftigt Frank dieses Argument nochmal. Er betont, dass er den Nutzen einer reinen Korrespondenz zwischen den Ärzten für gering halte. Überhaupt sehe er bei den Ärzten kein besonderes Hindernis, sich in der Sache der allgemeinen Gesundheit einig zu werden. Es müsse eher darum gehen, die Einsicht der Obrigkeit in dieser Angelegenheit zu erlangen. ${ }^{84}$

Obwohl sich das Handbuch der Staatsarzneykunde in seiner Definition der medizinischen Polizei auf die Definitionen Franks bezogen hat, blieben die weiteren Grundsätze relativ frei von dem von Frank propagierten universellen und auf das Wohl der Menschen gerichteten Zielen. ${ }^{85}$ Das Handbuch gesteht der medizinischen Polizei, die zuvor ein Bereich der gerichtlichen Arzneikunde war, einen Platz als wichtiger Bestandteil der Polizei zu. ${ }^{86}$ Deutlich wird aber auch, dass der medizinischen Polizei kein weiterer oder besonderer Grund für ihre Existenz beiseite gestellt wurde als dieser. Die Existenz der medizinischen Polizei und das Recht, mit dem sie handelt, beruht auf dem Recht des Staates und der Obrigkeit, die Ziele des Staates zu verwirklichen. ${ }^{87}$

Diese Konzentration auf das Individuum und dessen Führung, die ganze Technologie der Polizei war typisch für die deutschen Staaten und wurde der Polizei gewissermaßen zum Verhängnis. In Deutschland entwickelte sich die Regierung der Gesundheit eher wie eine wissenschaftliche Disziplin. Diese Disziplin war die Polizeiwissenschaft, von der die medizinische Polizei nur eine Untergliederung darstellte. Die Regierung der Gesundheit im Sinne der Medizinalverfassung und der Polizei entstanden eher nach dem Muster einer Disziplin, die zwar, soweit sie das Leben als ihren Gegenstand ansah, unendlich war, aber dennoch trotzdem weiterhin versuchte, sich zu vervollständigen und ihren Bereich genau zu definieren. Das heißt, man ging wie Frank davon aus, dass das Wissen über diesen Gegenstand einen Rahmen besitzen würde und es eine gewisse Abgeschlossenheit und Stabilität aufweise. Die Diätetik stellte hierzu einen Widerspruch dar, der bei dem Versuch, ihre Techniken auf die

83 Vgl. ebd.: S. $20 f$.

84 Vgl. ebd.: S. 29.

85 Vgl. Metzger: Handbuch der Staatsarzeneykunde enthaltend die medicinische Policey und die gerichtliche Arzneywissenschaft, 1787: S. 5f.

86 Ebd.: S. $8 f$.

87 Ebd. 
Bevölkerung zu übertragen, offenbar wurde. Man könnte sagen, dass die Regierung des Einzelnen mit den individualisierenden Techniken der Diätetik für den Staat sich schlicht als zu teuer und zu aufwendig gestaltete.

Das Problem der Ärzte und ihre Versuche, die Arzneiwissenschaft als Regierungswissenschaft zu vermitteln, hing grundsätzlich noch mit diesem Gedanken, die Regierung von einer Wissenschaft aus zu denken, zusammen. Die Krise der Medizin und ihr philosophischer Anspruch, wie er sich u.a. bei Schelling dargestellte, war angeregt durch das Bestreben, eine Wissenschaft nicht für die Regierung, sondern der Regierungsvernunft selbst zu sein. Das heißt, dass man von der ärztlichen Praxis und dem moralischen Selbstbewusstsein der Ärzte ausgehend meinte, eine dauerhafte Kritik der Vernunft, der Rationalität der Regierung ausüben zu können.

Wie bereits zu Anfang des Abschnitts erwähnt, nahm das Wissen in der Konstruktion dieses bei Gruner aufgezeigten und auch bei Frank angedeuteten Selbstverhältnisses der Ärzte eine sehr entscheidende Rolle ein. Das Wissen wirkte nicht selbst als Macht oder Fähigkeit im Sinne einer Kunst. Sondern die Wissenschaft bestand unabhängig. Es wurde quasi als das Medium gesehen, durch welches man die Natur und die Gesetze der Natur zum Sprechen bringen und verstehen konnte. Aus diesem Wissen ergab sich dann eine Art Pflicht, sich rational zu verhalten, eine weniger wissende Person zu leiten, und evtl. sogar Gewalt zum Wohle einer >ahnungslosen< Person anzuwenden. Dieser Imperativ befreite gleichzeitig die Person, die sich so verhielt, von anderen Gesetzen, z.B. des Staates, oder zwang sie, andere Gesetze zu überschreiten, um ihrem moralischen Selbst zu entsprechen. Es handelte sich um eine übergeordnete Gesetzmäßigkeit, die es verlangte, Menschenleben zu schützen und zu retten. ${ }^{88}$

Wir sehen hier zwei Ansätze einer Regierung von Gesundheit, die nicht unmittelbar miteinander verbunden waren, aber die man versuchte in eine Übereinstimmung zu bringen. Einmal war es die Notwendigkeit der Regierung, der Gesundheit der Bevölkerung durch den Regenten eine gewisse Aufmerksamkeit zu widmen. Die Bevölkerung konnte hier noch sehr unspezifisch als ein Gut betrachtet werden, als einen Reichtum, den es im Sinne der Staatsräson mit dem Ziel der Steigerung der Kräfte eines Staates zu regieren galt. Die Arzneiwissenschaft und die Ärzte wurden in dem Text von Gruner als für dieses Ziel unvergleichbar nützlich herausgestellt. Die Ärzte seien diejenigen, die den Menschen das Wissen und den Rat gäben, mit dem diese sich selbst, also ihre Gesundheit und ihr Leben erhalten können. Aber die Ärzte stellten auch für die Obrigkeit selbst den Zugang zu dem Wissen, auf dessen Grundlage diese besser und darüber hinaus >moralischer $<$ regieren sollten, zur Verfügung. Damit ist der zweite Ansatz der Regierung der Gesundheit benannt, der hier von den Ärzten und den >guten Bürgern< in gewisser Weise als ein eher menschliches, universelles, und damit eigentlich über dem Staat stehendes Gesetz der Regierung vorgelebt wurde.

»Die Gesundheit und das Leben der Bürger sind die vornehmsten Gegenstände, die der Staatsmann bei Bestimmung der Ursachen der Entvölkerung nie aus dem Gesichte verlieren muß, und die Selbsterhaltung bleibt ohnstreitig das beste Mittel, derselben zu steuern. Die Aerzte

88 Gruner: Gedanken von der Arzneiwissenschaft und den Ärzten, 1772: S. 587. 
predigen diese mit heller Stimme, und es ist Pflicht vor die Oberen, ihren Winken in einer so kitzlichen Materie, als diese ist, weit eher Gehör zu geben, als allen andern verderblichen Projektmachern. $\ll^{89}$

Es geht auch hier um eine Kritik an den Gesetzen der Obrigkeit und der medizinischen Polizei, die im Grunde aussagt: Die Gesetze und die Polizei bringen nichts, weil sie die Gesundheit und das Leben nicht als ein universelles Gut behandeln. Die Polizei könne die Gesundheit der Menschen nicht erhalten, wenn die Menschen nicht dazu gebracht würden, sich selbst besser zu erhalten. Die Idee war hier tatsächlich, eine diätetische Praxis der Regierung, die sich auf die Individuen, ihre Seelen, ihr Leben richtete, die zu dieser Zeit in einem Teil der bürgerlichen Klasse aufgegriffen worden war, auf die Prinzipien der staatlichen Regierung der Gesundheit zu übertragen. Die Bedeutung dieser Wiedergeburt der Diätetik hat das Selbstbewusstsein der Ärzte geprägt und ihre Praxis zumindest gegenüber den bürgerlichen, gebildeten Personen verändert. Genau von diesem neuen Standpunkt aus fühlten sich die Ärzte berufen, der Regierung einen Rat zu geben und ihr zu erklären, dass ihre Techniken irrational und unwirksam seien, solange diese allein auf den Staatszweck gerichtet blieben..$^{90}$

\section{Die wahren Ärzte}

Dieses Wiederaufgreifen und die Übertragung der Diätetik auf den Staat verbanden sich mit der Erneuerung des ärztlichen Selbstverständnisses. Es war das Ergebnis oder auch Teil einer Strategie der Ärzte, um sich gegen die verschiedensten alten und neuen Vorwürfe zu wehren und gleichzeitig auch, um ihren neuen Machtanspruch und ihre bedeutendere soziale Stellung zu legitimieren. Die Strategie bestand darin, ein >gutes $<>$ moralisches « Arzt-Selbst zu erschaffen, indem man das Wissen der Arzneiwissenschaft von dem Anspruch auf Teilhabe an der Regierung der Menschen und ihrer Gesundheit, mit anderen Worten, von dem Anspruch der Macht der Ärzte löste. Das Wissen der Arzneiwissenschaft wurde durch seinen Charakter der Objektivität und Rationalität, seine quasi natürliche Herkunft, von dem Arzt als Mensch, der dieses Wissen besaß und anwendete, abgespaltet. Die Ärzte sahen sich gewissermaßen nur als Mittler zwischen der Natur und damit auch Gott, der diese erschaffen hatte, und den Menschen.

»Der vernünftige Arzt kennt den Einfluß der Natur, deren Priester er ist. Mit einem scharfsichtigen Blicke spürt er wie ein stiller Beobachter, ihre Geheimnisse aus, betritt die Bahn, die ihm seine Göttin zeigte, bestätigt sich durch mehrere Beobachtungen [...].«11

Laut Gruner ist der Arzt nur eine Art Sprecher der Natur. Ein Arzt oder Arzneiwissenschaftler ist quasi nur Medium, ein Übersetzer und Entzifferer einer in der Natur verborgenen Wahrheit. Er ist jemand, der durch die Natur, die Gott erschaffen und

89 Ebd.: S. 621.

90 Vgl. ebd.: S. 23.

91 Gruner: Gedanken von der Arzneiwissenschaft und den Ärzten, 1772: S. 29f. 
mit Zwecken und Regeln versehen hat, den göttlichen Willen erkennen und diesen an die anderen Menschen vermitteln oder zur Grundlage seiner Handlungen machen kann.

Hier haben wir nun einen sehr eindeutigen Hinweis auf die Strategie, die für die moderne Regierung von Gesundheit eine große Rolle spielt. Sie entstand aus einer Reihe von Konflikten, bei welcher die Bedingungen für die Regierung von Gesundheit sehr umfassend ausgelotet wurden und durch die man eine neue Rationalität und Souveränität der Regierung einzurichten begann. Aus der Regierung des Lebens durch Gott übernahm sie die Nichtmenschlichkeit, die nun den Gesetzen der Natur zukommen. Die Natur und die Wissenschaft, welche diese erforscht, hält in sich die »Unmenschlichkeit« (Latour) als Beleg für ihre Objektivität, also Unabhängigkeit von menschlicher Leidenschaft und Willkür. ${ }^{92}$

Besonders deutlich findet sich dieses Muster auch in einem 1819 im Journal der practische Arzneikunde erschienen Aufsatz von Hufeland mit dem Titel Hippocrates und Galenus, Natur und Schule..$^{3}$ Hier macht Hufeland zwei verschiedene Kategorien von Ärzten auf, die er miteinander vergleicht: Den Naturarzt und den Schul$\operatorname{arzt}^{94}$. Unschwer ist hier erkennbar, dass der Naturarzt, der nach Hufeland, genau wie bei Gruner, nichts weiter als ein Priester und Vermittler der Natur ist, der wahre und gute Arzt ist. Die Moralität der Ärzte wird über ihr enges Verhältnis zur >nichtmenschlichen< Welt der Wahrheit und damit das Getrenntsein ihres Wissens von der Macht begründet. Für die legitime Leitung oder Anordnung eines bestimmten Verhaltens benötigt man noch einen zweiten Bereich, der wiederum einen expliziten menschlichen Charakter haben sollte. Dieser begründet sich über universelle und göttliche Gesetze der Liebe, die gute Intention, die Menschlichkeit in dem Anliegen der Ärzte und der Arzneikunde. ${ }^{95}$ Die Ärzte können sich selbst nicht zuschreiben, ein Recht auf Teilhabe an der Regierungsmacht zu haben, es sei denn, sie beweisen, dass sie moralischer sind als andere. Diese Konstellation von Wissen und Macht bildet auch die Grundlage für eine gute Existenz, ein moralisches Subjekt. Sie verdeutlicht, dass diese Beziehung zwischen Subjekt, Wissen und Macht den Charakter eines Netzwerks hat und zirkulierende Bezügen aufweist: ${ }^{96}$ Sie bewirkt die Ausweitung des Wissens, die Aufteilung der Macht und eine Konstruktion und Differenzierung verschieden bewerteter Subjekte und Gegenstände des Wissens. Typisch ist für die Zeit, also Ende des 18. und Anfang des 19. Jahrhunderts, die Abgrenzung der $>$ wahren Ärzteく von einer Reihe von anderen Figuren, wie z.B. dem »Schularzt«, wie Hufeland ihn nennt, oder dem »Afterarzt «, über den sich Gruner auslässt. ${ }^{97}$ Die Strategie

92 Latour: Die Hoffnung der Pandora, 2002: S. 266.

93 Hrsg.: Hippocrates und Galenus, Natur und Schule: in: JPA, 48=41, 1819, S. 1 - 14.

94 Die Selbstkonstruktion innerhalb dieser Konstellation, die schließlich eine neue und sehr viel effektivere Regierungsmacht beflügeln wird, ist beinahe unzertrennlich mit dem, was Foucault an einer Stelle (in seinen Vorlesungen zur Regierung des Selbst und der anderen) als moralische Differenzierung beschrieben hat. Ich werde später noch näher darauf eingehen.

95 Vgl. JNA, 32.9, 1802: S. 5.

96 Vgl. Foucault: Die Regierung des Selbst und der anderen I, 2009 [1982 - 1983]: S. 17ff.

97 Gruner: Gedanken von der Arzneiwissenschaft und den Ärzten, 1772: S. 34. 
der Ärzte bestand aber nicht nur in der Konstruktion einer Identität des guten Arztes und eines symbolischen Verhältnisses der Arzneiwissenschaft zur Regierung. Sondern die Ärzte forderten eine Institutionalisierung dieses Verhältnisses. Sie verlangten vom Fürsten oder Staat, dass dieser ihnen per Gesetz einen entsprechenden Status zusicherte, der ihnen den Vorrang vor den nicht ausgebildeten Ärzten und den sog. Scharlatanen verschaffen sollte. Die Forderung nach staatlicher Anerkennung der >ausgebildeten Ärzte< und die Verfolgung der sog. Scharlatane gingen Hand in Hand mit der Ermahnung der staatlichen Regierung, endlich ihren Pflichten und Aufgaben hinsichtlich der Gesundheit der Bevölkerung nachzukommen.

\section{Die Gegenleistungen des Staates}

»Die Regenten [werden] bei aller ihrer Vorsicht, womit sie dieselben hintertreiben wollen, dennoch den rechten Weg verfehlen, so bald sie die Sorge für die Gesundheit und das Leben ihrer Unterthanen vernachlässigen, oder die Aerzte nicht von den verunstaltenden Schalcken der Charlatans und ihrer Gesellschaft befreien. ${ }^{98}$

»Ein Regent, der diese Giftmischer duldet, liebt sein Volk nicht, weil er dessen Wohl nicht auf alle nur mögliche Art zu befördern sucht, und es jeder alten Vettel Preis giebt, das Glück der Gesundheit mit altväterlichen, aber geheimen oder ausländischen Arzneien zu tödten. « ${ }^{99}$

Der sog. Scharlatan verkörperte, nach den Beschreibungen der Ärzte, so sehr den absoluten Gegensatz zur rationalen, begrenzt wissenden und moralischen Figur des Arztes, dass ihn zu beseitigen gerade zur Pflicht des > wahren< und >guten < Regenten wurde.

Diese Haltung wird in dem Buch von August Friedrich Hecker zur Allgemeinen Geschichte der Arzneikunde am deutlichsten. Hecker führte die beschriebenen Strategien der Ärzte mit einem Diskurs zusammen, in dem die Rationalisierung der Regierungen (noch) über einen Modus des Vergleichs mit anderen Staaten organisiert wurde. Das Buch wurde 1793 gedruckt und vermutlich noch vor der Hinrichtung der französischen Königsfamilie geschrieben. Dennoch hatten die revolutionären Ereignisse in Frankreich bereits Einfluss auf den Autor genommen und ihn dazu veranlasst, die (Neu-)Verteilung von Macht unter den praktischen Ärzten, der Arzneiwissenschaft und der Staatsregierung mit einer gewissen Vorsicht zu behandeln. Hecker reformulierte die beschriebenen Regeln der Beziehung von Wissen und Macht, die das Wissen als Mittel der Regierung - die Polizeiwissenschaft als »Werkzeug der Staatskunst ${ }^{100}$ - und die Vernunft bzw. der Rationalität als Existenzgrund der Regierung definierte. Während Gruner den ganzen Rahmen an Begründungen für die Regierung des Lebens und der Gesundheit nachzeichnete, der ganz und gar der Gegenstand der Arzneiwissenschaft war, ging es bei Hecker darum, den Gegenstand, den

Ebd.: S. 379.

99 Ebd.: S. 582f.

100 Justi: Grundsätze der Policey-Wissenschaft, 1756: Vorrede [Ohne Seitennummerierung, S. 4]. 
die Regierung regiert, zu kennen und ihr auf diese Weise dienlich zu sein. Das eine Mal haben wir eine Aussage, die lautet: >Ein guter Regent muss eine bestimmte moralische Haltung beziehen, sonst ist er kein guter Regent und diese moralische Haltung kann er nur einnehmen, indem er sich auf die Wahrheit und Natur seines Gegenstandes bezieht.<Die andere Aussage lautet: >Wir Ärzte wissen, was man verbieten und erlauben muss, wenn man sich zum Staatsziel gesetzt hat, die Gesundheit und Stärke der Bevölkerung zu erhalten, zu schützen und zu regulieren.< Allerdings ist hiermit, im Gegensatz zu der früheren Idee der Staatskunst, bereits die Bedingung enthalten, dass die Obrigkeit akzeptiert hat, dass sie die Gesundheit regieren muss, um eine gute Regierung zu sein. Hecker wollte sagen, dass eine Regierung nur dann gut regieren kann, wenn sie auf den Rat der Arzneiwissenschaft und der Ärzte hört. Es ist gewissermaßen die argumentative Umkehrung dessen, was Gruner und Ackermann formuliert hatten. Hecker sagte nicht, dass eine Regierung, wenn sie eine wahre Regierung der Gesundheit der Menschen sein will, die Arzneiwissenschaft zu ihrer Grundlage machen muss. Sondern er sagte, dass die Güte der Regierung sich in dem Maße zeigt, wie sie sich bereits auf dieses Wissen bezogen hat und in Zukunft beziehen wird. Es war eine Strategie, die der Regierung und der Staatskunst gewissermaßen anbot, sich historisch als schon immer hippokratisch zu konstruieren. Hecker verschaffte der Regierung nicht nur die Aussicht auf eine gute moralische Existenz, sondern schlug ihr vor, sich eine Geschichte der guten Regierungen anzueignen. Somit drehte Hecker die Strategie um und trug der Arzneiwissenschaft auf diese Weise auf, sich selbst historisch als Regierungswissenschaft zu erkennen und sich der Regierung nützlich zu machen.

»Nicht die Fürsten und Obrigkeit allein, nicht die Besitzer und Lehrer der Kenntnisse allein, auch nicht allein die übrigen Stände der menschlichen Gesellschaft, können diesen großen Zweck [zu dem Genuss aller der grossen Vortheile und des Wohls, das aus der zweckmässigen Benutzung der physischen und medizinischen Kenntnisse nothwendig entspringt] erreichen; sondern nur sie alle in Verbindung, zur Bearbeitung eines Zweckes. Die Arzneikunde muss, was schon Pythagoras wollte: eine Dienerin und Gehülfin der Staatskunst und der Gesetzgebung werden. ${ }^{101}$

Zum einen hatte Hecker den Anspruch, eine Darstellung des historischen Verhältnisses von Arzneikunde und dem Gesundheitswesen von Staaten vorzunehmen. In dieser Hinsicht stimmt es, dass der Staat, der das Wohl des Staates im Sinn hat, erkennt, dass er eine Medizinalordnung benötigt, sich selbst das unterschiedliche Wissen, was er hierfür braucht, heranholt. ${ }^{102}$ Ich denke also, dass die Aussage über die Bedeutung der Arzneiwissenschaft hinsichtlich des Problems der >guten Regierung< in dem Text von Hecker nicht weniger als bei Gruner, aber wesentlich subtiler vorhanden ist. Der Text ist insgesamt vorsichtiger damit, eine direkte Kritik an der Obrigkeit zu formulieren. Es ist wichtig hierin eine weitere, für die Ärzte in Deutschland relevante Strategie zu erkennen. Eine Taktik, durch welche die Ärzte vom Staat die Regelung der verschiedenen medizinischen Professionen verlangen konnten. Man forderte auch

101 Hecker, August Friedrich: Allgemeine Geschichte der Arzneikunde, 1793, Leipzig: S. XI.

102 Vgl. ebd.: S. 205, 231. 
wegen den Laien, die behaupteten, keine Ärzte zu benötigen, die Hilfe der Fürsten, die den Ärzten politisch und gesetzlich einen mächtigeren, festeren und wichtigeren Posten im Staat verschaffen sollten. Hecker war in seiner Form der Kritik vorsichtig und legte es eher auf ein Bündnis, eine Aufteilung der Macht an, die dem Staat und den Ärzten nutzen sollte. Hecker und vermutlich auch andere Ärzte ließen besonders durch den Vergleich mit anderen Ländern (z.B. Frankreich) deutlich werden, welche Art von Reformen und zukünftiger staatlicher Regierung von Gesundheit sie am Beispiel Deutschlands als fortschrittlich ansahen. Nach Beginn der revolutionären Umwälzungen in Frankreich herrschte dort, laut Hecker, »eine vollkommene medizinische Anarchie $\ll^{103}$.

Auch Gruner hat an keiner Stelle in Frage gestellt, dass die Regierung der Fürsten dazu in der Lage sei, die Gesundheit und das Wohl der Menschen in ihrem Staat zu befördern. Darüber hinaus gab es tatsächlich eine gewisse Utopie, bei der man davon ausging, dass sich diese deutsche Variante der Regierung von Gesundheit mittels einer Medizinalordnung und einer sehr weitreichenden medizinischen Polizei nicht nur umsetzten ließe, sondern schließlich auch über die deutschen Staaten hinaus in andere europäische Staaten exportiert werden könnte. Diese Idee war, wie weiter oben erwähnt, einem speziellen Regierungs-Diskurs in Deutschland geschuldet, der wegen der vielen kleinen Staaten in einem Modus des Vergleichs der Regierungen strukturiert war und durch welchen man nach universelleren und verallgemeinerbaren Grundsätzen der Regierung suchte. Die in den Zielen der Staatsräson enthaltene und durch die Polizeiwissenschaft angepeilte Verwirklichung eines europäischen Gleichgewichts, also das Ziel einer in allen Staaten funktionierenden Polizei, wirkte noch nach. Für Hecker ebenso wie für Gruner bildete die moralische Subjektivität des »guten Landesvaters« eine Bedingung dieser Regierung auf der Grundlage einer Medizinalverfassung. ${ }^{104}$

\section{Die Regierung der Gesundheit und das Problem des sInneren`}

Die Staatskunst, oder auch die Staatsräson, hatte sich vor allem mit Rücksicht auf die außenpolitische Existenz und Sicherheit eines Staates konstituiert. Auch die Innere Sicherheit, die eine ihrer Aufgaben definierte, bezog sich darauf, die Kräfte des Staates zu erhalten und zu steigern, damit er sich gegenüber den anderen Mächten - also außenpolitisch - erhalten konnte.

»Die Staatskunst hat nichts als die äußerliche und innerliche Sicherheit der Republiken zum Endzweck; und ihr vornehmlichstes Augenmerk muß auf das Betragen, Verhältniß und Absichten der auswärtigen Mächte, so wohl gegeneinander selbst, als gegen den Staat, auf die VergröBerung der Macht der Republik in Ansehung der auswärtigen Staaten und vornähmlich auf ein vorsichtiges Bezeugen gegen andere Mächte gerichtet sein; ebenso wie die Staatskunst bemüht seyn muß, die verschiedenen Classen und Stände der Unterthanen in gerechter Ordnung und Verhältniß gegeneinander zu erhalten, ihre Neigungen und Absichten gegen einander selbst und gegen die Regierung zu erforschen, alle Partheyen und Berwegungen in ihrer ersten Ge-

103 Ebd.: S. 299.

104 Ebd.: S. 295f, 299ff. 
burth zu ersticken und vornähmlich alle innerliche Unruhen und Empörungen zu verhüten. Dahingegen beschäftigt sich die Policey mit nichts als das gesamte Vermögen des Staates durch gute innerliche Verfassungen zu erhalten und zu vergrössern und der Republik alle innerliche Macht und Stärke zu verschaffen, deren sie nach ihrer Beschaffenheit nur immer fähig ist. $\mathrm{Zu}$ dem Ende suchet sie die Länder zu cultivieren, den Nahrungsstand zu verbessern und gute Zucht und Ordnung in den gemeinen Wesen zu erhalten. ${ }^{105}$

Die ganze Logik der Staatsräson zielte auf das Problem, den Staat und seine Macht gegenüber anderen Staaten zu erhalten. Die Polizei produzierte nach und nach durch ihre eigene Logik und Praxis eine Rationalität, die im Widerspruch zu den Zielen der Staatsräson stand. Sie entstand zwar aus dem »Werkzeug« der Staatsräson, aber ihr Gegenstand (das Leben und die Ökonomie der Bevölkerung) brachte sie zur Entwicklung eigener Techniken und ausgeweiteter Ziele, die gegenüber dem begrenzten Ziel der Staatskunst ein nicht mehr zu integrierendes Ausmaß erreichten. Die Polizei wuchs der Staatsräson gewissermaßen über den Kopf.

Johann Heinrich Gottlobs Justi, der Autor des von Foucault so gerne angeführten Texts über die Polizeiwissenschaft, war derjenige, der die Realität dieses praktischen Gegensatzes erstmals benannte. In seinem »System einer Policey« stellte er »die Wissenschaft [der Policey] vollständig, von anderen Wissenschaften abgesondert « dar. ${ }^{106} \gg$ Der gemeinste Fehler in Ansehung der Policey ist zeither gewesen, daß man dieselbe mit der Staatskunst in eine Brühe geworfen und unter einander abgehandelt hat. $\ll^{107}$

Indem die Polizei begann, sich quasi zu verselbstständigen, produzierte sie einen unabhängigen Bereich der Innenpolitik. So wirkte die Polizei als eine Bedingung dafür, dass Regierungen dazu übergingen, ihre Zwecke über die Regierung des Inneren, des Volkes oder der Bevölkerung zu definieren und überhaupt ein entsprechendes Selbstbewusstsein auszubilden. Die Qualität der Polizei und der inneren Verfassungen wurde Ende des 18. Jahrhunderts immer weniger auf das bezogen, was die außenpolitische Existenz des Staates bedeutete und worauf die Staatskunst gezielt hatte. Stattdessen begann die Polizei, die Existenzbedingungen des Staates und die Bedingungen für eine gute Regierung an die innere Ökonomie, in einem sehr allgemeinen Sinne, nämlich als die gesamte Ökonomie des gesellschaftlichen und biologischen Lebens, zu koppeln. Diese Entwicklung fiel zusammen mit den sich verändernden materiellen Existenzbedingungen, den $»$ neuen Systemanforderung[en] ${ }^{108}$, einer sich weltweit ausweitenden kapitalistischen Produktionsweise: von der ursprünglichen Akkumulation des Kapitals durch $»$ Enteignung ${ }^{109}$ im 18. Jahrhundert bis zur Expan-

105 Justi: Grundsätze der Policey-Wissenschaft, 1756: Vorrede [Ohne Seitennummerierung, S. 3f].

106 Ebd.: S. [2].

107 Ebd.

108 Vgl. Kuhn, [1973] zitiert nach Sarasin/Berger/Hänseler/Spörri: Bakteriologie und Moderne: Studien zur Politik des Unsichtbaren, 2007: S. 9.

$109 »[\mathrm{D}]$ ie Enteignung der Volksmasse von Grund und Boden bildet die Grundlage der kapitalistischen Produktionsweise.« (Marx: Das Kapital I: MEW, 23, S. 795; vgl. S. 744) $»[$ K] apitalistische Produktions- und Akkumulationsweise, also auch kapitalistisches Pri- 
sion der industriellen Produktion ab dem 19. Jahrhundert . Es war damit auch eine Ergänzung der politischen Techniken gefordert, die zuvor auf äußere politische Existenz des Staates gezielt hatten, durch solche, die eine Art inneren Politik des Haushaltens ermöglichten. ${ }^{110}$ Die kapitalistische $»$ Enteignung $«{ }^{111}$ der privaten Mittel der (Re)Produktion, der Sorge um sich und gleichzeitig ihre fragwürdige Politisierung im Rahmen einer Regierung des Lebens der Bevölkerung als »Naturprozess $«{ }^{112}$, waren zwei Seiten der gleichen Medaille. Was dies für die ganze Transformation der Verhältnisse von Innen- und Außenpolitik bedeutet haben könnte, werde ich später anhand der Internationalen Gesundheitskonferenzen noch deutlicher zu zeigen versuchen. Vor dem Hintergrund dieser Transformation leuchtet es ein, dass die spätere Internationalisierung der gouvernementalen Rationalität und ihrer verschiedenen Technologien zur Regierung der Gesundheit notwendig wurde.

In den deutschen Staaten war der Gebrauch medizinischen Wissens und ärztlicher Regierungsrationalität innerhalb der Regierungspraxis umso relevanter geworden, je mehr auch andere Disziplinen, wie die Ökonomie oder hier die Kameralwissenschaft, Einfluss auf den Regierungsdiskurs nahmen und die Regierungskunst sich zunehmend der Kontrolle und Mehrung der Kräfte im Innern zuwandte. Die Verallgemeinerung des Gegenstands der Regierung, den die Ärzte selbst unterstützten, also die Konstruktion der Regierung des Lebens, mit all den Einflüssen, die positiv und negativ darauf einwirkten, verminderte den Bedarf nach einem spezifischen Wissen, wie es bisher die Arzneikunde, zum Beispiel bei ihrer Rolle für die Gerichtsmedizin, geliefert hatte. Stattdessen brauchte diese neue Gouvernementalität eine Philosophie des Regierens. Den Übergang von einem eher begrenzten (auf den Staat selbst gerichteten) Verständnis der Kunst des Regierens zu einer Regierung des Lebens, bildet meiner Meinung nach das Modell eines umfassenden Systems der Polizei und einer Reihe von disziplinären Technologien zur Regierung der Einzelnen (Pastorat, Diätetik, Pädagogik etc.). Die Polizeiwissenschaft stellte eine Wissensordnung bereit, die so umfassend war, dass sie diesen unendlichen Gegenstand des Lebens meinte hierdurch fassen und als Basis einer Regierung dienen zu können. Die Diätetik aber und

vateigentum, bedingen die Vernichtung des auf eigener Arbeit beruhenden Privateigentums, d.h. die Expropriation des Arbeiters.«: Ebd.: S. 802.

110 Vgl. Arendt: Vita Activa, 2010 [1958]: S. 75.

111 Ebd.: S. 85. Hanna Arendt hat in erstaunlicher Übereinstimmung zu einer Reihe von Beobachtungen Foucaults, sehr treffend, auf die Transformation des Politischen, bis hin zur Abschaffung einer bestimmten an der griech. polis orientierten Idee des Politischen im Zusammenhang mit dem Problem der menschlichen »Bedingtheit« (human condition) hingewiesen. Am Anfang von dem, was Arendt als »Vergesellschaftung des Menschen (ebd.: S. 87) in der Neuzeit bezeichnete, und was sie mit der Auflösung des Bereichs einer menschlichen politischen Existenz verband, steht die Enteignung der Menschen von dem, was ihnen als private Grundlage der Reproduktion gedient hatte: »In einer Gesellschaft von Eigentümern [damit meint Arendt in einer Gesellschaft in der die Menschen die Mittel zu ihrer Reproduktion, ihr Land oder ihr Haus wie die Bürger in der antiken Polis besitzen] steht immer noch die Welt und nicht die nackten Lebensnotwendigkeiten im Mittelpunkt menschlicher Pflege und Sorge.« Ebd.: S. 135.

112 Ebd.: S. 294. 
all das, was innerhalb der ärztlichen Praxis als ein Bereich der Führung des Verhaltens der Menschen bestanden hatte und welche ab dem Moment seiner Universalisierung eine wirkliche Quelle der modernen Regierungsrationalität dargestellt hatte, wurde in Deutschland schließlich von der Medizin losgelöst und einem Aufgabenbereich der Philosophie zugesprochen. Diese ganzen Verschiebungen und Neuverteilungen haben aber nicht nacheinander oder mit einer klaren Zielrichtung stattgefunden. Denn die Krise, die die Arzneiwissenschaft in Deutschland im Ausgang des 18. Jahrhunderts erlebte, begann mit dem Versuch einiger Ärzte, die sich auch als Philosophen betrachteten, die Arzneiwissenschaft von dem Image der Erfahrungswissenschaft zu befreien und sie stattdessen auf einer eher theoretischen und spekulativen Basis zu errichten. Auch die >ideale< Medizinalverfassung, über die sich Hecker den Kopf zerbrach und die das Verhältnis von Arzneiwissenschaft und Staat regeln sollte, war von diesem Streben geprägt. ${ }^{113}$ Die Medizinalordnung sollte nicht mehr an den Bedürfnissen eines spezifischen Staates ausgerichtet sein, sondern an der viel allgemeineren Definition der Natur des Menschen, den Bedingungen seines Lebens innerhalb einer natürlichen Ordnung, in der dieses Leben stattfand. Diese Universalisierung des Gegenstands gestattete erst die Formulierung eines allgemeingültigen, wissenschaftlich begründbaren Ziels der Regierungen und ermöglichte es, unterschiedliche Staaten zu vergleichen. Es bedeutet, aus der Arbeit des Vergleichs heraus, in der Lage zu sein, so etwas wie die Idee einer >Entwicklung< eines einheitlichen europäischen Wegs der Erkenntnis und des Fortschritts zu konstruieren und die Staaten, statt sie innerhalb einer Ordnung des Machtgleichgewichts aufzustellen, in eine hierarchische Ordnung zu bringen. Hecker nahm einen solchen internationalen Vergleich der Medizinalverfassungen verschiedener europäischer Länder vor. Während als idealer Ausgangspunkt die Medizinalordnungen einige deutsche Staaten (v.a. Preußens) dienten, die aber noch verbesserungswürdig seien, stellte Hecker alle Gesetze oder Maßnahmen, die in anderen Ländern vereinzelt mit dem Ziel, die Gesundheit der Bevölkerung zu erhalten und zu verbessern, eingerichtet worden seien, als Vorstufen oder unterentwickelte Anfänge eines allgemeingültigen Entwicklungsweges hin zur systematischen und vollständigen Medizinalordnung dar. Über die anderen deutschen Staaten schreibt Hecker:

»Wenn auch die gute Medizinalordnung, die in allen diesen Ländern mehr oder weniger eingeführt war, nicht immer genau befolgt wurde; so war doch schon allein durch das Daseyn und die Einführung einer solchen, ein wichtiger Schritt zur Beförderung des allgemeinen Gesundheitswohls gethan; - der in anderen Ländern also erst noch gethan werden muss, wenn mit Ernst an einer Verbesserung, einer der Menschheit so nahe angehenden Sache gearbeitet werden soll. $\ll^{114}$

Hecker zeigt im Anschluss daran auf, welche besonderen Umstände dazu geführt hätten, dass die Medizinalordnungen in einigen deutschen Staaten besonders ausgebildet

113 Vgl. Hecker: Allgemeine Geschichte der Arzneikunde, 1793: S. 197f; 215.

114 Ebd.: S. 190. 
seien. Auch Hecker deutete dabei an, dass es aufgrund der vielen kleinen Staaten ein stärkeres Konkurrenzverhältnis unter den Fürsten gegeben habe. ${ }^{115}$

\section{Wer regiert die Seele?}

Wie ich im vorangegangenen Abschnitt angedeutet habe, war die Kunst der Erhaltung der Gesundheit auch im 17. Jahrhundert bereits vermehrt Teil ärztlicher Praxis gewesen. Im 18. Jahrhundert wurde diese Praxis durch die Propagierung der Diätetik im Zuge der Herausbildung eines bürgerlichen Diskurses um >rationale< Ethik und Lebensführung herausgefordert und erhielt daraufhin einen weit höheren Stellenwert als zuvor. Die Diätetik war, weit über ihren Gebrauch durch die Ärzte hinaus, Teil einer bürgerlichen Selbstpraxis, ihrer sozialen klassenspezifischen Identität und funktionierte als Mittel der Abgrenzung zum Adel und zum dritten Stand. Philipp Sarasin betont, dass diese spezielle Systematisierung der Hygienelehre, die man hauptsächlich von Galens Schriften ableitete, erst während der Aufklärung erfolgte und im »neuen Kontext des bürgerlichen Zeitalters « das zentrale Element einer bürgerlichen Lehre der Lebensführung wurde: Hygiene bzw. Diätetik. Nach dieser Rezeption Galens teilt man dessen »Haus der Medizin« laut Sarasin in drei Bereiche:

»a) der Bereich des Gesunden mit den sieben res naturales (die Elemente, die Temperamente, die Körperteile, die Säfte, der Geist, die Fähigkeiten und die Handlungen), b) der Bereich des Kranken mit den drei res contra naturam (die Krankheiten, ihre Ursachen und ihre Symptome) und zwischen diesen beiden, c) die sex res non naturalis als >neutrale< Felder der auf das Individuum wirkenden Einflüsse und des gesundheitsrelevanten Handelns: 1. Licht und Luft (aer), 2. Essen und Trinken (cibus et potus), Bewegung und Ruhe (motus et quies), Wachen und Schlafen (somnus et vigilia), 5. Ausscheidung (excreta et secreta), 6. Gemütsbewegungen (affectus animi). Die sex res sind der Ort der Hygiene - diese umfasst daher die Gesamtheit der Lehren bezüglich all dieser Handlungsfelder. «116

Als die sechs nicht-natürlichen Dinge (sex res non naturales), von denen Galen schrieb, bezeichnete man den Bereich der Einflüsse, die von außen auf den Körper und die Gesundheit des Menschen einwirkten. Dieser Bereich wurde vor allem in Frankreich und England für die Entwicklung einer bestimmten Gruppe von Techniken zur Regierung der Gesundheit der Bevölkerung relevant, zu denen ich später noch kommen werde. Diese Aufteilung und die Konzentration auf den dritten Bereich verband sich mit einer Strategie der Regierung der Gesundheit nicht nur des Einzelnen, sondern einer ganzen Bevölkerung. Der Ursprung dieser Strategie lag in dieser neuen mit der Praxis der Diät (im einem sehr umfassenden Sinne) verbundenen Kunst der Lebensführung. Foucault schieb über die Diät:

»Ob man aus dem Diätwissen eine ursprüngliche Kunst oder eine spätere Ableitung macht - es ist klar, daß die >Diät< als Lebensregel, als Lebensweise, eine fundamentale Kategorie ist, in der die menschliche Lebensführung gedacht werden kann; sie charakterisiert die Weise, in der

115 Vgl. ebd.: S. 272.

116 Sarasin: Reizbare Maschinen. Eine Geschichte des Körpers 1765 - 1914, 2001: S. 6. 
man die Existenz führt, und ermöglicht es, die Lebensführung mit Regeln auszustatten: eine Problematisierung des Verhaltens im Hinblick auf die Natur, die man zu bewahren und der man sich anzupassen hat. Die Diät ist eine ganze Lebenskunst. «117

Die Praxis der Diätetik verband sich schließlich mit einer zunehmend öffentlich geführten Auseinandersetzung um >richtige< Lebensweise und Existenz, bei der die Ärzte eine bedeutende Rolle spielten. Für die Ärzte ergab sich die Möglichkeit, das, was dem Charakter einer Rationalität und Praxis des Regierens für die Ausübung des Arztberufs bedeutet hatte, zu de-individualisieren, zu politisieren und auf diesem Wege ihren sozialen Status zu verbessern und ihre Macht auszuwerten. Sie waren demnach Teil einer bürgerlichen Bewegung, die sich über das Selbstvertrauen einer eigenen moralischen Praxis und moralischen Beurteilung von Subjektivität und Lebensführung von anderen Institutionen und privaten Praxen der moralischen Selbstformung emanzipierte. In Deutschland blieb die Diätetik zunächst eine Form der Führung des individuellen Lebens, die man mehr oder weniger mithilfe der gleichen Techniken in den Aufgabenbereich der Polizei übertragen hatte wollen. Die Lehre der Diätetik betraf die Führung in Bezug auf die ganze Lebensweise: Essen, Trinken, Ruhe bzw. Schlaf, Arbeit, Sexualität, körperliche Anstrengung im Verhältnis zur geistige Anstrengung usw. Auf diese Weise geriet die Selbstregierung der Gesundheit und die Regierung und Rolle, in der sich die Ärzte sehen wollten, in einen Konflikt. Ganz anders als bei dem von den Ärzten als abergläubisch oder ungebildet beschriebenen $»$ Pöbel $\ll^{118}$, bestand der Widerstand hier zu dem Anspruch auf Selbstregierung und der mit ihr verbundenen Beförderung eines entsprechenden Subjektideals. Die Unwissenden und Unvernünftigen, die sich gegen die Verordnungen der Ärzte ebenso wie gegen die Anordnungen der Medizinalpolizei sträubten, wurden von den Ärzten leicht zu Opfern der Pfuscher, Betrüger und abergläubischer Großväter abgestempelt, denen sich die Arzneikunde und die Ärzte aus Mitleid und >Menschenliebe< annahmen. Nun stieß man hier auf eine Gegenmacht, deren Rationalität der >rationellen< Regierung der Gesundheit und des Lebens völlig entsprach. Nur bestand im >aufklärerisch< eingestellten Bürgertum die Ansicht, diese Regierungsaufgabe selbst erledigen zu können oder dies sogar zu müssen, insofern man sich als ein »selbstdenkender Mensch « verstand. ${ }^{119}$ Es kam deshalb, parallel zu der Entstehung dieses >moralischen< Diskurses innerhalb bestimmter Kreise, zu einer Veränderung im Selbstverhältnis der Ärzte. Allerdings war diese Veränderung am Anfang noch nicht so eindeutig. Wenn es zu einer Art zunehmender Polarisierung in der Frage des Verhältnisses der Regierung der Anderen und der Regierung des Selbst kam, bevor es sich am Ende der Auseinandersetzung in eine neue Ordnung dieses Verhältnisses auflöste, so deshalb, weil sich die Ärzte zu Beginn noch nicht recht entscheiden konnten, an welcher Stelle sie in diesem Verhältnis stehen wollten. Die Ärzte sahen sich gleichzeitig als Philosophen, Priester, Wissenschaftler und Bürger. Die Ärzte traten für die Selbstregierung ein, richteten sich gegen die Praxis der Verhaltensfüh-

117 Vgl. Foucault: Sexualität und Wahrheit II, 1998 [1984]: S. 131.

118 Gruner: Gedanken von der Arzneiwissenschaft und den Ärzten, 1772: S. 582.

119 Stieglitz: Bemerkungen über obrigen Gegenstand [Ueber die Stellung der Aerzte zum Staate, zum Publikum, und unter sich selbst]: in: JPA, 1.60=53, 1825, S. 17 - 112: S. 96. 
rung durch die Kirche, sahen sich aber auch in der wichtigen Rolle, eine Aufgabe bei der Führung gegenüber ihren Patienten und Ratsuchenden zu übernehmen. Daraus ergab sich der Konflikt der Ärzte. Von Seiten der bürgerlichen Diskurse und Auseinandersetzungen ergaben sich Einwände gegen die Medizin und gegen den Anspruch der Führung der Ärzte, Priester und Seelsorger. Es existierte die Einschätzung, man müsse sich im Zweifel als vernünftiger Geist den Regeln und Gesetzen der Natur beugen und nicht versuchen, sich sinnlos gegen diese aufzulehnen, was wiederum die Arzneiwissenschaft beeinflusste, sich stärker mit der ganzen Frage nach den von der Natur gesetzten Grenzen und Möglichkeiten der ärztlichen Praxis zu befassen. Auch die ganze Begeisterung für die brownsche Lehre und die Diskussionen über die Selbstheilungskräfte des Körpers hingen mit diesen Konflikten zusammen. ${ }^{120}$ Dieser ärztekritische, bürgerliche Diskurs hatte in Frankreich eine noch viel größere Bedeutung und nahm Einfluss auf die Herausbildung der sog. »Volksmedicin« in Deutschland. ${ }^{121}$ Es bestand also eine Verbindung zwischen der Frage, wie man sich selbst helfen kann, wenn kein Arzt in der Nähe ist, und der Frage, ob es oft nicht besser wäre, auf die zweifelhafte und teure Hilfe eines Arztes zu verzichten und sich stattdessen besser selbst zu behandeln. Diese Diskussionen beschränkte sich größtenteils auf bürgerliche Kreise. Hier ging es nicht in erster Linie darum, die Ärzte zu kritisieren, sondern es ging darum, eine Kritik an bürgerlicher Lebenspraxis und Lebensweise zu üben und an der Art und Weise, wie immer exzessiver auf den ärztlichen Rat und den Dienst der Ärzte zurückgegriffen wurde. Es handelte sich also um eine zunächst völlig auf den innerbürgerlichen Diskurs bezogene Kritik an einer Art Mode und an einem >irrationalen< bis >krankhaft< übermäßigen Konsultieren der Ärzte und der Medizin. Im Kontext dieser Kritik lassen sich wohl auch eine Reihe von Auseinandersetzungen um das Problem der Hypochondrie und Hysterie ${ }^{122}$ verstehen. Von allen Stimmen, die diesen Diskurs belebten, mag die von Kant zu den eher prominentesten gehört haben.

120 Vgl. Sensibilität als Lebensprincip der in der Organischen Natur: in: JNA, 6.2, 1794: S. 3 - 15. Vgl. Geschichte neuerer Untersuchungen der Kräfte der organischen Natur I: in: JNA, 6.25, 1798: S. 3ff. Vgl. Geschichte der neuesten Untersuchungen der Kräfte in der Organischen Natur. II: in: JNA, 8.25, 1798, S. 77 - 117.

121 Vgl. [Hrsg.]: Des Achzehnten Jahrhunderts Geschichte der Erfindungen, Theorien und Systeme in der Natur- und Arzneiwissenschaft: in: JNA: 7, 1798: S. LXXVIIIf. Besonderen Einfluss hatte wohl die in mehrere Sprachen übersetzte Schrift des französischen Arztes Samuel Auguste André David Tissot Avis au peuple sur sa santé, 1876, Lyon. Die deutsche Übersetzung von Hans Caspar Hirzel von 1789 habe ich bereits weiter oben zitiert. Tissot ist überhaupt eine interessante Figur, was die Herausbildung dieses neuen populären, moralischen und wissenschaftliche Bezug auf Gesundheit betrifft. Er veröffentlichte neben zahlreichen anderen Schriften auch ein Buch mit dem Titel L'Onanisme: dissertation sur les maladies produites par la masturbation, 1810.

122 Vgl. Kant: Von der Macht des Gemüths durch den bloßen Vorsatz seiner krankhaften Gefühle Meister zu sein, 1824 [1797]: S. 11. Vgl. Hauf: Ueber die Hysterie und ihr Verhältniß zur Hypochondrie: JPA 6.76, 1833, S. 1 - 97. Vgl. Luce, Johann Wilhelm Ludwig von: Versuch ueber Hypochondrie und Hysterie, ein praktisches Handbuch für angehende Aerzte. 1797. 
»Eine Art von Wahnsinn, [...] wo dann der Selbstquäler, statt sich selbst zu ermahnen, vergeblich die Hülfe des Arztes aufruft; weil nur er selbst, durch die Diätetik seines Gedankenspiels, belästigende Vorstellungen, die sich unwillkürlich einfinden, [...] aufheben kann.«123

Eines der bekanntesten Beispiele einer von bürgerlicher Seite geäußerten Kritik an den Ärzten und dem >Gebrauch < der Ärzte, sind die Äußerungen von Jean-Jacques Rousseau. Auf jeden Fall scheint es so, als hätten die deutschen Mediziner ihm seine Äußerungen über die Ärzte, in dem 1762 veröffentlichten Buch Émile ou de L'Education sehr übel genommen. Zumindest gibt es reichlich Empörung und Verwunderung wie z.B. auch bei Gruner, der sich fragt:

»Warum empört sich ein spottender Rousseau wider alles thierische und menschliche Gefühl? Und warum verbiethet er seinem Aemil, bei den heftigsten und schmerzhaftesten Zufällen des Körpers zu den Hülfsmitteln der Arzneiwissenschaft seine Zuflucht zu nehmen?« «24

Obwohl Rousseau natürlich keine direkte Stimme in den Diskussionen zwischen dem Bürgertum und den Ärzten in Deutschland besaß, scheint es mir aufgrund der Bezüge bei Gruner, Hufeland und anderen möglich, anhand seines Textes zu verdeutlichen, welche Art der Abneigung die bürgerliche Philosophie und die Bürger in ihrem Selbstverständnis zum Teil gegenüber der Macht und dem Einfluss der Ärzte empfanden und warum sie die Arzneikunst als »trügerische Kunst ${ }^{125}$ ansahen.

»Ein kraftloser Körper schwächt auch die Seele. Daher kommt die Herrschaft der Heilkunst, einer Kunst, die gefährlicher ist als alle Übel, die sie zu heilen vorgibt. Ich meinerseits weiß nicht, von welcher Krankheit uns Ärzte heilen, aber ich weiß, daß sie uns schlimme Krankheiten zuziehen: Feigheit, Kleinmut, Leichtgläubigkeit und Furcht vor dem Tode. Was nützt es uns, wenn sie wahre Leichen wieder zum Gehen bringen? Wir brauchen ganze Menschen, aber die sieht man aus der Hand der Ärzte nicht hervorgehen. [...] Die Ärzte mit ihren Verordnungen, die Philosophen mit ihren Vorschriften und die Priester mit ihren Ermahnungen entmutigen das Herz, so daß wir das Sterben verlernen. $\ll^{126}$

Weiter schrieb Rousseau, dass er es daher ablehne, dass Émile, die Figur seines Zöglings, einen Arzt benötigte: Er wolle sicher sein, der einzige Regent seines Zöglings zu sein!

»Man gebe mir also einen Zögling, der aller dieser Leute nicht bedarf, oder ich weise ihn zurück. Ich will nicht, daß andere mein Werk verpfuschen, ich will ihn allein erziehen oder garnichts mit ihm zu tun haben.« ${ }^{127}$

123 Kant: Der Streit der Fakultäten in drei Abschnitten, 2005 [1789]: S. 116.

124 Gruner: Gedanken von der Arzneiwissenschaft und den Ärzten, 1772: S. 9.

125 Rousseau: Emil oder über die Erziehung, 1958 [1762]: S. 34.

126 Ebd.: S. 33f.

127 Rousseau: Emil oder über die Erziehung, 1958 [1762]: S. 34. 
Auch hierin zeigt sich, dass die Ärzte in ihrer Rolle der Leitung und Führung der Menschen, bezogen auf deren nicht nur körperliche, sondern seelische und geistige Existenz, kritisiert wurden. Damit standen sie in der Tat, was die Rolle als Regierende anging, mit den Priestern und Seelsorgern und auch mit den Pädagogen in einem Konkurrenzverhältnis. ${ }^{128}$

Dabei ist es nicht so, dass Rousseau behauptet, man solle sich überhaupt nicht um seine Gesundheit kümmern, im Gegenteil. Allerdings solle man dies nach den Regeln der Hygiene, der »Gesundheitslehre«, deren Wissen jedem nützlich sei, tun und nach ihr seine Lebensführung selbst ausrichten. Im Gegensatz zur Medizin, die Rousseau als künstlich und widernatürlich ansah, betrachtete er die Hygiene als eine an den natürlichen Gesetzen ausgerichtete Wissenschaft:

»Gerade diese [naturgemäße] Lebensweise will ich meinem Schüler lehren, und er soll den gleichen Vorteil daraus ziehen. Der einzige nützliche Zweig der Medizin ist die Gesundheitslehre, und diese ist weniger eine Wissenschaft als eine Tugend. Mäßigkeit und Arbeit sind die beiden wahren Ärzte des Menschen. Die Arbeit fördert seinen Appetit, und die Mäßigkeit hindert ihn daran, ihn zu missbrauchen. $\ll^{129}$

Aus dieser Einstellung bei Rousseau resultierte aber auch, dass er sich nur der Erziehung eines »gesunden und starken Zöglings « widmen wollte. ${ }^{130}$ Wer, meinte Rousseau, nicht von »Natur aus « leben kann, muss eben akzeptieren zu sterben. ${ }^{131} \mathrm{Im}$ Grunde sagt Rousseau etwas Ähnliches wie die religiösen Kritiker, die die Ärzte für ihre Anmaßung einer göttlichen Macht über das Leben beschimpft haben. Rousseau sieht diese Anmaßung nur gegenüber der Natur. Sehr viel wichtiger an seinem Gedanken ist, dass sich auch seine Kritik im Grund nicht gegen die Ärzte richtet, sondern gegen die Menschen, die es nicht wagen, sich selbst zu regieren. Statt Wissen oder Kunst sei eine bestimmte Einstellung und Praxis der »naturgemäßen« Lebensweise der Weg zum Heil und zum Glück. ${ }^{132}$

Man kann verstehen, dass die >bürgerlichen< Ärzte, die sich selbst nah an den Idealen von Vernunft und Freiheit orientierten, von dieser Kritik scharf getroffen wurden. Gerade die neo-hippokratischen Ärzte wollten sich schließlich selbst als Aufklärer begreifen. Dies zeigt sich z.B. in der Weise, wie Ärzte auf die Kritik der sog. Selbstdenker und Nichtärzte ${ }^{133}$ und die Praxis der medizinischen Selbstregierung reagierten. Insofern galt auch hier die Unterscheidung verschiedener Subjekte, die legitimen oder illegitimen Gebrauch von ihrer Freiheit zur Selbstregierung machten. Zum einen gab es die, die ihre Lebensführung unter Einbeziehung des Ratschlags eines wirklichen - also wissenschaftlich gebildeten - Arztes und mit dessen bzw. ihres

128 Vgl. Foucault: Geschichte der Gouvernementalität I, 2004 [1977 - 1978]: S. 212.

129 Ebd.: S. 35.

130 Ebd.

131 Ebd.

132 Ebd.: S. 66.

133 Vgl. Stieglitz: Bemerkungen über obrigen Gegenstand [Ueber die Stellung der Aerzte zum Staate, zum Publikum, und unter sich selbst]: in: JPA, 1.60=53, 1825, S. $17-112$ : S. $94 \mathrm{f}$. 
eigenen Wissens über die Natur begründeten, wobei sie weiterhin die Urteile und Entscheidungen für sich trafen. Zum anderen verurteilten die Ärzte jene, die sich der Wahrheit der Medizin entzogen und sich aus Unwissenheit oder Vernachlässigung der Wahrheit anmaßten, sich selbst regieren zu können. Hecker berichtete über die Entwicklung und die Anhänger der sog. Volksarzneikunde und die Ärzte, die »medizinische Volksbücher, [...] voller praktischer Rathschläge und Rezepte ${ }^{134}$ schrieben:

»Doch fehlte es auch nicht an Aerzten, die uns mit einem praktischen Unterricht zur Selbsthülfe für iedermann, mit Pastoral und Ruralmedizin, mit medizinischen Noth- und Hülfsbüchern, Hauspostillen, usw. überreichlich versorgten. Und was hatte man nun alle dieser Popularität medizinisch-praktischer Grundsätze, die man gar oft als eine Frucht unserer Aufklärung, und unseres Eifers für allgemeines Menschenwohl rühmen hörte, hervorgebracht? Eine gewisse Kälte gegen die Ärzte, und ihre wohlthätigen Bemühungen, die nun aus einem ganz falschen Gesichtspunkte angesehen wurden; denn wie konnte man eine Kenntniss noch schätzen, die in dem vermeindlichen Besiz eins jeden war, oder doch leicht seyn konnte? «135

»So war, durch unserer Freunde der Popularität, die schwerste aller Künste, die Medizin, die mit einem seltenen Scharfsinn ausgeübt werden muss, wenn sie wahrhaft wohlthätig werden soll, den Aerzten, die alle ihre Kräfte auf die Erlernung und Ausübung derselben, zu werden verbunden waren, gewissermaßen entrissen, und anderen mehr oder weniger gebildeten Ständen, zur Nebenbeschäftigung gemacht worden. «136

Hecker beabsichtigte nicht zu sagen, dass die Menschen sich nicht in Maßen um sich selbst sorgen sollten. Er wollte eine Grenze ziehen und festlegen, bis zu welchem Grad und in Bezug auf welche Situationen und vor allem nach welcher Rationalität die Menschen sich also selbst regieren sollten und konnten. Hecker stimmte mit der Position überein, dass »die Volksarzneikunde, in so fern sie einen wahrhaft wohlthätigen Zweck erreichen soll, den Nichtarzt blos von solchen Dingen unterrichten müsse, die auf eine zweckmässige Kenntniss seines Körpers, und auf die Erhaltung desselben, einen Bezug haben $\ll \cdot{ }^{137}$ Eine entsprechende Bildung sollte, so Hecker, sogar vom Staat eingerichtet werden. ${ }^{138}$

\section{Selbsterkenntnis und Regierung des Selbst}

Die Selbstkenntnis und die Selbstregierung, die Askese und die Arbeit am Selbst hatten vor dem 18. Jahrhundert eher im Rahmen privater und religiöser Praxen (Fasten, Beichte, Buße, Geständnis und Läuterung) innerhalb der Lebensführung breiter sozialer Schichten einen Platz eingenommen. Die Kriterien für eine private moralische Existenz veränderten sich auch im Zuge fortschreitender Reformationsbemühungen

134 Hecker: Die Heilkunst auf ihren Wegen zur Gewissheit, oder die Theorien, Systeme und Heilmethoden der Ärzte seit Hippokrates bis auf unsere Zeiten, 1802: S. 206.

135 Ebd.: S. 207.

136 Ebd.: S. 206f.

137 Ebd.: S. 209f.

138 Vgl. ebd.: S. 209f. 
und mit der Verbreitung protestantisch geprägter Diskurse über die richtige Lebensweise. Das bedeutet, dass kein völlig neuer Anspruch auf Selbstregierung gestellt werden musste. Das Neue war eher, dass diese Selbstregierung einen zunehmend öffentlichen und allgemeinen Diskurs belebte, der nun seit langem wieder in einem sehr direkten Zusammenhang zur politischen Frage der Regierung des Selbst und der Anderen gestellt wurde. Das Problem der >richtigen Lebensweise< stellte sich nun in einer viel allgemeineren Form und bezog sich auch auf Bereiche, die vom Diskurs pastoraler Selbstpraxis bisher nicht berührt worden waren. Max Weber schrieb in seiner Protestantischen Ethik:

»Die christliche Askese, anfangs aus der Welt in die Einsamkeit flüchtend, hatte bereits aus dem Kloster heraus, indem sie der Welt entsagte, die Welt kirchlich beherrscht. Aber dabei hatte sie im ganzen dem weltlichen Alltagsleben seinen natürlich unbefangenen Charakter gelassen. Jetzt trat sie auf den Markt des Lebens, schlug die Türe des Klosters hinter sich zu, und unternahm es gerade, das weltliche Alltagsleben mit ihrer Methodik zu durchtränken, es zu einem rationalen Leben in der Welt und doch nicht von dieser Welt oder für diese Welt umzugestalten. $\ll^{139}$

Diese in die Öffentlichkeit getragene moralische Selbstpraxis und Ethik von der richtigen Lebensführung wurde von den Ideen der Diätetik und dem medizinischen Wissen kolonialisiert. Ich erinnere an dieser Stelle noch einmal an die Kritik, die man den Ärzten vorgehalten hat: Die vor allem religiösen, oder wie Gruner schrieb, >abergläubischen< Kritiker der Arzneiwissenschaft hielten den Ärzten vor, dass nur Gott die Macht über das Leben vorbehalten sei. Nur Gott alleine könne etwas so Allgemeines zum Gegenstand seiner Regierung haben. Die Öffentlichmachung der Selbstpraxis ermöglichte es, einen neuen Bereich der Macht und Regierung zu bestimmen, der materiell und weltlich war und dennoch an das Ziel der Rettung oder des Heils der Seele angebunden blieb. Dieser Bereich wurde nun aber nicht mehr nur durch die religiösen und dogmatischen Gesetze strukturiert, sondern, wie u.a. die Ärzte konstatierten, durch die Natur, die zwar göttlichen Ursprungs war, aber in der die Gesetze in der Arbeit wissenschaftlicher Forschung und Erkenntnis vom Menschen entschlüsselt werden mussten. Die Gesetze der Natur zu erkennen und nach diesen zu leben, war nun der von Gott oder der Natur selbst vorgesehene Zweck der Menschen. Dies ermöglichte eine Verweltlichung und Objektivierung von Erfahrungen mit der $>\mathrm{Na}$ tur und eine Rationalisierung im Umgang mit >natürlichen< Phänomenen oder erlaubt, wie Latour schreibt, eine gefahrlose $>$ Mobilisierung der Natur $<$ und damit die Eroberung ungeahnter Bereiche für die Produktion, in der Forschungspraxis und auch bei der Lebensführung und Praxis der Selbsterkenntnis und Selbstregierung. Im Zusammenhang mit dieser Transformation ist nun die hauptsächlich in der Philosophie des 17. und 18. Jahrhunderts neu aufgeworfene Frage des Verhältnisses von Körper und Seele zu sehen.

Bei einer Reihe von antiken Philosophen wie z.B. Pythagoras und Aristoteles war die Seele wichtiger als der Körper. Die Seele war das Element, was dem Körper Le-

139 Vgl. Weber: Die protestantische Ethik und der Geist des Kapitalismus, 1995 [1904/04]: S. 134. 
bendigkeit zufügte. ${ }^{140}$ Auch Leibniz hatte 1714 die Seele als die zentrale »Monade « eines organischen Körpers bezeichnet, also die Seele als vorrangig und den Körper als ihr nur anhängend und zugehörig bezeichnet, die dann gemeinsam das Lebewesen ausmachten. Der Körper war für Leibniz eine Art mit Seele ausgestattete »göttliche Maschine « oder »natürlicher Automat ${ }^{141}$. Für ihn, ebenso wie für Aristoteles, war damit auch der Beweis erbracht, dass andere Lebewesen, wie Tiere und Pflanzen, eine Seele haben müssten. Die Besonderheit des menschlichen Lebens und seines Willens wurde von Descartes problematisiert. Während die hydraulische Maschine des Körpers beim Tier automatisch gesteuert sei, so würde sich beim Menschen im Gehirn, und zwar in der »Zirbeldrüse« eine vernünftige Seele befinden. Wie Sarasin schreibt, suchten Anatomen bis Ende des 18. Jahrhunderts erfolglos nach einem solchen »somatischen Ort des kohärenten Ich-Bewusstseins im Gehirn $\ll^{142}$.

Für das Problem der Regierung, der Führung und Selbstführung und die mit ihr in Verbindung gebrachten Kriterien legitimer Machtausübung war die Fragen nach einem Ort, von dem aus die Vernunft über den Körper >regierte<, bedeutsam. Was macht den Menschen aus? Wo setzt die Regierung der Menschen an? Regiert die Seele den Körper und ist folglich die Regierung des Menschen nicht die Regierung seiner Seele? Gibt es beim Menschen noch anderes, nämlich Geist und Vernunft, die die wahren Regenten über die Leidenschaften und Empfindungen der Seele sind? Was ist aber die Seele und was ist der Geist? Handelt es sich um eine Art Organ, wie Descartes vermutete, oder ist er ebenso wie die Seele bei Leibniz, eine unteilbare und immaterielle und metaphysische Monade?

Immanuel Kant hat u.a. in Reaktion auf einige dieser Fragen in der Philosophie und auch mit Bezug auf Descartes, den metaphysischen und spekulativen Charakter der menschlichen (reinen) Vernunft ins Zentrum seiner Philosophie gestellt. Laut ihm entzieht sich der Geist oder die Vernunft selbst der Untersuchung und Erkenntnis. Es gibt also einen wissenschaftlich selbst nicht ergründbaren immateriellen Bereich, der Ausgangspunkt allen Denkens, aller Erfahrung und das zentrale Element des Wesens und auch der Selbstregierung des Menschen sein muss. Das heißt auch, dass der Grund, warum die Menschen sich nicht selbst regieren, darin besteht, dass sie sich, wie Kant es ausgedrückt hat, ihres Verstandes nicht bedienen. Kant hat damit eindeutig die Philosophie zur Königsdisziplin erkoren. Sie ist die Wissenschaft, die das eigentliche Wesen des Menschen bestimmen kann und daher wissen kann, wie dieser und in welchem Maße dieser gerecht regiert werden kann. Der Spott, den Kant gegenüber den empirischen Wissenschaften hervorbrachte, die er als »Vernunftkünstler « bezeichnete, und die an Kant anschließende idealistische Philosophie Schellings und Fichtes, hatte Ende des 18. Jahrhunderts vermutlich einen nicht unerheblichen Einfluss auf die Medizin und ihre Krise genommen.

Im Folgenden möchte ich versuchen, ein wenig genauer zu bestimmen, welchen Einfluss diese philosophische Auseinandersetzung um das Wesen des Menschen und das Verhältnis von Körper und Geist auf die Regierung von Gesundheit genommen hat. In einer 1769 in der Berlinische Sammlung zur Beförderung der Arzneywissen-

140 Vgl. z.B. Aristoteles: Über die Seele, 2006 [384 v.Chr. - 322 v.Chr.]: [II, 415b] S. 30ff.

141 Leibniz: Monadologie, 1847 [1714]: S. 26.

142 Vgl. Sarasin: Geschichtswissenschaft und Diskursanalyse, 2003: S. 107. 
schaft [etc.] ausgeschriebenen Preisfrage »über die Selbsterkenntniß« wurden Autoren aufgerufen, eine Abhandlung über die Selbsterkenntnis bei der Typographischen Gesellschaft ${ }^{143}$ einzureichen. ${ }^{144}$ Hintergrund der Ausschreibung ist die in der Anzeige formulierte Diagnose eines Mangels an Selbsterkenntnis. Diese wurde in der Anzeige auf die folgende Weise erörtert:

»Die Geschichte des menschlichen Verstandes lehrt genugsam, daß oft besondere Wissenschaft zu einer Zeit alles, und zu iener anderen gar nichts gegolten. Bey den Alten stand die Selbsterkenntnis im höchsten Ansehen, bey uns wird die fast gar nicht mehr geachtet. [...] Der Pöbel unserer Zeit ist von dem Pöbel des Alterthums in nichts unterschieden. [...] Zunächst aus Nichts angränzend, gedankenlos, und doch tyrannisch stolz, im Staube kriechend, mißkennt er beständig den Adel seiner Seele. ${ }^{145}$

Der Text verweist mit der Problematisierung der vernachlässigten Selbsterkenntnis auf die verkannte Fähigkeit der Menschen, zu urteilen und daraufhin sich selbst zu regieren. Das bedeutet, die Menschen haben das Potenzial sich selbst zu führen, und zwar, wie es weiter heißt, dank ihrer eigenen sinnlichen Fähigkeit, das Schöne zu erkennen. Sie haben grundsätzlich die Fähigkeit, das, was naturgemäß und wahr und gerecht für die einzelnen Menschen ist, aber auch was für einen Staat richtig ist, selbst zu erkennen. ${ }^{146}$ Auf jeden Fall läuft die Argumentation des Anzeigentexts darauf hinaus zu sagen, dass die Selbsterkenntnis, die im Grunde genommen die Erkenntnis über die eigene Urteilskraft und die eigene Vernunft ist, etwas absolut Vernachlässigtes sei. Außerdem habe die Selbsterkenntnis eine ungemein große politische Relevanz. Nämlich in der Hinsicht, dass nur eine Regierung oder ein Regent, der sich auf eine Vernunft beruft, die die Macht dieser Urteilskraft kenne, gut regieren könne. Die »Selbsterkenntniß habe nicht die mindeste Verbindung mit der Staatswissenschaft und mit der Staatsklugheit«, vielmehr sei sie die Grundlage der »Kenntniß der Natur« und aller wirklicher Zusammenhänge. Aus diesem Grund sei sie auch die Grundlage aller »Staatswirthschaft« und der »klugen« Regierung ${ }^{147}$. Die Menschen selbst, als Erkenntnissubjekte, als erkennende Wesen seien die Quelle aller vernünftigen, moralischen Gesetze, die man sich selbst und dem Staat auferlegen könne. Die Fähigkeit der Menschen das Gute selbst zu erkennen verleihe ihnen die Fähigkeit der Regierung ihrer Selbst. Die Art und Weise, wie wir uns selbst führen müssen und wie der Staat seine Aufgabe der Führung vernünftig ausüben könne, lieBe sich durch nichts anderes gewährleisten, als dadurch, dass man sich dieser inneren Natur der menschlichen Vernunft an sich selbst bewusst wird. Diese Aussagen bilden

143 Die 1767 in Magdeburg gegründete und nur weniger Jahre bestehende Gesellschaft war der Zusammenschluss einiger aufklärerischer Autoren, die versuchten, das etablierte Verlagswesen zu umgehen, und von Kaufleuten, die sie unterstützten. Vgl. Schmidt: Klopstock, Werke und Briefe 2, 2002: S. 373.

144 Vgl. Typographische Gesellschaft: Zu erörternde Fragen über die Selbsterkenntniß, und Anzeige eines auf deren Beantwortung gesetzten Preises: in: BS, 3.1, 1769, S. 413 - 425.

145 Ebd.: S. 413f.

146 Ebd.: S. 418f.

147 Ebd.: S. 420f. 
den Hintergrund der Preisfrage zur Selbstkenntnis. Vielleicht ist es sogar die Aussage, dass jeder Gegenstand nur nach der Erkenntnis seines Wesens, seiner Natur nach gut regiert werden kann. Das Ziel der Regierung der Seelen zielt auf die Schönheit des Selbst, seine Moralität und Güte. Die Regierung des Körpers, auch innerhalb der Diätetik, richtet sich auf seine Stärke und Gesundheit, indem sie die >Natur< dieses Körpers berücksichtigt und zur Entfaltung bringt. ${ }^{148}$

Ich denke, dass dieser Text auf die Zuspitzung eines Problems oder eines Widerspruchs aufmerksam macht. Dieses Problem bestand, mit den Worten Foucaults gesprochen, in der >Neuverteilung < von Macht und dem Verhältnis der Regierung des Selbst und der Regierung der Anderen. ${ }^{149}$ Das mitunter größte Problem stellte sich dabei mit der Bestimmung des Verhältnisses von Körper und Seele oder auch des Verhältnisses von Körper und Verstand. Bestand die Möglichkeit dieses Verhältnis und die Substanz der Seele ebenfalls naturwissenschaftlich zu erklären? Dieses erkenntnistheoretische Problem stellte sich am deutlichsten mit der Aufgabe der Selbsterkenntnis und löste gewissermaßen eine ontologische Fragestellung ab. Wenn ich mich selbst, also meine Seele oder meinen Verstand durch Anschauung und sinnliche Nachforschung erkennen kann, wo ist dann aber das Subjekt dieser Erkenntnis, was kann Ich überhaupt erkennen und v.a. wie kann die Seele oder der Verstand den Leib regieren, wenn sie bzw. er selbst nichts weiter als ein Organ ist? Diese Frage hat sich u.a. Descartes gestellt. Als Beispiele für die unterschiedlichen Auseinandersetzungen können u.a. Lockes Physiologie des Verstandes, Descartes Rationale Psychologie oder auch seine Äußerungen zur Physiologie der Seele wie auch Samuel Sömmerrings Schrift zum Organ der Seele von 1796 dienen. Letztere löste eine Diskussion und Empörung bei vielen Ärzten aus. ${ }^{150}$ Bekanntermaßen war Immanuel Kant einer der vehementesten Verteidiger des metaphysischen Geistes. ${ }^{151}$ Meiner Einschätzung nach hielt die Mehrheit der Ärzte in Deutschland die Thesen Sömmerrings für falsch. In dem Journal der Erfindungen, Theorien und Widersprüche in der Natur und Arzneiwissenschaft fand über mehrere Ausgaben hinweg eine Auseinandersetzung über den Streit zwischen Sömmerring und Kant statt. Auf Kants Transzendentalphilosophie hätten die Theologen mit der »Anwendung der transcendentalen Principien auf die Moral« und die Juristen mit der »Anwendung derselben auf das Naturrecht« reagiert, hieß es in dem Artikel. ${ }^{152}$

148 Ebd.: S. 424.

149 Foucault: Die Regierung des Selbst und der anderen I, 2009 [1982 - 1883]: S. 53.

150 Vgl. Spiegel zu Braunschweig, D.: Vorläufige Bemerkungen über die Streitigkeit: vom Organ der Seele: in: JNA, 18.5,1796: S. 59 - 70.

151 Immanuel Kant kritisierte in der Kritik der reinen Vernunft mehrfach das Modell der rationalen Psychologie, wendet sich auch in seinem Vorwort gegen Lockes Vorschlag (vgl. Kant: Kritik der reinen Vernunft 1, 1968 [1. Aufl. 1781, 2. Aufl. 1787]: S. 12/AX) und äußerte in einem Kommentar zu Sömmerrings Schrift, die 1796 erschien, seine Kritik an dessen These zum Sitz der Seele. Vgl. Kant in: Sömmerring: Über das Organ der Seele, 1796: S. 81f; 86.

152 Vgl. Spiegel zu Braunschweig, D.: Vorläufige Bemerkungen über die Streitigkeit: vom Organ der Seele: in: JNA, 18.5, 1796: S. 59 - 70: S. 59. 
»Eine einzige Fakultät hat sich bei der großen Revolution, die im Reiche des Wissens vorgefallen ist, beinahe ganz ruhig verhalten, hat wenig auf sie Rücksicht genommen - ich meine die medicinische. Wie geht dies zu? ${ }^{153}$

Wenn der Ausgangspunkt aller Erkenntnis dem metaphysischen Bereich der Vernunft und der Seele entsprang, was war dann noch die Medizin als Erfahrungswissenschaft? Alles, was Ärzte zu erkennen vermochten, beruhte auf einem Problem, dass nicht mehr ihr Gegenstand sein konnte. Sie können über das, was der Mensch ist oder werden könnte, nichts mehr sagen. ${ }^{154}$ Sömmerring, der tatsächlich die Flüssigkeit des Gehirns für den Ort der Seele hielt, habe, so heißt es in dem Artikel, »von [der] transzendentalen Philosophie nichts verstanden. ${ }^{155}$

»Kant hat damit ganz im Sinne seiner Philosophie darauf verwiesen, was sich sinnvollerweise nicht mehr behaupten lässt, und auf diese Weise den ontologischen Dualismus von Leib und Seele in einen erkenntnistheoretischen gewandelt: zwischen dem, was Hirnphysiologen, und dem was Philosophen aussagen können. «156

Was bedeutet dieser Einwand Kants für die Auseinandersetzung um die Verteilung der Regierung und das Verhältnis von Selbstregierung und Regierung der Anderen? Im Prinzip setzte er den Anfangspunkt, den konstitutionellen Grund für eine Regierung des Selbst. Fast jede Regierungsmacht benötigt zunächst einen solchen Grund, eine solche Wahrheit. Diese Wahrheit ist eine ganz theoretische Aussage über das, was wahr ist. Es ist gewissermaßen so etwas wie der Gründungsmythos der Selbstregierung seit der Aufklärung. Selbstbewusstsein durch einen Akt der Selbsterkenntnis befähigt zur Selbstregierung, nicht mehr die stetige Arbeit der Reflexion und die Praxis der Meditation. Im Grunde war es kein mangelndes Wissen, sondern ein sich selbst nicht erkennendes Selbst, was die Selbstregierung verhinderte. Kant setzte mit seiner Philosophie eine Transformation fort, die spätestens bei Descartes einen Bruch zur christlichen Selbstpraxis der Askese dargestellt hatte. Foucault schrieb zu diesem Bruch:

»[B]is zum 16. Jahrhundert, bleibt die Frage: >Welche Arbeit muss ich an mir selbst vollziehen, damit ich fähig und würdig bin, Zugang zur Wahrheit zu erlangen?^ Oder um die Dinge anders zu sagen, die Wahrheit hat stets ihren Preis; es gibt keinen Zugang zu Wahrheit ohne Askese. [...] Ich denke, dass Descartes damit gebrochen hat, indem er sagte: Um Zugang zur Wahrheit zu erlangen, genügt es, dass ich ein beliebiges Subjekt bin, das sehen kann, was evident ist.< Die Evidenz ersetzt die Askese am Verbindungspunkt zwischen der Beziehung zu sich und der Beziehung zu anderen, der Beziehung zur Welt. $\ll^{157}$

153 Vgl. ebd.: S. 59.

154 Vgl. ebd.: S. 60.

155 Vgl. ebd.: S. 64.

156 Vgl. Wiesing: Immanuel Kant, seine Philosophie und die Medizin, 2005: S. 88.

157 Foucault: Zur Genealogie der Ethik, 2005 [1983]: S. 497. 
»Weiter darf man nicht vergessen, dass Descartes >Meditationen< geschrieben hat - und Meditationen sind eine Selbstpraxis. Doch das Außerordentliche an den Texten von Descartes ist, dass er es geschafft hat, ein Erkenntnispraktiken begründetes Subjekt an die Stelle eines dank Selbstpraktiken konstituierten Subjekts zu setzten. $\ll^{158}$

Kant griff meiner Meinung nach genau dieses alte Problem der Selbsterkenntnis als >moralisches< wieder auf, wobei er den Schritt von einer privaten Praxis der Arbeit am Selbst in eine Art Konstitution des Selbst (bei Descartes durch die Fähigkeit der Meditation begründet) mitgeht. Bei der Konstitution des Selbst war für Kant aber die Selbsterkenntnis ausschlaggebend, nicht die Meditation.

Er wollte es aber dabei nicht belassen, sondern fügte der Bedingung der Allgemeingültigkeit der moralischen Gesetze und für die Moralität eines Selbst, die öffentliche Praxis der Anwendung hinzu. Wo Descartes die Rationalität von der Moral gewissermaßen befreit hatte, hat ihr Kant eine andere Praxis moralischer Subjektivierung ${ }^{159}$ wieder hinzufügt.

»Nach Descartes hat man ein Subjekt der Erkenntnis, das für Kant das Problem des Verhältnisses zwischen dem moralischen Subjekt und dem Subjekt der Erkenntnis stellt. [...] Kants Lösung war, ein universales Subjekt zu finden, das in dem Maße, wie es universal ist, das Subjekt der Erkenntnis sein konnte, das aber nichtsdestoweniger eine ethische Haltung erforderte eben jene Beziehung zu sich, die Kant in der Kritik der praktischen Vernunft vorlegt. «160

Wenn die Regierung, wie die Freiheit der Menschen, an der Frage des Erkenntnisbereichs von Erfahrungen hing, der immer graduell und defizitär gegenüber einer göttlichen allwissenden Macht stand, dann war die Selbsterkenntnis nicht als Erkenntnissubjekt, sondern als Vernunftwesen und als »Subjekt des moralischen Gesetzes ${ }^{161}$ zugleich die Versöhnung mit - und die Befreiung von dieser Macht. ${ }^{162}$

»Die alte Frage wurde folglich wieder eingeführt: >Wie kann ich mich selbst als ethisches Subjekt konstituieren? Mich selbst als solches erkennen? Brauche ich dazu Übungen in Askese? Oder aber jene kantische Beziehung zum Universalen, die mich moralisch macht, indem sie mich der praktischen Vernunft konform macht?< So führt Kant eine neue zusätzliche Bahn in

158 Ebd.: S. 496.

159 Unter Subjektivierung verstehe ich hier und im Folgenden das, was Foucault als eine bestimmte Pragmatik des Selbst, als historisch sich verändernden Verfahren zur Konstruktion moralischer Subjektivität bezeichnet hat. Vgl. Foucault: Die Regierung des Selbst und der anderen II, 2010 [1983 - 1984]: S. 18.

160 Ebd.: S. 497f.

161 Vgl. Kant: Kritik der praktischen Vernunft, 2000 [1788]: S. 211.

$162 »$ Die Endabsicht, worauf die Spekulation der Vernunft im transzendentalen Gebrauche zuletzt hinausläuft, betrifft drei Gegenstände: Die Freiheit des Willens, die Unsterblichkeit der Seele, und das Dasein Gottes.« Vgl. Kant: Kritik der reinen Vernunft 2, 1968 [1. Aufl. 1781, 2. Aufl.1787]: S. 672/A 789. 
unserer Tradition ein, dank welcher das Selbst nicht einfach gegeben, sondern in einem Selbstverhältnis als Subjekt konstituiert ist. «163

Das Sich-bewusst-werden über die moralische Urteilskraft ist gleichbedeutend mit der Erkenntnis der eigenen Freiheit und des Heraustretens aus der Unfreiheit und der Fremdregierung. »Er [der Mensch] urteilet also, daß er etwas kann, darum, weil er sich bewußt ist, daß er es soll, und erkennt in sich die Freiheit, die ihm sonst ohne das moralische Gesetz unbekannt geblieben wäre. « ${ }^{164}$

Fünfundzwanzig Jahre nachdem in den Berlinischen Sammlungen die Preisfrage zur Selbsterkenntnis ausgeschrieben wurde, antwortet Kant auf eine andere Preisfrage. Sein Aufsatz zu der Frage, »Was ist Aufklärung? « erschien 1784 in der Berlinischen Monatsschrift. Gleich zu Anfang heißt es hier:

»Aufklärung ist der Ausgang des Menschen aus seiner selbstverschuldeten Unmündigkeit. Unmündigkeit ist das Unvermögen, sich seines Verstandes ohne Leitung eines anderen zu bedienen. Selbstverschuldet ist diese Unmündigkeit, wenn die Ursache derselben nicht am Mangel des Verstandes, sondern der Entschließung und des Mutes liegt, sich seiner ohne Leitung eines andern zu bedienen. Sapere aude! Habe Mut, dich deines eigenen Verstandes zu bedienen! ist also der Wahlspruch der Aufklärung. Faulheit und Feigheit sind die Ursachen, warum ein so großer Teil der Menschen, nachdem sie die Natur längst von fremder Leitung freigesprochen (naturaliter maiorennes), dennoch gerne zeitlebens unmündig bleiben; und warum es anderen so leicht wird, sich zu deren Vormündern aufzuwerfen. Es ist so bequem, unmündig zu sein. Habe ich ein Buch, das für mich Verstand hat, einen Seelsorger, der für mich Gewissen hat, einen Arzt, der für mich die Diät beurteilt usw., so brauche ich mich ja nicht selbst zu bemühen.«165

Sehr ähnlich zu dem Text von Kant ging es in der Anzeige vom 1768 um die Feststellung, dass die Menschen sich in einem Zustand der Unwissenheit und Unmündigkeit befinden, für die ihnen selbst die Schuld gegeben werden muss. Der Zustand der Unmündigkeit ist bei Kant kein Zustand, der sich aus der >natürlichen< Begrenzung der Existenz ergibt. Ebenso ist er kein Zustand, der sich aus der >natürlichen $<\mathrm{Be}$ grenzung der Erkenntnis ergibt. In dem Text Was ist Aufklärung? ${ }^{166}$ und in seinem späteren Bezug auf die gleiche Analyse im Rahmen der Vorlesungen zur Regierung des Selbst und der Anderen am Collège de France stellt Foucault zwei Aussage Kants heraus. Erstens sei der Zustand der Unmündigkeit kein >natürlicher< Zustand der Ohnmacht »als die Menschen völlig in der Lage sind sich selbst zu steuern«. Zweitens sei das einzige, was ihnen fehle, der Mut und der Wille davon Gebrauch zu machen. ${ }^{167}$ Die Selbsterkenntnis könne, nach Kant, nur zu dem Selbstbewusstsein führen, mittels seines Verstandes und eines universalen moralischen Gesetzes selbst ur-

163 Foucault: Zur Genealogie der Ethik, 2005 [1983]: S. 498.

164 Vgl. Kant: Kritik der praktischen Vernunft, 2000 [1788]: S. 139f.

165 Kant: Beantwortung der Frage: Was ist Aufklärung? in: Berlinische Monatsschrift, 1784: S. $482 f$.

166 Vgl. Foucault: Was ist Aufklärung, 2005 [1984]: S. 687 - 707.

167 Foucault: Die Regierung des Selbst und der anderen I, 2009 [1982 - 1883]: S. 47. 
teilen zu können. Was auch immer die Wissenschaft an Kenntnissen liefern könne, leite sich doch aus ihr keine Vernunft, keine Urteilskraft und keine Handlung ab. Kein Fachwissen könne die Vernunft ersetzten, die für Selbstbestimmung nötig sei. ${ }^{168}$ Was bedeutet das für das Selbstverhältnis? Es bedeutet, die Konstituierung des Subjekts nicht nur als zum Denken Fähiges, welches aus der Evidenz eine objektive Wahrheit erkennen kann. Sondern es bedeutet, die Konstituierung eines Subjekts, welches in der Lage ist, auch wenn es aus irgendeiner Schwäche heraus sein Handeln daran nicht immer ausrichtet, zu erkennen, was Gut und Richtig ist - und zwar in einem universellen, göttlichen, sogar heiligen Sinne. Daraus schließt Kant nicht nur auf die natürliche Fähigkeit und damit den natürlichen Zweck einer Selbstregierung, sondern er leitet davon auch die Grundlage vernünftiger Gesetze und guter Regierung ab, die mit diesem moralischen Gesetzen im Einklang stehen müssen. Foucault hat die von Kant rhetorisch aufgeworfene Frage verneint, ob »es [sich] bei diesem Begriff der Unmündigkeit [...] um einen juristischen oder politisch-juristischen Begriff « handele, »der sich auf die Tatsache bezieht, daß die Menschen derzeit der legitimen Ausübung ihrer Rechte aufgrund irgendeines Umstandes beraubt sind « ${ }^{169}$. Das nächste Bemerkenswerte an dem Text von Kant sei, so Foucault, dass dieser nicht bei der Feststellung bleibt, dass die Menschen aufgrund ihrer Faulheit und Feigheit in diesem ihrer Natur und allem Guten widersprechenden Zustand der Unmündigkeit verbleiben. Denn als zweites stelle Kant fest, dass die Menschen aufgrund dieses Verhältnisses zu sich selbst, also ihrer Feigheit und Faulheit, nicht selbst aus dem $\mathrm{Zu}$ stand der Unmündigkeit herauskommen werden. ${ }^{170}$ Kant prangerte keine Unterdrückung oder Regierung durch andere an, sondern, wie Foucault es an einer Stelle benennt, »eine Art Mangel im Verhältnis der Autonomie zu sich selbst«, die daran hindere, sich der Vernunft und Moral zu bedienen. ${ }^{171}$ Die Aufklärung hat nach Kant, so Foucault, das Ziel diese verdorbene Beziehung zwischen der Regierung des Selbst und der Regierung der Anderen neu zu verteilen. ${ }^{172}$ Das Verdorbene an ihr ergebe sich aus dem Verhältnis, was die Menschen zu sich selbst haben, welches widernatürlich sei. ${ }^{173}$ Foucault betont mehrfach, dass die drei Beispiele, die Kant nennt, dazu dienen, das Problem dieser Beziehung zu sich selbst und der Mangel an Autonomie zu sich selbst, deutlich zu machen.

»Drei konkrete Beispiele, drei Beispiele ohne den gewöhnlichen strahlenden philosophischen, juristischen oder politischen Status, nämlich das Buch, der Seelsorger und der Arzt. Aber es sind die drei Kriterien. Mir scheint, dass man die Analyse der Unmündigkeit mit Blick auf diese drei Kriterien lesen muss, die in dem Text untergründig und implizit vorhanden sind. «174

168 Vgl. Kant: Beantwortung der Frage: Was ist Aufklärung?: in: Berlinische Monatsschrift, 1784: S. 484.

169 Foucault: Die Regierung des Selbst und der anderen I, 2009 [1982 - 1883]: S. 54.

170 Vgl. ebd.: S. 54.

171 Ebd.: S. 53.

172 Vgl. ebd.: S. 53.

173 Vgl. ebd.: S. 52f.

174 Ebd.: S. 50. 
Laut Kant ist für dieses Heraustreten aus der Unmündigkeit ein Raum der Öffentlichkeit und nichts weiter als die Freiheit in diesem Bereich nötig. ${ }^{175}$ Die Selbstregierung der Bürger und ihre Aufklärung durch eine Öffentlichkeit als Ort der kritischen Aktivität der Philosophie gehören für Kant zusammen. Kant schrieb, sich zum platonischen Ideal der republica noumenon bekennend, dass die Philosophen dazu fähig seien, den allgemeinen Willen, eben aufgrund ihres Wissens von den natürlichen Rechten der Menschen und ihrer natürlich-richtigen Existenzweise theoretisch zu simulieren. Daher seien sie unentbehrlich für einen Staat und eine Staatsregierung, die gerecht herrschen wolle. Gerecht heißt aber auch erfolgreich und fortschrittlich. Die Aufklärung im Sinne Kants bedeutete, auf dem Weg der Öffentlichkeit und der öffentlichen Kritik am Verhalten der Menschen, dem Volk, aber vor allem dem Staat, von der spekulativen Theorie aus zu erklären, was von Natur her eine bessere Lebensweise und Regierung sei. Ziel dabei war, ganz wie in der Selbstpraxis oder Diätetik: die Besserung des Menschen, bzw. des Volkes.

»Volksaufklärung ist die öffentliche Belehrung des Volkes von seinen Pflichten und seinen Rechten in Ansehung des Staates, dem es angehöret. Weil es hier nur natürliche und aus dem gemeinen Menschenverstande hervorgehende Rechte betrifft, so sind die natürlichen Verkündiger und Ausleger derselben im Volk nicht im Staat bestellte amtsmäßige, sondern freie Rechtslehrer, d.i. die Philosophen, welche eben um diese Freiheit willen, die sich erlauben, dem Staate, der immer nur herrschen will, anstößig sind, und werden unter dem Namen Aufklärer, als für den Staat gefährliche Leute verschrien; obzwar ihre Stimme nicht vertraulich ans Volk (als welches davon und von ihren Schriften wenig oder gar keine Notiz nimmt), sondern ehrerbietig an den Staat gerichtet, und dieser jenes sein rechtliches Bedürfnis zu beherzigen angeflehet wird; welches durch keinen anderen, als den der Publizität geschehen kann, wenn ein ganzes Volk seine Beschwerde vortragen will. So verhindert das Verbot der Publizität den Fortschritt eines Volkes zum Besseren, selbst in dem, was das mindeste seiner Forderung, nämlich bloß sein natürliches Recht angeht. « ${ }^{176}$

Kant machte die Unterscheidung zu der von ihm, ebenso wie von Platon, negativ konnotierten Demokratie klar, die eher der republica phenomenon, quasi der empirischen Rechtsgebung, zugehöre.

»[Es ist] Pflicht der Monarchen, ob sie gleich autokratisch herrschen, dennoch republikanisch (nicht demokratisch) zu regieren, d.i. das Volk nach Prinzipien zu behandeln, die dem Geist der Freiheitsgesetze (wie ein Volk mit reifer Vernunft sich selbst vorschreiben würde) gemäß sind, wenngleich dem Buchstaben nach es um seine Einwilligung nicht befragt würde. «177

Das war es, was Kant forderte und was einer bestimmten sehr erfolgreichen Strategie entsprach, nämlich die Traditionen der Selbstpraxis in einer Weise umzuformen, dass eine Selbstregierung, moralische Kritik der Regierung und die Konstitution eines zur

175 Kant: Beantwortung der Frage: Was ist Aufklärung? in: Berlinische Monatsschrift, 1784: S. 486.

176 Kant: Der Streit der Fakultäten in drei Abschnitten, 2005 [1789]: S. 101f.

177 Ebd.: S. 104. 
Regierung potenziell fähigen Subjekts möglich ist, ohne zu viel Widerstand zu wecken. Dies hatte eine Reihe ganz praktischer Auswirkungen, die ich hier nur andeuten kann. In Bezug auf die Regierung der Gesundheit bedeutete es auf jeden Fall, dass die Rolle der Ärzte hinsichtlich der Regierung der Menschen in Frage gestellt und zumindest theoretisch eingeschränkt wurde. Für Kant besteht das Problem in der Unfreiheit, die durch die selbstverschuldete Unmündigkeit und Abhängigkeit verursacht wurde. In dem ärztlichen, medizinischen Diskurs war der Zustand, in dem sich ein Subjekt als nicht aufgeklärtes und unwissendes befand, weniger ein Zustand der Unfreiheit und Unmündigkeit. Sondern es bedeutete unter Umständen vor allem Krankheit oder sogar Tod. Es konnte heißen, der Willkür von sog. Giftmischern und Quacksalbern ausgesetzt zu sein. Die Ärzte hatten gemäß ihrem bürgerlichen moralischen Selbstverständnis allen Grund, an der Führung und Anleitung der Menschen mit dem Ziel einer vernünftigen Selbstregierung mitzuwirken. ${ }^{178}$ Allerdings hatte die transzendentale Philosophie die Macht der Ärzte und die Bedeutung des medizinischen Wissens für die Regierung und die Existenz der Menschen auf einen marginalen Platz verwiesen.

Der folgende Text ist ein von dem Arzt und Autor Christoph Wilhelm Hufeland herausgegebener Nachdruck, der 1779 bei Reclam erschien. Der Originaltext von Kant war bereits dreißig Jahre zuvor entstanden. Es handelte sich dabei um ein Antwortschreiben Kants an Hufeland. Der Arzt hatte ihm zuvor sein Buch über Macrobiotic (»die Kunst das Leben zu verlängern«) zugesandt und Kant um seine Meinung dazu gebeten. ${ }^{179}$ Im Vorwort von 1779 schrieb Hufeland:

»Der Geist allein lebt. Das Leben des Geistes allein ist wahres Leben. Das Leben des Leibes muß jedem immer untergeordnet von ihm beherrscht werden, nicht umgekehrt der Geist sich den Launen, Stimmungen und Trieben des Körpers unterordnen, wenn das wahre Leben erhalten werden soll. Diese große Wahrheit wurde von jeher von den Weisesten dieser Welt als der Grundpfeiler aller Sittlichkeit, aller Tugend, aller Religion, genug alles dessen, was groß und göttlich ist am Menschen, und sonach auch aller wahren Glückseligkeit, betrachtet und gepredigt. $\ll^{180}$

Wieder geht es hier nicht nur um die Fähigkeit, sondern auch um die Pflicht und die Verantwortlichkeit, die der Regierung zukomme. Diese Verantwortung, sich selbst zu regieren, obliege den Subjekten selbst. Ihre Abhängigkeit, Unfreiheit und vor allem Unwissenheit sei selbst verschuldet. Außerdem klingt aber in der Verteidigung der metaphysischen Seele bzw. der Vernunft durch Hufeland genau jene Angst an,

178 Vgl. Osterhausen: Ueber medicinische Aufklärung, 1798.

179 »Als Beitrag zu dieser wichtigen Lehre und als Beförderungsmittel der Herrschaft und Heilkraft des Geistes über den Körper möchten auch folgende Worte Kant's, die letzten, die dieser große Geist zu uns gesprochen, dienen. Er schrieb sie auf meine Veranlassung vor 30 Jahren, und gern habe ich der Aufforderung des Herrn Verlegers zu einem neuen besonderen Abdrucke gewillfahrt, und die mit einigen Vermerkungen versehen. Mögen sie ihren Zweck erreichen!« Hufelands Vorwort: in: Kant: Von der Macht des Gemüths durch den bloßen Vorsatz seiner krankhaften Gefühle Meister zu sein, 1824 [1797]: S. 9.

180 Ebd.: S. 5. 
die Latour ironisch als die »Angst vor dem Mob« bezeichnet hat und aus der die Notwendigkeit begründet wurde, dass es keinen weltlichen, materiellen und menschlichen Ausgangspunkt von Moral geben könne. ${ }^{181}$ Weiter heißt es in Hufelands Vorwort:

»Wenn, wie in den neusten Zeiten geschehen selbst die Philosophie, sonst die Trägerin des geistigen Lebens, in den Identitäts-System den Unterschied zwischen Geist und Körper ganz aufhebt, und sowohl Philosophen als Aerzte die Abhängigkeit des Geistes von dem Körper dergestalt in Schutz nehmen, daß sie selbst alle Verbrechen damit entschuldigen, Unfreiheit der Seele als ihre Quelle darstellen, und es bald dahin genommen sein wird, daß man gar nichts mehr Verbrechen nennen kann. [...] Führt sie nicht zum gröbsten Materialismus? Vernichtet sie nicht alle Moralität, alle Kraft der Tugend, die eben in dem Leben der Idee und ihrer Herrschaft über das Leibliche besteht? Und somit alle wahre Freiheit, Selbstständigkeit, Selbstbeherrschung, Selbstaufopferung, genug das Höchste, was der Mensch erreichen kann: den Sieg über sich selbst. ${ }^{182}$

Worauf es also hinsichtlich des Verhältnisses des moralischen Selbst zu seinem Körper ankommt, meint Hufeland, ist die Kenntnis, Beherrschung und Regierung der inneren Natur. Nur durch die Beherrschung des Körpers, seiner Leidenschaften und Neigungen kann nicht nur das geistige, seelische Wohlergehen, sondern auch die physische Gesundheit erreicht werden:

»Ewig wahr und bleibt das Sinnbild, den Menschen als den Reiter eines wilden Pferdes sich zu denken; einen vernünftigen Geist mit einem Thiere vereinigt, das ihn tragen und mit der Erde verbinden, aber von ihm nun wiederum geleitet und regiert werden soll. Es zeigt die Aufgabe seines ganzen Lebens. Besteht sie nicht darin, diese Thierheit in ihm zu bekämpfen und der höheren Macht unterzuordnen? Nur dadurch, daß er sich dies Thier unterwirft und sich möglichst unabhängig davon macht, wird sein Leben regelmäßig, vernünftig, sittlich, und so nur glücklich. [...] Aber nicht blos für das höhere geistige Leben und dessen Gesundheit bedarf es dieser psychischen Selbstbeherrschung, sondern sie dient eben so sehr zur Erhaltung und Vervollkommnung des physischen Lebens und zu dessen Gesundheit, und wird dadurch eines der wichtigsten Diät- und Heilmittel. ${ }^{183}$

Im Grunde genommen bat Hufeland in diesem Briefwechsel Kant darum, ihm zuzustimmen, dass aufgrund dieser Konstellation und dieses Verhältnisses von Geist und Körper auch den Ärzten die Aufgabe einer moralischen Regierung zukommen müsse. Aber Kant erwiderte auf Hufeland Folgendes:

»Sie verlangen von mir ein Urtheil über Ihr Bestreben, das Physische im Menschen moralisch zu behandeln; den ganzen, auch physischen Menschen als ein auf Moralität berechnetes Wesen

181 Vgl. Latour: Die Hoffnung der Pandora, 2002: S. 266.

182 Hufelands Vorwort: in: Kant: Von der Macht des Gemüths durch den bloßen Vorsatz seiner krankhaften Gefühle Meister zu sein, 1824 [1797]: S. 5 f.

183 Ebd.: S. 6f. 
darzustellen, und die moralische Cultur als unentbehrlich zur physischen Vollendung der überall nur in der Anlage vorhandenen Menschennatur zu zeigen $[\ldots] . \ll^{184}$

Kant würdigte daraufhin Hufeland als »echten Philosophen«, der kein bloßer »Vernunftkünstler « sei, »sondern als gesetzgebendes Glied im Corps der Ärzte wirke « ${ }^{185}$, der »aus der reinen Vernunft hernimmt, welche zu dem, was hilft, mit Geschicklichkeit, auch das, was zugleich an sich Pflicht ist, mit Weisheit zu verordnen weiß ${ }^{186}$. Allerdings meinte Kant damit auch, dass Hufeland, indem er »das physische im Menschen moralisch [...] behandeln« wollte, nicht als Arzt, sondern als Philosoph auftrat. Das, was den Menschen ausmache und wie er zum Guten zu bewegen sei, also das, was die Aufgabe der Kritik der Regierung sei, könne nur die Philosophie leisten. ${ }^{187}$ Die Diätetik konzentriere sich nur auf eine ganze, die Gesundheit erhaltende und schützende »negative« asketische Lebensführung.

»Dergleichen Kunst aber setzt ein Vermögen voraus, das nur Philosophie, oder der Geist derselben, den man schlechthin voraussetzen muß, geben kann. Auf diesen bezieht sich die oberste diätetischen Aufgabe welche in dem Thema enthalten ist. «188

Um gesund zu sein und gut zu leben brauche man, laut Kant, mehr als nur einen Arzt. Denn dieser sei nur für das Heilen zuständig. Aber um sich gesund zu halten, um sich zu regieren, brauche man eher den Verstand und die Philosophie, denn die Diätetik fällt in ihren Bereich.

184 Kant: Von der Macht des Gemüths durch den bloßen Vorsatz seiner krankhaften Gefühle Meister zu sein, 1824 [1797]: S. 11.

185 Ebd.

186 Ebd.

187 Kant hat den Brief an Hufeland gemeinsam mit anderen Texten unter dem Titel: Der Streit der Fakultäten 1798 veröffentlicht. Hierin setzt er sich neben der medizinischen Fakultät auch noch mit der Rechtwissenschaft und der Theologie auseinander. In seiner Vorrede weist er die Beschuldigung zurück, er habe sich herabwürdigend über die christliche Religion geäußert. Stattdessen, schreibt er: Er habe es sich nicht zur christlichen Staatsreligion geäußert, sondern mit der Würdigung der »Naturreligion « beschäftigt. Im Grunde sagt Kant, dass die moralischen Gesetze, die sich aus ihr ableiten, universeller und besser seien, da sie von der Macht der Kirche getrennt über alle Zeit hinweg die gleichen Wahrheiten offenbarten: »Denn die hier aufgeführete Zusammenstimmung desselben mit dem reinsten moralischen Vernunftglauben ist die beste und dauerhafteste Lobrede derselben, weil eben dadurch, nicht durch historische Gelehrsamkeit [Methoden der Theologie und der Rechtslehre], das oft entartete Christentum immer wieder hergestellt worden ist.« Kant: Der Streit der Fakultäten in drei Abschnitten, 2005 [1789]: S. 10. Vgl. Giordanetti: Einleitung (2005): in: Kant [1789]: Der Streit der Fakultäten in drei Abschnitten: S. XXf.

188 Kant: Von der Macht des Gemüths durch den bloßen Vorsatz seiner krankhaften Gefühle Meister zu sein, 1824 [1797]: S. 12. 
»Obwohl sie nur negativ auf die Kunst wirkt, Krankheiten anzuhalten, setzt sie ein Vermögen voraus, welches lediglich aus dem Geist der Philosophie entspringen kann. Dieses Vermögen wird als die Macht des Gemüts, über seine krankhaften Gefühle durch den bloßen Vorsatz Meister zu sein, präsentiert. ${ }^{189}$

Die erste Einschränkung, die Kant vornimmt, bezieht sich auf die Arzneikunde bzw. auf die Philosophie. Denn das, was an sich Pflicht sei, die Selbstregierung durch den Geist, sei quasi der Anteil der Philosophie an der Diätetik. Regierung sei Sache der Philosophie, die Medizin sei die Kunst des Heilens. Ihre Aufgebe sei die Wissenschaft, die Kenntnisse über den Körper und die Krankheiten. Sie bringe die zusätzliche Erfahrung mit ein, die der Arzt gegenüber dem Laien habe. Aber aus der Wissenschaft vom Körper selbst leite sich keine Urteilskraft, also auch kein moralisches Bewusstsein ab, welches die Selbstbeherrschung gegen den Körper verlange.

Damit wurde eine Differenzierung vorgenommen, die die philosophische und medizinische Praxis der Regierung bzw. deren Funktion als Kritik der (Selbst-)Regierung voneinander trennte. Diese Differenzierung beendete, wenn auch nicht durch Kant, so doch durch diesen philosophischen Diskurs, die anfänglichen Versuche der Medizin, über den Weg der Praxis der Selbsterkenntnis und diätetischen Praxis, Stifter einer politischen Philosophie und Rationalität eines Verfahrens moderner Gouvernementalität zu sein. Die Philosophie erhebt nach dem Vorbild Platons erneut den Anspruch nicht nur »logos«, sondern auch »ergon im Bereich der Politik « zu sein. ${ }^{190}$ Während die Medizin sich von der Philosophie entfernte und sich der Physiologie und den Naturwissenschaften verschrieb, gaben die Ärzte ihre moralischen diätetischen Regierungspraktiken im Laufe des 19. Jahrhunderts immer mehr auf. 1861 wurde in Preußen das Philosophicum als Vorprüfung für Medizinstudenten durch das Physicum ersetzt. Während das Philosophicum an der Philosophischen Fakultät absolviert worden war, stand mit dem Physicum die Prüfung der naturwissenschaftlichen Grundlagen der Medizin im Vordergrund. Medizinethische und geisteswissenschaftliche Ausbildungsinhalte rückten also in den Hintergrund. Die Medizin wird als quasi >materialistische $<$ Disziplin und im Zusammenhang mit der wachsenden Bedeutung der >Humanwissenschaften < für die moderne Gouvernementalität im Laufe des 19. Jahrhunderts zu einer unverzichtbaren Wissens- und Legitimationsquelle für die Regierung werden.

\section{Die Differenzierung der Subjekte}

Die Definition des Menschen, die die Philosophie der Regierung als Grundlage einer den alten Regierungslogiken überlegenen Rationalität und Legitimität bereitstellte, hatte auf praktischer Ebene die Grenzen ihrer Gültigkeit gleich mit formuliert. Sie setzte das vernünftige Subjekt zum Ausgangspunkt der Begründung der Regierung und bedeutete gleichzeitig, dass alle Aushandlungen und Begrenzungen, die eine Regierung gegenüber dem Menschen einräumen musste, nur dann galten, wenn sich

189 Giordanetti: Einleitung (2005): in: Kant [1789]: Der Streit der Fakultäten in drei Abschnitten: S. XLI.

190 Vgl. Foucault: Die Regierung des Selbst und der anderen I, 2009 [1982 - 1883]: S. 292. 
dieser Mensch als vernünftig und fähig zur Freiheit, Moralität und zur Selbstregierung erwies. Diese Konstruktion ermöglichte die Kontrolle und Führung von Kindern, Wahnsinnigen, Frauen etc., denen man erhebliche Einschränkungen ihrer Vernunft oder deren völlige Abwesenheit unterstellte. Die Differenzierung erfüllt für die moderne Gouvernementalität die Funktion, die Wahrheit, Moralität und die gute Regierung in Abgrenzung zu denen zu konstruieren, die illegitim Macht ausüben, z.B., weil sie sich auf Unwahrheiten stützen, willkürlich herrschen oder die Wirklichkeit vernachlässigen, oder weil ihre Ziele und ihre Praxis einer >falschen < (irrationalen) Ethik angehören. Die Abgrenzung wird aber auch gegenüber denen vorgenommen, die regiert werden sollen, weil es ihnen an moralischer Praxis, an Macht über sich selbst und ihr Verhalten mangelt. Diese Konstellation von drei verschiedenen Subjektivitäten, ${ }^{191}$ die der Begründung einer legitimen Regierung dienen, ist sehr typisch. Im Gegensatz zu dem quantitativen Mehr oder Weniger, das ein Subjekt zur Regierung befähigt, geht es hier um eine Differenz zwischen dem, der regiert und den Regierten. Was nicht heißt, dass das quantitative Kriterium für die Macht im Sinne von Fähigkeit für den Wissenschaftler, Handwerker oder Künstler nicht weiter gilt. Aber für die Frage der Regierung, die sich auf das Leben bzw. in diesem Sinne, auf die Gesundheit richtet, ist die Differenz von Bedeutung. Denn die Fähigkeit sich selbst so zu führen, also in der Lage zu sein, die Krankheit von sich fernzuhalten, setzt ein Vermögen des Geistes und ein moralisches Bewusstsein im Sinne einer >Freiheit< voraus, welche Kant ja nur als Potenzial oder Begabung allen Menschen zugeschrieben hat. Mit der schrittweise eingeforderten und vollzogenen Neu- und Umverteilung der Regierung ab dem ausgehenden 18. Jahrhundert ging eine ganze Reihe von Differenzierungen von Subjekten einher, die eng verknüpft war mit der Trennung verschiedener Techniken und Bereiche der Regierung.

Ich möchte im Folgenden anhand einiger Beispiele aus Texten zeigen, wie eine Aufteilung der Regierung anhand der Differenzierung der Subjekte begründet wurde. Die Texte richten sich auf die Frage der Zurechnungsfähigkeit von Angeklagten in Strafverfahren. Es sind Texte aus dem Journal der practischen Arzneikunde von 1818 und 1826. Zunächst einmal wird hier erörtert, welche Aufgaben die Ärzte an den Gerichten haben und wie begrenzt ihre Rolle hier sei. Sie seien nichts weiter als Sachwissende, die zu einer bestimmten medizinischen Frage, die man an sie richtet, ein Auskunft geben sollen. Sie sollen weder urteilen, ob die Frage richtig gestellt sei, noch welchen Einfluss ihre Untersuchung auf die Entscheidung des Gerichts haben könnte. ${ }^{192}$

»Rechtskundige und Aerzte leben in dieser Rücksicht in einem Streite, der von dieser Seite nicht zu schlichten ist. Der Arzt geht von dem Grundsatze aus, daß man den Einfluß des Körpers so weit als möglich verfolgen müsse, ja er behauptet in seiner Kühnheit oft, der Richter dürfe keine Strafe aussprechen, ohne vorher einen Arzt gefragt zu haben. Käme es auf die me-

191 1. das gute, rationale und legitim regierende Subjekt, 2. das illegitim, irrational und unmoralisch regierende Subjekt und 3. das notwendig zu regierenden, möglicherweise vor der irrationalen, schlechten Regierung zu rettende Subjekt.

192 Vgl. Link, H.F.: Zurechnung aus ärztlichen Gründen. In Rücksicht auf Hofbauers Psychologie in Anwendung auf Rechtspflege: in: JPA, 1.47=40, 1818, S. 63 - 76: S. 64. 
dizinischen Fakultäten an, so wäre längst jedem Gerichtshofe ein Arzt als Beisitzer gegeben worden. Der Rechtskundige hingegen verwirft diese Anmaßung, und da er die Gewalt in Händen hat, so erlaubt er dem Arzte auch nicht ein Wort mehr zu antworten, als gefragt worden, selbst das Wort Zurechnung darf der gerichtliche Arzt nicht einmal aussprechen. ${ }^{193}$

Anschließend wird die Frage der Zurechnungsfähigkeit eines Angeklagten thematisiert ,über den der Arzt gebeten wird, sein Urteil abzugeben. Ein zentrales Argument in beiden Artikeln ist, dass es für das Gericht wenig Sinn mache, die unterschiedlichen Arten des Wahnsinns, die man in der Medizin verwende, zu kennen und den Arzt z.B. danach zu fragen, ob der Angeklagte an dieser oder jener bestimmten $>$ Krankheit< leide. Stattdessen sei für das Gericht nur erheblich, ob eine Person in irgendeiner Weise wahnsinnig sei. Wahnsinn bedeutet die im kantschen Sinne gemeinte Unfreiheit des Verstandes und damit die Abwesenheit von Urteilskraft und moralischem Gesetzt, die von einer >krankhaften< Ursache herrühre. Aber diese Abwesenheit der Vernunft sei eine innerliche Angelegenheit, die man nicht einfach aus einer unvernünftigen Handlung ableiten könne. Hier benötige man also den Mediziner, der die Person untersucht. ${ }^{194}$

»Die Ausübung der Rechte und Pflichten, so wie die Betrachtung des Gesetzes überhaupt, kann nur bei demjenigen vorausgesetzt werden, der nicht geisteskrank ist; der Geisteskranke hingegen verkennt, ohne es zu wissen, die innere Stimme der Vernunft und das gebietende Wort des Gesetzes, und handelt daher nach einer ihm selbst und dem Richter unbekannten Regel. Es kann für ihn der Vortheil der Selbstständigkeit und äußern Freiheit, auf welche ein jeder Mensch, nach seinen individuellen Verhältnissen, im Staate, Anspruch machen kann, nicht gelten; er kann kein Recht ausüben, weil er eben nicht von den Gründen geleitet zu werden vermag, welche bei der Ausübung desselben vorausgesetzt werden; er hat nicht die den andern Bürgern obliegenden Pflichten zu erfüllen, weil die Vernunft, welche zur Pflichterfüllung bewegt, ihn nicht leitet; er muß endlich unter die besondere Obhut des Staates gesetzt werden, weil der Staat und alle andern Bürger gegen ihn die Pflicht haben, ihn selbst und die Gesamtheit für alles Uebel zu bewahren, welches er vermöge der Abwesenheit der Vernunft, anrichten könnte. ${ }^{195}$

Mit anderen Worten: Ein Mensch, der dem Menschen nicht entspricht, nach dessen Natur sich die Regierung des Staates orientiert, fällt notwendig aus der Regierung desselben heraus. Was das Wesen des Wahnsinnigen ausmacht, ist Sache des Arztes und fällt somit der Regierung der Ärzte zu. Die Ärzte, die diesen körperlich kranken Menschen kennen und die Regeln der Krankheit, die ihn bestimmen, erforschen und somit erforschen, wie er zu einem besseren Verhalten geleitet werden kann, sind zu-

193 Ebd.: S. 65.

194 Ebd.: S. 64f.

195 Lichtenstädt: Ueber den Begriff, die Benennung und Beurteilung der Geisteskrankheiten: in: JPA, 42.63=56, 1826, S. 1 - 51: S. 42. 
ständig. Dem Staat, den Gerichten fällt nur die Aufgabe zu, diese Differenz festzustellen und den >Irren< in die Obhut der Ärzte zu geben. ${ }^{196}$

»Der Wahnsinnige, dessen Moralität man nicht tadeln kann, darf nur so weit unschädlich gemacht werden, daß er in seinen Einbildungen nicht anderen schadet. Es giebt auch ein Gesetzbuch für Irrenhäuser.« ${ }^{197}$

An diesem Beispiel wird sehr deutlich, wie die Regierung des >gesunden Menschen<, dem man auch seine Freiheit und Vernunft unterstellt, dem Staat und seinen Gesetzen überlassen werden muss. Die Ärzte und ihre Urteile, vielleicht sogar ihre Regierung, kommt ins Spiel, wenn man es quasi mit einem Menschen zu tun hat, der mehr Körper als Seele bzw. Geist ist. Dies trifft also auf den >wahnsinnigen< Menschen zu und ist der Grund, warum der Wahnsinn eine so wichtige Grenze zwischen der Regierung der Ärzte, der Selbstregierung und der Regierung des Staates und seinen Gesetzen markiert. ${ }^{198}$

»Der Mangel aller moralischen Ursachen einer That müssen Vermutungen erregen, daß körperliche Ursachen einen solchen Zustand hervorbrachten. Dem Arzt liegt es nun ob, in dem Gesundheitszustande zu forschen, ob der Beklagte einer Krankheit ausgesetzt gewesen, welche mit plötzlichen Aufwallungen und Erregungen verbunden, oder ihrer Natur nach seyn kann, und nach diesem wird das Vermuthliche entweder nur vermutlich bleiben, oder bis zur höchsten Wahrscheinlichkeit gesteigert werden. Dahin muß die Forschung sich richten. «199

Aber es gibt hier eine weitere genauere Differenzierung: Nämlich zwischen dem, der $>$ krank $<$ ist, und dem, der sich nur keine Mühe gibt, von seiner Vernunft Gebrauch zu machen. Wie bei Kant sehr deutlich geworden ist, bedeutet die Anlage vernünftig zu sein, noch lange nicht, dass Menschen für sich selbst Verantwortung übernehmen, z.B. weil sie den Mut dafür nicht besitzen. Die >Krankheit< soll nicht als Entschuldigung dafür dienen, von der Pflicht der Selbstregierung befreit zu werden.

»Der Verf. schiebt hier sogleich das Wort >der Kranke< ein, ohne zu untersuchen, ob es nicht Fälle giebt, wo der Mensch seiner Vernunft die Kraft nicht geben will, welche es ihr möglich macht, die Ausbrüche eines gewaltthätigen Zorns zu hindern. [...] Eine Tollheit, auf diese Weise entstanden, ist eine Selbstverschuldete Tollheit und macht dem, der sie äußert, sehr wohl Zurechnung unterworfen. $\ll^{200}$

Ein weiteres Problem betrifft die Frage, ob es Grade der Vernunft oder des Wahnsinns geben könne. Die Antwort ist hier sehr eindeutig: nein. Es möge unterschiedli-

196 Vgl. Link, H.F.: Zurechnung aus ärztlichen Gründen. In Rücksicht auf Hofbauers Psychologie in Anwendung auf Rechtspflege: in: JPA, 1.47=40, 1818, S. 63 - 76: S. 75.

197 Ebd.: S. 76.

198 Vgl. ebd.: S. $65 f$.

199 Ebd.: S. 72.

200 Ebd.: S. 67. 
che Grade geben, wie sehr Menschen Gebrauch von ihrer Vernunft machen würden, aber nicht bei der Frage, ob sie wahnsinnig seien oder nicht. ${ }^{201}$

»Die Vernunft kann durch erhöhte Körperlichkeit nur unterdrückt, und also nur relativ, nicht absolut geschwächt oder gar verändert werden. In der Fähigkeit zu urtheilen und zu schließen sind keine Grade, keine Verschiedenheit möglich; wer in der einen Figur schließen kann, vermag das auch in der anderen. $\ll^{202}$

Obwohl es in dem Artikel eigentlich um Angeklagte in Strafprozessen geht, fallen hier die Kinder unter den gleichen Ausschluss wie die als > wahnsinnig< bezeichneten Personen.

»Vernunft nennt Hoffbauer mit Kant das moralische Vermögen im Menschen. [...] Es wird erst mit dem Alter erlangt und Kinder sind daher vor keinem Gericht der Zurechnung unterworfen. $\ll^{203}$

Die moralische Differenzierung findet also noch zwischen denen statt, die grundsätzlich als vernünftige Menschen angesehen werden. Zwischen ihnen gilt die moralische Erhöhung und die Differenzierung der Subjekte nach dem Grad ihrer Beherrschtheit. Dagegen rechnet der >Wahnsinn< den Menschen gänzlich aus diesem Maßstab heraus. Die Einheit der reinen Vernunft macht gerade die Konstitution der Selbstregierung und der Rationalität der modernen Regierung aus. Da die Vernunft, nach Kant, wie die Seele eine Einheit bildet, ist es konsequent, dass eine Abstufung der Vernunft selbst nicht möglich ist. Aber man kann das Problem auch andersherum betrachten. Denn es gab auch gerade aus dem Bestreben, Menschen für ihre Taten verantwortlich zu machen, die Notwendigkeit, einem Relativismus vorzubeugen, der alles Handeln aus der Natur und dem Körper ableitet und damit eine Verantwortlichkeit der Menschen gänzlich in Zweifel stellte. So hatte z.B. Hufeland begründet, warum es wichtig sei, im Allgemeinen von der Herrschaft der Seele über den Körper auszugehen. ${ }^{204}$

\section{Ärzte - Staat - Subjekt - Verhältnisse und neue Ordnung}

Die letzten beiden Abschnitten habe ich zwei Bereiche ein und desselben Diskurses beleuchtet: Ich habe erstens die Strategie der Ärzte beschrieben, durch welche sie die in ihrer Praxis vorhandene Regierung von Menschen auf eine neue und universellwissenschaftlich-moralische Grundlage zu stellen versuchten und durch welche sie zugleich eine bedeutendere Rolle bei der Rationalisierung der Regierung des Staates anstrebten. Zweitens habe ich in dem darauf folgenden Abschnitt gezeigt, wie die Regierungspraxis der Ärzte den Veränderungen bürgerlicher Subjektentwürfe unterworfen war. Bzw., wie die Selbsterkenntnis und die Selbstpraxis in einem bestimm-

201 Vgl. ebd.: S. 68.

202 Ebd.: S. 75.

203 Ebd.: S. 75.

204 Vgl. Hufelands Vorwort: in: Kant: Von der Macht des Gemüths durch den bloßen Vorsatz seiner krankhaften Gefühle Meister zu sein, 1824 [1797]: S. 5f. 
ten bürgerlichen Milieu durch die bürgerliche Philosophie und Öffentlichkeit zum Grundstein einer modernen Regierungsrationalität wurde, von der die Ärzte weitestgehend ausgeschlossen wurden. Schließlich habe ich nachgezeichnet, wie die Philosophie als Wissenschaft vom Menschen, von seiner Vernunft und seinen moralischen Gesetzen die Medizin auf ihren Platz als Wissenschaft vom menschlichen Körper verwies. Diese Auseinandersetzungen und Strategien haben in der Zeit um 1800 starken Einfluss auf die Aus- und Umgestaltung der bereits vorhandenen Medizinalordnungen und die Verteilung und Begründung der Regierung der Gesundheit in den deutschen Ländern genommen.

Im Folgenden habe ich zum Abschluss noch einige weitere Texte ausgewählt, um zu zeigen, wie sich der Diskurs zum Ende dieser diskursiven Verdichtung durch eine bestimmte Ordnung stabilisiert hatte. Hier lässt sich erkennen, wie das Verhältnis von Staat, Ärzten und regierten Subjekten und die Verteilung der Regierung der Gesundheit unter ihnen von den vorangegangenen Auseinandersetzungen geprägt war. Ein Artikel im Journal der practischen Arzneikunde von 1825 trägt den Titel Ueber die Stellung der Aerzte zum Staate, zum Publikum und unter sich selbst. ${ }^{205}$ In dem Artikel von Hufeland und auch in dem Buch von Christian Friedrich Nasse (1778 1851 ${ }^{206}$, Von der Stellung der Aerzte im Staate, zeigen sich eine ganze Reihe von Problemen in der Praxis, die von Hufeland und Nasse unterschiedlich reflektiert werden. Grundlage ist die Feststellung, dass die Situation der Ärzte nicht mehr akzeptabel ist. Erstens, es gebe zu viele Ärzte und dadurch zu viel Konkurrenz. Hierdurch würde das Ansehen der Ärzte sinken, was man auch am Sinken ihrer Löhne sehen könne. Zweitens veranlasse die Notsituation manche Ärzte dazu, zu Hilfsmitteln zu greifen und mit »verächtliche[n] Künste[n]« (Hufeland) ihr Leben zu bestreiten. Hierdurch würde dem Ansehen der Arzneiwissenschaft und der Ärzte aber noch mehr Schaden entstehen. Die Ärzte hatten die Rolle der moralischen Leitung in vielerlei Hinsicht eingebüßt. Das hohe Ideal der hippokratischen Ärzte, dass sie sich selbst auferlegt hatten, konnte unter diesen Bedingungen dem materiellen Druck nicht standhalten.

Nasse und Hufeland kommen zu unterschiedlichen Vorschlägen, die allerdings beide zunächst auf eine Begrenzung der Ärzte zielen, sowohl in ihrer Anzahl, als auch in ihrer Tätigkeit. Diese Begrenzung kann auf zwei unterschiedlichen Wegen passieren. Nasse schlägt ein sehr stark vom Staat strukturiertes System vor, dass sowohl die Anzahl der Ärzte als auch die Bezahlung der Leistungen der Ärzte genau festlegt. Im Prinzip sollen die Ärzte zu Dienern des Staates gemacht werden, die auf diese Weise kontrolliert, versorgt und an den Staatszweck gebunden werden sollen. ${ }^{207}$

»Die Sorge der Aerzte für die öffentliche Gesundheitspflege (medicinische Polizei) kommt Allen im Staate zu Gute, den Gesunden wie den Kranken, auch die miteinbegriffen, die für ihren besonderen Dienst keinen Arzt bedürfen oder keinen mögen. Daß nun die Aerzte für ein die

205 Vgl. Hufeland, C.W.: Ueber die Stellung der Aerzte zum Staate, zum Publikum, und unter sich selbst: in: JPA, $1.60=53,1825$, S. $1-16$.

206 Vgl. Nasse: Von der Stellung der Aerzte im Staate, 1823.

207 Vgl. ebd.: S. 361f, S. 372. 
Gesammtheit ihrer Mitbürger angehendes Geschäft den Lohn aus Kassen empfangen, zu denen alle Steuerfähige, einjeder nach seiner Kraft, beitragen, ist ganz passend und diesen Lohn mag man denn mit Recht aus der Gemeindekasse nehmen. $\ll^{208}$

Dabei sollte auch das Budget der Patienten und die Schwere der Krankheit, also die Wichtigkeit der Behandlung in ein Berechnungssystem einbezogen werden. Sei die Person sehr krank, aber auch sehr arm, werde der größte Teil der Behandlung aus der staatlichen Kasse bezahlt. Sei der Patient selbst zahlungsfähig oder seine Krankheit so gering, dass nicht unbedingt ein Arzt erforderlich ist, so übernimmt der Staat keine Kosten.

Hufeland schlägt eher ein Gremium von Ärzten vor, dass nötige Regulierungen und Umverteilung unter den Ärzten als auch die Examen der Ärzte überwachen soll. Hufeland kritisiert rückblickend, dass die staatliche Regulation zum Nachteil der Ärzte ausgefallen sei und in vielen Fällen ihre Zwecke verfehlt habe.

»Der Versuch, durch obrigkeitlich eingesetzte Medicinalbehörden Alles zu dirigieren und zu controllieren, ist nicht gelungen. Der ärztliche Stand hat dabei weder an Reichthum noch an Macht gewonnen, nur an Freiheit verloren. «209

Im Grunde greift Hufeland damit die Idee der alten Medizinal-Kollegia wieder auf, will sie aber nach britischem oder schottischem Vorbild der College of Physicians in London und Edinburgh zu ärztlichen selbstverwalteten Kollegien umgestalten und liberalisieren. ${ }^{210}$ Hufeland ging gleichzeitig auch davon aus, dass sich die Anzahl der Ärzte nach einiger Zeit aber auch der Nachfrage anpassen würde. ${ }^{211}$ Auf der anderen Seite stellte er Nasses Vertrauen in die Macht des Staats als naiv und realitätsfern dar.

»Der Wunsch einer umfassenden Medicinalpflege, und jeder Vorschlag zu einer solchen für Reich und Arm ist eitel, wenn nicht vorab die Betrachtung des Verhältnisses der Armen zum Staate, der Fortschritt der Population, und der Macht der Regierung überhaupt angestellt wird. Wenn Menschen heirathen, die nicht im Stande sind elterliche Pflichten zu erfüllen, wenn Menschen heirathen ohne gesammelten Vorrath, so ist es, Ausnahmen abgerechnet, unvermeidlich, dass Noth und Elend und Krankheit in der Welt vermehrt werde, trotz allen Aerzten und Medicamenten. $\ll^{212}$

208 Ebd.: S. 337.

209 Hufeland, C.W.: Ueber die Stellung der Aerzte zum Staate, zum Publikum, und unter sich selbst: in: JPA, $1.60=53,1825$, S. $1-16:$ S. 12.

210 Man muss dazu sagen, dass es genau zu dieser Zeit, also Anfang des 19. Jahrhunderts, eine große Umstrukturierung der englischen und schottischen Organisation der Ärzte, Chirurgen und Apotheker gegeben hat.

211 Hufeland, C.W.: Ueber die Stellung der Aerzte zum Staate, zum Publikum, und unter sich selbst: in: JPA, $1.60=53,1825$, S. $1-16: 1-9$.

212 Ebd.: S. 15. 
Hufeland warf Nasse vor, in seiner Kompromisslosigkeit, was moralische Ziele und materielle Misstände betreffe, nicht in der Lage zu sein, einen brauchbaren Vorschlag für die Lösung des aktuellen Problems zu liefern. Es sei nicht zu machen, schreibt Hufeland, dass »alle Ärzte reich werden und alle Menschen 100 Jahre alt werden, aber es ist möglich, sich diesem Ziel ein wenig anzunähern ${ }^{213}$. Um diesem Ziel also näher zu kommen, meinte Hufeland, könne »ein zweckmäßiger Verein der respectablen Aerzte « dienen. ${ }^{214}$ Dieser Pragmatismus ist im Vergleich zu den älteren Texten eine bemerkenswerte Veränderung. Diese Art der übergeordneten Regierung der Ärzte, die Hufeland entwirft, ist von ihrer Struktur und Funktion her eher mit einer staatlichen Behörde vergleichbar.

Interessant ist, dass Hufeland in seinem >aristokratischen Modell< ein Gremium vorschwebt, welches die ethische Position der Ärzte vertritt, indem man es mit respektablen und angesehenen Ärzten besetzt. Dieses Gremium würde, wenn man ihm die entsprechende Macht überließe, für das Ansehen der ganzen Ärzte sorgen, die unter seiner Kontrolle stehen. Man würde die einzelnen Ärzte damit ein Stück weit ihrer Pflicht, durch ihre eigene Praxis das Zutrauen der Patienten zu gewinnen, entheben. Die Verfahren und Praxen, durch welche die Ärzte in ihrem Verhältnis zu den Patienten ihre Moralität bewiesen haben, werden irrelevanter. Das hat den Vorteil, dass die Ärzte nicht mehr in so einem unangenehmen Konflikt zwischen der Sicherung ihres Lebensunterhalts und ihrem Ideal des selbstlosen aufopfernden Menschenfreunds stehen. Es hat den Nachteil, dass die Enthebung von der Pflicht, diesem Subjekt mit den bekannten Anforderungen gerecht zu werden, den Arzt herabstuft. Aber wie man es dreht und wendet, muss er entweder zu einem Bediensteten des Staates oder zu einem Geschäftsmann werden. Diese Einrichtung nimmt ihm gewissermaßen die Mittel zur Begründung seiner Regierungsmacht, die Angewiesenheit auf einen Verdienst macht ihn unmoralisch.

Der Vorschlag von Nasse, der vordergründig etwas anderes will als der von $\mathrm{Hu}$ feland, hat im Grunde das gleiche Ziel. Nur bei ihm wird die Zwickmühle der Ärzte auf den Staat übertragen. Dieser ist aber, wie Hufeland sagt, genauso wenig in der Lage, alle Ärzte reich und alle Kranken gesund zu machen. Man ist also gezwungen, einen Kompromiss zu finden. Ich denke, dass diese Zielsetzung im Sinne eines bestmöglichen Grades an Gesundheit der Bevölkerung und einer möglichst effektiven Einrichtung der Kollegien und des Medizinalwesens eine Veränderung spiegelt. Statt der Idee einer in baldiger Zukunft erreichten Vollkommenheit, steht hier eher ein Modus der Einbeziehung von gegeneinander stehenden Kräften und Bedingungen im Zentrum.

In einem acht Jahre älteren Artikel aus dem gleichen Journal, der allerdings von einem »Regierungs-Medicinalrath«, Johann Joseph Kausch verfasst wurde, heißt es bezüglich der Medizinal-Kollegien, dass diese lediglich für die »Erledigung wissenschaftlicher Aufträge« zuständig sein könnten, wenn man wolle, dass die Regierung 
im Hinblick auf die Gesundheit der Bevölkerung effektiv sei. ${ }^{215}$ Kausch macht sich sichtlich wenig Sorge um das Ansehen und die Macht der Ärzte. Ihm geht es um die Regierung, die durch den Staat ausgeübt wird. Dennoch lassen sich hier Parallelen zu der Argumentation von Hufeland ziehen. Von den Behörden und der Polizei sei, laut Kausch, in dem Bestreben eine gute Medizinalordnung aufzubauen, oft mit zu großem Aufwand und zu detailliert eingegriffen worden. ${ }^{216}$ Auch hier erkennen wir jenen ökonomischen Pragmatismus wieder, der besagt, man müsse den Aufwand der Regierung für Medizinalverwaltung und Polizei mit Rücksicht auf die vorhandenen Gelder effektiver berechnen. Nachdem es Ende des 18. Jahrhunderts noch eine Auszeichnung für die Fürsten und Regenten gewesen war, bei der Verbesserung des Medizinalwesens und bei den Aufwendungen zum Schutz der Gesundheit der Untertanen keine Kosten und Mühen zu scheuen, findet sich zu dieser Zeit das Kriterium des ökonomischen Kalküls und der Effizienz für die Rationalität der Regierung immer häufiger.

»Die Zeiten sind daher vorüber, wo der kurzsichtige Tadler und der knickernde Staatswirth noch Gehör findet, wenn er seine Klagen gegen jeden Aufwand zu Gunsten der Sanitätsangelegenheit erhebt. Desto wichtiger bleibt indeß die große Frage: wie bei der allseitigen Beschränktheit der Fonts aller jetzt bestehenden Staaten mit der geringsten Summe von Mitteln dem höchsten Zwecke, in dieser Hinsicht, am meisten approximiert werden könne? «217

Nun, da die Wichtigkeit der Gesundheit und der öffentlichen Gesundheitspflege anerkannt sei und daran kein Zweifel mehr bestehe, sei es völlig legitim, die Finanzierung der Behörde und der Polizei als Sachfrage zu behandeln. Ihre Finanzierung sei eine reine haushaltspolitische Frage, da die Intention des Staates nicht mehr so sehr zur Disposition stehe. Die Frage nach einer guten Medizinalordnung solle eher als ein Problem der Praxis und der Effektivität behandelt werden und nicht mehr als ein moralisches, bei dem man der Obrigkeit vorwerfe, die Wichtigkeit der Gesundheit und des Lebens nicht genügend anzuerkennen. Auch rückblickend sind es, laut Kausch, nicht der Aufwand und die Aufmerksamkeit der Regierung an sich, sondern die Effektivität ihrer Regierung und ihre Leistung in der Praxis, die man prüfen müsse. ${ }^{218}$ Kauschs Argumentation zielt auf die Begründung einer Hierarchie: Nur eine Medizinalregierung, die sich bei ihren Entscheidungen unabhängig von den moralischen und wissenschaftlichen Geplänkel der Ärzte mache, sei in der Lage, effektiv zu sein. ${ }^{219}$ Man könne sich nicht erlauben, dass z.B. verschiedene Ärzte, die womöglich über eine Untersuchung uneinig sind, das Engagement der Polizei bremsen. Besonders wenn es um Maßnahmen der Prävention ginge, seien Zeit und Energie bei der

215 Vgl. Kausch: Wie viel des Guten lässt sich von den, in den neuern Zeiten erfolgten, Veränderungen der öffentlichen Handhabung des Medicinalwesens im Preussischen Staate als wirklicher Erfolg nachweisen?: in: JPA, 4.45=38, 1817, S. 1 - 42: S. 3 f.

216 Vgl. ebd.: S. 6.

217 Ebd.: S. 8.

218 Vgl. ebd.: S. 10.

219 Vgl. ebd.: S. 11. 
Durchführung die wichtigsten Kriterien für ihr Gelingen. ${ }^{220}$ Das Problem an der Heilkunde, an der Arzneiwissenschaft sei, dass sie viel zu sehr mit der Wissenschaft beschäftigt sei und sich hier alle möglichen Auseinandersetzungen liefere, die für die Praxis und die Effektivität der Polizei schädlich seien. ${ }^{221}$

Man muss bedenken, dass die Einführung der Impfung gegen die Blattern mit Kuhpockenserum erst wenige Jahrzehnte zurücklag. Sie verkörperte die Erfahrung einer Praxis, die präventiv und effektiv ermöglichte, eine große Anzahl von Menschen vor der Krankheit zu bewahren, ohne dass die Medizin in der Lage war, den Vorgang der Impfung wissenschaftlich zu erklären. Nun lässt sich einfacher nachvollziehen, warum Hufeland bei seinem Vorschlag für die Wiederermächtigung der Medizinal-Kollegien ein liberales Modell zum Vorbild genommen hat und an Nasser kritisierte, das Dilemma nur auf den Staat übertragen zu wollen, anstatt eine rationelle Lösung für die Regierung vorzuschlagen.

Ebenfalls von 1825 ist der Aufsatz von dem Arzt Johannes Stieglitz. ${ }^{222}$ Dieser Aufsatz ist beispielhaft und interessant durch seine Aussagen zum Verhältnis der Regierung zur Selbstregierung. Stieglitz äußerte sich wie Hufeland ${ }^{223}$ aus der Perspektive der Ärzte zu dem Problem, dass sich, wenn man keine Regelungen trifft, eine Aufteilung ergibt, bei der die ärmeren Leute die Apotheker, Wundärzte und nicht bzw. schlecht ausgebildete Ärzte besuchen, weil die billiger sind, während die Reichen sich die richtigen Ärzte leisten. ${ }^{224}$ Für Stieglitz ist daraus die Konsequenz zu ziehen, dass das gesamte zugelassene Medizinalpersonal, auch die Apotheker, Wundärzte usw. eine universitäre Ausbildung durchlaufen müssten. Er war im Gegensatz zu Hufeland und Nasse der Meinung, dass die Ärzte nicht an Ansehen verloren hatten. Man muss aber dazu sagen, dass er auf ein anderes Ansehen schaut. Im Grunde sagte Stieglitz, das Ansehen der Ärzte als Ärzte und Wissenschaftler sei gestiegen und zwar gerade deshalb, weil sie endlich aufgehört hätten, regieren zu wollen. Für das Ansehen gibt es seiner Ansicht nach zwei Gründe: Erstens, die Entwicklung und der Fortschritt der Wissenschaft.

»Der ärztliche Stand ist wie ich gerne wiederhole, in seiner Achtung und Bedeutung nicht gesunken, hat sich vielmehr, wie sich wohl darthun liesse, merklich gehoben. Die höhere Stufe, welche die Medicin unstreitig erreicht hat, lässt weniger Selbstdünkel aufkommen, dringt Bescheidenheit mehr auf und duldet weniger Charlatanerie, da gerade diese größeren Fortschritte die Mängel und Lücken des ärztlichen Wissens und Leistens jedem Kenner seines Fachs mehr ins Licht stellen und auffallender machen. $\ll^{225}$

220 Vgl. ebd.: S. $12 f$.

221 Vgl. ebd.: S. 15.

222 Vgl. Stieglitz: Bemerkungen über obrigen Gegenstand [Ueber die Stellung der Aerzte zum Staate, zum Publikum, und unter sich selbst]: in: JPA, 1.60=53, 1825, S. $17-112$.

223 Hufeland, C.W.: Ueber die Stellung der Aerzte zum Staate, zum Publikum, und unter sich selbst: in: JPA, $1.60=53,1825$, S. $1-16$ : S. 1 .

224 Ein Problem, was übrigens in England Anfang des 19. Jahrhunderts sehr bedeutend war.

225 Stieglitz: Bemerkungen über obrigen Gegenstand [Ueber die Stellung der Aerzte zum Staate, zum Publikum, und unter sich selbst]: in: JPA, 1.60=53, 1825, S. 17 - 112: S. 94f. 
Zweitens, das verbesserte Benehmen der Ärzte. Stieglitz meint damit einerseits die Anerkennung durch die bürgerlichen >Selbstdenker $<$. Andererseits nennt er die Anerkennung der begrenzten Erkenntnis der Ärzte. Das ganz zu Anfang des Kapitels vorgeführte Regieren der Ärzte im Sinne des Sçavoir faire ${ }^{226}$ scheint als solches entlarvt und weniger legitim zu sein. Ein Arzt ist dann ein guter Arzt, wenn er nicht versucht, eine Strategie anzuwenden, Menschen zu regieren, sondern sich bei seiner Behandlung und Empfehlung einfach nur auf die Wissenschaft von der Natur und die aus ihr resultierenden Fakten stützt; während er gleichzeitig ehrlich die Unvollkommenheit seines Wissens und der Wissenschaft überhaupt gesteht.

»Das Benehmen der Aerzte im Allgemeinen ist offenbar veredelt und jetzt würdiger als ehemals. Es bietet der Wahrnehmung scharfer Beobachter und Selbstdenker unter den Nichtärzten nicht mehr so viele Blößen und Stoff zur Satyre dar als die Montaigne, Mollière, der Verfasser des Gilblas, Rousseau u.s.w. zu ihrer Zeit fanden. Hellere Begriffe über vieles, eine treffendere Beurtheilung aller Verhältnisse, sind sehr verbreitet. So schwer auch die ärztlichen Beziehungen von dem größeren Publikum richtig aufzufassen sind, so hat doch dasselbe mehr Blick für Wahrheit und unbefangenes Benehmen im Allgemeinen sich angeeignet und weiß, daß alles menschliche Wissen nur Stückwerk und unvollkommen ist. Viele Täuschungen und schlechte Künste, die noch nicht vor lange zum nöthigen Savoir faire, zur unentbehrlichen, sogenannten medicinischen Politik zu gehören schienen, sind jetzt gar nicht mehr anwendbar, werden von vielen durchschaut und haben Mißtrauen und Verachtung zur Folge. Ein Arzt, der, wenn die Umstände es erfordern, offen eingesteht, daß eine Krankheit dunkel, nicht zu heilen und selbst, wie sie zu behandeln wäre, nicht klar sey, macht gerade einen günstigen Eindruck und flößt ein größeres Vertrauen ein. $\ll^{227}$

Das bedeutet, die Macht der Ärzte sei größer, wenn sie nicht versuchen würden, klug und geschickt zu sein, wenn sie nicht versuchen, Regierungskünstler zu sein, sondern sich auf die Wissenschaft zurückziehen würden. Stieglitz schrieb auch, dass es hiermit zu einer Verbesserung gekommen ist, weil die Praxis der Ärzte nicht mehr im Widerspruch zu ihrer Wissenschaft stehe. Die Qualität der Ärzte in ihrer Praxis ergebe sich aus ihrer Wissenschaftlichkeit und ihrem Rückzug auf die Wissenschaft. ${ }^{228}$ Die neue Macht der Ärzte liege in ihrer Professionalisierung, in ihrer Rolle als Experten, die gerade befreit seien von dem Druck, immer handlungsfähig zu sein, der auf einer Regierung laste. Aber auch die andere Seite kritisiert Stieglitz. Es gebe laut ihm nämlich Personen, »für die fortwährende Unterhaltung mit einem Arzt, sein Rath und seine Leitung in allem Bedürfnis ist « und bei denen, »ihre Abhängigkeit von ihm [ihrem Arzt] selbst krankhaft geworden ist. «229 Die Ärzte sollten und wollten nicht mehr in alter Form regieren und die Menschen, ihre Patienten, sollten und wollten sich auch nicht mehr von den Ärzten regieren lassen, das ist die eine Seite der Ent-

226 Vgl. Vogel, S.G.: Einige allgemeine Bemerkungen über das Sçavoir faire in der medicinischen Praxis: in: JPA, 3.1, 1795, S. 295 - 324.

227 Stieglitz: Bemerkungen über obrigen Gegenstand [Ueber die Stellung der Aerzte zum Staate, zum Publikum, und unter sich selbst]: in: JPA, 1.60=53, 1825, S. 17 - 112: S. 96.

228 Vgl. ebd.: S. $98 f$.

229 Ebd: S. 100. 
wicklung. Auf der anderen Seite, dies zeigt der Text von Kausch, hatte sich die Regierung der Gesundheit durch den Staat mit einem neuen Selbstbewusstsein und einer eigenen gouvernementalen Rationalität ausgestattet, die sich von der der Wissenschaft abgegrenzte.

»Je entschiedener die Triumphe der Medicinalpolizei gegen jene der Heilkunde sind, bei welchen letzteren des cito et jucunde [sicher und angenehm] immer noch so sehr problematisch ist, desto schöner ist das Verdienst der Staaten, [...] den hohen Staatszweck auch von dieser Seite, wo man des Erfolgs gewiß sein kann, möglichst zu fördern. Haben wir auch für die Typhus, Löserdürre, Scharlach u.s.w. keine wohltätige Vaccine, so haben wir doch für sie alle, bis zur mörderischen Pest und zum würgenden gelben Fieber hinauf, die entschiedensten Mittel zu ihrer zuverlässigen Ausrottung in den Händen. «230

\section{FRANKREICH}

Wie im vorangegangenen Kapitel erwähnt, existierte im Frankreich des 17. und 18. Jahrhunderts ein verhältnismäßig radikaler ärztekritischer und hygienisch-philosophischer Diskurs. Auf dem Höhepunkt dieser Kritik wurde behauptet, dass jeder vernünftige Mensch selbst genug und besser wisse, wie er mit seiner Gesundheit umgehen könne und dass die Ärzte und ihre Ratschläge in aller Regel eher die Krankheit als die Gesundheit befördern würden ${ }^{231}$. Ausgangspunkt war, wie in Deutschland, aber auch eine im gebildeten Bürgertum entstandene Reflexion über moralische Existenz und gute Lebensführung, die in erster Instanz Teil der Formierung einer bürgerlichen Identität gewesen war. Die alten Heiler und sog. charlatans stellten zu diesem Diskurs keinen besonderen Widerspruch dar. Ihre Praxis bezog sich kaum auf die Fragen einer >natürlichen $<>$ guten $<$ und $>$ gesunden $<$ Lebensführung. Angegriffen wurden die Ärzten, die sich auf eine universellere und moralische Position berufen wollten, die ihren Patienten einen allgemeinen Rat zu ihrer Lebensweise erteilten und sich damit in die Rolle der Leitung und Führung von Menschen begaben.

Diesem verhältnismäßig frühe Anti-Ärzte-Diskurs möchte ich mich aber nicht in erster Line anhand der Texte von Molière, Rousseau oder Montaigne annähern, die relativ bekannt sind. Sondern ich möchte mir ansehen, wie auf der anderen Seite die Stimme der Ärzte in diesem Diskurs geantwortet hat. 1695 erschien etwa in Paris die Histoire chronologique de la médecine, et des médecins von Jean Bernier. Bernier hat, so etwas wie eine Verteidigungsschrift geschrieben, die Ähnlichkeiten zu der von Gruner (Breslau) oder auch von Hecker (Leipzig) aufweist. Letztere hatten erst gegen Ende des 18. Jahrhunderts über Ärzte und zur Geschichte der Arzneikunde ihre Texte verfasst. Die einzige Möglichkeit, sich dem Spott und der Kritik an den Ärzten zu entziehen sei, stellte Bernier bereits im ausgehenden 17. Jahrhundert fest, die Rationalisierung der Medizin und die Professionalisierung der Ärzte. Natürlich benutzte Bernier nicht das Wort >Rationalisierung $<$ und $>$ Professionalisierung $<$, sondern

230 Ebd.: S. 15.

231 Ramsey, Matthew: The popularization of medicine in France, 1650 - 1900, 2001: S. 97 $133,98 \mathrm{ff}$. 
er schrieb, man müsse die Medizin unter Rückbezug auf die antike Medizin in eine objektive Wissenschaft verwandeln. Um die Medizin und den Ruf der Ärzte zu retten, müsse man beweisen, dass die Ärzte sich nicht willkürlich verhalten, sondern die Medizin eine wahre Wissenschaft sei. Das war in etwa das, was Bernier in diesem Text zum Ausdruck brachte. ${ }^{232}$ Ebenso wie Hecker hob Bernier den historischen und universellen Wahrheitsgehalt der Medizin hervor, die sich stets auf Beobachtung und Untersuchung der Natur berufen hatte. Außerdem bemühte sich Bernier um die Abgrenzung und klare Unterscheidung der > wahren< Ärzte von den unwissenden, ungelehrten Heilern. Bernier schreibt vom Leichtsinn mancher Ärzte und schließlich von den sog. Scharlatanen. Im Unterschied zu den demagogisch vorgebrachten Vorwürfen und Vorurteilen der »déclamateurs « und »satyriques« bemühte sich Bernier seiner Ansicht nach - um eine präzise Unterscheidung und genaue Begründung, warum manche Ärzte tatsächlich keine oder nur schlechte Ärzte seien. Im Gegensatz zu den Texten von Hecker und Gruner enthält das Buch von Bernier keinerlei Äußerungen zu dem Verhältnis der Ärzte oder der Arzneiwissenschaft zum Staat bzw. über die Aufgaben des Staates, die Gesundheit der Bevölkerung betreffend. Daraus lässt sich vermuten, dass die Verteidigung, um die es Bernier ging, und die Position und Berechtigung, die er den Ärzten und der Medizin verschaffen wollte, relativ losgelöst von einem staatlichen Interesse an der Gesundheit der Bevölkerung und ausschließlich auf den bürgerlichen Diskurs zur Selbstregierung bezogen stattfand, wie er auch bei Molière thematisiert wird. ${ }^{233}$ Es könnte also sein, dass sich die Kritik an den Ärzten und die Bestrebungen, die Medizin und die Ärzte zu verbessern, im 17. Jahrhundert noch keine diskursiven Bezüge zu der Auseinandersetzung um eine gute Regierung der Bevölkerung aufwies. Rousseaus Émile (1762) dagegen stellt mit Fragen nach einer Gesellschaft und nach der Subjektivität und Tugendhaftigkeit eines Mannes, der in einer Regierung des Staates Aufgaben übernehmen soll, diese Verknüpfung her. Rousseaus hier geäußerte Kritik an den Ärzten ist aber auch ein knappes Jahrhundert jünger. ${ }^{234}$ Also kann man vielleicht davon ausgehen, dass die Auseinandersetzungen, die die Ärzte um ihre Bedeutung und soziale Anerkennung mit dem bürgerlichen Publikum führten, Ende des 18. Jahrhunderts - zum Beginn meiner Analyse der Zeitschriften - bereits einige Zeit zurücklagen und dass sie zunächst relativ unabhängig von der Herausbildung einer staatlichen Gesundheitspflege stattgefunden hatten. Diese unter dem Druck von Konflikten entstandenen Diskurse bildeten eine wichtige Grundlage für die weitere Transformation einer staatlichen, auf Bevölkerung bezogenen Praxis der Regierung von Gesundheit, die sich zum Teil aus einer in Frankreich bereits lange existenten Praxis der Polizei und einem Diskurs entwickelte, den man vielleicht als Staatsbürger-Diskurs bezeichnen kann. Im Folgenden möchte ich zunächst auf die alte Praxis der Polizei eingehen.

232 Vgl. Bernier: Histoire chronologique de la médecine, 1695: S. 5.

233 Die Komödie von Molière, Le Malade imaginaire, in welcher er sich über das Verhältnis des hypochondrischen, ängstlichen und wohlhabenden Agan und dessen Ärzten, die ihn, obwohl keine wirkliche Krankheit vorliegt, immer weiter behandeln und sich bereichern, lustig macht, stammt von 1673.

234 Vgl. Rousseau: Emil oder über die Erziehung, 1958 [1762]: S. $65 f$. 


\section{Neue Bedingungen für Polizei und Medizin}

Das in vierbändige Werk Traité de la police von Nicolas DeLamare wurde zwischen 1709 und 1738 veröffentlicht, wobei der letzte Band fünfzehn Jahre nach DeLamares Tod postum erschien. Der Text umfasst die Geschichte der Institution als auch alle polizeilichen Verordnungen, die es bis dahin in der Stadt Paris gegeben hat. Vom Umfang her könnte man durchaus sagen, dass die Bücher ähnlich detailreich wie das System der vollständigen medicinischen Polizei von Frank ist. Aber es gibt einen entscheidenden Unterschied. Gegenstand dieser polizeilichen Verordnungen waren weder, wie bei Frank, die Techniken, mit denen man die Gesundheit der einzelnen Untertanen eines Staates regieren sollte, noch wurde die Aufgabe der staatlichen Regierung im Gegensatz zum Staatszweck problematisiert. Die moralische Verantwortung der Fürsten spielt keine Rolle. Das Problem ergibt sich für die Regierung aus der Stadt selbst. Der hier erkennbare Gegenstand der Polizei umfasst den ganzen Bereich der sozialen, logistischen und gesundheitlichen Probleme, die das Zusammen->Leben< in der Stadt mit sich bringen. Auf den ersten Seiten des ersten Bandes des Traité de la police wird unter dem Titel Idée générale de la Police eine Erklärung und Begründung über den Ursprung der Notwendigkeit der Polizei dargelegt. Der Ursprung lag zunächst in dem sehr allgemeinen historischen Ereignis, dass sich Menschen zu Gemeinschaften zusammenschlossen, Dörfer und Städte bildeten und sich schließlich $\mathrm{zu}$ einem Staat vereinigten. Dabei entstand so etwas wie ein Gemeinwesen und dieses erforderte eine einheitliche Regelung des Bereiches gemeinsamer und nichtpartikularer Angelegenheiten. Das Ziel der Polizei war jedoch, ähnlich zu der Vorstellung der Polizei bei Justi ${ }^{235}$, ein Mittel zur Herstellung der inneren Sicherheit zu sein, um die Stärke und Macht des ganzen Staates nicht zu gefährden. Als historisches Vorbild dieser auf die Stadt bezogenen Polizei diente die antike Polis und deren Gesetze, die größtenteils sogar in ihrer Unterteilung, wie sie in Athen eingerichtet waren, übernommen wurden. ${ }^{236}$

»Notre Police ayant donc été formée sur ces grands modelés de l'Antiquité, nous avons aussi conservé à peu de choses près, leur même Méthode dans la division des matières. $\ll^{237}$

»Quand nous avons repris pour second objet la conservation de la vie, nous avons encore suivi à cet égard la même subdivision, en appliquant les soins de notre Police à ces deux choses importantes; la santé, \& la subsistance des Citoyens. [...] La Police selon nous, est donc toute renfermée dans ces onze parties que l'on vient de parcourir: la Religion; la Discipline des mœurs; la Santé; les Vivres; la Sûreté, \& la Tranquillité publique; la Voirie; les Sciences, \& les Arts Libéraux; le Commerce, les Manufactures \& les Arts Mécaniques; les Serviteurs Domestiques; les Manouvriers; \& les Pauvres. $\ll^{238}$

235 Vgl. Justi: Grundsätze der Policey-Wissenschaft, 1756: Vorrede [Ohne Seitennummerierung, S. 4].

236 Vgl. DeLamare: Traité de la police I, 1729: S. 1ff.

237 Ebd.: S. 3.

238 Ebd.: S. 4. 
Die Stadt stellte eine besondere Umwelt dar und die Polizei war nur insofern verantwortlich, wie es um den Zusammenhang von Krankheiten mit dieser speziellen Umgebung ging. Alle Faktoren, wie Kälte, Wärme, Feuchtigkeit, die Luft, das Wasser und die Nahrung in der Stadt, wurden zu den Einflüssen dieser Umgebung gezählt, die unter bestimmten Umständen krank machen. Unter dem Abschnitt De l'Épidémie, Contagion, ou Peste geht es zunächst um die Definition dieser Arten von Krankheiten. ${ }^{239}$ Über die Definition des Gemeinwesens wird nun unterschieden, welche Krankheiten als Angelegenheiten des Gemeinwesens und damit zu den Aufgaben der Polizei zählen und nicht ausschließlich zu denen der Ärzte gehören können. Bei aller Verschiedenheit der Krankheiten, die nach einer rein medizinischen Betrachtungsweise zu ganz unterschiedlichen Klassifikationen führen könnten, werden die Krankheiten hier nach ihrem Verhalten und den Möglichkeiten ihrer Regierbarkeit und ihres Risikos für das Gemeinwesen differenziert. Relevant sind beispielsweise Krankheiten, die sich schnell auf einen ganzen Bezirk, eine ganze Stadt oder Region ausweiten können, ansteckende Krankheiten, gegen welche die Medizin kein effektives Mittel im Sinne eines Heilmittels anwenden kann oder besitzt. Diese Krankheiten gehören in den Aufgabenbereich der Polizei. Das Hauptmittel gegen diese Krankheiten ist nicht die Kunst des Heilens, sondern die Prävention. »Il est aisé de comprendre qu'une telle maladie demande de la part de la Médecine, de puissants remèdes, \& de celle des Magistrats, de grandes précautions pour en arrêter le progrès. $\ll^{240}$

Die Reihe der Beispiele, die nach einer ähnlichen Logik das Eingreifen und die Notwendigkeit der Macht der Polizei in dem Traité de la police begründen bzw. ihren Bereich der Macht in Abgrenzungen zu anderen >privaten $<$ Bereichen definieren, ließe sich lang fortsetzen. Ich möchte noch ein weiteres letztes, etwas beliebiges, Beispiel anführen, das zugleich die Sicht auf die Umwelt im Verhältnis zur Gesundheit verdeutlicht und auch sichtbar werden lässt, wie die ganzen Unterscheidungen zwischen Medizinern, Apothekern und Chirurgen in diesem Netzwerk aus Akteuren und bei der Verteilung der Regierung der Gesundheit auf diese Akteure begründet werden konnte.

»Que l'on jouisse toujours, s'il est possible, de l'air le plus sain, de l'eau la plus pure, \& de tout ce qu'il y a de meilleur entre les autres aliments, la constitution du corps en seroit sans doute plus forte; mais elle ne seroit pas pour cela inaltérable. Il resteroit toujours ce combat perpétuel entre les quatre premières qualités qui le composent; le chaud, le froid, le sec \& l'humide, qui en troubleroient quelquefois les humeurs \& en dérangeraient le tempérament. II y resteroit encore à craindre ces maladies de plénitude, qui arrivent le plus souvent par l'usage des meilleures choses; ou celles que cause cet état, où le trouvent les plus forts tempéraments que les Médecins nomment santé athlétique, c'est-à-dire qui est à son plus haut période, \& qui doit nécessairement tomber par la règle des révolutions: c'est pourquoy dans la division que les Anciens ont fait, \& que nous suivons, ils ont mis les Remèdes au quatrième rang des choses qui contribuent à la santé. $\aleph^{241}$

239 Vgl. ebd.: S. 537.

240 Ebd.: S. 537.

241 Ebd.: S. 516. 
Die Gesundheit sei nicht in erster Linie durch die Krankheiten bedroht, sondern durch eine Vielzahl von Faktoren, die in der Umwelt bestehen würden und in dem Verhalten des Individuums in dieser Umwelt. Aber es scheine im Grunde nicht möglich, der Gefahr einer Krankheit zu entgehen. Daher solle die Einnahme von Mitteln - also die Medizin - zur Förderung der Gesundheit ein ganz grundsätzlicher Bestandteil sein. ${ }^{242}$ Dies sei im Grunde der Platz, der den Ärzten in dieser Ordnung zukomme. Denn da das Wissen über diese Mittel nicht in Besitz aller sei und die Gefahr, die von einer falschen Anwendung ausgehe, zu groß sei, sei es wichtig, klar zu regeln, welche Personen mit welchen Qualifikationen für die Zusammenstellung, Verordnung und Verabreichung der Medikamente zuständig sein sollen. Auch hier bezieht man sich sehr stark auf die antike, von Galen vorgenommene Unterteilung der verschiedenen Professionen. »La Médecine Dogmatique, ou qui enseigne \& qui ordonne; la Pharmacie qui compose $\&$ débit les remèdes, la Chirurgie qui opère de la main. Et c'est l'état où elle se trouve encore aujourd'huy. ${ }^{243}$

Die Art und Weise, wie hier die Gesundheit in einem allgemeineren Sinne, also nicht bezogen auf die einzelnen Menschen, sondern bezogen auf die Angehörigen einer Stadtbevölkerung, problematisiert wurde, ist sehr wichtig für die Herausbildung der Sicherheitstechnologien als typisches Instrument einer Regierung der Bevölkerung. Eine Technologie, die sich nicht wie die Disziplin und, ich würde sagen, auch anders als es aus Sicht der Polizeiwissenschaft vorstellbar ist, nicht in einer individualisierten Weise äußert, sondern totalisierend wirkt. Trotzdem kann man, von der Polizei und von der Problematisierung der Gesundheit im Rahmen der Organisation und Verwaltung der Städte ausgehend, nicht einfach von dem Ort der Entstehung der Gesundheitspolitik sprechen. Meine These ist, dass die Technologie der Polizei von einer neuen Rationalität kolonialisiert wurde oder diese in sich aufnahmen und sich dadurch der Charakter der Polizei völlig veränderte. Dabei spielte ein von einer gebildeten bürgerlichen Schicht ausgehender hygienischer Diskurs und die hiermit verbundene Auseinandersetzung um Selbstpraxis eine entscheidende Rolle. Ein erster Hinweis auf eine solche Kolonialisierung ist der Traité de la police von DeLamare selbst. Denn er stellt gewissermaßen eine Idealisierung der Polizei dar, ein Modell und gleichzeitig auch eine Kritik. Foucault hat in Wahnsinn und Gesellschaft die Polizei, die DeLamare hier entwarf »als das bürgerliche Äquivalent zur Religion für die Errichtung einer vollkommenen Stadt « bezeichnet. ${ }^{244}$ Gemeint war damit ein bestimmter Verweis auf die private Selbstpraxis, die wie mir scheint, die spätere Abgrenzung der hygiène privée als Pendant zur hygiène publique, also zu dem Aufgabenbereich der Polizei, gestützt hat. Aber es kam in Frankreich nicht in dem Maße wie in Deutschland zu dem Versuch, die Selbstpraktiken zu politisieren. Es existierte eher eine dem Verhältnis der religiösen Selbstpraxis ähnliche Korrespondenz zwischen sozialer Ordnung und individueller Disziplin. Das Verhältnis zwischen der Regierung des Staates und individuellen Selbstpraktiken, durch welche die moralische Subjektivität und Ordnung von Subjekten im Verhalten des Einzelnen hergestellt wird, war anders.

\section{Vgl. ebd.}

243 Ebd.

244 Vgl. Foucault: Wahnsinn und Gesellschaft, 1992 [1973]: S. 97. 
»Man sieht unter den Institutionen der absoluten Monarchie [...] die große bürgerliche Idee, die sich bald die Republik zu eigen macht, dass die Tugend ebenfalls eine Angelegenheit des Staates sei, dass man Dekrete erlassen könne, um sie herrschen zu lassen, dass man eine Autorität einsetzen könne, um ihr Respekt zu verschaffen. $\ll^{245}$

Die »moralische Gemeinschaft, von der das bürgerliche Bewusstsein im 17. Jahrhundert zu träumen anfängt $\ll^{246}$ bleibt, so schreibt Foucault, denen vorbehalten, die sich dieser »Souveränität des Guten« von »Anbeginn unterwerfen $\ll^{247}$. Es ist genau im Schatten dieses Traums von der tugendhaften und moralischen Gemeinschaft, wo die neuen Mechanismen der >moralischen Differenzierung< des Ausschlusses und der Internierung entstehen, von denen Foucault in Wahnsinn und Gesellschaft schreibt. Dieser Traum ist im Grunde der Gleiche, den auch Rousseau als ein Wegbereiter der Französischen Revolution propagiert hat und der u.a. wie auch in DeLamares Traité über die Polizei von Paris schon die Hoffnung beinhaltete, dass sich alle Probleme, selbst die der Krankheit durch ein tugendhaftes Leben in einer tugendhaften Gesellschaft auflösen lassen würden.

»Dann gäbe es ohne weiteres kein Sittenverderbnis mehr; die Mäßigung hielte die Krankheiten fern; der Arbeitseifer; die Fruchtbarkeit und eine kluge Vorrauschau würde stets die für das Leben notwendigen Dinge vorhanden sein lassen. Wenn die Liebe die Laster ausschalte, wäre die öffentliche Sicherheit gewährleistet. $\ll^{248}$

Die Entwicklung der Humanwissenschaften, die Medizin, die Psychologie und die Biologie im 19. Jahrhundert haben die notwendigen Trennungen, Dichotomien und Ausschlussmechanismen wissenschaftlich unterfüttert, praktisch ermöglicht und mit den Träumen dieses bürgerlichen Bewusstseins, mit diesem Ideal von Gesellschaft versöhnt. ${ }^{249}$

Die Polizei, deren Geschichte, laut Hugues de Montbas zumindest auf Paris bezogen, bis ins 13. Jahrhundert zurïckreicht, hat im Laufe der Zeit immer wieder Veränderungen durchlaufen, in deren Verlauf sie mal mehr und mal weniger Befugnisse hatte oder mal mehr, mal weniger der Kontrolle des Königs unterstanden hat. Aber erst ab ca. Mitte des 17. Jahrhunderts wurde unter Louis XIV. eine von wenigen Autoritäten gesteuerte Institution, die lieutenance générale de police geschaffen, der nun ein umfassender Bereich von Problemen zugeordnet war. Dieses System blieb bis zur Revolution zumindest offiziell bestehen. Ich habe diese Entwicklungen nicht genau und anhand von Texten nachvollziehen können. Hugues de Montbas hat 1949 über die Pariser Polizei unter Louis XVI., geschrieben, dass der Aufgabenbereich dieser Polizei enorm gewesen sei. ${ }^{250}$ Betrachtet man die zwölf Zuständigkeitsbereiche, die

245 Ebd.: S. 94.

246 Ebd.

247 Ebd.

248 DeLamare: Traité de la police I, 1729: S. 287f, zitiert nach Vgl. Foucault: Wahnsinn und Gesellschaft, 1992 [1973]: S. 97.

249 Vgl. Foucault: Wahnsinn und Gesellschaft, 1992 [1973]: S. 125f.

250 Vgl. De Montbas: La Police Parisienne Sous Louis XVI, 1949: S. 44. 
ich zuvor aus dem Traité de la police von Nicolas DeLamare (1729) zitiert habe ${ }^{251}$, könnte man den Eindruck gewinnen, die Kontrolle durch die Polizei sei absolut gewesen. Aber dies sei, laut de Montbas, eben nicht der Fall gewesen. Eher sei es aus verschiedenen Gründen zu einer Abnahme der Macht der Polizei gekommen:

»Pratiquement, pour de nombreuses raisons, - progrès des >lumières<, relâchement croissante des disciplines individuelles et sociales traditionnelles, craintes des chefs et des subordonnés de passer pour rétrogrades, - elle n'use guère de ce droit, sauf cas exceptionnels, que dans la stricte mesure imposée par la maintien de l'ordre extérieur. $\ll^{252}$

Daraus lässt sich annehmen, dass die Polizei in der vorrevolutionären Zeit eine beschränkte Handlungsfähigkeit besaß. Auch wenn man die von de Montbas vermuteten Gründe bezweifelt kann, sind seine Belege für den praktischen Machtverlust der Polizei überzeugend. Meine These ist, dass sich die Polizei bereits vor der Revolution mit einer hygienischen Kritik und einer damit verbundenen sinkenden Legitimation ihrer Macht auseinandersetzen musste. Den Hintergrund dieser Kritik an der Polizei bildeten zum einen Diskurse bürgerlicher Provenienz um die gute Lebensführung, aber auch um die Macht und Bedeutung der Medizin, oder besser gesagt, der Heilberufe allgemein.

Im letzten Drittel des 18. Jahrhunderts zeichnete sich in Frankreich ein Diskurs um die Erneuerung der Medizin als Wissenschaft und als Heilkunst im allgemeinsten Sinne ab. Dieser Diskurs wurde sowohl von der Kritik an der elitären Faculté de la Médecine als auch von der Initiative einiger Ärzte und Bürger zur hygienischen Aufklärung der Bevölkerung ${ }^{253}$ belebt. Die Bestrebungen in Richtung eines allgemeinen Nutzens des medizinischen Wissens und der Heilkunst, ihrer Vermittlung an Laien und damit der Entmachtung der Faculté standen in einem engen, aber auch paradoxen Verhältnis zu dem Anspruch, die Medizin rigoroser einer wissenschaftlichen Rationalität zu unterstellen und die Praxis der Heilkunst im Sinne einer Professionalisierung enger an diese Wissenschaft zu binden. Diese Konstellation war, wie auch Foucault schrieb, bereits das Gemisch an Positionen und Kritiken, mit denen man sich bei der Umgestaltung der art de guérir auch später während der Revolution auseinandersetzen musste. ${ }^{254}$ Dieses Gemisch prägt auch das Feld von Aussagen, das man in den ersten, also vor der Revolution veröffentlichten Ausgaben der Gazette de Santé ausgebreitet findet. ${ }^{255}$ Hier vermischte und verband sich die Kritik >aufklärerischer und liberaler Ärzte an der elitären Faculté mit Elementen eines diätetischen

251 Vgl. DeLamare: Traité de la police I, 1729: S. 4.

252 De Montbas: La Police Parisienne Sous Louis XVI, 1949: S. 102.

253 Der Einfluss der französischen »Medicina popularis« reichte auch bis nach Deutschland. (Vgl. [Hrsg.]: Des Achzehnten Jahrhunderts Geschichte der Erfindungen, Theorien und Systeme in der Natur- und Arzneiwissenschaft: in: JNA: 7, 1798: S. LXXVIII.)

254 Vgl. Foucault, Michel: Die Geburt der Klinik, 2008 [1963]: S. $61 f$.

255 Vgl. Ramsey, Matthew: The popularization of medicine in France, 1650 - 1900, 2001: S. 97 - 133, S. 114. 
hygienischen Diskurses, welcher die neue Grundlage für alle Heilberufe, aber auch, wie Foucault schrieb, der Polizei liefern sollte. ${ }^{256}$

Die Spannungen zwischen dem Ziel einer Popularisierung und dem Streben nach einer Rationalisierung und Professionalisierung der Medizin, die auch Matthew Ramsey für diesen Zeitraum diagnostizierte, sind in der Zeitschrift deutlich zu erkennen. ${ }^{257}$ In der ersten Ausgabe der Gazette de Santé von 1773 befindet sich eine Mitteilung der Herausgeber, in der sie das Anliegen vortragen, welches sie zu der Gründung der Zeitschrift bewogen hatte. Der kurze Text macht deutlich, dass sie das Ziel der medizinischen Aufklärung mindestens für ebenso wichtig befinden, wie den Fortschritt der Medizin. Ziel war nicht nur, medizinisches Wissen zu verbreiten. Die Zeitschrift wendet sich explizit an ihre Leser mit dem Anliegen, ihnen die Mittel zu geben, um sowohl gesund zu bleiben, also auch, sich zu heilen, wenn sie krank geworden sind. ${ }^{258}$ So lautet die Unterüberschrift der Zeitschrift. ${ }^{259}$ Die Gesundheit wird präsentiert als ein allgemeines Gut. Ein Gut, das unabhängig von sozialer Stellung einen universellen Wert besitzt. Es ist ein Gut nicht nur für die, die krank sind, sondern für alle Menschen und zu jeder Zeit. Nach Ansicht der Herausgeber ist die Umwelt voll von Heilmitteln, aber das Wissen über diese befindet sich nur in den Händen einer begrenzten Personenzahl: den Ärzten. ${ }^{260}$ Genauso steht es um das Wissen, dass man benötigt, um sich gesund zu halten: die Hygiene. ${ }^{261}$ Das Ziel der Zeitschrift ist in erster Linie, durch die Verbreitung medizinischen Wissens und nützlicher Kenntnisse über die Gefahren der Krankheiten und die Nützlichkeiten für die Gesundheit in der Umwelt, eine >utilité publique<, dieses Wissen zu fördern. Sie beinhaltet auch Wissen über die Wirkung von Heilmitteln. ${ }^{262}$ Gleichzeitig vermittelten die Artikel Praktiken und Lebensweisen zur Gesunderhaltung, die in dem klassischen Sinne eines Ratschlags für eine gute Selbstpraxis vermittelt werden. Die Zeitschrift wollte darin unterrichten, wie man sich mit der richtigen Diät gesund halten könne. Nichts wird in autoritärer Weise verordnet oder vorgeschrieben. ${ }^{263}$ Leser und Autoren befinden sich eher auf Augenhöhe. Die Herausgeber fordern sogar, dass die Leser keine der Informationen oder Anweisungen unhinterfragt annehmen sollen, auch

256 Vgl. ebd.: S. 293.

257 Vgl. Ramsey, Matthew: The popularization of medicine in France, 1650 - 1900, 2001: S. $97-133$, S. 122.

258 Vgl. [Hrsg.]: Prospectus d'une Gazette de Santé, Contenant les nouvelles Découvertes sur les moyens de se bien porter, \&de se guérir quand on est malade. Par on Docteut-Régent de la Faculté de Médecine de Paris: in: GS, 1.1773, S. 1 - 2: S. 1.

259 Vgl. ebd.

260 Vgl. [Hrsg.]: Avis au Public de la Société royale de médecine, concernant les remedes pour lesquels on demande des permissions ou brevets: in: GS, 37.1779, S. $147-149$.

261 Vgl. [Anonym]: Aux Auteurs de la Gazette de Santé, De Sancoin, 8 Juin 1778: in: GS, 27.1778, S. 109 - 110: S. 110.

262 Vgl. [Hrsg.]: Prospectus d'une Gazette de Santé, Contenant les nouvelles Découvertes sur les moyens de se bien porter, \&de se guérir quand on est malade. Par on Docteut-Régent de la Faculté de Médecine de Paris: in: GS, 1.1773, S. 1 - 2: S. 1f.

263 [Hrsg.]: Supplement: in: GS, 6.1773, S. 25 - 26: S. 25. 
wenn man sich um die größte Korrektheit bemühe. ${ }^{264}$ Auch ist die Kritik an der Medizin oder den Ärzten keine grundsätzliche, wie sie etwa bei Rousseau formuliert wurde. Eher wird bemängelt, dass die Ärzte und die Medizin ihre Aufgaben nicht richtig erfüllen. Die Ärzte würden nicht dafür sorgen, dass ihre neuen Entdeckungen und Erkenntnisse an die Öffentlichkeit kommen oder sie veröffentlichen sie nur in einer Sprache, die für den Nicht-Mediziner nicht nur unverständlich sei, sondern dem medizinischen Wissen zusätzlich einen gewissen geheimnisvollen und mystischen Anschein verleihe. Dieser mysteriöse Anschein sei, so eine Mitteilung der Gazette von 1773 , besonders gefährlich:

»Cette discrétion mystérieuse n'empêcheroit pas quelques particuliers de gouverner leur santé suivant leurs propres lumières, le plus grand nombre auroit toujours recours aux Charlatans, les Gens de l'Art d'en seroient pas plus consultés, \& le préjugé dominant l'esprit du Peuple, le rendoit sans cesse victime de son ignorance $\&$ de sa crédulité. ${ }^{265}$

Dies sei der Grund, warum sich viele auf die Scharlatane einließen, anstatt sich bei der Sorge um ihre Gesundheit auf ihren Verstand zu verlassen. Es handelt sich hier also um eine andere Kritik, als jene, gegen welche sich etwa Gruner oder Hecker in Deutschland verteidigen mussten. Der wichtigste Unterschied zu dem deutschen Diätetik-Diskurs scheint aber zu sein, dass das ganze Problem der Krankheit in dem französischen Diskurs der Hygiene auf das ganze Verhältnis zwischen den Menschen und ihrer Umwelt bezogen wurde. Die Luft, das Wasser, der Boden, die Nahrung, überall sind krankmachende Einwirkungen, gegen die die Hygiene die Menschen rüsten will. ${ }^{266}$ Auch wenn besonders die Herausgeber der Gazette de Santé in Anlehnung an eine Art Selbstpraxis der gesunden Lebensweise großen Wert auf den praktischen Nutzen der Medizin legen und daher den medizinischen Theorien und Systemen abgeneigt sind, ${ }^{267}$ so soll die Suche nach den Ursachen für Krankheit in der Umwelt dennoch nach einer wissenschaftlichen Methode erfolgen. Was fehlt, so die Kritik, ist eine Wissenschaft von diesen Ursachen der Krankheit. »L'art d'entasser remèdes sur remèdes, recettes sur recettes, n'est donc pas celui de la vraie médecine; c'est celui des Empiriques qui ne peuvent jamais guérir que par hasard. «268 Was man benötige, sei eine Wissenschaft, die sich mit der Erforschung der Ursachen von Krankheiten

264 Vgl. [Hrsg.]: Prospectus d'une Gazette de Santé, Contenant les nouvelles Découvertes sur les moyens de se bien porter, \&de se guérir quand on est malade. Par on Docteut-Régent de la Faculté de Médecine de Paris: in: GS, 1.1773, S. 1 - 2: S. $1 f$.

265 Ebd.

266 Vgl. u.a. [Anonym]: De Paris, le 2 Octobre »On a beau prévenir le peuple contre les dangers qui l'environnement.«: in: GS, 40.1775: S. 161. Vgl. [Anonym]: »Danger de environnement «: in: GS, 26.1774: S. $110-111$.

267 »[L]e but soit surtout de simplifier la Médecine parmi le peuple, \& de la mettre à portée du plus nombre; nous nous attacherons principalement à faire connoître les véritables intérêts des hommes, les découvertes \& observations neuves \& vraiment utiles, les ouvrages de Médecine [...] d'éclaircir quelque point lumineux dans l'art de guérir, ou capable de soulager l'humanité.« [Hrsg.]: Avertissement: in: GS, 32.1776, S. 124 - 125: 124. [Hrsg.]: De Paris: in: GS, 36.1776: S. 155 - 156: S. 155. 
beschäftigen solle. Die Abgrenzung der Ärzte von den ungelernten Praktikern, den »pestes publiques « ${ }^{269}$, die, wie eben, häufig auch als Empiriques bezeichnet wurden, ist vom Muster her ähnlich wie in den deutschen Zeitschriften. Das Bild des geldgierigen, unwissenden und betrügerischen Praktikers, der das Unwissen seiner Patienten zum eigenen Vorteil ausnutzt und hierdurch großen Schaden anrichtet, ${ }^{270}$ ist in der Gazette de Santé und dem Journal Général de Médecine, die ich in meine Analyse für diesen frühen Zeitabschnitt einbezogen habe, sehr präsent. Auch in Frankreich mangelte es nicht an Aufforderungen an die Regierung, entsprechende Gesetzt zu erlassen, um den sog. Scharlatanen ihre Praxis zu verbieten. ${ }^{271}$ Der Vorschlag aber, den man aus diesen ganzen Konflikten zwischen Professionalisierung allgemeiner Nutzbarmachung der Medizin für die Gesellschaft ableitete, war, die Hygiene von der Lehre oder Selbstpraxis, die sie bisher war, in eine Wissenschaft zu verwandeln bzw. sie mit der Medizin zu einer großen Wissenschaft zu vereinigen. Diese vereinigte Wissenschaft sollte das große Ziel haben, die Ursachen der Krankheit zu erforschen und so nicht nur die Menschen, sondern die ganze Gesellschaft vor aller Krankheit zu schützen bzw. sie von den unvermeidbaren Krankheiten heilen.

Die in der Mitteilung der ersten Ausgabe der Gazette de la Santé vorgestellte Zielsetzung, die Zeitung an ein nicht-medizinisches Publikum zu richten, blieb nicht lange in dieser Weise bestehen. Während man hier den Anspruch deutlich macht, das Publikum durch Vermittlung von Wissen gegen die Betrüger zu wappnen, geht die Entwicklung in den Jahrzehnten darauf eher in Richtung eine Professionalisierung der Medizin. 1776 ging die Redaktion der Gazette in die Hände der neu gegründeten Société de Médecine über. ${ }^{272}$ In dem von den Herausgebern geschriebenen Avertissement wurde zwar an dem Ziel der gesundheitlichen Aufklärung festgehalten, gleichzeitig aber die Notwendigkeit einer Gesellschaft begründet, die sich nach Art einer Wissenschaft um die Perfektionierung des typischen Wissensbereichs kümmern müsse, den man später der >hygiène publique< oder >épidemiologie< zurechnete. Daneben stand das Ziel der Erhaltung der Gesundheit im Vordergrund. Im Unterschied zu dem vorrangigen Ziel der Medizin, Krankheit zu heilen, verdeutlicht dies die starke Ausrichtung an der Hygiene. Worauf richtet sich die Hygiene als Wissenschaft? Sie interessiert sich nicht wie die Medizin für Arzneien und Heilmittel und ihre Wirkungen auf den menschlichen Körper. Die Hygiene wollte die allgemeine Gesundheit verbessern, die Menschen vor Krankheiten bewahren und schützen. Sie konzentrierte sich daher auf die Ursachen der Krankheit und darauf, wie man sie vermeiden kann.

»L'Art de conserver la santé étant, sans contredit, le plus utile, le plus nécessaire dans nos mœurs actuelles, \& peut-être le moins connu, on ne sauroit trop multiplier les ressources qui tendent à le rendre plus parfait ou plus fructueux. Mais peut-on se flatter d'arriver à sa perfection, si on ne connoît les vrais causes des maladies [...]. Tout l'art de se conserver consiste donc

269 [Hrsg.]: Charlatanisme: in: GS, 12.1784, S. 49 - 51: S. 49.

270 Bericht über einen Scharlatan in Sibirien und ein Vergleich mit einem in Frankreich: Vgl. [Hrsg.]: Médecine étrangere: in: GS, 3.1774, S. 15 - 16. Vgl. [Hrsg.]: De Paris: in: GS, 46.1776, S. $212-213$.

271 Vgl. [Hrsg.]: De Paris: in: GS, 43.1774, S. 286 - 287.

272 Vgl. [Hrsg.]: Avertissement: in: GS, 32.1776, S. 124 - 125: S. 124. 
à connoître ce qui nous nuit, malheureusement cette connoissance qu'on suppose toujours acquise, n'est presque jamais là. C'est pour l'acquérir enfin une fois, sur un des objets les plus importants, que le Gouvernement vient de créer une Société, composée de Médecins éclairés, dont le travail soutenu d'une correspondance établie dans tout le Royaume \& ailleurs, doit avoir principalement pour objet la recherche des causes des maladies épidémiques \& épizootiques, malheureusement trop fréquentes dans nos climats, \& la perfection des moyens de les guérir, d'en arrêter les progrès, \& d'en tarir, s'il se peut, entièrement la source.« «73

Die Idee der Selbstpraxis auf das Problem der Gesundheit der Bevölkerung angewendet, wird - etwas vereinfacht formuliert - die Grundlage der modernen Epidemiologie sein. Das Problem eines >zu wenig « an Wissen bleibt auch im Laufe der weiteren Hinwendung der Zeitung zu einem wissenschaftlichen Publikum zentral. ${ }^{274}$ Es zeigt sich bereits hier, was die Logik der Hygiene von der der Medizin grundsätzlich unterschiedet. Während die Hygiene durch die Art und Weise, wie sie ihren Gegenstand formuliert, ihr Wissen fortwährend erweitert und auch das Wissen anderer Disziplinen in sich aufnimmt, will die Medizin als wissenschaftliche Disziplin einen eigenen Bereich des Wissens für sich beanspruchen, diesen weiter aufteilen, sich nach innen spezialisieren und ihr Wissen eher in die Tiefe erweitern. Im Sinne der Hygiene beginnt man also, eine Vielzahl von Bezügen zu den unterschiedlichsten Wissenschaften, die dem besagten Ziel - der Erhaltung der Gesundheit - dienen können, beliebig herzustellen: Alles ist wichtig: »tout ce qui se rapporte à la santé«. ${ }^{275}$ Damit waren zunächst Medizin, Chirurgie und Pharmazie gemeint, aber auch die Chemie und die Physik sowie die Naturwissenschaften generell. ${ }^{276}$ Die Gazette de Santé war in gewisser Hinsicht das Ergebnis dieses widersprüchlichen Kräfteverhältnisses zwischen der Medizin, dem Diskurs der bürgerlichen hygienischen Selbstpraxis und der Ideen der >Aufklärung< und Befreiung, die sich Ende des 18. Jahrhunderts in einem Diskurs um das Problem der Gesundheit formierten. Die Herausgeber der Zeitung forderten die Reform der Medizin, der Ausbildung der Ärzte und eine Ausrichtung dieser Ausbildung, wie der gesamten Wissenschaft, an dem Ziel der Erhaltung der Gesundheit der Bevölkerung. ${ }^{277}$ Einerseits propagierte man das Problem der Gesundheit als ein universelles, ursprüngliches, menschliches und daher jeden Einzelnen betreffendes Thema. Dies hatte zunächst die Funktion erfüllt, die Gesundheit vom Leben und der Praxis des Lebens aus zu bestimmen, also als Bereich des Individuellen, der von dem existierenden öffentlichen Bereich und der politischen Macht losgelöst war. Dies funktionierte jedoch nur, indem dieser Bereich eine neue Öffentlichkeit schaffte, die eine ganz andere Rationalität der (Selbst-)Regierung von Gesundheit ermöglichte. Anderseits strebte dieser Diskurs, der zuerst ein moralischer Diskurs über die richtige Lebensführung war, zu einer allgemeinen philosophischen und politischen Bedeutung, die größer wurde als diese Praxis, die ihr Ausgangspunkt gewesen war. Dies musste also auch eine Veränderung und Erweiterung der o.g. Praxis

273 Ebd.: S. 125.

274 Vgl. [Hrsg.]: Avertissement: in: GS, 1.1785: S. 1.

275 Ebd. 14.

276 Vgl. ebd.: S. $13 f$.

277 Vgl. M.S.U.: Hygiène: in: GS, 30.1808, S. 239 - 243: S. 240. 
nach sich ziehen. Dieses Spannungsfeld zwischen der Popularisierung und Universalisierung des Problems der Gesundheit und der Professionalisierung und wissenschaftlichen Rationalisierung der Heilberufe bestimmten eine Reihe von Auseinandersetzungen in den medizinischen Zeitschriften im ausgehenden 18. Jahrhundert in Frankreich und trugen zu der Entwicklung der Idee einer übergreifenden Wissenschaft von der Gesundheit bei. ${ }^{278}$ Das Verhältnis zwischen Polizei und Medizinern ist zunächst noch über die Regierung vermittelt gewesen. Dies lässt sich etwa an dem von dem Anatom Félix Vicq-d'Azyr 1776 veröffentlichten Exposé über die Bekämpfung der Viehseuchen veranschaulichen. ${ }^{279}$

Was ich im Folgenden anhand einiger Beispiele genauer zeigen möchte ist, dass es von Seiten der Ärzte ein Interesse daran gab, die Polizei, was ihre Rationalität betraf, zu verändern oder aus ihrer Sicht zu verbessern, indem man ihr diese neue vereinigte Wissenschaft zugrunde legte. Dieses Interesse äußerte sich in der Idee der Formung einer Organisation, die den Aufgabenbereich der Polizei, der die Regierung der Gesundheit berührte, mit der Expertise und Wissenschaftlichkeit der gelehrten Mediziner verbinden sollte.

In den frühen Ausgaben der Gazette de Santé findet eine kritische, aber zugleich wohlwollende Auseinandersetzung mit der Polizei und ihren Aufgaben statt. Ärzte und Chirurgen verfassten Berichte, in denen sie die Missstände zum Beispiel bei der Überwachung bestimmter Berufsgruppen durch die Polizei bemängelten, oder in denen sie Vorschläge unterbreiteten, was die Anordnungen der Polizei enthalten sollten. Die Polizei sollte z.B. die Ammen darüber aufklären, dass Neugeborene nicht eingebunden werden sollten, welche Ernährung für die Säuglinge am besten sei und wie man sie gegen bestimmte Umwelteinflüsse abhärten und unempfindlicher machen könne. ${ }^{280}$ Der Artikel in der Gazette de Santé enthält aber auch die klare Aufforderung an Polizei und Chirurgen bei Fragen, die die Gesundheit der Bevölkerung betreffen, zusammenzuarbeiten. ${ }^{281}$ In der Haltung der Autoren bzw. Herausgeber der Gazette zeigt sich eine große Nähe zu dem bürgerlichen, diätetischen und im Prinzip auf die vermeintliche Nutzlosigkeit der Mediziner abzielenden Diskurs und dessen Aussagen: Wenn die Polizei auf die Ärzte und ihr diätetisches Expertenwissen hört, dann werden die Ärzte, die die Menschen behandeln, wenn diese krank geworden

278 Vgl. [Hrsg.]: Cours de Hygiène. Faculté de Paris - Faculté de Montpellier: in: GS, 13.1828, S. 97 - 99: S. 98. Vgl. [Hrsg.]: rospectus du nouvel éditeur: in: GS, 12.1819, S. 369 - 370: S. 369.

279 Vicq-d'Azyr, Exposé des moyens curatifs et préservatifs contre les maladies pestilentielles des bêtes à cornes, 1776 .

280 Vgl. [Hrsg.]: [Inspection établie en faveur des nourrissons]: in: GS, 7.1776, S. 26 - 27: S. 27. Und die Fortsetzung: in: GS, 8.1776, S. 30 - 31: S. 30. Vgl. Vgl. [Hrsg.]: [sur l'alimentation des nourrissons]: in: GS, 14.1776, S. 54 - 56: S. 54. U.a. empfahlen sie z.B., die Säuglinge in kaltem Wasser zu baden. Eine Methode, die übrigens auch Rousseau in Émile vorgeschlagen hat, und die man Rousseau teilweise vorgehalten hat. Vgl. MussetPathay: Avis de l'éditeur: in: Rousseau: Émile, 1827, S. 7 - 8.

281 Vgl. [Hrsg.]: [Inspection établie en faveur des nourrissons]: in: GS, 7.1776, S. 26 - 27: S. 27. 
sind, bald nicht mehr nötig sein. ${ }^{282}$ Natürlich ist es nicht wirklich im Interesse dieser liberalen Ärzte, die Medizin abzuschaffen. Sondern es geht darum, ihr einen neuen Platz an der Seite der Polizei zu geben, deren gemeinsame Regierung das Ziel haben muss, die Ursachen für die Krankheiten möglichst abzuschaffen.

Ähnliche Artikel finden sich zu dem Problem der Kontrolle der Wein- und Milchlagerung und der Durchführung und Kontrolle der Impfung gegen die Pocken. ${ }^{283}$ Unter der Überschrift Police Medical findet sich ein weiterer sehr interessanter und vorerst letzter Artikel zu Police in einer Ausgabe der Gazette de Santé von April 1789, also kurz vor den Ereignissen, die die Revolution einleiteten. ${ }^{284}$ Es ist ein Artikel über die Memoiren eines ehemals in Avignon praktizierenden Arztes, der von einer Reihe von Ärzten aus Auxerre, wo er ebenfalls praktizieren wollte, angeklagt wurde, keine wirkliche Qualifikation zu besitzen. Obwohl der Autor des Artikels selbst davon überzeugt ist, dass der besagte Verfasser der Memoiren nichts weiter als ein Empyrique ${ }^{285}$ ist, der seine Zulassung in Avignon aufgrund einiger juristischer Tricks erworben hat, so nimmt er den Fall meiner Meinung nach zum Anlass, um eine spezifische Kritik am Verfahren der Polizei zu üben. Im Grunde geht es ihm darum, zu sagen, dass die Frage, ob jemand die Erlaubnis erhalten sollte, als Arzt tätig zu sein, nicht aufgrund der formal rechtlich vorliegenden Qualifikation durch eine Universität oder ein anderes formales Recht entschieden werden könne. Denn das Einzige, was hier zum Urteil führen könnte, wäre die Prüfung seiner wirklichen Fähigkeit. Diese Frage, ob der Mann seinen Fähigkeiten und Intentionen nach ein >wahrer Arzt< sei, ließe sich nicht juristisch oder administrativ durch die Polizei bewerten. Schließlich, fährt der Autor des Artikels fort, sei angesichts des Zustandes der Universitäten und der Weise, wie hier der Grad des Doktors der Medizin verliehen werde, durch diese Formalität längst keine Garantie mehr für eine tatsächliche Fähigkeit und Moralität des Arztes gegeben. ${ }^{286}$ Man sieht hier, dass die Kritik an der Polizei einhergeht mit einer Kritik an den Ärzten generell und den Fakultäten und der universitären medizinischen Ausbildung: Das ganze System der Medizin in Frankreich sei verdorben und müsse von Grund auf erneuert werden. Von dieser Kritik ausgehend geht Artikel in die Begründung einer Reform der Medizin oder der Kunst des Heilens im Allgemeinen sowie einer Reform der Polizei, die sich an ihr zu orientieren hat, über.

282 Vgl. ebd.: S. $26 f$.

283 Vgl. [Hrsg.]: Ordonnance de Police concernant les précautions contre la petite-vérole: in: GS, 12.1778, S. 47 - 49. Vgl. [Hrsg.]: [Petite-vérole, réglements au sujet de la contagion de cette maladie]: in: GS, 15.1780, S. 57 - 58: S. 57. Vgl. z.B. Sumeire: Considérations définitives sur l'inoculation: in: GS, 38.1780, S. $154-155$ : S. 154.

284 Knapp einen Monat später berief Louis XVI. am 5. Mai 1789 die Versammlung der Generalstände ein. Sein Ziel war es, durch eine merkantilistische Politik der hohen Verschuldung Frankreichs entgegenzuwirken. Dort kam es zu Auseinandersetzungen unter den Vertretern der Stände, diese gelten als die ersten Auslöser der Französischen Revolution.

285 Vgl. [Anonym.]: Police Medical: in: GS, 18.1789, S. 69 - 70: S. 70.

286 Vgl. ebd.: $69 f$. 


\section{Kraft eines revolutionären Diskurses}

Der Gedanke der Vereinfachung und der Vereinigung der medizinischen Professionen und auf Gesundheit gerichteten polizeilichen Einrichtungen verwies auf einen einheitlichen Gegenstand - die Gesundheit der Bürger - den man hier konstruierte. In der Sorge um diesen universellen Gegenstand schien es nun absurd, dass es überhaupt eine Konkurrenz zwischen den verschiedenen ärztlichen Professionen gegeben hatte und dass man sich nicht bereits zuvor in einem engeren Zusammenhang mit der Polizei über die Ziele und Mittel verständigt hatte.

Nach der Entsendung des Arztes Vicq-d'Azyrs zur Ermittlung von Maßnahmen gegen die Verbreitung der in Südfrankreich aufgetretenen Viehseuchen veranlasste Louis XVI. im April 1776 einen Erlass, der den Austausch zwischen den Ärzten der Hauptstadt und den Provinzen über das Auftreten und die Maßnahmen gegen Epidemien und Tierseuchen dauerhaft ermöglichen sollte. 1778 gründete sich daraufhin die Société royale de médecine aus einem Zusammenschluss der Commission de médecine à Paris und der Commission pour l'examen des remèdes secrets et des eaux minérales, die seit 1772 durch einen Erlass Louis XV. bestanden hatte. ${ }^{287}$ Damit war bereits zu dieser Zeit begonnen worden, nicht nur die wissenschaftliche Expertise der Ärzte für die Regierung der hygiène publique einzubeziehen. Darüber hinaus wurde der Gegenstand vom Problem der Stadt entkoppelt und als eine nationale Aufgabe betrachtet. Die Société war die erste Institution, die diese neue Vereinigung von medizinischer Wissenschaft und auf Gesundheit gerichtete staatliche Politik repräsentierte. $\gg[R]$ endre des services à la Nation \& d'acquérir en même temps des lumières intéressantes pour l'art de guérir. L'émulation qui doit en résulter, produira sans doute ce double avantage. $\ll^{288}$ Doch bestand diese Vereinigung innerhalb der Société royale de médecine nur durch die Erlasse des Königs und vermittelt durch sein Interesse.

1790, also ein Jahr nach der Einrichtung der Nationalversammlung und zwei Jahre vor der Hinrichtung der französischen Königsfamilie, in einer Zeit der Reformen und der Möglichkeit der Einrichtung einer Art konstitutionellen Monarchie, legte die Société royale de médecine der Nationalversammlung einen umfassenden Reformplan zur Abstimmung vor. Im Untertitel des Plans hieß es: »Vues générales sur la réforme dont la Médecine est susceptible, \& sur la nécessité de la rappeler à l'état d'unité \& de simplicité ou elle étoit du temps d'Hippocrate, en la réunissant a la Chirurgie $\ll{ }^{289}$ Das Paradoxe an dieser Bestimmung ist, dass der 200 Seiten umfassende Reformplan ein derartig detailliertes und umfassendes administratives Gesamtvorhaben enthält, dass die Ankündigung, man strebe eine Rückkehr zu den Grundlagen der hippokratischen Grundsätze an, beinahe unglaubwürdig wirkt. Tatsächlich aber besteht hierin kein besonderer Widerspruch, denn der Plan war eine völlige Neuord-

287 Diderot; D’Alembert: Encyclopédie Méthodique, Par Une Société De Médecins, 1824: S. 360.

288 Vgl. Société Royale der Médecine: Histoire de la Société Royale de Médecine, Anée 1776, 1779: [Preface S. viii].

289 Société royale de médecine (Paris): Nouveau plan de constitution pour la médecine en France, 1790: S. 1. 
nung und Verteilung der Regierung von Gesundheit und der bisher an dieser beteiligten Akteure und Institutionen, ausgenommen die private individuelle Selbstregierung. Ziel des Plans war die Vereinigung der medizinischen Professionen, allen voran der Chirurgie und der Medizin ${ }^{290}$, und ihren Grundausbildungen. Man schlug die Verschmelzung der Bereiche vor, die vorher der Polizei bzw. der Wissenschaft zugerechnet worden war. ${ }^{291}$ Kein Arzt könne seinen Beruf richtig und zum Wohle der Bürger und der Kranken ausüben, wenn er nicht richtig oder nur einseitig ausgebildet sei und keine Administration könne erfolgreich die Gesundheit schützen, wenn es keine Ärzte gebe, die die Rolle der Medizin und der medizinischen Wissenschaft für die öffentliche Gesundheit anerkennen würden.

»Que peut-on attendre, en effet, de quelques années Vices dans d'étude, qui se passent à dicter ou à lire des Prolégomènes de Médecine, uniquement formés de définitions \& de divisions stériles? Que peut-on attendre d'Écoles dans la plupart desquelles on n'enseigne ni l'Anatomie complète de l'homme, ni l'Art de la dissection, ni la Botanique, ni la Chimie médicale dans toute son étendue, ni la Pharmacie, ni l'Art de formuler, ni la Nosologie, ni l'Histoire de la Médecine, ni le Traité des maladies; où l'on ne dit pas un mot des fonctions publiques du Médecin; où nul encore n'a professé son Art près du lit des malades; $\&$ d'où l'on sort enfin sans avoir rien appris de ce qu'un Médecin praticien doit savoir? «292

Ziel war nicht allein die Vereinigung wissenschaftlicher und politischer Ziele, vielmehr wollte man die Bindung der Wissenschaft an ein politisches Interesse und eine moralisch begründete Machtposition. Die Macht der Ärzte über das Leben der Bürger im Bereich ihrer privaten Praxis sei zu groß und die öffentliche Macht zu schwach. Die Streitigkeiten, die es gegeben habe zwischen der Medizin und der Polizei über die Definition von Krankheiten, der Streit unter den Professionen um ihre Kompetenz, all das, alle Rivalitäten und Diskussionen, sollten angeblich beendet werden durch eine neue Ordnung, vereint durch das Band einer gemeinsamen politischen Rationalität der Regierung von Gesundheit, die allen Parteien von einem einzigen gemeinsamen Prinzip ausgehend eine Funktion und ein Existenzrecht einräumte. ${ }^{293}$ Der Bezug auf die Lehre Hippokrates wurde zur Schnittstelle, die die unterschiedlichen Bezüge auf dessen Texte miteinander verbinden sollte. Die Lehre stand einerseits für eine bestimmte Rationalität und Praxis der Führung der Menschen und andererseits für die Wissenschaft von der Erhaltung bzw. Wiederherstellung der Gesundheit.

Im zweiten Teil des Plans »de l'Exercice de la Médecine considérée dans ses rapports avec la salubrité publique« heißt es:

290 »Est-ce que la Chirurgie n'a pas toujours été régardée comme une partie de la Médecine? : Ebd.: S. 5.

291 Nouveau Plan de constitution pour la médecine en france, présenté à l'Assemblée Nationale par la Société royale de médecine, Paris, 1790: S. 2f.

292 Ebd.: S. 3.

293 Vgl. ebd.: S. 9. 
»De la Manière dont les Médecins \& les Chirurgiens doivent être distribués pour secourir le peuple des Campagnes \& des Villes. C'est principalement pour prendre soin des malades pauvres, \& pour veiller au traitement des épidémies que les Médecins ou les Chirurgiens doivent être répandus dans les campagnes. $\ll^{294}$

Das heißt, die Niederlassung und Verteilung der Ärzte sollte dem Bedarf in den Bevölkerungen angepasst werden, um eine flächendeckende medizinischen Versorgung zu gewährleisten. In dem Abschnitt zur Polizei heißt es wiederum, dass die Bereiche der Polizei, die sich mit der öffentlichen Gesundheit befassen, von Medizinern geleitet werden sollten.

»Rien ne devant être plus libre que la confiance, chacun doit pouvoir consulter qui lui plaît sur sa santé, comme sur tous les autres besoins de la vie. La loi se contentera de n'autoriser à prendre le titre de Médecin, que ceux auxquels il aura été conféré par les Corps qui en auront le pouvoir. $\ll^{295}$

Ein weiterer Effekt der Vereinheitlichung und Vereinfachung auf der Seite der Prinzipien und der Ausweitung der Regierung auf der anderen Seite war, dass man gleichermaßen die Gesundheit in einem umfassenderen Sinne als zuvor betrachten musste. Man kann sich vorstellen, was es bedeutet, wenn der Bereich, der zuvor der Pragmatik der Polizei unterstand, die vor allem einer historischen Praxis der Herstellung einer gewissen städtischen Ordnung entsprungen war, nun unter die Rationalität einer Disziplin fällt. Die Sterblichkeit wird in Folge dieser Veränderung auch innerhalb der Medizin zu einem allgemeinen Thema. Man wird deshalb die Sterblichkeit auch nicht nur vom Standpunkt einer auf Anatomie und Physiologie konzentrierten Medizin betrachten können. Stattdessen wird es nötig werden, herauszufinden, was die Bedingungen für Krankheit oder Sterblichkeit im Allgemeinen sind. Man wird sich mehr dafür interessieren, wie sich das Klima, das Milieu eines Kranken, sein Temperament, seine soziale Situation usw. auf diese Normalität auswirkt. Der Reformplan der Société royale de médecine wurde in dieser Form nicht umgesetzt. Einige der Vorschläge, die hier gemacht wurden, wurden jedoch später zu unterschiedlichen Zeiten wieder aufgenommen.

Worin bestand das Ziel einer solchen Reform der Medizin und einer einheitlichen Ausbildung der Mediziner? Sicherlich war sie in diesem konkreten Fall zunächst von dem Interesse der in der Société versammelten Ärzten vorangetrieben worden, die damit hoffte, ihren Status zu verbessern, ihre gesellschaftliche Position innerhalb einer neuen politisch Ordnung zu sichern und sich endlich der Konkurrenz der sog. Scharlatane und ungebildeten Praktiker zu entledigen. So war dies jedoch bei Weitem nicht der einzige Antrieb. Das Zusammenschließen bestehender Diskurse und Praktiken ermöglichte es, zu begründen, warum eine Regierung der Gesundheit nicht trotz, sondern gerade wegen ihres politischen und moralischen Anspruchs von der medizinischen Wissenschaft abhängig war. Die Vereinigung aller Disziplinen in der Medizin und gleichzeitig die Einordnung der Medizin in einen administrativen und 
zur Regierung geschaffenen Apparat sollte den Machtkampf zwischen Ärzten, Chirurgen, Apothekern usw. beenden und den Anfang für eine Ausweitung dessen setzten, was überhaupt zum Gegenstand einer Regierung von Gesundheit gehörte. Die Jahre, nachdem die Société royale de médecine ihren Reformplan unterbreitet hatte, waren geprägt von einschneidenden politischen Ereignissen und kurzlebigen Vorstellungen einer noch grundlegenderen Umgestaltung der Profession. Im August 1793 erfolgte per Erlass die Auslösung der Gesellschaft und die Schließung der alten wissenschaftlichen Fakultäten, auch der Faculté de Médecine. Auch die (medizinische) Polizei wurde zeitweise abgeschafft und nur nach und nach wieder eingesetzt. Nach allem, was später in den Zeitschriften über diese Periode steht, wurde sie als Zeit des Rückschritts und großen Durcheinanders empfunden. 1796 nutzten Ärzte das in der neuen Konstitution festgesetzte Recht auf Vereinigung zur sog. Société Libre, zur Gründung der Société de la Santé, deren Hauptorgan die Veröffentlichung des Recueil périodique de la Société de Santé de Paris darstellen sollte. ${ }^{296}$ Der Name wurde aus strategischen Gründen gewählt. Da nach 1793 die Bezeichnung médecin als elitär verschrien war, hatte man, wie auch Matthew Ramsey schrieb, alle medizinischen Professionen und Praktiker unter dem Begriff der Officiers de la Santé zusammengefasst. ${ }^{297}$ Mit der Bezeichnung Société de Santé vermieden ihre Gründer die Worte Médecine und Médicin, um sich dem Vorwurf zu entziehen, eine elitäre Struktur wieder errichten zu wollen, die man mit den alten medizinischen Organisationen des Ancien Régime und der alten Faculté verband. ${ }^{298}$

»C'est ainsi qu'à l'époque de délire révolutionnaire, des ignorants se couchaient perruquiers et se levaient un beau matin officiers de santé, une patent à la main, ayent compté pour thèses de licences les rêves de leur nuit. N'est-il donc pas un moyen de réfréner ces missionnaires sans titre, ces praticiens sans clinique, ces professeurs sans théorie, ces écrivains sans talent? «299

In der ersten Ausgabe der Recueil périodique de la Société de Santé de Paris befindet sich ein Abdruck der zur Gründung festgelegten Reglements der Organisation. Daran lässt sich die Allgemeinheit der Ziele der Organisation, ebenso wie ihre Ausrichtung auf das Ziel, allem zu dienen, was nicht der Medizin, sondern der Kunst des Heilens (»1'art de guérir «) im Allgemeinen zugute komme, erkennen. ${ }^{300}$

Die Kritik an der elitären Ausrichtung der früheren Faculté schlug in eine allgemeine Popularisierung der Medizin um. Jeder, der sich für die Gesundheit und die Heilung der Menschen nützlich machen könne, war aufgefordert, sich unter dem Begriff der Officiers de santé zu versammeln: »La Société appelle dans son sein tous les hommes qui dirigent utilement leurs travaux vers l'art de guérir. $\ll^{301}$

296 [Hrsg.]: Reglement: in: RP, 1.V, S. 5 - 24: S. 3.

297 Vgl. Ramsey: Professional and popular medicine in France, 1770 - 1840, 1988: S. 74.

298 Vgl. [Hrsg.]: Précis Historique De La Société De Médecine De Paris: in: RP, 2.V, S. 234 -242: S. 237.

299 [Hrsg.]: Des Officiers de Santé: in: GS, 20.1810, S. 54 - 55: S. 54. Vgl. [Hrsg.]: Chronologie Medical: in: GS, 2.1808, S. 9 - 12: S. 9.

300 [Hrsg.]: Reglement: in: RP, 1.V, S. 5 - 24: S. 5.

301 Ebd.: S. 5. 
»Plusieurs Officiers de santé, convaincus que l'isolement des personnes qui cultivent l'art de guérir nuit à ces progrès, et est entièrement préjudiciable aux intérêts de l'humanité, ont concerté entr'eux un mode d'organisation d'une Société de Santé, à laquelle chaque membre peut offrir le tribut de son expérience et de ses méditations. «02

Die Tatsache, dass anscheinend kurz darauf allen möglichen Personen, die sich selbst als Heiler, Ärzte und Apotheker bezeichneten, den Titel der Officiers de santé für sich beanspruchten und unter diesem zu praktizieren begannen, sorgte in der Société de Santé für Empörung.

»La médecine en France alloit retomber dans la barbarie; mais ces grands hommes avoient laissé des contemporains, des collaborateurs dignes d'eux. Il ne falloit que les rallier sous l'égide d'une constitution qui venoit de s'élever sur les ruines de l'anarchie; il falloit même profiter de la dissolution générale, pour rattacher tout les branches de la médecine humaine et vétérinaire au même tronc «. ${ }^{303}$

Schon sehr kurze Zeit später wandelte die Société de Santé ihren Namen wieder in Société de Médecine um und bekannte sich im Vorwort des zweiten Bandes der nun in Recueil périodique de la Société de Médecine de Paris umbenannten Veröffentlichung offen, ihren vorherigen Namen aus strategischen Gründen gewählt zu haben. ${ }^{304}$ In den Jahren der Revolution und nachdem die Société de Médecine gegründet worden war, finden sich die alten Leitideen der medizinischen Reform wieder, die vor der Revolution durch die Veröffentlichungen der Société Royal de Médecine $e^{305}$ deutlich geworden waren.

Der Gedanke der Einheit der medizinischen Professionen auf der Grundlage einer Vereinfachung bzw. Vereinheitlichung der Ziele im Sinne der Erhaltung der Gesundheit der Menschen wird unter dem Begriff der hygiène publique zusammengefasst. Diese Einheit aus Hygiene und Medizin sollte sich auf das Wohl der Menschen richten, indem sie sich auf eine von Hippokrates und Galen abgeleitete Lebenskunst und auf das Wissen der (natur)wissenschaftlichen Medizin stützte. ${ }^{306}$ Das bedeutete, die Medizin die Erhaltung der Gesundheit im Sinne der Hygiene und Diätetik auszurichten, ihr gleichzeitig aber eine innere Ordnung zu geben, die jeder einzelnen branche erlaubte, ihren Teil zu der Erforschung der Bedingungen und Ursachen von Krankheit beizutragen und so die Heilkunst im Sinne einer >Kunst der Erhaltung< der Gesundheit zu perfektionieren. ${ }^{307}$ In dem plan de travail vom 22. Dezember 1796 gibt

302 Ebd.: S. 3.

303 Vgl. [Hrsg.]: Précis Historique De La Société De Médecine De Paris: in: RP, 2.V, S. 234 -242 : S. 236.

304 Ebd.: S. 237.

305 Ich meine hier vor allem die zwischen 1776 und 1779 jährlich unter dem Titel der Histoire et mémoires de la Société royale de médecine erschiene Veröffentlichung.

306 Vgl. Lafisse: Extrait d'un ouvrage ayent pour titre: Observations sur les maladies qui régnait le plus fréquentes en Angleterre...: in: RP, 1.V, S. 69 - 73: S. 69.

307 Vgl. [Hrsg.]: Précis Historique De La Société De Médecine De Paris: in: RP, 2.V, S. 234 $-242: 236$. 
die Gesellschaft einen Überblick über ihre geplante Tätigkeit und ihren Anspruch: »un plan de travail qui puisse la conduire sûrement au but qu'elle se propose, le perfectionnement de l'art de guérir«. Darin heißt es:

»Si jamais ils y ont une circonstance favorable aux progrès de cet art salutaire, ce doit être sans contredit celle où, après la destruction de tout les corps savants, après une inertie totale de plusieurs années, le désir d'être utile à ses semblables, le besoin d'acquérir de nouvelles lumières et de les répandre, ont réuni dans cette Société les hommes les plus distingués dans les différentes parties de la Médecine, qui sans autre motif que leur zèle, dans autre lieu que la douce habitude produite par la communauté de travail, sans autre intérêt que celui de l'humanité, s'empresseront de s'éclairer mutuellement, et ne conserveront des anciennes rivalités que la noble émulation de faire bien. $\ll^{308}$

Die Arbeit der Erneuerung der gesamten Heilkunst war zu diesem Zeitpunkt noch eine vage Vision, wurde aber bereits als Vorhaben der Société formuliert. Zu diesem Zweck sollten alle Fakten und bestehende Kenntnisse recherchiert und einer kritischen Prüfung unterzogen werden, »afin de fixer en quelque sorte l'état actuel de la médecine, d'en évaluer les progrès, de déterminer leurs époques et de mesurer la carrière qui reste encore à parcourir. ${ }^{309}$ Hierbei spielte die Idee der Vereinigung und der Vereinfachung eine zentrale Rolle. ${ }^{310}$ Man hatte die Vorstellung, dass alle medizinisch relevanten Wissenschaften auf bestimmte Prinzipien und Gesetze der Natur (»principes généraux qui, n'étant fondés que sur la nature«) einerseits und auf das gemeinsame Ziel oder die Pflicht (»une grande impulsion«) der Heilung der Gesellschaft, bzw. der Einrichtung einer Gesellschaft ohne nennenswerte Krankheiten, auszurichten sei. ${ }^{311}$ Die Idee der medizinischen Wissenschaft, wie die Société de Médecine formulierte, entsprach im Kern dem, was Foucault als Eigenschaft der Humanwissenschaften bezeichnet hat. Die Medizin sollte eine Wissenschaft vom Leben und den Bedingungen der Existenz dieses Lebens werden. Sie war zugleich Pathologie, Anatomie und vor allem Biologie. ${ }^{312}$ Dies verschaffte ihr den ersten Platz auf der Seite der Wissenschaften vom Menschen, wie Foucault schrieb. ${ }^{313}$ Nicht die Bildung von Theorien und Systemen sollte ihr Ziel sein, sondern sie solle anstreben, durch die Beobachtung der Natur die Geheimnisse des Lebens freizulegen. »[Les observations]

308 [Hrsg.]: Plan de travail, présenter à la Société de Médecine: in: RP: 2.V, S. iii - xxii: S. ivf.

309 Ebd.: S. v.

310 Vgl. Lafisse: Extrait d'un ouvrage ayent pour titre: Observations sur les maladies qui régnait le plus fréquentes en Angleterre...: in: RP, 1.V, S. 69 - 73: S. 69.

311 Vgl. [Hrsg.]: Plan de travail, présenter à la Société de Médecine: in: RP: 2.V, S. iii - xxii: S. v.

$312 »[\mathrm{D}]$ estiné $[\ldots]$ à l'explication des phénomènes de la nature, à de la recherche de leurs causes, à l'examination de la structure de l'organisation des êtres vivans, à l'art de décomposer et de recomposer les corps, à la connoissance des vertus et de préparation des médicaments; enfin à la distinction et à la classifications des êtres innombrables qui les produisent.«: [Hrsg.]: Prospectus: in: RP, 9.V, S. iii - xv: S. vi.

313 Vgl. Foucault, Michel: Die Geburt der Klinik, 2008 [1963]: S. 51. 
qui éclairent l'homme sur sa conservation, en lui dévoilant les plus importants secrets de la nature. $\ll^{314}$

Die Reform der Medizin und ihre enge Verzahnung mit dem zuvor relativ eigenständigen und von ihr unabhängigen Bereich der öffentlichen Gesundheit (salubrité publique) in den Händen der Polizei wirkte expansiv auf den Bereich, auf den die Medizin und öffentlich Gesundheit jeweils für sich Macht über die Gesundheit der Menschen ausgeübt hatten. Die Medizin als Wissenschaft, die Ausbildung aller Mediziner, die Zuständigkeiten der Einzelnen und die Bereiche, in denen sie Rechte und Pflichten besaßen, sowohl im Hinblick auf die Öffentlichkeit als auch in der privaten Praxis, die Festlegung der Gehälter und die staatlich finanzierte medizinische Versorgung sollten zunehmend gesetzlich und in Form umfassender Verwaltungsstrukturen geregelt werden. Die Medizin war in die staatliche Verwaltung eingebunden und die Hygiene, die vorher ihrem Inhalt nach am ehesten zum praktischen Aufgabenbereich der Polizei gehört hatte, unterlag nun den Anforderungen einer Wissenschaft. Die Idee der Herstellung der Ordnung, eines Zustandes von Ordnung, in dem es keine Krankheiten mehr gab, eines Zustandes, wie er in der idealen Idee der Hygienelehre existiert hatte, war nun zum wissenschaftlichen Problem der Medizin geworden und entfachte eine unbändige Nachfrage nach Wissen über alles, was in der Umwelt und der Gesellschaft der Menschen auftrat und in Zusammenhang mit dem Auftreten von Krankheit gebracht werden konnte. ${ }^{315}$

Neben der Idee der Vereinigung all dieser verschiedenen Akteure unter einem Dach bestand die Idee der Vereinfachung der medizinischen Theorie. Die Medizin strebte nach einer einheitlichen Episteme und nach einer einheitlicheren Methode. Die Krankheiten müsse man dementsprechend klassifizieren und dann könne man auch wenige, einfache und sichere Methoden finden, die Krankheit gänzlich aus der Welt zu schaffen. Dazu gehörte etwa auch, die Ordnung der Krankheiten und ihre Unterscheidung nach ihrer Regierbarkeit, wie sie die Polizei vorgenommen hatte, in Frage zu stellen. Diese Ordnung hatte darauf beruht, die ansteckenden, epidemischen Krankheiten als Problem der Polizei und die Anderen als Problem der Ärzte zu definieren. Wonach soll man aber die Krankheiten und damit verbunden die Formen ihrer Handhabung nun ordnen?

»On a supposé que les maladies épidémiques d'une constitution différoient totalement de celles d'une autre constitution, par leur nature, par leur cause, et par leur traitement. Cette opinion a été généralement adoptée, quoiqu'on ignore sur quel fondement elle est établie. S'il étoit vrai cependant que cette différence existât, l'art de guérir ne parviendroit jamais à des résultats assurés, puisque l'expérience, de ce qui auroit été fait avec succès dans une circonstance, s'apprendroit pas aux médecins ce qu'il y a dans une autre. $\mathrm{Si}$, au contraire, en comparant les maladies épidémiques de tous les temps, et de tous les pays, on apperçoit entre elles une res-

314 [Hrsg.]: Prospectus: in: RP, 9.V, S. iii - xv: S. v.

315 Vgl. [Sur une Addition importante à faire aux Tables de mortalité] Nouveau Plan de constitution pour la médecine en france, présenté à l'Assemblée Nationale par la Société royale de médecine, Paris, 1790: S. 132ff; 262ff. Vgl. Table de proportion de mortes dans ... [proportionale Sterblichkeit durch verschiedene Fieber in verschiedenen Ländern]: in: RP, 1.V, S. 262ff. 
semblance marquée, alors on pourra supprimer un grand nombre de distinctions superflues; alors il sera possible d'établir des règles de pratiques plus générales et plus sûres. «116

Die Medizin strebte, was meiner Meinung nach schließlich wieder zu einem Bruch mit der Rationalität der Hygiene führte, mit der Nosologie, der Klassifikation der Krankheiten danach, sich ähnlich wie andere Naturwissenschaften eine Ordnung zu geben, die scheinbar der Ordnung eines bestimmten Bereichs der Natur völlig entsprach. Diese typische Bewegung der Disziplin, sich selbst zu begrenzen und sich zu vertiefen, um innerhalb bestimmter Regeln und Kriterien Wahrheit über einen bestimmten Bereich zu akkumulieren, stellte für die Hygiene ein Problem dar. Sie orientierte sich an Fragen der Praxis, des Umgangs und der Regierung. Was die beiden ungleichen Rationalitäten der Medizin und der Hygiene für diese kurze Zeit zusammenschweißte, war die Utopie einer Regierung von Gesundheit innerhalb eines >revolutionären Diskurses $<$. In ihr war einerseits das Ziel der Perfektionierung der medizinischen Wissenschaften enthalten, im Sinne einer völligen Erkenntnis über die grundlegenden Gesetze der Natur und damit die Möglichkeit, jegliche schlimmere Erkrankung ausschließen zu können. Andererseits beinhaltete diese Utopie eine Perfektionierung und Rationalisierung der Gesellschaft, die sich - orientiert an den Naturgesetzen - selbst Gesetze geben und in welcher jeder tugendhaft im Sinne dieser Gesetze auf sich selbst achten würde. Es existierte auch die Idee, dass die Revolution selbst, also die Erneuerung der Gesellschaft, bereits eine Reihe von Krankheiten beseitigen würde, die man zuvor als Folge eines krankhaften Gesellschaftszustandes angesehen hatte. ${ }^{317}$

Hieraus begründete sich die Notwendigkeit der Reform bzw. der Neuerfindung der Medizin und der medizinischen Polizei. Sowohl die Vereinigung der medizinischen Professionen in der Heilkunst als auch die Idee einer auf sie gestützten medizinischen Polizei standen unter dem starken Einfluss einer durch die bürgerliche Rationalisierung der Selbstpraxis der Hygiene motivierten Ethik. Der Wunsch nach einer neuen Polizei konzentrierte sich von Seiten der Medizinreformer auf zwei Aspekte: Erstens die Ablösung der juridischen Logik der Polizei durch eine ökonomische, die sich nicht an den Gesetzen, sondern an dem Wissen über die Krankheiten orientieren sollte. Zweitens, eine enge personelle und institutionelle Verzahnung mit der Wissenschaft und der Art de guérir.

Gewissermaßen ein Kondensat dieser Ansprüche stellte das Problem und die Diskussion über die sogenannten Charlatans dar. Die alte Polizei hatte nur nach der rechtlichen Grundlage eines Arztes zu praktizieren gefragt. Hatte er das Recht zu praktizieren durch ein Zertifikat erworben, so durfte er praktizieren, hatte er es nicht, dann nicht. Sie besaß keine Instrumente, kein Wissen und keine Legitimität, um gegen einen Arzt vorzugehen, der formal ein Diplom besaß, aber nach medizinisch-

316 Lafisse: Extrait d'un ouvrage ayent pour titre: Observations sur les maladies qui régnnet le plus fréquentes en Angleterre...: in: RP, 1.V, S. 69 - 73: S. 71f.

317 Vgl. Léveillé: L'influence des violentes et subites affections de l'âme sur la santé. Des observations de M.A. Petit S.M. Et chirurgien en chef de l'hôpital de Lyon, sur l'influence que peuvent avoir sur la santé les violentes et subites affections de l'âme. RP, 3.V, S. 426 - 441: S. 427. 
wissenschaftlichen oder -praktischen Gesichtspunkten inkompetent war oder eine Gefahr für seine Patienten darstellte. Da es noch viel expliziter als zuvor die Aufgabe der Polizei sein sollte, im Sinne Hippokrates' die medizinische und gesundheitliche Sicherheit der Bürger zu gewährleisten, konnte diese hier nicht anders handeln als auf der Grundlage der Wissenschaft, der Medizin. Sie musste für sich zur Bedingung haben, dass die Institutionen, die Schulen und Universitäten, die die Ärzte ausbilden sollten, nicht nur Teilwissen und Praxiswissen vermittelten; sie brauchte eine Regelung der Ausbildung der Ärzte, die sich direkt mit ihren Aufgaben verbinden ließ, um klarer unterscheiden zu können, wer als Arzt anerkannt und wer als Scharlatan entlarvt werden müsste. Die Polizei und ihre Aufgabe verlangte plötzlich, eine Domäne der wissenschaftlichen Medizin zu werden, um in der Lage zu sein, alle die Bereiche, in denen Bürger oder Ärzte nicht durch ihr Verhalten oder ihre Behandlung für die Herstellung oder Erhaltung der Gesundheit in der Gesellschaft sorgen konnten, abzudecken.

Im Recueil périodique der gerade wieder frisch gegründeten Société de Médecine bettelten ihre Mitglieder 1798 geradezu um eine staatliche Anerkennung, finanzielle Unterstützung und die Einrichtung einer exekutiven Gewalt. Die Mediziner sahen sich verantwortlich, aber machtlos, angesichts der Masse von unausgebildeten Ärzten, die unter dem Deckmantel des officer de santé praktizierten. Sie verlangten eine politische Würdigung ihrer Aufgabe der Verbesserung der Gesellschaft auf dem Wege zu einer Gesellschaft ohne Krankheiten und ohne >gefährliche Leidenschaften ${ }^{318}$. Unter der sehr allgemein gehaltenen Überschrift »vue sur la police médicale « bekundete die Gesellschaft ihre erfolglosen, machtlosen Bemühungen gegen Epidemien (»fléau dévastateur ${ }^{319}{ }^{\text {}}$ ) und hinsichtlich der »nécessité très-urgente de réprimer les charlatans qui infestent la République«, ihr Bestreben, die medizinische Profession neu zu organisieren. ${ }^{320}$

Es soll eine Medizin und durch sie eine medizinische Polizei geschaffen werden, die anders ist als die, die es zuvor unter dem Ancien Régime gegeben hatte. Die Polizei soll mit der Medizin »le bienfaiteur spécial de l'humanité souffrante « ${ }^{321}$, als Wissenschaft über die Natur und die Natur des Menschen verbunden werden. Somit soll das Regime der Polizei und alle ihre Eingriffe auf eine objektive Basis gestellt werden. ${ }^{322}$ Dafür müssen vor allem zunächst die wissenschaftlichen Institutionen mit diesem Ziel - der öffentlichen Gesundheit zu dienen - wieder etabliert werden. ${ }^{323}$

Die Société de Médecine de Paris bot also der Regierung an, das »projets de règlement « umzusetzen und Frankreich von der »horde assassine des empiriques « zu befreien. ${ }^{324}$ Auch der Bericht der sechsten öffentlichen Sitzung der Société de Méde-

318 Vgl. [Brief an den Konsul] Vue sur la police médicale: in: RP, 10.V, S. 179 - 202: S. $200 f$.

319 [Hrsg.]: [Brief an den Konsul] Vue sur la police médicale: in: RP, 10.V, S. 179 - 202: S. 197.

320 Ebd.: S. 197.

321 Ebd.: S. 198.

322 Vgl. ebd.: S. 199.

323 Vgl. ebd.: S. 200f.

324 Ebd.: S. 201. 
cine vom 22. pluviôse ${ }^{325}$ des 9. Revolutionsjahres beschreibt den Plan der Institutionalisierung der Regierung von Gesundheit durch eine police médicale in enger Vereinigung mit einer allgemeinen medizinischen Wissenschaft. Der Bericht verrät auch, dass der Bezug auf Hippokrates mehr bedeutet als die Übernahme einer Struktur für die Ordnung eines Gemeinwesens, wie es bei der Polizei noch im 17. Jahrhundert der Fall war. ${ }^{326}$ Genau deshalb, weil die Aufgabe einer medizinischen Polizei nun eine viel umfassendere Bedeutung hatte, indem sich ihr moralischer Auftrag mit einer politischen Utopie von einer besseren Gesellschaft verband, konnten die persönlich an der Umsetzung dieser Arbeit Beteiligten nicht irgendwelche Personen sein. Sie müssten als Leiter der Menschen, ihrer Seelen und Körper selbst moralische Subjekte sein. Auch aus diesem Grund dürfe die Ernennung der Ärzte keine formale, juristische Angelegenheit sein, sondern müsse mit einer umfassenden wissenschaftlichen und moralischen Prüfung einhergehen. ${ }^{327}$

»Et le médecin savant, modeste et philosophe, celui dont les travaux n'ont en pour but, que d'assurer à ses semblables les jouissances de la vie par celle de la santé; ces hommes, dis-je, sans cesse humilié d'avoir à partager ses fonctions honorables avec de vile charlatans, seroit forcé d'abandonner une profession, dans laquelle il lui foudroit continuellement lutter contre l'intrigue et l'ignorance. «328

Die Französische Revolution wurde von einem Diskurs begleitet, der alles Übel - also auch die Krankheiten -, an denen die Menschen bisher gelitten hatten, auf einen Fehler der Regierung, ein falsches Prinzip der politischen Herrschaft zurückzuführen versuchte. Die Heilung der Menschen von ihren Krankheiten musste deshalb auch auf dem politischen Wege bewirkt werden. An diesem politischen Heilungsprozess wollten sich die Ärzte beteiligen. Es ist, wie Foucault schrieb, eine Art »Übergangsrolle ${ }^{329}$ Denn wer könnte besser als sie von diesen Leiden der alten Gesellschaft wissen? Wer könnte besser als der, der die Menschen bereits in ihrer >natürlichen Gleichheit< behandelt, von der Falschheit dieser Herrschaft und Ungleichheit wissen, wenn nicht der Arzt?

»)Wer soll denn dem Menschengeschlecht die Tyrannen anzeigen, wenn nicht die Ärzte, die den Menschen zu ihrem einzigen Studium machen und die jeden Tag, beim Armen und beim Reichen, beim einfachen Bürger und beim Mächtigeren, unter dem dürftigen Strohdach und unter der kostbaren Vertäfelung die menschliche Erbärmlichkeit betrachten, welche keinen anderen Ursprung hat, als Tyrannei und Sklaverei?«.«330

325 Fünfter Monat des Republikanischen Kalenders der Französischen Revolution.

326 [Hrsg.]: [Séance publique de la Société de Médecine de 22. pluviôse d'an 9] Vue sur la police médicale: in: RP, 10.V, S. 203 - 209: S. 203.

327 Vgl. ebd.: S. 206.

328 Ebd.: S. 203.

329 Foucault, Michel: Die Geburt der Klinik, 2008 [1963]: S. 51.

330 Lanthenas zitiert nach Foucault ebd. 
Der Arzt und Jakobiner François Xavier Lanthenas (1754 - 1799), auf den sich Foucault hier bezieht, veröffentlichte 1795 ein Buch mit dem Titel Religion civile proposée aux républiques pour lien des gouvernements représentatifs, in welchem er einen umfassenden moralischen Verhaltenskodex ausarbeitete. Foucault schreibt in Die Geburt der Klinik, dass es in den Jahren vor und direkt nach der Revolution zwei Mythen gab, die auf den ersten Blick als gegensätzlich erschienen:

»Den Mythos eines ärztlichen Berufsstandes, der in der Art des Klerus organisiert ist und der auf der Ebene der Gesundheit und des Körpers mit ähnlichen Vollmachten ausgestattet ist wie jener im Hinblick auf die Seelen; und dann den Mythos eines vollständigen Verschwindens der Krankheit in einer Gesellschaft, die zu ihrem heilen Ursprung zurückgefunden hat und ohne Wirren und Leidenschaften lebt. Der offensichtliche Widerspruch der zwei Gedanken darf aber nicht darüber hinwegtäuschen, daß beide Traumbilder - in schwarz und weiß - auf ein und dieselbe Erfahrung verweisen. Die beiden Träume sind isomorph. Der eine schildert rigorose, militante und dogmatische Medikalisierung durch eine quasi religiöse Bekehrung und die Einsetzung eines Klerus der Heilkunst; der andere Traum erzählt von der selben Medizinisierung, aber in einer triumphierenden und negierenden Tonart, nämlich von der Verflüchtigung der Krankheit in einem korrigierten, organisierten und überwachten Milieu, in dem schließlich der Gegenstand der Medizin selber verschwindet.«331

Der zweite Mythos entsprang, laut Foucault, aus einer »konsequent vorangetriebenen historischen Reflexion. «332 Dieser revolutionäre historische Diskurs wird von Foucault noch zu einem Zeitpunkt und mit Blick auf einen ganz anderen Gegenstand benannt, nämlich bezogen auf den politischen Diskurs oder man könnte auch sagen, den Diskurs über die generellen Existenzbedingungen politischer Herrschaft. ${ }^{333}$

»Die Idee der Revolution, die alle politischen Mechanismen und die gesamte Geschichte des Abendlandes seit mehr als zwei Jahrhunderten durchzieht und in ihrem Ursprung und ihrem Gehalt im Übrigen höchst rätselhaft ist, kann, denke ich, vom Auftreten und der Existenz einer Gegen-Geschichte nicht getrennt werden.«334

Lanthenas Text beinhaltet, genau den von Foucault geschilderten doppelseitigen Mythos: Die Möglichkeit der durchdringenden moralischen und physischen Führung der Menschen durch eine medikalisierte Politik und das Ziel der Abschaffung der Krankheiten und damit auch der Medizin als Kunst des Heilens bzw. ihre Ersetzung durch eine Hygienewissenschaft, die auf die Erhaltung der Gesundheit zielt. Bemerkenswert an Lanthenas ziviler Religion ist, dass sie im Modus der Meditation bleibt. Die Art der Selbstpraxis und die auf das Individuum gerichteten Regierungstechniken, die er vorschlägt, stellen im Gegensatz zu der Aufforderung Kants zur Selbsterkenntnis, keinen wirklichen Bruch zur religiösen Selbstpraxis des Pastorats dar. Überall in

331 Foucault, Michel: Die Geburt der Klinik, 2008 [1963]: S. 48f.

332 Vgl. ebd.

333 Vgl. Foucault: In Verteidigung der Gesellschaft, 2001 [1975 - 76]: S. 98.

334 Ebd.: S. 98. 
Lanthenas Schrift taucht die Aufforderung zu dieser Art der Meditation auf: Kenne dich selbst! Nicht, wie bei Kant: Erkenne wer du bist!

»Connois-toi, relativement aux lois de ton existence [...]. Habite avec toi-même! [...] Connoistoi, relativement à ce qui te conserve, prends soin de ta personne! Connois-toi, relativement aux causes de ta destruction Souviens-toi de la mort! «335

Sich zu kennen, bedeute, sich stetig erforschen zu müssen, die aufkeimenden Leidenschaften, die Lüste und Kräfte zu kennen und zu kontrollieren. Aus dieser reflexiven Arbeit am Selbst entstehe erst die Möglichkeit der Verbesserung, der Perfektionierung des seelischen, wie des physischen Zustandes des Einzelnen und von da ausgehend auch der Gesellschaft: »Étudie [...] ce que tu dois être dans une société régénérée « ${ }^{336}$. Denn es gehe bei dieser Gesellschaft einerseits um die Überwindung des Naturzustands und andererseits um die Überwindung eines Zustandes der falschen, schlechten Gesellschaft, »une société barbare ou corrompue « ${ }^{337}$. Gesundheit beruhe darauf, sich selbst und die Gesetzte seiner Existenz zu kennen und stetig zu reflektieren. ${ }^{338}$

Das Wichtige an dieser Fortsetzung der meditativen Praxis der Reflexion über sich selbst ist, dass kein so eklatanter Widerspruch zwischen der Regierung des Körpers und der Seele entsteht. Die französischen Ärzte müssen sich nicht entscheiden, ob sie Philosophen oder Ärzte sind, sie sind beides, oder sie sind eher Priester und Ärzte. Die ganze Idee der Praxis des Selbst bleibt hierdurch aber weiterhin so etwas wie eine private Praxis der Subjekte, die indirekt zur Bedingung der rationellen Regierung der Gesellschaft gesetzt wird. Diese Verbindung von Immoralität der alten Herrschaft und die Aussicht, durch die Revolution in einen Prozess der Wiederherstellung einer mit der Natur übereinstimmenden Ordnung zu treten, findet sich hier übertragen auf das Problem der Regierung von Gesundheit. Die Freiheit des citoyen sich selbst zu führen, ist die Bedingung einer guten Regierung der Gesundheit in der Republik. Dieses konstitutive Verhältnis von Regierung und Regierten als Teil eines Staatsbürgerdiskurses blieb in Frankreich lange Zeit prägend, auch wenn die Kraft dieses revolutionären Diskurses angesichts der realen Anforderungen an die staatliche Regierung zu Beginn des 19. Jahrhunderts rasch zu schwinden schien. ${ }^{339}$

Zwischen 1789 und 1830 gab es in Frankreich mindestens neun verschiedene Verfassungen und weitaus mehr wechselnde Regierungen. Das politische System wechselte zwischen Republik, konstitutioneller Monarchie, Kaiserreich und Monarchie hin und her. Der Regierungsdiskurs in Frankreich blieb auch infolgedessen in einer wiederkehrenden Phase der Neubegründung, die mit einer ganz bestimmten Art von Aussagen über die Regierung verbunden war. Es handelt sich um Aussagen, die die Existenz einer Regierung formal und juridisch bestimmen. Auf dieses Muster von

335 Lanthenas: Religion civile proposée aux républiques pour lien des gouvernements représentatifs, 1795: S. 78.

336 Ebd.: S. 79.

337 Ebd.

338 Vgl. ebd.: S. 207f.

339 Foucault, Michel: Die Geburt der Klinik, 2008 [1963]: S. 51. 
Aussagen bin ich im Rahmen meiner Analyse immer wieder gestoßen, auch in der von mir als revolutionären Diskurs bezeichneten Aussageformation. Der revolutionäre Diskurs, der Diskurs der Regierungsneu(be)gründung hat in Frankreich nach der Französischen Revolution und bis weit ins 19. Jahrhundert hinein eine permanente Wiedergeburt erlebt. Gründungs- und Revolutionsdiskurse hängen Mythen, Utopien, Prophezeiungen und einem gewissen passiven Geschichtsoptimismus an. Der Revolutionsdiskurs verlegt den Beginn einer besseren Gesellschaft und Regierung in die Zukunft. In Frankreich ist man, was die Regierung der Gesundheit betrifft, lange im Bereich dieser Vorstellung geblieben. Die Tatsache, dass dieser Diskurs wie auch andere revolutionäre Diskurse keine Regierungsrationalität für die Praxis und die wirkliche Ausübung der Macht zur Verfügung stellte, ist für die Entwicklung und Krise der Regierung der Gesundheit im postrevolutionären Frankreich wichtig. ${ }^{340} \mathrm{Ei}$ ne gouvernementale - also moderne - Regierung, die praktisch nicht erfolgreich ist, wird nicht von Dauer sein können. Im Gegensatz zur Regierung eines Souveräns, der sich dauerhaft auf eine Geschichte oder ein Recht, das daraus erwächst, berufen kann, sind die Existenzbedingungen der gouvernementale Regierung durch und durch ökonomisch. Nur im Moment ihrer Gründung sind sie juridisch oder historisch definiert. Ansonsten wird sie nach ihrer Leistung und einer wirklichen Effektivität in ihrer Praxis beurteilt. ${ }^{341}$

»Die juristische Gesellschaft war die monarchistische. Vom 12. bis ins 18. Jahrhundert hinein waren die europäischen Gesellschaften weitestgehend juristische Gesellschaften, in denen das Problem des Rechts das Grundproblem darstellte. Man kämpfte dafür und man machte Revolutionen deswegen. $\ll^{342}$

Foucault selbst hat das Eintreten in das >Zeitalter der Verhaltensführung< genau an diesem Umstand festgemacht. Er begründete dies damit, dass offensichtlich eine bestimmte Form der Regierung, die sich vorher vom religiösen Pastorat ausgehend auf einen privaten Bereich bezog, übersetzt, ausgeweitet, politisiert und an die Öffentlichkeit gebracht wurde. ${ }^{343}$ Bestimmte Teile dieser pastoralen Regierungspraxis und Führung der Seelen oder bestimmte Bedingungen ihrer Akzeptierbarkeit wurden in Frage gestellt. Doch das, was man ihr als die einzig wahre und richtige Regierung der Seelen entgegensetzte, nämlich eine Regierung, die den Menschen in seiner realen und >natürlichen< Existenz berücksichtigen sollte, eine Regierung der Menschen eben, wurde schließlich so weit verallgemeinert, dass selbst der Souverän, dessen Regentschaft nur juristisch begründet und in Frage gestellt worden war, mit diesen neuen Bedingungen konfrontiert wurde. Dies hatte zu Folge, dass auch der Souverän ab dem 16. Jahrhundert zunehmend mit >Leistungsaufgaben < belastet wurde, die in

340 Vgl. Foucault: Geschichte der Gouvernementalität II, 2004 [1978 - 1979]: S. 134f.

341 Vgl. ebd.: S. 226f.

342 Ebd.: S. 240.

343 Vgl. Foucault: Geschichte der Gouvernementalität I, 2004 [1977 - 1978]: S. 335f. Hanna Arendt hat diese Verschiebung übrigens in ihrer »vita activa « aus einer anderen Perspektive und mit einem ganz anderen Forschungsinteresse beschrieben. Ebd.: S. 88f. 
ihrer Grundstruktur der Seelenleitung entlehnt waren. ${ }^{344}$ Dies geschah gerade deshalb, weil im Gegensatz zur pastoralen Führung der Seelen, die sich auf das Heil der Seele nach dem Tod konzentrierte, nun, da man sich für die reale weltliche Existenz der Menschen interessierte, eine direkte Überprüfbarkeit gegeben war. Die Führung der Menschen bezog sich nicht auf ein imaginäres Ziel, das den Erfolg der guten frommen Lebensweise in den Bereich des Ungewissen verschob, sondern die Lebensweise und ihre Richtigkeit wurde selbst an der Praxis ihrer Existenz gemessen. ${ }^{345}$ Der erste unglaubliche Einwand, dem es gelingt, tatsächlich dieses alte und feste Gebäude eines Regierungsdiskurses in Frage zu stellen, steht im Zusammenhang mit der zunehmenden Durchsetzung einer kapitalistischen Produktionsweise und Ansammlung von Kapital. Aber, wie auch Foucault es ausgedrückt hat, es finden diese Veränderungen, die zu neuen Ansprüchen auf politische Herrschaft führen, nicht parallel oder getrennt von diskursiven Krisen und Veränderungen statt. Die Diskurse sind ebenso Austragungsort dieser Konflikte, wie Schlachtfelder, Fabriken und die Straße. Diese diskursiven Schlachtfelder liegen in den Texten schwarz auf weiß vor. ${ }^{346}$ Der wichtigste Punkt, auf den ich hinaus will, ist allerdings, dass sich die nach politischer Macht strebenden Bürger, die sich selbst als peuple bezeichneten, zunächst einmal des juristischen Diskurses bedienten - bedienen mussten, um überhaupt einen $\mathrm{Zu}$ gang zu diesem Regierungsdiskurs zu erhalten. Foucault schrieb:

»Als sich die Bourgeoisie schließlich der monarchistischen Macht entledigte, tat sie das wiederum mit Hilfe dieses juristischen Diskurses, der doch eigentlich der Diskurs der Monarchie war und den sie nun gegen die Monarchie selbst wendete. $\ll^{347}$

In Frankreich blieb man auch nach der Französischen Revolution, was das Regierungsdenken betraf, in vielerlei Hinsicht der juridischen Logik treu. Das Prinzip des Rechts in Frankreich als wieder aufgegriffenes Recht wirkte noch in seiner alten Funktion, den Souverän aufgrund gewisser natürlicher und unveräußerlicher Rechte zu begrenzen. Foucault sprach in Bezug auf Frankreich vom juristisch deduktiven Weg oder auch revolutionären Weg. ${ }^{348}$ Man versuchte in der Nationalversammlung, in der Verfassung und später durch vereinheitlichte umfassende Gesetzesbücher (code civile)

344 Ebd.

345 Vgl. Foucault: Die Maschen der Macht, 2005 [1981]: S. 236.

346 Vgl. ebd.: S. 243. Drei Jahre früher hatte Foucault in einem Gespräch mit Trombadori erläuterte: »Ich mache einen Unterschied zwischen Regierenden und Regierten. Ich bemühe mich zu erklären, warum und wie ein System in welcher Zeit, in welchem Land, zur Erfüllung welcher Bedürfnisse entstanden ist.«Foucault: Gespräch mit Ducio Trombadori, 2005 [1978]: S. 112.

347 Foucault: Die Maschen der Macht, 2005 [1981]: S. 227. Foucault erklärt hier, dass es ihm bei Überwachen und Strafen darum ging, einen bestimmten Typus der Macht - die Disziplin - zu zeigen, der im 18. Jahrhundert in Europa auftauchte und zu erklären, unter welchen Bedingungen und warum er nicht in der bürokratischen Monarchie oder im Feudalsystem auftreten konnte.

348 Vgl. Foucault: Geschichte der Gouvernementalität II, 2004 [1978 - 1979]: S. 65f. 
»festzulegen, was die natürlichen oder ursprünglichen Rechte sind, die jedem einzelnen zukommen, und [...] anschließend [...] [zu bestimmen], unter welchen Bedingungen, aufgrund wovon und nach welchen idealen oder geschichtlichen Gepflogenheiten man eine Begrenzung oder einen Austausch dieses Rechts akzeptiert [...]. Mit anderen Worten, dieser Ansatz besteht einfach darin, von den Menschenrechten auszugehen, um über die Konstitution des Souveräns zur Begrenzung der Gouvernementalität zu gelangen. Ich meine, daß das grob gesagt der revolutionäre Weg ist. Es ist eine bestimmte Art von idealem oder wirklichem Neubeginn der Gesellschaft, des Staates, des Souveräns und der Regierung, das Problem der Legitimität und der Nichtübertragbarkeit der Rechte zu stellen. $\ll^{349}$

Als Beispiel hierfür führte Foucault Rousseaus Staatstheorie an. Er merkte aber auch an, dass die moderne Regierung diesen alten Diskurs der Monarchie, diesen juristischen Diskurs schnell wieder verließ. Laut Foucault war die Schwäche dieser juridischen Konstituierung der modernen Regierung im Rahmen revolutionärer Diskurse im 18. und 19. Jahrhundert ein wichtiger Grund, warum die liberale Gouvernementalität sich im 20. Jahrhundert gewissermaßen als Gegengewicht zu diesem Diskurs etablieren konnte: Macht ist im Zeitalter der Gouvernementalität nicht juristisch bestimmt. Die Gouvernementalität wird sich stattdessen begründen, indem sie sich positiv auf eine Realität und eine materielle Wirklichkeit heterogener Machtkonstellationen und Kräfteverhältnisse bezieht, die sie regieren will. Die Gouvernementalität muss, schrieb Foucault, »mit realen Dingen umgehen, mit dem Körper und dem Leben «, »[s]ie beschränkt sich nicht mehr im Wesentlichen auf den rechtlichen Aspekt $\ll$. 350

Meine These ist, dass es in Frankreich einen Konflikt zwischen verschiedenen Machttechnologien gegeben hat, der u.a. die Regierung der Gesundheit in Frankreich vom Beginn des 19. Jahrhunderts an behindern hat. Genauer gesagt, handelt es sich um den Konflikt zwischen der juristischen Machttechnologie und der positiven und pragmatischen Machttechnologie der Gouvernementalität, den Sicherheitstechniken, die ihr gegenübersteht. Foucault stellte ebenfalls die spezielle Herausbildung einer bestimmten französischen Regierungsmacht am Beispiel der »médecine sociale« als »médecine urbaine ${ }^{351}$ zu Beginn des 19. Jahrhunderts heraus. Diese Entwicklung hatte, laut Foucault, eine sehr praktische und konkrete Folge für die Handlungsfähigkeit der ab 1800 wieder eingerichteten Polizei, etwa in Bezug auf alle Aktivitäten, die den privaten Besitz, »problème de la propriété privée, principe sacré«, und den privaten Bereich an sich tangierten. ${ }^{352}$ Mir scheint, als hätte der Konflikt dieser verschiedenen Regierungstechnologien genau in der Fragestellung der Begrenzung der Regierung des Selbst und der Anderen und dem Versuch, diese mal wissenschaftlich mal juristisch festzulegen, stattgefunden. Die Auseinandersetzungen über den Bereich, in dem eine öffentliche Regierung der Gesundheit eingreifen sollte, fanden in einem noch sehr stark juristisch geprägten Denken eines Gegenübers von Regierten und Regierung statt, bei welchem bestimmte, natürliche Rechte von den Mitgliedern einer

349 Ebd.: S. 66.

350 Ebd.: S. 236.

351 Foucault, Michel: La naissance de la médecine social, 1994 [1974]: S. 215.

352 Ebd.: S. 223. 
Gesellschaft qua Verfassung an den Staat abgegeben wurden. Dies führte anders als in Großbritannien dazu, dass man die heterogene Macht, die innerhalb der Gesellschaft bestand, die Heterogenität der Lebenspraxis der verschiedenen Klassen und Gruppen nicht auf pragmatische Weise zum Thema machte. Etwas vereinfacht könnte man sagen, der Regierungsdiskurs in Frankreich formulierte seinen Gegenstand als Verhältnis des Staates, der Regierung zu den Regierten, den Untertanen, die nun Bürger waren, während die Regierung in Großbritannien in der Lage war, das Klassenverhältnis als ihren Gegenstand, als eines ihrer zentralen Probleme zu erkennen.

In Frankreich hat man im 19. Jahrhundert große stadtplanerische Projekte umgesetzt. In Paris baute man vor allem unter dem Einfluss von Napoleon Bonaparte während der Zeit des Konsulats und unter der Herrschaft Louis Napoleon III und dem Präfekten Hausmann in der Zeit des zweiten Imperiums mit großem Aufwand die Innenstadt um. Dabei spielten auch hygienische Aspekte eine Rolle, aber in erster Linie wollte man Paris als prestigeträchtige Stadt und Zentrum der europäischen Moderne umgestalten. Die arme Bevölkerung und die hygienischen Probleme, die mit ihren Wohn- und Lebensverhältnissen zusammenhingen, wurden lediglich aus der Innenstadt und aus Angst vor Aufständen möglichst weit von den Regierungsgebäuden an den Stadtrand verschoben. Die Gefahr, die man in den unteren Klassen sah, bezog sich hauptsächlich auf die Bedrohung der Regierung des Staates und nicht der öffentlichen Gesundheit oder des Ablaufs kapitalistischer Produktion. ${ }^{353}$ So schrieb auch Foucault:

»Ce qui caractérise la médecine urbain français, c'est le respect de la sphère privée et de la règle de n'avoir pas à considérer le pauvre, la plèbe ou le peuple comme un élément menaçant de la santé publique. $\ll^{354}$

Beide Aspekte, die Foucault beschrieben hat, sehe ich mit der vorwiegend juristischen Problematisierung des Verhältnisses von Regierten und Regierung verbunden. Diese Begrenzung hatte u.a. den Effekt, dass sich die Regierung in Frankreich in der Tradition der Polizei vorwiegend auf die Hygiene der Umwelt und der Städte und Milieus konzentrierte, aber nicht auf die Menschen und den menschlichen Körper. ${ }^{355}$ Der Körper wurde in Frankreich nicht zum direkten Gegenstand der Regierung durch den Staat und die Polizei. Die Polizei, ebenso wie die gesamte médecine publique oder hygiène publique, war damals von dem Widerspruch dieser beiden verschiedenen Machttechnologien durchzogen. Die Folge ist eine Hemmung praktischer Regierungsaktivität einerseits und andererseits die Entfaltung einer enormen Aktivität auf dem Gebiet der Hygiene als Wissenschaft. Innerhalb dieser Wissenschaft bewirkt sie eine Konzentration auf die Bereiche, die weniger das Individuum als eher dessen Umgebung betreffen. Die Konflikte und die Strategien, die sich aus dieser Konstellation ergaben, werde ich im Folgenden an verschiedenen Diskussionen und Konzentrationen, die es in Frankreich im ersten Drittel des 19. Jahrhunderts im Hinblick auf

353 Vgl. Chevalier: Classes laborieuses et classes dangereuses à Paris pendant la première Moitié du XIXe siècle, 2002 [1958]: S. XIXf.

354 Foucault, Michel: La naissance de la médecine social, 1994 [1974]: S. 223.

355 Vgl. ebd.: S. 220. 
die Regierung von Gesundheit gegeben hat, darzustellen versuchen: Erstens, die Trennung und Definition der hygiène publique und der hygiène privée. Zweitens, die Konzentration auf die Beobachtung und Analyse der Umwelt, der Luft, des Wassers und des Milieus - vor allem auf die Stadt bezogen. Drittens, die Diskussion über das Verhältnis und die Zwecke der médecine moderne und der hygiène als Wissenschaft. Dabei wird sich mehr oder weniger an verschiedenen Stellen zeigen, dass es über längere Zeit einen kritischen Diskurs gab, der der Polizei, der hygienischen Wissenschaft und der Medizin ihre praktische Ineffektivität vorwarf. Diese Ineffektivität wird gemessen an den Geburtenzahlen und den Sterblichkeitsziffern, die man immer detaillierter für alle Milieus und Stadtbezirke ermitteln und in immer komplizierterem Zusammenhang zu anderen Daten setzte, die man über diesen Ort angesammelt hatte. Gérard Jorland schrieb 2010 in seinem Buch Une société à soigner:

»En Angleterre et en Allemagne, la baisse de mortalité a pu compenser la baisse de natalité et soutenir la croissance de la population en fin de période. Ce ne fut pas le cas en France où, à postérieures reprise dans la second moité de siècle, la mortalité l'a emporté sur la natalité. La question est donc de savoir pourquoi l'État ne s'est pas impliqué.«356

\section{Die Entstehung der hygiène publique}

Im Februar 1800, dem 28. pluviôse des 8. Revolutionsjahres wurde durch die neue Verfassung Frankreichs, die die alte Verfassung aus dem dritten Revolutionsjahr ablöste, die Organisationen von Polizeipräfekturen in ganz Frankreich beschlossen. Paris wurde in zwölf städtische arrondissements aufgeteilt und ein Préfet de Police ernannt. ${ }^{357}$ Paul Augustin Olivier Mahon, den Nadia Maria Filippini als Begründer der postrevolutionären Gerichtsmedizin in Frankreich bezeichnet hat, war ehemaliges Mitglied der Société royale de médecine und seit 1794 Professor der Gerichtsmedizin an der École de Santé. Er verfasste 1801/02 seine dreibändige Schrift Médecine légale, et police médicale, in welcher er sich im dritten Band ausführlich der Police médicale widmete. Hierbei ließ sich Mahon u.a. von Johann Peter Frank beeinflussen. ${ }^{358}$

»Ce n'a été que vers le commencement de ce siècle, que l'attention générale a paru se fixer d'une manière plus spéciale sur les avantages qui pouvoient résulter d'un système général et régulier de la salubrité, et que se sont formées, dans plusieurs pays, des compagnies auxquelles on a confié le soin de la santé publique.«359

Mahon schrieb weiter über die besondere Aufgabe der medizinischen Polizei, die hier erstmals, auch dem Wortlaut nach, sehr im Sinne Franks als eine Wissenschaft bezeichnet wird. Eine Polizeiwissenschaft, wie sie in Deutschland aus der Abgrenzung

356 Vgl. Jorland: Une société à soigner, 2010: S. 318.

357 Vgl. Raisson, Horace: Histoire de la Police de Paris, 1844: S. 14, 210.

358 Vgl. Filippini: Die »erste Geburt« 2002, S. 115. Vgl. Mahon: Médecine légale, et police médicale, Band 3, 1811: S. 32ff.

359 Mahon: Médecine légale, et police médicale, Band 3, 1811: S. 7f. 
der Sorge des Staates, ausgehend vom Inneren, gegenüber der Staatskunst, die vom Äußeren ausging, konstruiert wurde. Bei Mahon vermischte sich die moralische Idee oder Kritik der Polizei von Frank mit der Tradition der Polizei in Frankreich. Nach dieser ergibt sich die Notwendigkeit einer Polizei aus den besonderen Umständen eines gesellschaftlichen Zusammenlebens von Menschen. Die von Galen abgeleiteten drei Bereiche der Umwelt, aus denen die Ursachen der Krankheiten entstehen können, strukturierten die für die medizinische Polizei zentralen Betätigungsfelder. ${ }^{360} \mathrm{Ihr}$ Ziel war es, die Gesundheit zu erhalten, nicht nur, indem sie selbst eine von der Regierung aufgetrage und durch Gesetze vorgegebene Aufgabe erfüllte. Sondern die Polizei hatte auch als Wissenschaft die Aufgabe, der Regierung aufzuzeigen, durch welche Regelungen sie das Ziel der Erhaltung der Gesundheit der Mitglieder einer Gesellschaft möglichst erreichen kann. Die medizinische Polizei war für Mahon gleichbedeutend mit einer auf die Gesellschaft angewendeten Hygienewissenschaft:

»La Police médicale est une des parties les plus importantes de cette science que l'on a appelée Police, et de laquelle dépendent, dans un corps politique, la sûreté intérieure et le bonheur des membres qui le composent. C'est, en effet, la Police médicale qui indique aux législateurs des moyens, des mesures certaines pour conserver la santé des hommes réunis en société, [...] Sous ce point de vue, la Police médicale, qu'on peut aussi appeler Hygiène ou Médecine publique, seroit l'art de se tenir sur la défensive, c'est-à-dire, celui de se préserver des suites fâcheuses qu'entraîne, par elle même, la cohabitation. «361

Die Vorstellung verschiedener Zustände der Gesellschaft und der Natur, wie sie bei Rousseau am bekanntesten dargelegt wurde, begründete die Aufgabe der Polizei ebenso wie der Medizin:

»Du moment que l'homme eut cessé de vivre isolé et dans l'état de nature, cette science étoit devenue non-seulement d'une très-grande utilité, mais même d'une nécessité indispensable. « ${ }^{362}$

Man hatte es mit einer besonderen Situation zu tun: Im Gesellschaftszustand könne sich das Individuum nicht mehr wie zuvor im Naturzustand auf seine Instinkte und seine eigenen Erfahrungen verlassen.

»Cependant chaque homme, en naissant, a reçu de la nature une sorte d'instinct qui le porte à éviter les choses qui peuvent lui être nuisibles, lorsqu'il les connoît par telles, soit par des épreuves personnelles ou étrangères, soit à l'aide du simple raisonnement: chaque individu semble même être sous la sauve-garde particulière des ministres de santé auxquels il a accordé sa confiance; et on n'est pas tenté de croire d'abord, que ce soit un des devoirs de l'administration générale d'une nation, de prescrire à chaque citoyen ce qu'il sait lui-même être nécessaire par sa propre conservation.«363

360 Vgl. ebd.: S. 12.

361 Ebd.: S. 4.

362 Ebd.: S. 9.

363 Ebd.: S. 10. 
Der Mensch im Gesellschaftszustand habe die Fähigkeit verloren, sich in Gänze um sich zu sorgen, der Instinkt reiche nicht mehr aus, man muss die Vernunft und die Wissenschaft heranziehen, um das Ziel der Erhaltung und des Glücks des Gesellschaftsmenschen zu erreichen. Aber erst der Humanismus habe diese Aufgabe der Regierung zur Ausformulierung gebracht.

»C'est ainsi que l'amour de l'humanité à fait, en quelque sorte, jeter les fondemens d'une nouvelle science, ou du moins cimenter les bases du perfectionnement de l'art de guérir; et les progrès de toutes les autres sciences ont évidemment concouru à hâte ceux de la médecine. Malgré ces efforts, combien peu sommes nous encore avancés dans l'art de conserver la santé par des moyens continués et soutenus, en employant les forces prises dans la nature même de l'homme, autant que le comportent les formes sous lesquelles existe la société humaine! «64

Wo liegt aber die Grenze des Individuums, sich selbst um sich zu sorgen? Wo muss die Regierung allgemeine Maßnahmen ergreifen? Bei den Umwelteinflüssen? Bei den Verführungen der Zivilisation, denen die Menschen nicht widerstehen können und die zu Krankheiten führen? Wo muss die Grenze dieser privaten Praxis der Selbstsorge und der Sorge des Staates und der Polizei gezogen werden?

»Mais s'il existe certaines causes de maladies dont l'influence soit générale, n’y a-t-il pas par conséquent certains moyens de guérison qui ne peuvent être adoptés et mis en usage que d'un accord également général, et avec le secours de loix ou de réglemens auxquels tous sans exception soient obligés de se soumettre. $\ll^{365}$

Man müsse als Regierung den Menschen, den Bürgern des Staates etwas Zusätzliches zur Verfügung stellen, ohne den natürlichen Instinkt und die >natürliche< Fähigkeit, sich um sich zu sorgen, außer Acht zu lassen. Dies war die französische Version der erneuten Aushandlung des Verhältnisses der Regierung des Selbst und der Anderen und die Geburt einer spezifischen gouvernementalen Regierung der Gesundheit in Frankreich. Der Mensch, der in der Gesellschaft lebe, entscheide sich aus Vernunft, sich der Leitung einer Autorität zu überlassen. Denn der Mensch sei nicht nur vernünftig, sondern er habe auch bestimmte Leidenschaften. Die medizinische Polizei solle dem Umfang dieser Aufgaben entsprechend Instrumente haben, um die Ursachen der Krankheiten zu beseitigen, egal, ob diese in den Leidenschaften der Menschen liege oder in der Umwelt, die die Menschen umgibt und gegen die sie nichts ausrichten können. ${ }^{366}$

»L'expérience des sages a cependant prouvé avec quelle facilité on éviteroit le plus grand nombre des maladies, si l'on savoit s'abstenir constamment des choses connues pour être nuisibles. Puisque le pouvoir de la raison est si souvent méprisé, et que la plu part des hommes, à l'appas du plus léger plaisir, courent à leur perte, il est donc évidentment nécessaire que les

364 Ebd.: S. 10.

365 Ebd.: S. 11.

366 Vgl. ebd.: S. 11. 
magistrats leur arrachent, pour ainsi dire, des mains, ces instrumens de corruption, soit physique, soit morale, lesquels deviendroient autant de causes de maladies. «367

Mahon schrieb, dass alles, was in den menschlichen Körper eindringt oder von ihm aufgenommen wird, alles, was er tut und alles, was ihn umgibt, zu diesen Ursachen gehört und daher die Aufmerksamkeit und Kontrolle der Polizei verdient. AnschlieBend wendet sich Mahon ausführlich diesen drei Bereichen zu (gesta, ingesta und irruentes externa injuria $)^{368}$. Dann nennt er den Bereich, wo die die öffentliche Medizin (médecine publique) Einfluss auf das Verhalten nimmt, auf Sitten, welche die Gesundheit gefährden können. Der dritte Bereich, die Umwelt, sei, so Mahon, nur auf den ersten Blick außerhalb der Reichweite der Medizin (»hors du domaine de la Médecine ${ }^{369}$ ). Aber dies sei nicht richtig, denn bei den Einflüssen, die man nicht beeinflussen (steuern) könne, wäre es immer noch möglich, Vorsichtsmaßnahmen zu ergreifen, wenn sie nicht zu ändern seien. ${ }^{370}$

Mahons Buch zeichnet ein so umfassendes Programm der Polizei, wie wir es vom System der medizinischen Polizei bei Frank kennen. Es enthält eine Mischung aus moralischen Ratschlägen zur richtigen Lebensführung, was Ernährung, Kleidung, Sexualität und die Beherrschung der Leidenschaften betrifft; es ist zugleich ein Regierungsprogramm für einen Staat, der für gesunde Nahrung, gesunde Luft und genügend Wohnraum in den Städten sorgen soll. Schließlich ist das Buch auch Grundlage einer polizeilichen und gesetzlichen Unterbindung z.B. der Prostitution und des Alkoholismus. Individuelle und gesellschaftliche Regierung von Gesundheit, Selbst-, Sicherheits- und Disziplinartechniken verbinden sich zu einer umfassenden Idee von einer vollständigen Regierung und Kontrolle der Ursachen für Krankheiten. Einen großen Bereich nimmt die Epidemiologie ein. Zur Bekämpfung der Epidemien müsse sich die Polizei in allen drei genannten Bereiche einmischen. Die Ursachen für die Epidemien und ihre Verbreitung würden sowohl an individuellen wie an allgemeinen Faktoren hängen.

Das Buch von Mahon beschreibt die Polizei in einer neuen Form und mit einem neuen Inhalt. Die Regierungsmacht wurde gewissermaßen neu verteilt und die Frage nach ihrer richtigen Verteilung wurde daraufhin in den kommenden Jahren der Konsulatsregierung und während der Zeit der Restauration immer wieder gestellt. Von der gouvernementalen Vernunft aus sollten die Grenzen und Unterschiede zwischen den Menschen bestimmt werden: Erstens, was ihre Möglichkeiten betrifft, sich selbst $\mathrm{zu}$ regieren, und zweitens, was die Möglichkeiten des Einzelnen betrifft, im Angesicht bestimmter Krankheiten und Gefahren, Einfluss auf seine Gesundheit zu nehmen. Ärzte und Beamte sollen unentwegt nach den grundlegenden, den einfachen Ursachen der Krankheiten forschen. Sie halten damit an der Utopie fest, dass die Medizin ab einem bestimmten Punkt unnötig werden wird. Für die Gesellschaft wäre die Hygiene als Wissenschaft die Grundlage der gesundheitspolitischen Techniken und der Gesetze, die alle >unnötigen « und >unnatürlichen< Krankheiten von vornherein

367 Ebd.: S. 11.

368 Vgl. ebd.: S. 12.

369 Ebd.: S. 12f.

370 Vgl. ebd. 
ausschließt. Allerdings wird die Phase des Forschens und Suchens nach den grundlegenden, den einfachen Ursachen der Krankheiten und Epidemien im gesellschaftlichen Zustand andauern. Siebenunddreißig Jahre nach Mahon schriebt Horace Raisson in seiner Histoire de la Police de Paris über die Entwicklung der Polizei:

»Une ère nouvelle s'était ouverte pour la politique, pour l'art de la guerre, pour les sciences et pour l'industrie. La Police qui, elle aussi, est une science et une art, ne pouvait rester en arrière au milieu de ces perfectionnemens divers. [...] Elle fallait faire plus encore.« ${ }^{371}$

Die Polizei und die Hygiene, die bei Mahon als eigentliches Praxis-Wissen und Technik des Regierens bestimmt wurden, werden kaum diesen Status einnehmen. Stattdessen wird die Hygiene ebenso wie die Polizei in einem Kreislauf wissenschaftlich gestellter Fragen festhängen. Fragen, die den einfachen, kleinen und legitimen Bereich dieser Regierung erhellen sollten, wie: Was sind die natürlichen Gesetze und wo wird gegen sie verstoßen? Welche Krankheiten sind vermeidbar bzw. >unnatürlich $<?^{372}$ Wo liegt der einfache und effektive Ansatzpunkt einer Polizei oder hygienischen Praxis?

Um das Umfeld dieser Fragen entwickelte sich der Problembereich der öffentlichen Hygiene in Abgrenzung zur privaten Hygiene. Dass der Anspruch der genauen Begrenzung der Regierung, der Klärung der Grenzen und der Aufgaben faktisch zu einer Ausdehnung dessen geführt hat, was allgemein als regierbar angesehen wurde, ist dabei typisch in der Geschichte der Herausbildung moderner Regierung.

Jean Noël Hallé gilt als der offizielle Begründer der Idee der wissenschaftlichen Hygiene. Sie bildete im Frankreich des 19. Jahrhunderts das Fundament gesundheitspolitischer Rationalität. Hallé begründete im Traité d'hygiène, das er gemeinsam mit Étienne Tourtelle schrieb und das 1798 in der ersten Auflage erschien, auch die Trennung privater und öffentlicher Hygiene. Die Grundidee der Hygiene schöpfte sich auch für Hallé und Tourtelle in Anknüpfung an die antike Lehre aus dem Verhältnis des Individuums zu seiner Umwelt. Von der Umwelt gehen die Gefahren aus und die Umwelt liefert alles, was der Mensch zu seiner Erhaltung benötigt. Im Traité d'hygiène heißt es:

»L'homme est environné de dangers; sa frêle existence est sans cesse menacée de mille fléaux destructeurs; son organisation est sujette à éprouver à chaque instant des altérations qui l'exposent à une multitude de maux. Ses premières vues dûrent donc se diriger naturellement vers les moyens de s'en préserver et d'y remédier: de là l'origine de la médecine, qui est peutêtre aussi ancienne que le monde. « ${ }^{373}$

Die Hygiene solle mit dieser Normalität umgehen. Sie solle aus der Wirklichkeit des Verhältnisses von Mensch und Umwelt einen Weg finden, Krankheit weitestgehend zu verhindern. Interessant an der weiteren Problematisierung von Hallé und Tourtelle

371 Raisson: Histoire de la Police de Paris, 1844: S. 112.

372 Auch Jorland schrieb: »Le concept de maladies évitable devient cardinal dans la santé publique du XIXe siècle.«Vgl. Jorland: Une société à soigner, 2010: S. 224.

373 Hallé/Tourtelle: Traité d'hygiène, 1855 [1798]: S. iif. 
ist, dass dieses Verhältnis von Mensch und Umwelt historischen Entwicklungen unterworfen ist. Auch hier besteht die Verbindung zu dem historischen Diskurs der Regierung: Das Leben der Menschen und die Menschen selbst verändern sich, wenn sie sich zu Gesellschaften zusammenschließen. Auch wenn im >Naturzustand<von einer bestimmten Normalität der Bedrohungen durch Krankheiten ausgegangen wird, so verändert sich diese Situation im 〉Gesellschaftszustand $<$ Trotz dieser relativ eingeschränkten Perspektive liegt der Art und Weise, wie mit diesem Verhältnis umgegangen wird, eine Rationalität zugrunde, die typisch ist für die moderne gouvernementale Regierung. Die Gouvernementalität bedeutet eine Regierung der Normalität, eine Ökonomie, ein Haushalten mit den verschiedenen Kräften und Faktoren. Sie arbeitet mit Techniken der Berechnung mit dem Ziel der Förderung, des Ausgleichs, der Angleichung, der Abschwächung, der Korrektur und letztlich der Steigerung und Verbesserung dieser Kräfte. Anstatt sich selbst als den Ausgangspunkt der Macht zu begreifen und zu inszenieren, übernimmt sie die Steuerung der Kräfte, deren Materialität und Wirklichkeit sie kennen und anerkennen muss. Der Ausgangspunkt dieser Regierung ergibt sich in Frankreich aus der Behauptung, es habe zu anderen Zeiten in der Geschichte ein besseres, ein optimaleres System der (Selbst-)Regulierung des Verhältnisses der Menschen, ihrer natürlichen Kräfte und ihrer Umwelt gegeben.

»Néanmoins les premiers hommes ne durent pas être sujets à un aussi grand nombre de maladies, et celles-ci durent être aussi bien moins graves que celles qui règnent de nos jours. La nature était alors dans toute sa vigueur, et par conséquent capable d'une plus grande énergie, et d'une plus forte réaction contre les agents morbifiques. Nos pères n'étaient pas soumis à l'influence d'autant de causes délétères qui se sont multipliées d'une manière effrayante avec les révolutions qu'a essuyées le globe et la dépravation qu'ont subie les mœurs. « ${ }^{374}$

Mit Revolutionen meinte Hallé allerdings nicht die sozialen Revolutionen. Eher bezog er sich auf einen generellen Begriff von Fortschritt und gesellschaftlicher sowie technischer und industrieller Umwälzung und Weiterentwicklung. Diese Entwicklung sei ebenfalls im Zusammenhang mit den Umweltbedingungen einer Gesellschaft zu sehen, wie etwa dem Klima. Laut Hallé verändere sich die Umwelt also auch unabhängig von den Menschen und konfrontiere diese mit neuen Lebensbedingungen. Die Menschen würden mit der Entwicklung ihrer Techniken auf diese Veränderungen reagieren. ${ }^{375}$

»À la plus grande inégalité des saisons, produite par ces causes, a bientôt succédé leur irrégularité, et dès lors l'homme est devenu la proie d'une foule de maux inévitables qu'il ne connaissait pas auparavant, et qui ont acquis avec le temps de nouvelles forces. Certains météores, qui ont paru plus fréquemment, ont changé totalement la constitution des années, et les maladies chroniques ont étendu leur empire à mesure que le froid et l'humidité ont augmenté. On peut faire remonter au seizième siècle, par exemple, la constitution pituiteuse qui est le produit de ces causes, et qui domine aujourd'hui dans nos climats: c'est à cette époque qu'on a vu régner

374 Ebd.: S. iif.

375 Vgl. ebd.: S. ivf. 
les maladies propres à cette constitution, et imprimer en quelque sorte son sceau sur celles qui en sont indépendantes, au point de les rendre méconnaissables.«

Dass das Klima sich verändere, bedeute, dass die Natur nicht immer gleich bleibe und dass der Naturzustand, in dem die ersten Menschen lebten, nicht mehr wieder herzustellen sei. Die Natur verändere sich, bzw. habe sich verändert. Aber auch der Mensch verändere seine Lebensweise und dagegen sei nichts einzuwenden. Er müsse sie verändern. Es sei seine Bestimmung, aus dem Naturzustand herauszutreten (Rousseau). Aber die Gesellschaft werde durch diese Entwicklung zu einem eigenen Problem, das die Gesundheit der Menschen mit einer Vielzahl von neuen und noch viel schrecklicheren Krankheiten bedrohe. ${ }^{376}$ Neben dem problematischen Verhältnis zur Natur gibt es also noch ein zweites Spannungsverhältnis, das Hallé benennt, und das es zu regulieren gilt. In welcher Weise verändern die Menschen ihre Lebensweise in der Gesellschaft zum Guten oder zum Schlechten? Welche sind die moralischen Ursachen, die das Leben des Menschen verkürzt haben »causes morales qui ont abrégé la vie de l'homme? « ${ }^{377}$ Welche Veränderungen in ihrer Lebensweise wirken sich auf ihre Existenz positiv und welche negativ aus? Der Kern des zweiten Spannungsverhältnisses besteht darin, dass der Mensch nicht anders als in einer Gesellschaft leben kann und diese Gesellschaft aber ebenso voller Gefahren für seine Gesundheit steckt. ${ }^{378}$ Wie muss also die Gesellschaft gestaltet sein, damit die negativen Folgen für die Gesundheit der Menschen am geringsten sind? Vor allem müsse man die >extremen< und > unnatürlichsten< Auswüchse des gesellschaftlichen Lebens regulieren. Als Beispiel nennt Hallé die Großstädte, in denen die Menschen auf zu engem Raum leben:

»[D]es cités de quatre a cinq cent mille hommes, sont des monstruosités dans l'ordre naturel; l'air en est infecté, les eaux corrompues, et la terre épuisée à de grandes distances. La vie y est nécessairement plus courte, les douceurs de l'abondance moins senties, et les horreurs de la disette extrêmes. Elles sont souvent des foyers de maladies épidémiques et nerveuses. C'est l'asile du crime et de l'immoralité. «379

Diese unnatürlichen Lebensumstände hätten nicht nur Folgen für die körperliche Gesundheit, sondern seien, laut Hallé, auch verantwortlich für den moralischen Zustand einer Gesellschaft. Je mehr sich die Lebensweise einer Gesellschaft gegen die natürliche Ordnung wende, desto schädlicher und gefährlicher würden die Folgen für die Menschen sein. Sie produzierten, um mit Louis Chevaliers Worten zu sprechen, eine »société criminelle ${ }^{380}$. Die Gesetze, die diese negativen Einflüsse nicht auszuschalten vermochten bzw. ihnen vorzubeugen nicht in der Lage waren, seien die Grundla-

376 Vgl. ebd.: S. vi.

377 Eine Frage, die, wie Hallé meinte »est une qui mérite de fixer l'attention du philosophe«. Ebd.: S. vi.

378 Vgl. ebd.: S. vi.

379 Ebd.: S. vi.

380 Vgl. Chevalier: Classes laborieuses et classes dangereuses à Paris pendant la première Moitié du XIXe siècle, 2002 [1958]: S. 118. 
ge für den physischen wie auch moralisch krankhaften Zustand einer Gesellschaft. ${ }^{381}$ »[L]es passions et les vices qui en résultent, les dégradent tant au physique qu'au moral, et préjudicient autant à la santé de chaque individu qu'au bonheur social.« ${ }^{382}$

Die Situation, die Hallé hier zeichnet, enthält eine Reihe von bedeutenden Aussagen, die für die Analyse der Herausbildung einer neuen Rationalität des Regierens von Gesundheit äußerst spannend sind. Zunächst einmal handelt es sich um Aussagen, die den Zustand einer Normalität ausdrücken. Es geht insgesamt nicht darum, ein bestimmtes Problem durch ein bestimmtes Mittel zu beseitigen oder eine bestimmte Handlung zu verbieten. Sondern es geht um zwei Normalitäten: Erstens, um die Normalität des natürlichen Auftretens der Krankheit, und zweitens, um jene der Gesellschaft und des vermehrten Auftretens der Krankheit in der falsch regierten oder unregulierten Gesellschaft. Das Ziel einer Regulierung soll sein, das Risiko der Krankheit in der Gesellschaft so gering wie möglich, also so nah an dem Level der Norm unvermeidlicher natürlicher Gefahren für Krankheit, zu halten. Die Aufgabe, die Normalität zu regulieren, bringt eine ganz bestimmte Rationalität des Regierens ins Spiel. Eine Regierung, die gut regieren soll, müsse laut Hallé nämlich die Normalität, die Wirklichkeit und nicht irgendein Ideal zur Grundlage ihrer Regierung machen. Aber es gebe eine Besonderheit, die man nur mit Rücksicht auf die spezielle Situation in Frankreich besser verstehen könne. Denn es bestehe ein Unterschied zwischen der natürlichen Normalität der Krankheit, mit der ein Individuum unter >natürlichen< Umständen fertig werden könnte, und der Verfassung der Gesellschaft Frankreichs. Dieser Gesellschaftszustand habe zusätzlich eine Reihe von >unnatürlichen< Gründen für Krankheit hervorgebracht. Daraus ergab sich für Hallé eine Unterscheidung, die für die Regierung wichtig ist. Während im >Naturzustand < die private Hygiene, also das individuelle Verhalten und Wissen ausreiche, um sich in einer akzeptablen Normalität gelegentlicher Krankheit mit selten verheerenden Folgen zurechtzufinden, ließe der zweite Zustand erst die Regierung durch eine andere Macht $\mathrm{zu}$, die in gewisser Hinsicht korrigierend wirke. Denn das, was diese Regierung an Problemen zu ihrem Gegenstand machen solle, ist nur das, was bereits durch eine andere Macht, durch eine von Menschen verübte unvernünftige oder unüberlegte Akti-

381 Louis Chevalier hat die pathologisierende Sprache, mit der Autoren des frühen 19. Jahrhunderts sich dem Problem der Kriminalität in Paris v.a. unter den ärmeren und arbeitenden Schichten annäherte, untersucht. Als Ursache für die Kriminalität wurde der Zustand einer ganzen, kranken, jenseits einer natürlichen Norm befindlichen Gesellschaft ausgemacht. Einer Gesellschaft, die eher falsch eingerichtet sei, als falsch regiert würde. Ähnlich wie in der Vorstellung der hygiène privée musste es auch für die Gesellschaft zu bestimmende Prinzipien geben, wie ihr >Krankwerden`verhindert werden könnte. Man suchte in den Gesetzen ein erschöpfendes Instrument der Prävention von Kriminalität. Allerdings nicht in dem Sinne einer Abschreckung durch hohe Strafen, sondern im Sinne einer gerechten Konstitution, die den >Gesellschaftskörper< gesund halten sollte. (Vgl. Chevalier: Classes laborieuses et classes dangereuses à Paris pendant la première Moitié du XIXe siècle, 2002 [1958]: S. XIV.)

382 Hallé/Tourtelle: Traité d'hygiène, 1855 [1798]: S. vi. 
vität gegen die Gesetze der Natur bzw. die einer Gesellschaft, die im Einklang mit denen der Natur stehen soll, verursacht wurde. ${ }^{383}$

Die Hygiene als Wissenschaft beschränkte sich nicht darauf, nur den Bereich zu erforschen, der für eine staatliche Regierung relevant ist. Auch das, was für die Individuen wichtig ist, um sich im Sinne der hygiène privée selbst zu erhalten, ist Gegenstand der Hygiene als Wissenschaft. Dennoch ist der Aufbau und die Unterscheidung der Hygiene Teil, bzw. Abdruck einer Auseinandersetzung um die Frage der Aufteilung der Regierung der Gesundheit zwischen den Individuen und der staatlichen Regierung. Die Empfehlungen, die Hallé im Namen einer hygienischen Wissenschaft in Bezug auf die hygiène privée aussprach, richtete sich nicht an Ärzte, die Verwaltung oder die Regierung, sondern faktisch an die Einzelnen als Regierende ihres Selbst bzw. ihrer Kinder, Familien usw. Diese Unterscheidungen bilden einen Teil der Regeln ab, nach denen das Verhältnis von Selbst-Regierung und Regierung der Anderen hier etabliert wurde. Auch die Medizin war von dem Sog dieser Auseinandersetzung um Macht gezeichnet. Foucault hat die Veränderung des ärztlichen Blicks, des forschenden Blicks der Medizin untersucht, die sich ab dem 19. Jahrhundert darauf konzentrierte, Krankheiten zu bestimmen, zu klassifizieren und die Normalität des >relativ < gesunden Körpers von dem >kranken< zu trennen. Die praktische Frage der Heilung wurde dadurch tatsächlich vernachlässigt. Die Medizin wurde auf den Weg der Erkenntnis und des völlig physiologischen Verständnisses des Körpers geschickt, was schließlich das Ziel ihrer Abschaffung mit einschloss. ${ }^{384}$ Man begann mit der wissenschaftlichen Erschließung eines Bereichs der Normalität und dies hatte gleichzeitig als notwendige Folge, eine Landkarte der Abweichungen und Dichotomien zu entwerfen.

»Die Medizin des 19. Jahrhunderts [orientiert sich] mehr an der Normalität als an der Gesundheit. Sie bildet ihre Begriffe und verordnet ihre Eingriffe unter Bezugnahme auf bestimmte organische Funktionen oder Strukturen. Die physiologische Erkenntnis, die für den Arzt früher nur eine rein theoretisch betriebene Randdisziplin darstellte, rückt nun - Claude Bernard bezeugt es - in das Zentrum der gesamten medizinischen Reflexion. « ${ }^{385}$

Die Medizin wird im Frankreich des 19. Jahrhunderts, laut Foucault, zwei Regelsystemen folgen: Das eine ist auf der konkreten Ebene die genaue Ergründung und nosologische Klassifizierung von Krankheiten. ${ }^{386}$ Das andere ist auf der globalen Ebene das kontinuierliche Entdecken geographischer und klimatischer Gegebenheiten der Medizin. ${ }^{387}$ Die Aufgabe der Hygienewissenschaft sollte, nach Hallé, sein, innerhalb

383 Vgl. ebd.: S. x.

384 Vgl. Double, F.J.: [Révolution et réforme de la médecine] Littératur médicale française: Coup d'oeil sur les révolution de la médecine; par P.J.G. Cabanis, membre de Sénat conservateur, de l'Institut national: in: JGM, 20.1804, S. 184 - 197: S. 192f.

385 Foucault, Michel: Die Geburt der Klinik, 2008 [1963]: S. 51.

386 Vgl. hierzu auch M.: Exposition de la Doctrine Médicale de M. Broussais: in: GS, 22.1821, S. 170 - 172: S. 172. Vgl. auch M.: Doctrine Médicale: in: GS, 15.1826, S. 113 -115 .

387 Foucault, Michel: Die Geburt der Klinik, 2008 [1963]: S. $67 f$. 
dieses Bereichs von Faktoren zu erforschen, was diese »gesunden Gesetze der Natur « (»saintes lois de la nature «) seien, an denen sich eine Regierung oder jegliches menschliches Handeln in Bezug auf Gesundheit orientieren, begrenzen und legitimieren müsse. Die Hygienewissenschaft sollte herausfinden, welcher Bereich von Krankheiten durch den Verstoß gegen diese Gesetze, durch eine falsche menschliche, unnatürliche Macht außerhalb der natürlichen Normalität liege. Aus diesem Wissen sollte sich dann ein Bereich ergeben, auf den sich eine staatliche Regierung der Gesundheit legitim konzentrieren könne oder sogar konzentrieren müsse.

Die Natur erfüllt hier tatsächlich die Rolle einer göttlichen Macht über das Leben, der sich die Macht der Menschen und der Regierung fügen muss. Wir sehen hier auch deutlich, wie die Verteilung der Regierungsmacht weiter nach einer juridischen Logik erfolgte, in welcher die Macht der Einen durch die Rechte der Anderen begrenzt ist. So schrieb auch Rousseau:

»Oh Mensch, zieh dich in dich selbst zurück, und du wirst nicht mehr elend sein. Bleibe an der Stelle, die die Natur dir in der Ordnung der Wesen anweist, und nichts wird dich daraus vertreiben können. [...] Deine Freiheit und deine Macht erstreckt sich nur so weit, wie deine natürlichen Kräfte und nicht darüber hinaus. ${ }^{388}$

Gegen diese Macht oder Ordnung zu handeln sei zwecklos, schädlich und irrational. Der Spielraum der menschlichen Regierung der Gesundheit und des Lebens ergebe sich aus der Situation eines bereits von Menschen begangenen Fehlers, dessen Korrektur wiederum im Interesse der Menschen nur durch Menschen erreicht werden kann.

»Il résulte de ce que je viens d'exposer, que la multitude de ces maux, dont quelques-uns sont inévitables, et d'autres l'ouvrage de l'homme, le rend l'objet d'une science destinée à l'éclairer sur la nature et le choix des moyens propres à conserver sa santé, et à le préserver des maladies: c'est cette science, ou plutôt cette partie de la médecine qui a été appelée par les Grecs Hygiène. $\ll^{389}$

Zur Geschichte der öffentlichen Hygiene betonte Hallé einige Seiten weiter noch einmal, dass es sich bei der Entdeckung der privaten Hygiene und ihrer Unterscheidung von der öffentlichen Hygiene um eine für die Freiheit und Gesundheit essentielle, in der Antike bestehende und lange vernachlässigte Ordnung handele. Innerhalb des Problems der Gesundheit und Gesundhaltung sei die Trennung des Gemeinwesens und der Öffentlichkeit von den privaten Angelegenheiten zu beachten. ${ }^{390} \mathrm{Ob}$ wohl die Argumentation von Hallé, wie auch Sarasin schrieb, im Kern bereits das enthielt, was sich später als liberale Logik und Rationalität des Regierens bezeichnen lässt, finden sich hier noch bestimmte Begrenzungen. ${ }^{391}$ Die Hygienewissenschaft in Frankreich beschränkte sich auf die Untersuchung dieses Verhältnisses der Men-

388 Rousseau: Emil oder über die Erziehung, 1958 [1762]: S. 66.

389 Hallé/Tourtelle: Traité d'hygiène, 1855 [1798]: S. x.

390 Vgl. ebd.: S. 14f.

391 Vgl. Sarasin: Geschichtswissenschaft und Diskursanalyse, 2003: S. 131f. 
schen, des Individuums oder einer ganzen Gesellschaft von Menschen zu ihrer natürlichen und sozialen Umwelt und den Möglichkeiten der Regulierung dieses komplexen Verhältnisses in den beschriebenen Grenzen. Hallé und Tourtelle stimmten mit der Vorstellung von Mahon überein, dass der Eintritt in den Gesellschaftszustand, dem Beginn des menschlichen Zusammenlebens in einer Gesellschaft, die Möglichkeiten des Individuums, aus seinen eigenen Beobachtungen und Erfahrungen seiner Umwelt ausreichend für seine Erhaltung sorgen zu können, beschränkt hatte. Die Wissenschaft sollte schließlich nicht nur den Staat, sondern auch das Individuum befähigen, vernünftig und auf der Grundlage eines rationellen, weil objektiven, an der Natur erforschten Wissens, zu regieren ${ }^{392}$. Das Problem der konkreten Zivilisation, wie sie sich entwickelt habe, sei aber, dass sie gerade die natürliche Fähigkeit der Individuen, für sich zu sorgen, zerstöre.

Hier liegt genau der Rahmen, in welchem die neue hygiène publique entfaltet wurde. Die Regierung darf auf keinen Fall weiter zerstörerisch auf diese Natur des Menschen und seine Fähigkeiten der Selbstregierung einwirken. Denn diese Natur ist die eigentliche Quelle des Glücks, zu deren Verwirklichung auch die Gesellschaft dienen soll. Das Ziel war - nach wie vor - eine politische Utopie Wirklichkeit werden zu lassen. Angestrebt wurde eine Gesellschaft, in der die unnatürlichen Ursachen für Krankheit beseitigt sein würden und das Verhältnis der öffentlichen Hygiene und der privaten Hygiene durch eine Wissenschaft perfekt reguliert und an der Natur ausrichtet wäre. Bemerkenswert ist hieran, dass man das Glück eines Menschen oder einer Gesellschaft nicht in der Abwesenheit von Krankheit suchte, sondern in einem bestimmten Verhältnis, das frei ist von den unnatürlichen Gründen für Krankheit. In einer solchen Gesellschaft würde man die Medizin schließlich nicht mehr brauchen, denn alle Krankheiten, die in dieser Gesellschaft auftauchen könnten, würde man, weil sie natürlich wären, noch nicht einmal mit Hilfe der Medizin zu heilen versuchen. Ich zitiere an dieser Stelle noch einmal Rousseau, der im Émile haargenau die gleiche Position einnahm:

»Man wird einwenden, dass die Tiere naturgemäßer leben und daher weniger Leiden unterworfen sind als wir. Das ist es ja! Gerade diese Lebensweise will ich meinen Schüler lehren, und er soll den gleichen Vorteil daraus ziehen. Der einzige nützliche Zweig der Medizin ist die Gesundheitslehre, und diese ist weniger eine Wissenschaft als eine Tugend. Mäßigkeit und Arbeit sind die beiden wahren Ärzte des Menschen. Die Arbeit fördert seinen Appetit, und die Mäßigkeit hindert ihn daran, ihn zu missbrauchen. $\ll^{393}$

Im Französischen heißt es: »La seule partie utile de la médecine est l'hygiène; encore l'hygiène est-elle moins une science qu'une vertu. « ${ }^{394}$ Die Hygiene ist eine Tugendlehre. Würden sich die Menschen ihrer Natur zuwenden und sich nach dieser richten, so würden sie merken, dass die Medizin nicht benötigt wird, um glücklich zu sein. Oder vielmehr, dass das Verlassen auf die Medizin selbst bereits ein Unglück bewirke bzw. das Merkmal einer unglücklichen Gesellschaft sei. »Lebe natürlich, sei ge-

392 Vgl. Hallé/Tourtelle: Traité d'hygiène, 1855 [1798]: S. 38.

393 Rousseau: Emil oder über die Erziehung, 1958 [1762]: S. 35.

394 Vgl. Rousseau: Émile, 1827 [1762], S. 64. 
duldig und schicke den Arzt von dannen; dann wirst du dem Tode zwar nicht entgehen, aber du fühlst ihn nur einmal. «395

Man kann auch bei Hallé und Tourtelle beobachten, wie die private ethische Praxis, die vor der Französischen Revolution in der bürgerlichen und aufklärerischen Philosophie Frankreichs propagiert wurde und die innerhalb der bürgerlichen Lebensweise praktiziert und moralisch reflektiert wurde, ihren Weg in die Anfänge der politischen und öffentlichen Regierung, der Gouvernementalität der Gesundheit genommen hat.

Wie ich bereits erwähnte, war die Gazette de Santé, was auch ihr Name verriet, bereits vor der Revolution eine Zeitschrift der bürgerlichen medizinischen Reformer. Bevor man versuchte, den Anspruch der Reformbestrebungen in ein politisches Programm und eine institutionelle Struktur zu übersetzen, gab es dort einen Bezug auf Hygiene, der sich weitgehend auf die private Praxis bezog, die zu diesem Zeitpunkt noch keine Unterteilung in hygiène publique und hygiène privée brauchte. Es gab schlicht und ergreifend nur die hygiène privée. Die Hygiene sollte die Kunst sein, die Gesundheit zu erhalten: »l'art de conserver la santé«. In diesem Sinne war die Hygiene etwas Positives, etwas in die Zukunft Gerichtetes und mit der Idee der Verbesserung des Selbst und der Menschen Verbundenes. Die Hygiene als private Praxis war eine Arbeit am Selbst, eine Strategie der Ermächtigung über das Leben und die »Pragmatik des Selbst«, durch die man sich selbst zu einem moralischen Subjekt machte. ${ }^{396}$ Die frühen Artikel in der Gazette de Santé über die Hygiene sind praktisch orientiert. Das heißt, sie sind voller praktischer Anleitungen zur Lebensführung. Im Rahmen dessen wurden auch klimatische Bedingungen und die der Umwelt für die eigene hygienische Praxis thematisiert. ${ }^{397}$ Die Hygiene war hier noch eine moralische Praxis, eine Praxis der Meditation ${ }^{398}$, eine »Tugend «, wie Rousseau meinte, aber keine Wissenschaft. Sie wurde hier allein mit Blick auf ihren privaten Gebrauch betrachtet.

Die spätere hygiène publique, die eine bedeutende Rolle in der Etablierung der Gesundheitspolitik in Frankreich einnahm, hat ihre Herkunft in einem solchen, zunächst noch nicht politischen, aber sich mehr und mehr an die Öffentlichkeit und in die politischen Philosophien (über die bessere Gesellschaft) einschleichenden, bürgerlichen Diskurs. ${ }^{399}$ Dieser Diskurs ist kein wissenschaftlicher, sondern vor allem ein Regierungs-Diskurs, der zunächst vor allem den Zweck erfüllte, eine private mo-

395 Rousseau: Emil oder über die Erziehung, 1958 [1762]: S. 66.

396 Foucault: Die Regierung des Selbst und der anderen II, 2010 [1983 - 1984]: S. 18.

397 Vgl. M.P.: Hygiène: in: GS, 36.1784, S. 141 - 142. Vgl. M.P.: Suite: Hygiène: in: GS, 46.1784, S. 181 - 182. Vgl. [Hrsg.]: Hygiène: in: GS, 5.1785, S. 17 - 19. Vgl. [Hrsg.]: Hygiène: in: GS, 27.1787, S. 105 - 106. Vgl. [Hrsg.]: Hygiène: in: GS, 13.1788, S. 57 62.

398 Vgl. [Hrsg.]: Hygiène: in: GS, 31.1784, S. 221 - 222.

399 In einem dieser Artikel betont der Autor, dass Rousseaus schlechte Meinung von den Ärzten und seine Bedingung, die Ärzte aus der Erziehung raus zu halten, heute, da die Ärzte eine andere Rolle einnähmen, nicht mehr angemessen sei. Vgl. [Hrsg.]: Hygiène Publique. Cours d'éducation physique et morale par M. Amoros (1): in: GS, 34.1821, S. $271-272$ : S. 271. 
ralische Existenz zu begründen. Er schaffte eine zur pastoral geprägten Selbstpraxis alternative diskursive Praxis der Subjektivierung über `die gute Lebensführung «. Man konnte nach ihm ein moralisches Subjekt sein, weil man moralisch lebte.

»C'est à la coutume, dit Montaigne, de donner forme à notre vie, telle qu'il lui plaît. ${ }^{400}$ Dieses wurde an den Anfang eines Textes gestellt, der eine Serie von Artikeln zum Thema Hygiene in der Gazette einleitete. Michel de Montaigne ${ }^{401}$ war ein anderer Philosoph, auf den man verwies, weil er, wie Rousseau, ein erklärter Feind der alten Medizin und der Ärzte (ebenso wie der Priester) war. In diesen Artikeln, die hauptsächlich Beispiele aus der Antike und den >naturnahen< Lebensweisen von nichteuropäischen >Völkern< enthalten, wurde über richtige Diät, Nahrung und Getränke, das im Verhältnis zu Schlaf und Anstrengungen oder bei Krankheit, über Sauberkeit, Bäder, Gymnastik, bestimmte Gefahren und Unfälle und wie man sie vermeiden könne, unterrichtet. ${ }^{402}$ Niemand kann sich so gut um sich selbst kümmern und so gut kennen, wie man selbst, sagte man (»Personne n'est, dit-on, mailleur juge de ce qui convient à sa constitution que soi-même ${ }^{403}$ ), aber in Wirklichkeit, so heißt es in dem Artikel, benötige man die Hygiene und das objektive Wissen über die Natur (der Wissenschaften) und die Philosophie über die richtige Lebensführung, um sich selbst regieren zu können.

»La nature de l'homme ne peut être autrement connue, \& toute autre marche produit des principes peu solides, \& mène souvent à des inductions contradictoires. Je dois, sur le même fondement, prévenir, ce qu'on en pourroit conclure; que l'homme peut impunément se livrer à tous les écarts, \& ne consulte dans sa manière de vivre que ses goûts \& caprices, ou s'abandonner aveuglement aux circonstances qui disposent de sa destinée. $\ll^{404}$

Ebenso könne aber auch der Arzt nichts sinnvolles ohne die Hygiene ausrichten. Aber wenn er die Lehre der Hygiene und das Wissen über die richtige Lebensführung seinen Patienten näher bringen wolle, könne es ihm passieren, dass sich die Person,

400 Montaigne sei, so heißt es hier, der Überzeugung gewesen, dass der menschliche Instinkt die Sitten der gesunden Lebensführung (z.B. im Hinblick auf Ernährung) formen würde. Vgl. M.P.: Suite: Hygiène: in: GS, 46.1784, S. 181 - 182: S. 181.

401 Montaigne hat z.B. in einem seiner Essays De l'institution des enfants Platon zitiert, wie dieser sagte, es gehe bei der Erziehung der Kindern nicht nur darum, ihnen die Fähigkeiten ihrer Väter weiterzugeben, sondern darum, die Fähigkeiten ihrer Seele auszubilden. Montaigne führt darauf hin aus, dass die Philosophie dazu da sei, den Menschen das rechte Leben zu lehren; nicht nur die Kinder, sondern alle Menschen, egal welchen Alters, müssten dieses Lernen fortsetzten: »Puisque la philosophie est celle qui nous instruit à vivre, et que l'enfance y a sa leçon comme les autres âges, pourquoy ne la luy communique on?« Vgl.: Montaigne: De l'institution des enfants: in: Essais de Montaignes, 1834 [1580]: S. 68.

402 Vgl. z.B. [Anonym]: Hygiène: in: GS, 47.1789, S. 185 - 187. Vgl. M.P.: Hygiène: in: GS, 36.1784, S. 141 - 142: S. 141. Vgl. Vgl. M.P.: Suite: Hygiène: in: GS, 46.1784, S. 181 - 182. Vgl. [Hrsg.]: Hygiène: in: GS, 5.1785, S. 17 - 19: S. $17 f$.

403 Ebd.: S. 17.

404 Ebd. 
die er behandelt, abwendet. Weil die Hygiene letztlich die Selbstregierung lehre und nicht wie die Charlatane einfach ein Mittel verabreichen lässt. ${ }^{405}$

Die Hygiene kommt nicht ohne die Selbstpraxis aus. Die gute (asketische) Lebensführung (Bescheidenheit, Maß, Übungen) verlangt Disziplin. Diese Praktiken bezog man aber nicht nur auf die physische Gesundheit, sondern ebenso auf die geistige. Im Edinburgh Medical and Surgical Journal wurde 1807 das ein Jahr zuvor von Pierre-Jean-Georges Cabanis herausgegebene Buch, Coup d'œil sur les révolutions et sur la reforme de la médecine, besprochen und in großen Abschnitten zitiert. In einem dieser Abschnitte wurden Cabanis Äußerungen über die »constant relations between the moral and the physical constitution of the man« wiedergegeben.

»From their [lunatics/criminals] inspection you may learn, that criminal habits, and aberrations of reason, external from the body, in the features, or in the physiognomy. [...] Henceforth no one can, with propriety, undertake to illustrate these subjects, who is not possessed of an exact and circumstantial knowledge of the connection between good or bad physical habits, and good or bad intellectual and moral dispositions. $\ll^{406}$

Diese Beziehungen zwischen moralischer und physiologischer Gesundheit wird besonders in Pierre-Jean-Georges Cabanis Schrift Révolutions et réforme de la médecine deutlich. ${ }^{407}$ In den Artikeln der Gazette zeigt sich, dass eine bestimmte Art von Krankheiten in besonderem Maße von der Beachtung der Hygiene und einer entsprechenden Lebensführung abhängig war: Die kontagiösen Krankheiten. Die Problematisierung der Epidemien haben in einer besonderen Weise zu der Herausbildung der hygiène publique geführt, wie sie schon in der Aufteilung der Polizei von Gemeinwesen und Privatem, dem Gemeinwesen zugeordnet waren. In der Ordnung der Krankheiten, wie sie aus der privaten Hygiene hervorging, gab es zwei Arten von Krankheiten, die ihrer Rationalität und ihrer Praxis gewissermaßen entgingen. Dies waren erstens, die Krankheiten, die laut der Medizin innere Ursachen hatten. Das heißt Krankheiten, die, wie Mahon sie nannte, nicht auf die gesta, ingesta und irruentes externae injuriae zurückzuführen waren. ${ }^{408}$ Dies waren Krankheiten, die nach der alten Aufteilung bei Galen, zu den res naturalis gehörten und nur bedingt durch Aspekte der sog. res non naturalis, Licht und Luft (aer), Speise und Trank (cibus et potus), Arbeit und Ruhe (motus et quies), Schlaf und Wachen (somnus et vigilia), Absonderungen und Ausscheidungen (secreta et excreta) oder Anregung des Gemüts (affectus animi) beeinflusst wären: Also Krankheiten, die eher auf Prozesse im Körper zurückzugeführt wurden.

Zweitens waren es Krankheiten, deren gesellschaftliches Ausmaß und deren Gewalt den Handlungsrahmen privater Hygiene überschritten. Mahon nannte mit Bezug auf Galen den einen Bereich der aer - von der Luft »l'air« - , meinte dann aber im

405 Vgl. ebd.: S. 18.

406 A Sketch of the Revolutions of Medical Science, and Views relative to the Reforms. By P.J.G.: Cabanis, Member of the Natural Institute, \&c. Translated from French by Alexander Henderson, M.D. London, 1806: in: EMSJ, 3.1817: S. $241-244$.

407 Vgl. Cabanis: Révolutions et réforme de la médecine, 1828 [1806]: S. $276 f$.

408 Vgl. Mahon: Médecine légale, et police médicale, Band 3, 1811: S. $12 \mathrm{f}$. 
Folgenden alle Aspekte der Umwelt, die krank machen könnten, aber sich entweder ganz dem Handlungsrahmen der Menschen, in jedem Fall aber der individuellen Hygiene entzögen. Also diese beiden Arten von Krankheiten entgingen der Praxis der privaten Hygiene: Erstens, die Krankheiten, die aus dem ganzen Raster des Verhältnisses von Mensch und Umwelt herausfielen, weil sie auf innere Prozesse des Körpers zurückzuführen seien, und zweitens Krankheiten, die zwar in dieses Raster passten (vielleicht sogar mehr als jede andere), aber die den Handlungsrahmen privater Hygiene überschreiten würden. »Cette alternative prodoit non-seulement des maladies de cause interne, mais encore expose à contracter celles qui sont contagieuses. On en a vu en exemple dans la peste de Marseille. « ${ }^{409}$

Zunächst ging es bei der Auseinandersetzung um Hygiene um generelle Fragen: Wie soll man sein Leben führen, und wie soll man das Leben derer leiten, für die man verantwortlich ist? Wie soll man sich richtig verhalten, was Nahrung, Schlafen, Übungen, Arbeit und Anstrengen betrifft? Auf welche Zeichen des Klimas, des Körpers etc. muss man achten? Schließlich stellte man auch die Frage, die in der antiken Philosophie sehr präsent war: Wie muss jemand, der andere Menschen oder etwa einen Staat regiert, sich selbst führen? Foucault hat sich im zweiten und dritten Band von Sexualität und Wahrheit und in seinen letzten Vorlesungen am Collège de France zur Regierung des Selbst und der anderen mit verschiedenen, in der antiken Literatur sehr präsenten Problemen der Selbstpraxis, der Selbstregierung und der Regierung der Anderen beschäftigt. Ich vermute, dass sein Interesse an diesen Problemen auch darin bestand, herauszufinden, woran man später ab dem 17. Jahrhundert angeknüpft hat, um von dort aus eine ganz anders strukturierte moderne Gouvernementalität, eine neue sehr effektive und wirkungsvolle (positive) Macht über das Leben zu etablieren.

Im Traité d'Hygiène versuchten die beiden Autoren Hallé und Tourtelle erstmals, die Hygiene, wie sie sich als bürgerlicher Diskurs und Lebenskunst im 18. Jahrhundert herausgebildet hatte, als eine Wissenschaft zu definieren. Sie soll gewissermaßen als ein Teil dieser neuen politischen, moralischen, umfassenden Medizin betrachtet werden. Dieser Versuch, die alte Hygiene als eine wissenschaftliche Ausgabe zur Erforschung der Ursachen von Krankheiten, zu definieren und sie mit der Medizin zu vereinen bzw. in ein hierarchisches Verhältnis zu setzten, setzte eine große Diskussion in Gang, die sich weit ins 19. Jahrhunderts hinein fortsetzte. Hierzu werde ich im nächsten Abschnitt noch Genaueres erläutern. Hallé schreibt 1798 in der Einleitung des Traité d'Hygiène:

»L'hygiène est cette partie de la médecine dont la fin est la conservation de la santé. - La médecine peut être complètement divisée en deux grandes parties; l'une a pour objet tout ce qui concerne l'homme sain: c'est l'hygiène, dans le sens le plus étendu de ce mot; l'autre a pour objet tout ce qui concerne l'homme malade: c'est l'iatrique, ou si l'on veut, la thérapeutique, en prenant ce mot, comme celui d'hygiène, dans sa plus vaste acception. ${ }^{410}$

409 [Hrsg.]: Hygiène: in: GS, 5.1785, S. 17 - 19: S. 18.

410 Hallé/Tourtelle: Traité d'hygiène, 1855 [1798]: S. 13. 
Die Hygiene benötige, ebenso wie der andere Teil der Medizin, umfassendes Wissen über die Chemie und Physiologie des menschlichen Körpers, um zu erkennen, wie Einflüsse auf ihn wirken, bzw. gewirkt haben. Oder um zu erkennen, mit welchen Mitteln man den Körper vor den (negativen) Einflüssen schützen kann. ${ }^{411}$

Zusätzlich zu diesem Bereich nennt Hallé aber noch einen sehr umfassenden anderen Bereich, der außerhalb des menschlichen Körpers liegt und alles, was sein Verhältnis zu diesem Außen beinhaltet: »[1a] connaissance des choses non naturelles « ${ }^{412}$ Es kommen also die Mittel hinzu, mit denen man nicht auf den Körper direkt, sondern auf die äußeren Bedingungen einwirken kann, um die Gesundheit zu erhalten. ${ }^{413}$ Die Hygienewissenschaft in Frankreich wird sich auf die Untersuchung dieses Verhältnisses der Menschen, des Individuums oder einer ganzen Gesellschaft von Menschen zu ihrer natürlichen und sozialen Umwelt und den Möglichkeiten der Regulierung dieses komplexen Verhältnisses konzentrieren.

Der Unterschied, den man aber auch hier schon zu der deutschen Variante der Entwicklung von diätetischer Selbstpraxis sehen muss, ist, dass man in dem deutschen Diskurs viel stärker von der Praxis der Selbsterkenntnis ausgeht. In Frankreich ist in dem privaten Hygiene-Diskurs bereits das Verständnis des Menschen eingebaut, der durch schlechte Umstände einer Gesellschaft, durch die falschen Gesetze oder die Abwesenheit einer naturgemäßen gesellschaftlichen Organisation davon abgehalten ist, glücklich, frei und weitestgehend gesund zu sein. ${ }^{414}$ In diese ganzen Vorstellungen bettet sich der Gedanke der Revolution, des Sturzes einer >falschen<

411 Philipp Sarasin meinte, dass diese Verknüpfung der Aufforderung sich selbst zu kennen mit der Analyse des Verhältnisses der Menschen und ihrer Umgebung vor allem vom zweiten Drittel des 19. Jahrhunderts datiert. Ich denke, die Verknüpfung hatte ihren Ursprung bereits früher. Sarasin schrieb: »1837 fragte sich der Hygieniker Joseph Henri Gabriel Réveillé-Parisé: >... was vermag heute die Medizin? Sie ist die Wissenschaft des Menschen (science de l'homme) im weitesten Sinne. Ohne sie ist es auf immer unmöglich, die Lösung des berühmten Problems Erkenne dich selbst zu finden [...]. Tatsächlich, um sich selbst zu kennen, genügt es nicht, sich ins menschliche Herz zu vertiefen< man muss auch den Körper untersuchen.« (Zitiert nach Sarasin: Reizbare Maschinen. Eine Geschichte des Körpers 1765 - 1914, 2001: S. 118.) Im Original heißt es bei RéveilléParisé allerdings nicht »man muss auch den Körper untersuchen«, sondern: »il ne suffit pas d'approfondir le cœur humain, il faut encore apprécier tout ce qui exerce une influence quelconque sur l'homme, et ce point de vue médico-philosophique, constitue le double but que doit atteindre la médecine. Il est des sciences qui se bornent à l'étude de l'univers matériel, d'autres à celle de l'homme moral; plusieurs traitent des rapports des hommes réunis en société, mais il n'appartient qu'à notre art d'embrasser le vaste cercle des connaissances humaines.« Worauf es mir aber hier ankommt, ist zu sagen, dass sein Vorschlag zur »solution du fameux problême connais-toi toi-même« ein von Sokrates bzw. Platon aufgeworfenes Problem der Selbst-Praxis aufgreift, von dem sich Kants Aufforderung der Erkenntnis des Selbst unterscheidet. (Vgl. Réveillé-Parisé: Physiologie et Hygiène des Hommes livrés aux travaux de l'esprit [...], 1834: S. ixf.)

412 [Hrsg.]: [Histoire de l'Hygiène]: in: RP, 16.VII, S. 216 - 225: S. 225.

413 Vgl. Hallé/Tourtelle: Traité d'hygiène, 1855 [1798]: S. 13f.

414 Vgl. Die Regierung des Selbst und der anderen I, 2009: S. 48. 
Ordnung und der Errichtung einer rationellen Ordnung, deren Basis die Natur und die Gesetze der Natur sind, ein. Das, was Foucault u.a. an den Texten von Kant besonders überrascht und fasziniert hat, lag genau in diesem Unterschied. ${ }^{415}$ Kant hat, laut Foucault, auf die Frage, »[o]b das menschliche Geschlecht im beständigen Fortschreiten zum Besseren sei«, nämlich in Bezug auf die Französische Revolution, eine eher ambivalente Antwort gegeben. ${ }^{416}$ Die revolutionäre Umwälzung war für Kant selbst nicht der Akt des Fortschritts der Menschen, sondern sie hatte eher zwei andere Funktionen für den Fortschritt: Erstens zu prüfen, wie weit sich der menschliche Fortschritt, nämlich der Fortschritt, der sich eher auf der Ebene der Erkenntnis der eigenen Vernunft ereignete, schon abgespielt hatte: also erstens, die Revolution als Prüfung. Zweitens hatte das revolutionäre Ereignis und gerade auch sein Scheitern den ebenso operativen Zweck, daran zu erinnern, dass der Fortschritt sich gegenwärtig ereignet. ${ }^{417}$ In Frankreich spielte die Idee der Verbesserung einer Gesellschaft durch einen revolutionären Bruch, durch die radikale Änderung der Gesetze und die Korrektur und Organisation im Gesellschaftszustand gemäß der natürlichen Rechte, die man den Menschen durch eine naturwidrige Regierung weggenommen hatte, in dem bürgerlichen philosophischen Diskurs schon seit dem 17. Jahrhundert eine Rolle. 1789 wurde der Nationalversammlung ein erster Reformplan für die Medizin vorgelegt, der den Titel trug: De l'Exercice de la médecine dans ses rapports avec la salubrité publique. In einem Artikel des Recueil de la Société de Médecine von 1798 wurde dieser Text gemeinsam mit anderen wieder aufgegriffen, um hieraus die Grundlage einer neuen gesundheitspolitischen Gesetzgebung zu verwirklichen: »[P]arce qu'ils présentent ensemble des matériaux nécessaires pour former une science dont l'amélioration physique de l'homme et sa perfection morale sont l'objet, et deviendront le résultat. ${ }^{418}$

Diese ganze Struktur des Problems der richtigen Regierung und der richtigen Gesetze im Gesellschaftszustand durchziehen auch die Debatten um die Regierung der Gesundheit im Frankreich des 19. Jahrhunderts. Wie kann also eine Regierung ihre Aufgabe wahrnehmen, ohne weiter zerstörerisch auf diese Natur des Menschen zu wirken? Das wird genau eine Frage der Hygiene als Wissenschaft sein. Die Hygiene ist, ihren historischen Regeln und Praxen nach, derentwegen sie wieder aufgegriffen wurde, keine Disziplin; sie ist vielmehr eine Regierungskunst. Aber sie wird gerade

415 Foucault betont an verschiedenen Stellen, das Beeindruckende an dem Text von Kant sei, dass er das Sein und die Erkenntnisfähigkeit der Menschen als Problem einer konkreten historischen Situation betrachtet. Was ist das für eine Zeit und wer sind wir, was ist unsere Rolle? Vgl. Foucault: Die Regierung des Selbst und der anderen I, 2009 [1982 - 1883]: S. 50f.; ders.: Zur Genealogie der Ethik, 2005 [1983]: S. 498; ders.: Was ist Aufklärung?, 2005 [1984]: S. 700; 706; ders.: Die politische Technologie der Individuen, 2005 [1982]: S. 999.

416 Foucault, Michel: Die Regierung des Selbst und der anderen I, 2009: 32ff.

417 Vgl. Foucault: Die Regierung des Selbst und der anderen I, 2009 [1982 - 1883]: S. 36ff.

418 [Hrsg.]: Notice et observations médicales sur le recueil des mém. relatifs aux rétablissements d'humanité, trad. de l'anglais et de l'allemand, et publié par ordre du Ministre de l'intérieur; onze numéros de 6 à 8 feuilles: in: RP, 16.VII, S. 53 - 65: S. 65. Vgl. auch [Hrsg.]: [Histoire de l'Hygiéne]: in: RP, 16.VII, S. 216 - 225: S. 225. 
in diesem Moment, Anfang des 19. Jahrhunderts in Frankreich als eine Wissenschaft, als eine Disziplin etabliert. Sie wird als ein Bereich gesehen, der immer schon zur wahren, nämlich politisch und moralisch bedeutsamen Medizin gehört hat. Eine Medizin, die ihrem Mythos nach schon immer und in Wahrheit auf die Gesundheit der Menschen gerichtet war. So, wie man diesen umfassenden ethischen und wissenschaftlichen Rahmen der Medizin unter dem Einfluss des revolutionären Diskurses und des bürgerlichen Hygiene-Diskurses zu jener Zeit festgelegt hatte, behauptete man, dass der Bereich der Hygiene von der alten Medizin vernachlässigt worden war. Das sollte sich nun ändern.

Foucault schreibt in seinem 1977 verfassten Text zur Geburt der »médecine sociale«, dass sich Anfang des 19. Jahrhunderts in Frankreich der Begriff der salubrité gegenüber dem zuvor von der bürgerlich geprägten hygienischen Reformbewegung verwendeten Begriff der santé herausbildet. Das Begriffspaar drückt die Begrenzung aus, die der neuen gesundheitspolitischen Ausrichtung der Polizei und der hygiène publique obliegt. ${ }^{419}$ Sie enthält aber auch wesentliche Merkmale einer gouvernementalen Regierungstechnologie. Die Technik der salubrité publique besteht nicht in erster Linie in einer negativen Praxis, etwa indem sie verbietet und beschränkt, sondern sie hat ein positives Ziel; ihre Techniken müssen sich in einer positiven hervorbringenden Weise auf bestimmte Phänomen richten. Außerdem richtet sich ihre Macht nicht auf die einzelnen Individuen mit dem Ziel einer Verhaltensänderung, sondern auf den von der privaten Hygiene abgespaltenen Bereich der Regierung der Gesundheit, der der Polizei oder dem Staat legitimerweise zufällt: Der Bereich in dem Verhältnis von Menschen und Umwelt, der sich der Macht der Selbstpraxis entzieht. Diese Techniken, die sich totalisierend auf die Zirkulation des Lebens einer ganzen Bevölkerung richten, hat Foucault auch als Sicherheitstechniken bezeichnet. ${ }^{420}$

»Il faut signaler que la salubrité ne signifie pas la même chose que la santé, mais se réfère à l'état du milieu ambiant et à ses éléments constitutifs que permettent précisément d'améliorer la santé. La salubrité est la base matérielle et sociale capable d'assurer la meilleure santé possible aux individus. Lié à cela apparaît le concept d'hygiène publique comme technique de contrôle et de modification des éléments du milieu qui peuvent favoriser cette santé ou, au contraire lui nuire. Salubrité et insalubrité désignent l'art des choses et du milieu en tant qu'ils affectent la santé: l'hygiène publique est le contrôle politico-scientifique de ce milieu. «21

Worin liegt aber der beschränkende Einfluss? Foucault schreibt, dass man sich in Frankreich auf Grund einiger Beschränkungen nicht auf die Individuen konzentrieren konnte und sich daher auf die Umwelt und das Milieu konzentriert hat. ${ }^{422}$ Der Idee nach bezog man sich dabei auf eine Art sozialen und historischen Materialismus. Es wird angenommen, dass die Existenzweise der Menschen einem bestimmten sozialen

419 Vgl. Foucault, Michel: La naissance de la médecine social, 1994 [1974]: S. 223.

420 Vgl. Foucault, Michel: Geschichte der Gouvernementalität II, 2004 [1978 - 1979]: S. 17ff. Vgl. auch ders.: Die »Gouvernementalität«, 2000 [1978]: S. 66.

421 Vgl. Foucault, Michel: La naissance de la médecine social, 1994 [1974]: S. $222 f$.

422 »Ne pas la circulation des individus, mais des choses et des éléments, principalement l'eau, et de l'air.« Ebd.: S. 220. 
Zustand entsprechen muss, also, dass auch eine Änderung der Existenzweise über die bessere Organisation der Gesellschaft erreicht werden kann. Die Regierung war nicht imstande zu begründen, warum sie die Menschen selbst führen, zu einer besseren Existenzweise anleiten kann. Dafür bestand keine Legitimation. In dem entsprechenden Diskurs über die hygiène publique fanden sich die private Praxis der Hygiene und der Bereich staatlicher Eingriffe voneinander getrennt wieder, die man allein in der Hygiene als Wissenschaft unproblematisch vereinen konnte. Das Hauptargument, mit dem man in Frankreich begründet, wo die Grenzen dieser Selbstregierung liegen sollten, wird nämlich nicht so sehr am Subjekt selbst, also an seiner Mündigkeit und auf Basis seiner Vernunft und seine nachweisliche Fähigkeit zur Selbstregierung festgemacht. Stattdessen wird man eher so etwas sagen wie: Der Hauptgrund, warum Menschen krank werden, liegt in ihrer Umwelt und den unendlichen Einflüssen, die dort auf ihn einwirken. Aber ein Subjekt kann selbst unmöglich alles über diese Umwelt wissen, um sich um seine Gesundheit zu sorgen. Es ist wichtig und sehr interessant, dass es tatsächlich die Umwelt war und nicht die Natur. Denn die Natur war gewissermaßen etwas Unschuldiges, während man die Umwelt als einen zum großen Teil unnatürlichen Bereich ansah, z.B. in den Städten. Das Problem waren weniger die inneren Leidenschaften, die zu einem falschen Verhalten führten, durch welche das Individuum seine Gesundheit gefährdete, als die gefährliche Umwelt, die den Einzelnen von allen Seiten mit Krankheiten bedrohte.

\section{, L'environnement‘ und die gesundheitlichen Zustände}

Im Zuge der Adaption der neuen umfassenden Medizin, die die Hygiene samt ihres vom Bürgertum neu besetzten politischen und moralischen Ansatzes einschloss, begannen die von mir analysierte Zeitschriften regelmäßig mit ausführlichen Berichterstattungen über die sog. constitution médicale. Diese Berichte geben detaillierte Auskunft über den Stand und die Entwicklung des für die Gesundheit relevanten Gesamtzustandes einer Gesellschaft. In der Gazette de Santé und auch in dem Journal général de Médecine sind zwischen 1800 und 1829 der >medizinische Zustand< oder die >medizinischen Bedingungen< die dominierenden Themen der Leitartikel. Den Berichten im Journal stellte man stets eine Tabelle zur Seite, die die Bedingungen des Wetters für jeden Tag des vergangenen Monats genau beschreibt. Das Journal général de Médecine setzte damit den Plan der Société de Médecine de Paris fort, den sie bereits im Recueil de la Société de Médecine bekannt gegeben hatte. ${ }^{423}$ In diesen Artikeln geht genau um das durch die Hygiene zu regelnde Verhältnis von Umwelt und Menschen, wie Hallé meinte. Auf der einen Seite enthalten die Artikel ausführliche Beobachtungen über das Wetter und das Klima, den Wechsel von Wärme bzw. Hitze und Kälte, Trockenheit und Luftfeuchtigkeit. Stück für Stück werden erste Messgeräte für Luftdruck, Windgeschwindigkeit, Luftfeuchtigkeit etc. eingeführt. Klassifikationen für die unterschiedlichen Wetterphänomene wie Regen, Hagel, Wind, Sturm, Schnee oder enger definierte Adjektive wie sonnig, bedeckt etc. wer-

423 Vgl. Chamseru, Rousille: Appercu médical du pemier sémestre de l'an XI. Constitution Médicale: in: JGM, 15.1802, S. 203 - 207: S. 203. 
den erklärt und in den Beschreibungen verwendet. ${ }^{424}$ Ergänzt werden die Beschreibungen durch die Berichte über auftretende Krankheiten. Bestimmte Gefahren, die durch den jeweiligen meteorologischen Zustand für den Menschen im Gesellschaftszustand (»le sort de l'homme en société «) bestehen, werden geschildert. ${ }^{425}$ Auf der anderen Seite werden Ratschläge erteilt, die Vorsichtsmaßnahmen gegen die Krankheiten und Einwirkungen des Wetters betreffen. Themen sind Kleidung, Lüftung der Wohnungen, Ernährung etc. ${ }^{426}$ Letzteres wird in den Artikeln und der Rubrik $\mathrm{Hy}$ giène noch ausführlicher abgehandelt. In den Artikeln zur constitution médicale geht es aber auch um die andere Seite des besagten Verhältnisses. So wie das Klima und das Wetter in seiner allgemeinen Lage und Entwicklung beschrieben werden, so werden auch das Verhalten und die Sitten der Menschen unter hygienischen Gesichtspunkten und bestehende Mängel dargestellt. Auch Aufforderungen zur guten Lebensführung finden sich hier. ${ }^{427}$ Das einzige Mittel gegen die Leiden der Krankheit, unter denen die Gesellschaft unnötig leidet, bietet die Hygiene, und es gibt im Zustand der Gesellschaft einen Bereich von Aufgaben der öffentlichen Hygiene, den die Indivi-

424 Es wäre interessant genauer zu erforschen, inwiefern sich die Meteorologie im Zuge dieses Interesses an der Regierung der Gesundheit der Bevölkerung verändert hat.

425 Vgl. Chevalier: Constitution Médicale: in: GS, 9.1807, S. 209 - 212: S. 209.

426 Vgl. Chamseru, Rousille: Constitution médicale du printemps de l'an XI, observée à Paris: in: JGM, 17.1803, S. 163 - 174. Vgl. Double, F.J.: Histoire de la constitution médicale de trois derniers mois de l'an XI, observée à Paris: in: JGM, 18.1803, S. 151 - 163. Vgl. Double, F.J.: Histoire de la constitution médicale des trois premiers mois de l'an XII, observée à Paris: in: JGM, 19.1804, S. 36 - 56. Vgl. Double, F.J.: Histoire de la constitution médicale du dernier trimestre de l'an 13, observée à Paris: in: JGM, 24.1804, S. 158 - 175. Vgl. Double, F.J.: Histoire de la constitution médicale, observée à Paris pendant le primier trimestre et les dix jours de nivôse an 14: in: JGM, 25.1806, S. 175 - 192. Vgl. Moreau, Jacque L.: Essais dur l'histoire médico-topographique de Paris ou Lettres à M. d. Aumon, professeur en médecine de Valence, sur le climat de Paris, sur l'état de la médecine [...]: in: JGM, 23.1805, S. 78 - 81. Vgl. Double, F.J.: Histoire de la constitution médicale du troisième trimestre de l'an 1806, observée à Paris: in: JGM, 27.1806, S. 181 - 198. Vgl. Double, F.J.: Histoire de la constitution médicale du premièr trimestre de l'an 1808, observée à Paris: in: JGM, 32.1808, S. 172 - 191. Vgl. Double, F.J.: Histoire de la constitution médicale du 2e trimestre de l'an 1810, observée à Paris: in: JGM, 38.1810, S. 451 - 474. Beaulac, L.: Histoire de la constitution épidémique observée chez les soldates française dans l'hôpital militaire de Vienne en Autriche, depuis le mois de juin jusqu'au mois de novembre 1809: in: JGM, 40.1811, S. 201 - 209. Vgl. Benoiston de Chateauneuf: Constitution Médicale: in: GS, 5.1807, S. 33 - 38. Vgl. Marie de Saint-Ursin: Constitution Médicale: in: GS, 1.1808, S. 1 - 4. Vgl.: Constitution Médicale: in: GS, 1.1809, S. 1 - 4. Vgl. Marie de Saint-Ursin: Constitution Médicale: in: GS, 7.1809, S. 49 - 50. Vgl. Marie de Saint-Ursin: Constitution Médicale: in: GS, 8.1811, S. 53 - 60. Vgl. Chevalier: Constitution Médicale: in: GS, 2.1817, S. 9 - 10. Vgl. Chevalier: Constitution Médicale: in: GS, 8.1818, S. 81 - 82. Vgl. [Hrsg.]: Constitution Médicale: in: GS, 8.1819, S. 465 - 468. Vgl. Hortet, Marcel: Influance du climat: in: JGM, 27.1806, S. 3 17.

427 Vgl. Chevalier: Constitution Médicale: in: GS, 30.1807, S. 241 - 244: S. 243. 
duen nicht überblicken können. ${ }^{428}$ Außerdem finden sich in den Artikeln und Berichten zur constitution médicale Beobachtungen über die Entwicklung eines Fortschritts oder eines Verfalls der Gesellschaft, teilweise auch begleitet von Vergleichen mit anderen Staaten. ${ }^{429}$ In vielen Artikeln, vor allem in der Gazette de Santé finden sich vereinzelt Vergleiche unterschiedlicher Länder und Gegenden Frankreichs. Man muss berücksichtigen, dass das damals vorhandene statistische Material noch nicht sehr umfangreich und nur sehr lückenhaft war. Man versuchte darüber hinaus, jenseits der Mortalitätsraten auch noch weitere Daten zu sammeln, um diese miteinander korrelieren zu können, etwa um den Zusammenhang zwischen der unterschiedlich hohen Sterblichkeit in den verschiedenen Stadtbezirken von Paris erklären zu können. Das Ziel der hygiène publique ist die Senkung der Sterblichkeit durch allgemeine Maßnahmen, wie die Reinigung der Straßen, die Kanalisation, die Reinigung der Luft etc.

»La différence de la mortalité, relativement à la population, est très-grande entre les divers arrondissements de Paris; ainsi elle est très-considérable, par exemple, entre le deuxième et le huitième, [...] il nous paraît important de rechercher la raison de cette différence, et de voir s'il ne serait pas possible de détruire une partie des causes qui occasionnent une mortalité aussi forte dans quelques arrondissements, et probablement dans tel ou tel quartier de ces mêmes arrondissements. En faisant cette recherche, on pourrait encore parvenir, jusqu'à un certain point, à connaître la classe et peut-être la profession des individus les plus communément frappés de maladies mortelles. Une telle investigations conduirait sans doute l'administration à prendre des mesures d'hygiène publique, qui auraient, sous le rapport de la salubrité, heureuse influence. [...] Plus la ville de Paris s'agrandit et devient industrielle, plus il est important de l'assainir, et de veiller à la santé de ses habitants. Les recherches que nous venons d'indiquer mènent directement à ce but; car ces causes une fois connues, il sera facile, ou de les écarter, et même de les détruire si elles sont susceptibles de l'être, ou de les diminuer par des précautions convenables, si l'on ne peut entièrement se soustraire à leur influence. « ${ }^{430}$

Der Verfall der Sitten in den unterschiedlichen Klassen, bei den Reichen wie den Armen, wird beklagt. Gerade bei den Reichen weiß man ihn zu kritisieren. ${ }^{431}$ Es ist die Übertragung eines bürgerlichen Diskurses um Lebensweisen, der sich zu verallgemeinern versucht, dessen Ansprüche an die Subjekte aber die Heterogenität und materielle Realität der verschiedenen Klassen nur wenig berücksichtigt.

Die Kernaussage der Mehrzahl der Artikel lautet aber meist: Man kann der Natur nicht die Schuld geben, die Natur macht nie etwas Sinnloses. Der Einzige, der Fehler macht und sich nicht richtig verhält, ist der Mensch. Er kann selbst seine Gesetze und sein Verhalten an die Natur anpassen. Im Prinzip ist das genau das, was Hallé sagt: Die Menschen müssen sich selbst gegen die Gefahren, die ihnen aus der Umwelt um

428 Vgl. Marie de Saint-Ursin: Constitution Médicale: in: GS, 24.1810, S. 185 - 187: S. 185.

429 Vgl. Marie de Saint-Ursin: Constitution Médicale: in: GS, 16.1809, S. 121 - 123: S. 121.

430 [Hrsg.]: Hygiène Publique. Rapport générale sur les travaux du Conseil de salubrité pour l'année 1823: in: GS, 34.1824, S. 269 - 270: S. 270.

431 Vgl. Chevalier: Constitution Médicale: in: GS, 30.1807, S. 241 - 244: S. $243 f$. Vgl. Benoiston de Chateauneuf: Constitution Médicale: in: GS, 5.1807, S. 33 - 38: S. 33. 
sie herum drohen, schützen. Es bringt nichts, heißt es in einem weiteren Bericht zur constitution médicale vom 11. Juni 1809, nur die Beobachtungen über das Wetter zu machen, ohne diese mit der Bedeutung der Hygiene zu verbinden. ${ }^{432}$

\section{Der produktive Konflikt zwischen Medizin und Hygiene}

Wie bereits erwähnt, kam es im Zuge der mehr oder weniger politisch motivierten Vereinigung von Medizin und Hygiene zu einer großen Wissenschaft zu gewissen Widersprüchen. Als Merkmal dieses Konflikts wurde sich in den ersten Jahrzehnten des 19. Jahrhunderts immer wieder die Frage gestellt, was zuerst da war, die Hygiene oder die Medizin und wie man sie zueinander ordnen sollte. Zunächst stellt sich unter dem Einfluss der Revolutionsjahre, also in dem Moment, wo die Reform der Medizin unter dem Druck ethischer und politischer Forderungen und des hygienischen Diskurses stattfand, die Frage, ob man die Hygiene nicht zum eigentlichen ursprünglichen Ausgangspunkt der Medizin machen müsste. War also das Problem der Medizin, so verstanden, nicht schon immer ein politisches?

»La médecine est-elle une science solitaire et bornée à l'observation de l'homme malade et des moyens de le soulager? Ou bien cette science qui, en effet, s'occupe principalement de l'art de guérir, ne se dirigeroit-elle point encore vers celui de conserver, d'améliorer l'espèce humaine; et sous ce point de vue, ne trouveroit-elle pas, dans le sujet et les moyens de l'hygiène publique, la preuve qu'elle emprunte, et donne tour-à-tour à la science de l'économie politique, comme à toutes celles dont l'étude et le bonheur de l'homme sont spécialement l'objet? «333

Ist die Hygiene, das Politische der Medizin, wirklich nur ein Bereich der Medizin? Auch dreißig Jahre später ist dieser produktive Prozess der Klärung des Verhältnisses von Medizin und Hygiene noch immer im Gange:

»La hygiène a formé de tout temps partie intégrale de la médecine; mais à quel titre? On a dit que c'était l'art de conserver la santé et de prévenir les maladies. C'est donc une médecine préventive; c'est un art qui, arrivé à la perfection, rendrait inutile la science dont il fait partie. La médecine proprement dite ne serait donc qu'un art provisoire, qui devrait s'effacer et disparaître insensiblement devant les progrès toujours croissans de la science hygiénique; et, à ce compte, on pourrait dire rigoureusement, non que l'hygiène est une partie de la médecine, mais que la médecine est une partie de l'hygiène. «434

Besonders die politische Utopie, mit der die Hygiene verknüpft war, verlieh ihr gröBere Bedeutung als der Medizin. Innerhalb der Geschichte des Fortschritts, auf dem

432 Vgl. Chevalier: Constitution Médicale: in: GS, 17.1809, S. 129 - 132: S. 130.

433 [Hrsg.]: Notice et observations médicales sur le recueil des mém. relatifs aux établissemens d'humanité, trad. de l'anglais et de l'allemand, et publié par ordre du Ministre de l'intérieur; onze numéros de 6 à 8 feuilles in -8 chacun; Paris, chez Agasse, rue des Poitevins, n. 18: in: RP, 16.VII, S. $53-65$ : S. 53.

434 [Hrsg.]: Cours de Hygiène. Faculté de Paris - Faculté de Montpellier: in: GS, 13.1828, S. 97 - 99: S. 97. 
Weg zu einer Gesellschaft, die die Medizin nicht mehr benötigen würde, musste die Hygiene übergeordnet werden. ${ }^{435}$ Die Medizin wurde folglich nur als eine weitere Hilfswissenschaft der Hygiene betrachtet. Gegen diese Auffassung und gegen die Stärkung der Hygiene gegenüber der Medizin gab es eine Vielzahl von Einwänden, die in den Zeitschriften zur Sprache kamen. So wurde etwa kritisiert, dass durch einen so umfassenden Problembereich die Hygiene ihre genaue Bestimmung und die Möglichkeit, sie zu studieren oder zu lernen, gänzlich verloren gehe. ${ }^{436}$

Wieso oder vielmehr inwiefern kam es zu diesen Konflikten? Gerard Jorland stellte 2010 in seiner Untersuchung »Une société à soigner« fest:

»L'hygiène publique n'est pas une discipline. C'est un ensemble connexe de disciplines qui, outre la médecine, comprend la pharmacie, la chimie, la médecine vétérinaire, le génie civil et militaire, l'administration publique, les statistiques et l'économie politique.«437

Ich stimme Jorland in diesem Punkt völlig zu: Die Hygiene, wie sie zu dieser Zeit verstanden wurde, war keine Disziplin. Jorlands kurz darauf angeführten These, dass sie, wie sie sich in Frankreich herausbildete, eine Episteme war, kann ich jedoch nicht beipflichten. Vielmehr war die Hygiene, die sich von einer Selbstpraxis und Lebenskunst aus entwickelt hatte, weiter ein Problembereich oder Aufgabenfeld der Regierung. Die Hygiene diente der Entwicklung von Regierungstechniken und war auf diese Weise Bestandteil der Technologie einer Regierung, die sich auf das Leben richtete. Sie erfüllte die Funktion eines Filters, der jeden erdenklichen Zufall in das Muster und die Problemstellung einer Regierung übersetzte. Sie stellte einen wissens- und handlungsbasierten Zugang zu dem her, was Hauptgegenstand der gouvernementalen Regierung ist: Das Leben der Menschen, des Individuums und der Bevölkerung und die Rationalität der Hygiene entsprach weiterhin der Diätetik. Sie war eine »strategische Kunst, insofern sie erlauben soll, auf die Umstände in einer ständigen, also nützlichen Weise zu antworten. ${ }^{438}$ Die Hygiene ist keine Wissenschaft, im Sinne einer Disziplin, die sich, was ihren Wissensbereich und ihre Methoden angeht, gegenüber anderen verwandten und entfernten Disziplinen abzugrenzen versuchte. Bestenfalls ist die Hygiene eine Lehre. Viel eher aber entspricht das Verhältnis der Hygiene zur Medizin einem Verhältnis von Wissenschaft und moderner Regierung. ${ }^{439}$

Das Bestreben der Disziplin ist es, einen bestimmten Bereich bis ins Detail zu ergründen, den Körper, die Krankheit oder die Psyche bis aufs letzte Molekül zu durchdringen; die Disziplin strebt daher nach einer Tiefe des Wissens. Medizin generiert einen bestimmten, klar abgegrenzten Gegenstand, wie etwa den Körper und die Phänomene, die in einem gesunden oder einem kranken Körper vor sich gehen. Die Bewegung des Wissens der Gouvernementalität entspricht einer permanenten Ausdeh-

435 Vgl. XZ.: Hygiène Publique. Rapport général sur les Travaux du Conseil de salubrité pendent l'année 1827: in: GS, 36.1828, S. 283 - 284: S. 284.

436 Vgl. M. [défendre un système de médecine]: in: GS, 15.1825, S. 113 - 115, S. 113.

437 Jorland: Une société à soigner, 2010: S. 19.

438 Ebd.: S. 137.

439 Vgl. Foucault: Sexualität und Wahrheit II, 1998 [1984]: S. 129. 
nung. Ihr Gegenstand vergrößert sich dauernd und in gleichem Maße benötigt sie Wissen aus allen möglichen Bereichen, die den Gegenstand ihrer Regierung - das Leben - berührt. Und da dieser Gegenstand quasi unendlich ist, ist auch der Wissensdurst der Gouvernementalität unbegrenzt. Es gibt für sie keine Begrenzung des Wissens, nur die Begrenzung der Regierung durch die Begrenztheit ihres Wissens. Sie hat kein Bestreben, das Wissen in einen systematischen, einheitlichen Zusammenhang innerhalb einer jeweiligen Episteme zu setzen. Die Kriterien für Wissen orientieren sich an ihrer $>$ Nützlichkeit $<$ nicht an ihrer $>$ Wahrheit< oder, anders gesagt, ihre Nützlichkeit ist ihre Wahrheit. Es besteht in der Vereinigung von Medizin und Hygiene ein Konflikt zwischen der Tendenz der Disziplin, sich zu begrenzen, und dem Modus der Regierung, sich auszudehnen. Das zeigt sich in dem Konflikt zwischen Hygiene und Medizin, aber auch zwischen der Kunst des Heilens, die auch eine Regierung ist und der Medizin als Disziplin. Gesundheit herzustellen und zu erhalten sind Praxisanleitungen, Verhaltensmodi, Existenzweisen, Lebensweisen von Menschen, praktische Erfahrungen und sich an ihr messende und erneuernde Wissensbereiche. Sie sind miteinander verknüpft und vermitteln moralische, normative und politische Werte. Die Hygiene steht im Gegensatz zur wissenschaftlichen Disziplin, die sich frei machen will, sich unabhängig wähnt oder gerade in ihrer Unabhängigkeit bestehen bleiben muss, um der Regierung und der Praxis als legitimierend und begrenzend zur Seite stehen zu können. Die Verfahren der Regierung haben ein praktisches, politisches, normatives Ziel. Die Hygiene bewertet und richtet ihre Praxis daran aus, inwiefern sie eine Annäherung an dieses Ziel erreicht. Sie ist permanent dabei, sich selbst zu überarbeiten, zu perfektionieren, optimieren, neue Aufgaben, Räume, Territorien zu bevölkern und schließlich immer neues Wissen zu integrieren. Wenn die Hygiene eine Wissenschaft wäre, dann wäre sie eine universelle Wissenschaft, eine Wissenschaft, die keine Grenzen hat:

»Allons plus loin: la vie de l'homme, se trouvant continuellement influencée par tous les agens physiques, sans cesse modifiée par les institutions, appartenant de droit à l'hygiène, voilà les sciences physiques et morales absorbées dans une seule et les connaissance humaines réduites à l'unité. Arrivée à ce terme, l'hygiène n'est plus rien, elle se perd dans la science universelle. $«^{440}$

Wirksamkeit und Macht der modernen Regierung, die sich auf Wissen stützt, hängen jedoch von der formalen und klaren Trennung von dem Wissen und der Wissenschaft mit ihren spezifischen Verfahren der Erkenntnis ab. Insofern lässt sich der Konflikt, zwischen Medizin und Hygiene eher als gegenseitiger Optimierungsmodus verstehen. Die moderne Gouvernementalität bezieht Wissen ein und verfährt mit ihm je nach Nützlichkeit. Die Macht dieser Regierung ist an ihren Bezug auf >objektives< Wissen gebunden und provoziert hierdurch neue Anforderungen an die Wissenschaft, die z.B. auch zu der Entstehung der médecine sociale führen. Bald regt dieses neue Verhältnis der Regierung des Lebens und der Bevölkerung die Etablierung anderer Disziplinen an, die hier noch als Teil der Medizin gelten oder denen man erst durch

440 [Hrsg.]: Cours de Hygiène. Faculté de Paris - Faculté de Montpellier: in: GS, 13.1828, S. 97 - 99: S. 97. 
die Problematisierung der Hygiene Aufmerksamkeit zukommen lässt: die Biologie, die Erziehungswissenschaft, die Soziologie, die Psychologie usw. Foucault hat das Auftauchen einer neuen Disziplinen, die Entstehung der von ihm als sciences humaines bezeichneten Wissenschaften im Laufe seiner Arbeit mehr und mehr in Zusammenhang mit der Neuerfindung des Subjekts, den Selbsttechniken und der Entstehung einer gegenüber der souveränen Macht überlegenen Form der Regierung des Verhaltens von Menschen gesehen. ${ }^{441}$ Die sciences humaines waren nicht nur essentiell für die Bestimmung und Unterscheidung dessen, was der Mensch und das Subjekt sei und was nicht, sie waren unverzichtbar für die Einsetzung von Techniken, um diesen Menschen oder jenes Subjekt zu erschaffen und seinem Wesen entsprechend $\mathrm{zu}>$ befreien $<$, um es anders und besser zu regieren.

»Les sciences humaines aussi sont des savoirs qui permettent de connaître ce que sont les individus, ce qui est normal, ce qui ne l'est pas, qui est responsable et qui ne l'est pas, qui est apte et à faire quoi, quelles sont les comportements prévisibles des individus, quel sont ceux qu'il faut éliminer. L'importance de la statistique vient justement du fait qu'elle permet de mesurer quantitativement les effets de masse des comportements individuels. Il faudrait encore ajouter que les mécanismes d'assistance et d'assurance, outre leurs objectifs de rationalisation économique et de stabilisation politique, ont des effets individualisants; ils font de l'individu, de son existence et de son comportement, de la vie, de l'existence, son seulement des tous mais de chacun un événement qui est pertinent, qui est même nécessaire, indispensable pour l'existence du pouvoir dans les sociétés modernes. $\ll^{442}$

Deshalb muss die Medizin - trotz der neuen Anforderungen - dem Anspruch einer reinen und von allen gesellschaftlichen und subjektiven Einfluss gereinigten, exakten Wissenschaft genügen. Ihre Verbundenheit mit der Gesellschaft, die durch die Brille der Hygieniker betrachtet und zu steuern versucht wird, ist zu offensichtlich. Die Probleme, die sie nun behandeln soll, machen sie mehr und mehr zu einer sozialen Medizin, aber sie darf auf keinen Fall eine politische, interessengeleitete Medizin sein. ${ }^{443}$ Die Medizin kämpfte vor und nach der Französischen Revolution um eine einheitlichere Episteme und eine Anerkennung als >exakte< Wissenschaft. Diesen Anspruch musste die Medizin nun mit den neuen Anforderungen verbinden. ${ }^{444}$ Es ist

441 Foucault betonte die Bedeutung dieses Wissens über den Menschen und v.a. über den menschlichen Körper für die politische Regierung. Ab dem Moment, wo diese zur Regierung kapitalistischer Produktion avancierte, war sie sukzessive mit neuen Anforderungen konfrontiert. Um diesen zu entsprechen, benötigte die Regierung das spezifische Wissen über den Menschen. Vgl. Foucault: La scène de la philosophie, 2001 [1978]: S. 587. Vgl. Foucault: La poussière et le nuage: in: ders.: Dits et Écrits II, 2001 [1980]: S. 837.

442 Foucault: La philosophie analytique de la politique, 2001 [1978]: S. 551.

443 [Hrsg.]: Notice et observations médicales sur le recueil des mém. relatifs aux rétablissements d'humanité, trad. de l'anglais et de l'allemand, et publié par ordre du Ministre de l'intérieur; onze numéros de 6 à 8 feuilles. in: RP, 16.VII, S. 53 - 65: S. $53 \mathrm{ff}$.

444 Vgl. Double, F.J.: [Révolution et réforme de la médecine] Littératur médicale française: Coup d'oeil sur les révolution de la médecine; par P.J.G. Cabanis, membre de Sénat conservateur, de l'Institut national: in: JGM, 24.1804, S. 184 - 197: 189. Vgl. Aisenberg: 
also nicht nur die Hygiene, die sich aus der >Zwangsvereinigung « mit der Medizin zu lösen versucht. Auch die Medizin wird sich in verschiedener Weise gegen die Hygiene und die Anforderungen an die Regierung abgrenzen. Dies betrifft vor allem den Bereich, in welchem es darum geht, die Bedrohung der Individuen in einem Staat oder einer Gesellschaft zu mindern, ihre Gesundheit zu erhalten, etc. Die Medizin begrenzt sich in zweierlei Hinsicht. Erstens, indem sie sich, wenn überhaupt, vor allem auf das Ziel der Heilung und nicht auf das Ziel der Erhaltung der Gesundheit beziehen will, zweitens, indem sie sich nur auf ihre Aufgabe der Begrenzung und Vertiefung des medizinischen Wissens konzentriert und nicht, wie die Hygiene, um die Ausdehnung ihres Wissensbereichs bemüht. Die Medizin behauptet, nichts zu wissen von der Ökonomie und von der Architektur, sie bietet also nur einen Teil der Expertise, die eine gute Regierung von Gesundheit einer Bevölkerung berücksichtigen muss. Der Arzt nimmt, ebenso wie die Medizin, gegenüber der Regierung und gegenüber dem Individuum eine Außenposition ein. Beide bringen ein bestimmtes Wissen ein, dass sich auf einen begrenzten Bereich möglichst erschöpfend und in die Tiefe gehend konzentriert. Die Medizin beruft sich auf die Notwendigkeit der Trennung von Wissen und Macht und positioniert sich explizit außerhalb der Regierung, um ihren eigenen Verfahren und Kriterien von Objektivität und Wahrheit gerecht werden zu können. Damit umgeht sie das ganze Problem der juridischen Aufteilung der Regierungsmacht zwischen Staat und Individuen. Die Medizin gilt für alle und immer. Die Hygiene muss der Aufteilung Folge leisten. Sie muss außerdem auf die permanente Einbeziehung von Wissen und von Wissensbereichen setzen, um ihren Machtbereich und die Aufteilung weiter zu klären und auszudehnen. Über das, was sie regiert, kann sie nicht genug wissen, aber was sie legitimiert, ist nicht das Wissen, sondern seine praktische Anwendung und ihr Erfolg. Allerdings lag wohl der wichtigste Grund, warum man die Hygiene in Frankreich trotzdem vor allem als Wissenschaft entwickelte und wenig Praxis aus ihr folgen ließ, in den Begrenzungen der postrevolutionären Regierung, die ich bereits beschrieben habe. Gérard Jorland, der ebenfalls das Paradox zwischen der Entwicklung der Hygienewissenschaft und der gesundheitspolitischen Praxis in Frankreich ${ }^{445}$ betonte, vermutete als Hauptgrund, übereinstimmend mit Foucault, dass mehrere Maßnahmen, die weniger direkt auf die Gesundheit gerichtet waren, sondern eher dazu dienten, den Lebensstandard der armen arbeitenden Bevölkerung anzuheben, Verbesserung der Behausung etc., in Frankreich durch den Status der proprieté privée ausgebremst wurden. »Elles ont été contrariées en France par la sanctuarisation de la propriété privée jusqu'à l'institution des casiers sanitaires en fin de siècle. $\ll^{446}$ Auch Jorland hat die mangelnde Legitimität der postrevolutionären französischen Regierungen als Grund genannt.

Contagion. Disease, Government, and the »Social Question« in Nineteenth-Century France, 1999: S. 8f.

445 »En France, on écrivait des romans. Et pourtant Chadwick en Angleterre et Virchow en Allemagne se sont inspirés des travaux théorétiques des hygiénistes français.«: Jorland: Une société à soigner, 2010: S. 318. 
»La seconde raison, c'est que l'État français manquerait de légitimité pour s'imposer à la société civile. L'hygiène publique met à nu sa faiblesse au XIXe siècle. Soit il ne parvient pas à faire exécuter ses ordres par ses propres représentants locaux, les préfets, eux-mêmes impuissants à trouver des agents d'exécution dans la société civile comme dans le cas des enquêtes. Soit les conseils généraux font obstruction à l'application de ses lois en refusant d'assumer leur part de la charge financière. Soit, enfin, il n'ose tout simplement pas imposer à la population des mesures qui portent atteinte à la propriété, à la famille ou aux libertés individuelles. «477

Weiter konstatierte Jorland, dass die Legitimität des Staates auch an dem ständigen Wechsel und den unsteten politischen Verhältnissen litt. Keine der zwischen 1789 und 1914 bestehenden Regierungen, schreibt Jorland, dauerte lange genug, um in der Gesellschaft Wurzeln schlagen zu können (»s'enraciner dans la société civile!«). Matthew Ramsay fragt sich ebenfalls, warum ein Land, das als erstes in Europa eine bürgerliche aufklärerische Hygienebewegung hervorbrachte und die Hygiene so umfangreich als Wissenschaft etablierte, solche Schwierigkeiten damit hatte, praktische Hygienemaßnahmen umzusetzen. ${ }^{448}$ Ramsays Hauptthese ist, dass der auch nach der Französischen Revolution beibehaltene zentralistische Aufbau der Regierung in Frankreich das Haupthemmnis für eine effektive Gesundheitspolitik gewesen sei. ${ }^{449}$ Keiner der von Jorland und Ramsey angeführten Gründe steht im direkten Widerspruch zu meiner eigenen These, dass die Passivität der Regierung in einem bestimmten Bereich auch durch einen Konflikt verschiedener Regierungstechniken bedingt war. Die medizinischen Reformen in Frankreich fanden zur Zeit des Übergangs vom 18. zum 19. Jahrhunderts vor dem Hintergrund eines revolutionären Mythos statt. Insbesondere die ständige Neugründung von Regierungen in der ersten Hälfte des 19. Jahrhunderts verlangte die ständige Wiedergeburt von Regierungsdiskursen, die die jeweils neue Regierung historisch, formal und juridisch begründen sollten. Eine praktische Begründung war in diesem Moment noch nicht möglich. Andererseits war gerade der aufstrebende und im Verhältnis zur juridischen Begründung von Regierung weitaus mächtigere Regierungsdiskurs - der sich auf eine heterogene Existenz von Macht und die realen Bedingungen des Lebens konzentrierte und der seine Legitimation durch den praktischen Erfolg zog, auf eine gewisse dauerhafte Praxis angewiesen. Die juridische Identität und Logik der Regierung stellte eine reale Begrenzung ihrer Macht gegenüber den Rechten der Individuen her. Es war ihr nicht möglich, ohne ihre eigene Rationalität zu verletzen, diese Rechte zu überschreiten. Die Einheit der individualisierenden und totalisierenden Maßnahmen, die man in Frankreich auf die hygiène privée und hygiène publique verteilte, war außerhalb der Hygiene als Theorie und Wissenschaft also praktisch nicht möglich.

447 Ebd.: S. 322.

448 Vgl. Ramsey: Public Health in France, 1994: S. 45.

449 Vgl. Porter, D.: Introduction: in: The History of Public Health and the Modern State, 1994: S. 7. 


\section{GrossbritANNIEN}

\section{Die Macht der Ärzte und die medizinische Reform}

In England, Irland und Schottland war die Inanspruchnahme professioneller oder unprofessioneller medizinischer Dienste und Hilfen eine Privatsache. ${ }^{450}$ Als ausgebildete Ärzte, sog. learned physicians, wurden in der Regel nur die anerkannt, die Absolventen des Londoner Royal College of Physicians waren: »The first medical practitioners recognized by the state, were the physicians. ${ }^{451}$ Das College war eine vergleichbar elitäre Einrichtung, wie die Faculté Royale de la Médecine in Frankreich. Die Inanspruchnahme eines dort ausgebildeten Arztes war nur für eine kleine reiche Oberschicht bezahlbar. Die meisten Menschen nahmen die Dienste von sog. nichtausgebildeten Heilern (healers), Apothekern (apothecaries) und Wundärzten (surgeons) in Anspruch, die im Vergleich zu der Gruppe der chirurgiens in Frankreich, ein - weitaus geringeres - Ansehen genossen, ${ }^{452}$ da sie keine im engeren Sinne universitäre, also philosophische, sondern nur eine praktische Ausbildung besaßen. ${ }^{453}$ Allerdings hatte sich auch in Großbritannien die Nachfrage nach medizinischer Hilfe im 17. und 18. Jahrhundert deutlich gesteigert. Ian Mortimer hat auf der Basis der sehr spärlichen Quellenlage von administrativen Dokumentationen von Sterbefällen in East Kent, West Sussex, Berkshire und Wiltshire gezeigt, dass die Inanspruchnahme ausgebildeter Ärzte im 17. und 18. Jahrhundert für die im Sterben liegenden oder verstorbenen Personen signifikant anstieg. Bei einer deutlich zunehmenden Zahl an Personen, die in den Sterberegistern verzeichnet wurden, war der Tod durch einen Arzt und nicht mehr durch einen Priester festgestellt worden. Diese Veränderung beschränkte sich nicht auf die Oberschichten, sondern wurde - abgesehen von einem relativ kleinen, sehr armen Teil der Bevölkerung - auch von den unteren Schichten verstärkt in Anspruch genommen. ${ }^{454}$ Neben verschiedenen logistischen und praktischen Veränderungen, die es Ärzten ermöglichten, mehr Patienten auch in ländlicheren Gebieten zu besuchen, nennt Mortimer als wesentlichen Grund für die Zunahmen der Inanspruchnahme professioneller medizinischer Hilfe in England eine Änderung der geistigen Haltung. Statt allein, wie häufig zuvor, auf priesterliche Seelsorge und

450 Vgl. Porter, R.: The patient in England, c. 1660 - c. 1800: S. 95.

451 [Anonym]: To the Editors of the Medical and Physical Journal. Memoir on Medical Reform: in: MPJ, 30. 1813, S. 265 - 296: S. 269 f.

452 Vgl. Ramsey: Professional and popular medicine in France, 1770 - 1840, 1988: S. $20 \mathrm{f}$

453 Dies ist die allgemeine Beschreibung der Situation der medizinischen Versorgung in Großbritannien im 17. und 18. Jahrhundert, gegen Ende des 18. Jahrhunderts, wie sie z.B. auch in den kritischen Beschreibungen zur Lage der Medizin in Großbritannien in französischen und deutschen Zeitschriftenartikeln und Büchern Ende des 18. und Anfang des 19. Jahrhunderts dargestellt wurde. Vgl. Vaidy, J.V.F.: Etat de la médecine en Angleterre: in: JGM, 53.1815, S. 112 - 118: S. 112f. Vgl. Hecker: Allgemeine Geschichte der Arzneikunde, 1793: S. 293; 295.

454 Vgl. Mortimer: The dying and the doctors, 2009: S. 204f. 
palliative Medizin zu setzen, versuchten Angehörige der Sterbenden diese durch die Hilfe eines ausgebildeten Arztes vor dem Tod zu retten. ${ }^{455}$

»Fundamental attitudes towards death and healing, as well as towards medicine, must be considered and, in particular, the perceived power of God to punish sinners with illness and, conversely, to save the penitent from death. [...] The findings of this study show that the rise of medical strategies coincided with the decline in exclusive reliance on spiritual strategies. « ${ }^{456}$

Mortimer konstatiert, dass um 1600 noch die Mehrheit der Sterbenden kurz vor ihrem Tod ausschließlich spirituellen und geistlichen Beistand erhielten, während um 1700 die allergrößte Mehrheit medizinische Hilfe erhielt. Allerdings muss man hier vorsichtig sein, wenn man diese Zahlen als ausschlaggebend für die gesamte medizinische Praxis nimmt und so wie Mortimer davon ausgeht, dass ausgebildete Ärzte in allen Fällen, wo medizinische Hilfe vonnöten war, in Anspruch genommen wurden. Um die spätere Debatte zur medical reform zu verstehen, ist es wichtig zu wissen, dass es eine sehr weite und sich im 17. und 18. Jahrhundert noch mehr ausweitende Praxis der »self-medication« und des »self-treatment « gegeben hat. ${ }^{457} \mathrm{Im} 17$. und 18. Jahrhundert bildete sich v.a. in England und Schottland eine private oder besser gesagt familiäre, kommunitären Praxis der gegenseitigen und auf sich selbst bezogenen medizinischen Praxis heraus. Diese wurde von medizinischem Wissen infiltriert und rationalisiert.

Bevor ich weiter auf die Debatte um die Situation der medizinischen Versorgung Ende des 18. und Anfang des 19. Jahrhunderts eingehe, die sich in den von mir analysierten Quellen darstellt, will ich daher noch einen weiteren Exkurs ins 17. Jahrhundert machen. Es soll anhand einer ganz anderen Art von Zeugnis gesehen werden, inwiefern die Auseinandersetzung zwischen religiösen und medizinischen Strategien gegen tödliche Krankheiten als Teil eines moralischen bürgerlichen Diskurses gesehen werden kann, an dessen Verbreitung und Durchsetzung auch Ärzte beteiligt waren. Man könnte auch sagen, dass es um die Befreiung eines bestimmten Bereichs ging, der dem Zugriff einer menschlichen Regierung entzogen war: das Leben und die Lebenskraft des menschlichen Körpers.

Von der Medizin ausgehend, begann man nach dem Ursprung der Lebenskraft im Innern des menschlichen Körpers selbst zu suchen: im Blut, im Herz, im Gehirn oder einem bestimmten Bereich des Gehirns, wo man die Seele vermutete. Thomas Browne, ein Londoner Arzt, begann damit, ein von ihm verfasstes Manuskript, ohne die Absicht dieses offiziell drucken zu lassen, an befreundete Kollegen zu verteilen und es kursieren zu lassen. Das Manuskript mit dem Titel Religio medici wurde aber bald nach der inoffiziellen Weitergabe 1642 unautorisiert veröffentlicht. 1643 erschien dann die autorisierte und abgemilderte Fassung. Brownes Schrift berührt aber kaum medizinische Themen. Stattdessen handelt es von der Legitimität der Anwendung der Vernunft und des Wissens über die Natur bei der Ausübung der ärztlichen Praxis. Unschwer ist die protestantische Forderung zu erkennen, dass alle Vorstellungen da-

455 Ebd.: S. 205.

456 Vgl. ebd.: S. 207.

457 Vgl. Porter, R.: The patient in England, c. 1660 - c. 1800: S. 98. 
von, dass das göttliche Wirken in der Welt in einem direkten Zusammenhang zu dem Verhalten der Menschen stehe - sie bestrafe oder zur Besserung anweise -, aufgegeben werden müsse. Gott walte nach seinem direkten Willen und seiner Planung, die Menschen könnten lediglich versuchen herauszufinden, welchen Zweck Gott allen Dingen und ihnen selbst gegeben habe.

»We do too narrowly define the power of God, restraining it to our capacities. I hold that God can do all things: how he should work contradictions, I do not understand, yet dare not, therefore, deny. I cannot see why the angel of God should question Esdras to recall the time past, if it were beyond his own power; or that God should pose mortality in that which he was not able to perform himself. I will not say that God cannot, but he will not, perform many things, which we plainly affirm he cannot. This, I am sure, is the mannerliest proposition; wherein, notwithstanding, I hold no paradox: for, strictly, his power is the same with his will; and they both, with all the rest, do make but one God.«458

Brownes Text ist ein persönliches Zeugnis, dessen Veröffentlichung vielleicht nie geplant war. Vermutlich war das Buch Teil einer privaten Korrespondenz oder Diskussion mit Freunden. Doch Brownes Text enthält genau wie die Publikation von Gruner, die ich weiter oben analysiert habe, zwei sehr wichtige Aussagen. Die erste Aussage hat das Ziel zu belegen, dass das, was ein vernünftiger Mensch, ein rationeller Arzt aus der Beobachtung der Natur ableitet, nichts sein kann, was die Macht Gottes, der ja die Natur erschaffen hat, in Frage stellt. Aber noch viel wichtiger ist die Aussage, dass eine Macht, die sich aus diesem Wissen über die Natur ableitet, nichts Willkürliches oder Betrügerisches beinhalten kann. Sie sei quasi willenlos. Sie sei direkter Ausdruck des göttlichen Willens und des Zweckes, den er den Dingen gegeben habe. Unterschiedliche britische Ärzte und Philosophen des 17. und 18. Jahrhunderts, wie u.a. Robert Burton, versuchten durch das Wiederaufgreifen alter Lehren, u.a. von Hippokrates und Galen, vorbei an den religiösen Beschränkungen menschlicher Erkenntnis und menschlichen Handelns, den Bereich auszumachen, in dem zunächst jeder Arzt oder jeder Einzelne Einfluss auf das Leben und die Gesundheit hatte. Vielmehr noch, sie definierten einen Bereich, wo ein falsches Verhalten oder eine Passivität, im Sinne der Unbeherrschtheit, moralisch als Fehlverhalten zu betrachten war. ${ }^{459}$ Dieser Schritt stand in England und Schottland, mehr als anderswo, in Verbindung mit der Entwicklung verschiedener puritanischer, methodistischer, protestantischer Bewegung bzw. mit einem vom Protestantismus stark durchzogenen bürgerlich-philosophischen Diskurs um die richtige - rationale - Lebensführung. Mit diesem ethischen Materialismus und Utilitarismus verband sich die Aufforderung, sein Leben und die Begabungen, die »Gifts of God «, wie Burton schrieb, ${ }^{460}$ zu nutzen. Die Aufforderung lautete: >Mach etwas aus deinem Leben und führe eine nützliches! ${ }^{461}$

458 Browne: Religio Medici, 1682 [1643]: §26.

459 Vgl. Pender: Subventing Disease, 2010, S. 193 - 218: S. 193ff.

460 Robert Burton. Zitiert nach: Pender: Subventing Disease, 2010: S. 193.

461 Vgl. Weber: Die protestantische Ethik und der Geist des Kapitalismus, 1995 [1904]: S. 80; $97 \mathrm{ff}$. 
Es erscheint, wie auch Max Weber in seiner protestantischen Ethik feststellte, durchaus paradox, dass das von Luther und später vom Calvinismus gepredigte Gebot, sein Leben nicht dem Ziel seines eigenen Seelenheils zu widmen, das alle hierfür vorgesehenen Rituale der Barmherzigkeit, der Buße und Askese aufhebt, und stattdessen alles weltliche Leben der Verherrlichung Gottes zu widmen, eine enorme Isolation des Individuums zur Folge hatte und zu der Gestaltung einer neuen überlegenen Sittlichkeit und sozialen Ordnung beitrug. ${ }^{462}$ Eine soziale Ordnung, die in ihrem Zentrum die Arbeit von ihrem >schmutzigen< Image befreite und zur sittlichsten Praxis schlechthin machte. ${ }^{463}$

Ein gutes Leben zu führen, hieß, ein nützliches zu führen. Dieser Aufforderung nachkommend entschloss sich der schottische Arzt James Mackenzie Mitte des 18. Jahrhunderts, nachdem er seine Praxis aufgrund seines fortgeschrittenen Alters aufgab, zur Veröffentlichung eines Buch mit dem Titel The history of health and the art of preserving it: Auch im Ruhestand dürfe er als erfahrener Arzt keineswegs untätig und nutzlos werden. ${ }^{464}$ Mackenzie beschrieb in seinem Buch die Regeln eines nützlichen Lebens, die er von Galens »Six Non-Naturals« herleitete, nach denen jeder Einzelne seine Gesundheit erhalten und sein Leben verlängern könne. In der Weise, wie Mackenzie Leben als Lebenszeit und somit Arbeitszeit definierte, zeigt sich die veränderte Problematisierung des Lebens und auch der Gesundheit. ${ }^{465}$ Arbeit galt auch für Mackenzie als die Aktivität, die die göttlichen Zwecke menschlichen Lebens am ehesten hervortreten lasse. An dieser Stelle verknüpft sich die puritanisch-asketische Anweisung zur Lebensführung mit dem von Hippokrates und Galen entliehenen Imperativ der hygienischen Führung, Verbesserung und Verlängerung des Lebens. Lebenszeit ist Arbeitszeit, Lebenszweck ist die Arbeit und somit ist auch die Gesundheit und ihrer Erhaltung diesem Zweck zugeordnet. Weber schrieb hierzu:

»Nicht Muße und Genuß, sondern nur Handeln dient nach dem unzweideutigen geoffenbarten Willen Gottes zur Mehrung seines Ruhms. Zeitvergeudung ist also die erste und prinzipielle schwerste aller Sünden. Die Zeitspanne des Lebens ist unendlich kurz und kostbar, um die eigene Berufung >festzumachen $<$. Zeitverlust durch Geselligkeit, >faules Gerede $<$, Luxus, selbst durch mehr als der Gesundheit zuträglicher Schlaf - 6 bis höchstens 8 Stunden - ist sittlich absolut verwerflich. [...] [Zeit] ist unendlich wertvoll, weil jede verlorene Stunde Arbeit [...] [dem] Dienst des Ruhmes Gottes entzogen ist. [Hervorhebungen Weber] «466

Wovon grenzt sich diese Ethik ab? Erstens, von einer römisch-katholischen Ethik, einer von der römische Kirche ausgehenden bestimmten Praxis der Barmherzigkeit, zweitens, von allen anderen spirituellen und religiösen Praxen, die auf die Heilung

462 Vgl. ebd.: S. 90f.

463 Vgl. ebd.: S. 91.

464 Vgl. Mackenzie: The history of health and the art of preserving it, 1979 [1760]: S. 1.

465 Vgl. ebd.: S. 2f, 4f.

466 Weber: Die protestantische Ethik und der Geist des Kapitalismus, 1995 [1904]: S. 137. 
der Seele hinauslaufen. ${ }^{467}$ Letzteres richtet sich einerseits direkt gegen die priesterliche Heilpraxis und die entsprechenden priesterlichen Aufgaben am Sterbebett etc., die auf das Heil der Seele gerichtet sind, und andererseits gegen alle möglichen (Heil-)Praxen, die in irgendeiner Form auf der Anrufung spiritueller und magischer Kräfte beruhen (die Methoden der sog quacks, wise womens witch craft etc. ebenso) - sie gelten unter Calvinisten sämtlich als Aberglaube ${ }^{468}$. Mit anderen Worten: Mit der puritanisch-protestantischen Ethik lässt sich nicht nur ein neuer Raum der Gestaltung und der Verhaltensweisen für die Regierung öffnen, sondern er schließt zugleich auch vorhandene Praxen, die sich nicht in diesem Sinne rationalisieren lassen und die sich mehr oder weniger auf die Lebensführung oder ethisch auf das Verhalten der Menschen bezogen, zunehmend aus. Diese unterschiedlichen Elemente können als Teile einer gewissen Vorentwicklung gesehen werden - auch dafür, wie sich die Identität und der Berufsethos der Ärzte in England und Schottland Ende des 18. und Anfang des 19. Jahrhunderts herausgebildet hat. Als Arzt reich zu werden oder mit seinem Beruf nach Reichtum und Erfolg zu streben, war, anders als in Deutschland und Frankreich, nichts moralisch Anrüchiges. Francis Bacon lieferte im Vorwort zu seinen Grundlagen des englischen Rechts die passende Beschreibung eines solchen

467 Es ist in dieser Hinsicht interessant, die Arbeit von Carmen Manigon zur Kenntnis zu nehmen, die sich mit katholischer Wohlfahrt und vor allem gesundheitlicher Pflege durch Ordensschwestern im England des 19. Jahrhunderts auseinandergesetzt hat. Ihrer Untersuchung nach könnte man meinen, es habe im Laufe des 18. Jahrhunderts und vor allem im Zuge des protestantisch geprägten Sanitary Movement im Hinblick auf die medizinische Sorge um die Armen und Arbeitenden eine Art Arbeitsteilung zwischen den übriggebliebenen katholischen Einrichtungen und den neuen Krank-, Armen-, und Arbeitshäusern gegeben. Sie schreibt »It is significant that the majority of institutions managed by women religious were specialist institutions which treated the chronically ill, those who needed permanent or long-term care or those who were convalescing.« (Vgl. Manigon: >Give them practical lessons $<$ Catholic women religious and the transmission of nursing knowledge in late nineteenth-century England, 2011: S. 92.) »British hospitals avoided admitting the chronical sick or incurable, leaving the state (through the poor law) to care for these patients. Significantly the medical institutions managed by women religious were viable alternatives to Poor Law hospitals.« (Ebd.: S. 93.) Die konträr zur protestantischen Ethik ausgerichtete katholische Krankenpflege richtete sich auf nicht nur auf den Körper, sondern auch auf die Seele. »What was unique about Catholic nurse training was the temporal needs of the patient were explicitly weaved into the spiritual. [...] The link between nursing the body and the salvation of the soul was imbricated in a religious sister's vocation.«(Ebd.: S. 102f.)

468 »Jener große religionsgeschichtliche Prozeß der Entzauberung der Welt, welcher mit der altjüdischen Propheterie einsetzte und im Verein mit dem hellenischen wissenschaftlichen Denken, alle magischen Mittel der Heilssuche als Aberglaube und Frevel verwarf, fand hier seinen Abschluß. Der echte Puritaner verwarf ja sogar jede Spur von religiösen Zeremonien am Grab und begrub die ihm Nächststehenden sang- und klanglos, um nur ja keinerlei >superstition<, kein Vertrauen auf Heilswirkung magisch-sakramenter Art, aufkommen zu lassen.« Weber: Die protestantische Ethik und der Geist des Kapitalismus, 1995 [1904/04]: S. 88. 
Berufsethos. ${ }^{469}$ Aber auch diverse Selbstbeschreibungen von Ärzten und Redaktionen von medizinisch-philosophischen Zeitschriften Ende des 18. Jahrhunderts machen die Unterschiede zu dem Ideal eines guten selbstlosen Arztes in Deutschland und Frankreich deutlich. ${ }^{470}$

Die beschriebene Vorentwicklung eines puritanisch-protestantischen und zugleich rationalistischen Diskurses bzw. einer entsprechenden Problematisierung der Praxis der moralischen Lebensweise prägte aber nicht nur die medizinische Wissenschaft und die ärztliche Praxis zu dieser Zeit, sondern legte auch den Grundstein für einen sehr spezifischen Zugang der Regierung auf den Körper und zu dem Problem der Gesundheit, was ich in diesem Kapitel noch ausführlicher behandeln werde. Die Darstellung dieser Vorgeschichte soll darauf hinweisen, dass sich die religiösethischen Praxis und der Diskurse um die gute Lebensführung zu Beginn meiner Analyse von Zeitschriftenartikeln Ende des 18. Jahrhunderts bereits einem relativ radikalen Wandel unterzogen hatte. Dies lässt sich u.a. aus den von Mortimer erhobenen Daten und aus dem von ihm konstatierten »change of attitude« ersehen, die ich untersucht habe.

Ende des 18. und Anfang des 19. Jahrhunderts bildeten die learned physicians eine berufliche Gruppe, die dem ersten Anschein nach, was ihren Beruf betrifft, in Konkurrenz zur wachsenden Zahl der surgeons und apothecaries stand. ${ }^{471}$ Dieser Konflikt bestand aber nicht trotz, sondern gerade weil sich auf der Ebene eines eher privat geführten Diskurses ein anderer Anspruch und eine andere Haltung zur eigenen Gesundheit herausgebildet hatte. ${ }^{472}$ Aus diesem Grund bestand die Konkurrenz

469 »I hold every man a debtor to his profession, from the which as men of course do seek to receive countenance and profit, so ought they of duty to endeavour themselves, by way of amends, to be a help and ornament thereunto. This is performed in some degree by the honest and liberal practice of a profession, when men shall carry a respect not to descend into any course that is corrupt and unworthy thereof, and preserve themselves free from the abuses where with the same profession is noted to be infected; but much more is this performed if a man be able to visit and strengthen the roots and foundation of the science itself; thereby not only gracing it in reputation and dignity, but also amplifying it in perfection and substance.«: Vgl. Bacon: Maxims of the Law, 1753 [1597]: S. 3.

470 Vgl. Yelloly, J.: System der Practischen Heilkunde; i.e. System of Practical Medicine, adapted for Lectures and for Practical Use; by Dr. Chr.W. Hufeland, Professor at Jena, (now Physician of the King of Prussia, Berlin). Vol. I. General Therapeutic. 1800, pp. 515, in large 8 Vol. Jena Leipzic: in: MPJ, 6. 1802, S. 170 - 174.

471 Die Zeitschriften Ende des 18. Jahrhunderts und vor allem zwischen etwa 1800 und 1810 sind voller Klagen über die Schwierigkeit, einen ehrlichen medizinischen Beruf auszuüben und davon leben zu können. Auch im Rückblick, nach der Verabschiedung des Apothecaries Act wird dieses Problem benannt.: Vgl. [Anonym]: To the Editors of the Medical and Physical Journal. Memoir on Medical Reform: in: MPJ, 30. 1813, S. 265 - 296: S. $269 f$.

472 Die Zahlen, die Mortimer analysiert, zeigen, dass sich auch das Spektrum der Bevölkerungsgruppen, das grundsätzlich wissenschaftliche professionell Medizin anerkennt, größer geworden ist, sie geben vor allem über diese Veränderung Auskunft. Vgl. Mortimer: The dying and the doctors, 2009: S. 207. 
auch auf der Ebene der Moralität und des damit verbundenen Anspruchs auf Macht. Diese These bestätigen Loudons Untersuchungen zu dem Hintergrund der medical reform. Sie konstatiert: Es kann nicht wirklich ein rein ökonomisches Problem und eine Konkurrenz unter den Heilpraxis ausübenden Personen angenommen werden. Eher war es so, dass die Zahl der in dieser Branche arbeitenden Personen zunahm, während sich ihr Einkommen außerdem noch erhöhte. Ärzte waren reich und auch die sog. surgeons-apothecaries erlebten eher einen sozialen Aufstieg als einen sozialen Abstieg. ${ }^{473}$ Warum sollte der wachsende Reichtum einen Widerspruch zu den Reformbestrebungen darstellen, wenn man nicht einen ökonomischen Hintergrund annimmt?

\section{Diskussionen um eine medizinische Reform}

Das Problem der medizinischen Reform ${ }^{474}$ war Anfang des 19. Jahrhunderts der Gegenstand einer sehr spezifischen Debatte, die sich aus verschiedenen Widersprüchen, Konflikten und neuen Ansprüchen verschiedener Gruppen entwickelte. Als diese Diskussion um die medical reform ausbrach, hatte sie auf den ersten Blick vor allem zum Ziel, die Situation der praktizierenden Ärzte und anderer Mediziner zu verbessern und das Verhältnis der verschiedenen Professionen zu ordnen. Ebenso gut könnte man aber sagen, es sei das Aufbegehren einer bestimmten Gruppe, einer Mittelschicht der medizinisch tätigen Berufsgruppen, die als ein Resultat verschiedener Entwicklungen an Macht gewonnen hatte und nun nach einer institutionellen, diskursiv verankerten Beteiligung an der Regierung der Gesundheit strebte. Ihr Anliegen und die Diskussion, die von hier aus in Gang gesetzt wurde, führte allerdings zu einer weitaus größeren Veränderung. Die neuformulierten Kriterien für Moralität und Rationalität bezogen sich sowohl auf die staatliche Regierung als auch auf die Ärzte, die Mediziner im Allgemeinen und ihr Verhältnis zu den Patienten. Außerdem förderte die Diskussion um die medical reform eine bestimmte Entwicklung der Medizin, das Bedürfnis nach einer großen Menge an neuem Wissen über Menschen, ebenso wie die Veränderung wissenschaftlicher und ärztlicher Praxis.

Innerhalb mehrerer medizinisch-wissenschaftlicher Zeitschriften wurde die Frage einer > verbesserten Ausbildung < aller medizinisch tätigen Personen bereits gegen Ende des 18. Jahrhunderts behandelt, erreichte aber 1806 ihren ersten Höhepunkt. Dies stand im Zusammenhang mit dem ersten deutlicheren Anstoß zu einer Reform und Regulierung der verschiedenen Berufsgruppen durch Edward Harrison. Auf einer Sitzung der Lincolnshire Benevolent Society 1804 stellte er eine grundsätzliche Reform der medizinischen Profession zur Diskussion. Nachdem sein Vorschlag dort und wenige Zeit später (1806) auch bei der Royal Society auf Zustimmung stieß, verschickte Harrison einen Rundbrief, der sich an alle Angehörigen der medizinischen Profession und die von ihnen gebildeten Verbände richtete. Er wandte sich mit seinem Anliegen auch an die leitenden Institutionen, das Royal College of Physicians,

473 Vgl. Loudon: Medical practitioners $1750-1850$ and the period of medical reform in Britain, 1992: S. 225f.

474 Die hundert Jahre zwischen 1750 und 1850 werden heute allgemein als die Zeit der medizinischen Reformen in Großbritannien angesehen, was sich in der Verabschiedung des Apothecaries Act 1815 und des Medical Act of 1858 manifestiere. Vgl. ebd.: S. 219. 
das College of Surgeons und an die Society of Apothecaries. ${ }^{475}$ In dem Medical and Physical Journal und dem Edinburgh Medical and Surgical Journal wurden 1806 die Korrespondenzen und Reaktionen, die auf diesen Rundbrief folgten, teilweise abgedruckt. ${ }^{476}$

Der Kontext der Diskussion um eine medizinische Reform und die teilweise starke Kritik des Vorhabens, die in dieser Korrespondenz offengelegt werden, lassen sich zunächst folgendermaßen umreißen: Einmal war von der Situation im England des 18. Jahrhunderts auszugehen, in welcher, noch stärker als in Frankreich, eine klare Hierarchie zwischen den learned physicians und anderen Professionen bestand. ${ }^{477}$ Nun begannen gegen Ende des 18. Jahrhunderts Absolventen des College of Surgeons, surgeons und Apotheker (apothecaries oder surgeon-apothecaries), sich wie die physicians in sozialen, politischen Gesellschaften zusammenzuschließen, die sich von der zuvor üblichen Vereinigungen auf Grundlage der Berufszugehörigen unterschieden. ${ }^{478}$ Diese neuen Zusammenschlüsse erhoben nicht nur den Anspruch, die Ausbildung der Mediziner zu verbessern und zu vereinheitlichen, sondern verknüpften dieses Ziel mit der Notwendigkeit einer staatlichen Gesundheitspolitik, die Verfügbarkeit und Sicherheit medizinischer Versorgung für die Untertanen sichern sollte. $^{479}$

»Under the comprehensive term Medical Justice, exists a master movement, which may, when duly organized, direct, control, inform, and animate, the whole machine. The association formed by the apothecaries and surgeons-apothecaries of England and Wales, has a direct reference, in its views and operation, to a leading principle in a system of a medical police. ${ }^{480}$

475 Vgl. ebd.: S. 232.

476 Vgl. ESMJ, 2.1806, S. 252 - 255. Vgl. MPJ, 16.1806: S. 94 - 95; 345 - 353; 455 - 459.

477 Vgl. Porter, R.: The patient in England, c. 1660 - c. 1800: S. $92 f$.

478 Yeatman John C.: On the Medical Reform: in: MPJ, 34.1815, S. 186 - 193: S. 193. Vgl. Bell, John (Surgeon): Letters on Professional Character and Manner: on the Education of a Surgeon and the Duties and Qualifications of a Physician: addressed to James Gregory, M.D. Professor of Practice of Medicine in the University of Edinburgh. Edin. 1810: in: MPJ, 24.1810, S. 343 - 344: S. 343. Ein Beispiel ist hier die Medical Society of London. Sie bestand bei ihrer Gründung 1773 aus je 30 Mitgliedern der verschiedenen Professionen und begriff sich als eine wohltätige und am Gemeinwohl interessierte Vereinigung. Im Unterschied hierzu hatten sich die apothecaries zuvor ebenso wie die surgeons eher in einer ökonomisch ausgerichteten Art Berufszunft (company) organisiert.

479 [Hrsg.]: New Medical and Surgical Society in London: in: Medical Intelligence III: in: ESMJ, 1.1805, S. 383 - 384. Vgl. auch: Medical and Chirurgical Society of London: in: ESMJ, 1.1805, S. 304 - 305. Vgl. Association for the medical reform: in: ESMJ, 1.1805, S. 252 - 254. Vgl. On the Plan for Medical Reform: in: ESMJ, 1.1805, S. 437 - 439.

480 [Hrsg.]: Half-yearly Report of the Progress of Medicine, from January to June, 1813: in: MPJ, 30.1813, S. 1 -22: S. 3. 
Zu dieser Zeit, also vor allem 1806 und 1807, nahm die Auseinandersetzung mit verschiedenen Entwürfen der medizinischen Polizei, Gerichtsmedizin und der Organisation der medizinischen Professionen, v.a. in Deutschland und Frankreich enorm zu. ${ }^{481}$

»Whatever aid the science of medicine can contribute towards the good of the state, and the execution of the laws, has been the Germans denominated State-Medicine [...].« ${ }^{482}$ Die Vertreter der ärztlichen Mittelschicht, der surgeons, apothecaries und surgeon-apothecaries proklamierten, dass der Großteil der professionellen, medizinischen Arbeit durch sie geleistet werde ${ }^{483}$, was nach dem Stand heutiger Forschung vor allem auf dem Land durchaus zutraf. ${ }^{484}$ Und von diesem Faktum leiteten sie ihren Anspruch auf Anerkennung und Beteiligung an Macht ab. Man muss bedenken, dass die Trennung zwischen professioneller und unprofessioneller Medizin zu dieser Zeit keineswegs so eindeutig geklärt war wie heute. Der allergrößte Teil medizinischer und hygienischer Praxis fand in einem privaten Rahmen statt oder zumindest innerhalb sozialer und familiär geprägter Strukturen. Die Ärzte des Royal College of Physicians waren zum allergrößten Teil in den Städten tätig und kontrollierten die Lizenzvergaben mehr oder weniger erfolgreich in den Städten und im Umkreis der Städte, wobei sie vor allem Gebühren forderten und eintrieben. Für die meisten Menschen auf dem Land war kein ausgebildeter Arzt verfügbar und da wo ein Landarzt erreicht werden konnte, war die Behandlung für kaum mehr als für eine dünne Oberschicht erschwinglich, was selbst für städtische Ärzte galt. Die physicians des College hatten selbst wenig Interesse diejenigen zu behandeln, die kein Geld hatten, um sie zu bezahlen. ${ }^{485}$

Es ist anzunehmen, dass vor diesem Hintergrund und der historisch entstandenen Arbeitsteilung der Mediziner, das Ansehen der learned physicians in der Bevölkerung keinen besonderen hohen Grad erreichte. ${ }^{486}$ Zumindest ist das der >Kummer $<$ der

481 Vgl. z.B. Görcke, D.: Critical analysis: Autentic Account of the Surgical Academy at Berlin: in: ESMJ, 1.1805, S. 111 - 117. Vgl. [Hrsg.]: Critical analysis: Les lois eclairees par les scientes physiques, ou Traite de medicine legale et d'hygiene publique, Paris, 1798; und Mahon, Pierre-Augustin-Olivier: De la Police Médicale: in: Médecine légale, et police médicale, Paris: in: ESMJ, 1.1805, S. 330 - 342.

482 [Hrsg.]: Critical analysis: Les lois eclairees par les scientes physiques, ou Traite de medicine legale et d'hygiene publique, Paris, 1798; und Mahon, Pierre-Augustin-Olivier: De la Police Médicale: in: Médecine légale, et police médicale, Paris: in: ESMJ, 1.1805, S. 330 - 342: S. 330.

483 [Anonym]: To the Editors of the Medical and Physical Journal. Memoir on Medical Reform: in: MPJ, 30. 1813, S. 265 - 296. [Hrsg.]: Half-yearly Report of the Progress of Medicine, from January to June, 1813: in: MPJ, 30.1813, S. 1 - 22: S. $3 \mathrm{ff}$.

484 Vgl. Porter, R.: The patient in England, c. 1660 - c. 1800: S. 93.

485 Vgl. [Anonym]: To the Editors of the Medical and Physical Journal. Memoir on Medical Reform: in: MPJ, 30. 1813, S. 265 - 296: S. 296.

486 Auch Loudon schrieb: »The rank-and-file practitioners of the eighteenth century have, on the whole, had a poor press « (Loudon: Medical practitioners 1750 - 1850 and the period of medical reform in Britain, 1992: S. 222.) Roy Porter war allerdings der Meinung, von der geringen Inanspruchnahme der Ärzte ließe sich nicht automatisch auf ein >ideologisches $<$ Ressentiment rousseauscher Couleur schließen. Dieses sei, seiner Meinung nach, 
Ärzte, den sie Ende des 18. und Anfang des 19. Jahrhunderts in den medizinischen Zeitschriften zum Ausdruck bringen. Somit war ein Anliegen der vorgeschlagenen medical reform, nämlich »to uphold the dignity and literary reputation of the profession «, auch ein Angebot an die bereits staatlich anerkannten learned physicians. ${ }^{487}$ Die Absolventen des College of Physicians befürchteten durch die Reform einen materiellen und sozialen Abstieg durch die Konkurrenz anderer staatlich anerkannter sog. general practitioners. Die meisten Ärzte waren, allein schon wegen der Kosten für die Ausbildung am College, zwangsläufig Söhne wohlhabender bürgerlicher, aristokratischer - in jedem Fall besitzender Familien. ${ }^{488}$

Aber auch hier leistete die Argumentation der Reformer überzeugende Arbeit, indem sie versicherten, gerade die besitzenden, oberen Schichten der Gesellschaft müssten Interesse an einer basalen allgemeinen und sicheren Gesundheitsversorgung v.a. der arbeitenden Bevölkerung haben. Man müsse nicht klug sein, um das einzusehen und man müsse kein Philanthrop sein, um die persönliche, soziale und ökonomische Notwendigkeit eines möglichst guten Zustands der Gesundheit der Bevölkerung anzuerkennen. Auf diese Weise machten die Verteidiger der Reform das Problem der Gesundheit der Bevölkerung und die Regulierung und Qualität der medizinischen Praxis zu einem öffentlichen Gegenstand, zu einem politischen Problem der ganzen Nation:

»To no being in society, indeed, whatever his place in the scale of social order, intellect, or moral feeling, can this subject be a matter of indifference. [...] All are equally concerned on the establishing a more perfect and efficient profession of physic, and should equally rejoice in every rational expectation of rescuing the wretched victims of disease from the venal and rapacious grasp of ignorance and quackery. $\ll^{489}$

Vor allem die Gesundheit einer bestimmten sozialen Schicht - die der armen und arbeitenden Bevölkerung - wurde zum Problem und Katalysator der Aushandlung und neuen Verteilung von Macht unter den unterschiedlichen Professionen und dem Staat, der diese Verteilung per Gesetz schützen sollte. Apothecaries und surgeons brachten gewissermaßen > von unten < eine neue ethische und politische Rationalität der Medizin in Gang, die die diskursive Überlegenheit ihrer Position und Forderung bewerkstelligen sollte. Sie profilierten sich in dem Streit als die >wahren Ärzte<: Sie waren es, die sich um die >notleidende < Bevölkerung kümmerten und damit der allgemein angesehenen hippokratischen Tradition der >wahren< Medizin alle Ehre machten. Darüber hinaus aber waren sie auch diejenigen, die sich mit der Krankheit

selten anzutreffen gewesen. Eher spreche vieles dafür zu sagen, dass bis auf bestimmte Notfälle und Krankheiten eine gewisse Ansicht über die Nutzlosigkeit oder geringen Notwendigkeit eines Arztes bestand. (Vgl. Porter, R.: The patient in England, c. 1660 - c. 1800: S. 99.)

487 Vgl. [Hrsg.]: An attempt to develop the Fundamental Principles which should guide the Legislature in regulating the Profession of Physic: in: ESMJ, 14.1818, S. 1 - 26: S. 14.

488 Vgl. [Anonym]: On Medical Reform: in: MPJ, 15.1806, S. 258 - 261: S. 260.

489 [Anonym]: To the Editors of the Medical and Physical Journal. Memoir on Medical Reform: in: MPJ, 30.1813, S. 265 -296: S. 265. 
und den Epidemien in ihrer Verbindung zu einem größeren sozialen und ökonomischen Problem beschäftigten. Mit der Reform wollten sie eine flächendeckende medizinische Versorgung aller Schichten und Klassen sichern. ${ }^{490}$ Diese gewissermaßen als >medizinische Mittelschicht< anzusehende Gruppe der apothecaries und surgeons setzte aber noch ein weiteres Instrument ein. Sie stellte in gewisser Weise die Identität, den Zweck und die Ethik des von König Henry V. eingerichteten College of Physicians und damit den Beruf des Arztes, der von dieser Institution ausging, in Frage. Trotz ihrer aufopferungsvollen Tätigkeit blieb man den apothecaries und surgeons eine angemessene soziale Stellung und staatlichen Anerkennung schuldig - diese ließ man nur den physicians zuteilwerden. Wer waren aber die physicians? Sie waren nach der Argumentation der apothecaries und surgeons einer alten Macht entsprungen, deren Fortschrittlichkeit, Rationalität und Souveränität mehr als in Frage stand.

»Of this general policy seems to have been to ensure a high degree of learning on the part of its members, rather than to supply the public with medical practitioners, proportionate to its necessities. And the effect has been in a great degree similar to what we have already seen to result from the Papal restrictions imposed on the clerical physicians of the continent. For, by requiring a high degree of literary qualification from its associates, it necessarily narrowed the institution, and rendered it inadequate to supply the wants of the community; while, by declaring all connection with surgery, it forced the public on calling into existence a class of practitioners, inferior indeed in learning and science, but more useful, as combining in their own persons the qualifications necessarily for giving relief in all the varied forms which disease assumes. $\ll^{491}$

Die Abgrenzung gegenüber dieser alten Rationalität, die mit willkürlicher Herrschaft verbunden schien, diente der positiven Darstellung einer ihr entgegenstehenden sich auf Ethik, Wahrheit und Rationalität berufenden Macht. ${ }^{492}$ Die Willkür des College of Physicians und die Nutzlosigkeit seiner Absolventen für die Bevölkerung machten den Kern der Problematik der Hierarchie unter den Professionen und der Rolle der learned physicians und des Colleges selbst aus. Nun wurde gefordert, den Zugang zu den Colleges nach Leistungskriterien und nicht mehr nach der Herkunft der Anwärter zu gewähren.

»[Autor zitiert Lord Mansfield:] >There can be little doubt that the Colleges are obliged, in conformity to the trust and confidence reposed in them by the Crown and the public, to admit all that are fit, and reject all that are unfit. But their conduct in the exercise of the trust thus committed to them ought to be fair, candid and unprejudiced, not arbitrary, capricious, or biased, much less warped by prejudice and personal dislike.< These various opinions, so unequivocally given by the highest legal authority that can be adduced, are surely more than enough to determine the illegality of the college proceedings. $\ll^{493}$

490 Vgl. ebd.

491 [Hrsg.]: An attempt to develop the Fundamental Principles which should guide the Legislature in regulating the Profession of Physic: in: ESMJ, 14.1818, S. 1 - 26: S. 5.

492 Vgl. [Hrsg.]: Expositions of the Present State of the Profession of Physic in England, and of the Laws enacted for its Government: in: ESMJ, 16.1820, S. 481 - 509: S. 497.

493 Ebd.: S. 494. 
Der Papst und die römisch-katholische Kirche wurden im englischen aufklärerischen Gesundheitsdiskurs immer wieder zum Sinnbild für willkürliche und unberechtigte Machtausübung. Auch später in der internationalen Diskussion um die Quarantäne wird es immer wieder eine Strategie sein, zu sagen: >Die Quarantäne kann nicht fortschrittlich und wissenschaftlich abgesichert sein, denn sie ist ja eine Erfindung des Papstes $<{ }^{494}$ Die Argumentation der Reformer ging aber noch weiter, indem sie behaupteten: >Die Aufteilung der Medizin ist unnatürlich!< Damit greifen sie in den britischen Journalen eine ähnliche Argumentation auf, wie sie von den hippokratischen Ärzten in der französischen Revolution mit dem Ziel der Vereinigung der medizinischen Professionen und Neuordnung der Medizin verbunden gewesen war. ${ }^{495}$ Auch in England sagten die Ärzte, dass die Aufteilung der Professionen das historische Ergebnis einer illegitimen Macht ist. Die Trennung der Professionen ist, gemessen an dem >natürlichen $<$ Zweck der Medizin und an den menschlichen Bedürfnissen, irrational. Sie hat damit auch das Recht des Arztes, seinem Zweck und seiner Begabung entsprechend seinen Beruf auszuüben, >plötzlich< entdeckt:

»Thus the public has been deprived of the matured experience of a highly qualified physician, and of the valuable services which he could so eminently have rendered, while he is prevented seeking those advantages to which his talents and acquirements entitle him. $\ll^{496}$

Die Organisation der Medizin hatte damit in jeder Hinsicht dem Ideal einer protestantischen Ethik und Berufsethos entgegengewirkt. Sie roch nach dem Muff einer alten irrationalen und illegitimen Herrschaft. Sie ist das direkte Ergebnis einer Unfreiheit und reproduziert diese.

494 Vgl. [Hrsg.]: 1. Origines Contagii: Scripsit Marx, C.F.H. Dr. Caroliruhae et Badae. Apud D.R. Marx. 1824. On the Origin of Doctrine of Contagion. By Dr. C.F.H. Marx. Carlsruhe and Baden. Published by D.R. Marx, 1824. 2. Contagio cognito agli storici e filosofi antichi, ignoranto dai medici Greci, Latini, Arabi, non immaginato da Papa Paolo III. Errore die Maclean. - Dottrina del contagio fondata nesecolo quinto decimo da Marsilio di Medicina compilati dal Signor Dottore Annibale Omodei. Milano 1822: in: ESMJ, 24.1825, S. 99 - 143: S. 105f; 135ff.

495 »Disgusted with the selfish and narrow views of those who have so lately dignified with the name of medical reform, a pitiful plan for the good of the trade, the reader must turn with delight to the philosophical views of the eloquent Cabanis, views, which lead to the substantial reform of science itself.«: (Handerson, Alexander: A Sketch of the Revolutions of Medical Science, and Views relative to Reforms. By P.J.G. Cabanis [...]: in: ESMJ, 3.1807, S. 241 - 244: S. 242.) Pierre-Jean-Georges Cabanis (1757 - 1808) hatte während der Revolutionsjahre mehrere Vorschläge für die Pläne der Neuordnung der Medizin in Frankreich unterbreitet. Er schrieb in diesem Zusammenhang Rapport sur l'organisation des écoles de médecine (1799); Quelques considérations sur l'organisation sociale (1799); Coup d'œil sur les révolutions et la réforme de la médecine (1804).

496 [Hrsg.]: Expositions of the Present State of the Profession of Physic in England, and of the Laws enacted for its Government: in: ESMJ, 16.1820, S. 481 - 509: S. 507. 
»[They] manifest their utter unsuitableness (even if faithfully and consciously administered) to those revolutions in the state of medical science and practice, and of society, which the lapse of three centuries has effected. $\ll^{497}$

Und nun, sagten die Reformer, können die surgeons und apothecaries, die wahren Allgemeinmediziner - »in fact general practitioners $\ll^{498}$ die wachsende Nachfrage, ausgelöst durch ein schnelles Wachstum an Reichtum wie auch der Bevölkerung, selbst nicht mehr ohne Hilfe eines »enlightened system of polity « bewältigen. ${ }^{499} \mathrm{Mit}$ dieser Strategie sollte es gelingen, ein gewisses Paradox zu verschleiern, nämlich, dass man den Staat und seine Macht des Gesetzes dafür einsetzten wollte, um eine freie Ausübung der medizinischen Berufe und den freien Zugang zu medizinischer Hilfe zu sichern, der durch eine alte staatliche illegitime Macht beschränkt worden sei. Im Laufe dieser Debatte wurden bestimmte Bedingungen für alle möglichen Schritte der Reform und alle möglichen Aussagen, die hier getroffen werden können, ausgelotet und Schritt für Schritt kanonischer. Niemand stellte grundsätzlich die Notwendigkeit einer Regulierung in Frage. Niemand konnte bezweifelte, dass es bei der Regulierung um mehr als nur um die Verbesserung der Lebensumstände einer nach bestimmten Kriterien bestimmten Gruppe von Medizinern gehen sollte. Das Allgemeinwohl, die Sicherheit der Bürger und ihr Schutz vor Betrügern und Mördern waren zentral in der Argumentation für die Reform.

Betrachtet man die Texte der Diskussion über die medical reform als eine Auseinandersetzung um Regierung, so lässt sich folgendes Bild nachzeichnen: Auf der Ebene des von Medizinern geführten Diskurses war man mit der Festlegung einer bestimmten Möglichkeit, Wissenschaft und Technik der Regierung von Gesundheit relativ weit fortgeschritten. Hierzu zählt eine Verdrängung religiöser Praxis und ein Aufgreifen antiken medizinisch-hygienischen Wissens. Mit dem >fortgeschritten $<$ beziehe ich mich hier lediglich auf die Geschichte einer spezifischen Auseinandersetzung, eines Konflikts zwischen verschiedenen älteren religiösen, epistemischen oder ontologisch beschaffenen Beschränkungen menschlicher Regierung >des Lebens « (und der Gesundheit) gegenüber einer göttlichen Macht usw. Dieses Problem war nicht mehr das Zentrum des Konflikts, was es sicherlich früher z.B. im 17. Jahrhundert zur Zeit Brownes noch gewesen ist. Es war im Grunde unnötig, dass man immer noch so lauthals seine Identität und Unschuld im Sinne einer Distanz zur Macht verkündete: »the arrangements be founded in the spirit of truth, disinterestedness, and regard for the welfare of the public «. ${ }^{500}$ Die Rationalisierung der Lebenswelt und Sittlichkeit, um mit Max Weber zu sprechen, war im gesundheitlichen Bewusstsein

497 Ebd.: S. 482.

498 [Hrsg.]: An attempt to develop the Fundamental Principles which should guide the Legislature in regulating the Profession of Physic: in: ESMJ, 14.1818, S. 1 -26: S. 5.

499 Ebd.: S. 6.

500 [Hrsg.]: Expositions of the Present State of the Profession of Physic in England, and of the Laws enacted for its Government: in: ESMJ, 16.1820, S. 481 - 509: S. 508. 
der Bevölkerung bereits relativ weit von diesem Konflikt entfernt. Das zeigt gerade auch die Studie von Mortimer. ${ }^{501}$

Es gab im 18. und 19. Jahrhundert, anders als in Deutschland und Frankreich, in Großbritannien keinen ausgeprägten (religiösen oder bürgerlichen) anti-ärztlichen Diskurs mehr. Auch scheint es nicht realistisch, davon auszugehen, dass die Praxis der sog. Quacksalber genau in diesem Moment einen kritischen Punkt erreicht hatte. Die Konsequenz der medical reform war nicht die Verdrängung der Heiler und der sog. Quacksalber oder die Auflösung der Konkurrenz unter den verschiedenen Professionen. Sondern die medical reform wird die Regeln, nach denen konkurriert wird, auf eine andere Basis stellen und damit automatisch einen anderen, nun deutlicher als >nicht-professionell< zu bezeichnenden Bereich medizinischer oder hygienisch-sittlicher Praxis ausschließen ihren Regeln unterwerfen und sie, wie Foucault in Bezug auf Frankreich schrieb, >medikalisieren ${ }^{502}$. Der Vorschlag der medizinischen Reform war im Grunde keine Absage an irgendeine Macht des Staates oder der Ärzte, sondern ein Angebot an sie, die Macht auf alle Bevölkerungsschichten auszuweiten, sie auf eine universelle wissenschaftliche wie normative Basis zu stellen, unter sich neu aufzuteilen und effektiver gegen eine illegitime Macht, nämlich die der »spreading widely evils of quakery ${ }^{503}$, mit der man aber eine soziale Organisation >medizinisch im Sinne einer »medical constitution, [...] providing for the wants and security of the public « meinte, in Anschlag zu bringen. In der Diskussion lassen sich eine ganze Reihe von für Großbritannien typischen Entwicklungen der Regierung von Gesundheit zeigen. Dies gilt auch, wenn man bedenkt, dass der von Harrison vorgeschlagene Plan in dieser Form nie umgesetzt wurde. ${ }^{504}$ Die Rationalität, die diskursiven Regeln und möglichen Subjektpositionen, mit deren Hilfe es dennoch gelang, die Regierung von Gesundheit in einer bestimmten Weise zu politisieren und in einer anderen Weise zu entpolitisieren, eine bestimmte Macht zu gewinnen bzw. auszuweiten und eine andere Macht zu verringern bzw. zu begrenzen, werden sich sich in den zu Anfang erwähnten Gesetzen (dem Apothecaries Act 1815 und des Medical Act of 1858) und in der späteren Rationalität der Regierung von Gesundheit in Großbritannien niederschlagen.

Es zeigte sich in dem englischen Diskurs erstmals eine Strategie der wirklichen Ablehnung der alten Tradition der Regierung des Verhaltens von Menschen. Der alten Kunst der Lebensführung, z.B. innerhalb der priesterlichen Sorge um die Seele, wurde etwas entgegengesetzt. Dies geschah, indem man die Frage der Lebensführung

501 Er schrieb aus seiner Betrachtung medizinischer Praxis des 17. Jahrhundert: »Indeed, it is clear that by 1700 , when most of the dying obtained some medical help shortly before death, an exclusively spiritual strategy could not have been the recourse of the majority, whereas in 1600 it could and probability was.« Mortimer: The dying and the doctors, 2009: S. 208.

502 Foucault: Die Geburt der Sozialmedizin (Vortrag), 2003 [1974]: S. 274ff. Vgl. auch Foucault, Michel: Die Geburt der Klinik, 2008 [1963]: S. 48f.

503 [Hrsg.]: Expositions of the Present State of the Profession of Physic in England, and of the Laws enacted for its Government: in: ESMJ, 16.1820, S. 481 - 509: S. 499.

504 Vgl. Loudon: Medical practitioners $1750-1850$ and the period of medical reform in Britain, 1992: S. 232f. 
von einem moralischen Diskurs entkoppelte und ganz materialistisch davon ausging, dass die ökonomische Rationalität ein direktes Resultat aus dem >natürlichen< menschlichen Streben nach Existenz ist. Gleichzeitig begann man das Streben nach Existenz als die Triebkraft aller gesellschaftlicher und individueller Entwicklung zu betrachten. Aus dieser Sicht war kein individueller Prozess der Bewusstwerdung, der Selbsterkenntnis - wie bei Kant - oder der Praxis des Selbst - wie in der christlichen oder antiken Tradition - erforderlich, um die Notwendigkeit und die Regeln der Regierung und der Selbstregierung der Gesundheit anzuerkennen. Man vollzog eine unheimliche Reduktion des Subjekts auf sein Streben nach materieller Existenz. Die Regierung sollte diese einfache Rationalität berücksichtigen, sich nach ihr richten und einen Rahmen für sie schaffen, in der sie sich entfalten konnte. Freiheit bedeutet nach dieser Regierungslogik genau das. Das Problem, was sich für eine solche liberale Regierungsidee ergab, war allerdings, dass die materielle Rationalität, von der sie ausging, noch nicht besonders etabliert war. Die Rationalität, die sie zu ihrem Regierungsprinzip machte, musste zunächst in der Gesellschaft hergestellt werden, indem man die Menschen dazu brachte, sich selbst als diese auf ökonomische Rationalität reduzierten Subjekte zu verstehen. Die Techniken, die man hierfür weniger erfinden als entdecken musste, ergaben sich aus den strukturellen Zwängen kapitalistischer Gesellschafts- und Produktionsverhältnisse. Also das Kriterium für die Subjekte, als wirkliche Subjekte zu gelten, ist eher, dass sie zu einer Berechnung und einem daran ausgerichteten Verhalten fähig sind, dass ihnen ermöglicht, unter den Bedingungen dieser Verhältnisse selbstständig zu existieren. Dies führt andererseits zu dem Umkehrschluss, dass Menschen im Sinne dieser Rationalität befreit werden müssen. Das ist der >moralische Auftrag < der Regierung - sie soll die Elemente beseitigen, die diese bestimmte Freiheit nach der eigenen Existenz zu streben, einschränken. Ich denke, dass diese Idee der Regierung noch nicht ganz so ausgeprägt war zum Zeitpunkt der medical reform, aber in den Diskussionen um sie durchaus als eine wirksame Strategie existierte. Etwa in dem Maße, wie sich das Ziel der medizinischen Reform in der Gewährleistung von zwei verschiedenen Sicherheiten bzw. Freiheiten lag: einmal die Freiheit der medizinischen Berufe und die Freiheit der Ausübung der Wissenschaft. $^{505}$

»The object of judicious legislation then clearly are, - first, to provide for the due qualifications of each species of practitioners, so as to ensure the competency of all to fulfil their respective duties, without insisting on such extraordinary endowments, as by narrowing the profession, and limiting the supply of legalized practitioners, must create a necessity for the intrusion of unqualified and contraband substitutes; and, secondly, to protect them in the free exercise of their several functions, unimpeded by corporation jealousy or intrigue. $\aleph^{506}$

505 [Hrsg.]: Resolution respecting the Medical Reform: in: MPJ, 22.1809, S. 328 - 329: S. 329.

506 [Hrsg.]: An attempt to develop the Fundamental Principles which should guide the Legislature in regulating the Profession of Physic: in: ESMJ, 14.1818, S. 1 - 26: S. 7. 
Auf der anderen Seite bestand sie in der Sicherheit der Bevölkerung vor dem Betrug und ihre Freiheit in der Wahl und dem Zugang zu professioneller medizinischer Praxis.

»The arrangement of medical profession on principals which shall insure to the public a sufficiency of duty qualified practitioners, who shall be able to accommodate themselves to the various classes and conditions of the community, $[\ldots] . \ll^{507}$

Ziel ist eine größere Sicherheit für das eigene Leben und Chancen auf ein längeres Leben etc. für die Einzelnen zu gewährleisten. Dabei wird aber nie versucht, die grundsätzliche Ungleichheit der verschiedenen Gruppen aufzuheben. Die Verteilung und Gestaltung der Reform soll gerade das Problem heterogener gesellschaftlicher Gruppen und Klassen berücksichtigen. Im Rahmen dieser Politik soll auch durch den Ausschluss aller illegitim praktizierenden Ärzte usw. eine Garantie und Sicherheit medizinischer Dienste gewährleistet werden.

»In this way will a due supply of medical man well calculated to combine the three branches of medicine in their practice, be afforded to the public. [....] In short, an effectual barrier will be then placed against the admission of uninformed persons into the profession; a sufficient guarantee given to the public of the competency of all its members to the practice of medicine; and then, and not till then, will that profession be enabled to enquire its proper dignity. ${ }^{508}$

Die Reformen sollen durchgeführt werden, ohne die natürlichen oder individuellen Rechte einzuschränken (»without the slightest trespass on natural rights « ${ }^{509}$, »without the slightest infringement of personal rights, or the injury of any individual $\ll^{510}$ ). Genau genommen liegt der Fokus der Problematisierung an einer anderen Stelle. Das Problem der Gesetze ist nicht, individuelle Rechte gegenüber dem Staat einzuschränken oder an ihn abzugeben. Viel eher soll ihre ganze Struktur einem rationalen Zweck dienen. Ziel ist »an enlightened legislature, anxious for the public good « ${ }^{511}$. Die Gesetze haben den Zweck, eine bestimmte individuelle Freiheit herzustellen. Sie sollen einen Rahmen schaffen, in dem es unproblematisch ist, die Individuen frei handeln zu lassen. Es ist eine Idee einer Regierung, die, statt den Regierten Grenzen in ihrem Handeln zu setzten, in erster Linie die Aufgabe hat, sie zum Handeln anzuregen (»a participation of its public labours and usefulness $\aleph^{512}$ ) oder sie bestimmten Bedingungen für die Rationalität ihres Handelns und ihrer Entscheidung frei auszu-

507 [Anonym]: To the Editors of the Medical and Physical Journal. Memoir on Medical Reform: in: MPJ, 30. 1813, S. 265 - 296: S. 265.

508 Yeatman John C.: On the Medical Reform: in: MPJ, 34.1815, S. 186 - 193: S. $192 f$.

509 [Hrsg.]: An attempt to develop the Fundamental Principles which should guide the Legislature in regulating the Profession of Physic: in: ESMJ, 14.1818, S. 1 - 26: S. 18.

510 Ebd.: S. 23.

511 Ebd.

512 Letter to the Editor of the Edinburgh Medical and Surgical Journal, explaining the Object of the Society of Physicians of the United Kingdom: in: ESMJ, 25.1826, S. 323 - 326: S. 323. 
setzen. Es ist sogar irrelevant, ob jemand eine Ausbildung zum Arzt hat, solange das, was er tut, nützlich und effektiv ist. ${ }^{513}$ Insgesamt ist die Diskussion um die medical reform geprägt von einer bestimmten ökonomischen Rationalität der Berechenbarkeit, Nützlichkeit und Effizienz: »a Plan calculated to give to the Medical Body in general an increased Usefulness $\ll{ }^{514}$. Eine weitere essenzielle Bedingung für die Rationalität einer Regierung der Wirklichkeit ist, dass sie die Heterogenität der Machtverhältnisse anerkennt und ihren Absolutheitsanspruch aufgibt. Sie orientiert sich an der Machbarkeit und Effizienz ihrer Techniken. ${ }^{515}$ Diese Rücksicht auf die Wirklichkeit geht trotz des teilweise moralischen Untertons der Artikel von dem Streben nach persönlichem Nutzen bei den Individuen aus. Nirgendwo findet sich das Ziel, dieses Verhalten oder Begehren zu beseitigen. Die Reform müsse so eingerichtet werden, dass sie genau von einem solchen Subjekt ausgeht. Die Kunst bestehe gerade darin, die Gesetze und die Institutionen so einzurichten, dass sie auf solche Subjekte zugeschnitten sind und die negativen Effekte seiner Eigenschaften ausbalanciert (balance) oder ihnen entgegengewirkt werden kann (»effectually counteract [...] all selfish and sinister tendencies «). ${ }^{516}$ Noch mehr aber müsse die Reform bewirken, dass es im Sinne der Interessen der einzelnen ärztlichen Gruppen und des Gemeinwohls sei, wenn diese kooperierten (»co-operate, both for their common interests, and for the public good «). ${ }^{517}$ Nach welchem philosophischen oder moralischen Ideal gehandelt wird spielt keine Rolle. Die Aussagen richten sich eher auf das Problem der Wirklichkeit auch einer historischen Wirklichkeit. Mit ihr wird einerseits begründet, warum bestimmte Gesetze nicht akzeptiert werden und andererseits, warum sie keinen Nutzen mehr haben. »[I]t is surely no political heresy to doubt the fitness of certain enactments framed in the fifteenth century for regulating the affairs of the eighteenth. ${ }^{518}$ Es war in diesem Sinne nicht denkbar, wie etwa in Frankreich, einen umfassenden medizinischen und polizeilichen Apparat aufzubauen, der auf ein zukünftiges Ziel ausgerichtet ist. Obwohl es durchaus Stimmen in dieser Diskussion gab, die meinten, die Aufteilung der Heilpraxis in die unterschiedlichen Bereiche sei unnatürlich, waren selbst sie sich bewusst, dass es außerhalb jeglicher Regierungsmacht lag, diese zu

513 Vgl. [Hrsg.]: An attempt to develop the Fundamental Principles which should guide the Legislature in regulating the Profession of Physic: in: ESMJ, 14.1818, S. 1 - 26: S. 22.

514 Underwood: Essay on Medical Economy, comprising a Sketch of the State of profession in England, and the Outlines of a Plan calculated to give to the Medical Body in general an increase Usefulness and Respectability [...] 1813: in: MPJ, 31.1814, S. $321-325$ : S. 321 .

515 Vgl. [Hrsg.]: An attempt to develop the Fundamental Principles which should guide the Legislature in regulating the Profession of Physic: in: ESMJ, 14.1818, S. 1 -26: S. 1.

516 Ebd.: S. 17f.

517 Ebd.

518 Barlow, Edward: Essay on the Medical Profession, showing its natural unity, and suggesting such arrangements as would render its condition conformably to just principales of Political Science, and conducive to interests both of the Profession and the Public [...]: in: ESMJ, 28.1827, S. 332 - 356: S. 334. 
einer institutionellen Vereinigung zu zwingen. ${ }^{519}$ Die Ärzte seien für verschiedene Klassen zuständig. Die physicians gehörten zu den höheren Klassen ${ }^{520}$, die surgeons für die mittleren und die general practitioners sollten nach der neuen Definition für alle zuständig sein:

»[T]heir utility rendering them necessary to the former [lowest degree of the community], while their humility and habits of active industry fit them for extending their services to the lowest extreme. $\ll^{521}$

Die Aufteilung, wie sie sich in der Gesellschaft und unter den ärztlichen Professionen herausgebildet habe, müsse respektiert werden: »respecting the real nature of the several departments, and the relation which they bear to each other, and to the community $\ll^{522}$.

»No legislature, however enlightened, can have a right to say to the public you shall employ physicians instead of surgeons, or the contrary. [...] The only rational object now is so to administer what is actually established, that it shall not have to encounter the counteracting influence of principles founded in nature, $[\ldots]$ should be disturbed as little as is compatible with the public welfare. $\ll^{523}$

Es gab nach dieser Auffassung unterschiedliche Klassen, die unterschiedliche medizinische Berufe ausüben sollten bzw. die unterschiedliche medizinische Hilfe benötigten und unterschiedliche Bedürfnisse hatten. ${ }^{524}$ Und darüber hinaus, das ist ein sehr wichtiger Punkt, sah man eine Öffentlichkeit, die nur begrenzt beeinflussbar war. ${ }^{525}$ »No system of medical policy can be complete, in which these several powers of the art are not fully recognised, and in which their mutual dependence [...]. $\ll^{526}$

519 Vgl. [Hrsg.]: An attempt to develop the Fundamental Principles which should guide the Legislature in regulating the Profession of Physic: in: ESMJ, 14.1818, S. 1 - 26: S. 7.

520 »And the mere physician is a character required principally for the higher ranks of society, to uphold the dignity and literary reputation of the profession, and improve its science by the collateral aids which general science and literature afford, perhaps sound and enlightened policy would require, that his qualification should rated rather above than below ordinary mean.« Ebd.: S. 14.

521 Ebd.: S. 8 .

522 Ebd.

523 Barlow, Edward: Essay on the Medical Profession, showing its natural unity, and suggesting such arrangements as would render its condition conformably to just principales of Political Science, and conducive to interests both of the Profession and the Public [...]: in: ESMJ, 28.1827, S. 332 - 356: S. 343.

524 Vgl. [Anonym]: To the Editors of the Medical and Physical Journal. Memoir on Medical Reform: in: MPJ, 30. 1813, S. 265 - 296: S. 295.

525 Vgl. ebd.

526 [Hrsg.]: An attempt to develop the Fundamental Principles which should guide the Legislature in regulating the Profession of Physic: in: ESMJ, 14.1818, S. 1 - 26: S. 2. 
Eine gute Reform und Regierung der Gesundheit müsse die heterogenen Machtverhältnisse anerkennen und ihre Techniken an ihnen orientieren. Auch wenn große Zweifel an den Fähigkeiten der einzelnen Mitglieder der Gesellschaft bestünden, sich bei der Wahl ihres Arztes rationell zu verhalten, so komme es dennoch nicht in Frage, ihnen eine Vorschrift in dieser Hinsicht zu machen. Ziel sei es stattdessen, einen Rahmen zu schaffen, der die Entscheidungsfreiheit gewissermaßen ungefährlich machen solle. Sie sollen die Wahl haben, indem man eine Situation schaffe, in welcher es Ärzte gebe, die für alle mehr oder weniger bezahlbar und die trotzdem ordentlich ausgebildet seien. ${ }^{527}$

\section{Quackery and strue، doctors}

Die Diskussion um die medical reform zeigt das Aufstreben einer bestimmten gesellschaftlichen Gruppe, die ihre selbst- und gruppenbezogenen Praxen der Regierung der Lebensführung, wenn man so will -, zu verallgemeinern und zu politisieren begannen. Die Aussagen rationalisieren eine bestimmte moderne Gouvernementalität, die in Begriff war, eine alte Ordnung der Macht abzulösen und sich zu verstaatlichen und gleichzeitig begann, sich auf das Leben, die Menschen und eben auch ihre Gesundheit zu richten. Allerdings war die Besonderheit in England, Schottland und Wales, dass die protestantische Lebenspraxis in ihren unterschiedlichen Ausprägungen $\mathrm{zu}$ einer Betonung der materiellen Bedeutung und Praxis menschlicher Existenz und Lebensführung führte. Dies zeigt sich u.a. in der Betonung und Bewertung der praktischen, mühevollen und strebsamen Arbeit der verschiedenen Mediziner. Die moralische Differenzierung der > wahren Ärzte $<$ bestand trotz dieser Koppelung an die praktische und >mühsame< Arbeit, wie in Frankreich und Deutschland, vor allem in der Unterscheidung von >rationaler< und irrationaler< Medizin. Ohne eine anerkannte und universitäre Ausbildung konnten die general practioners ihre Mortalität, ihre Unterscheidung von den sog. irregulars und quarks und damit ihren Anspruch auf Regierung vor der Debatte um die medical reform nicht deklarieren. ${ }^{528}$ Wie wird man sich derer entledigen, die von allen drei Berufsgruppen und denen, die sich auf die gleiche medizinische Ethik beriefen, gemeinsam als Problem ausgemacht werden? Die Vorschläge eine stärker von staatlicher Seite ausgehende Kontrolle und damit eine zunehmende Kriminalisierung der sog. Quacksalber, kam als Teil der selben Bewegung und etwas früher als die Diskussionen über die medical reform auf. Man kann auch die These äußern, dass sich der Plan für eine medizinische Reform aus den Diskussion um das Problem der quackery heraus entwickelt hat, oder dass diese zumindest ein wichtiger Anlass gewesen sind. So hieß es bereits 1799 in einem Brief an das Physical and Medical Journal:

527 Medicus: Letter to the Editor of the Edinburgh Medical and Surgical Journal, explaining the Object od the Society of Physicianx of the United Kingdom: in: ESMJ, 3.1807, S. 323 - 326: S. 325.

528 Vgl. Royston, W.: Historical Sketch of the Progress of Medicine in the Year 1806: in: MPJ, 18.1807, S. 1 - 43: S. 3. Vgl. [Antwort auf den Brief]: On Medical Reform: in: MPJ, 15.1806, S. 551 - 556: S. 551. Vgl. [Antwort auch die Antwort auf den Brief]: On Medical Reform: in: MPJ, 15.1806, S. 556 - 558: S. 556. 
»It is much to be wished, that some such regulations as are therein suggested, might be adopted to suppress the baneful compositions of the ignorant and daring self-created doctors, or at least to prevent their so very general circulation and use. $« 229$

Die Diskussion um quakery zeigt sehr deutlich, dass die Personen, die auch als irregular practitioners bezeichnet wurden, eine überaus heterogene Gruppe waren. Sie beinhaltete u.a. sog. »empirics $«{ }^{530}$, »illiterate persons «, »self-created surgeons «, »bonesetters, farriers, prescribing druggists and grocers, practising quakes and ignorant women $\aleph^{531}$, oder $»$ wise women $«, ~ »$ nostrum-mongers, proprietors of patent medicines, urine-casters, astrologers, fortune-tellers $\ll^{532}$, bis hin $\mathrm{zu}$ sog. » $\gg$ lady doctors $\ll$ who bountifully dispense $>$ infallible remedies $«{ }^{533}$. Die Kriterien, die es überhaupt erst ermöglichten, eine derartig selbstverständlich wirkende Grenze zwischen den quacks und den >wahren< Ärzte von damals zu ziehen, mussten erst nach und nach geschaffen werden. Die Bemühungen zu einer klareren Unterscheidung wirklicher Ärzte von den quacks dienten vor allem dazu, die surgeons und die apothecaries aufzuwerten. Dies geschah, indem eine bestimmte rationelle und moralische, ideale Subjektivität entworfen wurde, wie auch in der Diskussion um die medical reform. Auf diese Weise wurden die physicians, für die in ihrer Stellung überhaupt keine Notwendigkeit bestanden hatte, sich gegen die quacks abzugrenzen, ebenfalls den neuen Bedingungen von Rationalität und Moralität des >wahren und guten Arztes< unterworfen. Trotz einer sehr dauerhaften Problematisierung während des 18. Jahrhunderts setzte sich auch zu Beginn des 19. Jahrhunderts keine einheitliche Position zur staatlichen und polizeilichen Bekämpfung der quacks durch. Ärzte führten daher eine ganze Zeit lang vor allem eine Art Medien-Krieg, der in dem Versuch bestand, der Werbung und den Versprechungen der quacks, die sie in Zeitungen und an öffentlichen Orten machten, etwas - nämlich eine andere Form des Wissens - entgegenzusetzen.

»It is evident that the only way a quack-medicine gets very celebrated, is, by its being constantly puffed off in advertisements. [...] What should hinder professional men, who are daily witnessing the mischiefs occasioned by these noxious drugs, from publishing them to the world? « ${ }^{534}$

Ziel war es, die sog. Öffentlichkeit in der Weise zu beeinflussen, dass sie die Unterschiede und den Wert einer Unterscheidung > wahrer und >falscher< ̈̈rzte erkennen

529 S.M.: [A Letter on the suppression of Quack Medicine] To the Editors of the Medical and Physical Journal: in: MPJ, 2.1799, S. 150 - 152: S. 150.

530 Forbes, Duncan: On the origin and progress of Empiricism: in: MPJ, 14.1805, S. $437-$ 441: S. 438.

531 Yeatman, John C.: On the Medical Reform: in: MPJ, 34.1815, S. 186 - 193: S. $192 f$.

532 Royston, W.: Historical Sketch of the Progress of Medicine in the Year 1806: in: MPJ, 18.1807, S. 1 - 43: S. 3.

533 An Essex Practitioner: To the Editors of the Medical and Physical Journal [On Medical Reformin: MPJ, 23.1810, S. 209 - 212: S. 209.

534 S.M.: To the Editors of the Medical and Physical Journal [A Letter on the suppression of Quack Medicine]: in: MPJ, 2.1799, S. 150 - 152: S. 150. 
konnte. Die Initiatoren der Diskussion, die die Forderungen nach Gesetzen erhoben und von denen die >Medienoffensive< gegen die quacks ausging, waren Mitglieder von Gesellschaften, Zusammenschlüsse von Ärzten und andere bürgerliche und wohlhabende Gentlemen. ${ }^{535}$ Worin bestanden also nach Ansicht der Autoren von Briefen und Artikeln, die zumeist surgeons oder apothecaries waren, die Eigenschaften der sog. Quacksalber? Sie bestand in erster Line in einer bestimmten Methode der Erkenntnis - der Untersuchung (investigation) - oder einem bestimmten Verhältnis zwischen der Methode und der über die Erfahrung festzustellenden prinzipiellen Zwecke und Gesetze der Natur, welche den oberflächlichen Phänomenen und Symptomen zugrunde lagen. Man warf den >Quaksalbern $<$, anders als in Deutschland, nicht vor, nur auf der Grundlage von Erfahrungswissen, also ohne Kenntnis medizinischer Theorien zu arbeiten, sondern eine falsche Methode, ein falsches Verfahren der Erkenntnis anzuwenden. Man warf ihnen vor, zu wenig Zeit und Mühe in die genaue Untersuchung eines Falls und der ganzen umfassenden Bedingungen einer Krankheit zu investieren.

»The medical empiric is one, who ignorant of the operations of nature, and disregarding her laws; ignorant too of the causes and characteristic symptoms of a disease, and a stranger to the opinions which at different periods have been entertained regarding it, and to the light reflected on it, by the observations and experiences of the past ages, simply asks its name, and then, without any view to rational indications of cure, administers his nostrums in random succession. Now we may fairly argue that this man's experiment must be fails, and that he must inevitably plunge himself deeper and deeper in error. $\ll^{536}$

In einem Artikel, der den Charakter einer Enthüllungsgeschichte hat, wird die Wahrheit über einen Arzt namens Van Mayersbach dargelegt und seiner Methode die eines >wahren Arztes< gegenübergestellt. Während der gelehrte Arzt in der Darstellung alle möglichen Anzeichen und Eigenschaften des Körpers, der Sekrete und Absonderungen wie auch der Umweltbedingungen in seine Überlegungen für eine Diagnose und Therapie einbezieht, ${ }^{537}$ behauptet der besagte Scharlatan, seine Schlüsse allein aus dem Lesen des Urins ziehen zu können. »>He [Doctor Van Mayersbach] tells every person, by his uncommon knowledge of urine, not only their disease, but likewise how to cure them<. «338

\section{Vgl. ebd.}

536 Forbes, Duncan: On the origin and progress of Epiricism: in: MPJ, 14.1805, S. $437-441$ : S. 438.

537 Ietros: To the Editors of the Medical and Physical Journal [Letter II. on Quacks and Empiricism. Characters II. and III. Dr. Griffenberg and Dr. Mayersbach]: in: MPJ, 12.1804, S. 213 - 216: S. 213. Vgl. auch: Ietros: To the Editors of the Medical and Physical Journal [On Quacks and Empiricism. Characters II. and III. Dr. Griffenberg and Dr. Mayersbach]: in: MPJ, 11.1804, S. 553 - 555.

538 Ietros: To the Editors of the Medical and Physical Journal [Letter II. on Quacks and Empiricism. Characters II. and III. Dr. Griffenberg and Dr. Mayersbach]: in: MPJ, 12.1804, S. 213 - 216: S. 214. 
Eine weitere Form der »Ermittlung « und Aufklärung, die man ansetzte, war die bereits erwähnte öffentliche Bloßstellung der quacks anhand von Steckbriefen, Fallund Personenbeschreibungen. ${ }^{539}$ Die Bekämpfung der quacks durch den Staat mittels gesetzlicher Verbote und Strafen blieb dagegen umstritten. Einige Ärzte hielten scheinbar eine Taktik der Umstimmung und Aufklärung der Bevölkerung über die besagte Informationspolitik für >effektiver $<{ }^{540}$ Die Unterscheidung zwischen >guter $<$ und >schlechter<, > wahrer $<$ und >falscher $<$ Mediziner bestand in ihrem Verhältnis zur Macht, bzw. in der Freiheit oder Abhängigkeit der Ärzte von willkürlicher Herrschaft.

Wie bereits erwähnt, war es ein explizites Ziel der medical reform, die Freiheit der Ausübung des Arztberufs zu sichern. Dies versuchte man auf verschiedenste Art und Weise, wie z.B. durch die Unabhängigkeit der Colleges von der Herrschaft einer kleinen Elite, den Zugang zu einer staatlich anerkannten Ausbildung, um ehrenvoll praktizieren zu können, usw. zu erreichen. Die Medizin sollte von zwei Arten der Willkür befreit werden: Erstens von der Willkür eines unwissenden Publikums und zweitens von der Willkür des College of Physicians. Interessant ist an dem zuletzt zitierten Schreiben an die Herausgeber des Medical and Physical Journal, dass dort eine Geschichte der Methode der sog. quacks erzählt wird und in Verbindung gebracht wird mit einer alten >irrationalen< und >ungerechten< Macht: Unter der als religiösdogmatisch und tyrannisch bezeichneten mittelalterlichen Herrschaft war die Medizin unfrei und daher gezwungen, ihre eigentliche Aufgabe, nämlich der Untersuchung der Naturgesetze und der Funktion des menschlichen Körpers zu vernachlässigen. Das ist der Ursprung der Methoden und des Wissens der Quacksalber. Diese >falsche< Medizin ist tief verbunden mit einer alten tyrannischen, willkürlichen und irrationalen Herrschaft. Sie ist das Ergebnis von Unfreiheit und steht der freien und zugleich wahren Medizin als ihr Gegenteil gegenüber. ${ }^{541}$

Das Beeindruckende an diesen auf den ersten Blick relativ unbedeutenden Verknüpfungen verschiedener Aussagen und Diskurse ist die Unterscheidung zwischen zwei unterschiedlichen Formen von Gouvernementalität, die in ihnen zum Vorschein kommt. Foucault schätzte den Zeitraum der ersten Entstehung dieser Machtstrategie, die mit einer spezifischen Verfahren der Veridiktion, der Untersuchung (ênquete) zusammenhing, »dieses Recht Zeugnis abzulegen, der Macht die Wahrheit entgegenzusetzen«, auf das 5. Jahrhundert v.Chr.

»Das Recht, einer Macht ohne Wahrheit eine Wahrheit ohne Macht entgegenzusetzen, führte zu einer Reihe großer kultureller Formen, die charakteristisch für die griechische Gesellschaft war. Da ist erstens die Entwicklung der rationalen Formen des empirischen und logischen Be-

539 Ietros: To the Editors of the Medical and Physical Journal [Letter II. on Quacks and Empiricism. Characters II. and III. Dr. Griffenberg and Dr. Mayersbach]: in: MPJ, 12.1804, S. 213 - 216. Vgl. auch Ietros: Letters IV. On Quacks and Empiricism: in: MPJ, 12.1804, S. $423-326$.

540 Vgl. S.M.: To the Editors of the Medical and Physical Journal [A Letter on the suppression of Quack Medicine]: in: MPJ, 2.1799, S. 150 - 152: 152.

541 Vgl. Forbes, Duncan: On the origin and progress of Epiricism: in: MPJ, 14.1805, S. 437 441: S. 439. 
weises, wie man sie nennen könnte: [...] Diese Formen sind: die Philosophie, die rationalen Systeme, die wissenschaftlichen Systeme. $\ll^{542}$

Die Technik der >Untersuchung< überdauerte und veränderte sich im Laufe des Mittelalters als Technik in gerichtlichen, juristischen und religiösen Verfahren der >Wahrheitsfindung «. Bis zu ihrer Blütezeit in der Renaissance verdrängt sie als Verfahren der Veridiktion nach und nach andere Formen, wie die $>$ Probe $\iota^{543}$ oder das göttliche Orakel. Diese verschiedenen Vorgänge der Ablösung alter Verfahren der $>$ Wahrheitsfindung < durch die Form der >Untersuchung < haben in der Abgrenzung der wahren Mediziner von den quacks in Großbritannien, innerhalb einer Strategie der Macht der surgeons und apothecaries, eine besondere Rolle gespielt. Auch Foucault ging von einem historischen Zusammenhang der Veränderung von Veridiktionsverfahren, der »Geburt des medizinischen Positivismus « und der Subjektivität wahrer Ärzte aus. ${ }^{544}$ Möglicherweise veränderte sich das ganze Selbstverständnis der Disziplin über den Weg der Gerichtsmedizin und durch die Anforderungen, die hier an die medizinischen Verfahren der Wahrheitsfindung gestellt wurden. So heißt es in einem Artikel zu dem Problem der medizinischen Jurisprudenz im Edinburgh Medical and Surgical Journal von 1823:

»The theories of medicine would not have been so proverbially baseless, if they had been surveyed with the same minuteness and caution with which medical inquiries at law must be conducted; and we cannot help thinking, that the diffusion of this new branch of knowledge is well calculated to check the growing credulity, the exuberant empiricism, and the habits of hasty induction, which characterize the works of many modern authors in our profession. $\ll^{545}$

Foucault selbst war von der Ausbreitung der gerichtlichen Verfahren der Veridiktion in andere gesellschaftliche, politische und wissenschaftliche Bereiche überzeugt. Er betonte, dass diese Veränderungen nicht aus dem Fortschritt irgendeines nach Vernunft strebenden Erkenntnissubjekt abzuleiten wären, sondern sich unter den Bedingungen einer Vielzahl von Konflikten, politischen Kräfteverhältnissen und Machtstrategien ergeben hätten. ${ }^{546}$

»Ganz allgemein verbreitete sich die gerichtliche Untersuchung [^enquêteく] [Ergänzung des Übers.] in zahlreichen anderen - sozialen und ökonomischen - Praxisbereichen und auf vielen Wissensgebieten. $\ll^{547}$

542 Foucault: Die Wahrheit und die juristischen Formen, 2003 [1974]: S. 53.

543 Obwohl es diese noch weiterhin gab, im Rahmen von Praktiken, die uns auch als besonders >irrational< scheinen, wie zum Beispiel im >Duelk $<$ das in der Renaissance und zu Beginn der Moderne noch weiterhin existierte.

544 Vgl. Foucault: Ärzte, Richter und Hexer im 17. Jahrhundert, 2001 [1969]: S. 973.

545 Paris, J.A./Fonblanque, J.S.M.: On Medical Jurisprudence: in: ESMJ, 23.1823, S. 601 630: S. 604.

546 Vgl. Foucault: Die Wahrheit und die juristischen Formen, 2003 [1974]: S. 74f.

547 Ebd.: S. 74. 
»Zusammenfassend können wir sagen: die Untersuchung [...] ist kein Wissensinhalt, sondern eine Form von Wissen. Eine Wissensform, die sich am Knotenpunkt zwischen einer Form von Macht und einer Reihe von Erkenntnisinhalten befindet. $\ll^{548}$

Foucault hat 1973 in der Vorlesung, die ich hier zitiere, kritisiert, dass immer versucht werde, dieses Verfahren der Erkenntnis auf ein Erkenntnissubjekt zurückzuführen, anstatt die Entstehung eines bestimmten Verfahrens der Erkenntnis historisch im Kontext von Kräfteverhältnissen und Konflikten verschiedener Machtstrategien zu sehen. Er ergänzte 1983 in seinen Vorlesungen zur Regierung des Selbst und der anderen, dass eben genau dieses Verfahren der Herstellung eines bestimmten Erkenntnissubjekts als moralisches, besseres Subjekt ebenso Teil einer historischen Konstellation und gegenseitigen Verknüpfung von Macht, Wissen und Subjekt seien. ${ }^{549}$ Auch das Subjekt als Subjekt der Erkenntnis, als Subjekt, das auf eine bestimmte Weise regiert werden oder selbst regieren kann - ist historische Form. Die Subjektform ist ein ebenso historisches Produkt von Konflikten und Kräfteverhältnissen wie die Wissensform. ${ }^{550}$

Man kann durchaus sagen, dass diese bestimmte Strategie, mit der sich die wissenschaftlichen Ärzte gegenüber den sog. Quacksalbern positioniert haben und wie sie sich gleichzeitig in ein bestimmtes Verhältnis zur Regierung des Selbst wie auch des Staates gesetzt haben, im Rahmen und als Teil einer bestimmten Machtstrategie zu verstehen ist. Die Wahrheit und Rechtschaffenheit des Subjekts, sowohl desjenigen, welches die Wahrheit ausspricht, wie auch desjenigen, welches die Macht ausübt, hängen an der Wahrung der Trennung von Macht und Wissen. Beide können auch nicht als Subjekte anerkannt werden; das Eine nicht als eines das Wahrheit spricht, das Andere nicht als eines das Macht ausüben kann (oder darf), wenn sie die Trennung von Wahrheit und Macht, die hier im Wesentlichen durch einen Zustand der Freiheit bezeichnet ist, nicht achten. Es ist eine spezifische Konstellation der Verfahren für Subjektivität, Wahrheit (bzw. Erkenntnis) und Macht (bzw. Gouvernementalität), die für die moderne Gouvernementalität typisch ist. Es ist das absolute Gegenteil von dem, was Hufeland Ende des 18. Jahrhunderts zum essentiellen praktischen Wissen tätiger Ärzte gezählt hat, um die Heilkunde auf Grundlage der Technik des Sçavoir faire als eine Regierungskunst zu beschreiben. Genau diese Subjektivität sollten die Mediziner nicht mehr anstreben. Auch in Deutschland sollten sie ihre Rol-

548 Ebd.: S. 77.

549 Vgl. Foucault: Die Regierung des Selbst und der anderen I, 2009 [1982 - 1883]: S. $16 f$.

550 Foucault erklärte hier rückblickend auf seine historischen Untersuchungen, es sei ihm im Grunde immer um eine bestimmte Verschiebung der Probleme gegangen: Erstens eine Verschiebung der Analyse der Machtausübung oder Geschichte der Herrschaft, zu einer Analyse der Verfahren der Gouvernementalität. Zweites eine Verschiebung von der Geschichte der Wissensformen hin zu einer historische Analyse der Veridiktion, und schließlich drittens, die Verschiebung einer Geschichte der Subjektivität zu einer historischen Analyse der Praktiken des Selbst. Foucault war der Meinung, die Theorie des Erkennens, der Macht oder des Subjekts durch eine historische Analyse der Praktiken zu ersetzen, würde zeigen, wie diese Theorien im Kern der Strategie entsprechend mit der Herrschaft heute ausgeübt wird. Vgl. ebd.: S. $17 \mathrm{ff}$. 
le als Regierende aufgeben. Sie sollten sich von der Sympathie der Patienten und deren Macht >frei< machen. In Großbritannien sollten sie sich von der Intuition und allen menschlichen Regungen frei machen. Sie sollten sich von allem frei machen, was politisch war und mit einer alten und anderen Form der Macht oder Willkür in Verbindung gebracht wurde. So forderte es ein Arzt namens Duncan Forbes in seinem Artikel On the origin and progress of Epiricism $1805 \mathrm{im}$ The Medical and Physical Journal. ${ }^{551}$ Die Wahrheit der Medizin und der Ärzte als »patient investigator « beweist sich durch eine Methode, die die Menschen und ihre Empfindungen überhaupt nicht braucht, sie sogar ausschließen muss, die sich an der Natur selbst mittels eines bestimmten Verfahrens - der Untersuchung, der Wahrheitsfindung herstellen lässt. ${ }^{552}$

Die Auseinandersetzungen, die zur Herausbildung eines starken anti-kontagionistischen Lagers in England und Schottland im ersten Drittel des 19. Jahrhunderts führten, zeigen ebenfalls deutlich, wie sich Machtstrategie mit dem Verfahren der Veridiktion verbanden. ${ }^{53}$ In gleicher Weise werden sich die wissenschaftlichen Mediziner in England und Schottland vor die Königin und das Parlament stellen und die Wahrheit darüber sagen, was eine gute Regierung der Gesundheit bedeutet. Eine gute Regierung muss die Trennung von Erkenntnis und Macht akzeptieren. Sie muss die Ärzte und andere Wissenschaftler als Experten heranziehen bei der Frage, wieviel Arbeit ein Kind eines bestimmten Alters erträgt, wieviel giftigen Staub die Arbeiter einer Chemiefabrik einatmen dürfen, welche Maßnahmen gegen eine Seuche angewendet werden sollen etc. Trifft sie Entscheidungen ohne dieses aus einer Reihe von Untersuchungen gewonnene Wissen, wird ihre Entscheidung als willkürlich und irra-

551 Vgl. Forbes, Duncan: On the origin and progress of Epiricism: in: MPJ, 14.1805, S. 437 441: S. 441.

552 Vgl. auch Royston, W.: Historical Sketch of the Progress of Medicine in the Year 1806: in: MPJ, 18.1807, S. 1 - 43: S. 1.

553 Vgl. z.B. 1. Origines Contagii: Scripsit Marx, C.F.H.: Caroliruhae et Badae. Apud D.R. Marx. 1824. On the Origin of Doctrine of Contagion. By Dr. C.F.H. Marx. Carlsruhe and Baden. Published by D.R. Marx, 1824. 2. Contagio cognito agli storici e filosofi antichi, ignoranto dai medici Greci, Latini, Arabi, non immaginato da Papa Paolo III. Errore di Maclean. - Dottrina del contagio fondata nesecolo quinto decimo da Marsilio di Medicina compilati dal Signor Dottore Annibale Omodei. Milano 1822: in: ESMJ, 24.1825, S. 99 - 143: S. 143. Es ist interessant zu sehen, wie um ein solches negatives Prüfungsverfahren der Wahrheit über ihre Verbindung mit Macht eine Vielzahl von Unterscheidungen von historischen Epochen und Regierungen getroffen werden. Stammt das Wissen aus einer Zeit, in der >richtige< Wissenschaft betrieben worden sei (hierzu zählen anscheinend die Antike - Rom und Griechenland - und auch die Moderne) oder stammt das Wissen aus einer Zeit wie dem Mittelalter, wo die Bedingungen der wahren Wissensproduktion nicht gegeben gewesen sei? Und zwar, weil die Herrschaft, die Regierungsform nicht entsprechend wäre, also die Freiheit nicht existiert habe. Auch wenn man hier nicht zu dem Schluss kommt, dass die Idee der Ansteckung völlig hinfällig ist, so ist doch klar gesagt, dass die Behauptung, es gäbe Ansteckung und die Gruppe der kontagiösen Krankheiten, auf keinen Fall einfach fortgeführt werden kann. Wer von Ansteckung also sprechen will, muss sich neue Beweise und Argumente suchen. Die Begründung der alte Doktrin ist nicht mehr gültig! 
tional angesehen werden und ihre Souveränität in ein fragwürdiges Licht gestellt. Sie kann auch nicht gut regieren.

\section{Von der Selbsttechnik zur Sicherheitstechnik}

\section{Moralität und Wirklichkeit}

Wie ich bereits kurz angedeutet habe, entwickelte sich in England und Schottland unter dem Einfluss des Puritanismus und Protestantismus und auch der materialistischen und liberalen Philosophie ein Diskurs um Selbstpraxis, der die christlichen und traditionellen Praxen des Selbst, asketische Praxen, Praxen der Besserung, der Beichte mit Ziel des Seelenheils, zum ersten Mal wirklich in Frage stellte. Dieser Diskurs erweckt den Anschein, eine Art reiner Anti-Moraldiskurs zu sein. Zwar blieb man einer Reihe von christlichen Bestimmungen des >Guten< treu, verlangte aber eine Transformation der Praxen und der Verhaltensformen, nach denen ein gutes Selbst bestimmt und hergestellt werden sollte. Doch der Diskurs geht nicht nur gegen Aspekte der alten Moral vor, er ist zugleich ein Gegendiskurs, der genau so wie jeder andere Diskurs um Selbstpraxis seit dem »Zeitalter der Verhaltensführungen $«{ }^{54}$ als Angriff auf bestehende Machtverteilung und Machtverhältnisse funktionierte. Auch dieser Diskurs ging nicht weniger als andere mit der Einführung oder dem Vorschlag eines neuen moralischen Verfahrens für moralische Subjektivität einher. Während Kant die Selbsterkenntnis des Subjekts als ein Vernünftiges zur Bedingung seiner Freiheit gesetzt hat, richtet sich das Augenmerk der englischen liberalen Philosophie auf etwas Anderes. Indem man dem Individuum die Freiheit gab, sich um seine eigene Existenz zu sorgen, oder vielmehr, indem man es den Bedrohungen seiner Existenz aussetzt, nötigte man es, sich seiner Vernunft zu bedienen. Was ist diese Vernunft? Sie ist die Fähigkeit, sich gemäß den Umständen und Bedingungen, die sich in seinen Erfahrungen als Probleme seiner Existenz stellen, entsprechend zu verhalten. Die Vernunft basiert auf einer durch eine bestimmte Praxis generierte Kenntnis über die Bedingungen und erfolgreichen Strategien der Existenz. Die Idee der Diätetik, der Sorge um sich und der Sorge um die Gesundheit, wurde gewissermaßen von ihrer moralisch-religiösen metaphysischen Klammer befreit und auf den materiellen Boden der Tatsachen geholt. Die geistige moralische Entwicklung der Menschen, ihre Selbsterkenntnis, ist nicht die Bedingung ihrer >Autonomie<, um die es letztlich auch bei Kant ging. Man ging im Grunde davon aus, dass eine bestimmte ökonomische Rationalität und Berechnung als bestimmender Faktor menschlichen Handelns naturgemäß vorhanden ist, d.h. im Zustand der Freiheit automatisch zum Tragen kommt. So könnte man in etwa auch David Humes Überlegungen zur Moral einordnen. Menschliche Wahrnehmung, Empfindung ${ }^{55}$ und Erfahrung sind laut ihm die Quelle von Moralität. Der wirkliche »Ursprung der Moral« ließe sich, so Hume, nicht aus der innerlichen menschlichen Natur, die nach Meinung der Einen schlecht und nach

554 Foucault nannte es das »Zeitalter der Verhaltensführungen« Foucault: Geschichte der Gouvernementalität I, 2004 [1977 - 1978]: S. 333.

$555 »[\mathrm{I}] \mathrm{f}$ virtue and vice be determined by pleasure and pain, these qualities must, in every case, arise from the sensations[.] Hume: A treatise of human nature. 2. Bd., 1817 [1739/1740]: S. 174. 
Meinung der Anderen gut sei, ableiten. Stattdessen sei das Universelle und Rationale moralischer Unterscheidungen von gut und schlecht nur von der Praxis gesellschaftlichen Zusammenlebens her zu bestimmten. Moralität leite sich nicht aus einem fernen, außerhalb der menschlichen Welt stehenden göttlichen Prinzip ab. ${ }^{556}$ Sondern dadurch, dass die moralischen Regeln den Menschen und der Gesellschaft nützlich, annehmbar oder sogar angenehm erschienen: »Usefulness is agreeable, and engages our Approbation $\ll .{ }^{57}$

Für Kant war es schlicht unmöglich zugleich >Empiriker< oder >Materialist< wie der, wie er ihn nannte, »kaltblütige« Hume oder der »aller transzendenten Spekulation abgeneigte [...] Priestley $\ll^{558} \mathrm{zu}$ sein und weiterhin moralische, religiöse oder auch nur normative Aussagen zu machen. In England hatten sich aufgrund verschiedener historischer Bedingungen im 17. und 18. Jahrhundert philosophische Strömungen des Empirismus, Materialismus und Realismus herausgebildet. Diese nahmen erheblichen Einfluss auf die politische Theorie und die Wissenschaftspraxis. Während Kant über u.a. Hume und Priestley herzog, machten sich britische Philosophen ebenso wie gelehrte Mediziner über die Metaphysik und die naturphilosophische Beeinflussung der Medizin in Deutschland lustig. In den von mir analysierten Artikeln, die sich mit den Aufgaben der Ärzte, dem Problem der irregular practitioners und der Medizin als Wissenschaft beschäftigen, wird die Empirie nirgends so negativ aufgefasst, wie das in den französischen und deutschen Zeitschriften in diesem Zeitraum der Fall war. Es herrschte allem Anschein nach große Skepsis gegenüber allgemeineren oder grundlegenden medizinischen Theorien über Krankheiten, Krankheitsursachen und Funktionsweisen menschlicher und tierischer Körper. Alle breiter angelegten Theorien wurde ihr notwendig spekulativer Anteil zum Vorwurf gemacht. Die Untersuchung der Fälle unter Einbeziehung einer möglichst großen Anzahl von Faktoren galten noch deutlicher als in den anderen beiden Ländern als einzig anerkannte Methode medizinischer Forschung. Besonders in der Entwicklung der Epidemiologie sollte dies später Konsequenzen haben. Hier zeigte sich, dass die Wahl der jeweiligen Techniken, seien es Techniken der Isolation oder Techniken der Desinfektion oder allgemeinen Hygiene jeweils von der spezifischen Beobachtung einer Seuche an einem Ort abhängig gemacht werden sollte. Hierzu gehörte auch, das Verhalten der Menschen, die sich an diesem Ort aufhielten, und ihre materialistische Natur als nur einen weiteren Faktor miteinzubeziehen. Wie sich die Regierung bei der Wahl ihrer Techniken nach der Wirklichkeit der jeweiligen Krankheit zu richten hatte, so musste sie sich auch der Wirklichkeit menschlichen Verhaltens beugen, indem sie das Wissen über die Krankheiten ebenso wie über die Menschen zur Rationalisierung ihrer Techniken anzuwenden hatte.

Es war legitim auf der Grundlage dieses Erfahrungswissens zu praktizieren und zu regieren. Das Verfahren blieb offen und war keiner moralisch oder politisch relevanten Philosophie verpflichtet. ${ }^{559}$ Die Abgrenzung der britischen wissenschaftlichen

556 Vgl. ebd.: S. 167.

557 Hume: An Enquiry Concerning the Principles of Morals, 1751: S. 82. Vgl. ebd.: S. 61.

558 Kant: Kritik der reinen Vernunft 2, 1968 [1. Aufl. 1781, 2. Aufl.1787]: S. 345f/A 745.

559 Ich werde weiter unten noch darauf eingehen, welche Art von Verbindung und Vorstellung von Moral sich hieraus ergaben. 
Mediziner gegenüber den sog. quacks erfolgte nicht wie z.B. in Deutschland über die Differenz von Theorie bzw. Philosophie und Empirie, sondern über die Methode der Untersuchung, des Verfahrens der Veridiktion. Weder nur Empirie und Praxis noch ausschließlich Theorie und Philosophie waren der Schlüssel zur Wahrheit, sondern die Untersuchung. ${ }^{560}$ Dementsprechend nahm man in England bereitwillig alles Neue an Erkenntnissen der Medizin aus Frankreich und Deutschland auf, während man gleichzeitig über die Wissensform, in welche man die Erkenntnisse übersetzten wollte, spottete.

»The scientific part of the medicine acquired in Germany and France, great additions of new materials, which, though treated in very different ways, and even prematurely formed into systems, never lose their value, however preposterously applied in some instances. $\ll^{561}$

In Frankreich strebten Mediziner eine vereinfachte Nomenklatur und ein System wie das der Chemie im Sinne Lavoisiers oder anderer Naturwissenschaften an. In Deutschland war, zumindest für eine kurze Zeit, die Philosophie das Vorbild der Heilkunst. Es waren unterschiedliche Strategien Wissen zu ordnen und über die Regierbarkeit von Gesundheit zu verhandeln, die sich an der Wahrheit über die Natur und den Menschen zu orientieren hatten. Das bedeutete im Umkehrschluss aber auch, dass mit jedem wissenschaftlichen Prinzip und jeder grundlegenden Erkenntnis möglicherweise die Grundlage, auf die sich politische Techniken und eine Regierung gerichtet hatten, hinweg gerissen werden konnte (wie z.B. in Frankreich). ${ }^{562}$ Oder man entschied sich, bevor die Medizin nicht zu der einfachen und tiefen Ursache von Krankheiten vorgedrungen war, von Seiten der Regierung lieber nichts zu unternehmen oder zumindest keine neuen Maßnahmen zu ergreifen (Deutschland). Besonders die Geschwindigkeit, mit der Anfang des 19. Jahrhunderts medizinisches und hygienisches Wissen produziert wurde, unterstützte diese Einstellung ebenso, wie sie teilweise deren Ergebnis war. Welcher Wissenschaft entsprach dagegen der erkenntnistheoretische Zugang, auf den sich die englischen Mediziner oder Epidemiologie beriefen? Ihr Vorbild war nichts anderes als die Politische Ökonomie. Die Politische Ökonomie war, wie Bohlender schrieb, im 18. Jahrhundert in England und Schottland das Ergebnis eines Versuchs zur Bewältigung einer Krise des Regierens. ${ }^{563}$

Die Argumentationen der liberalen Ökonomen war eine Strategie oder besser eine kritische Intervention im Diskurs um politische Ökonomie. Sie bestand in einer um-

560 Vgl. Abercrombie, John: Inquiries concerning the Intellectual Powers, and the investigation of Truth: in: ESMJ, 35.1831, S. 401 - 426: S. 401f. Vgl. u.a. auch: Regnault, J.B.: Considerations on the State of Medicine in France, from the Time of the Revolution to the present Period: in: MPJ, 42.1819, S. 455 - 462: S. 461.

561 Vgl. [Hrsg.]: Critical Review of the Stat of Medicine during the last Ten Years: in: ESMJ, 12.1816, S. 365 - 411: S. 386.

562 Vgl. Regnault, J.B.: Considerations on the State of Medicine in France, from the Time of the Revolution to the present Period: in: MPJ, 42.1819, S. 455 - 462.

563 »Genealogisch betrachtet entsteht die politische Ökonomie aus einer Problematisierung der Regierungsrationalität des Staates.«Vgl. Bohlender: Metamorphosen des liberalen Regierungsdenkens, 2007: S. 119. 
fassenden Kritik der Regierung, die von der Ökonomie her gedacht wurde. Eine Kritik, die sagte, der Markt und die Ökonomie sei in Wirklichkeit ein relativ perfektes selbstregulatives System und die Regierung dürfe diese Mechanismen und Kräfte der >Selbstregulation< und >Selbstheilung < nicht missachten. Die reformerischen Mediziner haben gesagt, die Medizin habe auch, wie die Nationalökonomie, keinen abgeschlossenen Gegenstand.

In einem Artikel aus dem Edinburgh Medical and Surgical Journal von 1831 wird die Erkenntnis des weiter oben bereits erwähnten französischen Arztes Cabanis ausgerechnet nicht wegen seiner Verdienste für die Reformierung der Medizin und Hygiene in Frankreich gelobt, sondern dafür, dass er festgestellt hatte, dass sich die Medizin $^{564}$ ähnlich wie Ethik nicht in einem bestimmten abgeschlossenen Gegenstand der Untersuchung begrenzen ließe. ${ }^{565}$

»The sum of those causes which tend to improve the physical part of our frame prepare the materials, or furnish the instruments, for putting others into the state of activity. All are in a state of contact; medicine is their natural centre. The science of medicine from its origin to the present time. $« 566$

Wie Andrew Aisenberg hervorhob, wendete sich Cabanis nach der Französischen Revolution immer weniger medizinische Themen und immer mehr dem Problem der Moralität zu. Seine Arbeiten lieferten einen entscheidenden Beitrag zu den Strategien und Begründungen staatlicher Gesundheitspolitik, auch über Frankreich hinaus. ${ }^{567}$

»Cabani's definition of reason is crucial to understanding the discursive operations of science that contributed the social and moral authority of the state. For Cabanis does not address explicitly why the recognition of individual physical differences necessitates the separation of

564 » The first author [...] who appears to have attempted to place this perculiar character of the medical sciences in its true light is Cabanis, who ranks medicine with ethics in this respect.« Abercrombie, John: Inquiries concerning the Intellectual Powers, and the investigation of Truth: in: ESMJ, 35.1831, S. 401 - 426: S. 407. Es handelt sich hier um einen für die Zeit der Revolution typischen extrem weit gefassten Begriff der Medizin im Sinne der Art de guérir, die die Aufgaben der Seelsorge, der praktischen Ärzte und der Medizin als Wissenschaft miteinander verbinden sollte.

$565 \mathrm{Vgl}$. Abercrombie, John: Inquiries concerning the Intellectual Powers, and the investigation of Truth: in: ESMJ, 35.1831, S. 401 - 426: S. 406. Interessant ist an Cabanis, dass er, wie Foucault schrieb, mit seinen Überlegungen zur Beobachtung und Methode der medizinischen Forschung die Entwickelung der Klinischen Medizin unterstützte. (Vgl. Foucault: Die Geburt der Klinik, 2008 [1963]: S. 131.) Dabei stand Cabanis, was seine Philosophie und gerade seine methodisch-epistemologischen Überlegungen anging, eher dem Empirismus Newtons näher als z.B. Descarts. Vgl. Labisch: Homo Hygienicus Gesundheit und Medizin in der Neuzeit, 1992: S. 107.

566 Abercrombie, John: Inquiries concerning the Intellectual Powers, and the investigation of Truth: in: ESMJ, 35.1831, S. 401 - 426: S. 407.

567 Vgl. Aisenberg: Contagion. Disease, Government, and the »Social Question« in Nineteenth-Century France, 1999: S. 8f. 
reason and morality. Nor does he explain why human reason is inadequate for making individuals both free and selfregulating, while scientific rationality makes the state ideally suited for assuming moral questions in a free society. His definition of reason becomes coherent only in relation to a vision of science as a source of legitimacy for the state in addressing the social problems and conflicts produced by democratic experience. $« 568$

Allerdings genügten Cabanis politische Schlussfolgerungen, die er aus der Vereinigung der Medizin mit der Hygiene und der hippokratischen Ethik zog, dem Autor des schottischen Journals noch nicht. Welchen Charakter müsste man dem eher weit gefassten und unbegrenzten Gegenstand einer solchen Medizin geben, damit diese eine »source of legitimacy«, ebenso wie eine Quelle der Rationalisierung für den Staat und seine Gesundheitspolitik sein könnte?

»This difficulty is recognized and still more distinctly averted to be the late Mr Stewart, who places medicine in this respect on the same footing with the science of political economy and who ascribes the imperfection of medicine $[\ldots] . \ll 69$

Die Probleme und Phänomene, mit denen sich die Nationalökonomie und die Medizin befassen würden, auch wenn sie gewissen Gesetzmäßigkeiten folgten, seien von keiner Wissenschaft vollständig zu durchdringen. Die Ökonomie sei das Zusammenwirken und das Spiel unzähliger Faktoren und Kräfte, die sich nicht auf ein bestimmtes natürliches Prinzip reduzieren ließen. Die Nationalökonomie richte sich auf die Untersuchung der Zusammenhänge und Verbindungen zwischen diesen Faktoren, ohne in der Lage zu sein, hierdurch alle Phänomene voraussehen zu können. In gleicher Weise müsse auch ein Arzt oder die Medizin ihre Aufmerksamkeit auf den Körper richten.

»The body politic, as well as the natural body, possesses within itself conservative properties, which accommodate it to every circumstance and situation, and by some counteracting influence weaken or render harmless what it cannot correct or remove. $\aleph^{570}$

Wie die Ökonomie im Zustand von Freiheit sei auch der Körper ein selbstregulatives System, dessen innere Zusammenhänge nicht in einem vollständigen Maße zu durchschauen, geschweige denn zu steuern seien. Deshalb sei die Medizin ebenso wie die politische Ökonomie eine unsichere Wissenschaft:

568 Ebd.: S. 9.

569 Abercrombie, John: Inquiries concerning the Intellectual Powers, and the investigation of Truth: in: ESMJ, 35.1831, S. 401 - 426: S. 407f.

570 Barlow, Edward: Essay on the Medical Profession, showing its natural unity, and suggesting such arrangements as would render its condition conformably to just principales of Political Science, and conducive to interests both of the Profession and the Public [...]: in: ESMJ, 28.1827, S. 332 - 356: S. 339. Ich vermute die Parallelisierung von »body politic « und »natural body« ist einem Text von Bacon entnommen. 
»As examples of the uncertain sciences, therefore, we may mention medicine and political economy; and their uncertainty is referable to the same sources, namely, the difficulty of ascertaining the true relation of things, or of tracing effects to their true causes and causes to their true effects; and the intervention of new causes which elude our observation, while they interfere with the natural tendencies of things, and defeat our attempts to produce certain results by bringing them into action. The scientific physician well knows the difficulty which attends all his efforts to produce particular results. A person, for example, affected with a disease, recovers under the cure of a particular remedy. A second is affected with the same disease, and uses this remedy without any benefit; while a third recovers under a very different remedy or without any treatment at all. [...] But in particular instance he may fail entirely in relieving the disease by the most assiduous use of these remedies; for the real and true tendencies of these bodies are interrupted by certain other causes in the constitution itself, which entirely eludes observation, and are in no degree under his control. « ${ }^{571}$

Die Aufgabe der medizinischen Wissenschaft richte sich auf die Untersuchung der Zusammenhänge, der Ursachen und Wirkungen mit dem Ziel, direkte und praktische Regeln zu entwerfen. Man suche nicht nach einem Prinzip, von dem aus eine Regierung, wenn sie es verstanden habe, alle Vorgänge bestimmen und steuern könnte. ${ }^{572}$ Francis Bacon, auf den sich der Autor des Artikels im Edinburgh Medical and Surgical Journal bezog, hat selbst in seiner Schrift De dignitate et augmentis scientiarum, die 1623 erschien, auf die Schwierigkeit der Arbeit der Ärzte verwiesen, die es mit einem unendlich komplizierten Gegenstand - dem menschlichen Körper - zu tun hätten.

»For of all natural bodies, we find none so variously compounded as the human [...]. This variable and subtile composition, and fabric of the human body, makes it, like a kind of curious musical instrument, easily disordered. $\ll^{573}$

Als Beispiel dieses komplizierten Zusammenwirkens sehr unterschiedlicher physiologischer wie auch mentaler und moralischer Probleme nennt der Autor des Journals, wie auch Cabanis zuvor, ${ }^{574}$ den $»$ Wahnsinn $«$ (insanity). ${ }^{575}$ Konsequent im Sinne der eher ökonomischen Analyse natürlicher und pathologischer Phänomene, wird auch die Naturgeschichte, die Vorgängerin der Biologie - wenn man so will, als eine

571 Abercrombie, John: Inquiries concerning the Intellectual Powers, and the investigation of Truth: in: ESMJ, 35.1831, S. 401 - 426: S. 408.

572 Vgl. ebd. Ein paar Seiten später wird auch auf Francis Bacon und dessen Abneigung gegen Letztbegründungen, »final causes« verwiesen. Vgl. ebd.: S. 411.

573 Bacon: The Works of Francis Bacon, 1. Bd., 1815 [1723]: S. 137f.

574 Im Edinburgh Medical and Surgical Journal wurde 1807 das ein Jahr zuvor von PierreJean-Georges Cabanis herausgegebene Buch Coup d'oeil sur les revolutions et sur la reform de la medicine besprochen: Vgl. Handerson, Alexander: A Sketch of the Revolutions of Medical Science, and Views relative to Reforms. By P.J.G. Cabanis [...]: in: ESMJ, 3.1807, S. $241-244$.

575 Vgl. Abercrombie, John: Inquiries concerning the Intellectual Powers, and the investigation of Truth: in: ESMJ, 35.1831, S. 401 - 426: S. 414. 
Grundlagenwissenschaft der Medizin - einer ähnlichen Erkenntnistheorie und Methode unterworfen. Man könne demnach die Natur und die menschliche Natur als quasi biologisches selbstregulatives System betrachten und auch so erforschen. ${ }^{576}$

Eine Wissenschaft vom Leben, die zuvor von der Physiologie behandelt wurde, wird nun zu einer Ökonomie der Existenz der menschlichen Gattung und der ökonomischen Gesetze, die diese Existenz steuern oder ihre Entwicklung vorangetrieben haben. ${ }^{577}$ Genau dieses »boundless field for enquiry « der Wissenschaft von der Ökonomie der Existenz rückte in das Interessenfeld der medizinischen und sonstigen wissenschaftlichen Presse ${ }^{578}: »[\mathrm{~T}]$ o gain more accurate and enlarged views of the nature of existence ${ }^{579}$. Der Grund dafür sei - vielleicht etwas vereinfacht ausgedrückt -, dass u.a. die Medizin, wenn sie gesellschaftlich und politisch einen gewissen Status einnehmen will, ihre Ähnlichkeit zur Ökonomie proklamieren muss. So wie die Mediziner in Deutschland Philosophen sein wollten, um die Regierung nicht nur mit einem Wissen, sondern mit einer Rationalität zu versorgen, wollen die Mediziner in Großbritannien Nationalökonomen sein. Denn das ist die Wissenschaft, die die Regierung in Großbritannien mit ihrer neuen Rationalität versorgen wird, die eine Forum der Kritik, der Korrektur und Ausgangspunkt ihrer Rationalisierung sein wird. Die > wahre $<$ (auch medizinische) Naturwissenschaft besteht nicht in der Suche nach ihrer grundlegenden chemischen oder physikalischen Gesetze, sondern in der Erforschung der Ökonomie, also des Zusammenspiels der heterogenen Kräfte, der ihr inhärenten »checks « und »balances «, die sie regulieren - »the laws which govern the creation $\ll{ }^{580}$ Aus genau diesen Überlegungen speist sich die Idee des »ever-active population-principle ${ }^{581}$. Die biologischen Gesetze, die die Population der Tiere und der Menschen regulieren, fährt der Autor mit Verweis auf das von Malthus aufgestellten Gesetzes fort, sei im Prinzip keine neue Erkenntnis, sondern zu jeder Zeit und auch schon unter Platon und Aristoteles beobachtbares Faktum gewesen. ${ }^{582}$ Was bedeutet es aber, die Frage der menschlichen Existenz, die traditionell eine philosophische, eine ethische und praktische war, auf diese Weise zu stellen? Es ist im Prinzip nichts weiter als zu behaupten, die Natur und vielleicht sogar Gott hat bestimmte Ge-

576 Vgl. Gold, F. [Royal College of Surgeons]: Pysiological Research on Life and Death. By Xavia Bichat [...]: in: MPJ, 34.1815, S. 41 - 55: S. 41.

577 Hierzu zählt auch die naturgeschichtliche Entstehungstheorie verschiedener >Menschenrassen< als eine Art frühes biologisch-rassistische Wissen. Vgl. Pitna, N.C.: Treatise on the Influence of Climate an the Human Species; and on the Varieties of Man resulting from it; including an Account of Criteria of Intelligence which the Form of the Head presents; and a Sketch of a rational System of Physiognomy as founded on Physiology [...]: in: MPJ, 28.1812, S. $488-494$.

578 Vgl. Fothergill, Charles: An Essay on the Philosophy, Study and Use, of natural History [...]: in: MPJ, 29.1813: S. 501.

579 Ebd.: S. 502.

580 Ebd.: S. 503.

581 Ebd.: S. 504f.

582 Vgl. ebd.: S. 504. 
setze zur Regulierung von Populationen eingerichtet, um Katastrophen, um Schlimmes zu verhindern (»in order to avoid greater evils «). ${ }^{583}$

Aus dieser spezifischen erkenntnistheoretischen Herangehensweise, dieser relativ neuen weniger naturwissenschaftlichen als der Ökonomie nachempfundenen Wissensform, die sich ihre Methode der Veridiktion einem juristischen Verfahren der Wahrheitsfindung - der Untersuchung - entlehnt hat und eben nicht so sehr eine Form der moralisch-religiösem Verfahren der Wahrheitsprüfung ist, begründet sich eine ebenso ökonomische politische Rationalität. Ein modernes Verfahren der Gouvernementalität, das sich von einem wissenschaftlichen Verfahren der Veridiktion abhängig macht, eine Regierung, die nur eine gute Regierung sein kann, wenn sie die Natur und Wirklichkeit dessen beachtet, was sie regiert, dieser Regierung wird nun offenbart, dass sie in Wirklichkeit nicht die innere Natur, den Ursprung von Moralität oder Gerechtigkeit aus der metaphysischen Vernunft der Menschen voraussetzen soll, sondern, dass sie es in Wahrheit mit einem historisch gewachsenen Feld zu tun hat, in dem heterogene Kräfte wirken. Matthias Bohlender hat hierzu angemerkt, dass Hume als einer der ersten Philosophen, die im 18. Jahrhundert eine Krise des juridischen Regierungsdenkens diagnostizierten, ein wirkliches Gegenmodell geliefert hat:

»Nicht Anerkennung und Ergänzung [wie es laut Bohlender Rousseaus Anliegen war], sondern völlige Zurückweisung dieses herkömmlichen Regierungsdenkens ist sein Ziel. Die Krise der politischen Rationalität - so wird sich bei ihm am Ende herausstellen - ist nicht der Effekt einer Schwäche, die es zu korrigieren gilt, sondern gründet zutiefst in der vermeintlichen Stärke des Rechts- und Gesetzesdenkens selbst, in seiner Rationalität, seiner Künstlichkeit und unnatürlichen Repressivität gegenüber den Bedürfnissen und Begehren der menschlichen Natur. Infolge dieser Umkehrung der Krisendiagnose verlässt Hume den epistemologischen Rahmen einer Suche nach der juridisch-politischen Legitimität von Herrschaft und ihrer Regierungsformen (Monarchie, Aristokratie, Republik/Demokratie) und fragt stattdessen nach der sozialen Empirizität menschlicher Ordnung (Familie, Gesellschaft, Regierung). $\ll^{584}$

Die Gesellschaft, schreibt Bohlender, sei für Hume eine historische Realität, sie sei kein kognitives oder juristisches Konstrukt, sondern die Antwort der Menschen auf ihre natürlichen Bedürfnisse, Schwächen und Neigungen. ${ }^{585}$ Die Gesellschaft wächst und reguliert sich historisch aus den Versuchen der Menschen ihre Bedürfnisse zu befriedigen und die Konflikte verschiedener Bedürfnisse aufzulösen. Nur vermittelt über die Bedürfnisse der Menschen lässt sich eine Gesellschaft regulieren. Welche Folge hat das für die Gesetze? Was sind die Gesetze, wenn sie selbst nicht mit Bezug auf eine ahistorische menschliche Natur entwickelt und an dieser geprüft werden können? Was sind die Gesetze, wenn sie nicht mehr außerhalb der Regierung als deren übergeordnetes und begrenzendes Prinzip stehen? Die Gesetze werden zum Mittel, sie werden zum Instrument der Regulierung. ${ }^{586}$ Sie werden der Regierung untergeordnet, ihrer Rationalität und der historischen Wirklichkeit auf die sie sich bezie-

583 Ebd.: S. 505.

584 Bohlender: Metamorphosen des liberalen Regierungsdenkens, 2007: S. 43.

585 Vgl. ebd.: S. 44.

586 Vgl. Hume: An Enquiry Concerning the Principles of Morals, 1751: S. 65. 
hen. »The Laws have, or ought to have, a constant Reference to the Constitution of Government, the Manners, the Climate, the Religion, the Commerce, the Situation of each Society. ${ }^{587}$ Durch eine Neuordnung des Verhältnisses von Gesetzen und Regierung werden die Gesetze aufhören, eine äußere und begrenzende Macht zu sein. Die liberale Regierung, die eine solche Beziehung zum Recht unterhält, ist zu einer weit umfassenderen Machtausübung fähig als etwa die Regierung in Frankreich, wo das juridischen Regierungsdenken als Grundlage der Revolution gedient hatte.

Im Unterschied zu der Vorstellung, dass sich eine Regierung an den fixen Naturgesetzen einer passiven Natur in newtonschem Sinne auszurichten habe, geht es hier um historische Kräfteverhältnisse und Strukturen, die anerkannt und regiert werden sollen. Die Regierung hat sich weniger mit dem zu beschäftigen, was die ideale Existenz der Menschen ist und in welchem Bereich dieser Existenz ihre Regierung legitim ist. Eher soll sie sich mit dem Problem und der Wirklichkeit der Kräfte befassen. Hume warf den Philosophen der Metaphysik vor, sie würden, da sie die Göttlichkeit (Deity) und den transzendenten Geist als Urheber aller Aktivität und Bewegung, die Materie hingegen nur als passiv und nur durch den Geist bewegt vorstellten, zu keiner rationalen Erkenntnis über die Wirklichkeit der »Kräfte«, weder von Geist noch von Körper, fähig sein. ${ }^{588} »[$ T] hey have no adequate idea of power or efficiancy in any object; since neither in body nor spirit, neither in superior nor inferior natures, are they able to discover one single instance of it. $"{ }^{589}$ Es handelt sich um einen stetig sich verändernden und komplizierten Gegenstand. Eine Regierung, die ihm gerecht werden will, die in der Lage sein will, ihn zu regieren, muss sich seiner veränderten Struktur anpassen. Sie muss sich offen gegenüber neuem Wissen zeigen, die ihr die Zusammenhänge des heterogenen und unsteten Gegenstands, den sie regiert, erhellen. Die Macht der Regierung hängt nicht an ihrer Übereinstimmung mit einem bestimmten Prinzip, im Sinne einer tieferen Wahrheit ab, die von den sozialen Interaktionen überlagert wird, sondern sie ergibt sich genau aus der Analyse dieser Interaktionen. Die Kunst der Regierung ist, sich nach einer Ökonomie, einem regulierten Spiel und den Beziehungen von Kräften zu richten und die Regeln dieses Spiels als ihre eigene Rationalität anzunehmen, gewissermaßen als ihr eigenes historisches Rationalisierungskonzept.

James Steuart, auf den in einem Artikel in Edinburgh Medical and Surgical Journal Bezug genommen wird, schreibt in seiner Inquiry into the Principles of Political Economy:

$»$ All actions, and all things indeed, are good or bad by relation only. Nothing is so complex as relations when considered with regard to a society, and nothing is so difficult as to discover truth, when involved and blended with these relations. [...] We are not to conclude from this, that every operation of government must become problematical and uncertain [...] A government must be continually in action, and one principal object of its attention must be, the conse-

587 Vgl. ebd.: S. 54.

588 »There are no ideas, which occur in metaphysics; more obscure and uncertain, than those of. power, force, energy, or necessary connexion« Vgl. Hume: An Enquiry concerning Human understanding, 1809 [1748]: S. 73.

589 Hume: Of the idea of necessary connexion, 1826 [1748]: S. $212 f$. 
quences and effects of new institutions. Experience alone will shew, what human prudence could not foresee; and mistakes must be corrected as often as expediency requires. All governments have what they call their fundamental laws; but fundamental, that is, invariable laws, can never subsist among men, the most variable thing we know: the only fundamental law, salus populi, must ever be relative, like every other thing. But this is rather a maxim than a law. «990

Adam Smith hat in seinem berühmten Text An Inquiry into the Nature and Causes of the Wealth of Nations der Medizin ebenso wie der Politischen Ökonomie die Aufgabe erteilt, das Wissen, das sie zur Regierung des Körpers oder des Staates liefern, nicht auf ein spekulativ abgeleitetes Recht oder ein Gesetz der Natur zu begründen, sondern es aus der materiellen Wirklichkeit des Gegenstandes der Regierung selbst abzuleiten. Wie gesagt, entsprach diese Argumentation einer bestimmten liberalen Strategie der Kritik der Politischen Ökonomie, die auf die gesamte Rationalität der Regierung zielte. Wobei sie zugleich einen Weg präsentierte, wie sich die Regierung in einer Weise rationalisieren und so die Krise ihrer Legitimität überwinden könnte. Eine Regierung und ein Arzt, schrieb auch Smith, müssen gleichermaßen, wenn sie keinen Schaden anrichten wollen, diese natürlichen Vorgänge und Regulierungsmechanismen respektieren oder sogar ihr freies Wirken fördern. Ich erlaube mir hier ein etwas längeres Zitat von Smith einzufügen, das meiner Meinung das bisher Gesagte sehr eindrücklich belegt.

»Some speculative physicians seem to have imagined that the health of the human body could be preserved only by a certain precise regimen of diet and exercise, of which every, the smallest, violation necessarily occasioned some degree of disease or disorder proportioned to the degree of the violation. Experience, however, would seem to show that the human body frequently preserves, to all appearances at least, the most perfect state of health under a vast variety of different regimens; even under some which are generally believed to be very far from being perfectly wholesome. But the healthful state of the human body, it would seem, contains in itself some unknown principle of preservation, capable either of preventing or of correcting, in many respects, the bad effects even of a very faulty regimen. Mr. Quesnai, who was himself a physician, and a very speculative physician, seems to have entertained a notion of the same kind concerning the political body, and to have imagined that it would thrive and prosper only under a certain precise regimen, the exact regimen of perfect liberty and perfect justice. $\mathrm{He}$ seems not to have considered that, in the political body, the natural effort which every man is continually making to better his own condition is a principle of preservation capable of preventing and correcting, in many respects, the bad effects of a political œeconomy, in some degree, both partial and oppressive. Such a political œconomy, though it no doubt retards more or less, is not always capable of stopping altogether the natural progress of a nation towards wealth and prosperity, and still less of making it go backwards. If a nation could not prosper without the enjoyment of perfect liberty and perfect justice, there is not in the world a nation which could ever have prospered. In the political body, however, the wisdom of nature has fortunately made ample provision for remedying many of the bad effects of the folly and injustice

590 Steuart: An Inquiry into the Principles of Political Economy, 1767: S. 11. 
of man, in the same manner as it has done in the natural body for remedying those of his sloth and intemperance. $\aleph^{591}$

Diese grundlegende Verschiebung der Regierungsrationalität von einer juridischen hin zu einer materiellen, ökonomischen wurde in England als erstes in dieser Radikalität vorgestellt. Die Phase des Liberalismus in Großbritannien, der sich in dieser Radikalität auf die Politik übertragen will, ist kurz. Nur auf knappe fünfzig Jahre - zwischen 1830 und 1870 wird die Blüte des Liberalismus gemeinhin bemessen. ${ }^{592}$ Aber es ist wichtig zu sehen, wie sich ab dieser Zeit in die Gesundheitspolitik, in der Art und Weise wie auf Körper und Gesundheit geblickt wird, diese materielle und ökonomische Rationalität eingenistet hat, wie sie sich auch allgemein in die Rationalität der modernen und auch heute noch gültigen Grundformation der Gouvernementalität festsetzte.

\section{Die Transformation der Selbsttechnik und spublic opinion}

Der Beginn der britischen Hygienebewegung (sanitary movement) wird in der Regel auf Mitte des 19. Jahrhunderts datiert. Somit liegen die zentralen Debatten, die ihre Entwickelung und weitere Ausrichtung bestimmt haben, grundsätzlich außerhalb meines ersten Untersuchungszeitraums. Allerdings lässt sich genau in der Phase seit Anfang des 19. Jahrhunderts bis zur Verabschiedung des Poor Law Amandman Act und des Public Health Acts die Implementierung jener Rationalität beobachten, die später grundlegend für das sanitary movement und die Techniken der Regierung im Gesundheitsbereich in England, Wales, etwas später in Schottland und auch in Irland waren. Die Idee einer solchen Rationalität des Regierens hatte sich auch in Großbritannien zu einem bedeutenden Teil aus verschiedenen Praxen und Techniken des Selbst heraus entwickelt. Während diese praktischen Verhaltensänderungen im Kontext protestantischer Lebensweisen und sozialer Kontrollen entstanden, entwickelte sich daraus parallel eine bestimme Philosophie der Moral und guter Lebensformen, die, einigen Einfluss auf den kritischen Diskurs der Politischen Ökonomie nahm.

»Die Weichenstellung hin zur liberalen Rationalität, die Ende des 18. Jahrhunderts mit den schottischen Autoren begann, war mehr als >nur eine Revolution der Denkungsart (wie Kant sagen würde), sie war auch eine folgenschwere Umkehrung einer Serie ganz konkreter Praktiken der Lebensführung. [...] Städte, Dörfer, Arbeits-, Lern- und Lebensformen, bis hin zu Diät, Körperkultur und Krankheits- und Gesundheitsbilder wurden verändert und zwar all dies in Hinblick auf den Wohlstand der Nation. « ${ }^{593}$

Von hier aus übertrug sich liberale, ökonomische Rationalität des Regierens ihrerseits erneut auf die Selbstpraxis und zwar als >Befreiung<. Wir haben es hier gewissermaßen mit einer Art Rückkopplung zu tun. Wer sich um seinen Körper und um seine Gesundheit kümmert und kümmern soll, sei dies nun in Form der Einhaltung

591 Smith: An Inquiry into the Nature and Causes of the Wealth of Nations, 2007 [1776]: S. 523.

592 Vgl. Bohlender: Metamorphosen des liberalen Regierungsdenkens, 2007: S. 92.

593 Ebd.: S. 10. 
bestimmter hygienischer Vorschriften, oder durch den Abschluss einer Krankenversicherung, ist kein besserer Mensch. Sondern er ist nichts weiter als ein Wesen, das wie jedes Tier nach einer bestimmten Ökonomie der Bedürfnisse und mithilfe einer an den Existenzbedingungen ausgerichteten ökonomischen Rationalität versucht, möglichst gut zu überleben. Statt wie bisher davon auszugehen, dass die Regierung und die Herrschaft vor allem in einer Beherrschung und Unterdrückung dieser Bedürfnisse liegen, geht es nun bei der Regierung genau um die Förderung dieser Triebe. Die Leidenschaften und das egoistische Streben nach Befriedigung seiner Bedürfnisse sind nicht die Gefahr, die die Gesellschaft bedrohen, sondern sind die Triebkraft, die ihr Wachstum und ihren Reichtum vorantreiben. Bohlender hat hierzu diesen passenden und beinahe zynisch klingenden Ausspruch von James Steuart angeführt: »Damals wurden die Menschen zur Arbeit gezwungen, weil sie Sklaven für andere waren; jetzt werden sie zur Arbeit angetrieben, weil sie Sklaven ihrer Bedürfnisse sind. ${ }^{594}$ Die Politik, die sich auf die Gesundheit richtet, konzentriert sich also auf die Förderung einer bestimmten >Menschennatur< eines Subjekts der Regierung, das nach dem Muster ihrer eigenen Rationalität entworfen und das empfänglich für sie ist. Man nimmt die Gesundheit nur deshalb als menschliches Bedürfnis wahr, weil Krankheit das Individuum daran hindert, ökonomisch für sich und seine Angehörigen zu sorgen. Der Wert der Gesundheit liegt in dem Potenzial der Kräfte eines gesunden, arbeitenden, produktiven und aktiven Körpers und Geistes.

Wenn man vor Augen hat, dass sich im 18. Jahrhundert ein stärkeres und spezifischeres Bewusstsein über Gesundheit herausbildete - nämlich eins, das bei den hygienischen Lehrsätzen aus der Antike, von Hippokrates und Galen Anschluss suchte so führte dies in der Praxis vor allem zu einer religiös-sittlichen privaten und explizit nicht staatlichen gesundheitsbezogenen Praxis. Der Anfang der Hygienebewegungen war in England, ebenso wie in Frankreich, Preußen oder Italien in der Praxis einer reformerischen, nach mehr politischer Autonomie, Aufklärung und Wissen strebenden bürgerlichen Schicht angelegt. ${ }^{595}$ Die Bedeutung und Macht dieser sozialen Praxis der Kontrolle war möglicherweise in Großbritannien, auch durch ihre spezifische christlich-protestantische Prägung, größer als in Frankreich oder z.B. in Preußen, wo paternalistische Vorstellungen vom Staat verbreiteter waren, aber auch die Strafpraxis keinen Anlass dazu geboten hatte, von bürgerlicher Seite ein derart rigides eigenes Instrument der sozialen Kontrolle aufzubauen. ${ }^{596}$

»Im England des 18. Jahrhunderts finden wir eine Form der sozialen Kontrolle, die zu Beginn außerhalb des Staates und in gewissem Sinne sogar gegen ihn agierte: Eine Verteidigungsreaktion religiöser Gruppen gegen den Herrschaftsanspruch des Staates, durch die sie für eine eigene soziale Kontrolle sorgten. $\ll^{597}$

Foucault hat in seinen Vorlesungen, die er 1973 an der Universität von Rio gehalten hat, eine sehr gute Zusammenfassung darüber gegeben, wie sich in England eine

594 Steuart zitiert nach: Ebd.: S. 137.

595 Vgl. Labisch: Homo Hygienicus - Gesundheit und Medizin in der Neuzeit, 1992: S. $11 \mathrm{ff}$.

596 Vgl. Foucault: Die Wahrheit und die juristischen Formen, 2003 [1974]: S. 113.

597 Ebd.: S. 113. 
bürgerliche, religiöse Reformbewegung als Entstehungsort von bestimmten Regierungstechniken hervorgetan hat, die später zur Grundlage staatlicher und der politischen Herrschaft avancierten.

»Ich möchte ihnen zeigen, dass es in Frankreich und vor allem in England eine Reihe von Mechanismen zur Kontrolle der Bevölkerung, zur permanenten Kontrolle der Menschen gab. Diese Mechanismen wurden im Laufe des 18. Jahrhunderts geschaffen, um eine Reihe von Bedürfnissen zu befriedigen, gewannen dann immer größere Bedeutung, bis sie sich in der gesamten Gesellschaft ausbreiteten und in die strafrechtliche Praxis Eingang fanden. $\ll^{598}$

Foucault fährt fort zu beschreiben, wie diese neuen Techniken und Kontrollmechanismen in England seit der zweiten Hälfte des 18. Jahrhunderts in bestimmten Gruppen und zunächst auf relativ niedriger Ebene der sozialen Hierarchie entstanden. Die Mechanismen haben die Aufgabe, die soziale Ordnung innerhalb der Gruppen aufrecht zu erhalten oder ggf. wieder herzustellen. Wichtig an Foucaults These scheint zu sein, dass sich diese Techniken nicht im Auftrag einer höheren Macht entwickelten, sondern von sehr vielen religiösen und kleinbürgerlichen Gruppen, Vereinen und Gemeinden, Methodisten und Quäkern, von denen es im 18. Jahrhundert in England sehr viele gab, selbst erfunden und innerhalb ihrer Gruppe eingesetzt wurden. ${ }^{599}$ Teilweise übernehmen die Pfarrer eine Art Polizeifunktion: »Jeglicher Fall von Unordnung: Trunkenheit, Ehebruch, Arbeitsverweigerung wurde ihm unterbreitet $\ll^{600}$. Ihr Ziel war es ganz im Sinne der sich, laut Weber, etablierenden protestantischen Ethik alles zu bekämpfen »worin sich eine Verachtung Gottes zeigte « ${ }^{601}$ und zu fördern was der Verehrung Gottes dienlich war - allen voran die Arbeit.

»Die Gemeinschaften hatten die zweifache Aufgabe des Überwachens und des Helfens. Sie machten es sich zur Aufgabe, denen zu helfen, die nichts zum Leben hatten und nicht arbeiten konnten, weil sie alt, krank oder geistesgestört waren. Und wenn sie ihnen halfen, nutzen sie zugleich die Möglichkeit und nahmen sich das Recht heraus, zu beobachten, in welcher Lage die Hilfe erfolgte, und zu klären, ob der Hilfebedürftige, der nicht arbeitete, tatsächlich krank war, ob seine Armut und Not nicht auf Ausschweifung, Trunksucht oder Laster zurückzuführen waren. Es handelt sich also um spontan entstandene Überwachungsgruppen, deren Ursprung, Arbeitsweise und Ideologie zutiefst religiös geprägt war. $\ll^{602}$

Aus welchem Grund wurden diese Techniken eingeführt? Man könnte einerseits sagen, sie waren die Folge einer noch sehr religiös geprägten Emanzipation einer bestimmten bürgerlichen Schicht, die ihrerseits auf eine Reihe von sozialen Veränderungen reagierte. Aber Foucault nennt noch einen weiteren Grund, der sehr wichtig ist. Denn es zeigt sich auch hier die Entwickelung einer eher bürgerlichen moralischen Selbstpraxis und Behauptung einer besseren Lebensführung, die praktisch eine

598 Vgl. Foucault: Die Wahrheit und die juristischen Formen, 2003 [1974]: S. 87.

599 Vgl. ebd.: S. 88.

600 Ebd.

601 Ebd.: S. 89.

602 Ebd.: S. 88. 
Strategie war, um gegenüber der aristokratischen, monarchischen politischen Herrschaft eine zunächst nur moralische Gegenmacht zu formulieren und praktisch auszuüben.

»Betrachten wir die erste Verschiebung. Anfangs kamen die Mitglieder dieser Vereinigung aus dem Volk genauer: aus dem Kleinbürgertum. Die Quäker und Methodisten, die sich Ende des 17. Jahrhunderts zusammen taten, um das Laster zu bekämpfen und die Sitten zu reformieren, waren Kleinbürger, die dafür sorgen wollte, dass in ihren Reihen und ihrem Umfeld Ordnung herrschte. Doch dieser Wille, Ordnung zu schaffen, war im Grunde ein Versuch, der politischen Macht zu entkommen, denn die politische Gewalt verfügte über ein Schrecken erregendes, grausames Instrument: das Strafrecht. Bei mehr als 300 Delikten drohte der Galgen. «603

Laut Foucault waren die Techniken, mit denen man versuchte, soziale Ordnung herzustellen, also zunächst eine Strategie, sich und sein soziales Umfeld der Macht eines »bedrohlichen und blutigen Justizapparats zu entziehen ${ }^{604}$. Allerdings gab es gegen Ende des 18. Jahrhunderts eine deutliche Verschiebung hin zu einer >Verstaatlichung < und Institutionalisierung dieser Techniken.

»Im Laufe des 18. Jahrhunderts veränderte sich nun aber die soziale Zusammensetzung dieser Gruppen; ihre Mitglieder rekrutierten sich immer seltener aus dem Volk und dem Kleinbürgertum. Ende des 18. Jahrhunderts gründeten in erster Linie Aristokraten, Kirchenmänner und Begüterte solche Sittlichkeitsvereine, solche Liegen der Bekämpfung des Lasters. «605

Diese Vereinigungen waren laut Foucault eine Reaktion auf die sozialen Veränderungen, sie waren Strategien zur Erfüllung neuer demographischer und sozialer Bedürfnisse, die sich aus der Industrialisierung und Kapitalisierung der Produktion, der Verstädterung usw. ergaben. Es entstand eine neue Form des Reichtums, die auf Kapitalakkumulation beruhte und das Bedürfnis der Kapitalbesitzer beförderte, ihre Anhäufung von Waren und Produktionsmitteln, wie auch die Abläufe der Produktion selbst, durch eine soziale, politische Ordnung sicher zu stellen. ${ }^{606}$ Auf jeden Fall sah Foucault die Verschiebung in der sozialen Zusammensetzung dieser Vereinigungen und Gruppen, die sich die moralische Reform auf ihre Fahnen schrieben, als einen Beweis dafür, dass es bei ihren Bemühungen nicht mehr um eine Strategie ging, sich der staatlichen Gewalt zu entziehen. Sondern, dass die Zusammenschlüsse vielmehr der Durchsetzung spezifischer Begehren nach Macht und Teilhabe an politischer Herrschaft, die sich verändert hatte, oder deren Ziele und deren Probleme sich geändert hatten, dienten. Diese Verschiebung führte, laut Foucault, gerade zum Gegenteil dessen, wozu diese Techniken ursprünglich erfunden worden waren: Sie wurden eingesetzt, um »die Macht des Strafsystem[s]« unterfüttert mit einer anderen Rationalität $»$ noch [zu] vergrößern $\ll^{607}$.

603 Ebd.: S. 91.

604 Ebd.

605 Ebd.: S. 92.

606 Vgl. ebd.: S. 90f.

607 Ebd.: S. 92. 
Diese neu gemischten Interessengruppen, Vereinigungen von neuen Kapitalbesitzenden, reichen Bürgern und Aristokraten kämpfte gegen Ende des 18. Jahrhunderts darum, »von der politischen Macht neue Gesetze zu erhalten, die ihre Bemühungen um die Sittlichkeit bestätigten. $\ll^{608}$ Genau zu diesem Zeitpunkt, oder besser gesagt an diesem Punkt einer Veränderung, findet auch die Diskussion um die medical reform statt. In der Diskussion um die medical reform zeigte sich, meiner Meinung nach, der Versuch, einen Teil dieser nicht-staatlichen und nicht-professionellen medizinischen Praxis zu schwächen oder zu beeinflussen. Dies war jedoch kein einfacher Schritt, sondern die Verschiebung ereignete sich langsam. Die Gesellschaften, die sich hier gründeten, waren nicht anti-staatlich ausgerichtet, sondern begannen eher eine bestimmte >positive< Praxis der Förderung und Beeinflussung der Gesundheit der Bevölkerung auf die Rolle der Gesetze zu übertragen. Gleichzeitig richteten sie sich gegen die staatlich nicht anerkannte und somit `irreguläre<, soziale und religiös geprägte Praxis der medizinischen Hilfe. Die Argumentation, mit der man schließlich forderte, Gesetze zu erlassen, musste mit der Behauptung einhergehen, dass die sozialen Kontrollmechanismen versagten, bzw. die Rationalität und Moral der einfachen Leute zu verkommen, zu schwach oder verkümmert sei ${ }^{609}$ Das ermöglichte den Stimmen der Gemeinden, der Kommunen und anderer sozialer Strukturen, in denen sich im 17. und 18. Jahrhundert ein religiös und sittlich geprägtes Netz aus medizinischer Unterstützung herausgebildet hatte, ihre Macht zu entziehen. Anderseits war es eine Reaktion auf den Zerfall diese Strukturen und der sozialen, sittlich-religiösen Kontrollstrukturen für eine wachsende Zahl an Menschen, die für die Produktion und die soziale, politische Ordnung äußerst wichtig waren: die schnell wachsende Zahl der arbeitenden, armen (labouring poor) Bewohner der Städte. Genau auf diese bestimmten Bevölkerungsschichten sollten die auf den Staat übertragenen Techniken der sittlich-religiöse Kontrolle angewendet werden. Sie sollen nun gerade dazu führen, dass die staatliche Macht bzw. die politische Regierung effektiver und angepasster an die sozialen Umstände, unter welchen sie ihre Macht erhalten will, regieren kann. Foucaults Untersuchung, die sich auf die Entstehung des modernen Strafsystems in England richten, lassen sich also in ähnlicher Weise auf die zunächst religiöse hygienische Praxis und die Heilpraxis hin zu einer staatlichen Gesundheitspolitik übertragen.

»Die religiöse Ideologie, die Ende des 17. Jahrhunderts in den kleinen Quäker- und Methodistengemeinschaften Englands entstanden war, wechselte nun an den anderen Pol, ans andere Ende der sozialen Hierarchie, auf die Seite der Macht, und wird dort als Instrument der Kontrolle von oben benutzt. Mittel zur Selbstverteidigung im 17. Jahrhundert, Machtinstrument im 19. Jahrhundert. Das ist der Mechanismus des Prozesses, den wir in England beobachten können. $\ll^{610}$

608 Ebd.

609 Wie schon weiter oben angemerkt, gab es dennoch auch Ärzte, die eine rein gesetzliche Lösung entweder für unmöglich oder falsch hielten. Gerade bei der Bekämpfung der sog. quakery gab es auch Ärzte, die auf die erfolgreiche Aufklärung und Beeinflussung der Öffentlichkeit setzte. Vgl. S.M.: A Letter on the suppression of Quack Medicine, To the Editors of the Medical and Physical Journal: in: MPJ, 2.1799, S. 150 - 152: S. 152.

610 Foucault: Die Wahrheit und die juristischen Formen, 2003 [1974]: S. 93f. 
Während die Techniken der sozialen Kontrolle in den Gemeinschaften der Methodisten und Quäker sich auf sie selbst und ihre Mitglieder richten, brachten die staatlichen Formen dieser Kontrolltechniken eine klare Differenzierung zwischen denen, die diese Kontrolle ausüben, und denen, die kontrolliert werden, mit sich.

Während die Selbst-Praxis im Sinne einer self-care oder eines self-treatment für das Individuum innerhalb einer bestimmten Schicht gerade als Mittel zur (Re-)Produktion seiner moralischen und sozialen Identität und Subjektivität diente, musste hiervon jene wohltätige Praxis unterschieden werden, die sich auf jemand anderes als die eigene Person richtete: Die irreguläre, auf christliche Barmherzigkeit und Nächstenliebe gestützte etablierte Praxis medizinischer Versorgung, vor allem in den unteren Klassen, wurde zunehmend abgelehnt. ${ }^{611}$ Es gab eine regelrechte Offensive gegen diese bisher legale und öffentlich anerkannte sog. irregulär medizinische Praxis, die sich jenseits staatlicher Anerkennung auf die Personen gerichtet hatte, die in irgendeiner Weise hilfebedürftig waren: Die unwissenden Armen, die Frauen und Kinder, die von ihren Männern, Eltern, Nachbarn behandelt werden etc. ${ }^{612}$ Diese wird man gewissermaßen vor der religiös geprägten Wohltätigkeit und moralischen Einflussnahme und Macht schützen, indem man die Sorge um die arbeitende arme Bevölkerung in eine staatlich finanziert und politische motivierte >rationale < charity überführt. Sie wird aber auch grundlegend sein für das Verständnis von Kriminalität, das Problem der Gesetze und Institutionen, wie Gefängnisse, Kranken- und Arbeitshäuser, die nun viel deutlicher dem Kriterium der Nützlichkeit für das Allgemeinwohl unterworfen sein werden.

\section{Liberale Rationalisierungen der Regierung von Gesundheit}

Ich möchte im Folgenden anhand einiger liberaler Theoretiker des 18. und 19. Jahrhunderts zu zeigen versuchen, was meiner Meinung nach der Hintergrund dieser neuen Aufteilung und Umgestaltung der »Beziehungen zwischen der Regierung des Selbst und der Regierung der anderen ${ }^{613}$ in England spezifisch machte. Die Entstehung einer bestimmten Idee, Rationalität und Technologie des Regierens der Gesundheit der Armen war komplementär zu einer spezifisch >liberalen< Sicht auf das Subjekt und zu der Weise, wie es sich selbst und seine Gesundheit regieren sollte, nämlich als ein auf seine individuellen Interessen konzentriertes, nach seinem persönlichen weltlichen Glück strebendes Subjekt.

Bei Adam Smith gilt happiness als das Ziel aller Lebenspraxis - auch der, die sich auf Gesundheit richtete. Diese Sichtweise stand im Gegensatz zu einer klassischen, christlichen, auf das Jenseits gerichteten moralischen (Selbst)Praxis, ${ }^{614}$ die sich an einem Set von Bedingungen und Bedürfnissen des Menschen ausrichtet. ${ }^{615}$ Die wichtigsten auf den Erhalt der Gesundheit gerichteten Praktiken, die grundlegen-

611 Vgl. ebd.: 209.

612 Vgl. [Anonym]: On Medical Reform: MPJ, 23.1810, S. 209 - 212: S. 211.

613 Foucault: Die Regierung des Selbst und der anderen I, 2009 [1982 - 1883]: S. 53.

614 Vgl. Smith: An Inquiry into the Nature and Causes of the Wealth of Nations, 2007 [1776]: S. 596.

615 Vgl. ebd.: S. 199. 
den Regeln der Regierung in dieser Hinsicht, mussten sich, nach Smith, aus den Gefühlen und Bedürfnissen des Körpers ableiten. Die Praxis der Erhaltung der Gesundheit und Selbstführung bestand also für ihn nicht in einer Regierung des Geistes über den Körper, die Gefühle und Leidenschaften. Smith schrieb 1790 in Theory of Moral Sentiments:

»The preservation and healthful state of the body seem to be the objects which Nature first recommends to the care of every individual. The appetites of hunger and thirst, the agreeable or disagreeable sensations of pleasure and pain, of heat and cold, etc. may be considered as lessons delivered by the voice of Nature herself, directing him what he ought to choose, and what he ought to avoid, for this purpose. The first lessons which he is taught by those to whom his childhood is entrusted, tend, the greater part of them, to the same purpose. Their principal object is to teach him how to keep out of harm's way. As he grows up, he soon learns that some care and foresight are necessary for providing the means of gratifying those natural appetites, of procuring pleasure and avoiding pain, of procuring the agreeable and avoiding the disagreeable temperature of heat and cold. In the proper direction of this care and foresight consists the art of preserving and increasing what is called his external fortune. «616

Die Art, wie der Körper zu regieren sei, sei am ehesten aus dem zu bestimmen, was der Körper dem Individuum selbst an Hinweisen darüber gebe, was für seine Gesundheit am besten sei. Wer sich selbst und seine Gesundheit ordentlich regieren wolle, müsse also auf diese Signale des Körpers selbst hören und seine Reaktionen und die Gefühle von Schmerz und Lust, die dieser Körper produziere, beobachten. Allerdings würden sich die Menschen, wenn es um die Art und Weise geht, wie sie sich selbst führen, nicht nur auf diese klaren und einfachen Signale des Körpers richten, sondern seien in großem Maße abhängig von dem Respekt und der Meinung anderer Menschen. Dies sei das Problem, das in der liberalen Philosophie immer wieder auftaucht: ${ }^{617}$ Die problematische Einflussnahme der Öffentlichkeit auf die private Lebensführung. Die Öffentlichkeit wird, wie auch bei Stewart Mill, aber nicht als ein Ort der Freiheit begriffen. Kulturell fixierte Moralvorstellungen, die sich nicht mehr an dem Nutzen, sondern nur an einer Tradition ausrichteten, sah Mill, wie Hume, als problematisch an, vor allem auch, wenn sie sich, wie oft, nicht nur auf gesellschaftliche Fragen, sondern auf die private Lebensführung richteten. ${ }^{618}$

Worauf ich hinaus will ist, dass die liberalen und utilitaristischen Ansätze der britischen Moralphilosophen und Ökonomen bereits als eine Reaktion auf bestimmte Entwicklungen und Ausbreitung der Gouvernementalität zu verstehen sind. Es ist eine erste und eindeutige Zurückweisung der Regierung im Sinne einer Verhaltensführung der Menschen, die sich seit dem 16. Jahrhundert zu entwickeln begonnen hatte. ${ }^{619}$ Mill sagte im Prinzip, diese modernen Reformen ${ }^{620}$, die sich auf die Führung

616 Ebd.: S. 198.

617 Vgl. ebd.: S. 198f.

618 Vgl. Mill: On Liberty, 2001 [1859]: S. 16f.

619 Vgl. Foucault: Geschichte der Gouvernementalität I, 2004 [1977 - 1978]: S. 333. Vgl. Foucault: Sexualität und Wahrheit I, 1997 [1976]: S. 137. 
des Verhaltens und auf die Verbesserung der Menschen gerichtet habe, sei zu weit gegangen. Dabei ist es wichtig zu bemerken, dass sich Mill mit dieser Kritik nicht, wie man denken könnte, in erster Linie gegen den Staat richtet, sondern gegen die ganzen sozialen Mechanismen der Kontrolle. ${ }^{61}$ Mill ist der absolute Fürsprecher des Individuums und seiner Freiheit im Handeln, die sich allein auf die Verwirklichung des eigenen Glücks richten. Die Verteilung und das Verhältnis von Selbst und der Sicherheitstechniken, von der Regierung des Selbst und der Regierung der Anderen, erhält hiermit seine spezifisch liberale Prägung. Es gibt keine Verbindung mehr zwischen der Selbstpraxis des Individuums und der Regierungspraxis des Staates, bzw. es gibt keinen Weg der Instrumentalisierung. Die Verbesserung der Gesellschaft findet nicht darüber statt, dass man die Individuen verbessert. Die Folge einer »fanatical moral intolerance of the Puritans $\ll^{622}$ ist, dass sich die Lebenspraxen nicht auf die Erfüllung eines weltlichen Glücks richten ${ }^{623}$, dass sie gewissermaßen irrational und unnütz sind. Moral und Selbstpraxis sollen ihre Wahrheit an der Praxis und der Erfahrung jedes Einzelnen, wie er sein Glück erreichen kann, belegt werden. Es ist eine Praxis, die nach dem Trial-and-Error-Prinzip verfährt und nicht auf der Grundlage einer >spekulativ verallgemeinerten< Diät oder Vorgabe der richtigen, auch gesunden Lebensweise beruht. Die Aufgabe und die Gesetze, die der Staat von diesem Standpunkt aus macht, richten sich auf die Ermöglichung des Spiels der Interessen Einzelner. ${ }^{624}$ Hier findet sich die Kritik von Mill an den Mechanismen sozialer Kontrolle und die Sorge, die bereits Smith in Bezug auf die Abhängigkeit des Menschen vom moralischen Urteil und der Anerkennung seiner Mitmenschen geäußert hat.

$»[T]$ here is considerable jealousy of direct interference, by the legislative or the executive power, with private conduct; not so much from any just regard for the independence of the individual, as from the still subsisting habit of looking on the government as representing an opposite interest to the public. The majority have not yet learnt to feel the power of the government their power, or its opinions their opinions. When they do so, individual liberty will probably be as much exposed to invasion from the government, as it already is from public opinion. But, as yet, there is a considerable amount of feeling ready to be called forth against any attempt of the law to control individuals in things in which they have not hitherto been accustomed to be controlled by it; $[\ldots] . \ll^{625}$

Diese individuelle Freiheit in Bezug auf die Lebensführung ist es, die von der public opinion weit stärker bedroht ist als vom Staat, dessen Techniken bisher eher negativ, sprich repressiv waren (nicht positiv wie bei Comte). Die Freiheit, die Mill problematisiert, ist die von einer positiv agierenden Macht, die auf Grundlage einer festgesetzten Vorstellung den Individuen sagt, wie sie sich verhalten sollen oder sie zu ei-

620 Mill kritisierte z.B. Auguste Comtes Système de Politique Positive. Vgl. Mill: On Liberty, 2001 [1859]: S. 17.

621 Vgl. ebd.

622 Ebd.: S. 77.

623 Vgl. ebd.

624 Vgl. Foucault: Geschichte der Gouvernementalität I, 2004 [1977 - 1978]: S. 497.

625 Mill: On Liberty, 2001 [1859]: S. 12. 
nem bestimmten Verhalten bringt. Diese Freiheit des Verhaltens bezog Mill auch auf die Regierung der Gesundheit. ${ }^{626}$

Eines der prägendsten Elemente der Praxis des Regierens, wie sie sich innerhalb von religiösen Gemeinschaften durch soziale Sanktionierung etabliert hatte, war das Ziel der Beherrschung der eigenen inneren Leidenschaften, der Gefühle, Bedürfnisse und des Körpers im Allgemeinen. Die soziale Ordnung sollte durch die Einhaltung sittlicher und moralisch-religiöser Verhaltensregeln durchgesetzt werden. Auf diese Weise sollten die Mitglieder einer Gemeinschaft vor den sehr strengen Gesetzen und Strafen der staatlichen Regierungsmacht geschützt werden. Die Praktiken der Askese blieben hier ein zentrales Element. Gegen diese Praxen richten sich die Vorschläge, die verschiedene liberale Theoretiker des 18. und v.a. 19. Jahrhunderts vorbrachten. Asketische Praxen lehnten sowohl Smith als auch Mill, ebenso wie Bentham und Malthus konsequent ab. ${ }^{627}$

Die Idee dieser liberalen Regierung entdeckt an sich jedoch bald schon ihre eigene praktische Grenze. Die Angst vor Epidemien, Revolutionen und Aufständen durch die arbeitende arme Bevölkerung geistert zu Beginn des 19. Jahrhunderts in England umher. ${ }^{628}$

»Man wird dieses Gespenst den Pauperismus nennen und meint damit eine Armutsbevölkerung, die dem alten Arbeitsregime zu entgleiten droht, für die aber noch kein neuer Raum, kein neues Regime bereitsteht, mit dieser Bevölkerung umzugehen. Woher kommen die Armen und wie soll man sie regieren? «629

\section{Die gesundheitsbezogene Regierung der Armen und Arbeiter}

In dem bedrohlichen Konstrukt des Pauperismus werden Krankheit und Armut eng miteinander verknüpft. Bohlender hat erklärt, wie aus dieser Krise liberalen Regierungsdenkens eine Reihe von neuen liberalen Strategien erwachsen, die sich spezieller der Frage widmen, wie man die Armen regieren kann.

»Was sich in dieser unübersichtlichen Problematisierung von Armut und Pauperismus herauskristallisiert ist die Einsicht, dass die von Adam Smith zum Programm erhobene Regierungsweise der Menschen in der zivilen Verkehrsgesellschaft eine entscheidende Schwäche aufweist: Allein über das Regime der freien Lohnarbeit lassen sich nicht alle Armen in der civil society integrieren. Es verbleibt neben dem Heer der arbeitenden Armen (labouring poor) eine

\section{Ebd.: S. 16.}

627 Bentham setzt das Prinzip der Askese als genaues Gegenteil des von ihm beschriebenen Prinzips der Nützlichkeit, dass er zur Grundlage der Regierung des Selbst - des Individuums, und zur Grundlage jeder Regierung macht, welche/s auf die Erreichung eines möglichst großen Grades an Glück des Individuums bzw. der Gesellschaft ausgerichtet ist. Vgl. Bantham: An Introduction to the Principles of Morals and Legislation, Bd. 1, 1823 [1798]: S. 1f; 13ff.

$628 \mathrm{Vgl}$. Lucas, James, Surgeon of the general Infirmary at Leeds, and Member of the Corporation of Surgeons of London: Remarks in febrile Contagion: in: LMJ, 10.1789, S. $260-$ 273: S. 262.

629 Bohlender: Metamorphosen des liberalen Regierungsdenkens, 2007: S. 141. 
immer zahlreicher und sozial wie politisch gefährlicher werdende Masse von >faulen $<$, >bedürftigen $<$, und moralisch >sorglosen $<$ Armen (idle, indigent, improvient poor); es öffnet sich gleichsam eine Schere zwischen dem sozialen Raum, der durch Freiheit und Produktivität regiert wird, und einem neuen, noch unbekannten, noch unregierten Raum, in dem sich die Armut nicht in Arbeit und diese wiederum in Reichtum verwandelt, sondern in Kriminalität, politische Agitation moralisches und physisches Laster. Das liberale Regierungsdenken antwortet auf diese Spaltung zunächst mit zwei differenten Strategien, [...] einer von Thomas Malthus inspirierten (Bio-)Politik der gänzlichen Abschaffung des alten Armenrechts, einem laissez faire - laissez mourir; und einer von Jeremy Bentham inspirierten utilitaristischen Rationalisierung des Armenrechts, einer über spezifische Technologien und Prozeduren durchgeführten economy of the poor. [Hervorhebungen von Bohlender].« ${ }^{630}$

Die Frage ist allerdings, reagiert das liberale Regierungsdenken auf diese Spaltung, oder ergibt sich diese Dichotomie von produktiv und unproduktiv nicht eher aus seiner eigenen Logik? Der Modus, in dem die liberale Regierung die Probleme nach ihrer >Regierbarkeit< ordnet, sie aufspaltet und ihnen verschiedene Techniken zuweist, ist nichts ihr Äußerliches oder ihr Widersprechendes. Die liberale Gouvernementalität entwirft sich selbst ein zu ihr passendes Subjekt, dem sie ihre eigene Rationalität zuschreibt. Sie ordnet das Wissen über das Wesen dieses Subjekts und behauptet, dass sich ihre eigene Rationalität, nach der sie regiert, aus dem Wesen dieses Subjekts ableitet. Aus dieser besonderen Konstruktion von Rationalität und Normalität der liberalen Gouvernementalität folgt die Einführung einer ganzen Reihe von für sie spezifischen Dichotomien. Die liberale Gouvernementalität wartet mit einem ihr eigenen Tableau solcher Differenzierungen auf.

»Während man in der Mitte des 18. Jahrhunderts noch staats- und moralphilosophisch nach der rationalen Regierungsweise der Menschen fragen konnte, so wird man am Ende dieses Jahrhunderts politisch-ökonomisch die Frage stellen, wie man die Armen regiert. « ${ }^{631}$

Obwohl ich Bohlenders Beobachtung hier voll und ganz teile, würde ich unterstreichen wollen, dass diese Entwicklung keinen klaren Bruch zur britischen moralphilosophischen Tradition bedeutet hat, sondern eher in einer gewissen Konsequenz aus den dort entwickelten Überlegungen zu einer vernünftigen Regierung erfolgte. Die Idee eines rational und ökonomischen, seine Handlungen kalkulierenden Subjekts, wirft selbst die Frage auf, wie man mit denen umgehen soll, die sich offensichtlich nicht so verhalten wie man es der liberalen Anthropologie nach von ihnen erwartet hat. Die Erfindung des Subjekts und der Techniken, es zu regieren, bringt die Abspaltung eines >anderen $<$ Subjekts mit sich, das anders regiert werden muss. Die Regierung muss ein Raum der geregelten Ausnahme - eine »Heterotopie« - ein Heterosubjekt schaffen. »Hetero-« deshalb, weil sie »ganz andere sind als alle Plätze [oder 
Subjekte], die sie reflektieren oder von denen sie sprechen. ${ }^{632}$ Sie kreiert einen Bereich, in dem sie selbst in der Lage ist, entgegen ihrer eigenen Rationalität und entgegen ihren eigenen Verfahren der Legitimation zu agieren. Die Genealogie von Regierungsdenken, ihren Praxen und Technologien ermöglicht es, die fragwürdigen Momente der Entstehung solcher dichotomen Ordnungen aufzuspüren und die Spezifik des historischen Moments, die Kräfteverhältnisse und die historisch materiellen Bedingungen ihrer Entstehung offenzulegen. Man muss sich darüber im Klaren sein, dass die Unterteilungen von Menschengruppen und Personen, Räumen, Krankheiten, Geschlechtern, psychischen Zuständen etc. in der Regel auf der Grundlage weniger Eigenschaften dieser geschehen und aus sehr komplexen umliegenden Bedingungen entstanden sind. Warum ist es gerade diese Eigenschaft, die die Identität und die Unterscheidungen der Dinge bestimmt? Der Medizin steht mit ihrer eigenen dichotomen Ordnung von krank und gesund, die Definitionsmacht darüber zu, den, der von der Norm abweicht, zu pathologisieren. Sie ermöglicht es, die abweichenden Personen mit einer nun medizinisch-politischen Technologie zu regieren, deren Existenz sonst im Widerspruch zu der Wahrheit und Normalität gestanden hätte, die man als Grundlage der politischen Vernunft gesetzt hat. Eine Technik und Praxis, die man ihrer Wissenschaft und ihrer Praxis entnahm und auf den >Gesellschaftskörper konnte. Die Spaltungen der Arbeitenden in (diseased) pauper und labouring poor und in able-bodied workers und non-able-bodied workers ähnlich wie Unterteilungen curable und uncurable diseases, preventable diseases und unpreventabe diseases sind Ergebnisse der Aufteilung und Abspaltung der zu regierenden Bereiche, als Folge einer oder als Konflikt mit der Rationalität der Regierung. Die Konzentration auf die Armen und die Arbeiter ist als Reaktionen einer Regierung zu sehen, die feststellt, dass ihre allgemeinen Regeln und Rationalitäten und Technologien Bereiche geschaffen habe, die durch diese nicht erfasst, also nicht regiert werden können. Malthus und Bentham reagierten auf diese >Erkenntnis<, von der auch Bohlender schrieb, mit unterschiedlichen Vorschlägen. Aber sie blieben beide den grundsätzlichen Maßgaben liberalen Regierungsdenkens treu. Ein Element der liberalen Regierungsperspektive besteht in der Überzeugung, dass eine Verbesserung der Gesellschaft nicht darüber stattfindet, dass man die Individuen durch moralische Praktiken oder über so etwas wie >reine< Erkenntnis verbessert. ${ }^{633}$ Nicht durch die Einsicht in die Prinzipien und die Macht der moralischen gesellschaftlichen Kontrolle, die sich gegen die Triebe und Bedürfnisse - also auch gegen die Kräfte des Einzelnen - richten, sollten die Grundlage der Verbesserung der Gesellschaft und der Menschen sein, sondern das Spiel dieser heterogenen Kräfte. Wer mit dem Ziel der Verbesserung alles ins Detail regeln will, wird schließlich die Grundlage dieser Verbesserung zerstören. Man kann

632 »Heterotopie« ist eine Wortschöpfung Foucaults, die ich mir erlaubt habe, auf diesen Vorgang der Abspaltung bei Subjektivitäten zu übertragen: Foucault: Andere Räume, 1992 [1967]: S. 39.

633 Beide beschäftigt zunächst die Frage, ob die Idee der Verbesserung der Menschen als Bedingung einer Regierung und als Bedingung eines gesellschaftlichen Fortschritts zu sehen ist. Malthus schreibt zu Beginn seines Aufsatzes zu Bevölkerung: »The discussion started the general question of the future improvement of society.« Malthus: An Essay on the Principle of Population, 1798: S. vii. 
Elend auf diese Weise nicht beheben. Man kann die Armen und die Arbeiter nicht auf diesem Wege verändern bzw. verbessern.

$»$ An amelioration of society to be produced merely by reason and conviction wears much more the promise of permanence than any change effected and maintained by force. The unlimited exercise of private judgement is a doctrine inexpressibly grand and captivating and has a vast superiority over those systems where every individual is in a manner the slave of the public. $\ll^{634}$

In der Konsequenz neigten Malthus und Bentham sogar dazu, was ihre vorgeschlagenen Technologien anging, noch radikaler in der Anwendung liberaler Regierungsrationalität zu sein, indem sie auf eine noch tiefere Wahrheit des Subjekts drängten, die bei aller Verschiedenheit der Phänomene die liberale Wahrheit vom Subjekt weiterhin konsistent und für eine erweiterte Regierung praktikabel machte. Bentham ging in An Introduction to the Principles of Morals and Legislation davon aus, dass alles Handeln des Menschen grundsätzlich durch die Aussicht und Erfahrung von Lust oder die Strategie zur Vermeidung von Schmerz bestimmt sei. Ein Menschenbild, das an die Philosophie von Hume ${ }^{635}$ und $\operatorname{Bacon}^{636}$ erinnern lässt.

»Nature has placed mankind under the governance of two sovereign masters, pain and pleasure. It is for them alone to point out what we ought to do. On the one hand the standard of right and wrong, on the other the chain of cause and effects, are fasted their throne. They govern us in all we do, in all we say, in all we think: every effort we can make to throw off our subjection, will serve but to demonstrate and confirm it. In words a man may pretend to abjure their empire: but in reality he will remain subject to it all the while. The principle of utility recognises this subjection, and assumes it for the foundation of that system, the object of which is to rear the fabric of facility by hands of reason an of law. Systems which attempt to question it, deal in sounds instead of sense, in caprice instead of reason, in darkness instead of light. « ${ }^{637}$

Auf dieselbe Weise, wie das Individuum auf seine Gesundheit achtet, indem es auf die Stimme des Körpers selbst und seine Bedürfnisse hört, so muss auch eine Regierung der Anderen sich auf ein Subjekt richten, dessen Handeln vom Streben nach individuellem Glück, also auf die Erfahrung von Lust (pleasure) und auf die Vermeidung von Schmerz (pain) ausgerichtet ist. Die Handlung jeder Regierung geht der Natur dieses Subjekts nach. Sie richtet sich an dieser Maxime der Erreichung von Glück durch die Vermeidung von Schmerz und die Vergrößerung der Lust aus und geht nach einem Prinzip der Nützlichkeit (principle of utility) vor. ${ }^{638}$

634 Ebd.: S. 63.

$635 »[\mathrm{I}] \mathrm{f}$ virtue and vice be determined by pleasure and pain, these qualities must, in every case, arise from the sensations[.] « Hume: A treatise of human nature. 2. Bd., 1817 [1739/ 1740]: S. 174.

636 Vgl. Bacon: The Works of Francis Bacon, 1. Bd., 1815 [1723]: S. 181.

637 Vgl. Bantham: An Introduction to the Principles of Morals and Legislation, Bd. 1, 1823 [1798]: S. 1f.

638 In der Fußnote zum »principle of utility« heißt es bei Bantham: To this denomination has of late been added, or substituted, the greatest happiness or greatest felicity principle: this 
$»$ I say of every action whatsoever; and therefore not only of every action of a private individual, but of every measure of government. [...] But utility is meant that property in any object, whereby it rends to produce benefit, advantage, pleasure, good, or happiness, (all this on the present case comes to the same thing) or (what comes again to the same thing) to prevent the happening of mischief, pain, evil, or unhappiness to the party whose interest is considered: if that party be the community in general, then the happiness of the community: if a particular individual, then the happyness of that individual.«639

Eine Regierung, die dieses Prinzip zu ihrer Grundlage macht, kann nun wirklich auf jegliche Bedingung des Vorhandenseins einer spezifischen Abstraktion und Komplexität des Subjekts, die vernünftigem Handeln vorausgehen soll, auskommen. Es ist also die Entdeckung der Bedeutung und der Problematik der Regierung der Arbeiter, nicht der Bürger, die diesen Wandel ausmacht. Diese neue liberal geprägte Regierungsrationalität stellt nicht die Frage nach der Regierung der Bürger, sondern der Regierung der Menschen im weitesten Sinne, also auch der Arbeiter. Sie setzt keine moralische Entwicklung oder Selbsterkenntnis der Subjekte oder deren Befreiung voraus. Das Subjekt, ob gebildeter Bürger oder >pauper $<$ muss nicht mehr in der Lage zu einer bestimmten Selbstregierung im Sinne einer Selbstbeherrschung sein, um regierbar zu sein. Im Gegenteil sogar, die asketischen und meditativen Selbstpraxen >verfälschten< und störten das Subjekt und machen es für die Regierung unberechenbar. Wenn das Subjekt zu einer Maschine gemacht werden könnte, die auf Schmerz und Lust reagiert, hatten die Programme und Techniken der Regierung einer verhältnismäßig einfachen Logik zu folgen. Anstatt hier zwei völlig verschiedene Subjekte zu problematisieren - die einen, die sich selbst regieren und jene, die dazu nicht in der Lage sind - wird man eher eine Art Entwicklungshierarchie aufmachen. Diese quantitative Unterscheidung bezieht sich auf die Freiheit und die Rationalität eines Subjekts. Erst von hier aus wirkt sie auch zurück auf einen bürgerlichen privaten Diskurs der Lebensführung.

Der Staat und die Gesetze haben nun die Aufgabe dafür zu sogen, dass keiner, indem er seine persönlichen Interessen verfolgt, einem anderen schadet. Das ist im Grunde auch das, was John Steuart Mill Mitte des 19. Jahrhunderts schrieb. Foucault beschreibt das besondere Verhältnis von Recht und Regierung in England in Abgrenzung zu dem zuvor beschriebenen >französischen< Rechtsprinzip, oder dem, was Foucault den revolutionären Weg genannt hat. In Großbritannien wird statt von einem abstrakten >natürlichen< Recht vom faktischen Nutzen ausgegangen. Die Frage nach der Begrenzung der Regierung wird durch die Grenzen der Nützlichkeit ihrer Techniken und Gesetze geklärt. Foucault nennt dies den englischen Radikalismus. ${ }^{640}$

for shortness, instead of saying at length that principle which states the greatest happiness of all those whose interest is in question, as being the right and proper, and only right and proper and universally desirable, end of human actio: of human action in every situation, and in particular in that of a functionary or a set of functionaries exercising the powers of Government.«Ebd.: S. 1.

639 Ebd.: S. 3f.

640 Vgl. Foucault: Geschichte der Gouvernementalität II, 2004 [1978 - 1979]: S. 67. 
Wie auch schon bei der nur kurz angedeuteten Diskussion um einen gesetzlichen Rahmen der medical reform erwähnt, ${ }^{641}$ verband sich das Problem der Nützlichkeit der Gesetze mit dem Ziel der Sicherheit und der Sicherung. Hume hatte die ganze Frage nach den Gesetzen schon Mitte des 18. Jahrhunderts in dieser Weise gestellt: »The Safety of the People is the supreme Law « ${ }^{642}$ Die Gesetze, auf deren Grundlage sich der Großteil der britischen Gesundheitspolitik im 19. Jahrhundert herausbilden wird, richten sich in präventiver Form gegen Verhalten, was die Gefährdung der öffentlichen Gesundheit oder der Gesundheit einzelner zur Folgen hat oder potenziell haben könnte. Verwaltung und Legislative stützten sich auf wissenschaftliche Erkenntnisse, die auf Erfahrung, empirischen Verfahren und sichtbaren praktischen Veränderungen beruhten. Die Auseinandersetzung um die Verbesserung der öffentlichen Gesundheit wurde im 19. und bis ins 20. Jahrhundert hinein in weiten Teilen an den Fragen entsponnen, ob genügend und ausreichend effektive Gesetze existieren, um für die öffentliche Gesundheit gefährliches Verhalten zu bestrafen. Es existierte Anfang des 20. Jahrhunderts schließlich ein sehr dichtes Netz aus verschiedenen Gesetzen und Regelungen, die in Folge eines konkreten Problems, einer Gefahr, die man $\mathrm{zu}$ einem bestimmten Zeitpunkt festgestellt hatte, direkt oder indirekt zum Schutz der öffentlichen Gesundheit geschaffen worden waren. Die health and security laws sind hierfür exemplarisch und Teil einer Regierungstechnologie, die man mit Foucaults Worten als Sicherheitstechniken bezeichnen kann.

Die Hygienebewegung in Großbritannien konzentrierte sich nicht auf die Etablierung gesundheitsbezogener Selbstpraxis, sie versuchte diese auch nicht im Sinnes eines ergänzenden Systems aus hygiène privée und hygiène publique einzubinden, die Techniken der Public Health sind die Sicherheitstechniken ${ }^{643}$. Die Techniken, mit denen sich Gouvernementalität weniger auf den Einzelnen, als auf die biologisch begriffene Bevölkerung richtet, ${ }^{644}$ sind aber nicht $\mathrm{zu}$ verwechseln mit den staatlichen totalisierenden Techniken vor dem 18. Jahrhundert, die von der Regierung der Einzelnen noch nichts wusste.

Diese bürgerliche Bewegung also, die in England ab den 1830er Jahren als die sog. sanitary movement entsteht, unterscheidet sich von den Hygienebewegungen als

641 Vgl. z.B. [Hrsg.]: An attempt to develop the Fundamental Principles which should guide the Legislature in regulating the Profession of Physic: in: ESMJ, 14.1818, S. $1-26:$ S. 1.

642 Vgl. Hume: An Enquiry Concerning the Principles of Morals, 1751: S. 53.

643 Damit meine ich Techniken, die sich nach Foucaults Verwendung weder auf das Selbst, noch in disziplinierender Form auf andere Individuen und ihre Körper richten, sondern die totalisierend auf die Lebensbedingungen einwirken, um z.B. die Gesundheit einer Bevölkerung auf globaler Ebene zu sichern: Assanierung von Straßen, Stadtplanung, Wasser und Abwassersysteme in den Städten usw. Vgl. Foucault: Die Maschen der Macht, 2005 [1981]: S. 233. Ders. »Omnes et singulatim«. Zu einer Kritik der politischen Vernunft, 2005 [1979]: S. 167; 198. Vgl. Foucault: Die politische Technologie der Individuen, 2005 [1982]: S. 1000f; 1015.

644 Malthus spricht in seinem Aufsatz von »human improvement « und »Improvement of society « und zieht, was die Gesetze der Population angeht, diverse Vergleiche mit Tierpopulationen. Vgl.: Malthus: An Essay on the Principle of Population, 1798: S. 1; 3 und $80 \mathrm{ff}$. 
einer in hygienischer und moralischer Hinsicht engagierten bürgerlichen Öffentlichkeit in mehreren Punkten. Sie will nicht die Bürger zu einer besseren Lebensweise führen, sondern sie will die Bürger von der Notwendigkeit der Regierung der Arbeiter überzeugen und die Arbeiter regieren ${ }^{645}$ Eine Erfahrung, die man in Großbritannien Anfang des 19. Jahrhunderts machte, war, dass auch die >freien< Lohnarbeiter nicht automatisch ihr Verhalten in der erwünschten Form rationalisierten.

»[A]mong the uneducated labourers, to increase the price of labour, is only to encourage idleness; as those who can support themselves by the labour of three days, will drink, or be idle the other four [...]: even in London, some of those labourers [...] are, we have been informed, generally idle and drinking during Saturday, Sunday, and saint Monday. « ${ }^{646}$

»)Margaret Caroll, age 11, 9 The Brower, 9 Court, Gore Street. The child has been fourteen days ill. She lies on rags, in a state of great filth. The house is almost bare of furniture, and the people appear to be destitute. There are two or three other starved-looking children, and the mother wears only a single garment. The father, a strong, ablebodied man, tremulous with drink, volunteers the opinion that the child is suffering from want of food, and not from fever. He also states that he has been drinking hard for the last fourteen days, and considers that drink is more easily get than food. $\ll^{647}$

Die armen Arbeiter sollen dazu gebracht werden, sich selbst zu regieren, aber aus anderen Gründen und aus anderen Anreizen heraus, als sich die Bürger selbst regieren (sollen). Das Problem mit den Arbeitern sei nicht, dass sie ihre Leidenschaften und Genusssucht nicht zügeln können, sondern, dass sie keine Vorstellung von einem wirklichen Genuss haben (»true value of sensual pleasure ${ }^{648}$ ). Was also nötig sei, sei eine Erziehung, die sie lehre, besser auf ihre Bedürfnisse zu hören (»by improving understanding of the heart $\left.\ll^{649}\right)$.

Das Problem des Pauperismus gewinnt etwa zeitgleich mit dem Aufstieg des sanitary movement an Popularität. Die Regierung der Armen wird nie ausschließlich oder in erster Linie als Aufgabe des Staates betrachtet. Das sanitary movement wurde in England, Wales und Schottland von einer Vielzahl von Vereinigungen und wohltätigen Gesellschaften getragen. Es gründen sich private Initiativen und Gesellschaften

645 Vgl. Yeatman, John C.: Remarks on the Medical Care of Parochial Poor, with a few Observations on the Improvement of Poor Houses, and on the necessity of establishing small Infirmaries in Populous Towns in: MPJ, 39.1818, S. 331 - 334: S. 332.

646 Johnson: An Inquirie into the Laws of Epidemics; with Remarks on the Plans lately proposed for Exterminating the Small-pox. By Joseph Adams u.a.: in: EMSJ, 6.1810, S. 231 -244: S. 234.

647 Thorne, Richard Thorne: On the Progress of Preventive Medicine During the Victorian Era. Inaugural Address of Session 1887 - 88, November 9th, 1887: in: TES.2s, 7.1889, S. 1 - 46: S. 14.

648 Johnson: An Inquirie into the Laws of Epidemics; with Remarks on the Plans lately proposed for Exterminating the Small-pox. By Joseph Adams u.a.: in: EMSJ, 6.1810, S. 231 - 244: S. 234.

649 Ebd., S. 234. 
aus bürgerlichen Kreisen - zum geringeren Teil von Ärzten getragen, die wohltätige Einrichtungen zur medizinischen Versorgung der Armen förderten. ${ }^{650}$ Die Sanitäre Bewegung ist relativ unabhängig von der wissenschaftlichen Medizin und ihrer privaten Praxis. Sie entspringt eher einem von verschiedener Seite getragenen bürgerlicher Diskurs gegen den Pauperismus. Dieser wird im Zusammenhang mit der starken Urbanisierung, dem Bevölkerungswachstum in den Städten, der hohen Sterblichkeit in den Wohnvierteln der Arbeiter und einer zunehmenden Kriminalität gestellt. ${ }^{651}$ Die Lösung dieses Problems sollte aber nicht in der staatlichen oder kirchlichen Fürsorge bestehen. Eine relativ weit verbreitete These war, dass das sicherste Mittel, um die arbeitende Klasse vor Verelendung und Krankheit zu bewahren, die Arbeit selbst war. Um die Pauperisierung zu verhindern, müssten die Arbeitenden möglichst die ganze Woche arbeiten und dürften nur so wenig verdienen, dass sie gerade überleben und ihnen keine Zeit und kein Geld fürs Trinken und Nichtstun bliebe. Die Löhne müssten also niedrig und die Lebensmittelpreise hoch gehalten werden. ${ }^{652}$ Natürlich war es auch ungefährlicher, wenn man die Arbeiter auf diese Weise noch weiter in die Abhängigkeit vom Kapital brachte. Die Angst vor der Gefahr von Revolutionen und Aufständen durch die arbeitende arme Bevölkerung vermischten sich mit der Angst vor Seuchen und Epidemien, die von den Armenvierteln und den unhygienischen Lebensbedingungen und Gewohnheiten (unhealthy dwellings, habits) der Armen ausgingen. ${ }^{653}$ Neben den Lebensbedingungen und Verhaltensweisen der Armen wurden aber auch die Arbeitsbedingungen, die Luftverschmutzung durch die Fabriken und die Zustände der Häuser Anfang des 19. Jahrhunderts erstmals und in zunehmendem Maße problematisiert.

650 Vgl. z.B. [Hrsg.]: Report of the Committee of the house of Commons on the Petition respecting the Fever Institution: in: MPJ, 12.1804, S. 161 - 163: S. 161. Vgl. Alison, Pulteney William: Observations on the Epidemic Fever now prevalent among the lower orders in Edinburgh: in: ESMJ, 28.1827, S. 244 - 263: S. 243; 247.

651 [Hrsg.] On the increasing Populousness of England (Journal of Science and Arts): in: MPJ, 40.1818, S. 209 - 213: S. 209f. Vgl. [Hrsg.]: I. Report for the Select Committee on Contagious Fever in London, Ordered by the House of Commons to be printed [...]. II A Hill to Establish Fever Hospitals, and to make other Regulations for the Relief of the Suffering Poor, and for Preventing the Increase of Infectious Fevers in Ireland [...]. IV. Statement relative to the present Prevalence of Epidemic Fever among the Poorer Classes in Glasgow; together with some Suggestions both for affording more Adequate Assistance to the Sick, and for Checking the Further Progress of the Contagion [...]. V. Practical Observations on Continued Fever, especially that Form at present existing as an Epidemic, with some Remarks on the most Efficient Plans for its Suppression [...]: in: ESMJ, 14.1818, S. 528 - 548: S. 538.

652 Ebd.: S. 539. Das Ergebnis dieser Betrachtung des Autors ist, dass die Epidemien und das Elend der Armen in der Zeit hoher Lebensmittelpreise sogar zurückgingen. Vgl. ebd.

653 Vgl. ebd.: S. 540. Vgl. Roberton: A Treatise on Medical Police, and on Diet, Regimen, \&c. I, 1809: S. xviif. 


\section{Poor Law reform}

Die Kritik an einer falschen und politisch wie ökonomisch ineffektiven Armengesetzgebung wurde von einer Reihe von Politikern, Ökonomen und liberalen Theoretikern Ende des 18. und Anfang des 19. Jahrhunderts in England propagiert. Die Reform des Armenrechts sollte der >Pauperisierung< entgegenwirken, die Schäden der alten Gesetze beheben und zugleich die Entwicklung einer bestimmten (im Sinn Foucaults gemeinten) Subjektivität und ökonomischen Vernunft der arbeitenden Menschen auf die Sprünge helfen. ${ }^{654}$ Adam Smith und James Steuart hatten in ihren Theorien noch angenommen, dass sich die historische Notwendigkeit der poor relief mit der Weiterentwicklung kapitalistischer Produktion, der Zunahme von Reichtum und freier Lohnarbeit, selbst erübrigen würde. Andere Aspekte wie die restriktive Niederlassungspolitik sah Smith als hinderlich für die industrielle Produktion. ${ }^{65}$ Thomas Malthus plädierte etwas später für eine, wie Mathias Bohlender es ausgedrückt hat, »biopolitische Lösung « durch die völlige Abschaffung des alten Armenrechts. Jeremy Bentham ${ }^{656}$ setzte sich eher für eine Art utilitaristische und ökonomische Reformierung des Armenrechts ein. ${ }^{657}$

Was auch immer die unterschiedlichen Vorschläge waren, die schließlich in das neue Armenrecht einflossen, entscheidend ist meiner Meinung nach, dass sowohl Smith, als auch Malthus und Bentham ähnliche Vorstellungen davon hatten, welchen Einfluss Fürsorge auf den Charakter der Armen haben würde und wie man auf der anderen Seite durch eine Abschaffung oder Rationalisierung der Fürsorge eine Veränderung der Subjektivität oder des Verhaltens bewirken würde. Eine Selbstregierung, bei der es nicht von Nöten ist, eine bestimmte Lebensweise als die bessere anzuerkennen, sondern es ausreicht, einen gewissen Lebenswillen zu haben, der den Menschen dazu bringt, alles, was er tut, nach dem Nutzen für seinen Zweck des Überlebens zu berechnen und danach zu leben. Thomas Malthus schrieb in seinem berühmten Text An Essay on the Principle of Population, dass das alte Armenrecht die Armen dazu ermutige, sich und ihre Familien abhängig von dieser staatlichen Unterstützung zu machen. Anstatt rationelle Überlegungen anzustellen, würden sie Kinder in die Welt setzen in dem sicheren Glauben, der Staat würde für diese sorgen. ${ }^{658}$ Die Praxis der workhouses und Unterstützung, die die Armen erhielten, zerstöre den »spirit of independence«: »The poor laws are strongly calculated to eradicate this spirit. « ${ }^{69}$ Ähnlich wie Malthus hatte auch schon früher Steuart bemerkt, dass die Fürsorge für die Armen, sofern sie nur einen wohltätigen Zweck erfülle, unnütz oder

654 [Hrsg]: Reform of Charities, Hints on the Constitution of Dispensaries, with the view of being rendered of more extensive benefit to the labouring population, By John Storer, Consulting Physician to the general hospital near Nottingham: in: ESMJ, 1.1805, S. 417 431: S. 423.

655 Vgl. Steuart: An Inquiry into the Principles of Political Economy, 1767: S. 112.

656 Chadwick, der später führend bei der Reformierung des alten Armenrechts werden sollte, war Anfang der 30er Jahre des 18. Jahrhunderts übrigens Benthams Sekretär gewesen. Vgl. McLean: Public Health and Politics in the Age of Reform, 2006: S. 6.

657 Vgl. Bohlender: Metamorphosen des liberalen Regierungsdenkens, 2007: S. 142.

658 Vgl. Malthus: An Essay on the Principle of Population, 1798: S. 34.

659 Ebd.: S. 35. 
schädlich sei. Krankenhäuser und Fürsorgeeinrichtungen, die die Arbeiter und Armen nicht dazu bringen, unabhängiger zu werden, die lediglich linderten, aber nicht präventiv gegen die Pauperisierung wirkten, seien falsch. Sie dienten nicht der Bekämpfung der Armen, sondern förderten die Armut: »consequently, poor are in proportion to charity. $\ll{ }^{660}$ Die große Mehrheit der liberal eingestellten Ärzte teilte diese Kritik an der poor relief und der Wohlfahrt. ${ }^{661}$ Sie bildete einen wichtigen Teil des Hintergrunds, vor welchem das neue Poor Law von 1834 und der Public Health Act 1848 verabschiedet wurden. Ein konkreter Auslöser für eine Verschärfung dieser Kritik war der dramatische Anstieg der poor relief in Folge der Typhus-Epidemie in London 1837 - 38. Sie gab den Anstoß für Edwin Chadwicks erste Ideen einer effektiveren und kostengünstigen, nämlich präventiven Politik gegen krankheitsbedingte Verarmung und Pauperismus, die er zehn Jahre später in seinem Bericht Report on the Sanitary Condition of the Labouring Population of Great Britain genauer ausführen sollte. ${ }^{662}$ Die enge Verbindung, die man zwischen den Lebensbedingungen - vor allem Wohnungen der Arbeiter, dem Typhus und folglich der Gefahr des Pauperismus herstellte, blieben für die Sanitary Reform bedeutsam. ${ }^{663}$

Die Diskussion um die Wohlfahrt und das Armenrecht, in die Ärzte ebenso wie Beamte besonders involviert waren, wendete sich auch hier immer wieder dem Problem der Nützlichkeit zu (»general attention [...] to the tests of utility«). Dies galt auch für die medizinische Versorgung (»the important subject of the administration of medical charities «), die man auf diesem Wege der armen und arbeitenden Bevölkerung zukommen ließ. ${ }^{664}$ Eine immer wieder deutlich werdende Forderung war, dass die Fürsorgeeinrichtungen umgestaltet werden müssten. Sie sollten der neuen politischen Rationalität angepasst werden.

»The first object of charity, in all instances, is to perform the greatest good with the least means; whenever, therefore, a public institution relieves any of the distresses of the poor more effectually and economically than if they were individually assisted, and whenever the relief grated holds forth no temptation to increase the number of those applying for it, or in the most distant way to encourage vice or idleness, then are public institutions truly useful. « ${ }^{665}$

660 Steuart: An Inquiry into the Principles of Political Economy, 1767: S. 61. Vgl. Smith: An Inquiry into the Nature and Causes of the Wealth of Nations, 2007 [1776]: S. 62; 63.

661 Vgl. [Hrsg]: Reform of Charities Hints on the Constitution of Dispensaries, with the view of being rendered of more extensive benefit to the labouring population, By John Storer, Consulting Physician to the general hospital near Nottingham: in: ESMJ, 1.1805, S. $417-$ 431: S. 420.

662 Vgl. McLean: Public Health and Politics in the Age of Reform, 2006: S. 7.

663 Vgl. Thorne Thorne, R.: On the Progress of Preventive Medicine During the Victorian Era. Inaugural Address of Session 1887 - 88, November 9th, 1887: in: TES.2s, 7.1889, S. 1 - 46: S. 14.

664 Ebd.: S. 417.

665 [Hrsg.]: On the Inexpedency of erecting Foundling Hospitals. »Down then with the Foundling Hospitals, more noxious than pestilence and famine. (Kames)«: in: ESMJ, 1.1805, S. 319 - 329: S. 320. 
Neben dem Ziel der gesundheitlichen Verbesserungen der Arbeiter mussten die Techniken und Institutionen in einer Weise umgestaltet werden, dass sie die Armen gleichzeitig zu einem bestimmten Verhalten und zu einer bestimmten >rationalen< Subjektivität nötigten. Die Verknüpfung von Krankheit als Armutsrisiko und der damit einhergehende Freiheitsverlust wurde aber nach Meinung einiger durch die flächendeckende Einrichtung der workhouses noch verschärft. ${ }^{666}$ Wer von seinem körperlichen Zustand her gemessen dazu in der Lage ist, zu arbeiten, soll dazu angehalten werden, so schnell wie möglich wieder von seiner Arbeit leben zu können oder eben, wenn es nach Malthus ging, zu verhungern bzw. durch die Voraussicht der Eltern erst gar nicht geboren zu werden.

Das Ziel der Politiken richtet sich hier sich auf die Erhaltung bzw. Förderung der Arbeitsfähigkeit und die innere Sicherheit. Die aus diesen Diskussionen entstandene Idee einer >rationellen< Fürsorge richtet sich auch gegen eine Reihe von Moralvorstellungen und Motive der Barmherzigkeit, die man der Kirche und ihren Einrichtungen zurechnet. Diese würden die Armen und die Pauper zum >Objekt< ihrer Barmherzigkeit machen und entzögen ihnen den Status eines freien (ökonomisch selbstständigen) Subjekts. Diese Logik richtete sich gegen ein sozial und kulturell verankertes Empfinden von Mitleid und die dazu aufforderte, dieses Gefühl nicht nur als falsch, sondern eben als unmoralisch anzusehen. Unmoralisch deshalb, weil es dem Pauper, der die Hilfe in Anspruch nahm und sich von ihr abhängig machte, ein grundlegendes Element seiner Individualität und Freiheit entziehe, schrieb Malthus. ${ }^{667}$

Der utilitaristische präventive Charakter der Fürsorge für die Armen war verbunden mit der Aussicht, sie so schnell wie möglich wieder zu arbeitsfähigen freien Lohnarbeitern zu machen. Das Ziel der staatlichen Gesundheitspolitik richtete sich voll und ganz darauf, die Arbeiter und ihre Kinder, bzw. ihre Körper und ihre Gesundheit in dem Maße zu schützen oder wiederherzustellen, wie es eben nötig war, damit die, die arbeiten, sich als freie Lohnarbeiter selbst unterhalten konnten und somit unabhängig von sozialer, wohltätiger und staatlicher Unterstützung waren. In einem Artikel mit dem Titel Remarks on the Medical Care of Parochial Poor, aus dem Medical and Physical Journal von 1818 heißt es:

»The importance of this subject, and the manner it has so lately attracted legislative attention, induces us to the early notice of whatever relates to the management of the poor. We have several times remarked, how much the care of the sick and the remuneration of the medical attendant are implicated in the question. If the diseases of the poor are early attended to, the probability is, that they may be soon restored to a capacity of providing for their family. Even the children, by an early attendance, may be visited with a short, instead of an expansive, chronic complaint. $\ll^{668}$

666 [Anonym]: On The poor-law and workhouse-test: in: The Lancet, $1840-1841,2$ von 2 Bde., 3.4.1841, S. 50 - 53.

667 Vgl. Malthus: An Essay on the Principle of Population, 1798: S. 35.

668 Vgl. Yeatman, John C.: Remarks on the Medical Care of Parochial Poor, with a few Observations on the Improvement of Poor Houses, and on the necessity of establishing small Infirmaries in Populous Towns in: MPJ, 39.1818, S. 331 - 334: S. 331. 
Medizinische dichotome Klassifizierungen waren die Unterscheidungen von heilbaren und unheilbaren Krankheiten, arbeitsfähigen und arbeitsunfähigen Arbeitern usw. Vor allem der ablebodied worker: männlich, erwachsen, gesund usw. sollte zur Selbstsorge angeregt werden. Ihm wurde unterstellt, grundsätzlich dazu in der Lage zu sein, sich um sich selbst und um seine Familie kümmern zu können. Anderen, z.B. chronisch oder unheilbar Kranken, auch alten Personen, die man alle als non-ablebodied bezeichnete, wurde die Fähigkeit zur ökonomischen Selbstständigkeit abgesprochen. Was ihre Pflege betraf, war es vertretbar, sie in religiösen Einrichtungen unterzubringen, sie durfte oder sollte man zu einem »object of medical charity« machen. ${ }^{669}$

Im Bereich der Regierung von Gesundheit spielte sich also ein Diskurs ab, der sehr eng verbunden war mit den Debatten um die Reform des Armenrechts und dem Problem einer Regierung der Armen. Die Rationalisierung von staatlicher medizinischer Wohlfahrt stand in Verbindung mit der Rationalisierung bzw. Ökonomisierung von Krankenhäusern und Behandlungsmethoden. Die Frage, wieviel Nutzen eine bestimmte Therapie überhaupt und für wen hat und ob es nicht immer noch eine Möglichkeit gibt, dass die armen Patienten etwas für ihre Behandlung bezahlen, wurde diskutiert. ${ }^{670}$

Der Zweck der Regierungstechniken, die man anwendete, um die Menschen zur Annahme einer bestimmten Rationalität und zu einem bestimmten Verhalten, oder anders gesagt, zu einer vernünftigen Selbst- und Lebensführung zu bringen, zielte im Grunde nur auf ein (potentiell) arbeitsfähiges und im kapitalistischen Sinne >produktives< Subjekt. Sowohl die Techniken, mit denen man die Körper bearbeitete, als auch die Techniken, die sich auf die Seele richteten, wurden im Sinne dieses Interesses rationalisiert. Gleichzeitig hofften liberale Ärzte, Nationalökonomen und Beamte darauf, dass die Zwänge und Existenzbedingungen, denen die Einzelnen unter den zunehmend kapitalistischen Produktionsverhältnissen ausgesetzt waren, einen so starken regulativen Effekt einnehmen könnten, um die imperfekten >künstlichen Maßnahmen der Regierung unnötig zu machen. Die Technologie der liberalen Regierung richtete sich auf die >Regeneration $<$, Sicherung und Unterstützung dieser Mechanismen der >Selbstregulation $<$.

669 In einem Artikel der später und mit Rückblick auf die Reform des Armenrechts im The Lancet erschien, vertrat der Autor z.B. die Ansicht, es sei besonders falsch die disable bodied workers aus ihrem familiären Umfeld zu reißen, wo man sich um sie kümmern würde, und sie in ein Armenhaus zu stecken, wodurch sie nur Geld kosten würden. Vgl. [Anonym]: On The poor-law and workhouse-test: in: The Lancet, 1840 - 1841, 2 von 2 Bde., 3.4.1841, S. $50-53$.

670 Vgl. [Hrsg]: Reform of Charities, Hints on the Constitution of Dispensaries, with the view of being rendered of more extensive benefit to the labouring population. By John Storer, Consulting Physician to the general hospital near Nottingham: in: ESMJ, 1.1805, S. 417 - 431: S. 423. 


\section{Public Health und Medical Police}

Obgleich es zu Beginn des 19. Jahrhunderts einige wenige Vorschläge für die Einführung einer medizinischen Polizei in England und Schottland gegeben hat, erreichten diese Vorschläge keine große Popularität. Eher wurde ihnen mit Skepsis und Ablehnung begegnet. ${ }^{671}$ Aus heutiger Sicht wird gerne behauptet, diese Haltung resultierte aus der britischen Auffassung von Public Health, die Konzepten staatlicher institutioneller Gesundheitsadministration und -polizei in anderen europäischen Staaten und vor allem Deutschland entgegenstand. ${ }^{672}$ Die scharfe Abgrenzung und gesundheitspolitische Positionierung Großbritanniens ab Mitte des 19. Jahrhunderts kann im Anschluss an Foucaults Beschreibungen des »englischen Radikalismus $\ll^{673}$ auch als Teil einer spezifischen Strategie der englischen Regierung zu dieser Zeit gesehen werden. Dies hat z.B. Patrick E. Carroll in seinem Aufsatz Medical Police and the History of Public Health, der 2002 in der Zeitschrift Medical History erschienen ist, versucht zu belegen.

$»$ The rise to dominance of the idiom of public health did not, I suggest, clearly signal the discovery/construction of a new object or a new body of knowledge that made it possible for >public health $<$ to break free of >police $<$. The idiomatic shift was tactical in the political sense rather than epistemic in the cultural sense. $\ll^{674}$

In Anlehnung an Latour und Foucault stellte Carroll empirisch auf der Grundlage einiger englischer Quellen aus der ersten Hälfte des 19. Jahrhunderts heraus, dass die konkrete Praxis und Kultur der Regierung von Gesundheit, was ihre Rigorosität betraf, nur mit Mühe in einen Gegensatz zur Praxis der medizinischen Polizei, die es auf dem Kontinent gab, zu bringen sei. Carroll wollte zeigen, dass die Herausbildung und Durchsetzung dieser Strategie keine logische oder natürliche Folge bzw. Reaktion auf die veränderten Bedingungen etwa kapitalistischer Produktion waren. Public Health diente in der Weise, wie man es als Gegenmodell und in Abgrenzung zur antiliberalen deutschen Staatsmedizin propagierte, gerade der Legitimation der sich als liberal profilierenden englischen Regierung von Gesundheit.

»Rather than >public health< becoming a new scientific and government strategy that >reflected a new political reality, a new idiom emerged that refracted the representation of medical police practice in a way that sought to make it palatable to those who viewed police as the antithesis of liberty. I provide broad evidence for doubting the view that modern public health culture has ever, in England or elsewhere, been >opposed $<$ to police. ${ }^{675}$

671 Sinclare, J.: On Health and Longevity: in: MPJ, 13.1805, S. 527 - 532: S. 528.

672 Vgl. Fee: Introduction - Public Health, Past and Present, 1993: S. xxiv. Vgl. Porter, D.: Introduction: in: The History of Public Health and the Modern State, 1994: S. 7.

673 Foucault: Geschichte der Gouvernementalität II, 2004 [ 1978 - 1979]: S. 67.

674 Carroll: Medical Police and the History of Public Health, 2002: S. 464.

675 Ebd.: S. 464. 
Sicher lässt sich kein historisch-notwendiger oder logischer Zusammenhang zwischen der Entstehung der Public Health und der Ausdehnung kapitalistischer industrieller Produktionsweise und der mit ihnen verbundenen massiven sozialen Veränderungen behaupten. Ich plädiere allerdings dafür, den Ansatz der Public Health als eine besonders erfolgreiche Strategie anzusehen, die sehr wohl mit einer Reflexion dieser sich verändernden (materiellen und diskursiven) Bedingungen verbunden war. Erfolgreich war sie, indem sie eine bestimmte Opposition oder Begrenzung der Regierung, die in einem staatskritischen und liberalen Diskurs bestand, ausschaltete. Die logische Verknüpfung, in der wir heute wunderbar geübt sind, hindert uns daran zu begreifen, was liberale Regierung im Kern ausmacht. Nämlich der Gedanke, dass >liberal < intuitiv mit Freiheit und auf diese Weise mit einem >Weniger $<$ an Regierung verbunden sein muss. Diese Verknüpfung zu behaupten, war bereits im 19. Jahrhundert Teil einer neuen Strategie und Rationalisierung von Regierung, ${ }^{676}$ die sich durch die Abgrenzung von und Kritik an absolutistischer Willkürherrschaft, religiöser moralischer (Kontroll-)Praxis, päpstlicher und teilweise sogar patriarchaler Macht, an deren Stelle setzte und unter den gegebenen Umständen mehr und vor allem effektiver regierte. Sie hatte, wie sich an der Regierung der Gesundheit darstellen lässt, keine Freiheit vom Regiert-sein zur Folge, sondern eher den gegenteiligen Effekt: die Ermöglichung einer rigorosen Praxis der gesundheitspolitischen Exekutive. Die Strategie der britischen Hygienebewegung war nicht, die private, im bürgerlichen Lebensbereich entstandene Praxis zu ihrer eigenen moralischen Erhöhung zu verallgemeinern. Man hielt diese Strategie für unpraktikabel und ineffektiv, vor allem dann, wenn es um die Regierung der Arbeiter ging. Die praktischen ökonomischen und sozialen Probleme, die die Macht von Staat und Kapital materiell und politisch gefährdeten (Aufstände von Arbeiter Gewerkschaften, Arbeitskämpfe, Streiks) sollten gelöst werden, indem das Spiel und Wirken der unterschiedlichen sozialen Kräfte und Zwänge selbst als Regulationsmechanismen der Regierung eingesetzt wurden. Der Weg über den man eine liberale rigide hygienische Praxis institutionalisierte, erfolgte über ein umfassendes wie allgemeines Netz von Gesetzen, die grundsätzlich alle Handlungen kriminalisierbar machen, die eine Gefahr für die Gesundheit einer anderen Person oder für die Gesellschaft darstellen (könnten). Die Regierung richtet sich im Grunde nicht auf die einzelnen Subjekte. Ihre Seele, ihr Charakter und ihre Moralität sind nicht mehr Gegenstand der Techniken - und in diesem Sinne sind die Individuen tatsächlich >frei<, weil sich die Techniken nicht mehr so sehr auf eine moralische Verbesserung konzentrieren.

Die Vorstellung, dass Krankheiten und vor allem Epidemien, deren Schaden man für Gesellschaft und Ökonomie besonders hoch einschätzte, von vorwiegend externen, vom einzelnen Individuum nicht beeinflussbaren Faktoren ausgingen, führte zu der Herausbildung entsprechender politischer Techniken, die sich nicht auf Individuen konzentrierten, sondern auf Städtebau, Architektur und Wasserversorgung - ihr Ziel war »the removal of all the general causes of disease $«{ }^{677}$. Auch hier konnte die

676 Vgl. Foucault: Ein endliches System angesichts einer unendlichen Nachfrage, 2005 [1983]: S. 449f.

677 Roberton, John: Observations on the Propriety of adopting, in Great Britain, a Plan of Medical Police: in: MPJ, 18.1807, S. 558 - 564: S. 563. 
Regierung agieren, ohne ein Interesse an der Veränderung des Verhaltens des Individuums rechtfertigen zu müssen. Selbst in den wenigen Vorschlägen für eine medizinische Polizei war diese Konzentration bereits deutlich geworden ${ }^{678}$ John Roberton veröffentlichte 1809 eine zweibändige Abhandlung mit dem Titel: A Treatise on Medical Police, and on Diet, Regimen, \&c. Welche, da sie - mit Ausnahme der Arbeit des schottischen Arztes Andrew Duncan -, in dieser Zeit die einzige britische Publikation zur medizinischen Polizei war, eine besondere Aufmerksamkeit von Historikern erhielt, die sich ansonsten vor allem auf die viel umfassendere und ganz anders gestrickte Arbeit von Johann Peter Frank konzentrierten. ${ }^{679}$ Die genauen Praktiken, die Roberton für die medizinische Polizei im Sinn hatte, waren nicht völlig anderer Art, aber von ihrer Idee weit begrenzter, als die im Sinne Franks. ${ }^{680}$ Robertons Ideen konzentrieren sich auf die Durchführung von Inspektionen von Häusern und Wohnungen durch vorrangig medizinisch ausgebildete medical officers. Mit den Inspektionen verbindet er Instruktionen zu deren Verbesserung und Säuberung bis hin zum gesetzlich verfügten Abriss >ungesunder $<$ Behausungen.

Obwohl Robertons Vorschlag aufgrund seiner Person und seines >unehrenhaften< Status innerhalb der Vereinigungen britischer Mediziner nie große Bedeutung erlangte, so lassen sich doch eine ganze Reihe von Praktiken der später von dem general board of health und den local boards of health mit seinen Vorschlägen vergleichen. Robertons Vorschläge unterschieden sich vor allem deshalb von Franks, weil sie von einer ganz anderen Rationalität und einer sehr von Franks zu unterscheidenden Perspektive auf Gesundheit und Krankheit herrührten. Den Ausgangspunkt von Robertons Ausarbeitung einer medizinischen Polizei bildete das Problem der Arbeit und der Arbeitskraft. Er überschrieb die Einleitung seinem Treatise on Medical Police: »Exhibiting those Miseries of Mankind which the work is intended to obviate, and sketching the plan to be adopted for that purpose ${ }^{681}$. Die Aktivität und Arbeit des Körpers, die Ausübung eines Berufs oder einer Tätigkeit galten für Roberton sowohl als Mittel zur Gesunderhaltung, als auch generell als Quelle für Glück und Wohlbefinden des Körpers und der Seele. Krankheit zerstöre nicht nur die Gesundheit, sondern auch die ganze Möglichkeit über die Arbeit dieses Glücks oder seine Existenz $\mathrm{zu}$ bestreiten. $»[\mathrm{~L}] \mathrm{ife} \ll$, schrieb Roberton, $»$ is a state of force ${ }^{682}$. Roberton richtet sich z.B. mit seinem Vorschlag explizit gegen die Einrichtung von Krankenhäusern für die Armen, welche er durch eine frühzeitige Beseitigung der Ursachen für die Erkrankung der Armen in ihren Unterkünften und Stadtvierteln ein Stückweit unnötig machen wollte. ${ }^{683}$ Auch Roberton war der Ansicht, man müsse charity und philanthropy präventiv, rational und nützlich zu gestalten, um sie tendenziell unnötig zu machen. ${ }^{684}$ Roberton hob immer wieder hervor, dass Krankheiten aus Schmutz, Un-

678 Vgl. ebd.: S. 560. Vgl. auch Roberton: A Treatise on Medical Police, and on Diet, Regimen, \&c. I, 1809: S. xlvi.

679 Vgl. ebd.: S. 407.

680 Vgl. Roberton: A Treatise on Medical Police, and on Diet, Regimen, \&c. II, 1809: S. 350.

681 Roberton: A Treatise on Medical Police, and on Diet, Regimen, \&c. I, 1809: S. ix.

682 Ebd.: S. xiv.

683 Vgl. Roberton: A Treatise on Medical Police, and on Diet, Regimen, \&c. II, 1809: S. 351.

684 Vgl. ebd.: S. 350f. 
sauberkeit der Behausung, Dämpfe und Gerüche, die von verderbenden Abfällen, Abwässern und verwesenden Kadavern herrühren, entstehe: »various circumstances, may emit effluvia, destructive of health ${ }^{685}$. Während sich die Sicherheitstechniken der medizinischen Polizei in den deutschen Ländern vorwiegend mit dem Problem der Ansteckung auseinandersetzten, war für Roberton die Miasma-Theorie bedeutender und damit auch die von ihm vorgeschlagenen Techniken andere. ${ }^{686}$ Zur Zeit der Veröffentlichung von Robertons Buch stellten die Anti-Kontagionisten in Großbritannien bereits eine starke Fraktion der Ärzte dar. ${ }^{687}$ Auch Roberton stand der Theorie der Ansteckung skeptisch gegenüber. ${ }^{688}$

Bevor der Public Health Act 1848 verabschiedet wurde, gab es eine Reihe kleinerer Gesetze, die auf das von Roberton so viel beschworene Problem der Beseitigung der Ursachen von Krankheiten gerichtet waren. Hier ist besonders der Nuisances Removal Act und der Diseases Prevention Act zu beachten. Die Gesetze dienten der öffentlichen Sicherheit, die zum legitimen Spielfeld der liberalen Regierung wurde sie ist untrennbar von ihrer ökonomischen Rationalität. Auch Roberton macht in seinem Artikel im Medical and Physical Journal über seinen Plan für eine Polizei deutlich, dass die weitreichenden Ziele der Verbesserung der sanitären Verhältnisse Wohlstand und Reichtum der Nation sind. ${ }^{689}$

685 Ebd.: S. 355.

686 In seinen ganzen Ausführungen findet sich kein Wort zur Quarantäne und Isolation als Mittel der Prävention von Epidemien.

687 Vgl. Harvey, J., Secretary: Second Report of the Board of Health: in: ESMJ, 1.1805, S. 111 - 117: S. 111. Vgl. [Hrsg.] I. Report for the Select Committee on Contagious Fever in London, Ordered by the House of Commons to be printed [...]. II. A Hill to Establish Fever Hospitals, and to make other Regulations for the Relief of the Suffering Poor, and for Preventing the Increase of Infectious Fevers in Ireland [...]. IV. Statement relative to the present Prevalence of Epidemic Fever among the Poorer Classes in Glasgow; together with some Suggestions both for affording more Adequate Assistance to the Sick, and for Checking the Further Progress of the Contagion [...]. V. Practical Observations on Continued Fever, especially that Form at present existing as an Epidemic, with some Remarks on the most Efficient Plans for its Suppression [...]: in: ESMJ, 14.1818, S. 528 - 548: S. 540. Vgl. Rush, Benjamin: Fact intended to prove the Yellow Fever not to be contagious, and Instances of supposed Contagion explained upon other Principles: in: ESMJ, 1.1805, S. 324 - 352: S. 326. Vgl. auch Johnson: An Inquirie into the Laws of Epidemics; with Remarks on the Plans lately proposed for Exterminating the Small-pox. By Joseph Adams u.a.: in: EMSJ, 6.1810, S. 231 - 244: S. 234.

688 Vgl. Roberton: A Treatise on Medical Police, and on Diet, Regimen, \&c. II, 1809: S. 350.

689 Vgl. Roberton, J.: Observations on the Propriety of adopting, in Great Britain, a Plan of Medical Police: in: MPJ, 18.1807, S. 558 - 564: S. 561. 


\section{Die Kolonien als Experimentierfeld von Selbst- und Sicherheitstechniken}

An der frühen wissenschaftlichen Diskussion über die Ursachen und Eigenschaften epidemischer Krankheiten lässt sich bereits Gesagtes durchexerzieren. Zum einen ist es interessant, in der ganzen Entwickelung der Epidemiologie zu zeigen, wie sich ein bestimmtes Verfahren der Veridiktion - die Untersuchung nach dem Muster einer kriminologischen Ermittlung mit bestimmten politischen Rationalitäten und einem bestimmten Set an politischen Techniken zur Bekämpfung der Epidemien verknüpfte. Ein Grund für die vergleichsweise frühe und spezifische Auseinandersetzung mit Epidemien in England mag der speziellen Erfahrung und der Möglichkeit der Anwendung von Techniken gegen Krankheiten in den Kolonien geschuldet sein. Die Vorstellung, dass das Auftreten bestimmter Krankheiten mit lokalen Gegebenheiten der Umwelt, des Klimas und den Gewohnheiten der Bevölkerung verknüpft wäre, existierte zwar schon sehr lange und war in Europa relativ verbreitet, erhielt aber in den Diskussionen und Untersuchungen zu Krankheit und Gesundheit in den Kolonien eine neue praktische, politische und ökonomische Relevanz. ${ }^{690}$

Die von mir untersuchten Quellen vom Ende des 18. Jahrhunderts, die sich mit dem Problem der Epidemien oder mit häufigen Krankheiten in den Kolonien beschäftigten, ähneln in ihren Problemdarstellungen und Lösungsempfehlungen beinahe der Art bürgerlicher gesundheitlicher, diätetischer Ratgeberliteratur. Sie richten sich an die britischen Siedler in Kolonien oder an Ärzte, die in Übersee arbeiten, und geben sowohl Empfehlungen zur Kleidung und Ernährung, wie auch zur Bauweise und Bepflanzung. ${ }^{61}$ Ein sehr gutes Beispiel hierfür ist der von mir analysierte Auf-

690 Die Prägung des Begriffs der »Tropenkrankheiten« oder der »Diseases of Tropical Climate«, unter dem sich eine Vielzahl aus medizinisch-pathologischer Sicht völlig unterschiedlicher Krankheiten fassen lassen, entstammt dieser Zeit und diesem Denken. Vgl. z.B. Boyle: Treatise on the epidemic cholera of India, 1821: S. iiv. Vgl. Orton, Surgeon: An essay on the epidemic cholera of India, 1831 [1820]: S. v. Vgl. Annesley: Sketches of the most prevalent diseases of India, 1829 [1825]: S. $10 \mathrm{f}$.

691 Vgl. [Hrsg]: Remarks on the influence of climate, situation, nature of country, population, nature of food, and way of life; on the disposition and temper, manners and behaviour, intellects, laws and customs, for of government, and religion of mankind: in: LMJ, 3.1781, S. 409 - 418. Vgl. [Hrsg]: Medical Philosophy - I. An account of the voyage to the Levant, with remarks on the diseases that prevail there, the nature of the soil, and the temperament of the inhabitants: in: LMJ, 4.1784, S. 364 - 366. Vgl. [Hrsg]: Are tropical fiever contagious?: in: Medical facts and observations, Nr. 7, Band 4, London, 1799, S. 6 - 20. Vgl. Rush, Benjamin: An inquiry into the cause of the increase Bilious and Intermitting Fever in Pensylvania with hints for preventing them. [...]: in: MC, 1.1786: S. 170 - 175: S. 172. Von der Art her sehr ähnlich, wenn auch nicht auf warmes Klima und die Kolonien bezogen, aber im gleichen hygienischen Geiste verfasst, ist auch dieser Artikel: Guthrie, Matthew: A letter to Dr. Duncan, on the Effect of a cold Climate on the Land Scurvy etc.«: in: LMJ, 10.1782, S. 328 - 338. 
satz von Benjamin Rush. ${ }^{692}$ Rushs Vorschläge beziehen sich von den verschiedensten Ursachen der Krankheiten ausgehend und mit dem Ziel, die gesundheitlichen Bedingungen des Landes zu verbessern, auf Maßnahmen der Bewaldung, Entwässerung ebenso wie sie sich auf das konkrete Verhalten der Einzelnen mit dem Ziel einer gesünderen Lebensweise richten. ${ }^{693}$ Dieses Verschwimmen, oder man müsste eher sagen, diese noch nicht zu erkennende klare Trennung und Aufgabenverteilung von Sicherheits- und Selbsttechniken findet sich zu dieser Zeit in der Problematisierung der Epidemien und Seuchen auch schon in England, wie z.B. der Kommentar »Observations on the Typhus, or low contagious Fever, and on the means of preventing the production and communication of the disease « von D. Campbell in der gleichen Zeitschrift zeigt. Die Verbindung des Wissens aus den Kolonien und aus England zeigt sich in diesem Artikel besonders in den Verallgemeinerungen über die Mittel gegen die Übertragung von Krankheiten, die Campbell im zweiten Teil vornimmt. ${ }^{694}$ Hierzu zählen ebenso wie bei Rush Ratschläge zur Ernährung, Kleidung und Körperhygiene und die Empfehlung der Belüftung von Räumen und zu deren Reinigung. ${ }^{695}$ Weiter geht er auf die Desinfektion von infizierten Gebäuden oder Schiffen ein. ${ }^{696}$ Ebenfalls interessant an dem Kommentar von Campbell ist, dass dieser anscheinend eine Untersuchung der Ursachen und Vorgänge der Krankheit im Körper für relativ überflüssig oder auch unmöglich hält: »it is of too subtile a nature to be object of our senses, much less at present of our practice, otherwise than in tracing or observing its effects. $«{ }^{697}$ Die Situation in den Kolonien unterstütze die Überwindung einer Reihe von Barrieren, die die Liberalisierung und Rationalisierung der sanitären Praxis der Regierung behinderte. Britische Ärzte und Siedler wurden in den Kolonien mit völlig anderen klimatischen und umweltlichen Bedingungen konfrontiert. Man kann den Eindruck gewinnen, dass die Projektionen auf das kolonialisierte Land den beobachtenden Blick der Ärzte, der sich auf die inneren und äußeren Verhältnisse und Bedingungen von Krankheiten richtete, verstärkten. Der Blick auf das zu beherrschende und technisch zu erschließende Land als >unkultiviertes<, >unberührtes « und gleichzeitig gestaltbares und beherrschbares, $\mathrm{zu}>$ zivilisierendes $<$, > wildes $<$ Land und seiner Bevölkerung stand in Gegensatz zu den vorsichtigen Reformen der Medizin und zur gesundheitspolitischen Praxis in Großbritannien. Gesellschaftliche Konventionen und kulturell verankerte Praxen, die die Praxis der medizinischen Wissenschaft oder die Anwendung neuer politischer Regierungstechniken im Herkunftsland beschränkten, gab es in den kolonialisierten Gesellschaften zwar auch zuhauf, konnten hier aber mit anderen Mitteln ausgeschaltet oder übertragen werden. Gleichzeitig konnte bestehendes Wissen und bestehende Praxis auch aus dem Bereich der Bekämpfung von

692 Rush, Benjamin: An inquiry into the cause of the increase Bilious and Intermitting Fever in Pensylvania with hints for preventing them [...]: in: MC, 1.1786: S. $170-175$.

693 Vgl. ebd.: S. 172.

694 Vgl. Campbell, D: Observations on the Typhus, or low contagious Fever, and on the means of preventing the production and communication of the disease: in: MC, 1.1786: S. 195 - 215: S. 197.

695 Vgl. ebd.: S. 197.

696 Vgl. ebd.: S. $198 \mathrm{f}$

697 Ebd.: S. 214. 
Krankheiten und Seuchen beliebig angeeignet werden. Die gewonnenen Kenntnisse veränderten und erweiterten auch das Spektrum der Möglichkeiten medizinischer und politischer Praxis im Land der Kolonisatoren. Eines der berühmtesten Beispiele für Heilmittel, die britische Ärzte aus den Kolonien mitbrachten und expansiv in die Heilpraxis in Großbritannien einführten, war die Chinin-Rinde oder das Chinin (bark of the cinchona tree). Dies berichtete Hufeland in seinem Artikel zur englischen Medizin im Journal zur practischen Heilkunde Ende des 18. Jahrhunderts und belegen zahlreiche Vorschläge zur Behandlung aller möglicher Krankheiten in englischen Zeitschriften aus dieser Zeit. ${ }^{698}$

Noch mehr oder zumindest früher als in Großbritannien orientierten sich die Mediziner an ökonomischen Faktoren und richteten ihre Methoden und Regierungsempfehlungen an der praktischen >Nützlichkeit< und >Effektivität< aus. Auf der anderen Seite waren die Kolonien der Ort einer Reihe von Experimentierfeldern. Viele Ärzte, die ihre Erfahrungen auf von Sklaven betriebenen Plantagen oder im Militär gesammelt hatten, philosophierten über eine von ökonomischen Interessen und medizinischer Wissenschaft optimierten Regierung der Gesundheit von Soldaten und Kolonialisierten. ${ }^{699}$ Die Praxis der Regierung der Gesundheit der Soldaten wurde teilweise offen mit der generellen politischen Praxis der Regierung von Gesundheit in Verbindung gebracht. In einem Artikel aus dem ersten Band des Medical and physical journal von 1799 schrieb ein ehemaliger surgeon der Marine:

»While it becomes the province of the statesman to enact salutary laws, to prevent the baneful influence of principles subversive of all social order, it is no less the duty of the guardians and superintendents of health, to recommend and employ such precautions and means, as produce and experience have suggested, to prevent the introduction, and check the progress of a formidable enemy - pestilential disease [...]. $\ll^{700}$

Die Ärzte in den Kolonien, ob sie nun für Kompanien von Soldaten zuständig waren oder für Sklaven auf den Plantagen, hatten es immer mit der Behandlung von Gruppen oder einer bestimmen Menge an Menschen zu tun, die genau erfassbar waren, die unter relativ einheitlichen und einfach zu regulierenden Lebensbedingungen ${ }^{701}$ an ei-

698 Vgl. [Hrsg.] Medicinische und chirurgische Bemerkungen ueber London, und die englische Heilkunde ueberhaupt. Medical and Surgical Observations upon London, the State of rhe Healing Art in England in gerneral. By Dr. C.E. Fischer u.a, 1796: in: MC, 1.1786, S. $62-72$ : S. 67.

699 Vgl. Guthrie, Matthew: A letter to Dr. Duncan, on the Effect of a cold Climate on the Land Scurvy etc.: in: LMJ, 10.1782, S. 328 - 338: S. 328.

700 Henderson, Stewart, former Surgeon in the Royal Navy: An Account of the Means successfully employed in Preserving the Health of the Seamen, on board his Majesty's Ship Astrea; [...]: in: MPJ, 1.1799, S. 91 - 94: S. 91. Vgl. ebd.: S. 94.

701 Vgl. Dundas, W.: Regulation for Improving the Situation of the Medical Officers of the Navy: in: ESMJ, 1.1805, S. $241-246$. Vgl. Henderson, Stewart, former Surgeon in the Royal Navy: Suggestions for the Preservation of that insidious and destructive Foe to the British Troops in the West Indies, commonly termed Yellow Fever, which the outline of 
nem bestimmten Ort dem Regime einer Kommandantur oder eines Plantagenverwalters unterstanden. Prävention erschien in beiden Fällen um ein vielfaches effektiver als die Behandlung der bereits Erkrankten. ${ }^{702}$ Die Möglichkeiten einer erfolgreichen Übertragung und Durchsetzung hygienischer Maßnahmen, die sich nun auf die ganze Gruppe von Menschen richtete, wurde in der Armee und auf den Plantagen entlang ökonomischer Kriterien praktisch umsetzbar. ${ }^{703}$ Der Ausbruch einer Krankheit in einer Gruppe von Menschen, deren Alltag, Ernährung, Kleidung, Arbeitszeiten, Lebensverhältnisse einer zentralen und administrativen Kontrolle unterstand, dienten als Experimentierfeld und Ausgangspunkt der Verallgemeinerung von Techniken und Praktiken der Regierung der Gesundheit. Wie der Ausschnitt aus dem Bericht eines Arztes über ein Fieber auf mehreren Plantagen auf Mauritius deutlich macht, vermischten sich hier ökonomische Rationalitäten und medizinisch-hygienische Regierungspraxis. ${ }^{704}$

»The class of people who were most liable to its attacks, were those much troubled with visceral complaints, indigestions, worms, and all those disorders which arise from food consisting of much vegetable aliment, without much condiment, and insufficiently prepared for digestion by the process of cookery. [...] I myself had adopted a plan of feeding our people, which tended to prevent diseases of the stomach and intestines. [...] Our estate was, from these causes, more healthy than it had been for years. At the time the disease appeared at Port-Louis, when it began to spread and gain ground, I deemed it proper to still farther precautions, [...] In our population of nearly six hundred people on this estate, I lost seventeen by this disease, which was considered as a very small proportion; many habitations having lost 10 or 15 per cent of their people, and some even more, reduced in a few days, by this misfortune, from opulence to poverty. $\ll^{705}$

In der Regel war der Schluss, zu dem die Kolonialärzte kamen der, dass es einen mehr oder weniger erklärbaren, engen Zusammenhang zwischen den unterschiedlich beeinflussbaren Faktoren und dem Auftreten der Krankheit gab. Hatte man diese causes of disease gefunden, bestand die Aufgabe darin, durch eine Regelung das allgemeine Risiko des Auftretens der Krankheit zu verhindern. Man versuchte gewissermaßen zwischen den Kosten bzw. dem Aufwand der Maßnahme und dem graduellen Einfluss, den diese auf die Senkung des Risikos der Krankheit oder die Sterblich-

a plan for Military Hospitals, on a principle and construction tending to introduce a more successful treatment of the sick: in: ESMJ, 5.1809, S. 373 - 374.

702 Vgl. T.F.: Sketch of a Plan for Imprving the Medical Department of the Navy: in: ESMJ, 7.1811, S. 25 - 29: $25 f$.

703 Vgl. Henderson, Stewart, former Surgeon in the Royal Navy: An Account of the Means successfully employed in Preserving the Health of the Seamen, on board his Majesty's Ship Astrea; [...]: in: MPJ, 1.1799, S. 340 - 346: S. 346. [Fortsetzung des oben zitierten Artikels.]

704 Vgl. Telfair, C.: Account of the Epidemic Cholera, as it occurred at Mauritius. Communicated to Dr MacDonnel, Belfast: in: ESMJ, 17.1821, S. 517 - 529: S. 520.

705 Ebd.: S. 525. 
keit allgemein haben konnten, den günstigsten und nützlichsten Punkt zu finden. Der Punkt mit dem größten Nutzen, bei geringstem Aufwand. ${ }^{706}$

Durch die Auswertung von Statistiken und gesunkene Zahlen von Erkrankungen auf den Erfolg und die Effektivität der Maßnahmen zu schließen, war auch für die Praxis der öffentlichen Gesundheit in England üblich. ${ }^{707}$ Man fragte: Wie kann das Ausbrechen einer bestimmten Krankheit in einem Stadtteil oder einer bestimmten Bevölkerungsgruppe verhindert werden? Wie kann man grundsätzlich die Bedingungen, unter denen bestimmte Gruppen leben, allgemein und mit möglichst geringem Kostenaufwand (bzw. einem Kostenaufwand der die Kosten, die die Seuche verursacht, unterschreitet) so verändern, dass es insgesamt zu weniger Ausbrüchen dieser Krankheit und >Verluste< durch sie kommt? Oder wie kann man sie vielleicht sogar ganz verhindern $?^{708}$ Die Methoden der Epidemiologie als die praktische Suche nach den konkreten und beobachtbaren Ursachen von Krankheit waren in Großbritannien direkt verknüpft mit einer utilitaristischen und durch ökonomisches Wissen geprägten Praxis der Regierung im Sinne der Public Health. ${ }^{709}$ Deren Aufgabe war es, die Ursachen und Gefahren von Epidemien und Seuchen zu erkennen und entsprechende nützliche Gegenmaßnahmen und Regelungen in die Wege zu leiten. ${ }^{710}$ Obwohl die Beteiligung von Ärzten in dieser Praxis groß war, spielten medizinisches Wissen und die Regeln dieser wissenschaftlichen Disziplin keine vorrangige Rolle. Die Kolonien boten aber auch für die medizinische Wissenschaft die Möglichkeit, über politische und kulturelle Begrenzungen im Mutterland hinwegzugehen. In erstaunlich vielen Artikeln über Seuchen und Epidemien in den britischen Kolonien Englands wurde ganz beiläufig von routinemäßig vorgenommenen Obduktionen berichtet, vor allem dann, wenn es sich bei den obduzierten Körpern um die von Sklaven und Kolonialisierten handelte. ${ }^{711}$ Dazu kam, dass man es im Fall von Seuchen gleich mit einer großen Anzahl von Personen zu tun hatte, die an der gleichen Krankheit gestorben waren. Dies machte die Praxis der Obduktion für die Vertiefung und Vereinheitlichung von Wissen über Krankheiten in der medizinischen Wissenschaft besonders nützlich. ${ }^{712}$ Sie ermöglichte auf dem Gebiet der Klassifizierung von Krankheiten den Ab-

706 Vgl. Domeier, W: Essay on the Origin of the epidemical Fever in Spain, with an abridged Plan for his Cure, and some Proposals to present both Progress and Return of similar Epidemices: in: MPJ, 13.1805, S. 103 - 119: S. 111.

707 Vgl. Harrison: Medicine in an Age of Commerce and Empire, 2010: S. 288.

708 [Hrsg.]: Report of the institution for the Cure and Prevention of Contagious Fever in the Metropolis, 5. May 1804: in: MPJ, 14.1805, S. 340 - 341: S. $340 f$.

709 Vgl. Lawson, Robert, Inspector of the General Hospital: Errors in the usual Method of investigating the causes of Epidemics: in: TES, 3.1876, S. 474 - 484: S. 474.

710 Vgl. Thorne, Richard Thorne: On the Progress of Preventive Medicine During the Victorian Era. Inaugural Address of Session 1887 - 88, November 9th, 1887: in: TES.2s, 7.1889, S. 1 - 46: S. 2.

711 Vgl. Telfair, Charles: Report of a contagions disease prevailing in Mauritius, Communicated to Dr MacDormel, Belfast: in: ESMJ, 17.1821, S. 519 - 526: S. 525.

712 Vgl. [Hrsg]: Are tropical fiever contagious?: in: Medical facts and observations, 7.4.1799, S. 6 - 20: S. 6. 
gleich der äußerlichen Symptome mit den inneren Merkmalen einer Krankheit und sorgte für eine Vielzahl nosologischer Erkenntnisse. ${ }^{713}$

Die Praxis und Erfahrung in den Kolonien und die hier entstandene Konstellation aus politischen Techniken der Kontrolle und der Sicherheit, ökonomischer Rationalität und hygienischem Praxiswissen sickerte in die Entwicklung einer englischen Regierung von Gesundheit ein und prägte diese nachhaltig. Die englische Regierung der Gesundheit war eine Regierung, die sich auf das Ziel der Förderung der Produktivität und auf den Arbeitskörper (als Quelle des Reichtums) ausrichtete. Dies beinhaltete auch die Verknüpfung einer spezifischen Form von Freiheit mit Gesundheit.

Unter dem Einfluss liberaler politischer Theorie kam es zu einem strategischen Bündnis von professioneller Medizin und einer sozialen Klasse von Besitzenden, die nach einer Lösung der Regierungskrise und mehr Sicherheit durch die Instanzen der Staatsregierung suchten. Die Ausrichtung der Gesundheitsregierung an einer (ontologisch) reduktionistischen ökonomischen Rationalität erfolgte parallel zu der Ausschaltung einer bestimmten Kollektivität. Eine in Opposition zum Staat etablierte Gesundheitsversorgung, die bisher in kommunitäre soziale Kontrollpraxis und moralisch-religiöse Selbstpraxis eingebettet war, aber aufgrund massiver ökonomischer und sozialer Veränderung bröckelte, wurde bekämpft. Der Staat sollte die Praxis der sozialen Kontrolle und des positiven und aktivierenden Managements der >Community< übernehmen und in eine sichere gesetzliche Form bringen. Mehr Freiheit vor sozialer, moralisch-religiöser Kontrolle und >lebensweltliche< Unabhängigkeit für die Individuen, Sicherheit für das Eigentum und geschlossene Verträge waren notwendig verbunden mit der Rationalisierung sozialer Beziehungen und der an sie gebundenen medizinischen Versorgung bestimmter Bevölkerungsgruppen. Die arbeitenden Armen, die angesichts bröckelnder sozialer Strukturen, Verstädterung und Verelendung außer Kontrolle zu geraten schienen, mussten unter ein neues rationalisiertes Regime gebracht werden. Genau in dieser klaffenden Nische etablierte sich in Großbritannien eine Regierung der Gesundheit von Bevölkerung, die aufgrund der historischen Gegebenheiten aus denen sie entsprang, in spezifischer Weise einer liberalen ökonomischen Rationalität unterlag, wie auch auf den Menschen als ökonomisches Subjekt und den Körper als Arbeitskörper gerichtet sein musste.

713 Vgl. M'Cabe, James: Copy of a Quarterly Report of the Royal York Rangers, at Trinidad, for the quarter ending the 24th December 1816. Transmitted to the Army Medical Board [...]: in: ESMJ, 15.1819, S. 179 - 186: S. 182. 


\section{Die Cholera als diskursives Ereignis 1829 - 1892}

Die heutige Zählung der Cholerapandemien im 19. Jahrhundert deckt sich nicht mit der Erfahrung der Choleraepidemien in den von mir untersuchten Ländern. Denn die Seuchenzüge der einzelnen Pandemien führten zu epidemischen Ausbrüchen in den Staaten, zwischen denen oft mehrere Jahre lagen. Die erste Cholerapandemie gelangte nach Europa nur im äußersten Südosten. Auf europäischem Boden wurden erstmalig im Herbst 1823 Fälle epidemischer Cholera in Russland, in der an der Wolgamündung liegenden Stadt Astrachan, gemeldet. Deutsch- und französischsprachige russische Ärzte unterhielten Korrespondenzen mit Ärzten in Preußen und Frankreich, in welchen sie von den Ereignissen in Astrachan berichteten. Keines der von mir untersuchten Länder fühlte sich zu diesem Zeitpunkt unmittelbar von der Gefahr eines Ausbruchs der epidemischen Cholera im eigenen Land bedroht. Erst die zweite Pandemie, im Rahmen derer die Cholera 1829 wieder zunächst in Astrachan und kurz darauf in Moskau ausbrach, erregte die Aufmerksamkeit der europäischen medizinischen Zeitschriften und Gesellschaften. In Reaktion auf die Berichte aus der russischen Provinz setzte die wissenschaftliche und politische Auseinandersetzung mit der epidemischen Cholera in Deutschland und Österreich ein ${ }^{1}$ - verhältnismäßig spät also, verglichen mit Großbritannien, das zu diesem Zeitpunkt bereits schon seit 1817 umfassende Erfahrungen mit der Krankheit in Indien gesammelt hatte. ${ }^{2}$ Auch in Frankreich war sowohl das medizinische als auch das politische Interesse an der epidemischen Cholera gering. Man nahm die Berichte in britischen Journalen und aus Russland zur Kenntnis, blieb aber dabei, die »choléra asiatique« von der Cholera, wie

1 Vgl. Rehmann, J., Russ. Kaiserl. Staatsrath etc.: Erklärung die ostindische Cholera zu Astrachan betreffend: in: JPA, 1.66=59, 1828, S. $124-130$ : S. 124. Vgl Thiele: [Kurze Nachrichten und Auszüge:] 1. Maaßregeln der Königl. Preussischen Regierung gegen die Cholera: in: JPA, 5.72=65, 1831, S. 114 - 122. Vgl. Albers: Kurze Nachrichten und Auszüge: 2. Auszug aus einem amtlichen Berichte des Königl. Preussischen Regierungs- und Medicinal-Raths: in: JPA, 5.72=65, 1831, S. $122-133$.

2 Vgl. z.B: [Hrsg.]: Reports on the Epidemic Cholera, which has raged throughout Hindostan and the Penisula of India, since August 1819. Published under the autority of Government. Bombay 1819: in: ESMJ, 16.1820, S. 458 - 270: S. 462. 
man sie in Europa schon zu kennen meinte, zu unterscheiden. ${ }^{3}$ Die zweite Cholerapandemie erreichte Mitteleuropa erst 1830. Nach und nach wurden u.a. Preußen, Großbritannien, Frankreich und 1836 auch Bayern zum Schauplatz großer Epidemien, die sich erst 1837 abschwächten. Diese Serie stellte in der Wahrnehmung der von mir berücksichtigten Länder die erste große Epidemie dar. Dieser ersten einschneidenden Erfahrung folgten weitere Epidemien. Die dritte pandemische Welle erreichte Zentraleuropa in zwei Wellen Ende der 1840er Jahre und noch einmal zwischen 1852 und 1855. In der damaligen zentraleuropäischen Wahrnehmung entsprach dies der zweiten und dritten Epidemie. Mitte der 1860er Jahre und Anfang der 1870er Jahre führte die vierte Cholerapandemie zu weiteren epidemischen Ausbrüchen in weiten Teilen Europas. Dies war die letzte Pandemie, die sich in allen drei von mir untersuchten Ländern auswirkte. Großbritannien blieb ab 1866 frei von Choleraepidemien. Deutschland und Frankreich erlebten weitere teils sehr lokal begrenzte epidemischen Ausbrüchen im Rahmen der fünften und sechsten Pandemie, die Mitte der 1880er und noch einmal in der ersten Hälfte der 1890er Jahre erneut Europa mit einbezogen.

Meine Beschäftigung mit der Cholera in Form einer Analyse von Texten aus dem 19. Jahrhundert, die vorrangig von Medizinern, Hygienikern und Beamten geschrieben wurden, soll zeigen, wie heterogen zunächst das Wissen und die entwickelten Theorien über die Ursachen der Choleraepidemien waren. Es ist daher schwer zu sagen, ob es sich bei der hier beschriebenen Cholera vom Standpunkt des heutigen medizinischen Wissens durchgängig um die gleiche Krankheit - die Cholera asiatica gehandelt hat. Selbst wenn wir die Identität einer Krankheit durch die DNA ihres Erregers definieren und diese in alten Funden und Proben aus der Zeit für jeden beschriebenen Fall nachweisen könnten, bliebe diese Erkenntnis wenig aussagekräftig für die Perspektive der Geschichte der von Foucault als Brennpunkte der Erfahrung bezeichneten Bereiche. Vom Standpunkt der Diskursgeschichte ist die Frage nach der genetischen Identität, nach der wirklichen Krankheit nicht von Bedeutung. Interessant ist hingegen, anhand der diskursiven Auseinandersetzung mit der Cholera einen Wandel konkurrierender und paralleler Wissensbezüge und Strategien des Umgangs mit der Krankheit nachzuvollziehen. Es geht hier also weniger um die Geschichte der Krankheit als um die Diskursgeschichte der Erfahrungen mit einer Krankheit.

\section{Das Wissen ÜBer die Cholera vor 1829}

Im heutigen Bewusstsein ist man geneigt zu sagen, die Cholera sei eine aus Indien stammende Krankheit ${ }^{4}$ gewesen, die erst im 19. Jahrhundert ihren Weg nach Europa fand. Tatsächlich existierte die Cholera längere Zeit endemisch in Indien, genauer in Bengalen. Dort wurde sie 1817 das erste Mal in einer neuen Weise epidemisch und begann sich pandemisch auszubreiten.

3 Vgl. z.B. François, D.M.: Voyage médical autour du monde, exécuté sur la corvette du Roi La Coqille, pendant les années 1822, 1823, 1824 et 1825; par M. Lesson: in: JGM, 10.1829, S. 246 - 251.

4 Vgl. Dettke: Die asiatische Hydra, 1995: S. 1. 
Allerdings existierte der Diskurs über die Krankheit in Europa bereits vor 1829. Nach den Erfahrungen von 1817 griffen die britischen Ärzte verstärkt auf ältere Beschreibungen des englischen Arztes Thomas Sydenham (1624 - 1689) zurück, der ausführlich über eine Choleraepidemie in England 1669 berichtet hatte und versuchten diese mit den Beobachtungen aus Indien in Zusammenhang zu bringen: »[T]he disease described by Sydenham as epidemic in 1669, agrees very accurately with that under our consideration. « ${ }^{5}$ Sydenhams Beschreibung der besagten Choleraepidemie lieferte den Ärzten des 19. Jahrhunderts einen umfassenden Bericht über eine bereits bekannte Krankheit, Erfahrungen mit verschiedenen, mehr oder weniger hilfreichen Mitteln und über den Zusammenhang ihres Auftretens mit klimatischen Bedingungen. ${ }^{6}$ Die Interpretation antiker Texte von Hippokrates führten Sydenham und seine Zeitgenossen zu dem Schluss, die Cholera sei durch eine übermäßige und krankhafte Ausschüttung von gelber Galle (gr. $\chi 0 \lambda \eta ́)$ verursacht. ${ }^{7}$ Dementsprechend richteten sie ihre Heilmethoden an den Symptomen der Krankheit aus. Eine epidemiologische Erforschung der Krankheit, wie sie erst ab dem 19. Jahrhundert begann oder eine diätetische Betrachtung nahm Sydenham zu dieser Zeit nicht vor. Diesen (diätetischen) Teil der Überlieferung antiker Quellen, wie z.B. von Hippokrates, eigneten sich Ärzte und Gelehrte ab dem 18. Jahrhundert an, als diätetisches Wissen der Antike allgemein wieder größeres Interesse auf sich zog. So untersuchte und übersetzte Johann Friedrich Karl Grimm etwa die hippokratischen Schriften v.a. auf deren diätetischen Gehalt hin. ${ }^{8}$ Es bestand zumindest im 17. und 18. Jahrhundert, als die Medizin als Wissenschaft erst begann nach einer Professionalisierung und Verwissenschaftlichung zu streben, kein erheblicher Druck, das heterogene Wissen über die Krankheit >Cholera $<$ zu vereinheitlichen. Man wusste, wie über die meisten Krankheiten, wenig Genaues. Aber dies bedeutete keineswegs, dass man sich zu der Aussage hätte verleiten lassen, im Grunde nichts über die Cholera zu wissen. Dieser Ausspruch wurde erst zu einer Zeit - nämlich ab ca. 1820/1830 geläufig, geradezu populär - als die Cholera als bedrohliche und tödliche Epidemie in den Blick der zunehmend modernen medizinischen Wissenschaft und den Blick einer modernen Regierung der Bevölkerung geriet. Die Medizin musste, da sie mit ihren Theorien und Erklärungen die brennende Frage der Regierungen, nach dem Umgang mit der Cholera, nicht beantworten konnte, die Frage und einen ganzen Bereich von Problemen an die Regierung gewissermaßen zurückreichen. Die Cholera wurde zum Gegenstand der Epidemiologie, der Statistik und anderer im Aufstreben befindlichen >Hilfswissenschaften< der Gesundheitspolitik. In dieser Bewegung wies man einen Teil der alten medizinischen

5 Anderson, William Steuart, Member of the Royal College of Surgeons, London: An Account of Cholera Morbus Epidemic in India in 1817 and 1818: in: EMSJ, 15.1819, S. 354 372: S. 356.

6 Sydenham, Thomas: Of the Cholera Morbus of the Year 1669, 1788 [1670]: S. 218f.

7 Vgl. z.B. auch die Äußerungen des Schweizer Arzt, Johann von Muralt: »Cholera oder Brechsucht, Cholera ist eine Gallen-Krankheit, so dieselbe stäts übersich und untersich vom Menschen bricht mit Herzwehe und großer Beschwärde herzurührend von der ersten Schärffe derselbigen und allzu sauerscharffem Megenhebel verursacht offt den Tod.« Muralt: Hippocrates Helveticus, 1692: S. 200.

8 Vgl. Grimm: Werke von Hippocrates, Bd. 1, 1781: z.B. S. 378. 
Interpretation von Hippokrates zurück. Die neuen Erfahrungen mit der Cholera machten deutlich, dass es sich nicht um eine Gallenkrankheit handelte. Weiter war diese rein nosologische und innerhalb der Medizin ebenfalls umstrittene Bestimmung der Cholera wenig nützlich, um präventive Maßnahmen gegen sie zu entwickeln. ${ }^{9}$ Andererseits wurde gerade der diätetische Teil dieses alten Wissens, der auf die Erhaltung der Gesundheit und die Vorbeugung der Krankheit gerichtet war und somit die grundsätzliche Logik des Regierens transportierte, wieder relevanter. Nach dem Auftreten der epidemischen Cholera in Europa erlangten die alten und antiken Quellen eine so enorme diskursive und strategische Bedeutung, dass sie sehr vielfältig interpretiert wurden. Ging man etwa, wie die radikalen britischen Anti-Kontagionisten und Lokalisten davon aus, dass die Cholera spontan aus lokalen Bedingungen entstand, war man auch geneigt, die vorhandenen Quellen entsprechend zu interpretieren - also zu behaupten, es habe auch die epidemische Cholera schon vor 1829 in Europa gegeben. So konnte man zu dem Schluss kommen, die Cholera sei nie gewandert oder jemals durch menschlichen Verkehr transportiert worden:

»Es kann keinen Zweifel darüber obwalten, dass die Krankheit nicht allein in Gestalt isolierter Fälle, sondern auch als Epidemie in England, Schottland, Frankreich, Deutschland, Amerika und anderen Ländern des Westens existierte, lange ehe die grosse bengalische Epidemie von 1817 und die europäische Epidemie von 1832 die allgemeine Aufmerksamkeit auf sie lenkte. $\ll^{10}$

Demgegenüber war es in der Geschichtsschreibung der Cholera durch die Kontagionisten, die von einer Ansteckung und Einschleppung als alleinigem Grund für die Choleraausbrüche in Europa ausgingen, eher üblich, von der Invasion der indischen und asiatischen Cholera zu sprechen, wie auch die meisten von Barbara Dettke verwendeten, aus Norddeutschland und Preußen stammenden Quellen gezeigt haben. ${ }^{11}$ Die früheren Texte zur Geschichte der Cholera in Frankreich und Deutschland gingen fast durchgängig von eher sporadischen Fällen aus, zu denen man Wissen über verschiedene symptomatische Behandlungen und diätetische vorbeugende Mittel besaß. In einem, vermutlich um 1829 in Leipzig erschienen Handbuch zur Diätetik hieß es:

»Die nächste Ursache dieser Krankheit liegt in einer heftigen, convulsivischen Bewegung des Magens und Darmkanals und eine Anlage dazu haben junge, reizbare Personen, die an einer großen Reizbarkeit der Verdauungswerkzeuge leiden. Sie kommt mehr in heißen Ländern und Jahreszeiten vor und zeigt sich bei uns sehr sporadisch, doch auch, wie in der jetzigen Zeit, wo sie ganze Länder verheerte, epidemisch. Gewöhnlich entsteht sie zu Ende des Sommers und Anfang des Winters, wo bei heißen Tagen die Nächte kühl werden. In unsern Gegenden entsteht die gewöhnlich sporadisch, durch Verkältung, Zugluft, feuchtes Lager auf dem Erdboden oder feuchtem Stroh, nach großer Anstrengung des Körpers, Übermaß in Speisen und Getränken, besonders in Branntwein, nach Obst, wenn es unreif, sauer ist und in Mengen genossen

9 Vgl. Gillkrest: Letter VII: in: Letters on the Cholera Morbus, 1831: S. 44.

10 Cuningham, J.M.: Die Cholera. Was kann der Staat thun, sie zu verhüten?, 1885: S. 32.

11 Vgl. Dettke: Die asiatische Hydra, 1995. 
wurd, auch haben manche Speisen sie mehrmals hervorgebracht, wie Milchschokolade, Milch und Wein kurz nach einander genossen, die Eier der Barben und Hechte, Austernmuscheln, fettes Fleisch, fetter Kuchen, scharfer Käse, die Erdbeere und die Gurke, saures, hefiges oder zu junges Bier. [...] Auch heftige Leidenschaften, wenn sie stark und plötzlich einwirken, können die Krankheit hervorbringen, wie Zorn, Aerger, Neid, Schrecken; [...] Die diätische Behandlung der Cholera muß sich besonders auf die Entfernung der Gelegenheitsursachen beziehen. [...] Um sich gegen die Krankheit zu schützen, ist es nothwendig, sehr mäßig zu leben, sich vor Verkältung zu hüten und sich keinen Leidenschaften zu überlassen. $\ll^{12}$

Die alte diätetische Betrachtung der Cholera wurde angesichts des Ausmaßes der Epidemien bald als unzureichend angesehen. Auch wenn dieses Wissen ebenso wie die symptomatischen Behandlungsmethoden weiterhin in den Berichten und Empfehlungen der Ärzte auftauchten, verblüffte die Cholera zunächst als eine Krankheit, die junge, alte, als gesund oder kränklich angesehene Menschen, Arme wie Wohlhabende befiel und bald unter den unterschiedlichsten klimatischen und lokalen Bedingungen epidemisch auftrat. Keine noch so gute gesundheitliche Verfassung konnte einen Menschen vor der Cholera schützen. Demgegenüber ging man vor allem nach der ersten europäischen Epidemie dazu über, nun auf Grundlage von Statistiken die Gruppen zu bestimmen, welche der Cholera am häufigsten zum Opfer fielen: die Armen und die Arbeiterklasse generell. Aber bevor es so weit war, stellte die Tatsache, dass die Cholera scheinbar unabhängig von der Konstitution einer Person und der Umwelt wirkte, für die diätetische Perspektive ein Problem dar. Die Abkehr von diesem diätetischen Wissen geschah nur langsam und gestaltete sich in den drei Ländern verschieden.

Als erstes stellten die Ärzte in den britischen Kolonien in Indien diese beiden Sichtweisen (die diätische und die klinisch-pathologisch) auf die Krankheit und das bisherigen Wissens über die sporadische Cholera der epidemischen gegenüber.

»The sporadic cases of cholera that we see in this country all arise in the hottest season of the year, and during the time that the subacid fruits, ripe and unripe, are greedily devoured by the people. Their appearance is sufficiently accounted for by obvious exciting causes, and none others can be suspected to act. But the epidemic of India has been so universal in its empire, extending even to the most dissimilar countries, and continuing during the most opposite seasons, that its prevalence cannot be accounted for by causes peculiar to individuals, to the air, or to situation. $\ll^{13}$

Auch in Frankreich nahm man, bevor die Krankheit dort ausbrach, mit Überraschung die Berichte aus Indien und anderen Ländern zur Kenntnis, wo die Cholera epidemisch und scheinbar unabhängig von der constitution médical wirkte. ${ }^{14}$ Laut einem

12 Vgl. Richter [Pseudonym für Dr. Carl Westphal]: Cholera: in: Vollständiges Handbuch der Diätetik, [ca. um 1820]: S. 81f.

13 [Hrsg.]: Reports on the Epidemic Cholera, which has raged throughout Hindostan and the Penisula of India, since August 1819. Published under the authority of Government. Bombay 1819: in: ESMJ, 16.1820, S. 458 - 470: S. 460f.

14 Vgl. [Hrsg.]: Choléra-morbus dans l'Inde: in: GS, 13.1829, S. 97 - 99: S. 97. 
wissenschaftlichen Bericht, den die französische Regierung angesichts der nahenden Cholera 1831 anforderte, hieß es, die Krankheit sei bereits Hippokrates bekannt gewesen ${ }^{15}$, der sie mit warmen Einreibungen (lotions) bekämpfte. ${ }^{16}$ Schon lange sei die Krankheit in allen möglichen Ländern immer wieder sporadisch bei einzelnen Individuen in Verbindung mit bestimmten Vorbedingungen aufgetreten. Auch >kleinere Epidemien< seien im 18. Jahrhundert beobachtet worden. ${ }^{17} \gg$ Mais, dans tout ces circonstances, le choléra n'a jamais été plus loin que l'influence de la constitution médicale à laquelle il se trouvait lié. ${ }^{18}$ In dem zitierten Bericht sind die Grundideen einer hygienischen bzw. diätetische Annäherung an das Problem der Cholera weiterhin enthalten - die sich im Bereich der hygiène privée bzw. »hygiène domestique ${ }^{19}$ sowohl auf das Verhalten zur Umwelt als auch auf die Moral und Lebensweise der Menschen, die nicht erkranken wollen, beziehen:

»Les douces habitudes d'ordre intérieur et de morale privée sont aussi profitables aux intérêts matériels de la vie. L'ambition, le chagrin, la frayeur, les agitations morales, et en général les passions fortes, quelles qu'elles soient, mises en jeu sans règle sans retenue, deviennent autant de causes certaines de la maladie. $\ll^{20}$

Ähnlich wie bei der Betrachtung der frühen Auseinandersetzung mit Epidemien in den britischen Kolonien bestand die technische, aber gewissermaßen auch ontologische Schwierigkeit in der Übertragung der Diätetik und der privaten Hygiene auf eine größere Gruppe von Menschen, die man mehr oder weniger zentral überwachen und regieren wollte. Die technischen Möglichkeiten der Überwachung und Regierung des Verhaltens der einzelnen Individuen - obwohl sie als Ideal in Deutschland und Frankreich noch am ehesten imaginiert wurden - waren nicht vorhanden.

Als aus der sporadischen eine epidemische Cholera wurde, stellte diese sich plötzlich als ein Problem der Regierung dar. Von diesem Moment an wurde die Wissensproduktion und Integration über die Krankheit zu einer Suche nach einer geeigneten Technik, um sie zu regieren. Im Zuge dessen wurde das gesamte vorhandene hygienische wie auch das neuere und ältere medizinische Wissen über die Cholera

15 Wie schon gesagt, ist es aus unterschiedlichen Gründen zu bezweifeln, dass es möglich ist, von der Cholera und ihrer Geschichte zu schreiben. Dennoch ist es nicht unerheblich, dass das Wissen Hippokrates über »die Cholera« im 19. Jahrhundert relativ allgemein anerkannt war und in zahlreiche Abhandlungen über die Geschichte der Cholera darauf Bezug genommen wurde. Z.B. außer in dem französischen Bericht noch bei James Cuningham (vgl. ders.: Die Cholera. Was kann der Staat thun, sie zu verhüten?, 1885: S. 32) und sehr ausführlich bei Nokidge Charles Macnamara (vgl. ders.: A History of Asiatic Cholera, 1876: S. 2ff.) Dieser zieht neben Hippokrates noch Galen und die Quellen antiker römischer Ärzte, Quellen aus China und in arabischer Schrift heran, die alle die vorherige Existenz der Cholera bezeugen sollen.

16 Vgl. Académie Royale de Médecine: Rapport sur le choléra-morbus I, 1831: S. 5.

17 Vgl. ebd.: S. 6.

18 Ebd.: S. 7.

19 Ebd.: S. 138.

20 Ebd. 
zur Lösung der Regierungsaufgabe mobilisiert und mit einer Reihe von politischen Fragestellungen konfrontiert. Etwa wie eine ganze Bevölkerung vor der Cholera beschützt werden könne und was die Bereiche und Handlungsmöglichkeiten einer Regierung in Bezug auf dieses Ziel erlauben würde. Denn an der epidemischen Cholera erkrankten, nach dieser neuen Perspektive, keine Individuen mehr, sondern ganze Länder und Bevölkerungen, oder wurden zumindest von ihr bedroht. Die Cholera war ein >politischer Feind <, eine >Invasion $<$. Die Berichterstattung über den >Vormarsch< der Krankheit wurde mit Karten und Routenbeschreibungen nachverfolgt und gespickt mit Metaphern des Krieges, je mehr man versuchte, ihr mit militärischen Mitteln zu begegnen. Die Cholera war eine Gefahr, die den Wohlstand und die Sicherheit ganzer Nationen bedrohte und die dazu über die Grenzen der Staaten hinweg zog, Landstriche >entvölkerte< und Städte >belagerte<. Mit dem Beginn der Cholerapandemie in Europa verschärfte sich die Diskussion um die wahren Ursachen und die besten Möglichkeiten der Prävention und Begrenzung der Krankheit durch die jeweiligen Regierungen. Bereits in den ersten Berichten über den Ausbruch der Cholera in Russland, in Orenburg, St. Petersburg, Moskau und Astrachan machten deutlich, dass die Cholera nicht einfach in das vorhandene Tableau von Sichtweisen und Unterteilungen von Krankheiten integriert werden konnte.

»Ueber die Natur der Krankheit und über die uns so überaus wichtige Frage: ob und in wie fern die Cholera ansteckend und verschleppbar ist herrscht gegenwärtig noch die größte Meinungsverschiedenheit. In der, unserer Ansicht nach, irrigen Vorrausetzung, daß diese Frage nach den bisherigen Erfahrungen über die Natur bekannter Contagion entschieden werden müsse, haben sich zwei Partheien, die Contagionisten und die Anticontagionisten, gebildet, deren erste Meinung hauptsächlich von den Behörden und Aerzten Petersburgs, letztere dagegen fast ohne Ausnahme von allen hiesigen [Moskau] Aerzten und Einwohnern auf das lebhafteste vertheidigt wird. $\ll^{21}$

Die Cholera schien am deutlichsten allen Ansätzen der Erklärung, sowohl der von klimatisch und lokal ursächlichen Epidemien wie auch dem Bild einer kontagiösen Krankheit, zu widersprechen. Bei den Berichten über die Choleraepidemien in Russland und Polen, die in Frankreich, England und Deutschland allseits Beachtung erfuhren, handelte es sich meist um deutsche Texte, die deutsche und deutschsprachige russische Ärzte und Regierungsbeamten zunächst an die medizinischen Journale in deutschen Ländern schickten, oder anderweitig in Deutschland veröffentlichten. Von dort aus wurden sie ins Englische und Französische teilweise übersetzt oder in englischen und französischen Zeitschriften besprochen. ${ }^{22}$

Während die russische Regierung unter dem Zaren Nikolaj I. in Moskau, ähnlich der preußische Regierung, von einer Übertragbarkeit der Cholera von Mensch zu

21 Vgl. Albers: Kurze Nachrichten und Auszüge, 2. Auszug aus einem amtlichen Berichte des Königl. Preussischen Regierungs - und Medicinal-Rathslera: in: JPA, 5.72=65, 1831, S. 122 - 134: S. 126.

22 Vgl. z.B. Christinson, R.: Selected from the German Edition of the Reports by Professor Lichtstädt of St. Petersburg. (With a Map of the Province of Orenburg): in: Supplement on cholera: in: ESMJ, 38. 1832: S. i. 
Mensch oder auch durch Gegenstände ausgegangen war und folglich die Einrichtung von Kordons, Sperren und Quarantänestationen befehligt hatte, regte sich in St. Petersburg, wo die Cholera 1829 epidemisch grassierte, vor allem im Kreise der liberalen Petersburger Intellektuellen und Ärzte schnell Kritik gegen die Maßnahmen, die den praktischen Erfahrungen der Krankheit zu widersprechen schienen. ${ }^{23}$

Trotz Quarantäne und Grenzsperren wurden weitere Fälle der Cholera in Orten westlich und im Umland von Petersburg gemeldet. In der englischen Rezeption fanden die Gegner der Quarantäne hierin die Bestätigung der anti-kontagionistischen und lokalistischen These. Sie sahen bestätigt, dass eine Ansteckung mit der Krankheit in jedem Falle anders als durch ein >contagium< und als bei der Pest erfolgen müsse: Folglich seien Quarantäne, Kordons und Desinfektion von Waren nutzlos. ${ }^{24}$ In der deutschen Debatte über die sich langsam der preußischen Grenze nähernden Epidemien bestärkte man vor allem die Tatsache, dass allein das geographische Fortschreiten genügend Bestätigung über die Kontagiosität der Cholera lieferte. Mit Sorge und Empörung reagierte man auf die von liberalen Ärzten durchgesetzte zurückgenommene Isolation der Stadt St. Petersburg. ${ }^{25}$

Ich möchte im Folgenden auf die Entwickelungen der Rationalität und Praxis der Regierung der Cholera in den deutschen Ländern, Frankreich und Großbritannien etwas genauer eingehen. Allerdings erhebe ich hier absolut nicht den Anspruch, eine annähernd vollständige Wiedergabe dieser Prozesse und Diskurse zu gewährleisten. Ich will exemplarisch anhand einiger Quellen zeigen, wie Regierungen, Ärzte und Journalisten sich der Herausforderung gestellt haben, die Cholera als ein Problem des Regierens zu behandeln. Wie sie sich strategisch auf Wissen bezogen, es neuen Rationalitäten unterwarfen und anderes Wissen marginalisierten. Ich habe meine Analyse darauf gerichtet, wie diese Akteure und Regierungen dabei ihre eigene Subjektivität und Existenz, als Ärzte, Wissenschaftler, Individuen und Staatsbürger produzierten und den Gegenstand ihrer Regierung: die Cholera, die Bevölkerung, die Armen, die Proletarier etc. oder sich selbst einsetzten.

23 Vgl. Bremer: Geschichtliche Nachrichten über die Verbreitung der asiatischen Cholera in Russland und Oesterreich. Aus den officiellen Petersburger, Wiener und anderen Zeitungen mitgeteilt und mit einigen Anmerkungen begleitet: in: JPA, 2.72=65.1831, S. $105-125$ : S. 106.

24 Craigie, David: Account of the Progress of Asiatic Cholera, as it appeared on the confines of Europe and Asia, and eventually proceeded to Moscow; translated from the German Edition of the Official Reports of the Russian Government, and preceded by a Topographical Account of the districts through which the disease advanced: in: Supplement on cholera: in: ESMJ, 38. 1832: S. 1xxxiii.

25 Bremer: Geschichtliche Nachrichten über die Verbreitung der asiatischen Cholera in Russland und Oesterreich. Aus den officiellen Petersburger, Wiener und anderen Zeitungen mitgeteilt und mit einigen Anmerkungen begleitet: in: JPA, 2.72=65.1831, S. $105-125$ : S. 105 . 


\section{Die Cholera in Deutschland}

In Preußen, wo die Cholera 1831 zum ersten Mal epidemisch ausbrach, reagierte man schon im Vorfeld und während der Epidemie mit vorrangig militärischen Mitteln, die sich auf die Eindämmung der Verbreitung der Krankheit konzentrierten. Schon vor dem >Eintreffen< der Cholera wurden die sehr ähnlichen Methoden des österreichischen Kaisers als vorbildlich propagiert. So konnte nach einem Bericht des Berliner Medizinalrats Bremer der Ausbruch der Cholera in Galizien durch »energische und schnell angewandte Maaßregeln [...] gleichsam in ihrem Keim erstickt $\ll^{26}$ werden. Hieraus zog Bremer den Schluss, dass die »zuverlässige Ausgrenzung« der Krankheit durch die Kordons an den Grenzen und Quarantäne grundsätzlich möglich sei und es daher Ziel der preußischen Regierung sein müsse, die »Verhütung des Eindringens der Krankheit, solange sie noch auf den Nachbarstaat beschränkt bleibt $\ll^{27} \mathrm{zu}$ erreichen. Die diesen Maßregeln zugrunde gelegte Annahme war, dass die Cholera eine ansteckende, >contagiöse< Krankheit ist, die sich durch Menschen- und Warenverkehr verbreitete. ${ }^{28}$ An die Frage, ob die Cholera, wie man hinsichtlich der Pest überzeugt war, ansteckend sei, koppelte sich eine ganze Tradition von Techniken und Begründungen der Regierung für ihre Maßnahmen. Die Quarantäne, wie alle Maßnahmen der Isolation und der Absperrung, existierten mindestens seit dem 16. Jahrhundert. Zunächst war das Zurückgreifen auf diese alten Techniken und diese Rationalität, mit der sie verbunden waren, das Naheliegendste. Die alten Techniken vermischten sich in den Berichten und Artikeln deutscher und russischer Ärzte mit Beobachtungen, die die Ärzte selbst tätigten. Diese Beobachtungen bezogen sich auf aktuelle wissenschaftliche und andere Diskurse und versuchten neuere soziale, ökonomische und politische Bedingungen zu berücksichtigen, die in keiner Verbindung zu der Technik der Regierung standen.

»Ich, wiederhole es, wir dürfen bei der Möglichkeit, daß das Contagium auf sehr mannigfache Art zu verschleppen ist, wenn nicht die strengsten Contumazanstalten von allen Seiten getroffen werden - Alles fürchten; unsere Beherrscher noch mehr als wir, denn die Krankheit wird alle Uebel wecken und entdecken. Die Aerzte können nur Einzelnen beistehen, deren leicht überall zu Viele seyn werden, welche ihrer bedürfen; die Regierenden müssen, weil sie es allein vermögen, Uns Alle schützen. Dieselben Maassregeln, wie man sie gegen die Pest ergreift, sind auch bei der Cholera anzuwenden, selbst wenn ihre Natur nicht besser erkannt werden sollte, als sie es jetzt ist. Wir können gegen die uns drohende Gefahr nicht zu viel thun. Lassen wir uns nicht betäuben durch das Gerede: die Inder, Araber, Perser, Russen, halten die Cholera nicht für ansteckend! ${ }^{29}$

Die Frage nach der >Pestartigkeit $<$ der Cholera bildete eine Barriere, die, so lange sie nicht negativ beantwortet wurde, die Kritik oder die Rationalisierung dieser Techni-

26 Ebd.: S. 119.

27 Ebd.: S. 126.

28 Vgl. ebd.: S. $119 f$.

29 Braun: Ueber die Behandlung der ostindischen Cholera von Seiten des Staates, 1831: S. 204. 
ken verhinderte. Bremer hatte in seinem Bericht über Österreich bestätigt, dass vor allem »die ärmsten schlecht genährten und unordentlich lebenden Menschenklassen « von der Cholera befallen würden. ${ }^{30}$ Bremers Pressebericht über die Erfahrungen aus Österreich war zusätzlich ein Dokument der österreichischen Regierung angefügt. ${ }^{31}$ Darin heißt es zu Beginn:

»§2. Bei dieser Unentschiedenheit über die bestimmte, vielleicht überall identische, vielleicht aber durch Nebenumstände modificierte Verbreitungsart dieser mörderischen Seuche, welche schon Millionen von Opfern hinwegraffte, zugleich aber bei den so laut sprechenden Beweisen für ihre contagiöse Natur, gebietet es die Klugheit und der philantropische Sinn jedes civilisierten Staates zum Wohle seiner Unterthanen und zur Sicherstellung der angränzenden Länder immer den schlimmsten und gefährlichsten Fall vor Augen zu haben, und kein Mittel außer Acht zu setzten, welches der ferneren Ausbreitung einer so schrecklichen Geißel Einhalt thun könnte. § 3. Es muß daher die morgenländische epidemische Cholera in medicinisch-politischer Hinsicht von diesem Standpunkte betrachtet, und es müssen gegen selbe alle jene Maaßregeln eingeleitet werden, welche eine auf Erfahrung und Vernunft gestützte Gesundheits-Polizei gegen pestartige Krankheiten vorschreibt.«32

Wobei die diätetischen Ratschläge etwa, die über die >sporadische $<$ Cholera lange vor 1829 existierten, zusätzlich wieder aufgegriffen und verbreitet wurden. Die Instruktionen der österreichischen Regierung enthielten z.B. umfassende Hinweise zu diätetischen, die Ansteckung mit der Cholera fördernden Umständen und Ratschläge zu Verhaltensweisen. ${ }^{33}$

In diesem Sinne soll auch die Bevölkerung zu entsprechendem Verhalten angeleitet werden. Allerdings wird in dem Dokument betont, dass die »Verhütung « der Cholera vorrangig Gegenstand der »medicinische Polizei« sei, die neben der »strengen Einschließung der angesteckten Orte « und anderer Maßregeln zur Verhinderung des

30 Vgl. Bremer: Geschichtliche Nachrichten über die Verbreitung der asiatischen Cholera in Russland und Oesterreich. Aus den officiellen Petersburger, Wiener und anderen Zeitungen mitgeteilt und mit einigen Anmerkungen begleitet: in: JPA, 2.72=65.1831, S. $105-125$ : S. 121.

31 »Instruktionen für die Sanitätsbehörden und für das bei den Contumanz-Anstalten verwendete Personale zum Behufe die Gränzen der k.k. Oesterreichischen Staaten vor dem Einbruche der im Kaiserlich Russischen Reiche herrschenden epidemischen Brechruhr (Cholera morbus), ihre Verbeitung zu hemmen. Auf allerhöchsten Befehl veranlasst. Wien, aus der kaiserl. königl. Hof- und Staats-Aerarial-Druckerey, 1830« Ebd.: S. 125 - 136.

32 Ebd.: S. 126.

33 Außerdem wird noch eine Reihe anderer Dinge empfohlen, wie das Tragen von Flanellkleidung oder Flanell-Bauchbinden: Vgl. Bremer: Schluß der Österreichischen Instruktioen für die Sanitätsbehörden etc.: in: JPA, 3.72=65.1831, S. 14 - 25: S. 22. Vgl. Bremer: Geschichtliche Nachrichten über die Verbreitung der asiatischen Cholera in Russland und Oesterreich. Aus den officiellen Petersburger, Wiener und anderen Zeitungen mitgeteilt und mit einigen Anmerkungen begleitet: in: JPA, 2.72=65.1831, S. 105 - 125: S. 128. 
»Eindringens « über die Grenzen und der Ausbreitung der Krankheit auch »unausgesetzte Wachsamkeit über Prävaricanten jeder Art « haben solle. ${ }^{34}$

Aus diesen wird deutlich, dass man es nicht mit einer Trennung und parallelen Existenz von Selbsttechniken im Sinne der hygiène privée und Sicherheitstechniken im Rahmen einer städtischen polizeilichen hygiène publique zu tun hatte. Die Polizei war gedacht als die Diätetik des Staates, die sich nicht nur auf die Kontrolle der StraBen und Gebäude, der Kanalisation und der Brunnen konzentriert, sondern sich auch um den Schlafplatz und die Fußbekleidung der Einzelnen zu sorgen hat. Die medizinische Polizei wirkte hier, zumindest in der idealen Vorstellung, als die exekutive Macht einer >landesväterlichen< Führung, die bis in den Bereich der diätetischen Lebensführung hinein aktiv eingriff. Die Polizei handelte hier nicht auf der Ebene von Gesetzen, wie in Großbritannien. Niemand wurde dafür verurteilt, keine Fußbekleidung zu tragen. Vielmehr lag die Macht der Polizei in ihrer Verkörperung der Autorität, aber v.a. der > väterlichen< und > vernünftigen< Fürsorge des Kaisers oder Fürsten, dessen Regierung sie ausführte. Bremer schrieb aus der Perspektive der preußischen Polizei und ihrer Bedeutung. Er projizierte diese Vorstellungen möglicherweise auch auf Österreich, das habe ich nicht überprüft. Alfons Labisch schreibt nämlich, dass die Idee der medizinischen Polizei in Österreich sehr schnell wieder versandete und man ihr gegenüber noch Ende des 18. Jahrhunderts »die bereits überholte Postoralmedizin wieder aufwertete $\ll^{35}$. In Preußen wurden kurze Zeit, nachdem Bremer seinen Artikel über die Maßnahmen des österreichischen Kaisers gelobt hatte, die Einrichtung ähnlicher Maßregeln, zunächst entlang der Grenze zu Polen, »in Allerhöchst landesväterlicher Fürsorge « durch den preußischen König veranlasst. ${ }^{36}$ Laut der Bekanntmachung vom 17. Mai 1831, die Hufeland in seinem Journal abdrucken ließ, hatte die preußische Regierung im Vorfeld eine Kommission von Sachverständigen »aus Räthen der Ministerien und aus Aerzten« damit beauftragt,

»an Ort und Stelle die Natur des Uebles genau zu erforschen und im Voraus die Maaßregeln zu ermitteln, durch welche die Krankheit von den Gränzen abzuhalten, und, im Fall solches nicht zu verhüten seyn sollte, die bestmöglichsten Einrichtungen zu ihrer kräftigen Unterdrückung vorzubereiten. ${ }^{37}$

$\mathrm{Zu}$ den von der preußischen Regierung erdachten Maßregeln zählte u.a. »eine strenge, militärisch unterstützte Gränzsperre, durch die Anlegung der erforderlichen Quarantaine-Anstalten für Reisende, durch Einrichtungen zur Reinigung derjenigen Sachen, welche die Ansteckung verbreiten könnten«, die man mit dem »Beistande bewaffneter Macht« versah, als auch eine »Bekanntmachung ärztlicher Vorschriften über das Verhalten der Einwohner bedrohter Gegenden ${ }^{38}$. Von »sämtlichen Ein-

34 Vgl. Bremer: Schluß der Österreichischen Instruktionen für die Sanitätsbehörden etc.: in: JPA, 3.72=65.1831, S. $14-25:$ S. 25.

35 Labisch: Homo Hygienicus - Gesundheit und Medizin in der Neuzeit, 1992: S. 105.

36 Vgl. Thiele: Kurze Nachrichten und Auszüge, 1. Maßregeln der Königl. Preussischen Regierung gegen die Cholera: in: JPA, 5.72=65, 1831, S. $114-122$ : S. 114.

37 Ebd.: S. 115.

38 Ebd. 
wohnern « erwartete man in der besagten Bekanntmachung, die »pünktlichste Befolgung der ertheilten Vorschriften mit Zuversicht und Vertrauen $\ll^{39}$ zu befolgen.

\section{Die polizeiwissenschaftliche Durchdringung der Cholera}

Es ist wichtig zu beachten, wie zwingend die Untermauerung der Entscheidung des preußischen Königs hier durch eine wissenschaftliche Kommission dargestellt ist. Wie handlungsfähig wäre die Regierung ohne eine wissenschaftlich belegte Versicherung darüber, dass die Cholera eine ansteckende Krankheit ist, gewesen? Welchen Anschein der Vernunft, der Rationalität und Rechtfertigung hätte sie sich geben können? Andererseits ist für Preußen auffällig, dass die Regierung kein separates Verfahren zu haben schien, um das, was z.B. die Medizin an Wissen zur Verfügung stellte, ihren eigenen Zielen und ihrer eigenen Rationalität unterzuordnen. Die medizinische Polizei besaß keine wirkliche gouvernementale Rationalität, sie war ein seltsames Hybrid: eine Vereinigung von Regierungspraxis und disziplinärem Wissen. Sie bezog sich einerseits tatsächlich auf einen Gegenstand, den weder die Arzneikunde, noch die Staatswissenschaft, noch alle Wissenschaften erschließen konnten. Andererseits war keine Disziplin, auch nicht die der Polizeiwissenschaft, im Stande, erschöpfend Wissen über einen Gegenstand zu liefern, der sich, weil er der Gegenstand der Regierung war, permanent ausdehnte und gerade noch gültige Grenzen verwarf.

»Da das von den Königlichen Behörden einzuleitende Verfahren sich nur auf die genaue Kenntniß von der Natur der Krankheit begründen konnte, so ist zunächst auf dem Wege wissenschaftlicher Prüfung die Frage zu lösen gewesen, ob die Krankheit zur Gattung der ansteckenden gehöre oder nicht, und ob im ersteren Fall die Ansteckung mittels eines in der Luft verbreiteten Ansteckungsstoffs oder mittels Uebertragung durch ein an dem erkrankten Individuum entwickeltes Contagium erfolgte. «40

Welche Auswirkungen hatte es für die medizinische Wissenschaft und die Regierung, in einem derart engen Verhältnis zu stehen? Bewirkte die Relativität des Wissens über die Cholera eine wirkliche Verunsicherung der Regierung? Hier zeigte sich ein Problem, das die gesamten Überlegungen und Schwierigkeiten v.a. der preußischen, aber im Grunde auch der französischen Regierung, bezüglich ihres Umgangs mit der Cholera im 19. Jahrhundert durchzogen hat. Der Anspruch einer rationalen Regierung bestand in der Notwendigkeit, eine exakte rationale und wissenschaftliche Grundlage für ihr Handeln zu liefern. Ein Wissen, dass möglichst vollkommen und systematisch sein sollte, um einer eher disziplinären (bis in die Details des Verhaltens der einzelnen Menschen hineinreichenden) als gouvernementalen Regierungsform als Grundlage zu dienen. Ähnlich wie die Medizin oder andere Naturwissenschaften bestrebt waren, ein tiefes und genaues Wissen über ihren Gegenstand zu haben, träumte auch die preußische Regierung von einer völligen polizeiwissenschaftlichen Durchdringung und polizeilichen Regierung der Gesundheit der Menschen. Aber die Medizin war gewissermaßen zu unvollkommen und ihre theoretischen Grundlagen selbst

39 [Alle Zitate] Ebd.: S. 116.

40 Ebd.: S. 116. 
zu wenig systematisiert als dass eine Regierungspraxis sich voll auf sie beziehen und mit ihrer Hilfe rationalisieren konnte. Noch eher zeigte sich dieses Problem in der Praxis. Die Regierung richtete sich mit ihrer disziplinären Praxis nicht auf die Insassen einer Anstalt oder auf die Soldaten eines Regiments, die vielleicht noch eher unter eine umfassende Kontrolle zu bringen wären. Ihr fehlte es noch an Techniken und Wissensformen, um effektiver auf diese unzähligen und niemals erschöpfend zu kennenden Prozesse und Beziehungen des Lebens einer Bevölkerung einwirken zu können. Die Regierung musste also auch zu diesem frühen Zeitpunkt, als sie das erste Mal selbst mit dem Problem der Cholera konfrontiert wurde, feststellen, dass die medizinische Wissenschaft keine eindeutige Lösung und keine eindeutige Maßgabe für ihr Handeln lieferte. ${ }^{41}$ In Preußen entschied man sich daraufhin, wie Bremer im Hinblick auf Österreich gelobt hatte, »immer den schlimmsten und gefährlichsten Fall vor Augen zu haben, und kein Mittel außer Acht zu setzten $\ll{ }^{42}$. Man reagierte auf die Unsicherheit über die Verbreitungsart der Cholera in der Medizin mit einer Regierungspraxis, die tendenziell von allen Möglichkeiten der Ansteckung, Verbreitung und Entstehung ausging. Die Frage, wie man mit geringem Aufwand großen Erfolg erzielen konnte, stellte sich die preußische Regierungspraxis nicht. Wenn es keine eindeutige Klarheit über die Art der Verbreitung der Cholera gab, mussten grundsätzlich alle für wahr angenommen werden und auf alles so umfassend und lückenlos wie möglich reagiert werden. Ein einziges Versäumnis, eine einzige Person, die die Grenze unkontrolliert überquerte, konnte das ganze System vom Maßregeln hinfällig machen.

»[U]m nicht durch eine verfehlte Anordnung in dieser Beziehung vielleicht den ganzen Zweck der Sicherungs-Maaßreglen zu vereiteln, mußte nothwendigerweise der Entschluss gefasst werden, diese Maßregeln auch auf Effekten und Waaren auszudehnen. Die daraus für einzelne erwachsene Nachteile werden durch die für das Ganze gewonnene Sicherheit, wie jeder unbefangene fühlen wird, bei weitem überwogen. [...] Die Maaßregel der Gränz-Sperrung ist gegenwärtig auf der ganzen zunächst bedrohlichen Landes-Gränze von Memel bis zur südlichen Spitze von Ober-Schlesien durch einen militärischen Sanitäts-Cordon ausgeführt worden. Es stehen zu dem Zwecke längs der Gränze Militär-Commando's, die, theils durch stehende Posten, theils durch Patrouillen, die Communication mit dem Auslande gänzlich aufheben und die autorisiert sind, gegen diejenigen Personen, welche auf die Zurückweisung nicht hören und den Eingang in das diesseitige Gebiet außer den Kontumaz-Plätzen wider das Verbot durchsetzen wollen, nöthigenfalls die Gewalt der Waffen zu brauchen. $\ll^{43}$

Die Strategie der Regierung Preußens bestand darin, sich vor allem entschlossen und aufopferungsvoll zu zeigen. Dies entsprach offensichtlich ihrer eigenen Konstruktion

41 Vgl. ebd.: S. 116.

$42 »$ Instruktionen für die Sanitätsbehörden [...]«: in: Bremer: Geschichtliche Nachrichten über die Verbreitung der asiatischen Cholera in Russland und Oesterreich. Aus den officiellen Petersburger, Wiener und anderen Zeitungen mitgeteilt und mit einigen Anmerkungen begleitet: in: JPA, 2.72=65.1831, S. $105-125$ : S. 126.

43 Thiele: Kurze Nachrichten und Auszüge, 1. Maaßregeln der Königl. Preussischen Regierung gegen die Cholera: in: JPA, 5.72=65, 1831, S. $114-122$ : S. 117. 
als >gute Regierung « und diente somit dazu, ihre moralische Identität zu bestätigen, »[N]icht ohne große Anstrengung « sei die Abwehr der Cholera zu bewerkstelligen! ${ }^{44}$ Sich handlungsbereit und handlungsfähig zu zeigen, war vor und während des Ausbruchs der Epidemie in Preußen sehr wichtig gewesen. Aber auch nachdem die Cholera trotz strenger Kontrollen die Grenzen Preußens passiert hatte, bemühte sich die Regierung darum, Zweifel an der Effektivität ihrer Maßnahmen auszuräumen und das Bild einer handlungsfähigen Regierung zu bestärken:

»Es hat der wachsamsten Vorsorge und den thätigsten Bemühungen nicht gelingen wollen, die asiatische Cholera, nachdem sie den strengsten Maassregeln ungeachtet über die Grenzen Meiner Staaten eingedrungen war, zu unterdrücken und ihrem Vorschreiten Einhalt zu thun. Ueberall jedoch, wo die erlassenen Vorschriften pünktlich befolgt worden sind, hat die pflichtmässige Sorgfalt der Behörden, mit den lobenswerthen Anstrengungen gewissenhafter Aerzte vereinigt, die Verheerungen der Seuche wirksam gehemmt und die Zahl ihrer Opfer in Vergleich mit andern Ländern beträchtlich vermindert. «5

Vor allem ihre Bereitschaft Opfer zu bringen, ihr Engagement und ihr Mut sollte, indem sie der Cholera wie einem Feind gegenüber trat, der an den Landesgrenzen lauerte, den Beleg für ihren guten Willen, ihre Macht und Kompetenz als Regierung liefern: $»[D]$ ie beste Absicht der Regierungen und die würdigste und treueste Sorgfalt für das Volkswohl« war mit »allen den unermeßlichen Anstrengungen und Opfern ${ }^{46}$ bewiesen. Ebenso erwartete sie schließlich auch von der Bevölkerung, die Regeln pflichtbewusst und unter Hinnahme der Einschränkungen zu befolgen. ${ }^{47}$

»Indem Ich den Erfolg auch dieses Beschlusses in die Hand Gottes lege und mit demüthiger Unterwerfung unter seinen höhern Willen seinem Segen befehle, erwarte Ich mit wohlwollendem Vertrauen auf die Anhänglichkeit und Folgsamkeit Meines treuen Volkes, den unbedingten Gehorsam desselben in Beobachtung der bekanntgemachten Vorschriften. $\ll^{48}$

44 Belehrungen über die gegen die ansteckende oder asiatische Cholera anzuwendenden Schutz-Maaßregeln und ersten Hülfeleistungen, Berlin, 1831, S. 3: zitiert nach Dettke: Die asiatische Hydra, 1995: S. 197f.

45 »Das Staats-Ministerium bringt, nach dem Befehle Sr. Majestät des Königs, die nachstehende Allerhöchste Bekanntmachung zur allgemeinen Kenntniss, Berlin, vom 13. September « in: Sachs: Tagebuch über das Verhalten der bösartigen Cholera in Berlin, 1831, S. 5 6: S. 5.

46 Harleß: Die Indische Cholera nach allen ihren Beziehungen, geschichtlich, pathologisch, diagnostisch, therapeutisch und als Gegenstand der Staats- und Sanitäts-Polizei, 1831: S. 696.

47 Vgl. »Belehrungen über die gegen die ansteckende oder asiatische Cholera anzuwendenden Schutz-Maaßregeln und ersten Hülfeleistungen« zitiert nach Dettke: Die asiatische Hydra, 1995: S. 197f.

48 Das Staats-Ministerium bringt, nach dem Befehle Sr. Majestät des Königs, die nachstehende Allerhöchste Bekanntmachung zur allgemeinen Kenntniss, Berlin, vom 13. September: in: Sachs: Tagebuch über das Verhalten der bösartigen Cholera in Berlin, 1831, S. 5 - 6: S. 6 . 
Die preußische Regierung reproduzierte damit das asketische moralische Ideal der Selbstbeschränkung als Tugend, die Hinnahme von Beschränkung für die allgemeine Verbesserung usw. Sie verpasste dem Staat im wahrsten Sinne des Wortes eine strenge Diät, die ihn ökonomisch schwächte, immense Kosten verursachte und alles andere als bequem war, um das Ziel der Erhaltung der Gesundheit des Staats und der Bevölkerung zu erreichen und sich gleichzeitig als gute Regierung zu zeigen. Je unbequemer die Maßregeln, desto mehr konnte man sich von ihnen einen Nutzen erhoffen. Die Einrichtung und die Aufgaben der medizinischen Polizei entsprachen einer Politik, die explizit keine Kosten und Mühen scheute, um ihr Ziel zu erreichen. Dieses Ideal der Regierung war auch schon früher, z.B. während der Typhus-Epidemien deutlich gemacht worden. Nicht selten war es auch von Ärzten und bürgerlichen Kritikern der Regierung, die diese zu größerem Engagement aufforderten ins Spiel gebracht worden.

Es ist interessant, wie häufig in den Texten zur Cholera-Politik die Annahme einer bestimmten wissenschaftlichen Position mit Eigenschaften des Geizes, der Bequemlichkeit und Tatenlosigkeit in Zusammenhang gebracht wird. Einmal werden die »Contagionisten « als bequem dargestellt, weil sie durch »ihre Ansichten an gewohnte Lieblingsdoctrien gefesselt $\ll^{49}$ vor einer genaueren wissenschaftlichen Untersuchung zurückschreckten. Ihnen wurde vorgeworfen, dass sie die sichtbaren Beweise, dass die Cholera nicht ansteckend ist, ignorierten, um weiter ihre alte nutzlose Praxis - die Quarantäne, Isolation etc. fortsetzen zu können. Aber auch die »AntiContagionisten « wurden angegriffen, weil ihnen die Maßnahmen der Quarantäne und der Sperren zu »unbequem« seien, sie davor zurückschrecken würden, diese umzusetzen. ${ }^{50}$ Der Sanitätspolizei wurde Untätigkeit, der Bevölkerung Bequemlichkeit und Resignation unterstellt ${ }^{51}$ und den Regierungen anderer Länder (Russland ${ }^{52}$, England und Frankreich ${ }^{53}$ ) wird zum Vorwurf gemacht, dass sie nur aus Geiz und Bequemlichkeit, um die »unbequeme, kostspielige « »Quarantäne los zu werden«, behaupten würden, die Cholera sei nicht ansteckend. ${ }^{54}$ Die Strategie, bei aller vorhandener wissenschaftlicher Unklarheit über die Cholera, sicherheitshalber von der Wahrheit aller oder der grundsätzlich schlimmsten Möglichkeit auszugehen, verschafft der Regierung eine moralisch erhöhte Position und gleichzeitig eine gewisse Unabhängigkeit von den wissenschaftlichen Streitigkeiten und der Vielfalt der Erklärungen, die es vor allem in den deutschen Ländern bald gab. Wenn man »neben dem contagiösen, auch einen miasmatischen Charakter annimmt « und außerdem davon ausging, dass »ein Diätfehler, eine Erkältung usw. hinreicht, um auch ohne alle Ansteckung der

49 Vgl. Behr: Die Cholera in Deutschland, 1848: S. 5.

50 Vgl. Bremer: Geschichtliche Nachrichten über die Verbreitung der asiatischen Cholera in Russland und Oesterreich. Aus den officiellen Petersburger, Wiener und anderen Zeitungen mitgeteilt und mit einigen Anmerkungen begleitet: in: JPA, 2.72=65.1831, S. $105-125$ : S. 106. Vgl. Behr: Die Cholera in Deutschland, 1848: S. 6.

51 Vgl. Brefeld: Die endliche Austilgung der asiatischen Cholera, 1854: S. 4f; 60.

52 Vgl. Behr: Die Cholera in Deutschland, 1848: S. 6.

53 Vgl. Pruner-Bey: Die Weltseuche Cholera oder die Polizei der Natur, 1851: S. 59f.

54 Vgl. [Hrsg.]: Von den Schutz- und Rettungsmitteln: in: MTKS, 1.2.1805/1806, S. 165 202: S. 172 - 174: $172 \mathrm{f}$. 
herrschenden Epidemie zu erliegen ${ }^{55}$, war wohl das Spektrum an Maßregeln, die eine Regierung gegen die Cholera anwenden konnte, besonders umfassend, die wissenschaftliche Begründung jeder einzelnen Maßnahme aber relativ schwach. Vor allem dann, wenn sich die verschiedenen Erklärungen widersprachen. Hinsichtlich der Positionen der Anti-Kontagionisten rieten aber auch einige Ärzte der Regierung, sie solle den unübersichtlichen Positionen und Auseinandersetzungen in der Wissenschaft nicht allzu große Bedeutung beimessen:

»Wenn dieses Schwanken, und diese Dissonanzen und Widersprüche in den Meinungen der Aerzte über die Natur und die Verbreitungs- und Mittheilungsverhältnisse dieser Krankheit nicht auch auf das Benehmen der europäischen Regierungen und der obersten Polizei- und Sanitätsbehörden gegen dieselbe einen entsprechenden Einfluß hatten, wie es ihn in der That auf Regierungs- und Sanitätsbehörden in dem englischen Ostindien (wenigstens bis noch vor Kurzem in Calcutta) geäußert hat, wenn vielmehr die russische, preußische, österreichische und bald auch die übrigen, von der Gefahr zunächst bedrohten Regierungen in der Betrachtung dieser Krankheit als einer ansteckenden - und in der Ergreifung energischer Sicherungsmaaßregeln gegen dieselbe übereinstimmen, so ist dieses bloß einer weisen und in jedem Fall höchst dankenswerthen Consequenz in der Befolgung des Grundsatzes zuzuschreiben, daß da, wo nicht bloß die Möglichkeit - sondern die Wahrscheinlichkeit eines nahenden Ungewitters vorhanden ist, man mit den Vorkehrungsmitteln nicht warten müsse bis erst der Blitz eingeschlagen und gezündet hat. $\ll^{56}$

Es konnte kein eindeutiger Beweis für die Ansteckung von Mensch zu Mensch oder von Gegenständen und Waren auf Menschen bewiesen werden, auch wenn man auf der Landkarte den Weg der Krankheit von Ort zu Ort nachzeichnen konnte, schien dieser teilweise auch ohne menschlichen Verkehr möglich. Andererseits gab es Menschen, die Tag und Nacht Zeit mit Cholerakranken verbrachten, die die Kleider der Kranken und Verstorbenen trugen und sogar Säuglinge, die weiter von ihren erkrankten Müttern gestillt wurden, ohne sich mit der Cholera zu infizieren. Teilweise erhofften sich Mediziner nach dem Abklingen der ersten epidemischen Welle sogar ein erneutes Ausbrechen der Krankheit, um diese genauer erforschen zu können: Man müsste die Choleraepidemie noch einmal »in ihrer ganzen Blüthe zu beobachten Gelegenheit gehabt haben «, um ihre Natur bestimmen zu können. ${ }^{57}$ Nach dem Abklingen der ersten Epidemie bis zum Ausbruch der zweiten Epidemie ab 1849 herrschte eine gewisse Krisenstimmung. Die enormen Einschränkungen und strengen Maßnahmen der Polizei hatten vor allem bei liberaleren Ärzten und Bürger dazu geführt,

55 Albers: Kurze Nachrichten und Auszüge, 2. Auszug aus einem amtlichen Berichte des Königl. Preussischen Regierungs - und Medicinal-Rathslera: in: JPA, 5.72=65, 1831, S. 122 133: S. 130.

56 Harleß: Die Indische Cholera nach allen ihren Beziehungen, geschichtlich, pathologisch, diagnostisch, therapeutisch und als Gegenstand der Staats- und Sanitäts-Polizei, 1831: S. vi.

57 Vgl. Albers: Kurze Nachrichten und Auszüge, 2. Auszug aus einem amtlichen Berichte des Königl. Preussischen Regierungs - und Medicinal-Rathslera: in: JPA, 5.72=65, 1831, S. 122 - 133: S. 134. 
die Hinweise auf eine nicht-kontagiöse Natur der Cholera ernster zu nehmen, um so die polizeiliche Praxis anzugreifen. Selbst in Berlin hatte man kurzer Zeit nach dem Ausbruch der Epidemie eine Reihe von polizeilichen Maßregeln wieder aufgehoben, nachdem sich diese als nutzlos erwiesen hätten.

»Nach längerer Beratung stellten die Magistratsmitglieder den Antrag, sämtliche Sperrmaßnahmen, Quarantäne-Einrichtungen wie Wohnungssperren, aufzuheben; auch die in Berlin bisher aufgetretenen Cholerafälle hätten nicht einmal den Verdacht einer direkten Ansteckung ergeben, wohl aber das Entstehen der Krankheit aus >diätischen< Ursachen, gegen die keine Sperrmaßnahmen helfen könnten. Überdies habe die Seuche bisher immer nur einen Bruchteil der Bevölkerung befallen, ob Sperrmaßnahmen angewendet wurden oder nicht. Um diese weniger Prozent der Einwohner vor einer vermeintlichen Ansteckung zu schützen, sei es nicht zu verantworten, den Lebensunterhalt der übrigen 97 oder $98 \%$ aufs Spiel zu setzten. Die Stadtverordnetenversammlung schloss sich einstimmig diesem Antrag an. $\aleph^{58}$

Die Kontagionisten kritisierten dagegen die Regierung, ihre Maßnahmen nicht hart genug durchgesetzt zu haben und die »Untertanen « für ihren mangelnden Gehorsam.

Als ein solcher Kontagionist könnte auch der Königl. Preuss. Regierungs- und Medizinal-Rath von Breslau, Dr. Franz Brefeld gesehen werden. Dieser verfasste 1854 einen Vorschlag, wie die bisherigen Maßregeln zu verbessern seien, wobei er gerade auch strategische Überlegungen einbezog, um die Akzeptanz der SanitätsPolizei zu steigern, damit schließlich die »endliche Austilgung der asiatischen Cholera ${ }^{59}$ erreicht werden könne. »Von den Sumpfregionen Asiens ist uns ein Feind zugeführt, der sich für immer bei uns einbürgern zu wollen scheint und mit schwerem Drucke auf uns lastet. ${ }^{60}$ Mit diesem Druck meinte Brefeld einerseits die wirtschaftlichen Lasten, mit denen man wegen der Cholera zu kämpfen hätte, und auch die Auswirkungen der Angst vor der Krankheit, die die »ganze Stimmung im Land « bedrückte. ${ }^{61}$ Brefeld ging davon aus, dass die Cholera als ein Eindringling von außen zu sehen wäre, den man ein für alle Mal und unter Anstrengung aller Kräfte loswerden müsse. Die im Rahmen der ersten Epidemie eingerichteten Kordons, Sperrlinien und Quarantänemaßregeln hatten sich bald als kaum umsetzbar, wenig effektiv und finanziell schwer tragbar erwiesen. Der Menschen- und Warenverkehr war stark beschränkt worden und die Loyalität der Bevölkerung gegenüber den Maßregeln sank erheblich.

»Die Sanitäts-Polizei hat nach dem Scheitern der im Jahre 1831 ergriffenen rigorosen Maassregeln so ziemlich vollständig die Hände in den Schooss gelegt. Allerdings bestehen gesetzlich noch Maassregeln gegen die Seuche, niemand hat aber Vertrauen zu ihnen [...] niemand führt sie aus. [...] Niemand kann sie aber auch perfect ausführen, indem es überall an Concordanz der Ueberzeugung über die Natur der Seuche gebricht, aller Orten Aerzte, Behörden und Publi-

58 Dettke: Die asiatische Hydra, 1995: S. 190. Dettke bezieht sich hier auf das Protokoll der Klausurtagung des Magistrats am 2.9.1831.

59 Vgl. Brefeld: Die endliche Austilgung der asiatischen Cholera, 1854: S. 3.

60 Ebd.

61 Vgl. ebd.: S. 4. 
kum sich einander hindernd im Wege stehen, und das letzte in der Sanitäts-Polizei nicht seine Rettung bringenden Schutz und Schirm erkennt, sondern sie nur als eine belästigende und beschränkende Potenz ansieht. $\ll^{62}$

Die preußische Regierung verfügte trotz der auf den ersten Blick enorm umfassend erscheinenden Maßregeln in Wirklichkeit nur über ein begrenztes Repertoire an polizeilichen Techniken. Begrenzt deshalb, weil es eng an eine bestimmte medizinische Wahrheit gebunden war. Mit der Wahrheit und Wirksamkeit dieser Techniken stand und fiel die Macht der Regierung über die Cholera. Aber nicht nur über die Cholera. Das Scheitern der Cholera-Politik in Preußen stellte eine Gefahr für die Regierung und die grundsätzliche Legitimität ihrer Rationalität und ihrer Techniken dar. Aus diesem Grund war das Interesse der Regierung, den kontagiösen Charakter der Cholera, auf die sich die meisten polizeilichen Techniken stützten, zu propagieren und zu beweisen, besonders groß. ${ }^{63}$ Der Arzt Christian Friedrich Harle ${ }^{64}$ fasste dieses Dilemma in seinem Buch Die Indische Cholera nach allen ihren Beziehungen, geschichtlich, pathologisch, diagnostisch, therapeutisch und als Gegenstand der Staatsund Sanitäts-Polizei, das etwa zeitgleich mit dem Ausbruch der Cholera in Preußen (im August 1831) veröffentlicht wurde, zusammen:

»Dieser Teil der Vorbauungs- und Abwehrungsmittel, welcher in seiner Ausführung für ganze Gemeinden, Städte, Districte, ja für ganze Provinzen und Länderstrecken den Staatsbehörden und der Medicina et Politia publica anheimfällt, ist unstreitig bei weitem der wichtigste, so wie er auch der umfassendste und kraftvollste in seinen Anstalten und Mitteln, wie in deren Durchführung ist. [...] Alles, was die Regierungen und obersten Sanitäts- und Polizeibehörden zur Prophylaris und Gegenwehr gegen die Cholera anordnen, und wie und in welchem Grade der Strenge sie es anordnen, [beruhet] lediglich auf den Grundsätzen und Feststellungen, [...] welche diese Staatsbehörden über die Natur der Krankheit und über die Verhältnisse und die Medien der Mittheilungs-, Verbreitungs- und Infectionsweise, und insbesondere über die Contagiosität der Cholera annehmen [...]. $\ll^{65}$

Weiter schrieb Harleß:

»Würde es nicht [...] ein schweres Unrecht und, eine nicht zu rechtfertigende Vernachlässigung der Sorge für die öffentliche Wohlfahrt und für die Erhaltung des Lebens und der Ruhe von vielen Tausenden seyn, wenn die Staatsbehörden bloß deswegen, weil diese Ansteckung nichtimmer und nicht unter allen möglichen Umständen einträte, alle und jede Sicherungsmaaßre-

62 Ebd.: S. 4f.

63 Vgl. Harleß: Die Indische Cholera nach allen ihren Beziehungen, geschichtlich, pathologisch, diagnostisch, therapeutisch und als Gegenstand der Staats- und Sanitäts-Polizei, 1831: S. 691f.

64 Harleß [auch Harles] (1773 - 1853) gab zwischen 1816 und 1818 gemeinsam mit Hufeland das Journal der practischen Arzneykunde heraus.

65 Harleß: Die Indische Cholera nach allen ihren Beziehungen, geschichtlich, pathologisch, diagnostisch, therapeutisch und als Gegenstand der Staats- und Sanitäts-Polizei, 1831: S. 690. 
geln ganz unterlassen und für unnöthig erklären wollten? Und würde es auf der anderen Seite nicht sehr hart und grausam seyn, wenn ohne den erforderlichen Beweis der Ansteckung nur auf einzelne ungewisse oder nicht gehörig geprüfte und constatirte Thatsachen oder Angaben hin die eine Interpretation für die Möglichkeit derselben zulassen, coercitive und abschließende Maßßregeln ergriffen würden, die dem freien Verkehre einer Provinz oder eines ganzen Staates unter seinen Bewohnern wie mit dem Auslande die lästigsten und nachtheiligsten Fesseln anlegten, oder ihn ganz unterbrächen? «66

Aus Sicht der preußischen Regierung und laut Brefeld, wäre ein Verwerfen der These der Kontagiosität einer Entmachtung der Regierung gleichgekommen. Für die Regierung bedeutete die These, die Cholera würde sich anders als über Ansteckung verbreiten, zu behaupten, dass die Regierung quasi nichts tun könne, dass sie selbst völlig hilflos und die Macht des Königs in seiner Rolle als Beschützer und Vater des Landes und seiner Untertanen, zumindest was die Cholera betraf, als unbrauchbar herausgestellt worden wäre. So stellte Brefeld fest:

»Die Frage nach der Contagiosität ist aber die entscheidende Präliminar-Frage. Beruht die Cholera auf einem tellurischen Miasma, dann können wir uns freilich ruhig darauf beschränken, unseren Kranken die letzte Stunde möglichst zu versüssen und die Todtenkisten zu bestellen; ist sie aber, wie nach gerade wohl bis zu einer in derartigen Dingen möglichen Evidenz feststeht, contagiös und nur contagiös, dann ist unsere Aufgabe eine ganz andere: dann haben wir die Seuche todt zu machen. Was contagios ist, das ist auch austilgbar! «67

Wenn die Cholera eine ansteckende Krankheit sei, wenn sie wie die Pest behandelt werden könne, dann wisse die Regierung, was zu tun sei, dann habe sie die Mittel und die Legitimität - nur dann. Auch ein bayrischer Landesgerichtsarzt aus Klingenberg namens Braun ${ }^{68}$ hatte in einem Artikel, den er 1831 in der Erlangener Cholerazeitung $^{69}$ zur Veröffentlichung gegeben hatte, diese Konsequenz betont: »Steht einmal dieses fest; so ist es auch höchst wahrscheinlich, daß dies Contagium, wie so viele andere, vernichtet werden kann. ${ }^{70}$ Der Umkehrschluss dieses Zusammenhangs bedeutete, dass man den Regierungen nicht mehr erlauben würde, überhaupt noch Maßnahmen gegen die Cholera durchzuführen. Auch Harleß, der eine zusätzliche Übertragbarkeit der Cholera über die Luft, ebenso wie eine bestimmte atmosphäri-

66 Ebd.: S. $691 f$.

67 Brefeld: Die endliche Austilgung der asiatischen Cholera, 1854: S. $53 f$.

68 Braun war ausgewiesener Anti-Kontagionist, der zumindest 1831 der Meinung war, dass die Cholera ähnlich wie die Pest übertragen werde. Braun: Mitteilungen des Neusten und Wissenswürdigsten über die Asiatische Cholera, 1831: S. 5.

69 Viele kommunale Verwaltungen veröffentlichten während der Epidemien diese speziellen Zeitungen. Sie dienten dazu, die Bevölkerung über die Maßnahmen gegen die Cholera zu informieren, sie enthielten aber auch Statistiken oder Listen mit an der Cholera verstorbenen.

70 Braun: Ueber die Behandlung der ostindischen Cholera von Seiten des Staates, 1831: S. 197. 
sche, klimatische Bedingtheit der Wirksamkeit des »Ansteckungsgifts « in Erwägung zog, hatte schon 1831 vor einer derartigen Schlussfolgerung gewarnt:

»Gegen die von mir als Wahrheit anerkannte Behauptungen $[\ldots]$ hat man von mehreren Seiten unter Mißbilligung dieser Ansicht die Frage aufgeworfen: >Wenn dieses so wäre, was könnten dann die Absperrungsanstalten, die Cordons, die Quarantainen und Contumazhäuser helfen? Warum sollte man in solchem Falle nicht lieber alle solche Sperrungs- und Reinigungsanstalten und jede von Staatswegen getroffene Abhaltungsmaaßregel aufheben $[\ldots] ?<. \ll^{11}$

Harleß war gut zwanzig Jahre vor Brefelds Versuch der Erneuerung und Verbesserung der polizeilichen Maßnahmen der Meinung gewesen, es sei nicht so gefährlich, von verschiedenen Ansteckungs- und Verbreitungsarten auszugehen, so lange die Kontagiosität selbst nicht in Frage gestellt würde. Er war der Überzeugung, dass

»Fürsten und Regierungen, die ihre Völker und Verwalteten lieben [...] sich sicherlich nicht durch eine Frage obiger Art irre machen lassen; sie werden sich nicht dadurch, daß es ihnen nicht gelingt, nicht gelingen kann, die verderbliche Seuche ganz und dauernd von ihren Völkern entfernt zu halten, weil eine höhere Gewalt mit im Spiele [sey] [entmutigen lassen.] « ${ }^{72}$

Dennoch leugnete er auch den Zusammenhang zwischen der Stärke der Beweise für die Kontagiosität und der Stärke der Maßnahmen, die man von staatlicher Seite gegen die Cholera durchsetzen konnte, nicht. Brefeld schloss dagegen, dass die früheren Maßregeln, die Absperrung und die Quarantäne, deren Unwirksamkeit ebenso evident war, schlicht und ergreifend nicht ordentlich durchgeführt worden waren. Sie wären, so Brefelds Argumentation, nicht gemäß der Bedingung der Wirksamkeit polizeilicher Techniken entsprechend, nämlich absolut lückenlos, ausgeführt worden. Die Faulheit, der Geiz und die Bequemlichkeit seien, laut Diagnose des Breslauer Medizinalrats, die Gründe, warum die so guten Maßregeln so wenig Wirkung gezeigt hätten. ${ }^{73}$ Diese Feststellung weitet er übrigens auch auf andere Länder aus. Dort würden sich die Regierungen vor der Anerkennung der »Wahrheit über die Natur der Cholera « und der mit ihr gebotenen Durchsetzung von strengen Maßregeln scheuen, z.B. weil die Quarantäne unbequem sei und wirtschaftliche Einbußen bedeutete. Damit würden sie sich aber auch an der Verbreitung der Cholera in benachbarte Länder schuldig machen.

»Erst dann, wenn aller Orten in unserm civilisierten Erdtheile jene grosse Wahrheit: dass die Cholera sich nur per contagionem verbreitet und der Austilgung zugänglich ist, zum allgemeinen Anerkenntnisse gelangt sein, und wenn dieser Ueberzeugung gemäss in geeigneter Weise

71 Vgl. Harleß: Die Indische Cholera nach allen ihren Beziehungen, geschichtlich, pathologisch, diagnostisch, therapeutisch und als Gegenstand der Staats- und Sanitäts-Polizei, 1831: S. 692.

72 Ebd.: S. 749.

73 Vgl. Brefeld: Die endliche Austilgung der asiatischen Cholera, 1854: S. 53f. 
aller Orten gegen die eingeschritten werden wird, erst dann wird die völlige Austilgung zur Wirklichkeit werden. $\ll^{74}$

Trotz dieser Diagnose beginnt Brefeld im letzten Teil seiner Ausführungen dennoch, strategische Vorschläge zu unterbreiten. Man müsse die Dummheit und die Uneinsichtigkeit der Bevölkerung einkalkulieren, man müsse die Maßnahmen so gestalten, dass sie nicht allzu viel Widerstand weckten und man müsste sie so durchführen, dass nicht an ihrer Wirksamkeit gezweifelt werden könne: »[Z]u rigorose Maassnahmen stoßen auf einen nicht zu bewältigenden Widerstand und verursachen zu panischen Schrecken, zu kostspielige Maassregeln scheitern an dem Kostenpunkte $\ll^{75}$.

Die Maßregeln müssen sich durch ihr Gelingen in der Praxis beweisen, um akzeptiert zu werden. Keine Maßregel, kein polizeiliches Eingreifen sei gefährlicher als ein halbherziges oder ungeeignetes, das keine Wirkung zeige. Wenn die Wirkung ausbliebe, stelle dies die gesamte Kompetenz der Regierung und ihrer Techniken in dieser Angelegenheit in Frage. »Ungeeignete Maßßreglen, sei es, weil nicht hülfreich, oder weil nicht ausführbar, taugen gar nichts, weil die den Credit der geeigneten untergraben. $\ll^{76}$ All dies seien die Fehler der ersten Epidemie gewesen. Das »Gefährlichste von Allem« sei es, wenn die Maßregeln »wahrhaft lächerlich« seien. Er berichtet dann von der Anerkennung der Maßregeln, wenn diese mit zunehmendem Erfolg ausgeführt und nicht mehr behindert worden seien, »dass man wohl der Hoffnung sich hingeben darf, für alle Folge der Seuche vollständig Herr zu werden « ${ }^{77}$. Man müsse teilweise akzeptieren, dass die Bevölkerung wenig einsichtig und dass sich mit Gewalt hier nicht unbedingt zu helfen sei. »Wir lassen uns eher die Cholera resigniert gefallen, als dies: nicht einmal in seinen gewohnten Vergnügen lässt sich das Publikum leicht stören. - Wer zu viel befiehlt, bekommt nichts. ${ }^{78}$ Statt der militärischen und mit großem Waffenaufgebot an den Grenzen begonnenen Vorgehensweisen gegen die Cholera weiter fortzuführen, müsse man nun einsehen, dass der Kampf gegen die Krankheit strategischer geführt werden müsse und man v.a. mit dem Widerstand der Bevölkerung umzugehen hätte, um doch noch das Ziel der >Unterdrückung< der Cholera zu erreichen.

Eine sehr wesentliche strategische Verschiebung, was die Techniken der Polizei in Preußen und den norddeutschen Ländern betrifft, die sich später aber bis zur Reichsgründung und danach in ganz Deutschland verallgemeinert, möchte ich nur kurz andeuten. Es handelt sich gewissermaßen um die Übertragung der gleichen disziplinären, militärischen und absolutistischen Logik auf einen neueren Bereich von Techniken, und zwar weg von den militärischen hin zur chemischen Bekämpfung der Cholera: den Techniken der Desinfektion. Es ist die Verlagerung des >Abwehrkampfes< von den Außen-Grenzen eines Staates, über den Kampf im Reichsinneren bis zum >Abwehrkampf< im Körper eines jeden Individuums. Zunächst im Landesinneren und später, nach der Bekanntmachung des Choleraerregers durch Robert Koch

74 Ebd.: S. 78.

75 Ebd.: S. 9.

76 Ebd.: S. 60.

77 Ebd.: S. 57f.

78 Ebd.: S. 60. 
1884, wird sich diese Verschiebung nahtlos um den Abwehrkampf im Körper ergänzen. Brefeld schreibt von der im Rahmen der ersten Epidemie gewonnenen »überzeugende[n] Einsicht, dass es einer viel exacteren und vollkommenern Administration von geeigneten Isolir- und Desinfektions-Maasregeln bedürfe, um der Seuche vollkommen Herr zu werden. ${ }^{79}$

»Für uns geht aber aus den damals gemachten Erfahrungen die eine Lehre hervor: Nicht an des Landes Grenzen, - zu Hause will die Cholera bekämpft sein! Nicht in grossen Schlachten ist sie zu überwältigen, - der kleine Vertilgungs-Krieg will gegen sie geführt sein. $\ll^{80}$

»Die sorgfältige und gründliche Desinfection, zum Exempel, auf welche bei der Cholera das grösste Gewicht fällt, und welche mit der größten Sorgfalt und Strenge erzwungen werden muss, wenn man die Seuche überwältigen will.« ${ }^{81}$

Die zweite strategische Verschiebung, von den militärischen Techniken ausgehend, war eine Art 〉Gleichschaltung〈, was das allgemeine Verständnis der Cholera anging. Hier ist auch ein erster Hinweis gegeben, in welcher Richtung sich die politischwissenschaftliche Opposition zur preußischen Cholera-Politik geäußert hat, welcher Art ihre Kritik war und welche alternativen Techniken sie der Regierung vorschlugen. ${ }^{82}$ Brefeld betont die Notwendigkeit der $\gg$ Concordanz der Behörden, Aerzte und des Publikums $\ll^{83}$. Für den Erfolg der Maßregeln sei es erforderlich, die Ansichten des Publikums und der Ärzte mit denen der Behörden in Einklang zu bringen. Sie alle müssten völlig überzeugt sein von der »Nützlichkeit und Angemessenheit« der Maßregeln und auch dann, wenn diese nicht gleich erfolgreich seien, weiter an dieser Überzeugung festhalten. ${ }^{84}$ Wichtig sei, laut Brefeld, daher, dass sich die Gesetzgebung bezüglich der Cholera zukünftig auf die alleinige Annahme der »rein contagiösen Natur« stützte. ${ }^{85}$

\section{Neues Wissen zur Ermächtigung der Regierung}

Welches Wissen ermächtigt die Regierung, gegen die Cholera zu handeln? Welches Wissen machte die Regierung mächtig, handlungsfähig und legitimierte sie in ihrer Regierung der Gesundheit der Bevölkerung?

Aus Sicht zumindest der preußischen Regierung wirkt die anti-kontagionistische Theorie entmachtend und das war es, was man den Vertreter dieser Theorie offen vorwarf. Aus der Rationalität und der Beschaffenheit ihrer Techniken der bestehenden Regierung, aus den Regeln und Verfahren ihrer eigenen Reproduktion sind keine anderen als polizeilichen Techniken vorgesehen. Techniken, die, wie die Disziplin,

79 Ebd.: S. 56.

80 Ebd.: S. 61.

81 Ebd.: S. 62.

82 Vgl. ebd.: S. 59.

83 Ebd.: S. 60.

84 Ebd.

85 Vgl. ebd.: S. 66. 
sich auf einen festen, begrenzten und gesicherten Bereich von Wahrheiten und Wissen berufen sollten. Techniken, die in Bezug auf ihren Gegenstand absolut erschöpfend und lückenlos sein sollten. Die moralische Identität dieser Regierungen ist bedingt durch das Postulat, väterlich und allwissend Sorge zu tragen; ihre Güte ist bestimmt durch ihre Bereitschaft, Unannehmlichkeiten in Kauf zu nehmen. Ich werde später zeigen, dass sich, was diese >asketische< Regierungsidentität angeht, auch ähnlich bestätigende Aussagen im Lager der sog. »Halb- und Anti-Kontagionisten « finden lassen. Das Interessante ist, dass sie in gewisser Hinsicht nur das, was die eine Rationalität und diesen einen begrenzten Bereich von Techniken angeht, der Regierung tatsächlich sagen: »Ihr könnt nichts ausrichten!« Hätte dieser Ausspruch nicht aufgrund seiner entmachtenden Wirkung eine solche Gegenwehr ausgelöst, die wiederum eine neue Gegenwehr und Identität der Anti-Kontagionisten als Gegner der Macht produzierte, so hätte man erkennen können, dass es sich hierbei keineswegs um eine grundsätzliche Entmachtung, z.B. des preußischen Königs gehandelt hat. Genauer betrachtet waren die Anti-Kontagionisten keine Regierungsgegner, auch wenn sie als solche erscheinen mussten und sich vor allem in England explizit als solche inszeniert haben.

Was wollten sie stattdessen sagen? Es gab tatsächlich eine Fraktion in Deutschland, vor allem während der ersten Epidemie, die behauptete: Die Cholera habe atmosphärische, tellurische (aus der Erde aufsteigende), ${ }^{86}$ klimatische Ursachen, und an diesem Punkt sei die Macht der Regierung wirklich begrenzt. Die Tatsache, dass die Einen erkranken und Andere nicht, lag nach ihrer Auffassung an der jeweiligen Konstitution der Individuen, für die sie teilweise unschuldig seien, teilweise aufgrund ihrer Lebensweise selbst verantwortlich gemacht werden könnten. Es gab auch in Deutschland eine kleine bürgerliche Fraktion, die dafür plädierte, dass sich die Menschen besser >selbst regieren< sollten und dass die Verhinderung der Ausbreitung der Cholera daher nicht Sache des Staates sein könnte. Allerdings gibt es einen sehr fließenden Übergang der Gruppe von Anti-Kontagionisten, die durchaus bemerkte, dass viele dieser Bedingungen, die die Infektion mit der Cholera begünstigen, gesellschaftliche und politische Ursachen hatten bzw. durch staatliches Handeln beeinflusst werden könnten.

In fast allen Texten wehren sich die anti- und halb-kontagionistischen oder auch lokalistischen ${ }^{87}$ Ärzte gegen den Vorwurf der Tatenlosigkeit und der Entmachtung der Regierung. Sie versuchen stattdessen gerade zu sagen, dass die Menschen und auch der Staat etwas unternehmen sollten und könnten. Sie behaupteten nicht, dass man weniger oder mit geringerem Kostenaufwand regieren solle, sondern, dass ein erfolgreiches Regieren der Menschen, eine erfolgreiche Bekämpfung der Cholera nur durch ein viel weiter gefasstes Verständnis von Regierung möglich sei. Die Staatsregierung sollte verstehen, wo ihre Aufgaben liege, wie groß dieser Bereich sei und wie umfangreich das Wissen und die Techniken ihrer Regierung daher sein müsse, wenn sie gut regieren wolle. Dafür zwei Beispiel-Texte - übrigens sehr unterschiedliche -

86 Behr: Die Cholera in Deutschland, 1848: S. 14.

87 Ärzte, die die Entstehung der Cholera auf lokale Ursachen zurückführen, wie Bodenbeschaffenheit, Klima und hygienische Bedingungen. Sie plädierten dafür, dass die Bewohner eines Ortes, an dem die Cholera ausbrach, diesen möglichst schnell verlassen sollten. 
zweier Ärzte, die aber beide ausgesprochene Gegner der Kontagiösitäts-These waren. Der erste war der Mediziner, Augenarzt und Anthropologe Franz Ignaz Pruner-Bey, der, als er den von mir analysierten Text verfasste, auch Mitglied der Bayerischen Akademie der Wissenschaften war. ${ }^{88}$ Er schrieb 1851 in Die Weltseuche Cholera oder die Polizei der Natur:

»Dem ungeachtet wagen wir es, in Folgendem zu zeigen, dass man gegen die Cholera viel sehr viel vermöge. Aber gegen ein Uebel, welches eine solche Macht und Allgemeinheit erreicht, liegen die Mittel nicht im engen Bereich der Arzneikunde, sie stehen nicht verzeichnet in den Lehrbüchern über Heilmittel und Dispensation. Sie sind nach bisheriger Erfahrung in einem viel weiteren Kreise zu suchen, der die ganze Organisation der menschlichen Gesellschaft umfasst. $\ll^{89}$

Ein Kreis-Physikus namens Mecklenburg, den man sicherlich als Halb-Kontagionisten bezeichnet konnte, kam zu dem Schluss, dass alle polizeilichen Techniken ${ }^{90}$, und genauer die »drei specifischen Schutzmittel«, die »die Wissenschaft gegen die Cholera empfohlen habe: »Sperre, Desinfection, und Prophylactica « als >nutzlos $<$, >nicht zuverlässig<bzw. >schädlichく abzulehnen seien. ${ }^{91}$ Aber auch laut Mecklenburg bedeutete diese Feststellung keineswegs Resignation oder die Machtlosigkeit der Regierung zu behaupten: »Sind wir vollkommen wehrlos gegen diese Krankheit? Ich antworte bestimmt! Nein! $\ll^{92}$ Mecklenburgs Vorschläge laufen, neben dem Verbot, Cholerakranke von einem Ort zum anderen transportieren zu dürfen (womit er ganz nebenbei alle Sperr- und Quarantänevorrichtungen wieder rechtfertigt), darauf hinaus, dass, da die Cholera »eine Krankheit des Proletariats« sei, »nach Möglichkeit dem Proletariate das Proletarische genommen werden« müsse. Außerdem nannte er »überwältigende äussere Einflüsse, gewisse Schädlichkeiten, die sie [die Cholera] verursachen und bösartig machen $\aleph^{93}$, worunter er grob gesprochen hygienische und sanitäre Bedingungen der Wohnverhältnisse versteht. In den beiden Beispielen von Pruner-Bey und Mecklenburg hängen die Überlegungen der Ausweitung der Regierung mit der Einbeziehung und Erstellung von statistischen Daten über die Bevölkerung zusammen. Pruner-Bay sieht eines der Hauptprobleme in der »Überbevölkerung.«

»Wir meinen damit das Zusammenleben vieler Menschen in verhältnismäßig kleinen, unzureichenden Räumen, besonders, wenn diese nicht gehörig gelüftet und gereinigt sind. « ${ }^{94}$

»Die aus Berechnungen gewonnene Wissenschaft der Neuzeit [Statistik] lehrt, dass unser Geschlecht auf Erden in seinen gesellschaftliche Verhältnissen - namentlich in denen, welche auf

88 Stolberg-Wernigerode: Neue deutsche Biographie, Bd.: 20, 2001: S. 747f.

89 Pruner-Bey: Die Weltseuche Cholera oder die Polizei der Natur, 1851: S. 84.

90 Vgl. Mecklenburg: Was mag die Sanitäts-Polizei gegen die Cholera?, 1854: S. 38.

91 Ebd.: S. $38-45$.

92 Ebd.: S. 45.

93 Ebd.: S. 45.

94 Pruner-Bey: Die Weltseuche Cholera oder die Polizei der Natur, 1851: S. 86. 
Geburt, Sterbefälle, ja sogar auf die numerische Verschiedenheit der Geschlechter sich beziehen - bestimmten physischen Gesetzen unterworfen ist. Gleich daneben zeigt dasselbe Mittel im Lichte einer genauen Beobachtung - dass es dem Menschen bis zu einem gewissen Grade möglich wird, diese Gesetzte zu seinem Vortheile oder Nachtheile schwanken zu machen. Alle Culturstaaten Europas liefern Belege für die erste Seite durch eine vermehrte und länger lebende Bevölkerung. ${ }^{95}$

Mecklenburg war der Meinung, dass das einzige, was für die »Umwandlung des Proletariats « benötigt wird, Geld sei. Im Anschluss an diese These rechnet er vor, wie viel Geld ein cholerakranker Armer die Kommune koste, und dass es sich folglich mehr lohne, diesen durch gewisse Maßnahmen vor der Krankheit zu schützen. Vor allem, da nur die Proletarier eines Cholerabezirks zu berücksichtigen wären. ${ }^{96} \mathrm{Zu}$ nächst bedeute das, laut Mecklenburg, dass bei dem Herannahen der Cholera eine Liste aller Proletarier - »Tagelöhner, Hausinnen und kleiner Handwerker « erstellt werden müsse, die auch Angaben zur Größe der Familie, und Informationen zu ihrer Lebensweise: »ob sie dem Trunke ergeben usw. « enthalten solle. ${ }^{97}$ Dazu müsse jeder Fall der Krankheit sofort gemeldet werden. Während Mecklenburg noch die Lebensweise der »umzuwandelnden Proletarier « und deren Lebensbedingungen gleichermaßen einbeziehen will, indem er schreibt:

»Wer die Cholera-Epidemie beobachtet hat, wird dies zugeben, und die Überzeugung theilen, dass nichts leichter ist, als sich die Krankheit, durch heftige Erkältung und bedeutende Diätfehler, absichtlich zuzuziehen. Schon, dass das Proletariat so unverhältnismäßig ergriffen wird, weist auf äussere Ursachen hin; $[\ldots] \ll^{98}$

so hält Pruner-Bay die Einbeziehung der Diät in statistische Berechnungen über die Cholera dagegen eher für schwierig:

»Viel schwieriger ist es, den Einfluss von Speis und Trank, abgesondert von den erwähnten schädlichen Verhältnissen, auf die Steigerung und Verminderung des Choleracontingentes zu bestimmen. ${ }^{99}$

Die Aufforderung, die Regierung solle von ihren sanitäts-polizeilichen Maßregeln, der Quarantäne und der Isolation zurücktreten, bedeutet alles andere als zu sagen: >Hört auf zu regieren!< Nein, es sagt eher: >Ihr setzt zu spät, zu klein, zu beschränkt an mit eurer Regierung, weil ihr den Gegenstand, den ihr regiert, noch nicht in einem richtigen Zusammenhang erkennen könnt.< Sie sagt außerdem, das Ziel einer vollständigen Lösung des Problems übersteige die Möglichkeiten einer Regierung, sie müsse ihre Begrenzung im Hinblick auf einen unbegrenzten Gegenstand einsehen.

95 Ebd.: S. 111.

96 Vgl. Mecklenburg: Was mag die Sanitäts-Polizei gegen die Cholera?, 1854: S. 46f.

97 Ebd.: S. 47.

98 Ebd.: S. 37.

99 Pruner-Bey: Die Weltseuche Cholera oder die Polizei der Natur, 1851: S. 96; [zu Diät]: S. $96-99$. 
Die Rationalität und die Wissensbezüge, die mit der Statistik möglich werden, sind keine disziplinären, sondern entsprechen einer gouvernementalen Logik. Diese bestätigt auch der Umstand, dass Pruner-Bey nicht die enge Medizin, sondern die Hygiene als eine geeignetere Wissenschaft über den zu regierenden Gegenstand hält:

»Mit Recht macht die Heilkunde Anspruch auf einen bedeutenden Theil am Verdienste der Errungenschaft - aber in einer anderen Art als vielleicht noch manchem dünkt. Es ist nicht im engen Kreise des Krankenbettes, es ist auf dem unerschöpflichen Felde der allgemeinen Hygiene, wo sich dasselbe geltend macht. $\ll^{100}$

Statt der »Austilgung der Cholera « (Brefeld) geht es ihm um die »Verminderung des Choleracontingentes «. Deshalb werfen die Vertreter der Polizei-Regierung dieser neuen, in Deutschland noch wenig einflussreichen gouvernementalen Regierungsökonomie auch Ungenauigkeit und Unentschlossenheit vor. Der Vorwurf wird andersherum mit dem Gegen-Vorwurf beantwortet, die Regierung habe durch Vernachlässigung eines riesigen Bereichs ihrer Verantwortlichkeit schon zu viel Zeit verloren.

»Gibt es nicht Millionen menschliche Wesen in der civilisierten Welt, welche alljährlich dieser Fahrlässigkeit ein Opfer werden? [...] Wie viel, wie unendlich viel kann und muss auf diesem Felde [der Hygiene] geschehen! $\aleph^{101}$

In Süddeutschland hatte man in Folge dieser Erfahrung relativer Erfolglosigkeit der »Anstalten der Abwehrung durch Sperrung von Häusern, Ortschaften, Districts- und Landesgränzen durch Cordons und Barrieren, so wie der Sicherstellung durch Contumazanstalten und Quarantainen, und [...] Putrificationsverfahren « ${ }^{102}$ während der Choleraepidemie in Norddeutschland 1831/32 bereits 1835, als die erste epidemische Welle quasi auf ihrem Rückweg Bayern erreichte, diese Maßnahmen zum großen Teil aufgegeben. Hufeland schrieb in einem Rückblick auf seine eigene Kindheit in München während der ersten Epidemie dort:

»Am 28. October 1831 wurde ein Gesetz erlassen, betreffend die Anwendung der Waffengewalt bei der Vollziehung der sanitätspolizeilichen Maassregeln zum Schutze gegen die Verbreitung der asiatischen Cholera. Alle Maassreglen waren den in Norddeutschland angenommenen nachgebildet, und streng contagionistisch. Als aber alle diese Maassregeln in Norddeutschland und anderen Ländern nicht den geringsten Erfolg zeigten, glaubte man in Bayern sich auf den entgegengesetzten Standpunkt stellen zu müssen. ${ }^{103}$

100 Ebd.: S. 111.

101 Ebd.: S. 113.

102 Vgl. Harleß: Die Indische Cholera nach allen ihren Beziehungen, geschichtlich, pathologisch, diagnostisch, therapeutisch und als Gegenstand der Staats- und Sanitäts-Polizei, 1831: S. 707.

103 Vgl. Pettenkofer: Ueber Cholera, mit Berücksichtigung der jüngsten Choleraepidemie in Hamburg, 1892: S. 35f. 
Was war der entgegengesetzte Standpunkt? Wie bereits gesagt, wäre es falsch davon auszugehen, dass sich die deutschen Anti-Kontagionisten verschiedenster Couleur vorwiegend als liberal, progressiv oder sogar auf sozialkritischem Feld verstanden. Die Einschätzung, dass die Cholera eine ansteckende Krankheit sei, galt von Seiten des Staates in weiten Teilen Deutschlands weiterhin als Doktrin. Allerdings gab es im Norden wie im Süden Deutschlands unter Ärzten und Mitgliedern einer gebildeten Oberschicht über die Cholera unterschiedliche Meinungen. Fast könnte man sagen, dass das Spektrum an Einschätzungen und medizinischen Theorien über Cholera in den deutschen Ländern, verglichen mit Großbritannien und Frankreich, sogar am breitesten war. ${ }^{104}$

»Als die Cholera im Jahre 1830 zum ersten Mal die Grenzen Europas überschritt, ein unbekanntes furchtbares Ungeheuer, in großen Sprüngen ihre Besuche machte, tauchten aus allen medicinischen Schulen sündfludartig Theorien zur Erklärung ihrer Verbreitung und ihres Ursprungs auf, chimärisch und phantastisch wie die Maßregeln zur Abwehr, die sie hervorriefen. $\ll^{105}$

\section{Einige deutsche Anti-Kontagionisten}

Es ist hier interessant zu bemerken, dass die Ansichten der Anti-Kontagionisten, die v.a. in Preußen eine >gefährliche< Gegenposition zur Politik des preußischen Staates einnahmen, sich so sehr auf so unterschiedliche Theorien über atmosphärische und klimatische Bedingungen oder tellurische Ursachen der Cholera, auf Dämpfe, die aus dem Boden aufstiegen usw., beriefen. Beinahe der Frage staatlicher Politik ausweichend, stand bei ihnen im Zentrum zu erforschen, welche Eigenschaften und Verhaltensweisen im Individuum selbst eine sog. Prädisposition und damit eine Anfälligkeit für die Krankheit ausmachte: »die Doctrin von der Prädestination, d.h. von der besonderen Empfänglichkeit für die Bedingungen der Krankheit « ${ }^{106}$. Die Fraktion der deutschen Anti-Kontagionisten war ihren Äußerungen nach in besonderem Maße auf die Selbst- und Körperpraxis, sowie die Lebensweise innerhalb eines engen und der moralischen Differenzierung dienenden, bürgerlichen Diskurses bezogen. Als Bürger fühlte man sich zu einer vernünftigen Lebensweise fähig und damit in der Lage sich vor der Krankheit zu schützen:

»Warum sind fast überall, und meine Erfahrungen im südlichen Rußland haben frühere Beobachtungen bestätigt, die wohlhabenderen Classen in ungleich geringerem Grade von der Cholera heimgesucht worden? «107

104 Die Cholera versuchte man atmosphärisch durch Klima oder »Electricität«, Galvinismus, Magnetismus, durch Gase aus dem Erdreich (tellurisch), durch Miasma, ein CholeraContagium oder sog »Infusionsthierchen«, die auf das Blut, die Verdauung oder das Nervensystem wirkten, zu erklären. Vgl. Siebenhaar, Friedrich Julius: Über die Cholera: in: JPA, 6.72=65.1831, S. $114-123$ : S. 114.

105 Behr: Die Cholera in Deutschland, 1848: S. 5.

106 Ebd.: S. 9.

107 Ebd.: S. 11. 
Obwohl praktische Erfahrungen solchen Thesen zumindest teilweise zu widersprechen schienen, lag für einige deutsche Anti-Kontagionisten, wie auch Dettke hervorhob, die Schuld für die Erkrankung in der falschen, unmoralischen, unvernünftigen und unhygienischen Lebensweise der Betroffenen - meistens der armen und arbeitenden Bevölkerung -, die als besonders anfällig für die Cholera eingestuft wurde. ${ }^{108}$ Man befand sich hier im Modus bürgerlicher Selbstvergewisserung und Selbstproduktion. Wenn es etwas Spezifisches in der Interpretation der Cholera in Deutschland gab, dann war es diese idealistische Projektion der aufklärerischen Ambitionen des Bürgertums zur Selbstregierung auf die Cholera. Die weit verbreitete, aus diätetischen Betrachtungen gezogene Ansicht, dass Leidenschaften und starke Gemütsregungen den Ausbruch der Cholera in einem Körper erheblich förderten, machte die Kontrolle im Sinne einer Herrschaft der Vernunft über den Körper und vor allem über die Gefühle zum Mittel der Prävention gegen die Cholera. ${ }^{109}$ Dieser bürgerliche Diskurs, der das persönliche Verhalten zur Prävention gegen die Cholera mit bestimmten Idealen der Subjektivität verknüpfte, war im Vorfeld der ersten Ausbrüche der Krankheit bereits sichtbar gewesen. Zu diesem Zeitpunkt wurde weniger auf Klassenunterschiede als auf Unterschiede von Nationen verwiesen, was deren $>$ Kultiviertheit<, >Fortschrittlichkeit< und >Zivilisiertheit< anging. In Deutschland bedeutete eine anti-kontagionistische Position zu vertreten, keinesfalls eine grundsätzlichere liberale Kritik am absolutistischen Staat und der Regierungspraxis des Königs zu formulieren, wie schon angedeutet. Einer der bekanntesten Anti-Kontagionisten, Sachs, schrieb 1832:

»Die Hoffnung, dass bedeutende, erleichternde Veränderungen in den getroffenen Schutzmaassregeln vielleicht noch ausgeführt werden dürften, hat sich bereits gerechtfertigt. Ertragen wir demnach willig die Beschränkungen, welche je nur zum Besten Aller angeordnet wurden, meiden wir namentlich jedes Aergerniss, und beherzigen wir auch jetzt wie immer, die trefflichen Worte, die unser stets väterlicher und fromm gesinnter Herrscher an uns richtet. «110

Die moralisch-diätetische Ansicht dieser Ärzte ließ zwei Varianten zu. Erstens, die Verbesserung der Menschen zur Minderung ihrer Anfälligkeit für die Cholera, indem man sie zu einem bestimmten Verhalten und zu einer bestimmten Lebensweise brachte. Zweitens ermöglichte dieser Diskurs eine eher philosophische, natur- und kulturgeschichtliche Erklärung der Krankheit, die nichts weiter tat, als die Seuche als eine Art >Reinigung <, als einen heilsamen Schock zu deuten, der in Folge die Verbesserung der Gesellschaft selbst herbeiführen würde. Letzteres war in Frankreich noch verbreiteter, wo die bürgerliche Presse und selbst die Académie Royale de Médecine, teilweise ein positives und >reinigendes< Verständnis, sogar von den so »großen und gewaltsamen Ereignissen « wie den Revolutionen oder eben den Seuchen, besaß. ${ }^{111}$ Die Revolution auf politischer Ebene sei möglicherweise unangenehm, aber kultur-

108 Dettke: Die asiatische Hydra, 1995: S. 301.

109 Vgl. etwa Burdach: Uber den Einfluß der Gemütsbewegungen auf die Entstehung der Cholera, 1832: S. 87.

110 Sachs: Tagebuch über das Verhalten der bösartigen Cholera in Berlin, 1831: 5. 4.

111 Vgl. Académie Royale de Médecine: Rapport sur le choléra-morbus I, 1831: S. 4. 
geschichtlich notwendig, und so seien es die großen Epidemien auf der Ebene der physischen Verbesserung eben auch. Welches Gewicht bei den Statistiken auf die >Anfälligkeit< der ärmeren und arbeitenden Klasse gelegt wurde, unterschied sich bei den Gegnern der Kontagiositäts-These von ihren Apologeten. Es bedeutete, der allgemeinen Definition der >pestartigen < Krankheit Cholera den Rücken zu kehren und anderen, pathologischen, lokalen, diätetischen und sozialen Faktoren eine größere Bedeutung beizumessen. Die Cholera als die »Krankheit des Proletariats ${ }^{112} \mathrm{zu}$ begreifen, konnte einerseits bedeuten, sie auf die »Unfähigkeit, [der Armen und Arbeiter] sich diätetischen Regeln zu unterwerfen ${ }^{113}$ zurückzuführen, oder sie zum Anlass zu nehmen, die schlechten objektiven Lebensbedingungen der Arbeiter zu problematisieren. Die Anfälligkeit für die Cholera sei »um so verderblicher, je schlechter die Nahrungsverhältnisse, je grösser die Ueberfüllung und Unreinlichkeit, je feuchter und enger die Wohnungen ${ }^{114}$, schrieb Medicinal-Rath Carl-Friedrich Koch 1868.

Die eine Gruppe, die eher praktisch tätigen Anti-Kontagionisten, blickten auf dem hygienischen Feld auf die Unterscheidung von sozialen Lebensbedingungen, die sie, wie schon gesagt, eher in einzelnen Fällen in einen engeren Zusammenhang mit dem Problem mangelnder Selbstpraxis brachten. ${ }^{115}$ Dagegen konzentrierte sich eine andere, mehr philosophisch geprägte Gruppe von anti-kontagionistischen Medizinern eher auf die Vermutung, dass die Cholera auf eine Schwäche des Geistes, der geistigen Herrschaft über den Körper und die Gefühle, bzw. des zentralen Nervensystems über das vegetative usw. zurückzuführen sei. Letztere lieferten damit nur eine andere Form der Erklärung für die prozentual stärker betroffenen Angehörigen der ärmeren und arbeitenden Klassen.

Dettke zitiert ebenfalls einen interessanten Text aus der Cholerazeitung von Königsberg aus dem Jahr 1832. Der Text interpretiert die Symptome und pathologischen Veränderungen im Körper einer an Cholera erkrankten Person als eine Art der Rebellion des Körpers gegen das Hirn - der Untertanen gegen den König. Dazu muss gesagt werden, dass die meisten Menschen, die an Cholera erkrankten, an der Folge des Flüssigkeitsverlustes und wegen der dadurch bedingten Verdickung des Blutes an einem Gehirnschlag u.ä. starben. ${ }^{116}$ Die Macht der Vernunft und die geistig-moralische Herrschaft über den Körper und die Leidenschaften waren die besten Mittel ge-

112 Ebd.: S. 9.

113 Koch, Dr. C.F: Die Cholera-Epidemie des Regierungsbezirks Merseburg im Jahre 1866. Nach amtlichen Ermittelungen, 1968: S. 8.

114 Ebd.: S. 9.

115 Damit wiedersprach er z.B. Pettenkofer, der gemeint hatte, die »meisten Erkrankungen seien allerdings in tief gelegenen Häusern vorgekommen «. Er war der Meinung »nicht im Grundwasser, sondern in den Schädlichkeiten eines unreinlichen Proletarierthums « läge der Grund für die Mortalität unter den Armen. Vgl. ebd.: S. 9.

116 Vgl. Dettke: Die asiatische Hydra, 1995: S. 302. - Viele Ärzte sowohl in Deutschland, Frankreich als auch in England beschrieben immer wieder, wie das Blut im fortgeschrittenen Zustand der Krankheit dunkel und zähflüssig wurde. Aderlass war zu einem frühen Zeitpunkt der Krankheit - wenn das Blut noch flüssiger war - allem Anschein nach zumindest teilweise ein Mittel, um den Tod hinauszuzögern und manchmal auch das Leben des Patienten zu retten. 
gen die Cholera, wie auch Burdach schrieb. ${ }^{117}$ Diese grundsätzliche Logik stützten auch eher pathologisch ausgerichtete Beschreibungen der Cholera, wie z.B. von den Ärzten Hübenthal oder Lincke:

»Vielfältige Beobachtungen berechtigen uns zu dem Schluss, dass nur ein zu Störungen geneigtes Gefäßsystem im Einklang mit einem leicht zu deprimierenden Nervensystem die Diathese der fraglichen Krankheit bedinge. ${ }^{118}$

Lincke gab zu, eine spekulative theoretische Erklärung der Cholera liefern zu wollen:

»Die Erscheinung der pandemischen Cholera wird eine wichtige Epoche in der Geschichte der Medizin ausmachen. Jeder gebildete Arzt, der nicht roher Empirie anhängt und die Heilkunde nur als Metier treibt, hat sich die Frage aufgeworfen, welches Organ wohl der Sitz, und was die Natur der Krankheit sei.«119

Ferner sei eine weitere Frage, welcher Zustand der Organe diese empfänglich für die Krankheit mache. ${ }^{120}$ Linckes Überlegungen führten - ähnlich wie bei Hübenthal - zu dem Schluss, dass der »Sitz der Krankheit« nicht etwa das Verdauungssystem, allerdings auch nicht das Gefäßsystem sei, dass sie weder eine Gallenkrankheit, ${ }^{121}$ noch eine Entzündung des Darms sei ${ }^{122}$, sondern, dass ihr Sitz lediglich im Nervensystem liege. ${ }^{123}$ Die Cholera sah er eher als eine Art Nervenkrankheit - eine »Affizierung des Nervensystems «, bei welcher Lincke den Prozess der Krankheit als eine Art Revolution des vegetativen Nervensystems gegen das zentrale Nervensystem beschrieb. ${ }^{124}$ Das Miasma, das die Krankheit auslöse, sei allerdings, laut Lincke, nur eine Art Stimulus. Als wichtigste Frage betrachtet er daher, wie die Krankheit von »dem Centralende des vegetativen Nervensystems die eigenthümlichen Zufälle der Cholera zu Stande $\ll^{125}$ bringe.

»[D]as Erste was es thut, daß es in dem Organe, wo es seinen Sitz hat, Empfindungen erregt, die den Grund von der Entstehung der Krankheit selbst, abgeben, und in nichts anderem weiter zu suchen sind. ${ }^{126}$

117 Vgl. Burdach: Uber den Einfluß der Gemütsbewegungen auf die Entstehung der Cholera, 1832: S. 87.

118 Hübenthal, C.P.W.: Darstellung und Behandlung der orientalischen Cholera, von der Persischen Gräze: in: JPA, 1.66=59, 1828, S. 88 - 103: $102 f$.

119 Lincke: Versuch das Wesen der pandemischen Cholera zu erklären, 1833: S. 3.

120 Vgl. ebd.: S. 2.

121 Vgl. ebd.: S. 4 f.

122 Vgl. ebd.: S. 12.

123 Vgl. ebd.: S. 56.

124 Ebd.: S. 57.

125 Ebd.: S. 57; vgl. auch S. 64.

126 Ebd.: S. 57. 
In Folge der nervlichen Erregung würden die Darm- und Magentätigkeit in einer Weise zu Zuckungen und krampfartigen Bewegungen angeregt, dass permanent jeder Inhalt ohne Verdauung und alle Flüssigkeit aus dem Körper befördert würde. Ähnlich werden von ihm auch der Einfluss des vegetativen Nervensystems auf Herz, Lunge etc. die für die verschiedenen Symptome der Cholera zu erkennen sind, beschrieben. ${ }^{127}$

Das zerebrale Nervensystem sei nicht betroffen, außer in Folge der Verdickung des Blutes, des Mangels an Sauerstoffe etc. Es träten Schwindel und Kopfschmerzen auf, auch Müdigkeit. Aber der Arzt dürfe, laut Lincke, den Patienten auf keinen Fall einschlafen lassen, das Gehirn des Kranken müsse gerade wach gehalten werden: $»$ Wenn der Kranke nicht in Folge eines Cerebralhirnschlags sterben soll. « ${ }^{128}$ Die Behauptung, dass allein die Angst vor der Cholera die Krankheit auslösen und daher die Verbreitung der Angst vor der Krankheit selbst quasi eine »moralisches Contagion ${ }^{129}$ sei, war eine These, die bei den Anti-Kontagionisten in Deutschland besonders weit verbreitet und in den 30er Jahren z.B. auch von der Bayrischen Regierung übernommen wurde. Die Idee der »geistigen Ansteckung « und die durch eine Schwäche des Geistes bedingte Anfälligkeit für die Krankheit lassen sich auch hier in das grundsätzliche Verständnis von Subjektivität und dem Ideal einer vom individuellen Geist und der Vernunft ausgehenden Selbstregierung einfügen. Bereits als die ersten Berichte des Ausbrechens der Cholera in Astrachan nach Preußen drangen, behaupteten einige Ärzte, u.a. Friedrich Hecker, zuerst, dies seien nichts weiter als gefährliche Gerüchte von Anhängern der Homöopathie, um »)Europa mit dem Schrecken einer neuen verheerenden Krankheit zu erfüllen. $«{ }^{130}$ Laut Max Pettenkofer, der erste deutsche Professor für Hygiene, der im letzten Drittel des 19. Jahrhunderts zum Kopf einer eher sozial-liberalen und progressiven Strömung von Anti-Kontagionisten ${ }^{131}$ avancierte, zitierte in einem Rückblick auf die erste Epidemie in Bayern die dort am 10. September 1836 erlassene »Ministerialentschliessung die asiatische Brechruhr betreffend «. Nach dieser »sind Furcht und Niedergeschlagenheit des Gemüthes die sichersten Verbündeten und die gefährlichesten Träger der in ihrem eigentlichen We-

127 Vgl. ebd.: S. 74- 95.

128 Ebd.: S. 97.

129 Behr: Die Cholera in Deutschland, 1848: S. 12.

130 Hecker zitiert nach Rehmann, J., Russ. Kaiserl. Staatsrath etc.: Erklärung die ostindische Cholera zu Astrachan betreffend: in: JPA, 1.66=59, 1828, S. 124 - 130: S. 124. Daraufhin verteidigte sich der Autor des von Hecker kritisierten Berichts 1828 in Hufelands Journal: »Diese [einige Ärzte, die Anhänger der Homöopathie in Grusien] haben jedoch mit der Cholera in Astrachan nichts zu thun gehabt; und die Ärzte, welche diese Seuche in jener Stadt beobachtet, behandelt und beschrieben haben, sind nicht nur ruhige, vernünftige, von jeder Systemsucht entfernte praktische Beobachter; sondern auch sehr gewissenhafte und würdige Staatsdiener erwiesen. [...] Konnten wir uns wohl alle vereinigt haben, um der Welt ein gigantisches medizinisches Mährchen dieser Art aufzubinden?« (Ebd.: S. 129f.)

131 Dagegen kann Sachs eher zu einer auf Diätetik gerichteten Kritik gerechnet werden, die eher auf die Verteilung von Regierungsmacht auf Staat, Medizin und Subjekte zielte, denn als Kritiker am absolutistischen Staat und seiner Politik. 
sen noch nicht vollständig ergründeten, in ihren Erscheinungen aber ziemlich genau constatierten Brechruhr. «132

»Oberster Grundsatz muss es daher sein, bei Annäherung sowohl, als auch bei wirklichem Vorhandensein dieser verderblichen Krankheit Alles zu vermeiden, was Beängstigung verbreiten, und sonach die moralische Empfänglichkeit erzeugen oder befördern könnte. Die königliche Kreisregierung, Kammer des Innern, in Verbindung mit ihrem Kreismedicinal-Ausschusse wird sämmtliche Polizei- und Sanitätsbeamte rechtzeitig hierauf aufmerksam machen und selbe entsprechend belehren. $\ll^{133}$

Das bayrische Staatsministerium des Innern ging laut Pettenkofer sogar soweit, eine Belehrung für Nichtärzte - »also für das Publicum« - über die epidemische Brechruhr amtlich bekannt zu machen. In dieser wollte man die Menschen über die Annahme der Kontagiosität beruhigen und empfahl ihnen ohne jede Sorge, die an Cholera erkrankten Familienmitglieder zu Hause zu pflegen: »>Familienglieder, Angehörige und Dienstboten können übrigens ohne jede Furcht vor Ansteckung dem Kranken jeden nötigen und nützlichen Dienst leisten $<.{ }^{134}$ Laut Pettenkofer war ausgerechnet diese Epidemie, die bald darauf (1836/37) München heimsuchte, die mildeste aller dort aufgetretenen Choleraepidemien, obwohl »alle Maassregeln« die man einleitete, »ein Hohn auf die contagionistische Lehre waren «. ${ }^{135}$

»Damals kannte man keine Cholerafurcht. Man wusste noch nichts von Bacterien und leitete die Cholera nicht vom Kommabacillus, sondern vom Genius epidemicus ab, von dessen himmlischem Wesen man getrost erwartete, dass er uns bald wieder gnädig sein werde. «136

Die weniger religiösen Vertreter der Anti-Kontagionisten beruhigten sich, wie schon gesagt, eher mit der Gewissheit einer guten »cholerafesten « Lebensweise, durch das Vermeiden nebliger Nächte, der Abend- und Morgenluft, durch eine entsprechende Diät und eine entsprechende Kleidung aus Flanell v.a. durch das Warmhalten der Füße und des Bauches. ${ }^{137}$

»Man hat allerdings und nicht mit Unrecht behauptet, daß die Choleraangst durch die beständige Erinnerung der Präventionsmittel nur noch erhalten und so der Gesunde zu sichern Opfer der indischen Würgerin werde. Dennoch wird Niemand in Abrede stellen, daß die Vermeidung Durchfall erzeugender Speisen, eine möglichst geordnete Lebensweise, der mäßige Genuß ei-

132 Pettenkofer: Ueber Cholera, mit Berücksichtigung der jüngsten Choleraepidemie in Hamburg, 1892: S. 37.

133 Bayerisches Staatsministerium des Innern zitiert nach ebd.: S. 37.

134 Bayerisches Staatsministerium des Innern zitiert nach ebd.: S. 37.

135 Ebd.: S. 38.

136 Ebd.: S. 39.

137 Behr, Dr. Otto: Die Cholera in Deutschland. Populaire Belehrungen über das Auftreten und die Bekämpfung dieser Seuche, 1848: S. 35. 
nes guten Rotweins, so wie das Trinken eines aromatischen Aufgusses von Camillen mehr geeignet sind die Krankheit fern zu halten.«138

Heinrich Heine empfand die Angst und darauf genommene Flucht seiner »Landsleute« aus dem von Cholera heimgesuchten Paris äußerst lächerlich. Schließlich wisse jeder, dass die Cholera vor allem die Armen befalle, schrieb er. Heine ging so weit, den Flüchtenden zu unterstellen, sie würden an ihrem eigenen Hochwohlgeborensein und Reichtum zweifeln und deshalb die Stadt verlassen. Weitaus »edler« schätzte er die Reichen, die in Paris blieben und noch mehr schätzte er die, die an ihre Dienerschaft Bauchbinden aus Flanell verteilten - zum Schutz gegen die Cholera. ${ }^{139}$ Heine erkannte sehr wohl den Bedeutungswandel wie auch den religiösen und moralischen Charakter der bürgerlichen Einstellung zur Diät und richtigen Lebensführung und schrieb:

»Die Sitten der alten Chevalerie sind nicht erloschen; sie sind nur ins Bürgerliche umgewandelt; hohe Damen versehen ihre Kämpen jetzt mit minder poetischen, aber gesündern Schärpen. Wir leben ja nicht mehr in den alten Helm- und Harnischzeiten des kriegerischen Rittertums, sondern in der friedlichen Bürgerzeit der warmen Leibbinden und Unterjacken; wir leben nicht mehr im eisernen Zeitalter, sondern im flanellenen. Flanell ist wirklich jetzt der beste Panzer gegen die Angriffe des schlimmsten Feindes, gegen die Cholera. >Venus würde heutzutage<, sagt >Figaro<, >einen Gürtel von Flanell tragen.< Ich selbst stecke bis am Halse in Flanell und dünke mich dadurch cholerafest. Auch der König trägt jetzt eine Leibbinde vom besten Bürgerflanell. $\ll^{140}[\ldots] »$ So hat jeder seinen Glauben in dieser Zeit der Not. Was mich betrifft, ich glaube an Flanell. Gute Diät kann auch nicht schaden. $\ll^{141}$

Was allerdings die deutschen Länder betraf, blieb die anti-kontagionistische Strömung tendenziell marginalisiert und ihr Einfluss auf die staatlichen Politiken und Techniken gegen die Cholera, von wenigen Ausnahmen abgesehen, gering. Eher wurden sie weiterhin als gefährliche Gegner der staatlichen Maßnahmen gegen die Cholera abgebildet. ${ }^{142}$

»In der letzten Epidemie um Jahre 1852/53 war die Ausführung der als erforderlich erkannten Maassregeln schon erheblich erleichtert. Die Zahl der Anti-Contagionisten hatte sich bedeutend gemindert, andere fingen an, in ihrem Glauben von der Nicht-Uebertragbarkeit der Seuche und der Wirkungslosigkeit der ergriffenen Maassreglen wankend zu werden. $\ll^{143}$

Vor allem im Zuge der zweiten epidemischen Welle Mitte der 50er Jahre des 19. Jahrhunderts setzten sich Strategien durch, die bürgerlichen Diskurse staatsaffirmativ zu transformieren. Die Botschaft vieler Anti-Kontagionisten an den Staat, er müsse

138 Vgl. Behr: Die Cholera in Deutschland, 1848: S. 34.

139 Vgl. Heine: Artikel VI: in: Französischen Zustände, 1833 [1832]: S. $65 f$.

140 Ebd.: S. 67.

141 Ebd.: S. 69.

142 Vgl. Dettke: Die asiatische Hydra, 1995: S. 297f.

143 Brefeld: Die endliche Austilgung der asiatischen Cholera, 1854: S. 57. 
doch weit mehr regiert werden, als man es zur Zeit der Pest getan hatte, wurde aufgegriffen. Dabei mag auch der von Dettke hergestellte Zusammenhang mit gesellschaftlichen Umbrüchen, die wenige Jahre zuvor durch den Weberaufstand 1844 und die Revolution von 1848 gegeben waren, als aufschlussreich angesehen werden. ${ }^{144}$

\section{Die Suche nach den Ursachen und Ausdehnung des Regierungswissens}

Obwohl die Regierung in Preußen grundsätzlich an der Richtigkeit ihrer militärischen Mittel festhielt und auch während der zweiten epidemischen Welle versuchte, diese - so weit es ging - umzusetzen, propagierte die Regierung mehr und mehr die Desinfektion als eine geeignete Technik der Sanitäts-Polizei gegen die Cholera und schrieb den Polizeibeamten zunehmend auch die Aufgabe der genauen statistischen Erfassung aller Fälle in den jeweiligen Polizeidistrikten zu. ${ }^{145}$ Schon nach der ersten Choleraepidemie begann man in Deutschland damit, immer detailliertere Datensammlungen zu erstellen, die möglichst alle Theorien der Übertragung und Verbreitung berücksichtigen sollten. Mitte des 19. Jahrhunderts wurde diese Arbeit des Sammelns von Daten zum Hauptarbeitsfeld der Epidemiologie, das nach und nach in der deutschen Diskussion um die Cholera an Bedeutung gewann. Sie bedeutete zumindest teilweise eine Art >Befreiung < der Regierung von dem disziplinären Verfahren der Veridiktion der Medizin, von deren Forschung und Theorien. Die Statistik produzierte Wissen für die Regierung und lieferte ein Mittel zur praktischen Prüfung der Regierung, ihrer Techniken und Kompetenz. Sie bot ein Mittel, den Erfolg und die Ökonomie hygienischer, polizeilicher Praxis in ihrer Wirkung auf die Bevölkerung sichtbar zu machen.

Die Ärzte und Hygieniker August Hirsch und Max Pettenkofer forderten 1872 die »Bildung einer Sachverständigen-Commission«, damit diese einen »gemeinsamen Untersuchungs- und Beobachtungsplan zur Erforschung der Verbreitungsart der Cholera« entwerfe, und um nach dem »Erlöschen der Epidemie« auf der Grundlage dieser Untersuchungen, »Vorschläge zur Ergreifung praktischer Maassregeln gegen die Weiterverbreitung der Cholera « zu formulieren. Diese Kommission wurde am 29. April 1873 durch den Bundesrat beschlossen. Im Juli darauf wurden fünf sachverständige Mitglieder zum »Zwecke einheitlicher systematischer Forschungen über die Verbreitung der Cholera und die Mittel zu deren Fernhaltung und Bekämpfung« durch den Bundesrat in die Kommission berufen. ${ }^{146}$

Mit dem statistischen Wissen war, so schien es, ein Mittel gefunden worden, den Erfolg von Regierungstechniken und Maßnahmen gegen die Cholera zu messen, zu beurteilen und zu vergleichen. Dieses Instrument des Vergleichs der Regierungen hatte vor allem auch auf der internationalen Ebene eine Art Diskurs um das gute Re-

144 Vgl. Dettke: Die asiatische Hydra, 1995: S. 7f.

145 Vgl. Brefeld: Die endliche Austilgung der asiatischen Cholera, 1854: S. 2 f.

146 Vgl. Die Choleracommission des deutschen Reichs: Pettenkofer, M.; Boeger; Hirsch; Günther; Volz, R.: Untersuchungsplan zur Erforschung der Ursachen der Cholera und deren Verhütung. Denkschrift, verfasst im Auftrag des Reichskanzleramts von der Choleracommission für das deutsche Reich: in: VöG, 5.1873, S. 591 - 616: S. 591f. 
gieren und die besten Politiken zur Bekämpfung der Cholera vereinfacht, indem es die Angleichung der Rationalitäten von Regierungen bedingte. Die vorrangig epidemiologische Sicht auf die Cholera war beeinflusst durch den Aufstieg der britischen Epidemiologie. Dies zeigt sich z.B. auch in einem Artikel des Sanitätsrats Semon aus der Deutsche Vierteljahrsschrift für öffentliche Gesundheitspflege über die Choleraepidemie von 1871 in Danzig.

»Der englische Ausspruch: >Die Cholera sei der beste Gesundheitsrath $<$, dessen Bestätigung England durch die Achtundvierziger Epidemie an sich so glänzend erfahren, scheint auch für Königsberg Geltung erlangen zu wollen. ${ }^{147}$

Auf der anderen Seite blieb, wie auch in diesem Artikel von Semon in der deutschen Interpretation, die schwerpunktmäßige Frage nach dem »Causalnexus zur Entstehung und Verbreitung der Cholera ${ }^{148}$, der der Logik der Epidemiologie zwar nicht entgegenstand, aber für sie relativ nebensächlich war, bestehen. Die $1873 \mathrm{im}$ neu gegründeten Deutschen Reich eingesetzte und von Hirsch und Pettenkofer geleitete »Cholera-Commission «, deren Hauptaufgabe die möglichst umfassende statistische Erfassung der Epidemien im Deutschen Reich sein sollte, musste sich ausdrücklich dafür rechtfertigen, so viele Faktoren zu berücksichtigen, deren direkte, kausale Verbindung mit der Cholera zu bezweifeln waren.

»Die Commission möchte ferner gleich Eingangs einem Einwande begegnen, der vielleicht erhoben werden könnte, nämlich, dass der folgende Untersuchungsplan sich grösstenteils nur mit Gegenständen befasse, welche durchaus nicht spezifisch für die Cholera sind, sondern mehr oder weniger bei jeder epidemischen Krankheit in Frage kommen. ${ }^{149}$

Es blieb für deutsche Ärzte, die die Diskussion um die Ursachen und besten Mittel gegen die Verbreitung der Cholera anführten, eine Schwierigkeit, aus statistischen Wahrscheinlichkeiten ungefähre Maßnahmen und Techniken abzuleiten. So sei etwa, wie es in dem Artikel von Semon zur Cholera in Königsberg heißt, der Bau einer »Canalisation der Stadt« und eines »Schwemmcanalsystems«, die ausgerechnet ein Vertreter der physikalisch-ökonomischen Gesellschaft der Stadtverordnetenversammlung empfohlen hatte ${ }^{150}$, ohne eine klare Theorie und Sicherheit für den kausalen Zusammenhang von Kanalisation und Cholera schwer zu rechtfertigen. ${ }^{151}$ Und dieser Beweis sei eben, laut Semon, nicht gegeben. Die englische Praxis, von Statistiken auf einen zumindest indirekten Zusammenhang zu schließen, war für Semon

147 Semon: Verbreitung der Cholera von 1871: in: VöG, 4.1872, S. 169 - 184: S. 178.

148 Ebd.: S. 174.

149 Die Choleracommission des deutschen Reichs: Pettenkofer, M.; Boeger; Hirsch; Günther; Volz, R.: Untersuchungsplan zur Erforschung der Ursachen der Cholera und deren Verhütung. Denkschrift, verfasst im Auftrag des Reichskanzleramts von der Choleracommission für das deutsche Reich: in: VöG, 5.1873, S. 591 - 616: S. 594.

150 Vgl. Semon: Verbreitung der Cholera von 1871: in: VöG, 4.1872, S. 169 - 184: S. 178.

151 Vgl. ebd.: S. 179. 
nicht akzeptabel, wie er am Beispiel der Stadt Danzig ausführt. ${ }^{152}$ Semon rief dazu auf, bei der Beurteilung genau und objektiv wissenschaftlich vorzugehen und nicht zu eilige und bequeme Schlüsse zu ziehen und äußerte seinen Zweifel an dem engen Zusammenhang von Kanalisation und Choleraepidemien in Städten. ${ }^{153}$ Nach Semon sei »das Hauptgewicht auf den diesmal eigentümlichen Gang der Cholera zu legen, womit er ihre Route auf der Landkarte und die Verbreitung der Epidemie von Ort zu Ort meinte. Während man den »wichtigen sanitären Verbesserungen einen gewissen und nicht unbedeutenden Einfluss zuschreiben ${ }^{154}$ könne. Es bliebe nach Semon also noch, »die Beziehungen der Cholera zu den menschlichen Lebensverhältnissen, zu Luft, Wasser, Boden, Verkehr usw. genauer zu erforschen«, wofür die »während der Epidemie von 1871 gewonnenen Erfahrungen« eine »segenreiche Verwertung für die öffentliche Gesundheitspflege ${ }^{155}$ finden würden. Auch wenn man in Deutschland bei der Verwertung der allgemeinen Daten zur Begründung politischer Maßnahmen vorsichtig blieb, begann die Regierung unter dem Einfluss von u.a. Hirsch und Pettenkofer, ab den 1870ern sukzessiv Daten über die Choleraepidemien zu sammeln und funktionierte die medizinische Polizei von ihrer polizeilichen und militärischen Kompetenz in einen Desinfektions-, Datenerfassungs- und Informationsapparat um. Damit die Statistik als Technik wirksam einsetzt werden konnte, also eine Messbarkeit und Vergleichbarkeit von Regierung zu ermöglichen, war zunächst deren flächendeckende und einheitliche Anwendung im neu gegründeten Deutschen Reich vonnöten.

Diese ganze Auseinandersetzung zeigt sehr anschaulich, wie es um die vermeintliche Objektivität statistischer Datensätze bestellt ist. Die Statistik war nicht in der Lage, einen epistemologischen oder grundsätzlichen Bruch in einer Ordnung des Wissens und der Erkenntnis zu befördern. Sie kann vielleicht niemals dazu dienen, eine Erkenntnis zu erbringen, die nicht bereits im theoretischen Horizont der jeweilig konzipierten Statistik angelegt ist. Oder, sagen wir es so, sie kann Annahmen widerlegen, aber nicht die Grundlagen des Denkens, auf denen diese Annahmen beruhen. Demgemäß konzentrierte sich die statistische Erfassung in Deutschland in einem weitaus größeren Umfang auf Faktoren, die der Beweisführung der Übertragbarkeit der Cholera durch Personen und Gegenstände dienen konnten.

»Es war daher das Bestreben der Commission, für den Untersuchungsplan einen Rahmen aufzustellen, innerhalb dessen alle Thatsachen Platz finden können, welche nur immer Bezug auf die Ursachen und die Verbreitung der Cholera haben, abgesehen von den oft so verschiedenen und widerstreitenden Ansichten, zu welchen diese Tatsachen bisher geführt haben mögen. Ohne der Auffassung und Beurtheilung der Frage nach der specifischen Natur und Entstehung der Cholera auch nur im geringsten vorgreifen zu wollen, glaubt die Commission doch der überwiegend zur Geltung gelangten Ansicht von der Uebertragbarkeit der Cholera besonders Rechnung tragen zu müssen, und sie hat demgemäss für nothwendig gefunden, eine mehr ins Ein-

152 Vgl. ebd.: S. 183.

153 Vgl. ebd.

154 Ebd.: S. 184.

155 Ebd. 
zelne gehende strengere Zergliederung alles dessen anzustreben, was man bisher unter der Bezeichnung >Verkehr und Infection $<$ ganz allgemein zusammengefasst hat. $«^{156}$

Die Arbeit der Kommission fiel mit dem Ausbrechen der Cholera in einigen Orten des Deutschen Reiches zusammen, so dass sie nach wenigen Monaten gewisse Grundsätze bezüglich der Maßregeln aufstellte. Die bisher geltende bloße »Anzeigepflicht « von »Choleraanfällen « wurde nun zum Ausgangspunkt eines bürokratischaufwändigen Verfahrens. Angaben zum Medizinal-Verwaltungsbezirk, Bezirk, Wohnung mit Beziehung zur Straße, Hausnummer, Stockwerk, Zahl der Bewohner des Hauses, genaue Angaben zum Erkrankungsfall, möglicher Ort der Infektion, Name des Erkrankten, Geschlecht, Alter, Stand oder Gewerbe, bei Kindern unter 14 Jahren das der Eltern, bei Personen, die gewöhnlich außerhalb ihrer Wohnung arbeiten, auch der betreffende Aufenthaltsort (z.B. Werkstätte, Fabrik, Bergwerk etc., wo sie arbeiten) mussten angegeben werden, ebenso der Tag der Erkrankung und ggf. der Tag des Todes nachträglich den Behörden mitgeteilt werden. ${ }^{157}$

Wahre >Glücksfälle< waren aus Sicht der Hygieniker und Statistiker die Ereignisse, bei denen die Cholera in einer Kaserne oder in einer Anstalt ausbrach. Diese Haltung hatte schon früher die Transformation des >ärztlichen Blicks< und der damit verbundenen Entstehung der Methoden der klinischen Medizin in erheblichem Maße gefördert. ${ }^{158}$ Demnach waren die Formulare und Datenmengen, die man hier durch die Militärärzte erheben ließ, noch weitaus umfangreicher als man sie laut des Untersuchungsplans der Kommission zur Erfassung der Cholera in der normalen Bevölkerung durchführen konnte. Dort war man wegen des Umfangs der Erhebung auf die Mithilfe aus der Bevölkerung angewiesen und daher gezwungen, das Formular entsprechend einfach und nicht zu umfangreich zu gestalten.

»Eine nach allen Richtungen des von der Commission aufgestellten Untersuchungsprogramms erschöpfende Erhebung ist in keiner anderen Berufsclasse so zu ermöglichen, wie gerade im Militär, wo ein großer Bruchtheil der Bevölkerung in gleichem Alter unter gleichen stets zu controllierenden Verhältnissen lebt. « ${ }^{159}$

156 Die Choleracommission des deutschen Reichs: Pettenkofer, M.; Boeger; Hirsch; Günther; Volz, R.: Untersuchungsplan zur Erforschung der Ursachen der Cholera und deren Verhütung. Denkschrift, verfasst im Auftrag des Reichskanzleramts von der Choleracommission für das deutsche Reich: in: VöG, 5.1873, S. 591 - 616: S. 593.

157 Vgl. ebd.: S. 594f. Vgl. Abb. III.

158 »Sobald für die medizinische Erkenntnis Häufigkeitsverteilungen relevant werden, braucht man nicht mehr ein natürliches Milieu, sondern einen neutralen, in allen seinen Teilen homogenen Bereich, der ausnahmslos für jedes pathologische Vorkommnis offen ist und somit den Vergleich ermöglicht.« Foucault: Die Geburt der Klinik, 2008 [1963]: S. 123.

159 Vgl. Die Choleracommission des deutschen Reichs: Pettenkofer, M.; Boeger; Hirsch; Günther; Volz, R.: Untersuchungsplan zur Erforschung der Ursachen der Cholera und deren Verhütung. Denkschrift, verfasst im Auftrag des Reichskanzleramts von der Choleracommission für das deutsche Reich: in: VöG, 5.1873, S. 591 - 616: S. 597. 
Einige Jahre später schrieb ein Rezensent von Pettenkofers Bericht über den Fall eines Ausbruchs der Cholera in der Gefangenenanstalt Laufen:

»Wenn es wahr ist, dass es eine öffentliche Gesundheit giebt, nicht nur eine, welche die Summe der Gesundheitszustände aller Einzelnen einer bestimmten menschlichen Gesellschaft bildet, sondern eine öffentliche Gesundheit in dem Sinne, dass jeder Einzelne daran als an einer vorweg gebildeten Basis seines individuellen Wohlseins participirt, dass seine eigene private Gesundheit innerhalb sehr grosser Breiten von den Schwankungen der präexistierenden öffenlichen Gesundheit fast ganz und gar abhängt, wenn dieser Satz wahr ist, auf dem allein gegenüber der Sanitätspolizei die Berechtigung einer tiefer reichenden öffentlichen Gesundheitslehre und -pflege beruht, dann giebt es nicht leicht, klinisch gesprochen, einen schulgerechtern Fall für die Beobachtung und Studium einer acuten Störung jener öffentlichen Gesundheit eines concreten socialen Organismus, als das tragische Object des vorliegenden Berichts als diese Krankheitsgeschichte in folio, die Choleraepidemie in der Gefangenenanstalt Laufen. ${ }^{160}$

Pettenkofer hatte sich selbst über die Isolation, das Ausmaß an Kontrolle über alle »Lebensverhältnisse « in der Anstalt und der absolut gleichen Bedingungen, unter denen die Menschen in der Anstalt lebten, gefreut. Niemand in der Anstalt könne irgendetwas individuelles, wie seine eigene Kleidung mitbringen usw. Dies mache eine Untersuchung der Cholera an diesem Ort »mustergültig ${ }{ }^{161}$. Die Möglichkeit der Untersuchung der Anstalt erscheint geradezu wie die Untersuchung in einem Labor, wo man eine Reihe von unbekannten Variablen künstlich ausschließen kann. Trotz dieser so >optimalen< Bedingungen für die Untersuchung kann der Bericht nur eine Aussage im Sinne von Wahrscheinlichkeiten aussprechen, nämlich, dass der Sitz der Cholera vermutlich in dem Ort selbst zu finden sei, anstatt ihn an den Personen oder den Gegenständen, die in die Anstalt kommen oder sie verlassen, festzumachen. ${ }^{162}$

Die früheren Erhebungen zur Mortalität der Cholera, bei welcher man lediglich die Fälle der Erkrankten und Verstorbenen notierte, waren nichts im Vergleich zu den Ergebnissen dieser neuen Statistiken. Eine amtlicher Bericht über die Choleraepidemie 1873 in Berlin bestand beinahe ausschließlich aus Statistiken und Tabellen über Erkrankte, Gestorbene und Genesene unter Berücksichtigung ihres Alters, ihres Geschlechts und ihrer Beschäftigung. ${ }^{163}$ Außerdem enthielt der Bericht eine Topographie der Stadt und die örtliche Verbreitung der Krankheit, aufgegliedert nach den verschiedenen Polizeirevieren. ${ }^{164}$ Darüber hinaus verzeichnete der Bericht - ähnlich einer kriminologischen Untersuchung -, Orte und Personen, mit deren Hilfe man ver-

160 Geigel: Kritische Besprechung des Bericht der Choleracommission für das deutsche Reich. Die Choleraepidemie in der königl. bayrischen Gefangenenanstalt Laufen a.d. Salzach. Im Auftrage der Commission bearbeitet und veröffentlicht von Max v. Pettenkofer. Berlin [...] (Kritische Besprechung): in: VöG, 5.1873, S. 291 - 321: S. 291.

161 Ebd.: S. 319.

162 »Die Engländer haben das in Indien sowohl für Casernen als auch Gefängnisse schon seit Jahren erprobt. So oft dort in einem solchen Gebäude die Cholera ausbricht, ist movement (Ortswechsel) ihre Hauptparole.« Ebd.: S. 320.

163 Vgl. Müller: Cholera-Epidemie zu Berlin im Jahre 1873, Amtlicher Bericht, 1874.

164 Vgl. ebd.: S. 4f. 
suchte, den Weg der Ansteckung und die Verbreitung der Krankheit darzustellen. Einbezogen wurden die Berechnung der Inkubationszeit, die sehr verschieden sein könne. Vor allem aber ging es darum, die Wege und Kontakte und das Verhalten der einzelnen Personen, die zuerst erkrankten, genau nachvollziehen - darunter auch ihre Essgewohnheiten usw. ${ }^{165}$ Beobachtungen, nach denen etwa das Personal in Krankenhäusern und Heilanstalten nicht an der Cholera erkrankte und auch niemand von den Arbeitern, die die Gruben gereinigt hatten, wurden ebenfalls nicht anti-kontagionistisch zu deuten versucht, sondern auf die erfolgte »sofortige und gründliche Desinfection $\ll^{166}$ zurückgeführt.

Der Bericht spiegelt deutlich, dass man, was die statistische Erfassung und die praktischen Maßnahmen gegen die Epidemie betraf, keinen besonderen Wert auf die Übereinstimmung mit einer rein auf Kontagiosität setzenden Theorie legte. Dennoch zeigen besonders die Form der Praxis der Isolation (Absperrungen, Quarantäne etc.) und die massive Praxis der Desinfektion, dass die These der Kontagiosität der Cholera unabdingbar für einen Großteil der Maßnahmen der Regierung gegen die Krankheit blieb. Auch in dem Bericht der Cholerakommission von 1873 hieß es: »Wichtigste und praktischste Maassregel bei Cholera, wie bei allen Infectionskrankheiten ist die Desinfection. ${ }^{167}$ Desinfektion bedeutete etwas anderes als einfach nur Sauberkeit oder Hygiene, welche in einem eher quantitativen Sinne gedacht wurde und eine unbegrenzte Menge an verschiedensten Praxen vermischte. Die Hygiene war eine Ansammlung von Sicherungsvorkehrungen. Die Desinfektion dagegen war eine >Waffe<. Laut der deutschen Cholera-Kommission konnte alles zum »Gegenstand der Desinfektion « werden, »was möglicherweise Sitz des unbekannten Krankheitsstoffes der Cholera ist «. Hiermit war tatsächlich alles gemeint: Trinkwasser, Nahrung, Stuben, Häuser, Möbel, Geräte, Betten bis hin zu den Menschen als den potenziellen Überträgern. ${ }^{168}$ Die Kommission war der Ansicht, dass die »Versuche der Desinfection in beiden Richtungen zulässig und geboten, aber viel exacter als bisher durchzuführen sind. ${ }^{169}$ Oft seien in der Vergangenheit aus Geiz zu geringe Mengen angewendet worden. Empfohlene und zur Anwendung gebrachte chemische »Desinfectionstoffe« waren u.a. »Carbolsäure «, »Chlor und Chlorkalk«, »Aetznatron« und »Eisenvitriol «. ${ }^{170} \mathrm{Ab}$ Mitte des 19. Jahrhunderts begann man außerdem, zunehmend sozialreformerische Perspektiven in die Strategien gegen die Cholera einzubeziehen. Anti-kontagionistische Ärzte und Politiker deuteten zunehmend weniger auf die angebliche moralische Verkommenheit der Armen hin, sondern betonten mehr und mehr die Lebensbedingungen der von der Cholera am stärksten betroffenen armen und arbeitenden Bevölkerungsschichten. Die in Großbritannien durchgeführten sani-

165 Vgl. ebd.: S. $2-14$.

166 Ebd.: S. 16.

167 Die Choleracommission des deutschen Reichs: Pettenkofer, M.; Boeger; Hirsch; Günther; Volz, R.: Untersuchungsplan zur Erforschung der Ursachen der Cholera und deren Verhütung. Denkschrift, verfasst im Auftrag des Reichskanzleramts von der Choleracommission für das deutsche Reich: in: VöG, 5.1873, S. 591 - 616: S. 612.

168 Ebd.: S. 612.

169 Ebd.: S. 613.

170 Ebd.: S. 613ff. 
tären Verbesserungen in den Städten, und die statistisch messbaren Erfolge dieser Unternehmungen wurden von ihnen zum Vorbild gemacht und mit der Aufforderung an die Regierung verknüpft.

Pettenkofer rief in einer sehr deutlichen Anlehnung an britische Anti-Kontagionisten bzw. Lokalisten wie Cunningham die Regierung dazu auf, die Assanierung der Städte voranzutreiben, für sauberes Trinkwasser zu sorgen und andere Maßnahmen zu unternehmen, die der generellen hygienischen Situation v.a. der ärmeren Bevölkerung dienen sollte. Wie aber auch frühere Anti-Kontagionisten, wie Pruner-Bey oder Mecklenburg ${ }^{171}$, war Pettenkofer, indem er die sanitätspolizeilichen Maßregeln kritisierte, gezwungen zu betonen, dass die Regierung selbstverständlich etwas gegen die Cholera tun könne. Die staatliche Regierung wurde auf diesem Wege darauf aufmerksam gemacht, dass der Bereich, in dem sie regieren sollte und in dem sie als verantwortliche aktiv werden musste, nicht kleiner wurde, sobald sie zumindest auch den lokalen Einfluss und die Umweltbedingungen, die die Cholera begünstigten, stärker anerkannte. Sondern im Gegenteil: Wenn die Regierung dies erkannte, veränderte und lockerte sich der Druck unter dem sie aufgrund ihrer eigenen Rationalität gestandenen hatte und der sie immer wieder in einen Zustand der Krise und der Instabilität gebracht hatte. Als eine Regierung, die sich auf begünstigende Bedingungen konzentriert, muss kein Anspruch der Vollständigkeit, der > völligen Austilgung< der Krankheit und der absoluten Macht mehr erhoben werden. ${ }^{172}$ Mit der Anerkennung der Begrenztheit der Regierung und ihres Bezugs auf eine »Naturalität « ${ }^{173}$, erweiterte sich gerade der Bereich ihrer Aktivität. Der Bereich, in dem sie legitim Macht ausüben konnte, das Spektrum an Techniken, das ihr zur Verfügung stand, das Wissen, auf das sie zurückgreifen konnte, wurde größer. Mit der Anerkennung des grundsätzlichen relativen, graduellen Verhältnisses ihrer Aktivitäten zu den Ergebnissen, wie sie etwa statistisch durch die Senkung der Choleraerkrankungen und -tode darstellbar sind, passte sich die Regierung ihren neuen Existenzbedingungen an, entfernte sich von den Bedingungen der Staatsräson und näherte sich der Ökonomie einer moderneren Gouvernementalität an. Für diese Veränderung war sowohl eine Neuordnung des Verhältnisses der Regierung zu disziplinären Praktiken und disziplinären Verfahren der Veridiktion erforderlich, von denen besonders die Regierung durch die medizinische Polizei völlig durchzogen war. Denn es kam bei dieser Verschiebung der Regierungsrationalität in den deutschen Ländern nur ansatzweise und schwächer als in Frankreich, viel weniger noch als in England, zu einer Variante der strategischen Annäherung an moderne Verfahren der Gouvernementalität kam.

Tatsächlich sorgte die Bekanntmachung des Choleraerregers durch Robert Koch für eine gewisse Regression in der Entwicklung der auf Gesundheit gerichteten Regierungsrationalität und Praxis in Deutschland. 1884 hatte Koch die Ergebnisse seiner Forschungen und seine >Entdeckung< des »Kommabazillus« veröffentlicht, ohne Bezug auf die Publikation des italienischen Mediziners Filippo Pacini (1812 - 1883)

171 Mecklenburg: Was mag die Sanitäts-Polizei gegen die Cholera?, 1854: S. 48.

172 Vgl. Pettenkofer: Ueber Cholera, mit Berücksichtigung der jüngsten Choleraepidemie in Hamburg, 1892: S. 9.

173 Foucault: Geschichte der Gouvernementalität I, 2004 [1977 - 1978]: S. 502ff. 
und dessen Beschreibungen des Mikroorganismus zu nehmen. ${ }^{174}$ Der von Pettenkofer spöttisch benannte »Bacillenfang « war technisch gesehen ein Rückfall der Regierung in eine zu direkte Abhängigkeit von der Disziplin und der von Medizin und Polizei vorgeschlagenen Veridiktionsverfahren und Techniken. Sie war zugleich völlig symptomatisch für die andauernde Modernisierungskrise der deutschen Regierung. Mit der Aussage, die Cholera werde durch ein Bakterium verursacht, schien die Position der Ansteckung und auch die Maßnahmen der Quarantäne und Desinfektion kurzerhand bestätigt und der Feind, gegen den die Regierung ihre Untertanen >an den Grenzen und im Innern< zu schützen hatte, endlich ausgemacht. Eine weitere Rückverschiebung vollzog sich bezüglich des Ortes, an dem der Kampf gegen die Cholera geführt werden sollte: von der Bevölkerung und der Umwelt zurück auf den Körper. Nun war es wieder der Körper selbst, wo »wir selber mit recht kräftigen Schutzwehren ausgerüstet ${ }^{175}$ sind. Es fand gewissermaßen eine biopolitische Re-Medikalisierung statt, die jedoch völlig anders war als der frühere Bezug auf den Körper des Einzelnen. Der Einzelne war nun Gattungsmensch.

Pettenkofer kritisierte diese Entwicklung und die mit ihr verbundene Abwendung von der Hygiene und den Erkenntnissen der Epidemiologie und Sozialmedizin ${ }^{176}$ :

»Die Fragestellung ist heutzutage nur mehr, wie man diesen Bacillus beikommt, wie man ihn vernichtet oder wie man seine Verbreitung verhindert. Dieser Bacillenkampf hält man jetzt für die wesentlichste und einzig wirksame Prophylaxis, und ignoriert die grosse Reihe epidemiologischer Thatsachen, welche ganz entschieden gegen die Annahme einer einfachen Contagiosität der Cholera sprechen. Viele sehen nur mehr auf das Verhalten des Kommabacillus im Reagensglase oder auf der Platte oder in seinen Culturen und kümmern sich nicht im geringsten um das Verhalten der Cholera bei ihrer thatsächlichen epidemischen Verbreitung. «177

Die Information über die sog. Entdeckung des Choleraerregers erlangte tatsächlich eine bemerkenswerte Popularität, passte sie doch hervorragend in das seit über einem halben Jahrhundert von der Regierung propagierte Bild der Krankheit, als eine aus Asien stammende ansteckenden Seuche, die Europa heimtückisch überfallen hatte. ${ }^{178}$ Als Koch das Bazillus als Verursacher der Cholera bekannt machte, beschloss der 78 Jahre alte Pettenkofer kurzerhand im Selbstversuch der Behauptung Kochs, das Bazillus löse die Krankheit aus, auf den Grund zu gehen. Er schlucke eine große Menge

174 Vgl. Howard-Jones: The scientific background of the International Sanitary Conferences 1851 - 1938, 1975: S. 17.

175 Dornblüth, Friedrich: Wie stehen wir zur Cholera?: in: VöG, 25.1893, S. 300 - 304: S. 304.

176 Die Angst davor, dass die Medizin ihren sozialen Bezug und ihre soziale Aufgabe verlieren könnte, hielt Foucault für unbegründet, da die Medizin seit dem 18. Jahrhundert nur noch als Sozialmedizin existiere. Vgl. Foucault: Krise der Medizin oder Krise der Antimedizin, 2003 [1976]: S. 59.

177 Pettenkofer: Ueber Cholera, mit Berücksichtigung der jüngsten Choleraepidemie in Hamburg, 1892: S. 3f.

178 Vgl. Dornblüth, Friedrich: Wie stehen wir zur Cholera?: in: VöG, 25.1893, S. 300 - 304: S. 304. 
einer Cholera-Reinkultur, die er sich aus einem Berliner Labor schicken ließ und zeigte, ebenso wie einer seiner Mitarbeiter, der den Versuch wiederholte, abgesehen von einer leichten Diarrhö keine »Choleraanzeichen «. ${ }^{179}$ Selbstverständlich wurde der Versuch von den Bakteriologen als nicht aussagekräftig angesehen. ${ }^{180}$ Aber anders als gedacht, bewirkte das Wissen über den »Cholerabazillus« keine Wende und Neupositionierung der sich auf internationaler Ebene politisch und wissenschaftlich im Streit befindenden kontagionistischen und anti-kontagionistischen Strömungen. In England war der >Schock $<$ über die sog. Entdeckung Kochs nur von kurzer Dauer. Im Gegensatz zu der engen Beziehung einer wissenschaftlichen Praxis zu ihrem Wissen und ihren Wahrheiten, bestand für die gouvernementale Rationalität und Regierungspraxis keine Gefahr durch die Produktion von neuen wissenschaftlichen Erkenntnissen oder gar neuen Verfahren der Veridiktion innerhalb einer Wissenschaft, der Bakteriologie oder der Medizin, die laut Hygieniker Dr. J. Soyka seit Mitte des 19. Jahrhunderts durch die »erfolgte innige Anlehnung an die Naturwissenschaften, durch den methodischen, exacten und experimentellen Aufbau aller medicinischen Disciplinen $\mathrm{zu}$ bedeutungsvollen und ungeahnten Fortschritten geführt $\aleph^{181}$ hätte. In der 1888 veröffentlichten Besprechung von Pettenkofers Text zur Cholerafrage schrieb Soyka:

»Die Fortschritte der Bacteriologie in diesem Lustrum sind zwar ganz ausserordentliche, aber man kann nicht sagen, dass gerade die auf diese Fragen gerichteten Untersuchungen zahlreich und erschöpfend genug sind, um eine Reihe von bedeutungensvollen, durch lange Jahre gesammelten und anerkannten Thatsachen einfach in das Bereich der Irrthümer zu verbannen, weil ihre Erklärung bisher nicht gelungen. ${ }^{182}$

Der Hygieniker hielt, ebenso wie Vertreter des von ihm erwähnten »Wiener hygienischen Congresses«, die strikte Trennung der Ansichten von »Contagionisten« und »Localisten«, deren Konflikt die Medizin so krampfhaft versucht hatte, durch eine enorme Wissensproduktion und die Ansammlung von Beobachtungen, Forschungen und Theorien, in Richtung der Wahrheit aufzulösen, für die Frage nach der »Wirklichkeit« für unnötig. Ebenso könne ihm zufolge die »schroffe Gegenüberstellung von Bakteriologie und Epidemiologie nicht aufrechterhalten werden ${ }^{183}$.

»Die Hygiene hat sich so vieler Hülfswissenschaften zu bedienen, die alle gleichwerthig und gleichberechtigt sind, und die sich nur durch wechselseitiges Zusammenarbeiten unterstützen müssen, was ja von Pettenkofer selbst wiederholt hervorgehoben wird; einen Gegensatz zwi-

179 Vgl. Pettenkofer: Ueber Cholera, mit Berücksichtigung der jüngsten Choleraepidemie in Hamburg, 1892: S. 6 ff.

180 Vgl. Dornblüth, Friedrich: Wie stehen wir zur Cholera?: in: VöG, 25.1893, S. 300 - 304: S. 303.

181 Soyka, J., Professor der Hygiene an der deutschen Universität in Prag: Besprechnung von Pettenkofer, Dr. Max v.: Zum gegenwärtigen Stand der Cholerafrage [...], 1887: in: VöG, 20.1888, S. 627 - 641: S. 639.

182 Ebd.: S. 639.

183 Ebd. 
schen Bacteriologie und Epidemiologie festzustellen, weil vorläufige Endresultate beider Forschungsweisen nicht zusammenkommen wollen, ist noch nicht zulässig. «184

Die Erkenntnisse der Bakteriologie wurden vom Standpunkt der Hygiene oder Epidemiologie nur als ein weiterer Baustein in einem unbegrenzten Kosmos interpretiert. Die Gouvernementalität könnte Erkenntnisse ebenso wie jedes andere Wissen für die Rationalisierung einbeziehen. Einer Regierung, die, je mehr sie durch die Integration von Wissen über ihren grenzenlosen Gegenstand - das Leben - erfährt, sich sukzessiv neue Bereiche erschließt und zugänglich macht. Auch die Bakteriologie wird die Regierung besser und effektiver machen. Als die Cholera, nachdem sie bereits seit 1867 in dem liberal und anti-kontagionistisch geprägten Großbritannien nicht mehr epidemisch geherrscht hatte, 1892, also nach der >Entdeckung< des Erregers durch Koch, noch einmal heftig und epidemisch in Hamburg ausbrach ${ }^{185}$, polemisierten Anti-Kontagionisten aus London, aber auch liberale sanitäre Reformer wie Pettenkofer in Deutschland, die Entdeckung des Bazillus sei medizinisch interessant, aber für die praktische Frage der Regierung völlig nutzlos und könne keine Grundlage für irgendeine politische Maßregel sein. Tatsächlich machte sich auch in Deutschland nach der Euphorie wieder Skepsis gegen die Theorie des Erregers und die Regierungstechniken breit. ${ }^{186}$

»Inzwischen hatte sich in der Reichsverwaltung das Bedürfnis nach einem zwischen Wissenschaft und Praxis vermittelnden Organ herausgestellt, welches eine freiere Stellung als das Kaiserliche Gesundheitsamt besitzen müsste, um die Entwicklung der Seuche verfolgen, die Nutzbarmachung der Epidemie für die Wissenschaft in die Wege leiten und den Behörden des Reichs wie der Bundesstaaten auf schnellstem Wege Auskunft und Rath ertheilen zu können. $\ll^{187}$

Zur Erledigung dieser Aufgabe wurde am 11. September 1892 eine erneute CholeraKommission eingesetzt, die in enger Zusammenarbeit mit dem Kaiserlichen Gesundheitsamt stehen sollte.

\section{Die Cholera in Frankreich}

In einem Vortrag, den Foucault 1974 in Rio hielt, stellte Foucault die Frage, wieso sich im 19. Jahrhundert das Problem der Armen als »Quelle einer medizinischen Gefahr gestellt $\ll^{188}$ hat, nachdem dies im 18. Jahrhundert noch nicht der Fall gewesen

184 Ebd.: S. 640.

185 Vgl. Spinger, J.: Denkschrift über die Cholera-Epidemie 1892: in: VöG, 25.1893, S. 308 -310: S. 308f.

186 Vgl. Dornblüth, Friedrich: Wie stehen wir zur Cholera?: in: VöG, 25.1893, S. 300 - 304: S. 300 .

187 Spinger, J.: Denkschrift über die Cholera-Epidemie 1892: in: VöG, 25.1893, S. 308 310: S. 310.

188 Vgl. Foucault: Die Geburt der Sozialmedizin (Vortrag), 2003 [1974]: S. 293. 
war. Foucault nannte zunächst politische und soziale Veränderungen, die die ärmeren und arbeitenden Schichten ab Ende des 18. Jahrhunderts als eine politische Kraft erscheinen ließen, die das Bürgertum einerseits für ihre Zwecke einzusetzen versuchte, aber dann zu fürchten begann. ${ }^{189}$ Zuletzt nannte Foucault noch einen weiteren Grund, oder besser gesagt, ein Ereignis, welches seiner Meinung nach dazu beitrug, warum man im 19. Jahrhundert begann, die Armen zugleich als eine Bedrohung für die Gesundheit der Bevölkerung als auch als eine Bedrohung für die politische und soziale Ordnung und Sicherheit anzusehen: Die Choleraepidemie von 1832. Die Argumentation Foucaults legt offen, dass er sich selbst wenig mit der Cholera im 19. Jahrhundert befasst hat. Dennoch bieten sich seine Schlussfolgerungen als Ausgangspunkt für die Analyse der Effekte an, die die Cholera als (diskursives) Ereignis in Frankreich hervorbrachte.

»Avec l'épidémie de choléra de $1832[\ldots]$ se cristallisèrent un ensemble de peurs politiques et sanitaires suscitées par la population prolétaire ou plébéienne. A partir de cette époque, on décida de diviser l'espace urbain en secteur riches et en secteurs pauvres. On considéra alors que la cohabitation entre pauvres et riches dans un milieu urbain indifférencié constituait un danger sanitaire et politique pour la cité. C'est de ce moment que date l'établissement de quartiers pauvres et de quartiers riches. Le pouvoir politique commença alors à intervenir dans le droit de la propriété et de l'habitation privée. Ce fut le moment du grand réaménagement, sous le second Empire, de la zone urbaine de Paris. Telles sont les raisons pour lesquelles, jusqu'au XIXe siècle, la population urbaine ne fut pas considérée comme un danger médical.«190

Der erste Ausbruch der Cholera in Frankreich ereignete sich im Frühjahr 1832 in Paris, nachdem Choleraepidemien bereits seit über einem Jahr aus Russland, Polen, Preußen, Österreich und Großbritannien und anderen Ländern gemeldet worden waren. Insofern hätten die Bedingungen für eine Vorbereitung auf die Epidemie für die Administration in Paris günstig sein müssen. Man wusste von der Cholera in Indien, ${ }^{191}$ Russland, Polen und Preußen und zuletzt auch von der Epidemie in Edinburgh (November 1831) und London (Januar 1832). ${ }^{192}$

Schon Anfang 1831 erreichten den Minister des Inneren, Camille Bachasson, Comte de Montalive, Nachrichten von den Behörden aus Marseille, dass dort Schiffe mit Cholerakranken an Bord eingetroffen seien. Mit dieser Meldung wurde die Aufforderung verbunden, nötige Maßnahmen zum Schutz vor einer Epidemie einzuleiten. Der Minister veranlasste daraufhin die Académie Royale de Médecine einen Be-

189 Vgl. ebd.: S. 293.

190 Foucault: La naissance de la médecine social, 1994 [1974]: S. 224f.

191 Siehe z.B. Gazette de Santé, Journal de Médecine et des Sciences accessoires. Par une Société de Médecins, Nr. 13, 56. Année, 5. Mai 1829, S. 97 - 99.

192 Vgl. u.a. Albert/Boudard/Dalmas/Dubled/ Sandras: Rapport lu à l'Académie Royale de Médecine et remis à M. le Ministre du Commerce et des Travaux [...], 1832; und Gérardin, A.; Gaimard, P.: Lettres adressées à M. le comte d'Argout, - Du choléra morbus en Russie, en Prusse et en Autriche pendant les années 1831 et 1832, Paris, 1832. Delaunay, Dr. Paul (Membre de la Société Français d'histoire de la médecine): Le Corps Médical et le Choléra en 1832, Paris, 1933: S. 5. 
richt über die Cholera anzufertigen, der möglichst alle zur Verfügung stehenden Informationen einbeziehen sollte:

»Symptomatologie du choléra, caractères nécroscopiques, siège et nature du mal, chances de salut ou de perte, traitement, marche géographique de la maladie sous l'influence des causes qui en favorisent l'extension, moyens prophylactiques et mesures sanitaires employées; nous avons tout abordé: sans compter que chacune de ces divisions a été successivement étudiée, d'abord en Asie, et ensuite en Europe.«193

Hin und wieder waren in einzelnen französischen Städten und auch im Département de la Seine sporadische Fälle von Cholera gemeldet worden. Keiner dieser Fälle zog Epidemien nach sich oder erhielt besondere Beachtung. ${ }^{194} \mathrm{Im}$ Juli 1831 hatte der Präfekt des Département de la Seine, in Erwartung, dass die Cholera auch bald Frankreich und die Hauptstadt erreichen würde, die Gründung zweier Kommissionen beauftragt. ${ }^{195}$ Vor diesem Hintergrund mag es eigenartig erscheinen, dass der Ausbruch der Cholera in Paris in der damaligen Wahrnehmung so überraschend war und so viel Unerklärliches an sich zu haben schien. Die Stimmung in Frankreich zeichnete sich vor dem Ausbruch der ersten Epidemie durch Optimismus aus. Auch der Bericht der Kommission zeugte von der Einschätzung, die enormen baulichen, sozialen, medizinischen und auch >moralischen< Verbesserungen v.a. in Paris und die Fortschrittlichkeit Frankreichs würden es verhindern, dass sich die Epidemie wie andernorts mit einer solchen Gewalt zeigen könnte.

»Par suite de l'immense amélioration des conditions sociales, depuis quarante années, autant que par l'effet des progrès récens des sciences physiques et médicales, l'hygiène publique et l'hygiène privée ont fait tant de progrès en France, que nous ne saurions résister au besoin d'énoncer nos espérances d'être préservés de l'invasion épidémique du choléra, ou tout au moins de voir s'amoindrir et s'éteindre à nos portes ses meurtrières dévastations. [...] La maladie ne put cependant pas prendre pied au sein de cette nombreuse population de la capitale, défendue tout-à-la-fois par les bienfaits chaque jour croissans de la civilisation, par l'amélioration du sort des individus, par l'accroissement des lumières, et par les progrès de l'hygiène. Pour arriver, à l'égard du choléra, à de semblables et même à de plus heureux résultats, les moyens prophylactiques que nous aurons à indiquer, sont de deux sortes, suivant qu'ils se rapportent ou aux individus ou à la société, selon qu'ils sont du ressort de l'hygiène privée ou de l'hygiène publique. $\ll^{196}$

Obwohl man auch seitens der französischen Regierung und auch der Mediziner zugab, keine eindeutige Erklärung und kein vollständiges Wissen über die Cholera zu besitzen, war man grundsätzlich der Ansicht, die geplanten Vorkehrungen, die sich in

193 Académie Royale de Médecine: Rapport sur le choléra-morbus I, 1831: S. 3.

194 Vgl. Delaunay: Le Corps Médical et le Choléra en 1832, 1933: S. 5.

195 Vgl. Les préfètes de la Seine et de police: Rapport sur la marche et les effets du choléramorbus dans Paris et les communes rurales du département de la seine, année 1832, 1834: S. 13.

196 Académie Royale de Médecine: Rapport sur le choléra-morbus I, 1831: S. 137f. 
einem stärkere Maße als in Deutschland und England explizit nicht nur an die Behörden, sondern, wie die Académie in ihrem Bericht empfahl, an die Ärzte und Bürger richteten sollte, ${ }^{197}$ seien ausreichend, um einer schweren Epidemie vorzubeugen. ${ }^{198}$ Einige Mitglieder der Académie, wie der Bericht ebenfalls zeigte, dichteten der Cholera innerhalb dieser optimistischen Erzählung selbst eine Funktion für den allgemeinen natur- und sozialevolutionären Fortschritt an. ${ }^{199}$ Die Cholera wurde gewissermaßen als ein natürliches und historisch notwendiges, wenn auch schreckliches Ereignis interpretiert. Die Heftigkeit der Ausbrüche der Cholera spiegelte ihrer Ansicht nach den Zustand einer Gesellschaft wider und zeigte an, wo es noch an gesellschaftlicher Entwicklung mangelte. Genau aus diesem Grund sei ihrer Meinung nach Frankreich weniger bedroht gewesen als Russland oder Deutschland. ${ }^{200}$ Die Perfektion des gesellschaftlichen Zustands lag nach Ansicht der Académie in der allgemeinen Verbesserung der Menschen und Klassen (»l'amélioration des classes $«{ }^{201}$ ), ihrer Aufklärung und der Bedingung der Einhaltung der unzertrennlichen privaten und öffentlichen Hygiene. In dieser Weise stellte auch der Bericht der Académie Royale de Médecine die Cholera als Herausforderung und als Chance der Weiterentwicklung - als Ausgangspunkt einer physiologischen und sozialen Revolution der gesamten Menschheit - dar: »[D]es grandes épidémies, dans l'ordre physique, comme des révolutions dans l'ordre politique [...], des violentes secousses et des changemens brusques qui, par intervalles, agitent les nations. ${ }^{202}$ Es ist wichtig, diese Interpretation, die schon vor dem Ausbruch der Epidemie existierte, in ihrer Bedeutung ernst zu nehmen. Denn sie nahm erheblichen Einfluss auf die Art und Weise, wie der Ausbruch der Cholera im Nachhinein bewertet wurde und wie sie als ein Zeugnis des gesellschaftlichen und moralischen Verfalls interpretiert werden konnte: Als ein Symptom sozialer und moralischer >Degeneration $<$, deren Quelle man, wie Foucault schrieb, in wachsendem Maße in der armen und arbeitenden Bevölkerung von Paris sehen würde. Ein Verfall, der vor allem in Paris in den Vierteln der Armen, wo die Cholera besonders viele Opfer gefordert hatte, deutlich geworden sei. Die französischen Regierungen, von wechselnden Existenzkrisen und (Be-)Gründungsmythen eingenommen, entwickelten oder entdeckten keine Technologie zur Regierung der Armen und Arbeitenden, anders als Großbritannien. Sie mussten sich von der Erfahrung dieser ersten Epidemie erholen. Nach 1832 war deutlich geworden, dass sowohl die vereinte Wissenschaft der Hygiene und Medizin, die vereinten Mediziner und Ärzte als Ratgeber, Seelsorger und Gesetzesgeber der Gesundheit als auch schließlich die Bürger in ihrer Fähigkeit zu Selbstregierung > versagt< hatten. Auf welche Techniken griff die Regierung schließlich zurück? Sie rekurrierte auf die städtische Polizei und die rationalisierte hygiène

197 Vgl. ebd.: S. 3f.

198 »Une deuxième partie, déposée le 13 septembre, résumait en quelques pages les conseils pratiques à proposer aux autorités, aux médecins, et aux citoyens. « Delaunay: Le Corps Médical et le Choléra en 1832, 1933: S. 36.

199 Vgl. Académie Royale de Médecine: Rapport sur le choléra-morbus I, 1831: S. 4.

200 Vgl. ebd.: S. 137.

201 Vgl. ebd.: S. 141.

202 Ebd.: S. 4. 
publique und salubrité publique, in welche die Fixierung auf den Ort und die Umwelt als »Quelle einer medizinischen Gefahr $\aleph^{203}$ eingeschrieben war.

\section{Im Vorfeld der ersten Epidemie}

\section{Verallgemeinerte hygienische Rationalitäten}

Die Regierung der Gesundheit wurde in Frankreich zu dieser Zeit nicht als alleiniger Gegenstand der staatlichen Regierung beansprucht, sondern gewissermaßen innerhalb eines Bündnisses verschiedener Akteursgruppen aufgeteilt. $\mathrm{Zu}$ diesem Bündnis gehörten die zur Selbstregierung fähigen Bürger, die Mediziner und die zuständigen staatlichen Einrichtungen. Die Trennung und gleichzeitig die hervorgehobene gegenseitige Abhängigkeit der hygiène privée und der hygiène publique, wie der Hygiene und der Medizin, entsprachen dem Ziel der Aufteilung der Regierungsmacht unter dem Siegel einer während der Französischen Revolution beschworenen Vereinigung von Moral und Wissenschaft. Nach der Julirevolution von 1830 und unter der Regentschaft von Louis Philippe strebte die Regierung Frankreichs zu Beginn der 1830er Jahre danach, ihre Rationalität in dieser Weise zu bekräftigen und sich durch liberalere Praktiken von der alten bourbonischen Regierung der Restauration abzugrenzen. $\mathrm{Zu}$ dieser liberalen Haltung gehörte auch die Ablehnung der Quarantäne und der Theorie der Kontagiösität der Cholera. Auch Mark Harrison stellte fest:

»The Orleanist regime enjoyed a relatively harmonious relationship with the Academy of Medicine, which had become increasingly hostile to contagion and quarantine. The abuse of sanitary cordons by the Bourbon monarchy had led to widespread criticism and had turned many away from quarantine to consider more liberal alternatives. $\ll^{204}$

Die anlässlich der drohenden Cholera in verschiedenen Departements und auch in Paris veröffentlichten Instructions Populaires hatten einen völlig anderen Ton als die Aufforderungen des preußischen Staates an seine Untertanen. Die Instruktionen verbanden sich kaum mit Anweisungen, der Sanitätspolizei Folge zu leisten, oder gehorsam und einsichtig gegenüber der >Weisheit< der königlichen Maßnahmen zu sein. Es handelt es sich vielmehr um Vorschläge zur Verteilung von Aufgaben bei Umsetzung einer möglichst umfassenden Vorbeugung. Ärzte sprachen zugleich als Repräsentanten der Wissenschaft und als Repräsentanten einer bürgerlichen Schicht, die Bürgern wie auch der Administration Ratschläge und Hinweise über Maßnahmen und Verhaltensweisen erteilten. Nicht der König oder die staatlichen Behörden wandten sich an die Untertanen, sondern Ärzte richteten sich an eine Gemeinschaft und ein Gemeinwesen, dem sie sich selbst zugehörig fühlten. Häufig sprachen die Ärzte in ihren Beschreibungen der Cholera und den Hinweisen zur Diät von einem >Wir $<$ : si la maladie venait à nous atteindre«, »conditions hygiéniques au milieu desquelles nous trouvons placés «, »l'observation ne nous a pas entièrement laissés sans guides ni sans lumières; nous avons des notions, nous possédons des données qui sont propres à cette maladie«; »[les] nations étrangères qui pourraient nous apporter le choléra«

203 Foucault: Die Geburt der Sozialmedizin (Vortrag), 2003 [1974]: S. 293.

204 Harrison: Disease, diplomacy and international commerce, 2006: S. 207. 
[Hervorhebungen von mir]. ${ }^{205}$ Auf der einen Seite dieser gemeinsamen Anstrengungen gegen die Bedrohung der Cholera stand eine Wissenschaft von den Ursachen der Krankheit, die Medizin und Hygiene in sich vereinigte. Auf der anderen Seite verteilten sich die Aufgaben der Regierung nach den jeweiligen Handlungsmöglichkeiten von Gemeinschaft und Individuen, >sich< gegen die Cholera zu schützen.

\section{Die starke Position der Medizin und der Ärzte}

Es ist wichtig zunächst vor Augen zu haben, dass die Mitglieder der Académie Royale de Médecine Ärzte oder zumindest Mediziner waren und dass diese in Frankreich nach der Revolution für eine Zeit lang eine ganz spezifische Rolle bei der Übertragung eines bürgerlichen hygienischen Diskurses auf die Techniken der nationalen Regierung einnahmen. Diese Rolle hatte mit der Revolution im Juli 1830 und dem Wiedererstarken eines republikanischen, revolutionären bürgerlichen Regierungsdiskurses eine Art kurze Wiedergeburt erlebte.

In dem ersten Bericht hatten die Mediziner, ich nenne sie hier der Einfachheit halber Ärzte, der Akademie die Rolle übernommen, nicht nur die Aufgaben auf Administration, Ärzte und Bürger zu verteilen, sondern sie hatten bestimmte Bedingungen für die erfolgreiche Bekämpfung und Vorbeugung der Cholera gestellt. Bei der Koordination dieser Aufgaben und bei diesen Bedingungen hielten sich die Ärzte an eine Grundstruktur, die gewissermaßen dem eingeübten Verhältnis zwischen Ärzten und bürgerlichen Subjekten treu blieb: auf der einen Seite die Medizin, die die Wahrheit über die Krankheit kennt und die Mittel zu ihrer Vorbeugung empfehlen kann und auf der anderen Seite die Bürger, die, beraten durch die Ärzte, ein entsprechendes gesundheitliches Verhalten befolgen sollten. Die Aufgabe der Medizin, die spezifische oder essentielle Ursache und die spezielle Natur der Cholera zu ergründen, stand also in enger Verbindung mit diesem Bereich der Techniken der (Selbst-) Regierung.

»Avec un Gouvernement constitutionnel où la responsabilité des ministres doit être aussi une vérité pratique, avec le système électif qui nous régit, les corps savans qui réunissent les connaissances nécessaires pour bien juger, devraient être exclusivement consultés dans ces circonstances. $\ll^{206}$

Aufgabe der Hygiene war es, die allgemeinen Ursachen für die Choleraepidemie zu versammeln und sie auf die Handlungsbereiche der Selbstregierung und der staatlichen Regierung zu verteilen. Die Wiederentdeckung und die Medikalisierung der hippokratischen Lehre über die gesunde Lebensführung erfolgte durch das Bürgertum: »la cause générale de l'épidémie, sur ce je ne sais quoi de divin, dont parlait Hippocrate ${ }^{207}$. Was nun die medizinischen Untersuchungen der Cholera anging, mit den Techniken der Medizin und der Chemie, der Analyse des Wassers, der Luft nach ihren Bestandteilen, die Obduktionen, die Beschreibungen der Krankheitsverläufe

205 Académie Royale de Médecine: Rapport sur le choléra-morbus I, 1831: S. 136ff.

206 Ebd.: S. 164.

207 Sandras: Du choléra épidémique observé en Pologne, en Allemagne et en France [...], 1832: S. 59. 
usw., so verlangte die epistemische Logik der Medizin gerade, dass man alle allgemeinen Ursachen und sog. »sekundären Symptome« beiseite ließ, um die Sicht auf die spezielle Krankheit, »cette maladie singulière« zu ermöglichen. Das Verfahren der Veridiktion verlangte ein Ausschlussverfahren, eine Verengung und Schärfung des Blicks auf kleinste Details. Die Académie Royale de Médecine hegte 1831 die Hoffnung, im Falle einer Epidemie schnell in der Lage zu sein, die geheime Ursache der Cholera zu finden und daraufhin eine präzise und sichere Behandlung und Prävention empfehlen zu können. »Mettons donc de côté ce que j'ai dit sur l'essence de la cause générale du choléra, et examinons par les faits seuls, comment il se propage. $\ll^{208}$

Eine medizinische Bestimmung sollte ein spezifisches Set von Handlungsoptionen zur Bekämpfung der Cholera liefern, die schließlich das Gebäude einer rationalen Gesetzgebung und rationelle Techniken der (Selbst-)Regierung zu errichten und $\mathrm{zu}$ vervollständigen, ermöglichen würde. ${ }^{209}$ Ohne verlässliches wissenschaftliches Wissen sollte keine vernünftige Regierung möglich sein. Diese Bedingung stellt auch Aisenberg in Contagion: Disease Government and the Social Question in 19th-Century France anhand der Äußerungen von französischen Medizinern dieser Zeit fest. ${ }^{210}$ Der Bezug auf die allgemeinen epidemischen Ursachen der »raison épidémique « schien dagegen weniger wertvoll, ungenau und lediglich notdürftig zu sein. ${ }^{211}$ Insofern bedeutete die tendenziell eher strategisch begründete Ablehnung der Quarantäne und der Absperrungen, ohne eine nennenswerte Alternative zu haben, aus Sicht der Regierung nicht unbedingt einen Verlust an Handlungsspielraum. Man erhoffte sich, bald bessere und effektivere Mittel gegen die Cholera zu finden. Die Akademie sah sich, abgesehen von den Kontrollen an den Grenzen zu den Ländern, wo die Cholera epidemische war, und von einigen sanitären Verbesserungen in den Häfen und Städten nach dem Gesetz vom 3. März 1822 und der Verordnung vom 7. August desselben Jahres, nicht in der Lage, Vorschläge zu machen, die einer Regierung als sichere Handlungsgrundlage hätten gelten können. ${ }^{212}$ Von dem, was man von der Cholera und der Art ihrer Verbreitung wusste, war für die Akademie schon 1831 offensichtlich, dass die Kategorie der maladies pestilentielles, auf der die französischen Quarantänegesetze beruhten, für die Cholera nicht taugte. Eher notgedrungen und mit wenig praktischer Konsequenz hielt man zunächst an dem Gesetz von 1822 fest. Der Bericht von 1831 hatte eher negative Aussagen darüber enthalten, welche Maßnahmen sich als nutzlos und schädlich erwiesen hätten, nämlich die Einrichtung von Kordons, Sperrlinien und einer Quarantäne, anstatt eine positive Handlungsperspektive für die Regierung zu eröffnen. Die Académie blieb hier auf dem Standpunkt, es gebe von Seiten der Medizin noch keine genauen Erkenntnisse, also auch noch keine zu empfehlenden sicheren Maßnahmen. ${ }^{213}$

208 Ebd.

209 Académie Royale de Médecine: Rapport sur le choléra-morbus I, 1831: S. 136.

210 Vgl. Aisenberg: Contagion. Disease, Government, and the »Social Question«..., 1999: S. 67.

211 Vgl. Académie Royale de Médecine: Rapport sur le choléra-morbus I, 1831: S. 143f.

212 Vgl. Bourdelais/Raulot: Une Peur Bleue, 1987: S. 33 - 36.

213 Vgl. Académie Royale de Médecine: Rapport sur le choléra-morbus I, 1831: S. 144. 
Techniken der Isolation und Absperrung, der Quarantäne und der Grenzkordons, seien diese nun auf das einzelne Individuum (z.B. in einem Krankenhaus) oder auf die ganze Bevölkerung bzw. den Staat bezogen, gab es. Die Tradition dieser Praxen bestand noch aus der Zeit der Pest. Zu dieser Zeit waren die Maßnahmen allerdings keinem so komplexen und modernen Verfahren der Veridiktion innerhalb der medizinischen Disziplin ausgesetzt. Im Grunde musste die Medizin selbst ihre alten Wahrheiten über die Kontagiosität der Pest verwerfen, da sie aus einer Zeit stammten, als keine rationellen Kriterien für Wahrheit bestanden. Das alte Wissen über die Pest war unsicher geworden und auch ihre Kontagiösität stand wieder zur Debatte. ${ }^{214}$ Wenn es eine anerkannte und legitime Praxis der Regierung gegeben hatte, gegen sog. pestartige Krankheiten vorzugehen, dann hatte die medizinische Wissenschaft nun die alten Begründungen und Definitionen dieser Art von Krankheiten in Frage gestellt. Dies bedeutete, ähnlich wie in Deutschland, dass eine Reihe von Techniken ohne die Bestätigung z.B. der Kontagiosität der Cholera und ihrer genauen Form der Kontagiosität Gefahr liefen, gänzlich irrational zu erscheinen. Alle Maßnahmen der Regierung, ob sie nun vom Individuum oder vom Staat ausgingen, die sich gegen eine spezielle Ursache wie die Kontagiosität, gegen das sog. Choleragift selbst richteten, bezogen sich, ähnlich wie alles, was die Ärzte im Körper des Kranken oder innerhalb einer Klinik gegen die Cholera unternahmen, auf das Wissen der Medizin. Dieser Zusammenhang wurde auch in den Instruktionen von 1831 deutlich. Ärzte, Individuen und Verwaltung sind ohne wirkliche Macht und können nicht erfolgreich sein, ohne die >medizinische Wahrheit< über die Gesetze der Cholera zu berücksichtigen. $^{215}{ }$ Chaque maladie communicable a des lois spéciales de transmission. $\ll^{216}$

Im nationalen Selbstbild Frankreichs und besonders nach der Julirevolution diente die Abgrenzung von der Quarantäne und den repressiven Mitteln der militärisch gesicherten Absperrungen in Preußen, Österreich und Russland als Mittel, um ihren eigenen rationellen, libertären Charakter zu belegen und sich als gegensätzlich zu einer willkürlichen Regierung zu profilieren. Die Frage der Cholerapolitik war längst ebenso zu einem Politikum geworden wie die Benennung der Gründe für ihr Ausbrechen in Europa. Was die Frage der Kontagiosität betraf, gab es, wie auch in Deutschland, unter den Ärzten unterschiedliche Meinungen. Die Académie Royale de Médecine zögerte, sich zu den unterschiedlichen Theorien zu äußern, wohl auch im Bewusstsein der politischen Macht, die ein solches Urteil hätte haben können. Man definierte die Cholera zwar zunächst formal als kontagiös, durchbrach aber den Automatismus zwischen der Definition der Krankheit als >pestartig< oder kontagiös und der alten, ungenauen, weil unwissenden anti-epidemischen Regierungspraxis aus der

214 Vgl. Burdin: De la contagion de la peste, et remarques dur les observations de M. le docteur Pariset relatives à son expérience de désinfection fait à Tripoli en Syrie: JGM, 111.1830, S. 289 - 310: $290 \mathrm{ff}$.

215 Vgl. Vgl. Instruction populaire sur le choléra asiatique. Imprimé aux frais du Gouvernement, 1831: S. 6.

216 Académie Royale de Médecine: Rapport sur le choléra-morbus I, 1831: S. 169. 
Zeit der Pest oder bezog sich auf irgendeine andere anerkannten Praxis im Umgang mit ansteckenden Krankheiten wie dem Typhus oder den Pocken. ${ }^{217}$

Der Bericht von 1831 stellt eher andere politische Bezüge her, die der Bildung einer moralischen Identität und Legitimität der Regierung dienen konnten. Etwa betonte er den Zusammenhang zwischen simperialen< Kriegen und Epidemie. Vor allem Russland, dessen Truppen während der Invasion in Polen die Cholera dort eingeschleppt hätten, lieferte das Exempel für eine libertär-republikanische Rhetorik. ${ }^{218}$ Diese alte, sinnlose und despotische Form des Krieges, wie Russlands Feldzug gegen den nationalen Aufstand in Polen, hatte die Ausbreitung der Cholera nach Europa befördert. Von solchen Kriegen, genau wie von der Seuche, wollte das aufgeklärte Frankreich Europa befreien: »Le monde entier le sait: la France par la bouche de son Roi, ou le Roi, parlant selon le cœur de la France, sa voulu préserver le midi de Europe du fléau de la contagion que la guerre $<[\ldots] . \ll^{219}$ Der Zusammenhang von Irrationalität, Despotismus und Epidemie erklärte und rechtfertigte die Position der Akademie innerhalb dieser republikanischen Logik, d.h. die Gründe, warum man gegen diese Staaten womöglich Grenzkontrollen und Sperren errichten müsse. Wenn die Regierung die Absperrungen vornehmen wolle, so sei dies nur an den Grenzen zu den anderen Nationen - »nations étrangères qui pourraient nous apporter le choléra $\ll^{220}$ - zu rechtfertigen. Im Innern müsse man dagegen »brüderlich $\ll^{221}$ zusammenhalten. Eine Absperrung einzelner Städte oder Landstriche sei unnötig, unmöglich und gefährlich:

»Les cordons sanitaires sur les frontières auront un véritable caractère d'utilité et une assez grande facilité d'application, sans présenter les désastreux inconvéniens qu'ils entraîneraient s'ils se resserraient, s'ils se circonscrivaient vers l'intérieur, et si l'on séquestrait, par exemple, un département des autres départemens, une ville d'une autre ville, ou même un quartier d'un autre quartier. $\ll^{222}$

Gerade deshalb schienen die hygienischen Maßnahmen, die historisch nicht aus dem Repertoire der alten absolutistischen Regime stammten, sondern aus einer bürgerlichen Kultur und von an Wissenschaft geknüpfter Rationalität und Praxis abgeleitet wurden, passender, fortschrittlicher, legitimer und überhaupt durchführbarer. ${ }^{223}$ Selbst wenn man ihnen nur eine gewisse Vorläufigkeit zuschrieb, waren die Maß-

217 »Qui voudrait cependant déclarer contagieuse cette maladie, qui d'ailleurs ne ressemble à nulle autre, qui est tout-à-fait nouvelle pour nous, et dont jusque-là nous ne pouvions pas même trouver l'analogue dans les annales de la science?«: Ebd.: S. 132.

218 »Le choléra-morbus, nous l'avons vu, arrive sur-tout à la suite des grandes agglomérations de troupes, par les privations, les fatigues, les excès qu'entraîne la vie de l'homme de guerre.«: Ebd.: S. 152.

219 Ebd.

220 Ebd.: S. 164f.

221 Vgl. ebd.: S. 164f.

222 Ebd.: S. 165.

223 Vgl. ebd.: S. 168. 
nahmen der »améliorations de la salubrité tant privée que publique «224 ${ }^{2 i n n v o l l e r ~ a l s ~}$ die Quarantäne und konnten angewendet werden, solange nichts Genaueres über die Cholera bekannt sei.

» $\mathrm{Si}$, malgré les mesures prises aux frontières, la maladie arrive jusqu'à nous, elle nous aura gagnés par voie épidémique: et alors les moyens hygiéniques sont les seuls admissibles; tous les moyens de séquestration seraient superflus. $\ll^{225}$

Demzufolge waren die Vorschläge, die die Akademie in ihrem Bericht unterbreitete, überaus vage. Sie bestanden aus einer Anzahl von Vorschlägen zur Verbesserung der Hygiene in den Städten. Teilweise versuchte man privat-hygienische und diätetische Ziele mit dem Ziel der Verbesserung der Gesundheit der gesamten Bevölkerung praktisch zu verbinden. Unter diese Kategorie fiel etwa der Vorschlag, der arbeitenden Bevölkerung Aufgaben der Stadtreinigung aufzutragen, um diese dadurch von anderen schwereren ungesunden Arbeiten zu befreien und gleichzeitig dem Wohl der Allgemeinheit einen Dienst zu erweisen.

Dennoch haben wir es in dem Bericht der Akademie, der, wie gesagt, eine starke Position der Mediziner widerspiegelte, im Prinzip mit dem Ausspruch der Bedingung zu tun, die besagt: Damit wir als Regierung gezielt gegen die Cholera vorgehen können, benötigen wir noch mehr Wissen über die Krankheit, da wir im Gegensatz zu anderen Regierungen in Europa keine überkommenen Maßnahmen anwenden, deren Erfolg nicht nachgewiesen werden kann und die andererseits negative Folgen für die Bevölkerung und die Ökonomie der Nation haben. Daraus ergab sich, dass, solange kein Wissen über die spezifischen Ursachen der Krankheit existierte, nichts weiter zu beachten war als die hygienischen Regeln, die vor allem vom Individuum ausgehend befolgt werden konnten. Die Stadtverwaltung unternahm kurzfristige Maßnahmen, um für mehr Sauberkeit in den Straßen, den Häusern und öffentlichen Gebäuden etc. zu sorgen. Durch die Aufstockung und Einrichtung von Krankenhäusern als auch die Einrichtung von sog. »bureaux de secours« oder »postes médicaux« als eine Art Erste-Hilfe-Stationen sollte die medizinische Versorgung gewährleistet werden. ${ }^{226}$ Diese Maßnahmen der salubrité publique waren, wie schon gesagt, von kurzfristiger Natur und sollten eher einen vorläufigen Charakter haben. Mit dieser Haltung ging einher, dass man sich in Frankreich stark auf die asketisch-moralische Praxis der privaten Hygiene konzentrierte und dass man hoffte, mithilfe der Instruktionen über die private Hygiene einen relativ sicheren Schutz vor einer schweren Epidemie gewährleisten zu können.

»Enfin la commission centrale fit publier une instruction (15 novembre 1831) sur le régime à suivre pour se préserver du choléra, et sur la conduite qu'il faudrait tenir si l'on s'en trouvait at-

224 Ebd.

225 Ebd.: S. 165.

226 Rapport sur la marche et les effets du choléra-morbus dans Paris et le département de la Seine par la Commission nommée, avec l'approbation de M. le minist re du commerce et des traveaux publics, par MM. les préfets de la Seine et de police, année 1832, 1834, Paris, S. 10 - 19: S. 18. 
teint; elle recommandait la propreté dans les vêtements et les habitations, la sobriété dans les aliments, la modération dans les plaisirs, et surtout elle engageait les citoyens à se tenir en garde contre les prétendus moyens curatifs dont les charlatans vantaient chaque jour les vertus dans les journaux et dans les affiches dont ils couvraient les murs de la capitale. $\ll^{227}$

\section{Das bürgerliche Ideal hygienischer Selbstregierung}

Die Académie hatte in ihrem Bericht von 1831 die Aufgaben der privaten und öffentlichen Hygiene, die Pflichten der Ärzte, der Administration und der Bürger ausbuchstabiert. Im Herbst 1831 veröffentlichte und verteilte die französische Regierung vierzigtausend Kopien sog. Instructions Populaires, die die Bevölkerung über die Möglichkeit der nahenden Choleraepidemie informierten und Auskunft über Statistiken und erste Hilfe vermittelten. ${ }^{228}$ Catherine Kudlick stellte anhand der Untersuchung mehrerer solcher Instructions Populaires fest, dass sich diese Texte offensichtlich an eine bürgerliche, wohlhabendere Schicht richten sollten. Die bereits angedeutete Rolle und Aufgabe der Mediziner und Bürger spiegelte sich in einem Verhältnis von hygienischen Ratgebern und Selbstregierenden in diesen Instruktionen wider. Ein Verhältnis, das man eindeutig auf einen bestimmten bürgerlichen Diskurs und die Entwicklung der Rationalisierung und Medikalisierung der von einer bürgerlichen Schicht > wiederentdeckten< hygienischen Selbstpraktiken zurückführen kann.

Welche Maßnahmen werden also in den kleinen ca. 20 Seiten umfassenden Broschüren vorgeschlagen? Es wird u.a. geraten, man solle im Winter die Zimmer ordentlich heizen und regelmäßig lüften ${ }^{229}$ und: »Ainsi il faut avoir soin de ne pas habiter, et plus encore, de ne pas coucher en trop grand nombre dans la même pièce $\ll^{230}$. Weiter wird für die Ernährung empfohlen:

»Lorsque le choléra règne, la manière de se nourrir est un point fort important. [...] Les viandes bien cuites, rôties et pas trop grasses, ainsi que les poissons frais et d'une digestion facile, les œufs, le pain bien levé et bien cuit, devront former la nourriture principale. Les viandes salées et les poissons salés ne conviennent pas; on usera le moins possible de charcuterie, et l'on s'abstiendra des pâtisseries lourdes et grasses. $\ll^{231}$

Dasselbe gelte für die Getränke und vor allem den Alkohol, den man nur in Maßen zu sich nehmen solle ${ }^{232}$ : »Il vaut mieux boire moitié moins de vin et le choisir de qualité supérieure. $\ll^{233}$ Es wird geraten, unreife Früchte, saures und wässriges Gemü-

227 Vgl. Chapitre premier: Précutions prises par l'administration avant l'invasion du choléra: in : Les préfètes de la Seine et de police [Hrsg.]: Rapport sur la marche et les effets du choléra-morbus dans Paris et les communes rurales du département de la seine, année 1832, 1834: S. 18.

228 Vgl. Kudlick: Cholera in Post-Revolutionary Paris, 1996: S. $105 f$.

229 Vgl. Commission Centrale de Salubrité: Instructions populaires sur les principaux moyens à employer pour se garantir du choléra morbus, 1831: S. 2.

230 Ebd.

231 Ebd.: S. 6.

232 Vgl. ebd.

233 Ebd.: S. 8. 
se und überhaupt alles, was Diarrhö verursachen könnte, zu meiden. Es besteht eine große inhaltliche Parallele zu dem diätetischen Wissen zur Vermeidung der Cholera, das bereits vor den Epidemien in Europa die Runde gemachten hatte. ${ }^{234}$ Dazu gehörten auch die Ratschlägen, sich besonders vor Erkältungen zu schützen und sich entsprechend und vor allem an den Füßen und am Bauch warm zu halten. ${ }^{235}$ Außerdem sollte man, um die Gefahr der Erkältung auszuschließen, sowohl auf das Waschen mit kaltem Wasser, welches vor allem eine »sehr schlechte Angewohnheit« der »weniger besitzenden « Klassen sei, als auch auf die »Angewohnheit«, die nackten Füße der Kälte auszusetzen, verzichten. ${ }^{236}$

Es wird empfohlen, man solle lieber warme Bäder nehmen oder sich mit warmem Wasser waschen. Nach dem Bad solle man sich warm halten und kräftig mit Flanell abreiben. ${ }^{237}$ Die Pariser Instruktionen empfahlen außerdem, sich, wenn möglich, körperlich nicht zu verausgaben: »[de] s'occuper, mener une vie active, en évitant autant que possible les excès de fatigue. ${ }^{238}$ Ebenso wie in Deutschland ging man in Frankreich, wie die Instruktionen zeigen, davon aus, dass die Cholera in besonderem Maße durch Furcht begünstigt werde. Das Anraten von Ruhe und Zuversicht hatte sicherlich auch dazu gedient, die Bevölkerung zu beruhigen und Massenpaniken zu vermeiden; es bedeutete aber auch, die Krankheit als Technik der Disziplinierung und Einübung bestimmter Verhaltensweisen in die Regierungspraxis zu integrieren.

»Le peu de danger que l'on court d'être atteint du choléra doit rassurer les esprits. Il faut donc ne pas s'inquiéter et ne penser autrement à la maladie que pour exécuter les précautions propres à s'en garantir. Moins on a peur et moins on risque; [...].« $\ll^{239}$

In Frankreich hing die sehr stark an eine bürgerliche Selbstpraxis angelehnte Idee der individuellen Vorkehrungen gegen die Cholera mit einer bestimmten Aufforderung zur >moralischen Prophylaxe < im Sinne einer Regierung und Beruhigung aller starken und v.a. ängstlichen Gefühle zusammen. ${ }^{240}$

In einer vergleichbaren Weise richtete sich schon der im Sommer 1831 veröffentlichte Bericht der Académie Royale de Médecine über die Cholera an die Bürger, um

234 Vgl. ebd.: S. 9.

235 Vgl. ebd.: S. 4. Heinrich Heine hat treffender Weise in Bezug auf die empfohlenen »Bauchbinden aus Flanell« auch vom »Bürgerflanell« gesprochen, mit denen nun sogar auch die Adligen versuchten, sich vor der Cholera zu bewahren. Heine: Artikel VI: in: Französischen Zustände, 1833 [1832]: S. 167.

236 Commission Centrale de Salubrité: Instructions populaires sur les principaux moyens à employer pour se garantir du choléra morbus, 1831: S. 4f.

237 Überhaupt zählte das Abreiben in Frankreich zu einer besonders häufig empfohlenen Form der Hautpflege. Vgl. z.B. das Textbeispiel von Sarasin: Ders. Geschichtswissenschaft und Diskursanalyse, 2003: S. 135.

238 Ebd.: S. 5.

239 Ebd.: S. 1f.

240 Vgl. Commission Centrale de Salubrité: Instructions populaires sur les principaux moyens à employer pour se garantir du choléra morbus, 1831: S. 1f. Vgl. auch Delaunay: Le Corps Médical et le Choléra en 1832, 1933: S. 50. 
ihnen mitzuteilen, was sie zur Vermeidung einer Erkrankung und des epidemischen Ausbrechens der Krankheit in der Stadt tun sollten. In dem Bericht finden sich sowohl hygienische bzw. diätetische Ratschläge der hygiène domestique, die sich sowohl auf das Verhalten zur Umwelt als auch auf das Verhalten in Bezug auf die eigene $>$ Moral< beziehen. ${ }^{241}$

Was ihre Sprache und was die Lebensbedingungen, die sie voraussetzte, betraf, aber schließlich auch die Weise, wie sie an die private hygienische Selbstpraxis des Bürgertums anknüpfte, blieben die Staatsführung in den Grenzen einer Regierung, die sich auf bestimmte bürgerliche Subjekte richtete. Fast könnte man meinen, die Cholera bot eine Gelegenheit, den bürgerlichen hygienischen Diskurs noch stärker als zuvor an die Öffentlichkeit zu bringen und die durch ihn propagierte >gute< Praxis der Selbstregierung als Bedingung für diese bürgerliche Subjektivität und als Bedingung eines moralischen Subjekts überhaupt, zu verallgemeinern. Aus dieser Konstellation von Regierung der Ärzte und Subjektivität von Bürgern reproduzierten sich aber eher eine Abgrenzung und ein Ausschluss anderer Gruppen. Gruppen, die sich mit den entworfenen Techniken als nicht regierbar darstellen würden und für die man eine andere Praxis würde finden müssen: die armen und arbeitenden Bewohner der Städte. Darüber hinaus zeigte sich nach dem Abklingen der ersten Epidemie aber auch eine Ernüchterung über die bürgerlichen und wohlhabenden Schichten, die sich aufgrund ihrer sozialen Position vor der Cholera sicher gewähnt und die Hygieneregeln ihrerseits vernachlässigt hatten.

Ein halbes Jahr nach der Veröffentlichung der Instructions populaires und nachdem das verheerende Ausmaß der Choleraepidemie in Paris sichtbar geworden war, schrieb die Redaktion des Journal de médecine et de chirurgie pratiques:

»Dans de nombreux écrits répandus aussitôt on invita les citoyens à purifier leurs maisons avec des lotions chlorurées, à se préserver du froid et de l'humidité, à se couvrir l'abdomen et les pieds avec la flanelle, boire peu de vin, prendre une nourriture substantielle, éviter tout excès et toute commotion morale; enfin, à suivre les régies de l'hygiène que nous ne rappellerons point ici, puisqu'elles sont dans la mémoire de tous les praticiens. [...] Mais ces instructions, dictées par une sage prévoyance, entraînèrent le peuple dans plusieurs démarches qui furent souvent nuisibles à sa santé, parce qu'il les interpréta mal, et força leur application. $\ll^{242}$

Es sind die Ärzte, die darauf hinweisen, dass die Regierung, die sich durch die Selbstregierung begrenzt hat, in anderer Hinsicht Grenzen hat. Es sind Grenzen, die nicht nur durch die offensichtliche Differenz zur Kompetenz der Ärzte und zur Macht des Staats festgelegt werden, sondern die eine ganz andere Art der Differenz anhand einer moralischen Differenzierung von Subjekten beinhalten, die entsprechend der unterschiedlichen Fähigkeit der Individuen, sich selbst >vernünftig< zu regieren, gezogen werden müssen. Es besteht eine Differenz zwischen den Regierenden (seien sie nun Bürger, die sich selbst regieren oder die nationale Regierung, die die übrigen

241 Vgl. Académie Royale de Médecine: Rapport sur le choléra-morbus I, 1831: S. 138f.

242 [Hrsg.]: Considérations pratiques sur le choléra-morbus de Paris, son invasion, sa marche, ses symptômes, son traitement, et les précautions prises par l'autorité pour en prévenir le développement ou arrêter ses progrès: in: Journal de médecine [...], 3.1832: S. 130. 
öffentlichen Aufgaben der Führung übernimmt) und den Anderen, die regiert werden. Im Prinzip sagen die Ärzte nichts Neues. Sie haben der Selbstregierung, die das Bürgertum und seine Philosophen propagiert haben, ${ }^{243}$ schon immer skeptisch gegenüber gestanden und sie als Angriff auf ihre Macht betrachtet. Aber das Bündnis mit dem Bürgertum und der nationalen Regierung bringt in dieser Hinsicht eine neue Richtung hervor, in welcher die Ärzte ihre Macht und die Selbstregierung ganz im Sinne der seit der Französischen Revolution adaptierten auf Gesundheit gerichteten Rationalität anbringen können, indem sie betonen, die Selbstregierung sei bei bestimmten Menschen nicht zu empfehlen. Gemeint sind hier im Speziellen die einfachen Leute, »les gens du peuple $\ll^{244}$, die Armen oder die arbeitende Klasse. Das Scheitern einer Regierung, die diese Subjekte, die eben zu dieser Selbstregierung in der Lage waren, zur Bedingung ihres eigenen Erfolgs gemacht hatte, wurde nun zum Katalysator einer Diskussion über die Regression und Verkommenheit der französischen Arbeiterklasse.

\section{Das Versagen der Ärzte und der Bürger}

Was die Cholera und die salubrité publique insgesamt betrifft, so trugen zwei Probleme während der ersten Epidemie zu einer Veränderung der Strategie der Regierung bei. Wie in dem Bericht der Cholera-Kommission der Präfektur von 1834 über den Verlauf der Cholera deutlich wird, war diese Änderung mit zwei Erfahrungen verbunden: Dies war zum einen die Erfahrung der Begrenztheit der privaten Hygiene. Es hatte sich gezeigt, dass die Bürger sich nicht vernünftig genug verhalten hatten und v.a., dass es bestimmte Teile der Bevölkerung gab, die scheinbar völlig unzugänglich für den bürgerlich-hygienischen Diskurs und seine Ziele der moralischen und physischen Verbesserung waren. Zum anderen war es die Erfahrung, dass die medizinische Wissenschaft und ihre Erkenntnisse - z.B. was die Kontagiosität bzw. den miasmatischen Charakter der Cholera betraf -, nicht ausreichten, um der Regierung eine spezifische Handlungsgrundlage zu geben. Diese beiden Erfahrungen trugen maßgeblich dazu bei, dass man das Verhältnis von privater und öffentlicher Hygiene neu definieren bzw. den Bereich der öffentlichen Hygiene zumindest theoretisch erheblich ausdehnen wollte. Diese Ausdehnung wurde insbesondere durch die Verschiebung eines medizinisch-pathologischen Blicks hin zu einem epidemiologischen Blick auf die Cholera unterstützt. ${ }^{245}$ Die Hinwendung zu dieser epidemischen Logik und Erkenntnispraxis der Hygiene war die Folge eines enormen Aufgebots der Datensammlung und Informationsoffenlegung über die Cholera, die der französischen Re-

243 Bestes Beispiel ist hier immer noch Rousseau, der davon träumte, eines Tages eine Gesellschaft zu ermöglichen, die überhaupt keine Ärzte mehr bräuchte.

244 [Hrsg.]: Considérations pratiques sur le choléra-morbus de Paris, son invasion, sa marche, ses symptômes, son traitement, et les précautions prises par l'autorité pour en prévenir le développement ou arrêter ses progrès: in: Journal de médecine [...], 3.1832: S. 130.

245 Dies bedeutete, dass man glaubte, die Ursache der Cholera weniger durch Untersuchungen des Körpers und der pathologischen Phänomen ergründen zu können, als durch die statistische, ätiologische und hygienische Erfassung aller Umstände, unter denen die Cholera aufträte. 
gierung als Legitimationsmechanismus gedient hatte. Auch die Eskalation des Streits um die Kontagiosität innerhalb der medizinischen Wissenschaft ist spürbar in dem Bericht von 1834, der ohne eine Stellungnahme zur Frage der Kontagiosität blieb. Bevor ich auf diesen Bericht der Präfektur eingehe, möchte ich mich noch näher mit den genannten Erfahrungen während der Epidemie beschäftigen.

\section{L'émeute}

Der Optimismus der französischen Oberschicht, mit dem sie den Ausbruch der Choleraepidemie in Paris erwartet hatte, speiste sich aus der Überzeugung, eine der fortschrittlichsten und aufgeklärtesten Nationen Europas zu sein. Der optimistischen Seite dieses nach der Julirevolution von 1830 wieder bestärkten Narrativs des gesellschaftlichen Fortschritts und der Verbesserung der Menschen, stand die Angst vor dem moralischen und physischen Verfall der französischen Nation gegenüber. Diese Angst manifestierte sich hauptsächlich in der Darstellung und Wahrnehmung der »unteren Klasse « (classe basse). Kriminalität, Aufstände und Krankheit wurden auf diese Bevölkerungsschichten bezogen, als Teil einer sozialen Pathologie und als Beleg für den >Krankheitszustand< der Gesellschaft und vor allem der Stadt Paris gewertet. Der schnelle Ausbruch dieser ersten Choleraepidemie im Frühjahr 1832 in Paris ließ diesen Diskurs hervorbrechen. Umso mehr, als die politische Lage kurz nach der Julirevolution ohnehin angespannt war und eine entsprechende Metapher zu bestätigen schien.

Kurz nach dem Ausbrechen der Cholera kam es am 1. April 1832 zu einem Aufstand der sog. chiffonniers. Leute, die mit dem Sammeln von Abfällen in den Straßen von Paris ihren Lebensunterhalt verdienten, protestierten gegen die von der police sanitaire durchgeführten neuen Aufräumarbeiten, die die Präfektur der Polizei angesichts der Cholera angeordnet hatte. ${ }^{246}$ Heinrich Heine beschrieb in seinem berühmten Text vom 19. April 1832, der wenig später in der Augsburger Allgemeine Zeitung abgedruckt wurde, den Ausbruch der Cholera in Paris. Darin äußerte sich Heine abfällig über den Aufstand der chiffonniers, die gegen die Rationalität und gute Bürgerlichkeit der neuen Regierungsmaßnahmen protestiert hatten:

»Als nun die Polizei, damit der Kot nicht lange auf den Straßen liegen bleibe, die Säuberung derselben in Entreprise gab, und der Kehricht, auf Karren verladen, unmittelbar zur Stadt hinausgebracht ward aufs freie Feld, [...]. Da sahen wir nun die widerwärtigste Emeute: die neuen Reinigungskarren wurden zerschlagen und in die Seine geschmissen; die Chiffonniers barrikadierten sich bei der Porte St. Denis; mit ihren großen Regenschirmen fochten die alten Trödelweiber auf dem Châtelet; der Generalmarsch erscholl; Casimir Périer ließ seine Myrmidonen aus ihren Butiken heraustrommeln; der Bürgerthron zitterte; die Rente fiel; die Karlisten jauchzten. Letztere hatten endlich ihre natürlichsten Alliierten gefunden, Lumpensammler und alte Trödelweiber, die sich jetzt mit denselben Prinzipien geltend machten, als Verfechter des Herkömmlichen, der überlieferten Erbkehrichtsinteressen, der Verfaultheiten aller Art. «²4 
In der Interpretation der rechten und reaktionären Gegner der Bewegung, die die Julirevolution ermöglicht hatte, war die Cholera das direkte Ergebnis der sozialen Unordnung, die der politische Umbruch verursacht hatte. ${ }^{248}$ Wie Heine in dem Verweis auf die klerikal und absolutistisch eingestellten »Karlisten « andeutete. »`C'est la Révolution des Juyet qui nous a produit ce fléau! « ${ }^{249}$ hieß es. Einen Tag nach den Aufständen der chiffonniers, machte am 2. April das Gerücht die Runde, dass die Cholera nur als Vorwand benutzt worden war, um Giftmorde unter den Arbeitern und der unliebsamen armen Bevölkerung vorzunehmen. ${ }^{250}$ Die Choleramortalität hatte sich bereits zu diesem Zeitpunkt unter den ärmeren Bevölkerungsschichten als besonders hoch erwiesen. Die Naivität und der Optimismus in der Oberschicht, die generell bezweifelte, dass die Cholera nach Paris gelangen oder dort großen Schaden anrichten könnte, hatte insgesamt Spekulationen über Vergiftungen und eine von Menschen willkürlich ausgelöste Epidemie begünstigt. Schließlich war es aber zuletzt auch möglich, innerhalb dieser Vorstellung von Geschichte und einer sich nach den Idealen bürgerlicher Tugend(en) weiter und zur Perfektion entwickelnden Gesellschaft, die Epidemie, selbst dem Wortlaut der Académie Royale de Médecine nach, als eine Art soziale Gesundheitskur anzusehen. Insofern hatte das Gerücht, die Cholera sei nur ein anderes Wort für ein Komplott zur Ermordung der armen Bevölkerung, einen gewissen ideologischen Begründungsrahmen. Auch wenn die meisten Ärzte und Hygieniker ernsthaft gegen die Ausbreitung der Cholera kämpften und auf >Aufklärung<, oder man könnte ebenso gut sagen, auf Seelsorge setzten, ${ }^{251}$ wurde die Auffassung, dass dies in bestimmten Teilen der Bevölkerung nicht möglich sei, durch die Beschuldigungen der Ärzte als »empoisonneurs« bestätigt. Ärzte, die arme Cholerakranke behandelten, wurden beschimpft und beleidigt. ${ }^{252}$

»Nous avons vu, dans les premiers jours de l'invasion du choléra, plusieurs individus, n'appartenant point à la dernière classe du peuple, refuser tout secours, disant qu'ils ne voulaient point être empoisonnés deux fois « ${ }^{253}$

reflektierte ein anderer Arzt in dem Journal de médecine et de chirurgie pratiques über den absurden Glauben (»absurde croyance «), den man nicht nur bei der »classe la plus misérable et la plus ignorante « teilte. ${ }^{254}$ Dass sich die Kritik an mangelndem hygienischen Bewusstsein und Nachlässigkeit nicht nur gegen die unteren Schichten, sondern sogar mit einer gewissen Schärfe gerade gegen die Angehörigen der bürger-

248 Vgl. Bourdelais/Raulot: Une Peur Bleue, 1987: S. 224.

249 Karrikaturbechriftung, 1832, zitiert nach Delaunay: Le Corps Médical et le Choléra en 1832, 1933: S. 13.

250 Vgl. Kudlick: Cholera in Post-Revolutionary Paris, 1996: S. 176.

251 Vgl. Académie Royale de Médecine: Rapport sur le choléra-morbus I, 1831: S. 178.

252 Vgl. Magendie, Leçons sur le choléra-morbus, 1832: 232f.

253 [Hrsg.]: Considérations pratiques sur le choléra-morbus de Paris, son invasion, sa marche, ses symptômes, son traitement, et les précautions prises par l'autorité pour en prévenir le développement ou arrêter ses progrès: in: Journal de médecine [...], 3.1832: S. 133.

254 Ebd.: S. 132f. 
lichen Schicht richtete, bestätigt nur die Funktion dieses Diskurses, eine moralische Differenzierung der verschiedenen Klassen vorzunehmen:

»[N]ous accusaient de joindre nos efforts à ceux de prétendus empoisonneurs, préjugés répandus non-seulement dans la classe la plus misérable et la plus ignorante, mais encore parmi des hommes que leur éducation semblait devoir mettre à l'abri d'une pareille stupidité. «255

Weiter schrieb er:

»On sent bien que ces idées d'empoisonnement répandues dans le peuple devaient favoriser le développement de l'épidémie; car ces malheureux, ne croyant point à la présence du choléra, négligeaient toutes les précautions indiquées par la prudence, se gorgeaient de liqueurs et ne réclamaient les secours de l'art que lorsqu'ils n'avaient que quelques heures à vivre. Nous avons vu des malades vomir d'abord une immense quantité de vin rouge et de matières alimentaires, et succomber en quelques heures aux plus violents symptômes du choléra. Les troubles dont cette croyance a été l'occasion, les passions violemment excitées, l'inquiétude, la crainte, le séjour dans les rues, voilà bien des causes qui ont pu contribuer à répandre le mal, à le faire sévir avec plus de fureur; $[\ldots] . \ll^{256}$

Überhaupt wurden die Unruhen und Aufstände, die im Zusammenhang mit der ersten Choleraepidemie in Paris auftraten, als bestätigend aufgefasst für das Bild, das sich die bürgerliche Schicht von den Armen von Paris gemacht hatte. ${ }^{257}$ Die optimistische Stimmung, die vor allem die Bürgerschicht und die Regierung noch bis in die ersten Tage des Ausbruchs der Cholera zu der Auffassung bewegt hatte, Paris könne, als die gewissermaßen modernste Stadt und als Zentrum der modernsten europäischen Nation, nicht zu schwer von der Cholera getroffen werden ${ }^{258}$, schlug nach den Ereignissen Anfang April 1832 in Angst vor dem Verfall der Gesellschaft um. In einem Artikel, der kurz nach dem Ausbruch der Epidemie in dem Journal de médecine et de chirurgie pratiques erschien, wurden die Bemühungen der Regierung beschrieben, die sich an alle Regeln der öffentlichen Hygiene gehalten habe, jedoch machtlos angesichts der Sitten und des Mangels an privater Hygiene der Bewohner der Stadt sei.

255 Ebd.

256 Ebd.: S. 133.

257 Vgl. Kudlick: Cholera in Post-Revolutionary Paris, 1996: S. 38.

258 »Le 2 avril, le Ministre des Travaux publics alertait les autorités départementales, d'ailleurs avec l'optimisme officiel: >Monsieur le Préfet, le choléra spasmotique vient de se manifester à Paris. Cet événement est fâcheux, mais il ne doit pas exciter d'inquiétudes exagérées. En s'avançant vers nos contrées, le choléra a beaucoup perdu de son intensité.« Zitiert nach Delaunay: Le Corps Médical et le Choléra en 1832, 1933: S. 16. 
»Mais on sent que ses mesures et ses conseils ne pouvaient avoir qu'un résultat bien imparfait, car il n'était pas au pouvoir des médecins qui s'étaient chargés de visiter et d'assainir chaque maison, de changer les mœurs de ses habitants. $\ll^{259}$

Heinrich Heine hatte in seinem Text nicht nur über »Lumpensammler und alte Trödelweiber« geschimpft, sondern auch viel Spott für die Reichen übrig, die nach dem Ausbruch der Cholera in Panik Paris verließen.

»Obgleich die Cholera sichtbar zunächst die ärmere Klasse angriff, so haben doch die Reichen gleich die Flucht ergriffen. Gewissen Parvenüs war es nicht zu verdenken, daß sie flohen; denn sie dachten wohl, die Cholera, die weit her aus Asien komme, weiß nicht, daß wir in der letzten Zeit viel Geld an der Börse verdient haben, und sie hält uns vielleicht noch für einen armen Lump und läßt uns ins Gras beißen. $\ll^{260}$

Aber wen oder was hat er hier genau verspottet? Er fand es in gewisser Hinsicht albern, dass Leute glaubten, der Reichtum würde sie vor der Cholera schützen. Das wirklich >Edle< zeigte sich nicht im Reichtum, sondern im Verhalten und der Weise, wie man der Krankheit begegnete.

»Die eigentlichen Repräsentanten des Reichtums, die Herren von Rothschild, sind jedoch ruhig in Paris geblieben, hierdurch beurkundend, daß sie nicht bloß in Geldgeschäften großartig und kühn sind. [...] Auch der junge Kronprinz, der Herzog von Orléans, welcher in Begleitung Periers das Hospital besuchte, verdient die schönste Anerkennung. Die ganze königliche Familie hat sich in dieser trostlosen Zeit ebenfalls rühmlich bewiesen. Beim Ausbruche der Cholera versammelte die gute Königin ihre Freunde und Diener und verteilte unter ihnen Leibbinden von Flanell, die sie meistens selbst verfertigt hat. Die Sitten der alten Chevalerie sind nicht erloschen; sie sind nur ins Bürgerliche umgewandelt; [...] Ich selbst stecke bis am Halse in Flanell und dünke mich dadurch cholerafest. Auch der König trägt jetzt eine Leibbinde vom besten Bürgerflanell. $\ll^{261}$

Obwohl Heine deutlich machte, welche Verhaltensweisen und Selbstpraktiken er für sich selbst bevorzugte und auch bei anderen anerkannte, war ihm gleichzeitig klar, dass es eine Gemeinsamkeit in den Praktiken gab, mit der sich die Einzelnen aufgrund ihrer Lebensweise, ihres Seins, Glaubens, Wissens und ihrer politischen Einstellungen für »cholerafest« hielten. Wer sich vor der Krankheit fürchtete, dem fehlte es an bürgerlicher Vernunft oder neuen bürgerlich gewordenen adligen oder einem in ähnlicher Weise hergestellten religiösen Selbstvertrauen: ${ }^{262} »$ Was mich betrifft, ich glaube an Flanell. Gute Diät kann auch nicht schaden. $\ll^{263}$ Eine sehr einprägende Er-

259 [Hrsg.]: Considérations pratiques sur le choléra-morbus de Paris, son invasion, sa marche, ses symptômes, son traitement, et les précautions prises par l'autorité pour en préve.nir le développement ou arrêter ses progrès: in: Journal de médecine [...], 3.1832: S. 129.

260 Heine: Artikel VI: in: Französischen Zustände, 1833 [1832]: S. 65.

261 Ebd.: S. 65f.

262 Vgl. ebd.: S. 69f.

263 Ebd.: S. 70. 
fahrung der ersten Epidemie war es also, dass es mit der Aufklärung der Pariser Bevölkerung, was deren Bereitschaft anging, sich nach einer bestimmten von der Medizin und der Polizei propagierten Vernunft selbst zu regieren, nicht sehr weit her war.

\section{Die Politik der Information während der ersten Epidemie}

Die Choleraepidemie in Paris hatte deutlich werden lassen, dass die medizinische Wissenschaft keine nützlichen Erkenntnisse über die Ursache der Cholera, ihre Kontagiosität bzw. ihren genauen miasmatischen Charakter erlangt hatte. Sie bot der Regierung kein Wissen, das ihr als neue rationale und liberale Handlungsgrundlage gedient hätte. Diese Erfahrungen trugen dazu bei, dass sich eine Verschiebung von dem zuvor bevorzugten medizinisch-pathologischen hin zu einem epidemiologischen Blick auf die Cholera vollzog. Diese Hinwendung zur Epidemiologie war ihrerseits die Folge eines über Informationsoffenlegung funktionierenden Legitimationsmechanismus der französischen Regierung, die mit einer unglaublichen Datensammlung über die Cholera einher ging.

»Die zweite Periode der Cholera in Paris haben sie die wissenschaftliche genannt $\ll^{264}$ schrieb Hufeland 1832 in seinem Journal über die Choleraepidemie in Paris. Diese Phase spiegelt den Versuch der Medizin wider, durch eine fieberhafte und möglichst genaue epidemiologische Betrachtung der Krankheit, zu einer Lösung des Choleraproblems zu gelangen. In diesem Prozess der Erforschung der Cholera beschloss man in der Académie de Science alle möglichen Theorien, die sich angesichts der Erfahrungen mit der Cholera sämtlich als widersprüchlich erwiesen hatten, beiseite zu lassen und sich darauf zu beschränken, >reine Fakten< abzubilden und andererseits sich durch keine Theorie über die Ursache der Krankheit in der Untersuchung einschränken zu lassen. ${ }^{265}$

»Le secret, disons-le tout d'abord, en est dans la méthode appliquée par le rapporteur. Il y a deux manières d'étudier le choléra-morbus. L'une qui consiste à noter historiquement et sans idée préconçue tout ce qui est phénomène d'observation; l'autre à recueillir et à présenter les faits comme preuves à l'appui de telle ou telle doctrine. ${ }^{266}$

Der Kanon der Académie Royale de Médecine forderte eine Lösung von allen Theorien und eine Konzentration auf die Fakten und v.a. auf eine Methode der reinen Analyse der Fakten »On se bornant au rôle d'observateur, [...] l'analyse rigoureuse des faits $\aleph^{267}$. Hufeland schrieb nun über diese Phase, die er oder die man in Paris die

264 [Hrsg.]: Die Choleraepidemie in Paris: Hrsg.: Die Choleraepidemie in Paris: in: JPA, 75.1832, S. 96 - 110: S. 96. Vgl. auch die Beschreibung der ersten Periode der Cholera in Paris: Hrsg.: Die Choleraepidemie in Paris: in: JPA, 74.1832, S. 110 - 116.

265 Vgl. Académie de Sciences: Travaux des Académies, Académie de Sciences: in: Gazette Médicale de Santé [...], et Journal spécial du Choléra-Morbus, 1832: S. 20.

266 Académie de Médecine: Sur le rapport de la nouvelle commission du choléra morbus: in: Gazette Médicale de Santé [...], et Journal spécial du Choléra-Morbus, 1832: S. 318.

267 Ebd.: S. 319. 
wissenschaftliche Phase genannt hat, wobei ich dazu neigen würde zu sagen, es war die Phase des Übergangs zur epidemischen Sicht auf die Cholera:

»Wir werden es daher hier nicht mit Beobachtungen zu thun haben, welche in einer bestimmten Absicht unternommen, oder für einen bestimmten Zweck mitgetheilt sind, sondern mit reinen Thatsachen, deren Deutung dem Mittheilenden gleichgültig, deren Vorhandenseyn verbürgt, deren Bekanntwerden wichtig ist. $\ll^{268}$

Aber was soll eine Regierung mit einer solchen Sammlung an Daten? Verlangt sie nicht von der Medizin, ihr eine Theorie zu präsentieren, eine Grundlage, auf der sie ihre Handlungen begründen kann? »Le but que le gouvernement s'est proposé en demandant à l'Académie une instruction sur le choléra-morbus. ${ }^{269}$ Aber die medizinische Wissenschaft nahm sich in gewisser Weise aus einem solchen engen Verhältnis heraus.

»[L]'Académie en rédigeant cette instruction, n'a pas été de présenter un tableau complet et détaillé de tout ce que la science a recueilli pendant l'épidémie de Paris, outre qu'il est encore un grand nombre de points sur lesquels on n'est pas d'accord, ce travail aurait compris une foule de détails inutiles à la pratique $[\ldots] . \ll^{270}$

Die Regierung nahm im Folgenden keinen spezifischen Bezug mehr auf die Medizin, sondern ihre Existenzbedingung hing lediglich davon ab, zu bekunden, dass sie nichts vernachlässigt habe, dass ihre Ökonomie, ihre Statistik, ihre hygienischen Regeln alles einbezogen habe, was die Wirklichkeit dessen, was sie regierte, ausmache. Und das Einzige, das nun von der Medizin erwartet wurde, war, dass sie alles offenlege, was sie durch ihre Forschung sichtbar machen könne.

Diese Transformation des Verhältnisses von Regierung und Medizin hatte die nach der französischen Revolution angestrebte Verschmelzung von Medizin und Hygiene, von Regierung und Wissenschaft weiter auseinander getrieben. Die Regierung musste sich nun nicht über die Präsentation der Wahrheit, auf deren Grundlage sie regierte legitimieren, sondern über die Präsentation eines möglichst umfassenden Wissens, durch das Einbeziehen dieses Wissens und über ihre eigene hygienische oder ökonomische Vernunft, nach welcher sie dieses Wissen sortierte und bewertete. Während der Choleraepidemie in Paris begann, eine umfassende Informationspolitik, die auf einem Zusammenspiel von wissenschaftlichen Institutionen und Kommissionen, Krankenhäusern, der Administration und der Presse beruhte, zu betreiben. Die Regierung kam damit einer Existenzbedingung moderner Gouvernementalität nach,

268 Vgl. [Hrsg.]: Die Choleraepidemie in Paris: in: JPA, 75.1832, S. 96 - 110: S. 96.

269 »Nicht mehr als Eigenliebe, nicht mehr für Paris allein werden einzelne Beobachtungen mitgetheilt, sondern als Aktenstücke in das Archiv der Wissenschaft gelegt, gehören sie allen an, die sie benutzen wollen. Eine möglichst schnelle Verbreitung derselben liegt daher eben so im Interesse der Wissenschaft, als im Wunsche der Pariser Aerzte, und beiden zu genügen ist der Zweck folgender Blätter.« Ebd.: S. 97.

270 Académie de Médecine: Sur le rapport de la nouvelle commission du choléra morbus: in: Gazette Médicale de Santé [...], et Journal spécial du Choléra-Morbus, 1832: S. 318. 
mit der sie sich von ihrem Gegenentwurf einer >willkürlichen « Regierung abzugrenzen und zu legitimieren versuchte, auch wenn sie nicht in der Lage war, die Epidemie abzuwenden. Die Ziele und Handlungen der Regierung sollten dem Urteil der Öffentlichkeit standhalten und sich seiner Überprüfung auf Grundlage der gemeinsam verfertigten Rationalität durch das Publikum aussetzen. ${ }^{271}$ Der Output der medizinischen Zeitschriften zur Cholera war Anfang der 30er Jahre des 19. Jahrhunderts enorm. Viele Journale brachten Sonderausgaben zur Cholera und Bibliographien heraus, in denen sich wissenschaftliche Artikel und anatomisch-pathologische Beobachtung an praktische Anleitungen zur Behandlung der Cholera, hygienische Ratschläge, private Erfahrungsberichte und von der Regierung veröffentlichte Bekanntmachungen, Berichte und Statistiken aneinanderreihten. ${ }^{272}$ In der auch von Paul Delaunay erwähnten Sonderausgaben zur Cholera durch die Redaktion der Gazette Médicale heißt es zu Beginn:

»La Gazette Médicale en prenant le titre de Journal Spécial du Choléra-Morbus, s'engage à faire connaître toutes les mesures sanitaires, tous les rapports officiels, tous les faits importans observés en ville et dans les hôpitaux, avec l'indication des différens traitemens employés par les médecins de ces établissements et les principaux praticiens de la capitale. La Gazette Médicale publiera en outre, tous les deux jours, un bulletin très-détaillé du nombre des malades, des morts, des quartiers de Paris où ils auront été observés, de leur âge, sexe et profession; de cette manière elle présentera l'histoire complète du choléra-morbus en France, sous le rapport administratif, statistique, hygiénique et médical.«273

Die Regierung veröffentlichte unter der Aufsicht des préfet de police von Paris selbst ein Journal des Commissions sanitaires, um >die Öffentlichkeit< über die von der Regierung formulierten Vorschriften (préscriptions) zu informieren. ${ }^{274}$ Als Höhepunkt dieser enormen Sammlung an Informationen und Daten über die Cholera kann der zweite Bericht der commission du choléra »sur la marche et les effets du choléramorbus dans Paris et le département de la Seine« angesehen werden.

271 Vgl. [Hrsg.]: Hygiène. Rapport du Conseil de Salubrité pour l'année 1824: in: GS 12.1826, S. 89 - 91: S. 89. Der Artikel endet nach einigen Auszügen aus dem Bericht in einer Kritik und Aufforderung an den Préfet de la Police mehr für die Staßenhygiene zu tun. Es sollen neue Häuser gebaut werden, eine Kanalisation und für mehr Licht und bessere Luft in den Straßen von Paris gesorgt werden: Vgl. ebd.: S. 91.

272 Vgl. Delaunay: Le Corps Médical et le Choléra en 1832, 1933: S. 6.

273 [Hrsg.]: Gazette Médicale de Santé [...], et Journal spécial du Choléra-Morbus, 1832: S. 3.

274 Vgl. Préfet de Police [Hrsg.]: Journal des Commissions sanitaires établies dans le département de la Seine, $1831-1832$. 


\section{Les effets du choléra-morbus dans Paris}

Der Bericht der commission du choléra bestand zu einem Großteil aus Tabellen und statistischem Material. Die Herausgeber erhoben den Anspruch, in diesem Bericht den ganzen Umfang der gesammelten Einzelberichte und Daten zusammenzuführen. ${ }^{275}$

Wie schon im ersten Bericht ausdrücklich betont, wurde in dem zweiten Bericht die enge Zusammenarbeit von Medizinern, aufgeklärten und reichen Bürger und Regierung hervorgehoben: »De concert avec les médecins aussi bien qu'avec les citoyens éclairés et riches [et] l'autorité administrative $\ll{ }^{276}$ Die Regierung der Gesundheit der Bevölkerung erfolgt nicht mehr nur über die expliziten staatlichen Maßnahmen, sondern verteilt sich auf eine unendlich große Zahl verstreuter Praxen und auf unendlich vielen Schauplätze: in der Arztpraxis, im Badezimmer der Familie, in der Schule, auf der öffentlichen Toilette einer privaten Firma. ${ }^{277}$ Überall sicherte die Regierung ihre Souveränität, indem sie eine moralische und moralisch erhöhte Position bezog. Diese moralische Erhöhung über die bzw. durch die Differenz zu den regierten Subjekten vollzog sie durch den Verweis auf die Lebenspraxis und eine als universell verstandene Vernunft. Durch diesen Verweis wurde die Regierung der weniger rationalen und weniger moralischen Subjekte gerechtfertigt. Die Technik der bürgerlichen, moralischen Praxis der Selbstregierung und seine Anbindung an wissenschaftliche Wahrheit ermöglichte eine zirkulierende und tendenziell allgegenwärtige Rationalität. Vor allem, weil dieser Bereich, den die Regierung der Gesundheit nun regieren musste, so ausufernd war. Weil es so viel Wissen und so viel zu tun gab, war diese Verteilung der Macht, die an die gleichen Bedingungen der Rationalität geknüpft blieb, eine, die die grundsätzliche Macht der Regierung erweiterte, statt dieser echte Grenzen zu setzen.

Schon zu Beginn des Berichts Rapport sur la marche et les effets du choléramorbus dans Paris et le Département de la Seine legten die Autoren offen, dass selbst diese umfangreiche Sammlung von Fakten nicht dazu geführt hätte, die Cholera und vor allem ihre spezifischen Ursachen herauszufinden: »la cause ainsi que la nature sont restées inconnues ${ }^{278}$. Der klinische, medizinische Blick in die Tiefe des Körpers hat nicht dazu verholfen, die Krankheit besser zu verstehen. Die unglaubliche Gelegenheit der Epidemie war vorüber, ohne dass ihr Geheimnis gelüftet worden wäre und ohne dass ein spezifisches Mittel Wirkung gezeigt hätte. ${ }^{279}$ Was bot die Académie also der Regierung an, wenn sie ihr keine handfeste Theorie und keinen Beweis über die spezifische Ursache der Cholera liefern konnte? Wenn die Medizin in dieser Weise versagt hatte, wie konnte sie der Regierung noch nützlich sein? »Toutes les conjectures, tous les systèmes ont été successivement admis, rejetés; l'art

275 Vgl. Les préfètes de la Seine et de police: Rapport sur la marche et les effets du choléramorbus dans Paris et les communes rurales du département de la seine, année 1832, 1834:

S. 8. (Introduction), S. 7 - 10]

276 Ebd.: S. 142. Vgl. ebd.: 7.

277 Vgl. ebd.: S. 14. (Chapitre premier: Précautions prises par l'administration avant l'invasion du choléra, S. 10 - 18.)

278 Ebd.: S. 12.

279 Ebd. 
a avoué son impuissance. ${ }^{280}$ Die Medizin lieferte der Regierung eine Sammlung der während der Zeit der Epidemie zusammengetragenen Berichte, Daten und Statistiken. Ein 500 Seiten starker Bericht, von dem gut zwei Drittel aus statistischen Tabellen besteht, verdeutlicht den Wechsel der Strategie: Von dem Versuch, medizinische Lösungen zu finden, hin zu einer epidemologischen Sicht auf die Cholera. Dieser Bericht sollte die Essenz der Informationen in eine Darstellung bringen. Anstatt aus ihr eine Theorie über die Cholera abzuleiten, war die Methode der Klinik, die Krankheit in ihrer ganzen Sichtbarkeit im Innern abzubilden, auf das soziale äußere und lebendige Phänomen der Epidemie übertragen worden. Die Methode wurde angewendet, weil man im Inneren, im toten Körper nichts gefunden hatte: »En vain on ouvre les cadavres de ceux qu'il a frappés; on interroge la mort: la mort ne révèle rien. ${ }^{281} \mathrm{Ge}$ nau hierin bestand die Wendung des Blicks, von dem Blick des Klinikers, der die Wahrheit im Körper und in der Untersuchung der toten Körper sucht, hin zum Blick eines Epidemiologen und Statistikers, der auf ein Feld heterogener Faktoren, ihrer Abhängigkeit und Wirkungen - auf das Leben schlechthin blickt. ${ }^{282}$

Diese Tendenz in Richtung einer Perspektive der Regierung hatte sich schon vorher angedeutet, die Cholera bot die Gelegenheit und die Begründung für diese Verschiebung. Die Krankheit als Epidemie war eher Gegenstand einer hygienischen Betrachtung der sozialen und natürlichen Umwelt, wie man sie aus den antiken und v.a. hippokratischen Lehren in direkter Weise auf eine Praxis der Führung und Regierung übertragen wollte, wie auch Aisenberg feststellt. ${ }^{283}$

Eine Perspektive, die seit dem ausgehende 18. Jahrhundert die zunehmend statistische Betrachtung von Krankheiten, vor allem in Städten, um eine erhebliche Anzahl von neuen Variablen bereichert hatte. ${ }^{284}$ Die Cholera wurde nun in ihrem Verhältnis zum gesamten »état physique « und »état sanitaire« der Stadt Paris betrachtet. ${ }^{285} \mathrm{Im}$ zweiten Kapitel des Berichts, »Coup d'œil sur l'état physique et sanitaire de la capitale au moment de l'invasion«, unternahm die Kommission den Versuch, diesen so allgemein wie nur möglich verstandenen >Zustand < der Stadt Paris zum Zeitpunkt des Ausbruchs der Epidemie zu beschreiben. Das Kapitel beginnt mit einer ausführlichen geographischen Beschreibung der Lage der Stadt, ihrer Höhen und Tiefen, der Fluss-

280 Ebd.

281 Ebd.

282 Vgl. ebd.: S. 12f.

283 Vgl. Aisenberg: Contagion. Disease, Government, and the »Social Question« in Nineteenth-Century France, 1999: S. 21.

284 Vgl. z.B. [Hrsg.]: Hygiène Publique. Rapport générale sur les travaux du Conseil de salubrité pour l'année 1823: in: GS, 34.1824, S. 269 - 270. »La differénce de la mortalité, relativement à la population, $[\ldots]$ entre les divers arrondissements de Paris [...] la classe et peut-être la profession des individus le plus communément frappés de maladies mortelleS. Ebd.: S. 270.

285 Les préfètes de la Seine et de police: Rapport sur la marche et les effets du choléramorbus dans Paris et les communes rurales du département de la seine, année 1832, 1834 : S. 18. 
läufe, sonstiger Gewässer, des Bodens und der Ausdehnung der Siedlungen. ${ }^{286}$ Dann folgt eine eher soziale Topographie der Stadt. ${ }^{287}$ Ein weiteres Kapitel beschreibt die Ausbreitung und Dauer der Epidemie in Paris ${ }^{288}$ und alles Weitere, was der Bericht wiedergibt, besteht aus Statistiken, Zahlen und dem Verhältnis von verschiedenen Variablen: »Rapport de la mortalité cholérique avec le sexe et l'âge «, ${ }^{289} \gg$ Rapport de la mortalité cholérique avec la température ${ }^{290}$ und $\gg$ Rapport de la mortalité cholérique avec les localités «. Letzterer beinhaltet auch Berichte über die Sterblichkeit im Verhältnis zu verschiedenen anderen Einflüssen (»les différentes expositions«), wie Wind, Lage ${ }^{291}$ und Feuchtigkeit an verschiedenen Orten der Stadt. ${ }^{292}$ Obwohl die Kommission sich eindeutig nicht zu einer Theorie über die Ursachen der Cholera bekannte, wirkten der epidemiologische Blick auf die Cholera und die verstreuten Faktoren, die sie begünstigten, als Unterstützung für die Miasma-Theorie und für die sog. Lokalisten. Dies ist vor allem in dem Bericht über die Epidemie im Süden Frankreichs noch deutlicher zu erkennen. ${ }^{293}$ Die statistischen Darstellungen waren vor allem geeignet, den Zusammenhang zwischen einem Ort und den Bedingungen einer bestimmten Lokalität mit der Cholera in ein Verhältnis zu setzten. Ebenso wurde durch diese Perspektive eine relative Verbindung zwischen der Cholera und der Lebensweise bzw. den Lebensumständen der Menschen, die an ihr erkrankten, möglich. Im siebten Kapitel des Kommissionsberichts wurde die Cholerasterblichkeit z.B. im Verhältnis zur Bevölkerungsdichte (la densité de la population) betrachtet. ${ }^{294}$ Die Verbindung von Elend, Schmutz und der Bildung pathogener Dämpfe (efflu$v i a)^{295}$, bezogen auf eine Lokalität, wirkte gerade deshalb so überzeugend, weil sie in die ohnehin vorhandene hygienische Doktrin passte und weil es sich um benennbare und beobachtbare Faktoren handelte, die während der Epidemie, statistisch gesehen, tatsächlich gemeinsam auftraten: »C'est là encore ce qui fait tant peser les épidémies sur les classes pauvres, dans les maisons et dans les quartiers où se rencontrent toutes

286 Vgl. Chapitre II Coup d'œil sur l'état physique et sanitaire de la capitale au moment de l'invasion, S. 20 - 38, ebd.: $20 \mathrm{ff}$.

287 Vgl. ebd.: S. 24ff.

288 »Chapitre III Invasion et dévelopement du choléra dans Paris«, vgl. ebd.: S. 39 - 63.

289 »Chapitre IV «, vgl. ebd.: S. $64-71$.

290 »Chapitre V«, vgl. ebd.: S. $71-74$.

291 »Rapport de la mortalité avec l'élévation du terrai - Le tableau suivant présente les quarante-huit quartiers de Paris placés selon une évaluation approximative de leur élévation moyenne et de mètre en mètre en nombres ronds, ou de trois pieds en trois pieds, audessus du 0 du pont de la Tournelle.« Ebd.: S. 91f.

292 »Chapitre VI«, vgl. ebd.: S. 75 - 110. Vgl. Abb. IV.

293 Vgl. Dubreuil/Rech: Rapport sur le choléra-morbus asiatique qui a régné dans le midi de la France en 1835, 1836: S. 187ff.

294 »Chapitre VII «: Les préfètes de la Seine et de police: Rapport sur la marche et les effets du choléra-morbus dans Paris et les communes rurales du département de la seine, année 1832, 1834: S. 110 - 125.

295 Vgl. ebd.: S. 125. 
les conséquences de la misère. « ${ }^{296}$ Schließlich beinhaltet der Bericht von 1834 noch ein weiteres Kapitel: »De l'influence des professions, des affections morales et du régime sur le choléra. ${ }^{297}$ Bei Letzterem, so gaben die Mitglieder der Kommission zu, handelte es sich um etwas, das sie selbst kaum erfassen können und über das es aus ihrer neuen Betrachtungsperspektive kaum noch Möglichkeiten der Darstellung gab. Statt die Lebensweise der Einzelnen, ihre Ernährung, Kleidung und Moralität zu berücksichtigen, wandte sich die Kommission der Betrachtung von Bevölkerungsgruppen zu, denen man, z.B. aufgrund ihrer gemeinsamen Wohnlage oder Profession, eine Gemeinsamkeit in ihrer Lebensweise zurechnete. ${ }^{298}$ Tatsächlich stand der Blick der Epidemiologie auf die Bevölkerung im Widerspruch zu dem Blick, der bis zum einzelnen Individuum und seiner Lebensweise vordringen konnte. Und dennoch blieb die Art der Regierung und das Interesse der Regierung im Kern der Idee der Führung der Einzelnen treu.

Nach noch weiteren Kapiteln, die Berichte über die Cholera und die Sterblichkeit aus den Hospizen und den Gefängnissen als auch Kasernen von Paris und dem Umland der Stadt enthalten, hob die Kommission den für ihren ganzen Bericht ausschlaggebenden Aspekt hervor: »L'influence des établissements réputés insalubres sur le choléra«. Hier kam die Kommission zu dem Schluss, dass von allen Faktoren, die man beobachten könne, es einen Faktor gebe, der die Cholera besonders begünstige und der ein absolut menschlicher und durch Menschen beeinflussbarer sei: $»$ L'insalubrité ${ }^{299}$. Auf diesem Weg wurde die Cholera nun wieder, nachdem die Medizin dies nicht vermocht hatte, durch die Wissenschaft zu einem Gegenstand der Regierung erklärt - zu einem regierbaren Problem. Der Schlüssel hierfür liege in der Untersuchung und im Vergleich verschiedener Dörfer, denen man allgemein eine ähnliche soziale und geographische Beschaffenheit zurechnete. Der Mangel an Regierung (»la mauvaise tenue du village $\aleph^{300}$ ), ebenso wie ihr Erfolg, könne über den Vergleich der Dörfer nun einfach bestimmt werden: Nämlich durch die statistischen Zahlen der Sterblichkeit in den Orten. ${ }^{301}$ Auch hier zeigt sich, wie die These des Zusammenhangs zwischen unsauberer Lebensweise, Schmutz, Gestank und dem Ausbrechen von Epidemien bei den Epidemiologen, ohne es darauf speziell angelegt zu haben, insgesamt die Miasma-Theorie in Frankreich gestärkt hat. ${ }^{302} \mathrm{Im}$ Resümee des Berichts heißt es, man könne den Bericht hier beenden: elle n'a rien de plus à ajouter à ces résultats. $\ll^{303}$ Man würde die Grenzen der $>$ Kunst $<$ zu weit überschreiten, wenn man nun auch noch politische Vorschläge unterbreiten würde. Solle doch die Öffent-

296 Vgl. Dubreuil/Rech: Rapport sur le choléra-morbus asiatique qui a régné dans le midi de la France en 1835, 1836: S. 191f.

297 »Chapitre VIII «: Les préfètes de la Seine et de police: Rapport sur la marche et les effets du choléra-morbus dans Paris et les communes rurales du département de la seine, année 1832, 1834: S. $126-144$.

298 Vgl. ebd.: S. 126.

299 Ebd.: S. 175. (Chapitre XII, S. 175 - 186.]

300 Ebd.: S. 180.

301 Vgl. ebd.: S. 176f. Vgl. S. 188f. (Résumé, S. 186 - 205]

302 Vgl. z.B., ebd.: S. 177.

303 Vgl. ebd.: S. 186. 
lichkeit darüber urteilen, welche Schlussfolgerungen sich aus diesen Fakten ergeben. Aber die Kommission fürchtete auch, man würde ihr ihre Zurückhaltung zum Vorwurf machen, ihr vorwerfen, keine Aussagen über die deutlichsten Ursachen der Cholera gemacht zu haben.

»[O]n ne l'accusera ni de n'avoir rien dit de la cause première du choléra, qui paraît devoir rester encore longtemps cachée sous le voile épais qui la couvre, ni d'avoir gardé le silence sur la question tant débattue de la contagion. [...] Elle a pensé, et plusieurs médecins parmi ses membres ont eux-mêmes pensé comme elle, qu'il lui appartenait surtout de demeurer, dans son rapport, étrangère à toute doctrine, à toute controverse médicale. $\ll^{304}$

Die pragmatische Haltung entspricht der Reflexion der Gouvernementalität der französischen Regierung, nicht der der Medizin. Die Mediziner stritten sich während des ganzen 19. Jahrhunderts über die Kontagiosität der Cholera. Aber die Regierungen, wie man auch später auf den internationalen Konferenzen betonte, sollten sich mit diesen Streitigkeiten nicht abgeben. Sie sollten ihre rationalen Entscheidungen möglichst auf Grundlage der Fakten und der Möglichkeiten ihrer tatsächlichen Handlungen und ihrer Optionen treffen. Die Kommission machte bereits deutlich, welchen Bereich der Regierung, der ganz unabhängig von der Frage der Kontagiosität bestehe, sie entdeckt hatte. Paris sei die Stadt, in der immer wieder um die politische Macht gekämpft worden war. Kämpfe, die die banale Existenz des Lebens über sich habe ergehen lassen müssen. ${ }^{305}$ Paris sei die Stadt, in der man sich gewissermaßen darauf verstehe, den Wert der politischen Souveränität zu kennen und um sie zu kämpfen. Aber wenn politische Souveränität und Existenz nun auf eine ganz andere Art bedroht sei, durch etwas, dass nicht vom Menschen, sondern von der Natur ausgehe, scheine man nicht zu verstehen, wie man sich gegen sie wehren solle, oder, anders gesagt, wie man seine Existenz verteidigen solle. Dabei sei der Kampf gegen dieses Übel gerade einer, der allen nütze, da niemand durch die Cholera verschont würde, so die Aussage des Berichts. ${ }^{306}$

Die Kommission machte hier einen fundamentalen Unterschied zwischen einem legitimen Aufbegehren gegen die Regierung oder Herrschaft, die als Teil einer Auseinandersetzung um die politische Souveränität gesehen wurde, und einem Widerstand gegen die Regierung, den man als unvernünftig und illegitim ansah, da es bei der Ausübung der Macht der Regierung nicht um die Ausübung einer Souveränität gegen eine andere Souveränität ging, sondern um die Verteidigung der gemeinsamen Existenz. Mit dieser Gegenüberstellung setzte die Académie Royale de Médecine mit ihrem Resümee an. Wenn man doch etwas gegen dieses Übel unternehmen wolle, dass sich von den Übeln unterscheide, die man in der Regel als politisch im Sinne von >streitbar< auffasste, dann müsse man die Bekämpfung dieses Übels genau deshalb zu einer Aufgabe der Regierung machen. Die Sicherung der Existenz der Bevölkerung sei die wirkliche Aufgabe der Regierung, wenn die Auseinandersetzung um ihre Souveränität beendet ist. Die Kommission war überzeugt, dass der einzige Weg

304 Ebd.: S. 189.

305 Vgl. ebd.: S. 190.

306 Vgl. ebd. 
gegen die Cholera vorzugehen in der öffentlichen Gesundheit und den Bestrebungen der Regierung läge, die Existenz, also das Leben ihrer Bewohner zu verbessern: »qui contribue à la salubrité publique, à rendre les rues plus propres, les maisons plus saines, l'existence de leurs habitants meilleure. ${ }^{307}$ Dies sei also der Weg, wie man mit dieser Art von Militanz und Aufruhr, die die soziale Ordnung gefährde, umzugehen habe, die von ihrer grundsätzlichen Natur anders und im Prinzip nicht als politisch anzusehen sei. Die Erkenntnis der Verantwortlichkeit der Regierung für diesen Bereich gingen einher mit einer ganz anderen Rationalität, mit der es ihr in Bezug auf diesen Bereich erlaubt sein sollte, die juristische politische Rationalität beiseite zu lassen. Es war eine Rationalität, die um die Frage des Rechts kreiste und die im Angriff gegen die politische Herrschaft die Frage nach der juristischen Legitimation eines solchen Angriffs stellte oder den Angriff abwehrte mit einem juridischen Diskurs des wahren Rechts der Regierung. Auch wenn der Fortschritt der Zivilisation in Paris nicht zu übersehen sei, wäre es nur zu offensichtlich geworden, dass es eine Klasse gebe, die daran nicht teilgenommen habe und deren Existenz den Fortschritt im Ganzen bedrohe, besonders, weil sie sich gegenüber der Regierung uneinsichtig verhalte. ${ }^{308}$ Diese Klasse sei nicht einfach die Arbeiterklasse. Schließlich sei die Arbeiterklasse eine sehr >nützliche Klasse $<$, sondern das Problem sei eben eine bestimmte, moralisch >degenerierte< Klasse, die sich in den dicht bewohnten Städten und vor allem in Paris immer weiter vermehre:

»Non-seulement il existe dans son sein une classe nombreuse occupée tout le jour à pourvoir par un travail pénible à sa subsistance, et sur laquelle les soins de l'administration doivent s'étendre en tout temps pour la garantir des dangers qu'elle ne peut ou ne sait pas combattre; mais au-dessous de cette classe utile et laborieuse, il en existe une autre partout reconnaissable à son dénûment absolu, à sa dégradation profonde. [...] créée dans nos villes populeuses et manufacturières par les revers de l'industrie, les fautes de l'imprévoyance, les désordres de l'inconduite, cette classe n'est nulle part plus nombreuse qu'à Paris [...] Sans domicile fixe, sans travail assuré, cette classe, qui n'a rien en propre que sa misère et ses vices, après avoir erré le jour sur la voie publique, se retire pendant la nuit dans les maisons garnies des différents quartiers de la capitale, qui semblent avoir été de tout temps destinées à la recevoir.«309

In dem abschließenden Teil des Berichts sind die Grenzen zwischen sozialer Unordnung und Unruhe, moralischer >Degeneration< und Kriminalität und der Gefahr von Seuchen verwischt. Die höhere Mortalität in den besagten Bevölkerungsschichten wird hier naturalisiert und, ähnlich wie bei Thomas Malthus, einem biologischen, natürlichen Regulationsmechanismus zugeschrieben. Allerdings bestand aus Sicht der Verfasser die Chance auf den gesellschaftlichen Fortschritt, die Verbesserung der Menschen weiter fort. ${ }^{310}$ Alles Schlechte und Schädliche sollte durch diese Kraft der Verbesserung ausgeschaltet werden: »[le] nuisible, alors elle les altère, les anéantit,

307 Ebd.: S. 190f.

308 Vgl. ebd.: S. 191.

309 Ebd.: S. 191f.

310 Vgl. ebd.: S. 192. 
les tue ${ }^{311}$ Diese (Bio-)Macht, dieser Einfluss, der hier beschrieben wird, sei nirgendwo so eindeutig bewiesen, wie durch die Auswirkungen einer Seuche wie der Cholera unter den ärmeren und als >degeneriert< angesehenen Bevölkerungsschichten. ${ }^{312}$

Besonders die Idee der Kontagiosität, die Gefahr, die von diesen Bevölkerungsschichten ausgehe, denen man mehr oder weniger die Schuld an der Heftigkeit der Choleraepidemie in Paris zuschrieb, könne nur gemindert werden, indem der Staat, wenn er schon die Lebensweisen, die Selbstführung dieser Menschen nicht effektiv beeinflussen könne, deren Lebensverhältnisse so verbessere, dass die Folgen dieser Lebensweise gemindert würden. ${ }^{313}$ Die »santé publique«, die es zu erreichen und zu schützen gelte, sei mehr als nur die Summe der gesunden Individuen, die wohl auch über die Propagierung der hygiène privée verstanden werden könne. Es sei ein »gesellschaftlicher Zustand «, ein état social, der sich nicht nur auf den physischen gesundheitlichen Zustand der Gesamtbevölkerung, sondern auf eine umfassende Vorstellung von physischer und >moralischer Gesundheit< sowie sozialer Ordnung beziehe. An der hilflosen Angst der Bürger sei es am deutlichsten abzulesen, dass niemand anderes als die Regierung die Macht habe, diese Aufgabe der Sicherung einer so verstandenen santé publique zu gewährleisten. ${ }^{314}$

Diese allgemeinen Maßnahmen, die man - mit Foucault gesprochen -, als Sicherheitstechniken bezeichnen kann, seien von so allgemeinem Interesse ${ }^{315}$ und universeller Rationalität, dass sie auch gegen die Freiheit und die Interessen Einzelner geschehen müssen und sich vor allem dann gegen die Einzelnen durchsetzen müssten, wenn sie sich offensichtlich gegen diese universelle Rationalität und Regierung wandten, deren Gesetze sich an der Natur und der Wissenschaft orientierten.

Das bedeutet, dass sich die Regierung völlig legitim von der Zustimmung, von dem Urteil und von der Legitimation derer zu befreien versuchte, denen man schon an ihrer Lebensführung die Unvernunft und Irrationalität ansehen konnte. ${ }^{316}$ Die Einsicht über dieses Verhältnis der Regierung zu diesen Regierten und die Verbesserung der Lebensbedingungen dieser Bevölkerungsschichten, d.h., die Beseitigung der Gefahr der öffentlichen Sicherheit und Gesundheit, sollten nur durch die Verbesserung der allgemeinen Lebensumstände in der Stadt bewirkt werden. ${ }^{317}$

Paradoxerweise hatte die Idee der Verbesserung des Lebensstandards und der hygienischen Verhältnisse, die in Frankreich bei sozialen Reformern, Hygienikern und Wissenschaftlern schon vor der ersten Choleraepidemie bestanden hatte und die ab den 30er Jahren des 19. Jahrhunderts von verschiedenster Seite propagiert wurde,

311 Ebd.: S. 194.

312 Vgl. ebd.: S. 195.

313 Vgl. ebd.: S. 194.

314 Vgl. ebd.: S. 203.

315 »ll s'agit ici de la santé, de la vie, ces deux premiers intérêts de l'homme.«: Ebd.: S. 198.

316 Vgl. ebd.: S. 203f.

317 Vgl. ebd.: S. 204. 
keine besonderen praktischen Auswirkungen. ${ }^{318}$ Die radikalen Forderungen nach einer vollständigen Assanierung der Stadt, einem Zugang zu sauberem Trinkwasser für alle ihre Bewohner und der Beseitigung und Neuerrichtung ganzer Straßenzüge, wie sie z.B. Anhänger der Saint-Simonisten ${ }^{319} 1832$ vortrugen, wirkten eher bedrohlich. Sie hätten Enteignungen und ein massives Eingreifen der Regierung in Angelegenheiten bedeutet, die als privat galten und rechtlich geschützt waren. ${ }^{320}$ Die Regierung war durch ihre Konstituierung und juridische Logik in ihrer Macht gegenüber individuellen Eigentümern real begrenzt, was einen Großteil der Sicherheitstechniken beschränkte. Laut Aisenberg war dies auch ein Grund, warum die Regierung nie auf individualisierende Praktiken gegenüber den Armen verzichtete. ${ }^{321}$ Mit dieser Art von Erklärung für die Cholera, wie der zweite Bericht der Cholera-Kommission ihn formulierte, forderten die Hygieniker die Regierung dazu auf, einen Bereich ihrer Macht zu erkennen, der ihr neue Regeln und Begrenzungen auferlegte. Für diesen neuen Bereich der Regierung hatte die alten juridischen Begrenzungen ihren Sinn verloren, weil es gar nicht um das Problem der politischen Souveränität, sondern allein um das der physischen, materiellen Existenz ging. Der Cholerabericht verlangte von der Regierung, zu erkennen, dass die Problemstellung der alten Souveränität dieser neuen gouvernementalen Vernunft sogar widersprach. Die Überschreitung der alten Begrenzungen gelang durch eine Umdeutung, indem man die Überschreitung des rechtlichen Kompetenzbereichs der Regierung, als im Sinne eines intérêt publique, welcher die Summe aller individuellen Interessen darstellte, deren Vertretung die Aufgabe der Regierung war, rechtfertigte. Auch als die Epidemie 1835 im Süden Frankreichs ausbrach, hieß es in dem Bericht der Kommissare der Faculté de Médecine de Montpellier von Dubreuil und Rech, wie auch in dem zweiten Bericht der Kommission, die Regierung müsse den Schutz des privaten Eigentums zugunsten des öffentlichen Interesses zurückstellen.

318 Auch Kudlick schrieb: »Until the second half of the eighteenth century, the French government took only limited steps to promote itself as the permanent and established guardian of the public's health.«: Kudlick: Cholera in Post-Revolutionary Paris, 1996: S. 34.

319 Die Saint-Simonisten waren eine Bewegung, die sich nach dem Tod von Henri de SaintSimon 1825 und auf der Grundlage seiner Lehre gründete. Sie wurde aufgrund ihrer Bestrebungen, die Eigentumsverhältnisse durch die Abschaffung von Grundbesitz und vererbtem Vermögen umzugestalten, zu den französischen Frühsozialisten gezählt. Anderseits hatten die Saint-Simonisten auch deutliche Züge einer reformchristlichen katholischen Religionsbewegung. Was sich nicht nur in der von ihnen gepredigten guten Lebensweise und der Rolle der Priester in ihrer Gesellschaftsutopie deutlich zeigte, sondern auch von einigen ihrer prominentesten Vertreter propagiert wurde. Vgl. Strube, Sozialismus, Katholizismus und Okkultismus im Frankreich des 19. Jahrhunderts, 2016: S. 105f; $203 f$.

320 Vgl. Delaunay: Le Corps Médical et le Choléra en 1832, 1933: S. 46.

321 Vgl. Aisenberg: Contagion. Disease, Government, and the »Social Question« in Nineteenth-Century France, 1999: S. 26. 
»[O]n sait bien que ce n'est pas ordinairement dans l'intérêt seul de la santé publique [...]. Il est vrai que l'autorité est presque toujours obligée d'intervenir; mais elle ne doit pas craindre alors de blesser quelques intérêts privés, puisqu'elle agit dans l'intérêt de tous. «322

Das sog. intérêt public, verbunden mit der ganzen Problematisierung dieses intérêt général und intérêt commun im Vorfeld und im Anschluss an die Französische Revolution, symbolisierte einen Widerspruch und waren gleichzeitig mit dem Versuch der Lösung dieses Widerspruchs verknüpft. Die vage Definition des »bien commun « oder eben des intérêt public setzte sich an die Stelle der »utilité publique«, die mit der alten Idee der Souveränität und der Staatsräson verbunden gewesen war. ${ }^{323}$ Nach der Französischen Revolution hat die Académie Française versucht, die juristische Bedeutung der utilité publique mit der politischen Bedeutung des intérêt public usw. zu übersetzen. Das mit dem Prinzip der utilité publique verbundene Recht des Souveräns oder der Regierung auf Enteignung (expropriation) wurde aber faktisch abgeschafft. Paradoxerweise mit der Begründung, dass es in der Republik die Gegensätzlichkeit der Interessen nicht mehr gebe: Die Gründe für eine Enteignung seien auf dieser Grundlage völlig willkürlich. Jede oder keine Enteignung könne mit dem öffentlichen Interesse zu rechtfertigen sein. In mehreren juristischen Auseinandersetzungen während der ersten Hälfte des 19. Jahrhunderts ${ }^{324}$ wurden die Definitionen des intérêt public und der utilité publique in ihrer negativen juridischen und positiven politischen Bedeutung differenziert. Juristische Unklarheiten wurden beseitigt, aber der Widerspruch blieb für die Regierungspraxis bestehen. ${ }^{325}$ Die Praxis einer gouvernementalen Regierung, die eigentlich, wie Guillaume de La Perrière es, laut Foucault, forderte, kein Territorium, sondern $>$ die Dinge $<$, die heterogene Realität, regieren sollte, ${ }^{326}$ war schwer vereinbar mit Diskursen, die die Regierung innerhalb einer juridischen Logik und durch eine entsprechende Problematisierung ihrer Souveränität konstruierte. Wichtig ist hier nicht der generelle hygienische und an einen bürgerlichen Bezug auf Diätetik anknüpfende Ansatz. Für Frankreich spezifisch war, dass die Regierung zunächst die Selbstführung im Sinne der hygiène privée, die sich aus diesem bürgerlichen Diskurs heraus entwickelt hatte, als ihre Bedingung setzte. Sie orientierte sich und ihre Rationalität so eng am Modell bürgerlich-hygienischer und medizinisch-wissenschaftlicher Vorgaben, dass sie das Problem der arbeitenden Klassen und der Armen, die besonders unter den Epidemien und schlechten Lebensverhältnissen in den Städten zu leiden hatten, ignorierte. Die französische Regierung war während der Ersten und Zweiten Republik ebenso wie während der Julimonarchie auf die Konstituierung ihrer Beziehung zu den Bürger-Subjekten konzentriert. Dies machte

322 Dubreuil/Rech: Rapport sur le choléra-morbus asiatique qui a régné dans le midi de la France en 1835, 1836: S. 290.

323 Vgl. Foucault: La »gouvernementalité«, 2001 [1978]: S. 645.

324 Die Auseinandersetzung fanden im Zusammenhang mit den Gesetzen vom 1808, 1810, 1841 und 1867 zur Enteignung statt.

325 Vgl. Lalleau: Traité de l'expropriation pour cause d'utilité publique 1, 1845: S. 213. Vgl. Bidart: Commentaire législatif de la loi du 15 novembre 1867 sur les expropriations pour cause d'utilité publique, 1868: S. 155.

326 Vgl. Foucault: La »gouvernementalité«, 2001 [1978]: S. 644f. 
es grundsätzlich schwerer, einen praktischen Begriff von öffentlicher Hygiene zu entwickeln, der relativ unabhängig von der privaten hygienischen Praxis der >Bürger war. In Frankreich bestand die Vorstellung der Zentralisierung und Vereinheitlichung bzw. der Harmonisierung der Verhältnisse von privater und öffentlicher Hygiene, bürgerlichem Subjekt und Gesellschaft, von Medizin und Hygiene und der Praxis der Regierung des Selbst sowie der Regierung der Anderen. Heterogenität, wie es sie schon durch die Klassenverhältnisse gab, stellte in dieser Regierungslogik ein wirkliches Hindernis dar. Die Choleraepidemie machte die Schwächen dieser Regierung nur deutlicher. Der Mangel an eigener praktischer Rationalität hatte die Regierung während der ersten Epidemie in ein enges Abhängigkeitsverhältnis zur Medizin und wissenschaftlichen Hygiene, wie auch zur bürgerlichen privaten hygienischen Praxis und deren moralische Begründungen, gedrängt. Auch wenn schon während der ersten Epidemie sowohl die Wissenschaft auf ihre Funktion der >reinen< Wissensproduktion und der Unterscheidung ihrer Verfahren der Veridiktion von den Verfahren der Gouvernementalität und ihrer Rationalität hingewiesen hatte, war dieser Prozess der Lösung und notwendigen Aufteilung und Trennung sowie die Anerkennung des sich wandelnden und heterogenen Gegenstands der Regierung in Frankreich nur langsam möglich.

Nachdem ich nun sehr ausführlich auf die erste Epidemie in Frankreich eingegangen bin, will ich im Folgenden einige Zeitsprünge machen, die es mir hoffentlich trotzdem ermöglichen darzustellen, wie sich die Regierung von Gesundheit weiter an den Epidemien abgearbeitet hat.

\section{Polizei, Cholera und städtische Hygiene}

Gut 15 Jahre nach diesem zweiten Bericht der Cholera-Kommission, als die Epidemie Ende der 40er Jahre des 19. Jahrhunderts erneut in Paris ausbrach, waren die genannten Prozesse der Aufteilung und Trennung von Regierung und Medizin als auch Hygiene und Medizin weiter fortgeschritten. In den Instructions sanitaires sur les moyens préservatifs du choléra-morbus von 1849 zeigte sich der Versuch, die soziale Realität und die Existenz unterschiedlicher Klassen stärker in die Überlegungen zur Choleraprävention einzubeziehen. ${ }^{327}$ Die in dem 1834 erschienen Bericht der Cholerakommission der Präfektur deutlich gemachte Hinwendung zu dem Problem einer vernachlässigten Klasse, ${ }^{328}$ fand ihren leisen Anklang in den Aufgaben und Instruktionen einer städtischen Polizei. Der 32seitige Text der Instructions von 1849 setzte sich aus verschiedenen Schriftstücken zusammen und begann mit einer Note sur

327 Vgl. Conseil de Salubrité/Comité Consultatif d'Hygiène Publique/l'Académie Nationale de Médecine: Instructions sanitaires sur les moyens préservatifs du choléra-morbus, Précédées d'une notice sur l'assainissement de Paris, 1849.

328 Les préfètes de la Seine et de police: Rapport sur la marche et les effets du choléramorbus dans Paris et les communes rurales du département de la seine, année 1832, 1834: S. $191 f$. 
l'assainissement de Paris ${ }^{329}$, in dem die sanitären Verbesserungen in der Stadt Paris seit der Epidemie Anfang der 30er Jahre desselben Jahrhunderts aufgezählt wurden und durch welche man die Hoffnung begründete, dass die Epidemie dieses Mal weniger schwer sein würde. Daraufhin folgte eine Ordonnance concernant la salubrité des habitations ${ }^{330}$. Während der Text der Instructions sanitaires von 1831 im Auftrag der Regierung von Medizinern verfasst worden war und sich so gut wie ausschließlich auf einen diätischen und kurativen Plan zur individuellen Vorbeugung und zum Umgang mit der Cholera bezog, wiesen die Instructions von 1849 darauf hin, dass die Regierung sich wieder stärker auf die Stadt und die Orte konzentrieren und polizeilichen Techniken zuwenden wollte. Statt das genaue Verhalten der Bürger und Ärzte während der befürchteten Epidemie durchzudeklinieren, legte die Polizei als Herausgeber der Instruktionen ihr Augenmerk auf die Häuser, Straßen und die Kanalisation. ${ }^{331}$ Die Individuen sollen sich hier nicht im Sinne einer persönlichen hygiène privée ergänzend und in Harmonie zur öffentlichen Hygiene verhalten, wie es noch in dem Bericht der Académie Royale de Médecine von 1831 stand. ${ }^{332}$ Vielmehr war die hygiène publique hier etwas Eigenständiges und von den moralischen Praktikern der Selbsttechniken wieder unabhängiger. In ihr vermischten sich die alte, auf die Stadt gerichtete Rationalität der Polizei und der Einfluss eines wissenschaftlichen Hygienediskurses, der sich Anfang des 19. Jahrhunderts immer stärker dem Problem der Umwelt zugewendet hatte. Man konzentrierte sich 1849 auf die Reinigung der Gebäude und der Wohnungen durch eine polizeiliche Ordonnance concernant la salubrité des habitations. Dieser Fokus setzte sich auch in den späteren Instructionen nach 1854, z.B. 1862, weiter durch. ${ }^{333}$ Die Regierung in Frankreich war nach 1835 mit verschiedenen >Erkenntnissen< konfrontiert worden, die man aus den Erfahrungen mit der ersten Epidemie gezogen hatte. Erstens hatte sich die >Fortschrittlichkeit< Frankreichs und insbesondere von Paris als Weltmetropole hinsichtlich der Cholera als Trugbild erwiesen. Zweitens hatte die Medizin die Cholera und ihren zu bekämpfenden Ursprung nicht entschlüsselt. Drittens waren große Teile der Bevölkerung und vor allem die ärmere arbeitende Klasse für die Verhaltensinstruktionen unzugänglich gewesen. Einige als besonders >degeneriert< betrachtete Bewohner von Paris hatten sich sogar in >irrationalster Weise gegen die Maßnahmen, ärztliche Behandlungen und Verhaltensregeln gewehrt. Die Mediziner und die >Bürger $<$ bzw. die einzelnen Individuen hatten als Adressaten und Relais der Gesundheitspolitik offensichtlich versagt. Dem gegenüber existierte eine Unmenge an gesammelten und produzierten Daten über ein breites Feld an möglichen hygienischen und anti-epidemischen Maß-

329 Vgl. Conseil de Salubrité/Comité Consultatif d'Hygiène Publique/l'Académie Nationale de Médecine: Instructions sanitaires sur les moyens préservatifs du choléra-morbus, Précédées d'une notice sur l'assainissement de Paris, 1849: S. 3 - 10.

330 Vgl. ebd.: S. $11-13$.

331 Vgl. ebd.: S. 1.

332 Vgl. Académie Royale de Médecine: Rapport sur le choléra-morbus I, 1831: S. 142.

333 Vgl. [Unter dem Punkt III. »Des mesures d'hygiène a prendre en cas d'invasion de l'épidémie«, S. 301 - 306] Ministre de l'agriculture et du commerce et des travaux publique (Hrsg.): Instructions sur les mesures à prendre en vue de la réapparition du choléra, 1962: S. 303f. 
nahmen, die gegen die Epidemien im Allgemeinen und damit auch gegen die Cholera durchgeführt werden könnten. Der Rückzug auf die Polizei war also nicht nur ein Rückbezug auf alte staatliche Techniken, sondern auch die Rückübertragung von Macht auf einen mehr und mehr rationalisierten und gouvernementalisierten Staat.

Wie aber schon in dem Abschnitt zur Regierung von Gesundheit in Frankreich erläutert, bestanden in Frankreich Konflikte zwischen dieser aufstrebenden gouvernementalen und einer eher monarchistisch geprägten, revolutionären und juridischen Logik. Begrenzend für die Logik und vor allem die neue Praxis der rationalisierten, v.a. von der städtischen Polizei ausgeführten hygiène publique blieb der nahezu unumgängliche konstitutionelle Schutz des privaten Eigentums. Der Einbau der Abflüsse in den Straßen, deren Reinigung und die Trockenlegung feuchter Böden - Maßnahmen, die nach der ersten Epidemie in Angriffe genommen worden waren, konnten letztlich nur erfolgreich sein, wenn die Besitzer der Häuser diese auch mit Abwasserrohren, Wasserleitungen und entsprechenden sanitären Anlagen ausstatteten. Die Instruktionen von 1849 enthielten einen kurzen Text mit dem Titel Conseil de Santé et des Conseils de Salubrité, der sich ebenfalls auf Häuser und Wohnungen bezog und der scheinbar das Ziel verfolgte, die Hausbesitzer und Bewohner von der Notwendigkeit dieser allgemeinen Maßnahmen zu überzeugen. ${ }^{334}$ Sehr deutlich ist in dem Text auch die eher beiläufige Annahme der Miasma-These beschrieben, die in Auseinandersetzungen von Medizinern zu dieser Zeit in den meisten Fällen als eine Art Gegenthese zur Kontagiosität der Cholera angeführt wurde. Interessant an dem Rückgriff auf diese Theorie durch den Conseil de Salubrité ist, dass nicht der Versuch unternommen wurde, die These eines Cholera-Miasmas zur Begründung der Maßnahmen darzulegen. Man findet in dem Text im Prinzip keine wirkliche Reflexion auf einen aktuellen medizinischen Wissensstand. Er enthält einen strategischen Bezug auf eine in Frankreich bestehende populäre Sicht auf epidemische Krankheiten. Auf jeden Fall wird in dem Text die Verunreinigung der Luft als größtes Problem angesehen, ebenso wie alle Quellen, von denen eine solche gefährliche, häufig mit Gestank einhergehende Verschmutzung ausgehen könne. ${ }^{335}$

Die Aufforderung des Conseil, regelmäßig zu lüften, war nicht mehr Teil einer von Ärzten angeratenen privaten hygienischen Praxis, die im Dienste der Erhaltung der Gesundheit empfohlen wird. Ziel war eher, einen Bereich von Maßnahme zur Vermeidung von Epidemien in Paris abzustecken. Dazu gehörte auch ein Verhalten, das aufgrund seiner Bedeutung für die öffentliche Gesundheit notwendig ist. Es bestand kein Interesse an den Wohnungen und den Menschen, die in diesen Wohnungen lebten, sondern um die Gefahr der Verursachung einer Epidemie, die von ihnen ausgehen und die sich auf die gesamte Stadt ausweiten konnte. Ein weiterer Text,

334 »Lu et adopté dans la séance du conseil de salubrité du 10 novembre 1848. Le VicePrésident, Guérard, le Secrétaire, Devergie. Vu et approuvé l'instruction qui précède pour être annexée à l'ordonnance de police concernant la salubrité des habitations. Le Préfet de Police, Gervais«: Conseil de Salubrité/Comité Consultatif d'Hygiène Publique/l'Académie Nationale de Médecine: Instructions sanitaires sur les moyens préservatifs du choléra-morbus, Précédées d'une notice sur l'assainissement de Paris, 1849: S. 15 - 19. 
nun vom Comité Consultatif d'Hygiène Publique ${ }^{336}$, ist in den Instruktionen abgedruckt und bezieht sich auf die allgemeinen Instruktionen im Falle einer Choleraepidemie. Es lässt sich sehr leicht erkennen, dass es die Perspektive der Regierung einer Stadt war, die hier zum Ausdruck kommt. Zunächst geht es um die Organisation der medizinischen Versorgung, die durch eine lokal gebildete Kommission durchgeführt werden soll, welche auch die Ärzte ernennt und nach dem Bedarf der Orte zusammenstellt. Zweitens geht es um Hygiene, zunächst als Problem der salubrité publique, die in den Aufgabenbereich der Polizei fällt und die dafür zu sorgen hat, dass die Kommunen die notwendigen Assanierungsmaßnahmen durchführen: »l'exécution des mesures d'assainissement réclamées par la salubrité publique «. Die Maßnahmen sollten dazu dienen, die Epidemie in ihrer Entwicklung zu hemmen oder abzuschwächen. ${ }^{337}$ Besonders die Behausungen, in denen viele Menschen wohnten oder die Werkhallen, wo die Arbeiter den ganzen Tag »verbringen«, die öffentlichen Schulen und andere Orte der Ansammlung von Menschen fielen unter ihre Aufsicht. Allerdings, so betont der Text, könne man hier keine detaillierten Angaben zu diesen Maßnahmen machen, da sich diese unter Berücksichtigung der genauen Umstände nur durch die lokalen Kommissionen bestimmen ließen. ${ }^{338}$

Bereits in der Einleitung der Broschüre hatte man die generellen Instruktionen relativiert und betont, dass die lokalen Behörden für spezifische und den Bedingungen des Ortes angepasste Instruktionen zuständig seien. ${ }^{339}$ Mit Blick auf die diätischen und privaten hygienischen Vorkehrungen wird in dem Text ebenfalls davon abgesehen, genauere Vorgaben zu machen. Eher war das Anliegen der Kommission hier, die bestehenden Vorurteile zu relativieren, die zu einer übertriebenen Vorsicht oder einer völligen Nachlässigkeit führen können. Das Comité consultatif d'hygiène publique rät zu Nüchternheit und Gelassenheit.

»A l'égard du régime à suivre et des occupations habituelles, il est important que les populations soient bien convaincues qu'il n'y a aucune profession qui soit de nature à faire naître le choléra, comme il n'y a aucune position sociale qui mette à l'abri de ses atteintes. Cependant, il est un fait qui ressort de toutes les observations faites jusqu'ici, c'est que l'ivrognerie, l'intempérance, les excès en tout genre paraissent prédisposer à la maladie, et rendre ses attaques plus graves. $\ll^{340}$

336 »Ministre de l'Agriculture et du commerce. Comité consultatif d'hygiène publique. Instruction concernant les mesures générales à prendre à l'occasion de l'épidémie du choléra«: in: Instructions sanitaires sur les moyens préservatifs du choléra-morbus, Précédées d'une notice sur l'assainissement de Paris, 1849: S. 20 - 27.

337 Ebd.: S. 20.

338 Vgl. ebd.: S. 21.

339 Vgl. Conseil de Salubrité/Comité Consultatif d'Hygiène Publique/l'Académie Nationale de Médecine: Instructions sanitaires sur les moyens préservatifs du choléra-morbus, Précédées d'une notice sur l'assainissement de Paris, 1849: S. 3.

340 Vgl. »Ministre de l'Agriculture et du commerce. Comité consultatif d'hygiène publique. Instruction concernant les mesures générales à prendre à l'occasion de l'épidémie du choléra «: in: Instructions sanitaires sur les moyens préservatifs du choléra-morbus, Précédées d'une notice sur l'assainissement de Paris, 1849: S. 23. 
Was die Ernährung angeht, so heißt es weiter:

»il n'en est aucune qui doive être proscrite d'une manière absolue.« ${ }^{341}$

»Il en est de même des craintes exagérées que l'on pourrait concevoir, des précautions excessives que l'on pourrait prendre: le calme de l'esprit, le courage, la confiance, sont les dispositions morales les plus efficaces à opposer au choléra, comme la tempérance et la régularité dans toutes les habitudes de la vie sont les conditions physiques les plus favorables dans lesquelles on puisse se placer pour affaiblir au éviter ses attaques. $\ll^{342}$

Zurückhaltend war das Komitee auch, was die Empfehlung einer angemessenen Kleidung betraf. Die Verkühlung sei nachteilig und anstatt wie in den Instruktionen von 1831 nur zu empfehlen, sich warm zu kleiden, schlägt der Text vor, die Polizei solle entsprechende Bauchbinden und Schuhe an die ärmere Bevölkerung ausgeben: »il serait [...] utile que les commissions sanitaires pussent disposer de quelques objets de vêtements, de ceintures de flanelle et particulièrement de chaussures $\ll^{343}$. Die Ratschläge zur Lebensweise seien ansonsten nicht die Angelegenheit der Regierung. Der Text verweist hier auf die Ärzte, die hierfür zu Rate gezogen werden sollen:

»C'est aux médecins qui connaissent la manière de vivre habituelle des populations qu'il appartient de leur indiquer les modifications qu'elles pourraient utilement y apporter; il en est de même en ce qui concerne les boissons, dont l'excès est à craindre bien plus que la qualité. ${ }^{344}$

Drittens wird unter dem Punkt »Conduite à tenir avant l'arrivée du médecin à l'égard des personnes supposées atteintes du choléra zunächst konstatiert, die Cholera sei keine kontagiöse Krankheit, und eine Übertragung von Mensch zu Mensch oder durch Gegenstände finde nicht statt. ${ }^{345}$ Noch einmal wird darauf insistiert, dass alle Maßnahmen der Polizei nicht nur im Interesse der Kranken seien, sondern auch im Interesse der öffentlichen Gesundheit, deren Hüter die Polizei sei (»non seulement dans l'intérêt des malades, mais aussi dans l'intérêt de la santé publique, dont ils sont les gardiens $\left.\aleph^{346}\right)$.

Erst zum Schluss der Broschüre ist der Text der Académie Nationale de Médecine angefügt: »Instruction populaire sur les précautions à prendre contre le choléra, sur les premiers signes de la maladie, et les premiers soins à donner aux personnes qui en sont atteintes. «Wenn man bedenkt, dass das Gewicht in den ersten Instructions Sanitaires von 1831 auf dem Verhältnis zwischen Wissenschaft und Selbstpraxis beruht hatte, war die Rolle der Académie, die sowohl die Ärzte als auch die Medizin repräsentierte, nun schwindend gering. Es blieb ihnen nichts weiter als der schmale Bereich der relativ wirkungslosen Linderung und Behandlung. Der erste Bericht der

341 Ebd.

342 Ebd.

343 Ebd.: S. 23f.

344 Ebd.: S. 23.

345 Vgl. ebd.: S. 24.

346 Ebd.: S. 24. 
Akademie hatte Empfehlungen enthalten, die sich den Aufgaben nach auf Administration, Mediziner, und Bürger verteilt hatte. In welcher Rolle befand sich die Académie nun? In der Einleitung der Broschüre, die sich an die Öffentlichkeit wandte, steht »pour lui tracer la conduite à tenir au point de vue hygiénique et médical« und es heißt:

»L'instruction de l'Académie Nationale de Médecine est rédigée à un point du vue entièrement médical et laisse nécessairement de côté toutes les questions administratives traitées dans l'instruction ministérielle. $\ll^{347}$

Die Hygiene ist Sache der Regierung und der Polizei geworden, sie war nicht mehr Sache der Medizin und der Ärzte, als Berater des sich selbst regierenden Subjekts, wie man es sich in dem Bestreben nach Vereinheitlichung nach der Französischen Revolution vorgestellt hatte. Der einzige Bereich, in dem den Ärzten die Regierung im Sinne der Hygiene noch zufiel, war jener, in dem sie als Ratgeber der Regierung oder der Selbstregierung der Bürger bei deren private Hygiene fungierten. Dies ist die neue Aufteilung der Aufgaben, die aus dem Ensemble von privater und öffentlicher Hygiene, bzw. ihrer gegenseitigen Bedingtheit, ergab. ${ }^{348}$ Was die Académie nun im Bereich der privaten Hygiene empfahl, unterschied sich inhaltlich nur geringfügig von früheren Empfehlungen, war allerdings weit mehr an ein breiteres Publikum gerichtet als 1831 und enthielt dementsprechend auch Empfehlungen, die die Lebensrealität der ärmeren Bevölkerung stärker berücksichtigen. Zwar wurde immer noch empfohlen, kein fettes Fleisch zu sich zu nehmen, aber der Grundton ging eher in Richtung der Empfehlung, alles wie gewohnt und mäßig zu betreiben ${ }^{349}$.

Je mehr sich die Techniken der Regierung in Richtung einer sécurité publique verschoben, desto mehr Möglichkeiten bestanden, den Widerspruch, der sich aus den Schutz des Privaten ergab, zu umgehen. Die Entfernung der Regierung von der bürgerlichen Selbstpraxis geschah, indem die Regierung einen Bereich der öffentlichen Gesundheit abgrenzte. Die Einheit von öffentlicher und privater Hygiene wurde aufgebrochen; die hygiène publique und damit das Aufgabenfeld der Polizei wird von der Logik der Sicherheitstechniken, den Techniken, die auf die Sicherung der Gesundheit der Bevölkerung gerichtet waren, überlagert, wobei die moralischen Selbstpraktiken ausgenommen waren. Im Zentrum der Maßnahmen der Prävention gegen die Choleraepidemie oder ihrer Abschwächung standen ab 1849 die Verbesserungen der Gebäude und der Wohnungen. Diese Maßnahmen richteten sich auf die Gegebenheiten von >Orten<. Das individuelle Verhalten wurde zu einem von vielen mögli-

347 Ebd.: S. 4.

348 Vgl. ebd.: S. 28.

349 »Ceux [..] qui ont un régime qui les maintient dans un bon état de santé, n'ont rien à y changer [...] généralement, ne conviennent pas, sont les viandes très grasses, la charcuterie mal préparée, les pâtisseries lourdes, les crudités, les légumes aqueux pris en trop grande quantité. [...] Chacun doit continuer ses occupatious ordinaires, mais d'une manière réglée et sans qu'il en résulte une trop grande fatigue.«: Ebd.: S. 29. 
chen Ansatzpunkten, die nicht mehr auf die Verbesserung der Subjekte zielten, sondern auf den Einfluss ihres Verhaltens auf die öffentliche Gesundheit. ${ }^{350}$

Mit den Sicherungsmaßnahmen der Polizei, mit der Reinigung der Straßen und der Kanalisation sowie dem Projekt der Verbesserung der Wohnungen und der Gebäude begann die Regierung sich einer ihr zuvor fremden Klasse zu widmen und diese als den praktisch möglichen und wirklichen Gegenstand ihrer Regierung anzuerkennen. Nicht, indem sie eine spezifische Technologie bemühte, um diese Klasse zu regieren, sondern, indem sie ihre Techniken möglichst so ausrichtete, dass die spezifische Subjektivierung anscheinend keine Rolle mehr spielte. Sie löste die Konflikte mit der bürgerlichen Macht, indem sie die Selbstregierung auf die private Sphäre begrenzte und sie gleichzeitig als Aspekt der Regierung der Bevölkerung einordnete. Sie löste den Konflikt um die Wahrheit, indem sie den Bereich der wissenschaftlichen Disziplin der Medizin von der Hygiene löste, indem sie die Hygiene zu einem Bestandteil ihrer eigenen Rationalität machte und das Wissen der Medizin in ein enges, praktisches und funktionales Verhältnis zu dieser Rationalität setzte. Diese beiden >Trennungen< der Hygiene von der Medizin und der Selbstpraxis machten die Entstehung einer Regierung der Gesundheit der Bevölkerung in Frankreich erst möglich.

\section{Strategien des Regierens und die >Ursachen` der Cholera}

Die Regierung begann den strategischen Umgang mit Wissen nach ihrer eigenen Rationalität und Strategie einzusetzen. Die umfangreichen Daten und Statistiken, die 1834 durch den Kommissionsbericht der Präfektur des Departements Seine noch unter dem Vorsatz einer möglichst objektiven Darstellung präsentiert worden war, wurde nun offensichtlich viel strategischer eingesetzt, um die Maßnahmen der Regierung zu begründen und die Realität in einer Weise darzustellen, dass sie mit den Mitteln der Regierung und in Harmonie zu ihrer Subjektivität und Rationalität regierbar erschienen. Auch bei Kudlick heißt es: »the administration's use of statistics had subtly shifted from a mere rendering of truth to the production of it. ${ }^{351}$ Die Aneignung eigener Verfahren der Legitimation, über die die Regierung bzw. die Verwaltung ihre Praxis unter der Verwendung von Statistiken und Mortalität-Zahlen ebenso wie durch die Auflistung ihrer Bemühungen, Ausgaben und Anstrengungen im Sinne des Allgemeinwohls, des intérêt publique und der santé publique, begründet hatte, diente ihrer Selbstproduktion. Diese Aneignung war in gewisser Weise aber auch die Übernahme einer durch die bürgerliche Klasse gestifteten Regierungsrationalität und der entsprechenden Beweis- und Produktionsverfahren moralischer Subjektivität. ${ }^{352}$

»On peut le dire hautement, l'administration, au milieu des difficultés qui entourent ses travaux, des résistances incessantes qu'elle éprouve pour l'exécution des mesures qu'elle prescrit

350 Ebd.: S. 9f.

351 Kudlick: Cholera in Post-Revolutionary Paris, 1996: S. 138.

352 Vgl. Conseil de Salubrité/Comité Consultatif d'Hygiène Publique/l'Académie Nationale de Médecine: Instructions sanitaires sur les moyens préservatifs du choléra-morbus, Précédées d'une notice sur l'assainissement de Paris, 1849: S. 5 f. 
dans l'intérêt général, a suivi constamment, depuis 1832, l'impulsion donnée à tous les travaux et améliorations que réclamaient la santé publique et la salubrité.«353

Gesundheitspolitik und das politische Betätigungsfeld wurden zum Bereich der Profilierung einer aufgeklärten, modernen und humanitären Regierung in Abgrenzung zu den Formen der alten willkürlichen Regierung, der >Unzivilisiertheit< und der Unvernunft. ${ }^{354}$

Im Vergleich zu Deutschland war es in Frankreich, da es dort einen generellen Diskurs der moralischen und physischen Verbesserung der Gesellschaft und der Menschen gab, sehr leicht, allgemeine hygienische Ziele der Cholerabekämpfung mit diesem Diskurs in Verbindung zu bringen. Man hatte vermutetet, die Cholera werde in Frankreich und besonders in Paris aufgrund des dort verzeichneten sozialen und wissenschaftlichen Fortschritts nicht so verehrende Folgen haben können. Auch nach der ersten Epidemie blieb man dieser Erzählung grundsätzlich treu. Nun wurde die Epidemie als Anzeichen der Degeneration von Paris und die Gefahr des Rückschritts durch die Krankheit als negativer Beweis für den Zusammenhang von Cholera und sozialem Fortschritt betrachtet. So wurde auch bei der Epidemie 1848 grundsätzlich an der revolutionären Erzählung und der Idee des gesellschaftlichen Fortschritts festgehalten, nur, dass die Regierung hier wesentlich selbstbewusster ihre Rolle an diesem Fortschritt einforderte. Die Verbesserungen im Rahmen der hygiène publique und der Fortschritt im Sinne der Durchsetzung gewisser privater hygienischer Praxen waren zwei Seiten dieser positiven Entwickelung, die man der Gesellschaft in der Zeit zwischen 1832 und 1848 zuschrieb und mit der man die relativ milde Epidemie von $1848 / 49$ begründete.

Im Gegensatz zu Deutschland, wo die anti-kontagionistischen Positionen für die Regierung und ihr limitiertes Repertoire von Techniken eine Gefahr der Entmachtung bedeutet hatte, gewann die französischen Regierung Macht, indem sie sich über die Verknüpfung der anti-kontagionistischen Position als moderne, humanistische und liberal Regierung profilierte und so vom absolutistischen und >willkürlichen< Staat und dessen Techniken abgrenzen konnte. ${ }^{355}$ Auch Kudlick schrieb: »By the time of the second epidemic the administration had clearly triumphed over the medical profession as by absorbing their anticontagionist ideas without relinquishing political power. ${ }^{356}$ In den Institutionen von 1849 schrieb das Comité Consultatif d'Hygiène Publique:

»Le choléra n'est point une maladie contagieuse; elle ne se transmet point par le contact; l'on peut, par conséquent, donner sans crainte aux personnes qui en sont atteintes les soins que leur état réclame. Il serait à désirer que cette opinion, qui résulte de l'expérience acquise pendant l'épidémie de 1832, et de tous les renseignements recueillis dans les diverses parties de l'Europe visitées par le choléra, fût propagée. En raison de la sécurité qu'elle donne aux ma-

353 Ebd.: S. 8 .

354 Vgl. ebd.: S. 6.

355 Vgl. ebd.: S. 27f.

356 Kudlick: Cholera in Post-Revolutionary Paris, 1996: S. 115. 
lades, assurés de n'être point délaissés sous l'influence d'une crainte aussi funeste qu'elle serait peu fondée. $\ll^{357}$

Mit der Hinwendung zu den allgemeinen Ursachen, die namentlich seit dem Kommissionsbericht von 1834 bekannt waren und wie es auch die Instruktionen von 1848 zeigten, war in Frankreich zunächst das Urteil gegen die Kontagions-These gefallen. Nachdem der milde Verlauf der Epidemie Ende der 40er Jahre zu neuem Optimismus geführt hatte, wirkte die relativ kurz darauf folgende Epidemie im Jahr 1853 ernüchternd.

"[La] troisième épidémie de choléra, [était] plus étendue et plus meurtrière que celles qui l'avaient précédée.[...] L'épidémie cholérique de 1853 - 1854 a envahi en France soixante-dix départements et 5,364 communes; elle y a fait 143,478 victimes, 40,000 de plus qu'en 1832, 43,000 de plus qu'en $1849 . \ll^{358}$

Die Forschungen und Berichte über die 1849er Epidemie waren noch nicht einmal ausgewertet, als die Cholera erneut ausbrach. ${ }^{359}$ Dementsprechend waren die veröffentlichten »Instructions concernant les mesures générales à prendre à l'occasion de l'épidémie du choléra « nahezu identisch mit den 1848 erschienenen Broschüren. ${ }^{360}$ Kurze Zeit später, nach dem Abklingen der 1853er Epidemie, gab die Regierung allerdings eine zweite veränderte Auflage der Instruktionen heraus. In dieser wurde verkündet, man habe, obwohl man die spezifische Ursache der Cholera noch immer nicht kenne, dezidierte Kenntnis darüber gewonnen, welche die die Faktoren seien, welche die Epidemie begünstigten,

»les causes qui favorisent le plus le développement de cette épidémie, et comment, en l'attaquer à son début«.361

»De tous les moyens préservatifs qu'on a essayé d'employer contre le choléra, l'hygiène s'est montrée jusqu'à présent le seul efficace $[\ldots] \cdot \ll^{362}$

Auch verkündeten die herausgebenden Minister der neuen Instruktionen, die Cholera sei nicht ansteckend und die Versorgung oder Pflege der Kranken sei nicht gefähr-

357 Conseil de Salubrité/Comité Consultatif d'Hygiène Publique/l'Académie Nationale de Médecine: Instructions sanitaires sur les moyens préservatifs du choléra-morbus, Précédées d'une notice sur l'assainissement de Paris, 1849: S. 24.

358 Ministre de l'agriculture et du commerce et des travaux publique (Hrsg.): Instructions sur les mesures à prendre en vue de la réapparition du choléra, 1962: S. VII.

$359 \mathrm{Vgl}$. Académie de médecine: Rapport sur l'épidémie cholérique de 1854: in: Revue Hebdomadaire, 19.1869: S. 249.

$360 \mathrm{Vgl}$. Ministre de l'agriculture et du commerce et des travaux publique (Hrsg.): Instructions sur les mesures à prendre en vue de la réapparition du choléra, 1962: S. 282 - 287.

361 Ebd.: ( S. $301-306$ ): S. 301.

362 Ebd.: S. 302. 
lich. ${ }^{363}$ Der Bericht über die Epidemie von 1853 erschien 1862 und sollte endgültig das nötige Wissen und vergleichbare Daten über die Cholera bekannt machen, um weitere Epidemien zu verhindern. Die »enquête générale « ${ }^{364}$ über die Choleraepidemie wurde nun im Auftrag der Regierung expliziter als zuvor auf das Ziel, die Bevölkerung in Zukunft vor einer weiteren Choleraepidemie schützen zu können, hin ausgerichtet. ${ }^{365}$

Schon in dem Auftrag für die Untersuchung hatte das Comité consultatif d'hygiène publique die Rolle der Regierung und der Verwaltung als Schützer der öffentlichen Gesundheit selbstbewusster formuliert als in den Jahren zuvor und darüber hinaus auch die Nützlichkeit einer solchen Untersuchung nicht nur für die Wissenschaft oder Frankreich, sondern für die ganze Menschheit beansprucht: »utile pour la science et pour l'humanité. « ${ }^{366}$ Was das Ziel des Berichts betraf, sah man sich mit Blick auf Großbritannien, wo es 1854 gelungen war, eine Verbreitung der Epidemie $\mathrm{zu}$ verhindern, auf dem richtigen Weg und verglich den französischen Bericht mit dem ähnlich aufgebauten Bericht und der Statistik des General Board of Health. ${ }^{367}$ Nur drei Jahre nach diesem Bericht erreichte die nächste pandemische Cholera Europa und auch in Frankreich brach die nächste Epidemie 1865/66 in Paris aus. Und noch eine weitere Choleraepidemie erlebte Frankreich im 19. Jahrhundert.

Die Untersuchungen Pasteurs bereiteten noch vor der Anerkennung von Pacinis und Hassalls Thesen ${ }^{368}$ und schließlich Kochs Isolation des Cholera-Erregers den Boden für deren Forschungen, indem er eine epistemologische Wende hin zu einer Betrachtung der organischen Vorgänge im Labor einleitete. Erst in Folge dieser Verschiebung geriet die These von pathogenen Miasmen weiter ins Abseits. Eine Aufnahme von Mikroorganismen über die Luft und ein Transport der Keime über weite Strecken durch Winde und Luftströme wurde unwahrscheinlicher. ${ }^{369}$ Aber die Ergebnisse aus den Laboren reichten nicht aus, um die Wirkung der Mikroorganismen auf dem menschlichen Körper zu erklären und blieben in dieser Hinsicht, so auch die Kritik der Académie de Médecine, rein hypothetisch. Das Experimentierfeld der Pathologie lag in der klinischen Medizin und ihren Methoden. Was die Erforschung des Cholera-Erregers benötigte, war die Epidemie selbst: Eine genügend große Zahl von

363 Vgl. ebd.: S. 302.

364 Ministre de l'agriculture et du commerce et des travaux publique (Hrsg.): Documents statistiques et administratifs concernant l'épidémie de choléra de 1854, 1962: S. VI.

365 Vgl. ebd.: S. VIIf.

366 Vgl. Ministre de l'agriculture et du commerce et des travaux publique (Hrsg.): Comité consultatif d'hygiène publique:, Instruction relative à une enquête dur la marche et les effets du choléra épidémique en France, 1962, S. 291 - 298: S. 298.

367 Vgl. Ministre de l'agriculture et du commerce et des travaux publique (Hrsg.): Documents statistiques et administratifs concernant l'épidémie de choléra de 1854, 1962: S. VIf.

368 Lange vor den Untersuchungen Kochs hatten 1854 der italienische Arzt Pacini aus Florenz und Hassall aus London die These über ein »microbio colerigeno« in den Choleraausschüttungen aufgestellt und Nachweise hierfür erbracht. Vgl. Bourdelais/Raulot: Une Peur Bleue, 1987: S. 153.

369 Vgl. Grancher, J.: De la contagion du choléra: in: SMP, 7.1884, S. 282 - 299: S. 289. 
Infizierten, Kranken und Choleraleichnamen zur Durchführung von Obduktionen. Trotz der Abwehr aus dem Lager der Epidemiologen und vieler Hygieniker, die bereits begonnen hatten, die Krankheit als ein viel umfassenderes soziales Phänomen zu betrachten, gewann die These der Kontagiosität in Frankreich wieder Boden. Auch, weil sie nun in anderer Weise rationalisierbar und mit den Theorien der Hygieniker vereinbar schien. ${ }^{370}$

Die Existenz der Regierung fußte zu einem nicht unerheblichen Teil auf ihrer moralischen und rationellen Selbstkonstruktion, welche ihre Techniken und ihre Praxis strukturierten. Die Lösung lag in der strategischen Zusammenführung von bakteriologischen und hygienischen Erkenntnissen, die sich sowohl mit der Idee einer indirekten Übertragung durch eine Art Miasma oder über das Wasser (nach den Untersuchungen des britischen Arztes Snow) als auch mit der These von Keimen bzw. Bakterien deckten, die Luft und Wasser als Reservoir nutzten. Der Arzt und Hygieniker Adrien Proust (1834 - 1903), der viele Jahre als Mitglied der französischen Delegation auf den Conférences Sanitaires Internationales wirkte, führte diese unterschiedlichen Erklärungsansätze in seinem Buch über die Cholera 1883 zusammen. ${ }^{371}$ Er referierte dort auch über die Thesen des britischen Arztes Snow, ${ }^{372}$ ging aber weiterhin von einer Übertragung des Cholerakeims durch das Wasser $u$ d durch die Luft aus. ${ }^{373}$ Nach 1884 und nach Kochs Isolierung des Bakteriums wurde die Infektion mit der Cholera über die Aufnahme von durch Choleraausschüttungen verunreinigtes Wasser, verunreinigter Nahrung oder Hände nachgewiesen. Aber auch dieses Wissen konnte dazu dienen, die Regierung in der Ausführung ihrer Sicherheitstechniken zu bestätigen. Jacques-Joseph Grancher (1843 - 1907) hielt 1884, also kurz nachdem Koch seine >Entdeckung < des Cholerabazillus, des »Bacille en virgule « (Kommabazillus) bekannt gegeben hatte, einen Vortrag vor der Académie de Médecine, in dem er Prousts Thesen der Übertragung über die Luft hinterfragte und die Konflikte verschiedener Positionen zur Frage der Kontagiosität der Cholera darstellte. Die Ansteckung könne, so Grancher, nur unter bestimmten, seltenen Umständen über die Luft (»par l'air atmosphérique «), oder durch eine »contagion indirecte«, wie auch, und dies sei die Regel, über die Aufnahme (»par les ingestas«), durch den Mund erfolgen. ${ }^{374}$

Der Einfluss aus den Laboren der Bakteriologie legte die Vermutung nahe, dass das Problem der Cholera, bisher ein Problem von Hygienikern, Statistikern und Epidemiologen, nun wieder ein Problem der Mediziner werden würde. Eher kam es aber zu einer Neuauflage der mit Hallé begründeten Idee der Hygiene. 1881 veröffentlichte Apollinaire Bouchardat sein Traité d'hygiène publique et privée und präsentierte eine Strategie, die die Hygieniker und die Regierung auch unter Einbeziehung der bakteriologischen Erkenntnisse nach 1884 handlungsfähig machen würde. ${ }^{375}$ Bakte-

370 Vgl. ebd.: S. 282.

371 Proust: Le Choléra. Étiologie et Prophylaxie, 1883: S. 68ff.

372 Ebd.: S. 88.

373 Vgl. ebd.: S. 103f.

374 Vgl. Grancher, J.: De la contagion du choléra: in: SMP, 7.1884, S. 282 - 299: S. 282.

375 Vgl. L'épidémie de choléra à Toulon et à Marseille; prophylaxie du choléra, Séance du 2. Juillet 1884 in: SMP, 7.1884, S. 259 - 271. Vgl. auch Vallin: Instruction populaire sur les 
riologische und epidemiologische Forschungsergebnisse aus England und Deutschland wurden im Sinne der Rationalität und den Techniken der französischen Regierung zusammengefügt: Wenn die Bakterien, die die Cholera-Erreger sind (Koch), über das verunreinigte Wasser und über die Aufnahme durch den Mund in den menschlichen Körper gelangen (Snow), können wir weiterhin davon ausgehen, dass die meisten restriktiven Maßnahmen, wie Isolation, Grenzkordons, Desinfektion und Quarantänebehandlung von Waren und Menschen ungeeignet und unnötig sind. Stattdessen sind eben die Maßnahmen, die sich allgemein auf die Hygiene in der Stadt und die Hygiene der Individuen richten, weiterhin die sichersten Mittel gegen eine Epidemie, schrieb auch Grancher. ${ }^{376}$ Dementsprechend entwarf die Académie im Vorfeld der fünften Epidemie die neuen Instructions Populaires. Der Text teilte sich in zwei Abschnitte, »hygiène individuelle ${ }^{377}$ und »hygiène publique «. ${ }^{378}$ Bemerkenswert daran ist, dass die Instruktionen ganz im Sinne der Maßnahmen einer Regierung entworfen sind, die das Ziel hat, eine Bevölkerung vor einer Epidemie zu schützen - es geht um Maßnahmen der Sicherung. ${ }^{379}$ Die Punkte, die 1831 unter hygiène privée geführt wurden und die wirklich als Rat von Ärzten an die Bürger, sich selbst vor der Cholera zu schützen, zu verstehen waren, sind nun unter dem Punkt hygiène individuelle abgefasst. Es sind die auf einen persönlichen Bereich bezogenen Aufgaben der öffentlichen Hygiene. Neben einer kurzen Erwähnung der alten, von der Académie Royale de Médecine verbreiteten Empfehlungen zu persönlichen Vorkehrungen enthält diese Instruktion hauptsächlich Informationen zu und Warnungen vor der Gefahr der Infektion über verunreinigtes Wasser: »L'usage d'une eau de mauvaise qualité est une des causes les plus communes du choléra. [...] Il faut renoncer complètement à se servir des puits en temps de choléra. ${ }^{380}$ Außerdem fordert der Text, im Falle der Erkrankung müsse eine umgehende Meldung des Falls an die Behörden gehen und die Ausscheidungen des Kranken seien zu desinfizieren. ${ }^{381}$ Unter dem zweiten Punkt zur hygiène publique geht es ausschließlich um Aufgaben der police sanitaire und der Behörden, die z.B. die Ansammlung von Menschen verhindern sollten und Abwasserkanäle (égouts), vor allem solche, die stagnierten, zu reinigen und zu desinfizieren. ${ }^{382}$ Die lokalen Polizeiquartiere stellten Desinfektionsmittel zur Verfügung, damit Hausbesitzer und Bewohner der Stadt die Desinfektionsmaßnah-

précautions d'hygiène privée et les mesures d'hygiène à prender en cas d'épidémie de choléra, Séance du 11 Juillet 1883: in: SMP, 6.1883, S. 269 - 276.

376 Grancher, J.: De la contagion du choléra: in: SMP, 7.1884, S. 282 - 299: S. $290 f$.

377 Wurtz (Präsident der Kommission)/Bouley/Brouardel/Du Mesnil/Durand-Claye/Ch. Girard/Grancher/Koechlin-Schwartz/Lereboullet/Levraud/Liouville/Martin/Napias/Pabst/ Pozzi/Proust/Rochard/Siredey/ThévenotTrélat/Vidal/Walther/Vallin: Instruction populaire sur les précautions d'hygiène privée et les mesures d'hygiène à prender en cas d'épidémie de choléra, au nom d'une Commission composée de [...], 1883: S. $201 \mathrm{f}$.

378 Ebd.: S. 207f.

379 Ebd.: S. 202.

380 Ebd.

381 Vgl. ebd.: S. 205f.

382 Vgl. ebd.: S. 207. 
men in ihren Häusern, Wohnungen usw. durchführen konnten. ${ }^{383}$ Im Gegensatz dazu hatte bis 1866 noch das Verteilen von Nahrung, Kleidung und sogar eine finanzielle Unterstützung der Familien der Kranken zu den Aufgaben der Polizei gehört. Die Hausbesuche in den Unterkünften der Armen durch die Inspekteure, an die diese Mittel geknüpft waren, hatten aber auch einen moralischen, erzieherischen Aspekt beinhaltet. ${ }^{384}$ Das Ziel der moralischen und physischen Verbesserung der Menschen und die Rationalisierung ihrer Lebensweise wurde durch den Einsatz anderer totalisierender Techniken angestrebt. ${ }^{385}$ Die moderne Regierung gründete sich auf der ethischen Differenzierung, wobei sich diese Differenzierung von einer Logik, die dem moralischen Diskurs entsprungen war, hin zu einer ökonomischen Logik verschob.

\section{Cholera und , hygiène publique،}

Ich möchte noch einen kurzen Blick auf die Entwicklung der hygiène publique werfen, um zu verdeutlichen, worin die Änderungen in der französischen Regierungsrationalität im 19. Jahrhundert gelegen haben und wie sich diese von der deutschen Idee der medizinischen Polizei unterschied. In dem ersten Bericht der Académie Royale de Médecine zur Cholera hieß es:

»De concert avec les médecins aussi bien qu'avec les citoyens éclairés et riches, l'autorité administrative, guidée d'ailleurs par les règles d'hygiène privée que nous venons d'établir, aura tout-à-la-fois le courage et la prévoyance de prévenir tous les besoins et de répondre à toutes les nécessités. En définitive, l'hygiène publique n'est que l'hygiène privée faite sur une plus grande échelle, l'hygiène portée des individus aux masses et des besoins domestiques aux exigences de la société tout entière. $\ll^{386}$

Worin besteht der Unterschied der Vorstellung einer Übertragung der hygiène privée auf die hygiène publique, zu der Übertragung der Diätetik auf die medizinische Polizeiwissenschaft, wie sie etwa Frank forderte (Diätetik des Staates ${ }^{387}$ ) und wie sie auch in Deutschland stattgefunden hat? Sie besteht erstens darin, dass die Polizeiwissenschaft eine Wissenschaft war, die versuchte, den Ansprüchen einer Wissenschaft nach Begrenzung ihres Feldes und der Tiefe des Wissens zu genügen und sich eigene Axiome festzulegen, nach denen sie ihre eigenen Verfahren der Veridiktion schuf. Sie war nicht fähig, die Eigenschaften des Regierungswissens, die mit der bürgerlichen Hygiene und Diätetik als Wissen für eine Lebenspraxis und Praxis der Selbstre-

383 Vgl. ebd.: S. 210.

384 Vgl. Aisenberg: Contagion. Disease, Government, and the »Social Question« in Nineteenth-Century France, 1999: S. 166.

385 Vgl. z.B. Levasseur: Le Progrès de la Vitalité par L'hygiène dans les Villes d'Angleterre: in: SMP, 17.1894, S. 114 - 121: S. 118.

386 Académie Royale de Médecine: Rapport sur le choléra-morbus I, 1831: S. 142.

387 »Die Medicinische Policey ist die Wissenschaft, das Gesundheitswohl der in Gesellschaft lebenden Menschen und derjenigen Thiere, deren sie zu ihren Arbeiten und Unterhalt bedürfen, nach gewissen Grundsätzen zu handhaben. Sie ist die Diätetik des Staates. (Frank)« Metzger: Handbuch der Staatsarzeneykunde enthaltend die medicinische Policey und die gerichtliche Arzneywissenschaft, 1787: S. $8 f$. 
gierung entstanden waren, zu übernehmen. Als solche hätten sie bereit sein müssen, neues Wissen zu integrieren und sich permanent auf einen wachsenden, schier unbegrenzten Bereich von Problemen auszudehnen. Dieser Widerspruch ist auch der Grund, warum die Hygiene in Frankreich versuchte, mit der Medizin zu verschmelzen: Man hoffte, dadurch diesen Widerspruchs zugunsten einer einer wirklich rationalen Regierung der Gesundheit aufzulösen. Gleichzeitig war man bemüht, die Regeln der Praxis und vor allem die asketischen, moralischen Verfahren der Subjektivität der Regierung des Selbst auf die der hygiène publique zu übertragen. Aber erst, als dieses scheiterte, bzw. die Regierung der Bevölkerung ihre eigene Rationalität mit ihrer eigenen Praxis, ihrem statistischen, ökonomischen Wissen verband und ihren Sicherheitstechniken unterlegte sowie sich gewissermaßen von den Beschränkungen der Medizin und der Selbstpraxis befreite, ist diese Übertragung der Verfahren der Regierung gelungen.

Die Choleraepidemie wirkte auf diese Neuordnung und Verschiebung und schließlich auf die Herausbildung einer modernen Regierung von Gesundheit wie ein Katalysator. Es war also zunächst die Erkenntnis, dass die Hygiene keine Wissenschaft wie die Medizin sein könne. Sie konnte ihre Wahrheit nicht ohne die Praxis bestimmen und ohne Erfolg in der Praxis hatte sie keinen Wert. Sie war, wie Rousseau sagt, keine Wissenschaft, sondern eine Tugendlehre (vertu). ${ }^{388}$ Das nicht zu erkennen, war der erste Fehler der deutschen Regierung. Aber es ist auch nicht so, wie man in der Französischen Revolution und von Rousseau abgeleitet gedacht hat, dass die hygiène publique, wenn schon keine Wissenschaft, so doch in gleichem Sinne wie die Selbstpraxis, eine Tugendlehre des Staates war. Das an Praxis gebundene Verfahren ihrer Veridiktion qualifizierte sie zur modernen Regierungswissenschaft, die sich wie die Ökonomie an der Heterogenität der Kräfte, Einflüsse, kurz der gesamten Realität der menschlichen Gesellschaft und ihren >Notwendigkeiten< und >Bedürfnisse< ausrichtete, wie es auch der französische Hygieniker Hallé hervorgehoben hat. ${ }^{389} \mathrm{Um}$ diese Praxis der Regierung auf die Bevölkerung zu übertragen, benötigte die Regierung ein Set an Techniken und Wissensformen, die anders waren, als die der Medizin, die sich unterschieden von dem der asketischen Tradition der Selbsttechnik und die den Gegenstand der Bevölkerung zu regieren ermöglichten. Die Selbstregierung war dagegen eine Regierung der Leidenschaften, eine Regierung des Körpers und der ganzen Lebensführung im Sinne einer rationalen Lebensweise; sie diente dem Zweck der Herstellung und Erhaltung, nicht nur einer physischen, sondern auch einer sozialen und moralischen Existenz. So war die Regierung der Gesundheit der Bevölkerung auf die ganze Wirklichkeit und alle Faktoren gerichtet, die in dem Menschen und um die Menschen herum existierten, die ihre Existenz bedingten. Sie lehnte die Forderung an die Menschen nach einer Arbeit an sich selbst ab und betrachtete den Menschen als beeinflusst und beeinflussbar durch verschiedene steuerbare Bedingungen seines Lebens. Diese Erkenntnis wird im Zuge sozialreformerischer Bestrebungen in Frankreich in der zweiten Hälfte des 19. Jahrhunderts immer deutlicher. Bei der Untersuchung von Zeitschriftenartikeln in dem Zeitraum von 1870 bis 1910 zum Thema Hygiene fällt auf, dass die hygiène privée nahezu völ-

388 Vgl. Rousseau: Émile, 1827 [1762]: S. 64.

389 Vgl. Hallé/Tourtelle: Traité d'hygiène, [1798] 1855: S. 38. 
lig aus den Texten verschwand. Es präsentierte sich tatsächlich eine reine hygiène urbaine, oder médecine urbaine, wie sie Foucault genannt hat.

»La deuxième forme du développement de la médecine sociale est représentée par l'exemple de la France, où est apparue, à la fin du XVIIIe siècle, une médecine sociale reposant apparemment non pas sur la structure étatique, comme en Allemagne, mais sur un phénomène entièrement différent: l'urbanisation. En effet, la médecine sociale s'est développée en France avec l'expansion des structures urbaines. $\ll^{390}$

Die Regierung konzentrierte sich auf Straßenbau, Beleuchtung, Baustellen, Brücken, Brunnen, Kanäle bzw. um öffentliche Schulen, Krankenhäuser oder Schwimmbäder. ${ }^{391}$ Die urbane Hygiene drückte die Möglichkeit aus, alles, was das menschliche Leben in Gesellschaft und vor allem in der Stadt beeinflusste, mit medizinischem Wissen einzukreisen und damit zum Gegenstand der Regierung der Gesundheit sowie der Aufgaben der hygiène publique zu machen. Dies war eine andere Hygiene als zunächst für die bürgerliche Selbstregierung in der antiken Diätetik bei Hippokrates gesucht worden war.

»Une des erreurs de l'hygiène ancienne est d'avoir voulu étudier l'homme indépendamment du milieu dans lequel il vit [...] on sent la nécessité d'étudier les collectivités humaines, les lois qui président à leur bien-être: c'est le but de la médecine sociale « ${ }^{392}$

Man müsse die kollektiven Phänomene erforschen, die großen Bewegungen, die Faktoren und ihre Abhängigkeiten, kurz die ganze soziale Realität. An diesem Wissen könne man erst erkennen, wie erfolgreich eine Regierung zu einem gesellschaftlichen, physischen und moralischen Fortschritt der Menschen, die zu dieser Gesellschaft gehören, beitragen könne. Diese Regierung werde nicht, wie im Fall der privaten Hygiene, die der hippokratischen, der antiken Praxis der Hygiene entsprechen, durch die moralischen Anrufe des Guten im Menschen erfolgen, sondern durch die Veränderung der realen sozialen Umstände, die praktisch erforscht werden müssen. ${ }^{393}$

»Que d'observations et d'expériences! [...] C'est ainsi que la première section s'occupe des bases même de l'hygiène, en étudiant tous les phénomènes qui se placent à la surface de la planète, et qui impressionnent l'organisme humain. Dans la deuxième section, nous trouvons des questions moins générales, sans doute, mais tout aussi importantes. Nous y avons groupé l'épidémiologie, la police sanitaire, l'hygiène internationale. « ${ }^{394}$

390 Foucault: La naissance de la médecine social, 1994 [1974]: S. 215f.

391 Vgl. Bechmann: Enquête statistique sur l'hygiène urbaine dans les villes Françaises: in: SMP, 15.1892, S. $132-138$.

392 Première réunion prépartoire le 23 mai 1877 de la Société de Médecine et D'hygiène Professionnelle: in: SMP, 1.1877, S. 21 - 31: S. 23.

393 Vgl. ebd.: S. 25.

394 Ebd.: S. 26. 
Die Idee der Geschichte des sozialen Fortschritts und der auch moralischen Verbesserung der Menschen wird in Frankreich trotz dieser Verschiebung aber nicht abgelegt. Die hygiène publique, so die Hoffnung, würde mit ihrer spezifischen Verknüpfung von Praxis und medizinischem Wissen, vom Staat ausgehend und mit seiner Macht und Übersicht über das Leben der Bevölkerung viel weiter gehen und viel erfolgreicher sein als die privaten Praxen. Die Verbesserung des Menschen durch eine bessere Lebensweise und Moral würde erst durch diese auf die ganze Gesellschaft gerichtete Regierung wirklich möglich.

»En rendant l'homme plus sain, on le rend meilleur. C'est ce qui avait sans doute fait avancer à Rousseau ce sophisme: >L'hygiène n'est pas une science, c'est une vertu<. La Société de médecine publique et d'hygiène professionnelle a de grandes espérances que nos efforts parviendront à réaliser, et les générations futures conviendront peut-être un jour que nous avons contribué à affermir la morale en consolidant la santé publique.«395

Henri Monod war zwischen 1887 und 1905 Directeur de l'Assistance et de l'Hygiène publique. Er veröffentlichte 1892 eine ausführliche, größtenteils ätiologische und epidemiologische Untersuchung der fünften Choleraepidemie von 1885/86 in Frankreich. Seine ersten Absätze widmete Monod dem Verhältnis von Wissenschaft und Regierung im Kampf gegen Epidemien: »Rôle de l'Administration dans la Lutte contre les épidémies. ${ }^{396}$ Hier heißt es:

»Ansi la science et l'administration s'entraident sans se confondre et, avec des tâches différentes, de valeur inégale, mais également nécessaires, elle travaillent l'une et l'autre à une œuvre commune, dont le dernier objet est la diminution de la mortalité, le prolongement de la vie humaine. $\ll^{397}$

Diese Idee der Trennung und des Aufeinander-Angewiesen-Seins hatten auch die Instruktionen des Conseil d'Hygiène nach der Epidemie von 1854 deutlich gemacht. ${ }^{398}$

\section{Die Cholera in Grossbritannien}

Als die Cholera Europa erreichte, war sie im britischen Diskurs bereits seit Längerem eine politische Angelegenheit und ein ökonomisches Problem. Dies ergab sich aus der Übertragung des in den Kolonien angehäuften Wissens und der dort bereits stattgefundenen politischen, militärischen und ökonomischen Problematisierungen der Krankheit. Auch wenn die Berichterstattung nach dem Ausbruch der Epidemie in England und Schottland weiterhin aus unzähligen methodisch sehr streng empirisch gehaltene Fallbeschreibungen bestand, die auch medizinische und klinische Beobach-

395 Ebd.: S. 31.

396 Monod: Le Choléra. Histoire d'une Épidémie, 1892: S. 5.

397 Ebd.: S. 6f.

398 Vgl. Ministre de l'agriculture et du commerce et des travaux publique (Hrsg.): Instructions sur les mesures à prendre en vue de la réapparition du choléra, 1962: S. 304. 
tungen der Krankheit enthielten, war man sich nach den Erfahrungen aus Indien bereits relativ sicher, dass die Mittel der Medizin für den Umgang mit der Krankheit begrenzt waren. Es scheint, als wäre bereits eine Aufteilung vorgenommen worden, durch welche die Cholera zum Gegenstand einer ganzen Reihe von Wissenschaften werden konnte, deren Wissensproduktion sich aber auch auf ein gemeinsames Ziel richtet: Der gesundheitspolitische Umgang mit der Epidemie. So wurden weit mehr Faktoren berücksichtigt, als zur Beantwortung der Frage nach der Kontagiosität notwendig gewesen wäre. Man ging bereits 1832 davon aus, dass man es bei der epidemischen Cholera mit einer neuen Form dieser Krankheit zu tun hätte, die das alte auch in Indien vorhandene Wissen über die Cholera in den Schatten stellte.

»Cholera is well known as a disease of tropical climates and warm seasons, but as far as our information extends, it has rarely prevailed to any great degree in this country [Indien], until the autumn of the year 1817; when it appeared in Bengal, in the form of a very peculiar and malingnant epidemic, which has since extended its ravages, apparently over the whole of the immense territories under the authority and influence of the British in India. «399

Wie schon weiter oben erläutert, stand die verhältnismäßig frühe Diskussion um Epidemien in Großbritannien in Verbindung mit der Problematisierung von epidemisch und endemisch auftretenden Krankheiten in den britischen Kolonien. ${ }^{400}$ Die Erfahrungen mit Epidemien innerhalb disziplinarisch kontrollierter Gruppen, wie Truppeneinheiten, Sklaven und Arbeiter auf Plantagen, Schiffen usw. und die erweiterten Möglichkeiten der Anwendung von Techniken zur Regulierung der Lebensweise, die Behandlung und klinische Erforschung der Krankheit beeinflussten nicht nur die späteren Diskussionen um die Cholera. ${ }^{401}$ Sowohl die Durchsetzung und Aufrechterhaltung der militärisch und politisch-institutionell gestützten kolonialen Herrschaft, als auch der ökonomische Nutzen durch die Ausbeutung von Ressourcen und Menschen, waren durch die häufig epidemisch auftretenden tödlichen Krankheiten sowohl in Siedlungen von Weißen, auf Plantagen, auf Handels- und Marineschiffen, als auch innerhalb der Truppen, bedroht. ${ }^{402}$ Die Kolonien boten eine Vielzahl von Möglichkeiten, politische Techniken in Bezug auf epidemische Ausbrüche der Cholera zu entwickeln und auszuprobieren, die der ökonomischen und militärischen Logik der Kolonisatoren, Siedler und Plantagenbesitzer entsprachen. Diese Techniken wurden dort nur wenig von den alten, lang tradierten und teilweise religiös-moralisch geprägten europäischen Diskursen und Praxen, die sich gegen sogenannte pestartige Krankheiten richteten, beschränkt. ${ }^{403}$ Die Mehrzahl der medizinischen Artikel zu Beginn der 1830er Jahre unterschied sich deutlich von der Art der Berichte über die Cholera. Abgesehen von wenigen Berichten über die Pocken und den Typhus hatte es zu diesem Zeitpunkt in den britischen medizinischen Zeitschriften, die sich weitestgehend der Praxis und der Methode der strengen empirischen Beobachtung verschrieben hat-

399 Orton, Surgeon: An essay on the epidemic cholera of India, 1831 [1820]: S. v.

400 Vgl. ebd.: S. xv.

401 Vgl. ebd.: S. 41ff.

402 Vgl. Lindemann, M.: Medicine and Society in Early Modern Europe, 2010: S. 218.

403 Vgl. Boyle: Treatise on the epidemic cholera of India, 1821: S. $10 \mathrm{f}$. 
ten, kaum epidemiologische Berichte gegeben. Längst gab es keine Krankheit mehr, die seit der Pest in diesem Maße pandemisch aufgetreten war. Die Beschreibungen individueller Krankheitsfälle bestanden aus genauen Beobachtung der Symptome, Krankheitsverläufe, Versuche der Medikation und Therapie und ggf. aus den Befunden der Obduktionen. Sie arbeiteten sich an den einzelnen Veränderungen und pathologischen Krisenzuständen der Verdauungsorgane, des Kreislaufs, dem Fieber oder Entzündungen ab. Was nun aber in den Berichten über die Cholera zusammengetragen wurde, war für die Techniken der praktischen Medizin - der Kunst des Heilens weitestgehend irrelevant. Schneller als in Frankreich oder etwa Preußen wurde die Cholera für die Epidemiologie zum Thema und war bald Gegenstand der entsprechenden sanitären Rationalität und Technologie. ${ }^{404}$

Das Auftreten der epidemischen Cholera in Europa hat die alte Verknüpfung von Epidemie, der Definition der >pestartigen<, ansteckenden Krankheit und dem einzigen Mittel gegen sie - Isolation und Quarantäne - selbst im liberalen Großbritannien wieder wachgerufen. Und auch in Großbritannien dauerte es eine Weile, dieses Muster zu revidieren und die Handlungsfähigkeit der Regierung auf eine neue gouvernementalisierte Grundlage zu stellen.

\section{Kontagiösitäts-These und liberale Rationalität}

In Großbritannien war man sich in den 20er Jahren des 19. Jahrhunderts bereits relativ einig, dass, wie bei kontagiösen Krankheiten üblicherweise angenommen, bei der Cholera keine Übertragung der Krankheit von Mensch zu Mensch stattfinden könnte

»The non-contagionists have repeatedly maintained that the persons who have to do with cholera patients remain exempt $\ll$. ${ }^{405}$

»[T] he non-contagious nature of the disease is very generally admitted by the medical authorities of India who have had sufficient experience of the disease. $\ll^{406}$

»If this question could have been decided simply by the opinions of a majority of medical men, it would have been already set at rest against the doctrine of contagion or infection $[\ldots] . \ll^{407}$

Die meisten Ärzte, die in den »East Indies« praktizierten und die seit 1817 mit der epidemischen Cholera in Kontakt gekommen waren, die umfangreiche Erfahrungen gesammelt und in der Regel unzählige Obduktionen vorgenommen hatten, waren bis

404 Vgl. z.B. Craigie, David: Account of the Progress of Asiatic Cholera, as it appeared on the confines of Europe and Asia, and eventually proceeded to Moscow; translated from the German Edition of the Official Reports of the Russian Government, and preceded by a Topographical Account of the districts through which the disease advanced: in: Supplement on cholera: in: ESMJ, 38.1832, S. lvii - lxxxix: S. lviii-lxxxi.

405 Ebd.: S. 1xxxi.

406 Annesley: Sketches of the most prevalent diseases of India, 1829 [1825]: S. 243.

407 James Johnson zitiert P. Scot, M.D. (Secretary of the Medical Board of Madras): Johnson: Medico-surgical Review - Epidemic Cholera, 1832: S. 181. 
1828 der Ansicht, die Cholera entstehe aus lokalen und atmosphärischen Gründen, mehr oder weniger $\operatorname{spontan}^{408}$ : »a disease essentially dependent upon the climate and intertropical position of the Indian territory $\ll^{409}$. Aber als die Cholera 1829 in Orenburg auftrat und schließlich 1831 ihren Weg nach Europa fortsetzte, kehrte sich in Großbritannien und auch in Indien die offizielle Position in Richtung der contagiousness-doctrin. ${ }^{410}$ Die Art, in welcher sich die Cholera entlang der Handelswege über den eurasischen Kontinent nach Westen bewegte, und die kontagionistischen Erklärungen, die u.a. in Russland dominierten, nahmen Einfluss auf die Debatte um die Cholera in Großbritannien und auch in Indien. ${ }^{411}$

»[T]he march of time and events, the great accumulation of facts and gradual removal of prejudices, have wrought in my mind the same revolution that they have in so many others. The opinion of the contagious nature of the disease has been gradually gaining ground even in India, and seems to be the general one in Europe. « ${ }^{412}$

Für die britischen Mediziner, die durch ihre Tätigkeit in Indien bereits Erfahrungen mit der Cholera gesammelt hatten, war der Ausbruch der Krankheit in Russland besonders rätselhaft. Die Berichterstattung aus Russland, die vor allem nach Deutschland erfolgte, wurde erst verhältnismäßig spät übersetzt und der britischen Ärzteschaft mitgeteilt. Als die Cholera, nachdem sie in Orenburg ausgebrochen war, bis nach Preußen und Österreich gelangte und eine Ausweitung der Pandemie nach Großbritannien wahrscheinlich wurde, begann man sich intensiver mit den Eigenschaften der Cholera - unter europäischen Bedingungen - zu befassen. ${ }^{413}$ Den Widerspruch zwischen den etablierten Positionen in Indien und den nun in Europa aus seiner alten Tradition zu neuer Stärke gekommenen Doktrin der Ansteckung versuchten einige Ärzte dadurch zu glätten, dass sie über eine Veränderung spekulierten, der die Krankheit auf ihrem Weg über den Kontinent unterworfen gewesen sein müsse. $^{414}$

»On these and other grounds we should expect to find the disorder more contagious in the colder countries than it has been in India. $\ll^{415}$

408 Vgl. White: Treatise on cholera morbus; the method of treatment, and means of prevention, 1834 [1831]: S. iii; 34 .

409 Annesley: Sketches of the most prevalent diseases of India, 1829 [1825]: S. 4. Vgl. auch Orton, Surgeon: An essay on the epidemic cholera of India, 1831 [1820]: S. 314.

410 Vgl. Johnson: [Medico-surgical Review - Epidemic Cholera], 1832: S. 177ff.

411 Vgl. Orton, Surgeon: An essay on the epidemic cholera of India, 1831 [1820]: S. xvf.

412 Ebd.: S. 314.

413 Vgl. Christinson, R.: Selected from the German Edition of the Reports by Professor Lichtstädt of St. Petersburg. \&c. (With a Map of the Province or Orenburg): in: Supplement on cholera: in: ESMJ, 38.1832, S. i - lvii: S. i.

414 Vgl. Annesley: Sketches of the most prevalent diseases of India, 1829 [1825]: S. 4f.

415 Orton, Surgeon: An essay on the epidemic cholera of India, 1831 [1820]: S. 346. 
»The number of medical man and hospital attendants attacked with the cholera during the present epidemic, in proportion to the whole employed and to the other classes of society, has been beyond all comparison greater here than in India under similar circumstances [...].« 416

Das London Board of Health gab 1831 eine Sammlung von Texten über die Cholera in Indien und Russland heraus, an welche sie außerdem eine Liste von Vorkehrungen und Regularien anfügte. Diese zeugten von einer kontagionistischen Einschätzung und unterstützte diese durch die Überzeugung, dass die »European cholera « von der indischen Cholera zu unterscheiden sei: »[T]he disease, as it has shown itself in this capital [Moskau], when closely compared with the Indian Cholera, appears to have undergone some modifications [...]. $\ll^{417}$ Wobei auch die Ärzte in Indien, die sich schließlich für kurze Zeit dem Lager der Kontagionisten anschlossen, die These über die lokalen und atmosphärischen Ursachen der Krankheit nie völlig aufgaben, ebenso wenig wie die Position, dass die Cholera sich in der Art und Weise ihrer Übertragbarkeit von der Pest erheblich unterschied. ${ }^{418}$

Wie auch in Frankreich und Deutschland war eine Folge der Debatte und der großen Verunsicherung bezüglich des medizinischen Wissens über die Cholera, eine allgemeine Schwächung der Rolle der Medizin in der Auseinandersetzung um Gesundheitspolitik und v.a. um die Lösung des Choleraproblems. Aus den medizinischen Erkenntnissen die richtigen Techniken zur Vermeidung der Cholera abzuleiten, gelang nicht. Die Hoffnung, die an diese Ableitungen geknüpften Techniken und vorhandenen Praxen der Regierung rationalisieren und begründen zu können, erfüllte sich nicht. Nirgends, weder in der Behandlung noch in der Prävention, zeigte sich das, was als eine »more universally successful practice ${ }^{419}$ hätte bezeichnet werden können. Andere Disziplinen, die sich in der frühen Diskussion um Epidemien einen Platz verschafft hatten, rückten in den Vordergrund. Die Medizin proklamierte nun, nichts über die Krankheit zu wissen, und zog sich auf ihre Methode klinischer und in die Tiefe des Körpers gerichteter Beobachtung zurück. Dies zeigen etwa auch die Schlussfolgerungen von James Boyle, ein Schiffschirurg der britischen Krone und James Annesley, ebenfalls Chirurg.

»The various opinions then, which meet the young medical enquirer, tend only to involve him in a dilemma of painful reflection, requiring his most patient observance of every grade and symptom of the disease; the only mode which is capable of conferring self-confidence, and without which, there can be but little hope of success. $\ll^{420}$

416 Russell: Extract from the joint Report, St. Petersburgh, July, 1831, 1831: S. 34.

417 Ebd.: S. 28.

418 Vgl. Orton, Surgeon: An essay on the epidemic cholera of India, 1831 [1820]: S. 347; S. 459. Vgl. Annesley: Sketches of the most prevalent diseases of India, 1829 [1825]: S. 236.

419 Boyle: Treatise on the epidemic cholera of India, 1821: S. 8.

420 Ebd.: S. 9.Vgl. Auch Annesley: Sketches of the most prevalent diseases of India, 1829 [1825]: S. xv. 
Die Strategie der Hygiene und der Epidemiologie hingegen bewegte sich in entgegengesetzter Richtung: Erkenntnisse, die zur Lösung der mit der Cholera verbundenen Probleme beitragen würden, lagen nicht im Detail medizinischer und klinischer Untersuchungen, sondern in der Weite und im Umfang der berücksichtigten, wenn auch nur groben und vereinfachten Faktoren. Alle Faktoren, die in irgendeiner Form die Gesundheit und das Leben betrafen und in Zusammenhang mit der Verbreitung, dem Ausbrechen und der Entwicklung der Choleraepidemien gebracht werden konnten, waren von Bedeutung. ${ }^{421}$ In so gut wie allen von mir berücksichtigten britischen Texten über die Cholera lässt sich die Unterscheidung von Krankheitsursachen als Merkmal einer Aufteilung auf diese unterschiedlichen Disziplinen festmachen. Während die »proximate causes of the disease ${ }^{422}$ vor allem durch die Untersuchung der Symptome und der pathologischen Vorgänge im Körper einer erkrankten Person oder den Zustand des Körpers nach dem Tod bestimmt wurden, maß man den »predisposing causes $\aleph^{423}$ und den »primary remote causes $«^{424}$ zunehmend Bedeutung bei, was die baldige Lösung des Choleraproblems betraf. Letztere beiden ließen sich im Sinne einer hygienischen Betrachtung allgemeiner diätetischer und lebenspraktischer Umstände von Menschen und Individuen bestimmen. ${ }^{425}$ Die Versammlung der ganzen Bandbreite der >remote causes < beinhaltete eine Betrachtung der Veränderung des Klimas, der Atmosphäre usw. in Verbindung mit Nahrung, Behausung und spezifischen Lebensverhältnissen und Lebensweisen. Es erging geradezu ein Aufruf an alle Ärzte, und Menschen, die Erfahrungen im Zusammenhang mit der Cholera gemacht hatten, ihre Beobachtungen zur Verfügung zu stellen, um den allgemeinen Pool der Informationen zu vergrößern. Die Logik der klinischen Methode, der Sammlung von Daten aus einer Vielzahl von Untersuchungen pathologischer Prozesse anhand von Fällen einer bestimmten Krankheit wurde in gewisser Hinsicht auf den Bereich der anderen Ursachen übertragen. ${ }^{426}$

»The want of a sufficient number of data is the great obstacle to the solution of every difficult problem; and this is particularly experienced in questions of pathology; but in cholera we are presented with a greater number of striking general facts, from which fixed principals may be deduced, than any other disease seems capable of affording. $\ll^{427}$

Auch von Seiten des London Board of Health wurde 1831 durch seinen Präsidenten Henry Halford verlautbart, die Erfahrungen mit der Cholera in Indien hätten in erster Linie zu Ernüchterung über die Möglichkeiten medizinischer Praxis bei der Behandlung der Cholera beigetragen.

421 Vgl. Boyle: Treatise on the epidemic cholera of India, 1821: S. 11.

422 Beispielsweise bei Orton, Surgeon: An essay on the epidemic cholera of India, 1831 [1820]: S. 56.

423 Ebd: S. 193.

424 Ebd: S. 237.

425 Vgl. Annesley: Sketches of the most prevalent diseases of India, 1829 [1825]: S. xv.

426 Vgl. ebd.

427 Orton, Surgeon: An essay on the epidemic cholera of India, 1831 [1820]: S. $56 f$. 
»Treatment of the disease in India: The modes of treatment adopted in India were very various. From the rapid accumulation of patient daily falling with the disease, and the small success of any treatment in the earlier appearance of it, a feeling of disappointment and almost despair seems at times to have dispirited the medical officers, and they described (from hopeless state which they found their patients) as changing from one extreme of practice to another. $\aleph^{428}$

Was Halford, der ebenfalls Präsident des Royal College of Physicians war, allerdings nicht davon abhielt zu hoffen, dass auch gerade diese enttäuschenden Erfahrungen helfen würden, die Ärzte Großbritanniens gut auf die Cholera vorzubereiten: wenn nicht dadurch, dass sie eine geeignete Behandlungsmethode gefunden und Sicherheit über die Ursachen der Krankheit gewonnen hatten, so doch dadurch, dass sie auf umfangreiche Erfahrungen und Wissen zurückgreifen können würden, sollte die Cholera auf den Britischen Inseln ausbrechen. Das London Board of Health sah es aufgrund der theoretischen Unklarheit als das Beste an, die möglichst unbegrenzte und offene Sammlung aller Beobachtungen und Erfahrungen voranzutreiben. ${ }^{429}$ Trotz des Eingeständnisses vieler in Indien tätigen britischen Mediziner, dass die Cholera möglicherweise doch kontagiös sein konnte, fürchtete man die mit dieser Doktrin verbundenen und als problematisch angesehenen Techniken. So beteuerte auch Annesley: »I cannot, however, but think it unfortunate that the idea was ever suggested, because the dread of contagion may lead to serious consequences « ${ }^{430}$ Annesley plädierte trotz der Anerkennung der Kontagiositätsthese der britischen Regierung dafür, auf die restriktiven Techniken der Regierung weitestgehend zu verzichten. Statt auf die Repression des Handels und Verkehrs zu setzten oder die Kommunikation und gegenseitige Hilfe der Bürger durch Isolation zu unterdrücken, forderte er eine Politik der positiven Mobilisierung und Sicherung von (Lebens-)Kräften, indem man sich auf die Beseitigung der sog. »predisposing and exciting causes $\aleph^{431}$ konzentrierte.

\section{Die liberale Kritik an der Quarantäne}

»[H]ow many months we have listened to the reports, and perused the statements made through various channels, respecting the cholera morbus all of which have only tended to strengthen our conviction that the disease is non-contagious, except under circumstances of filth and foul air; and that all our quarantine regulations (more especially internal quarantine) are worse than useless. $\ll^{432}$

428 Halford, (Präsident) in the name of the Board of Health: Report, 1831: S. 11.

429 Vgl. Keir: Extract from the Report on the Epidemic Disease called Cholera Morbus, which prevailed in the City of Moscow [...], 1831: S. 27.

$430 \mathrm{Vgl}$. Annesley: Sketches of the most prevalent diseases of India, 1829 [1825]: S. $243 \mathrm{f}$.

431 Ebd.: S. 244f (Im Anhang der Kapitel lieferte Annesley Statistiken über das Auftreten der Krankheiten in den europäischen Truppen und des damit einhergehenden »[g]eneral loss of European troops belonging to his Majesty's and the Honorable East India Company's« ebd: S. 363.)

432 Johnson: Medico-surgical Review - Epidemic Cholera, 1832: S. 179f. 
Solche Aussagen kennzeichneten die Reflexionen nach dem Ausbruch der Choleraepidemie auf den britischen Inseln. Überhaupt spielten die Diskussion um die Quarantäne in Großbritannien - und vor allem der Widerstand gegen sie -, eine zentrale Rolle bei der Festigung liberaler Regierensrationalität. Die Cholera war bei weitem nicht der Anfangspunkt oder der Endpunkt dieser Auseinandersetzungen. ${ }^{43}$ Die Ablehnung der Quarantäne hatte in Großbritannien zu dieser Zeit bereits eine längere Vorgeschichte. Dennoch stand die Krankheit über weite Teile der Diskussion im Zentrum der Debatten.

Die Quarantäne wurde von verschiedenen Autoren bereits im 18. Jahrhundert als Paradebeispiel für eine willkürliche, unliberale und rückschrittliche Regierungspraxis angeführt. Liberale Ärzte und andere Gelehrte argumentierten, die Quarantäne wäre eine Technik, die nur unter der Herrschaft von Willkür und Irrationalität, Furcht, Aberglaube und religiöser Verblendung etabliert werden konnte. Deshalb, so ihre Position, sollte diese Technik nicht einfach verändert, sondern tatsächlich gänzlich abgeschafft werden. Infolge dieser Angriffe erlebte die Praxis der Quarantäne im 19. Jahrhundert eine massive Veränderung, man könnte sagen, sie wurden einer wissenschaftlichen und ökonomischen Rationalisierung unterzogen, durch die sie später im letzten Drittel des 19. Jahrhunderts wieder eine vernünftige Praxis werden konnte.

Diese ganze Entwicklung der Quarantäne ist deshalb so interessant, weil sie deutlich macht, dass es in der Logik der liberalen Regierung nie darum ging, die Regierung >schwächer< zu machen, indem sie diese restriktiven Techniken und Mittel zu regieren wirklich ausschloss. Die Frage war durchaus nicht, ob man überhaupt restriktive und repressive staatliche Maßnahmen akzeptieren konnte, sondern nur, ob diese im Sinne einer bestimmten Berechnung, einer Ökonomie und Vernunft der liberalen Regierung als stimmig und effektiv eingeschätzt wurden. Das frühere Verfahren zur Prüfung dieser Techniken auf ihre Effizienz war weniger aufwändig gewesen: Hier hing die Legitimität einer Regierungstechnik, wie auch im Fall der Cholera, z.B. allein an der Frage der Kontagiosität. War eine Krankheit >pestartigく, also kontagiös, konnten alle Techniken der Quarantäne und Isolation ohne genauere wissenschaftliche Untersuchungen angewendet werden. Dieser Zusammenhang von Wissen und Regierungstechniken sicherten der Regierung eine formale Handlungsfähigkeit zu. Die alte Praxis der Quarantäne, von der viele britische Ärzte schon im 18. Jahrhundert sagten, sie sei ein historisches Relikt alter Willkürherrschaft, ein übriggebliebenes >rein machtpolitisches $<$ Instrument, musste, wenn die Regierungen sie weiter anwenden wollten, nun wissenschaftlich rationalisiert werden. Man musste zunächst die Kategorie der Kontagiosität aufbrechen und aus ihrem starren Verhältnis zur Praxis der Quarantäne lösen, damit die Rationalisierung der mit ihr verbundenen Techniken möglich wurde.

Dieser Modus der Rationalisierung der Regelungen war zur Zeit der ersten Choleraepidemie in Großbritannien eine einigermaßen etablierte Praxis. Die Quarantäne auf die Cholera anzuwenden, erforderte nach allen Erfahrungen und allem Wissen, die zu dieser Zeit bereits über sie existierte und bei aller Kritik, die man an der Quarantäne grundsätzlich übte, eine genauere Begründung als die einfache Definition der Krankheit als >ansteckend . Die Notwendigkeit bestand »for establishing a Specific 
Code of Sanitary Restrictions for that Disease [Cholera] «34. Zu Beginn des 19. Jahrhunderts, als Charles Caldwell im The medical and physical journal einen Aufruf an die amerikanische medizinische Gesellschaft in Philadelphia richtete, sich auf der Grundlage medizinischer Forschung gegen die Quarantäne zu stellen, befand sich die Debatte in Großbritannien vermutlich am Anfang dieser zweiten Phase der großen Re-Problematisierung der Quarantäne seit dem 18. Jahrhundert. ${ }^{435}$ Um über die Quarantäne, genauer genommen über ihre »rationality and usfulness«, urteilen zu können, war es laut Caldwell hilfreich, sich ihre Entstehungsgeschichte genauer anzusehen. Er sah es im Speziellen als eine Aufgabe der medizinischen-wissenschaftlichen Institutionen an, durch ihr Wissen und ihre Erkenntnisse für die Rationalisierung oder auch die Abschaffung alter und rückschrittlicher Techniken zu sorgen. ${ }^{436}$ Caldwell beschrieb die Bedingungen, unter denen die Quarantäne im 15. Jahrhundert eingeführt wurde. Er betonte, sie sei eine Reaktion auf die Pest gewesen. Aber schon zum damaligen Zeitpunkt sei sie alles andere als effektiv gewesen, auch weil es noch kein genaues medizinisches Wissen über die Krankheit (z.B. Inkubationszeit und $\ddot{A}$ tiologie) gegeben habe. ${ }^{437}$

Neben der Auflösung der Kategorie der Kontagiosität, auf deren formal-wissenschaftliche Bestimmung man die Quarantäne noch zu stützen versuchte, war eine weitere Forderung, dass man die Effizienz der Quarantäne vor dem Hintergrund einer weit größeren Zahl von nicht nur medizinischen, sondern auch sozialen Faktoren betrachten müsse: Die ökonomischen, politischen, sozialen und sogar psychologischen Konsequenzen fielen angesichts ihre relativen Ineffektivität schwerer ins Gewicht, »consequences which every people must expect, who proclaim their country to be nursery of contagion. $\ll^{438}$ Typisch für die Gegner der Quarantäne war es, schon zu diesem Zeitpunkt zu fordern, den Nutzen oder die Schädlichkeit der Maßnahmen in einem größeren Kontext zu sehen. ${ }^{439}$ Ein anderer Quarantäne-Gegner und AntiKontagionist, namens Adler, verspottete in der gleichen Ausgabe des Journals die Anhänger der Quarantäne und Kontagionisten, die vorgaben, sich bei der Empfehlung politischer Maßnahmen nur nach der medizinischen Indikation der Ansteckung zu richten:

434 Vgl. Central Board of Health/Council Office: Quarantine, 1832, London: S. 1.

435 Vgl. Caldwell, Charles: An Anniversary Oration on the Subject of Quarantines, delivered to the Philadelphia Medical Society: in: MPJ, 18.1807, S. 111 - 128: S. 112.

436 Vgl. ebd.: S. 123.

437 Vgl. (Medical Intelligence IV) Board of Health: in: ESMJ, 1.1805, S. 494 - 499. Vgl. Harvey, J., Secretary: Second Report of the Board of Health: in: ESMJ, 1.1805, S. $111-$ 117.

438 Ebd.: S. 124f.

$439 »$ Quarantine strictly enforced, [...] might do an injury which our trade and revenue could never recover «. Alder: (Letter I), To the Editors of the Medical and Physical Journal, On Contagion and Fever: in: MPJ, 18.1807, S. 423 - 426: S. 425. Vgl. auch Caldwell, Charles: An Anniversary Oration on the Subject of Quarantines, delivered to the Philadelphia Medical Society: in: MPJ, 18.1807, S. 111 - 128: S. 128. 
»But indeed, such gentleman, to be consistent, should burn our ships and their cargoes; for I cannot admit that quarantine could cleanse them from contagion! Under our present theoretic ideas then, we can not be sure the a present consciousness of safety to most places under certain circumstances will be sufficient to warrant us in the authority freely to continue to trade to such places under such circumstances; and we may fearfully apprehend circumstances will soon and often arise, which will render it almost, if not altogether, impossible to trade to such places for a great length of a time. $\aleph^{440}$

Um die doctrin of contagion, die sich historisch an der Erfahrung mit der Pest herausgebildet hatte, zu bestreiten, unternahm man auch medizinisch-epidemiologische Untersuchungen über die Pest. Einige Ärzte meinten nun, auf der Grundlage der modernen Medizin beweisen zu können, dass auch die Pest nie in diesem Sinne kontagiös gewesen sei, es also nicht einmal von der Pest ausgehend möglich sei, die Quarantäne zu rechtfertigen. ${ }^{441}$ Auf die Forderung eines Sir John Jackson und unterstützt durch F. Robinson, President of the Board of Trade, wurde 1819 eine Parlamentskommission eingerichtet, um eine Untersuchung »into the expediency of abrogating or modifying the restrictions imposed by the quarantine laws $\aleph^{442}$ vorzunehmen. Als Begründung für seine geforderte Untersuchung gab Jackson an, die Doktrin der Kontagiosität sei durch eine Untersuchung über das epidemische Fieber (»epidemic fever«), das kürzlich in London geherrscht hatte, erschüttert worden. Die Kommission, die man diesbezüglich vom Parlament beauftragt hatte, definierte das Fieber als nicht kontagiös. ${ }^{443}$ Die Fragen der Kommission, die Jackson vorschlug, lautete also:

»First: Is the plague capable of being communicated from person to person, either by immediate contact with those diseased, or, intermediately, by contact with infected goods? Or, secondly. Is it an epidemic depending only on a peculiar state of atmosphere? «44

Die Frage nach der Richtigkeit der Quarantäne blieb auch hier untrennbar von der medizinischen Bestimmung der Kontagiosität, so dass die Kommission insgesamt neunzehn Ärzte befragte,

»whose practical experience, or general knowledge of the subject, appeared to your committee most likely to furnish the means of acquiring the most satisfactory information. $\ll^{445}$

»All the opinions of the medical man whom your committee have examined, with the exception of two, are in favour of the received doctrine, that the plague is a disease communicable by

440 Alder: (Letter I), To the Editors of the Medical and Physical Journal, On Contagion and Fever: in: MPJ, 18.1807, S. 423 - 426: S. 425.

441 Diese Diskussion kam ab 1830 auch in Frankreich auf.

442 [Hrsg.]: Report from the Select Committee, on the Doctrine of Contagion in the Plague [...]. Orderes by the House of Commons to be printed, June 14, 1819: in: ESMJ, 16.1820,

S. 109 - 122: S. 109.

443 Ebd.: S. 109.

444 Ebd.

445 Ebd.: S. 109f. 
contact only, and different in that respect from epidemic fever [...] they see no reason to question the validity of the principles on which such regulations appear to have been adopted. «446

In einem anderen Brief hatte Adler schon 12 Jahre früher sichtlich verärgert über die Kontagionisten geschrieben: »can they not turn their attention to the existence of other causes of fevers, than their ideal contagion? «447 Die Rahmen der Rationalität der Quarantäne aufzubrechen und für andere Argumente zu öffnen, war schwierig. Die Cholera wirkte in dieser Hinsicht wie ein diskursiver Sprengsatz. Der große Konflikt zwischen den Kontagionisten und den Anti-Kontagionisten, die den Anhängern und Gegnern der Quarantäne entsprachen, ist nicht als ein vorrangig medizinischwissenschaftlicher Disput zu verstehen. Eher war es genau die Frage, wie es möglich sein könne, die Quarantäne, die so viele Wirkungen auf die ganze Gesellschaft, v.a. Ökonomie und den Handel habe, nur medizinisch zu betrachteten. Solange die Frage nach der Gültigkeit der Quarantäne quasi ausschließlich an die Frage der Kontagiosität geknüpft war, blieb sie der Rationalität der Politik und der Politischen Ökonomie verschlossen. Das Anliegen der Anti-Kontagionisten war es, diese Verknüpfung zu lösen und somit die Aufgaben und vor allem die Grenzen der Regierung neu zu definieren. Die Grenzen ihrer Regierung sollten sich nicht an denen des Wissens einzelner Disziplinen orientieren, sondern eher an den Grenzen des Verständnisses ihres komplizierten und grenzenlosen Gegenstandes - dem Leben, der Bevölkerung oder ganzen Nation.

Die Cholera war für die Medizin ein solches Rätsel, dass viele Ärzte nach kurzer Zeit bereit waren zu proklamieren, dass sie eben nichts über die Ursachen der Cholera wüssten ${ }^{448}$. Gerade diese Schwäche der Medizin, jahrzehntelang nicht in der Lage $\mathrm{zu}$ sein, eine einheitliche wissenschaftliche Erklärung hervorzubringen und einen halbwegs einheitlichen praktischen Umgang mit der Cholera zu empfehlen, verschaffte der Forderung der Anti-Kontagionisten, Epidemiologen und Vertretern dieser neuen liberalen ökonomischen Regierungsvernunft den Raum, ihren alten Thesen mehr Beweiskraft zu verleihen.

Im August 1831 stellte der Arzt Edward Seymour im Auftrag der Regierung eine Untersuchung über eine geeignete Quarantäneregelung zum Schutz vor der Cholera an. Das General Board of Health veröffentlichte die Untersuchung in der ersten Aus-

446 Ebd.: S. 110.

447 Alder: (Letter II), To the Editors of the Medical and Physical Journal, On Contagion and Fever: in: MPJ, 18.1807, S. 497 - 499: S. 497. »If the Gentleman would but turn their attention to the other causes of fever, or rather to the only causes of fever, they would soon see fever, whether epidemic, endemic or sporadic, might be caused without contagion; and then would soon perceive they could not be produced by contagion.«: Ebd.: S. 499. Siehe auch Alder: (Letter III), To the Editors of the Medical and Physical Journal, On Contagion and Fever: in: MPJ, 19.1808, S. 113 - 117. Vgl. auch: Alder: (Letter IV), On Quarantines, Contagion and Fever: in: MPJ, 19.1808, S. 198 - 204.

448 Der Typhus war im Übrigen ähnlich rätselhaft und trug sicherlich seinen Teil zu dieser Entwicklung bei. 
gabe der Cholera Gazette. ${ }^{449}$ Diese enthielt vor allem einen Vergleich der bisher bekannten Abstände zwischen einem möglichen Kontakt einer Person mit Cholera oder einem Cholerakranken und dem Ausbrechen der Krankheit bei derselben, also eine Art Untersuchung der vermutlichen Inkubationszeit der Cholera. ${ }^{450}$ Später beriefen sich die anti-kontagionistischen Mitglieder der Westminster Medical Society auf den Bericht und verurteilten ihn als inkonsistent. ${ }^{451}$ Man gab später angesichts der Untersuchung aber zu, dass keine Quarantäne mehr - von welcher Regierung auch immer - festgesetzt werden könne, ohne die Anerkennung und Einbeziehung des genauen Wissens über die jeweilige Krankheit und aber auch der Abwägung der sozialen Folgen und Kosten einer solchen politischen Technik. ${ }^{452}$ Selbst dieser grundsätzlich für Quarantäne stimmende und von der Kontagiosität der Cholera überzeugte Bericht des Central Board of Health von 1832 enthält bereits eine durch Diskussionen um die Quarantäne vollzogene Verschiebung ihrer Existenzbedingungen. ${ }^{453}$

\section{Die erste Epidemie}

Der Widerspruch der Praxis von Quarantäne, Isolation, Absperrung und Abgrenzung zur grundsätzlich liberal orientierten Ärzteschaft - v.a. im gerade im Aufstieg befindlichen ärztlichen Mittelstand jenseits des konservativen Royal College of Physicians, lässt sich bereits in der frühen Phase der ersten zögerlichen Vorkehrungen der englischen Regierung erahnen. Als das London Board of Health 1831 eine Sammlung von Texten über die Cholera in Indien und Russland herausgab, waren bereits Vorschläge über Maßnahmen gegen die Cholera an die Krone mitgeteilt worden. Im offensichtlichen Bewusstsein über den zu erwartenden Widerstand hielt man es vom Board aus allerdings für sinnvoller, solange noch keine akute Gefahr bestand, lieber auf die Veröffentlichung dieser Regularien zu verzichten. Stattdessen ging man vorsichtig vor und legte eine abgemilderte Variante dieser Regularien in Verbindung mit einschlägig die These der Kontagiosität stützenden wissenschaftlichen Aufsätzen der Öffentlichkeit vor. ${ }^{454}$

449 Unterzeichnet wurde die Untersuchung hier von all den Ärzten, die später zur Zielscheibe einer mächtigen anti-kontagionistischen Kritik wurden: E. Stewart, William Pym, J. Marshall, William Russell und David Barry: Vgl. Central Board of Health/Council Office: Quarantine, 1832: S. 7.

450 Vgl. ebd.: S. 1.

451 Vgl. Artikel 1: Westminster Medical Society, Discussion on the Cholera, Question of Contagion, 5. März, 1832: in: The Lancet London, 1832: S. 22. Gemeint sind hier vor allem Widersprüche in den Quarantäne-Berichten des Board of Health, die ebenfalls in der Cholera Gazette abgedruckt wurden: 1. Quarantine cholera reports. Details of cases of Cholera which have occurred on board coasting vessels, from ports infected in England, from 11th November, 1831, to 31st January, 1832: Ebd., S. 93 - 103. Und, 2. Quarantine cholera reports. 11th February 1832: Ebd., S. 115 - 116.

452 Vgl. Central Board of Health/Council Office: Quarantine, 1832, London: S. 3.

453 Vgl. ebd.: S. 6 .

454 Vgl. Board of Health (Hrsg.): Papers relative to the disease calles Cholera spasmodica in India now prevailing in the north of Europe, printed by authority of the lords of his Mahesty's most honourable privy council, 1831: S. vf. 
Vor allem Städte an der Küste wurden dazu aufgerufen, Vorbereitungen zu treffen, um das Ausbrechen einer Epidemie und die Verbreitung der Cholera, sollte diese aus Nord-Europa nach Großbritannien gelangen, zu verhindern. Dazu gehörte u.a. das Verhalten bei dem ersten Auftauchen eines Cholerafalls. ${ }^{455}$ Diese Verhaltensregeln ließen an Strenge nichts zu wünschen übrig. Dennoch unterschieden sie sich in wichtigen Punkten von den Maßnahmen, die man etwa in Berlin oder anfänglich in Moskau angewendet hatte. Anstatt Häuser oder ganze Straßenzüge zu isolieren, setzte man auf die »Entfernung der Kranken« aus ihren Häusern und aus den Städten:

»The best means of preventing the spreading of infection are, the immediate separation of the uninfected from the sick, by their prompt removal from the house of any infected person, or by the removal of any individual affected with the disease, if possible, to some house in a dry and airy situation, appropriated to the purpose; but in the event of such removal not being practicable, on account of extreme illness or otherwise the prevention of all intercourse with the sick, even of the family of the person attacked, must be rigidly observed, unless the individual who desire to stay shall submit to such strict rules of quarantine as the public safety may demand, and the local Board of Health, advising with the Board of Health in London, may consider expedient. $\ll^{456}$

Des Weiteren empfahl das Board of Health, die Räume, aus denen man die Kranken entfernte, um sie an andere Orte oder eigens eingerichtete Cholerakrankenhäuser zu schaffen, akribisch zu reinigen - »as the best means of preventing contagion ${ }^{457}$. Die Gegenstände und die Kleidung der Kranken sollten durch kochendes Wasser desinfiziert, gewaschen oder vernichtet werden. Die Verheimlichung oder verzögerte Meldung eines Krankheitsfalls würden außerdem unter Strafe gestellt werden. ${ }^{458} \mathrm{Um}$ geeignete Vorkehrungen zu treffen und die nötigen Maßnahmen im Falle einer Epidemie zu überwachen, wollte man sog. Local Board of Health gründen, die aus hohen Mitgliedern der Verwaltung, Medizinern, aber auch aus Geistlichen (clergyman) und einigen Angehörigen der ansässigen Bevölkerung zusammenzusetzen seien. Dieses Gremium wurde mit der Aufgabe betraut, dem Board in London über die Vorkehrungen, mögliche Cholerafälle, Erfolge von Maßnahmen und Behandlungen zu berichten, wie auch Hilfe durch das Board in London anzufordern. ${ }^{459}$

Im August 1831 brach die Cholera in Sunderland und Umgebung aus. Wenig später wurden epidemische Ausbrüche der Cholera in Newcastel und Umgebung gemeldet und noch vor Beginn des neuen Jahres hatte die Epidemie Tranent in Mussel-

455 Vgl. Halford: (Präsident) in the name of the Board of Health: Preliminary steps advised to be taken on the first appearance of the Disease, 1831: S. 36.

456 Ebd.: S. 36f.

457 Vgl. ebd.: S. 37.

458 Vgl. ebd.

459 Vgl. ebd.: S. 36. 
burgh in Schottland erreicht. ${ }^{460} \mathrm{Im}$ Januar wurde auch Edinburgh von der Epidemie erfasst. Am 9. Februar schrieb ein Arzt aus Nordengland an die Times in London:

»Sir, But one word. The proportion of deaths at Haddington is nearly one in two; at Musselburgh considerably more than one in three; and the same at Gateshead, Tranent, \&c. At North Shields it is only one in four; at Hettoa one in five; and at Wallsend (as yet), one in nine. « ${ }^{461}$

Im selben Monat erreichte die Cholera die Ufer der Themse und brach kurz darauf auch in London aus, bevor sie sich weiter im Westen Englands und schließlich auch in Irland ausbreitete.

Zur Zeit der ersten Epidemie in Großbritannien war die Kommunikation und der Austausch von Informationen zwischen den lokalen Regierungen, den Local Boards of Health und den Ärzten in den von Cholera betroffenen Orten und der Regierung bzw. dem Central Board of Health ${ }^{462}$ unkoordiniert. Unzählige Fallbeschreibungen einzelner Ärzte gingen in dem Büro des Board in London ein. Auch als die Cholera Ende Februar 1832 in London ausbrach, häuften sich die Berichte, die in erster Linie eine lose Zusammenstellung von Fallbeschreibungen beinhalteten. Diese sind sowohl klinischer als auch ätiologischer Art. Die ätiologischen Teile der Berichte ähneln teilweise kriminologischen Untersuchungen und enthalten Beschreibungen der Personen, ihrer Lebenssituationen, all ihrer Aufenthaltsorte, Tätigkeiten, Wege und Kontakte in den Tagen vor der Erkrankung. Die klinischen, pathologischen Beschreibungen des Krankheitsverlaufs, der versuchten Behandlung und schließlich der Obduktion standen diesen relativ isoliert gegenüber. Neben diesen einzelnen ausführlichen Darstellungen, die sich in der Regel auf die ersten Fälle eines epidemischen Ausbruchs in einer Stadt oder in einem neuen Distrikt bezogen, beinhalteten die Berichte oberflächliche Auflistungen von Fällen in Einrichtungen oder in bestimmten Straßen oder kleineren Distrikten der Stadt. Schließlich enthielten einige Berichte Zusammenfassungen dieser Fälle in Form von Statistiken, die Alter und Geschlecht der erkrankten bzw. gestorbenen Personen berücksichtigten, und Vergleiche dieser Statistiken zu den Daten anderer Gegenden oder Städte anstellten. Teilweise gab es auch Berichte über Vorkehrungen und Maßnahmen zur Eindämmung der Epidemie, die einzelne lokale Regierungen auf eigene Faust unternommenen hatten. Sie richteten sich an das Londoner Board mit der Bitte um weitere Instruktionen. Der Anteil der Berichte über sanitäre Maßnahmen war verhältnismäßig gering, zeigte aber deutlich,

460 Christinson, Robert: Art. XI. - Account of the Arrangements made by the Edinburgh Board of Health, preparatory to the arrival of Cholera in the City. 15th February 1832: in: Supplement on cholera: in: ESMJ, 38.1832, S. ccliv - cclxxxviii: S. cclxxxviii.

461 Central Board of Health: Notice of a Letter in the Times: in: The Cholera Gazette, 1832: S. 134.

462 Das Cental Board of Health übernahm ab November 1832 die Rolle des alte London Board of Health als zentrale Anlaufstelle und zur Leitung und Koordination der einzelnen Local Board of Health. Die Einrichtung einer nationalen Institution der öffentlichen Gesundheit fand aber nach dem Public Health Act 1848 statt. 
dass sich diese Maßnahmen so gut wie ausschließlich auf die sog. poor, pauper und vagants richten. ${ }^{463}$

Eines der ersten Ergebnisse der zusammengetragenen Informationen auf der Suche nach möglichen hilfreichen Präventivmaßnahmen, war die Feststellung, dass sich vor dem Ausbrechen der Cholera Durchfallerkrankungen gehäuft hatten und dass eine frühe Behandlung von Diarrhö das Ausbrechen der Krankheit möglicherweise verhindern konnte. Ohne dass man von Seiten der Medizin in der Lage gewesen wäre den Zusammenhang zu erklären, reichte dieser Hinweis, um hieraus präventive Maßnahmen zu entwickeln. Es wurden Handbills in den betroffenen Regionen verteilt, in denen die Bevölkerung dazu aufgefordert wurde, im Falle einer Durchfallerkrankung diese zu melden und umgehend ärztliche Hilfe anzufordern. Die >Früherkennung « als eine der ersten Ansatzpunkte präventiver medizinischer Mittel gegen die Cholera war besonders deshalb interessant, weil sie explizit aus den Schlussfolgerungen von Ärzten folgte. Jeder einzelne noch so unbedeutende Landarzt konnte durch seine Aufmerksamkeit und Behandlung dezentral einen Beitrag zur Vorbeugung der Epidemie leisten. Das London Board of Health schrieb Mitte Januar 1832 einen Aufruf an alle Ärzte, um diese Frage zu untersuchen. ${ }^{464}$ In Gateshead verabschiedete zeitgleich das Local Board eine Resolution »respecting the Treatment of the Preliminary Diarrhoea ${ }^{465}$. Daraufhin wurde auch beschlossen, zusätzlich zu den zuvor bereits veröffentlichten Handbills, die nur einige Hinweise zur ersten Hilfe im Falle eines Choleraanfalls enthalten hatten, ein neues Flugblatt zu veröffentlichen, welches noch einmal besonders die Pflicht zur frühen Meldung jeglicher Beschwerden, die als Vorboten der Cholera angesehen wurden, bekräftigen sollte. ${ }^{466}$ Im Unterschied zu den instruction populaire, die man in Frankreich verteilt hatte, richteten sich die Handbills explizit an die Armen und die arbeitende Klasse und enthielten so gut wie keine Ratschläge zu Diät, Lebensweise und zum persönlichen Verhalten. Sie zielten fast ausschließlich auf die Beobachtung und sofortige Meldung von Anzeichen einer möglichen Cholera - »careful in watching for the occurrence of stomach-complaints or bowel-complaints $\ll^{467}$, nicht nur durch die Familienoberhäupter, sondern durch alle, die in irgendeiner Weise als Autorität gegenüber den Arbeitern und ihren Familien fungierten. ${ }^{468}$

463 Eine Sammlung von Berichten und Auszügen aus Berichten wurde z.B. vom Central Board of Health in der Cholera Gazette veröffentlicht: The Cholera Gazette, consisting of documents communicated by the Central Board of Health, with intelligence relative to the disease, derived from other authentic sources, 2. Aufl., 1832, London.

464 Vgl. Maclean, Central Board of Health Council Office: Queries issued by the central board of health: in: The Cholera Gazette, 1832: S. 47f.

465 Board of Health, Gateshead: Resolutions respecting the Treatment of the Preliminary Diarrhoea: in: The Cholera Gazette, 1832: S. 49.

466 Central Board of Health: »Looseness of the bowels is the beginning of Cholera.«: in: The Cholera Gazette, 1832: S. 50.

467 Learmonth: Extracts from the second report of the Edinbugh board of health: in: The Cholera Gazette, 1832: S. 111.

468 Vgl. ebd. 
»With a view of impressing, in the strongest manner, upon the minds of all, but more particularly of the poorer classes, the very great importance of attending to the first and slightest warnings of the approach of an attack of Cholera, the Central Board recommend, that, in the infected districts, handbills to the following effect should be exhibited in conspicuous places. $\ll^{469}$

Im Grunde genommen handelte es sich bei der Maßnahme um eine Verschärfung der Meldepflicht, die man besonders bei den Armen und Arbeiter meinte durchsetzen zu müssen. Trat hier ein Cholerafall auf oder sogar nur ein verdächtiger Fall von Diarrhö, so wurde die Person, die der ärmeren Schicht angehörte und die nicht von alleine ein Krankenhaus aufsuchte, aus ihrem Haus »entfernt« (»removal of diseased persons $\ll)^{470}$ und in ein speziell errichtetes Cholera-Krankenhaus verbracht. ${ }^{471}$ Bei den Angehörigen der anderen Schichten gingen die Boards größtenteils davon aus, dass eine Behandlung im Haus der erkrankten Person angemessener sei.

Anders als in den französischen Instruktionen und anderen Aufforderungen an die Bevölkerung, um Vorkehrungen gegen die Cholera durch eine entsprechende Lebensführung zu treffen, die vor allem sie selbst und die Gesundheit ihrer Familien betrafen, wurde in den handbills vor allem die Verantwortung der Einzelnen mit Rücksicht auf die Vermeidung einer Epidemie und der Sicherheit einer ganzen Bevölkerung betont. Einen choleraverdächtigen Fall nicht zu melden, war ein Verbrechen gegen die öffentliche Sicherheit. Insofern enthielten die handbills sehr wohl einen moralischen Unterton, allerdings keinen, der sich in diätetischer Weise auf das Individuum und seine Lebensweise bezog. »Thousands of lives may be saved by attending in time to this complaint, which should on no account be neglected by either young or old, in places where the disease prevails. $\ll^{472}$

\section{Sanitary measures and preparatory arrangements}

Am 3. Januar 1832 sandte Major Macdonald einen Brief an das zentrale Board in London, um über die Durchführung der Maßnahmen in Sunderland, wo die Cholera zuerst ausgebrochen war, zu berichten.

»[A]ll houses and dwellings, wherein Cholera has occurred in Sunderland [...] have been thoroughly and effectually cleansed and limewashed: and that the Board are making every exertion to have the dwellings of every poor person cleansed and purified in a similar manner. The bedclothes and wearing apparel of persons dying of Cholera, have, in many instances, been wholly destroyed after death, and other articles in lieu thereof have been furnished by the Board, to their surviving relatives. $\ll^{473}$

469 Vgl. Central Board of Health Council Office: Form of handbills recommended for circulation in the infected districts: in: The Cholera Gazette, 1832: S. 50.

470 Ebd.

471 Vgl. Learmonth: Extracts from the second report of the Edinbugh board of health: in: The Cholera Gazette, 1832: S. 111f.

472 Central Board of Health Council Office: Form of handbills recommended for circulation in the infected districts: in: The Cholera Gazette, 1832: S. 50.

473 Vgl. Macdonald: Sanitary Measures adopted at the bottle works company, Sunderland: in: The Cholera Gazette, 1832: S. 8f. 
Neben den Angehörigen des Local Boards und den zuständigen medical officers übernahmen aber auch Privatpersonen, Firmen und Fabrikbesitzer, die eine größere Anzahl von Arbeiter beschäftigten, vergleichbare Aufgaben. ${ }^{474}$ Die Epidemie bot Anlass und Möglichkeiten, die Kontrolle auf die arbeitende Klasse zu erhöhen und die Macht - z.B. von Arbeitgebern über die von ihnen beschäftigten Arbeiter - zu verstärken. Große Versammlungen und Zusammenkünfte wurden untersagt mit der Begründung, sie würden die Wahrscheinlichkeit einer Infektion mit der Krankheit und einer Verbreitung der Epidemie insgesamt erhöhen. ${ }^{475}$ »The Board would recommend that, during the prevalence of the epidemic, all assemblages of large bodies of the working classes, unless at church, should be suspended or avoided.« ${ }^{476}$

Um zu verhindern, dass sich die zur >Risikogruppe< gehörenden arbeitslosen Personen (beggars, vagrants, poor, pauper) der Überwachung entzogen, ergingen Aufrufe an die Leitungen von Armenhäusern und anderen Asylen, während die Bedrohung einer Choleraepidemie andauerte, niemanden aus den Einrichtungen auszuweisen oder zu entlassen (»to abstain, as much as possible, from the removal of paupers $\aleph^{477}$ ), der auch nur das leiseste Anzeichen einer beeinträchtigten Gesundheit zu erkennen gab. 478

»They further recommend, that the health of all paupers and vagrants, who may come into any parish, may be most carefully attended to; and if any of them should be afflicted with symptoms of disease, that they may be lodged separately, and supplied with medical attendance, and every thing necessary. In case of diseases it will be advisable, also, that their bedding and clothes should be placed in an oven or stove, heated to 212 degrees of Fahrenheit, or immersed in boiling water, as the most effectual means of disinfection. $\ll^{479}$

In Sunderland, wo man diesen Aufruf folgte, schrieb der Sekretär des Boards am 13. Januar an das zentrale Board in London: »[T]he magistrates here have [...] invariably suspended the execution of orders of removal, in all cases where the slightest suspicion of disease has appeared. ${ }^{480}$ In größeren Städten, wie in Edinburgh, leitete man »police arrangements for the exclusion of vagrants « ein, um diese davon abzuhalten, überhaupt erst in die Stadt zu kommen. ${ }^{481}$ Nach einer späterer Berichterstattung des

474 Vgl. ebd.: S. 9.

475 Vgl. Gaskell, Samuel: Art. VI. - Remarks on the Malignant Cholera as it appeared in Manchester: in: EMSJ, 40.1833, S. 52 - 65: S. 52.

476 Vgl. Learmonth: Extracts from the second report of the Edinbugh board of health: in: The Cholera Gazette, 1832: S. 110.

477 Maclean [Central Board of Health Council Office: Important sanitary Recommendations: in: The Cholera Gazette, 1832: S. 19.

478 Vgl. ebd.

479 Ebd.

480 Stephenson, Geo. [Sek., Board of Health, Sunderland: Treatment of Vagrants and Removal of Paupers: in: The Cholera Gazette, 1832: S. 70.

481 Vgl. Cuninghame, W.G. [Sek. Board of Health Office: Adress issued by the Edinburgh board of Health on the appearance of the cholera in that city: in: The Cholera Gazette, 1832: S. 109. 
Boards in Edinburgh gehörte es zu den wichtigsten Maßnahmen der Prävention, »to limit movement of beggars and vagrants and to confine them as fast as possible in houses of refuge. ${ }^{482}$ Ermutigungen, auch die Armen dazu aufzufordern, ihre Häuser und Wohnungen sauber zu halten, oder ihre Lebensweise zu ändern, waren eher selten. ${ }^{483}$ Die Reinigung der Häuser der Armen wurde stattdessen von der Polizei und teilweise auf Initiative ${ }^{484}$ von sog. »public-spirited individuals« durchgeführt. ${ }^{485}$ Man rechnete den Weisungen und Instruktionen, die man von Geistlichen und Fabrikverwaltern gegenüber den Arbeitern vorzutragen empfahl, allerdings nur begrenzte Wirkung zu. »The lower population were likewise warned in all possible manners of the danger [...] In many instances of course these warnings were given in vain. [Hervorhebung von $\mathrm{mir}] \ll .{ }^{486}$

Man wurde andererseits nicht müde bei all den polizeilichen Maßnahmen, die sich speziell auf die Armen und die Arbeiterklasse oder auf Bettler, Landstreicher etc. richteten, zu betonen, dass man auf $>$ gute $<$ Behandlung und Versorgung Wert legte. ${ }^{487}$ Besonders die Objektivierung der Lebensumstände, die eine subjektiv beeinflusste hygienische Lebensweise schwierig machten, spielte der Argumentation in die Hände, dass die Verbesserungen der Lebensverhältnisse von oben und auf einer breiteren Ebene angelegt sein müssten. Gerade weil die Lebensumstände der arbeitenden Klasse gesundheitlich bedenklich seien, müssten sich die Arbeiter den Instruktionen und der Praxis der >Entfernung< von Kranken aus den Häusern fügen: »[I]t is impossible to apply them [ the necessary means] properly in the confined rooms and closets

482 Christinson, Robert: Art. XI. - Account of the Arrangements made by the Edinburgh Board of Health, preparatory to the arrival of Cholera in the City. 15th February 1832: in: Supplement on cholera: in: ESMJ, 38.1832, S. ccliv - cclxxxviii: S. cclxxxv, vgl. auch S. Cclxvi. Vgl. auch McLean: Public Health and Politics in the Age of Reform, 2006: S. $80 \mathrm{f}$.

$483 »[\mathrm{~T}]$ he Board would also beg that all clergymen will, on an early occasion, read the present Report, or such part of it as they may think fit, in the churches and chapels of the city, especially in those frequented by the working classes; and that they will also take advantage of the opportunity to enforce on the attention of the working classes all the points herein mentioned, which most nearly concern their welfare, but in particular, the necessity, during the prevalence of the epidemic, of being temperate in their manner of living. « Learmonth: Extracts from the second report of the Edinbugh board of health: in: The Cholera Gazette, 1832: S. 111.

484 »The Board have to announce, that under their directions the city and suburbs have been divided into thirty districts, and each put under the charge of two or more medical men, of whom upwards of 100 have volunteered their services for the purpose. « Ebd.: S. 110.

485 Vgl. ebd.: S. 110.

486 Christinson, Robert: Art. XI. - Account of the Arrangements made by the Edinburgh Board of Health, preparatory to the arrival of Cholera in the City. 15th February 1832: in: Supplement on cholera: in: ESMJ, 38.1832, S. ccliv - cclxxxviii: S. cclxvif.

487 Vgl. Stephenson, Geo. [Sek., Board of Health, Sunderland: Treatment of Vagrants and Removal of Paupers: in: The Cholera Gazette, 1832: S. $70 f$. 
commonly used by persons in this rank of life as sleeping-places ${ }^{488}$. Die massiven Eingriffe von staatlicher Seite oder auch von Seiten der Arbeitgeber, Hausbesitzer oder engagierter Philanthropen aus der bürgerlichen Schicht war eher eine Begleiterscheinung, ein Nebeneffekt eines viel größer angelegten, nicht auf das Individuum, sondern auf die ganze Bevölkerung und die ganze Stadt gerichteten Sicherheitsprogramms. Man bemühte sich geradezu, diese Effekte gering zu halten und die Durchführung möglichst ohne unnötige Nachteile für die Einzelnen umzusetzen. Trotz dieser rigorosen Maßnahmen, die sich vor allem gegen die arme Bevölkerung richteten, schrieb Macdonald, Mitglied des Boards in Sunderland, man sei äußerst bemüht gewesen, diese »liberally and humanely« durchzuführen. ${ }^{489}$ Er beschrieb die Maßnahmen als unangenehme Notwendigkeiten, bei denen man es nicht vermeiden konnte, in das private Leben einzugreifen.

Das persönliche Verhalten und das private Leben waren nur zufällig durch die Maßnahmen tangiert, sie waren nicht der eigentliche Gegenstand, auf den sich diese Techniken richteten. In Edinburgh, wo man die strengsten polizeilichen Maßnahmen durchführte, vermied man es konsequent, bestimmte Begriffe, wie Isolation oder Quarantäne, zur Beschreibung der angewendeten Techniken zu verwenden. Dies zeugte von dem Versuch, die Maßnahmen gegen eine Praxis abzugrenzen, die bewusst und intendiert auf Repression und Ausgrenzung von Kranken zielte, die Strafcharakter hatte oder in irgendeiner Weise eine persönliche Schuld der Kranken und ihrer Familien impliziert hätte. Für Formen der Isolierung von Personen, die man in Edinburgh und anderen Städten Schottlands und Nordenglands in erster Linie bei den Armen einsetzte, verwendeten die verschiedenen Boards den Begriff seclusion:

»There is some reason to fear, however, that the lower orders from misconstruing the nature and objects of the measure of seclusion, my be disposed to attempt escaping it by concealing their illness when they happen to be attacked. This has been stated as a powerful objection to the measure by some persons who disapprove of it. But the experience has shown, that the common people here are in general easily persuaded to submit to a temporary seclusion; that after being comfortably loged for a day or two they are far from pining for freedom; and that, the lower population generally may without difficulty be convinced of the advantage they are to derive from it. Farther, the Board are now organizing a system of daily inspection of houses, which will render it difficult to conceal any case. $\ll^{490}$

Gleichzeitig stellte sich das Board in Edinburgh auch ganz offiziell gegen jede Art von interner Quarantäne und Maßnahmen der Isolation, obgleich die Mehrzahl der Mitglieder des lokalen Boards die These der Kontagiosität der Cholera teilten. ${ }^{491}$

488 Learmonth: Extracts from the second report of the Edinbugh board of health: in: The Cholera Gazette, 1832: S. 111.

489 Macdonald: Sanitary Measures adopted at the bottle works company, Sunderland: in: The Cholera Gazette, 1832: S. 9.

490 Christinson, Robert: Art. XI. - Account of the Arrangements made by the Edinburgh Board of Health, preparatory to the arrival of Cholera in the City. 15th February 1832: Supplement on cholera: in: ESMJ, 38.1832, S. ccliv - cclxxxviii: S. cclxvii.

491 Vgl. ebd.: S. cclxv. 
Dies ist eine sehr bedeutende Kritik des Boards in Edinburgh am Central Board. Im Grunde genommen wurde in Edinburgh bereits im Laufe der Epidemie versucht, eine neue Strategie innerhalb der Praxis des Boards zu erproben. Es galt, eine Handhabe zu finden, mit der man sich aus einem Widerspruch befreien konnte, der sich zwischen der alten Theorie der Ansteckung und der an sie geknüpften politischen Praxis, zu dem Selbstbild und zur entstehenden liberalen Rationalität der britischen Regierungspraxis aufgetan hatte. So hieß es in dem zweiten Bericht des Boards aus Edinburgh zu Beginn der Schilderung der »measures of seclusion«:

"So satisfied was every one here, whether contagionist or non-contagionist, of the force of these objections, that I feel assured the respectable inhabitant of the city would have refused to a men to countenance the proposed restrictions. It does not follow, however, that all restrictive measures whatever are unattainable or unadvisable. «492

Es wäre an dieser Stelle falsch zu behaupten, es hätte sich hierdurch im Grunde nichts an der Praxis verändert, oder es hätte keinen Unterschied zwischen der Praxis der Isolation und der seclusion gegeben, denn den gab es. Dr. Greenwood, seinerseits ebenfalls Kontagionist, verteidigte die Praxis in einer Sitzung der Westminster Medical Society, indem er genau den Unterschied zur Isolation und der alten Praxis, die in den Zeiten der Pest angewendet worden war, zu verdeutlichen suchte:

»[O]bservations respecting the regulations adopted in the plague, [...] isolating the houses you shut up the dead, dying, sick, and healthy, altogether. There was some difference between this, and removing the sick to a place set apart for them. $\ll^{493}$

Seclusion war laut Greenwood etwas völlig anderes, weil sie einer anderen, diese alte Praxis sogar ausschließenden und ausschaltenden Idee unterlag. Dies wird vor allem in dem folgenden Abschnitt hoffentlich noch deutlicher werden. Es bestand einen Grund, warum man die Armen, die man verdächtigte, an der Cholera zu erkranken, nicht einfach in eine Quarantänestation verfrachtete, sondern besonderen Wert darauf legte, dass sie an den Orten, an denen man sie von der restlichen Bevölkerung und ihren Familien isolierte, in einen körperlich und gesundheitlich besseren Zustand verbracht wurden. ${ }^{494}$ Die Gesundheit (und nicht die Krankheit) der Armen (des einzelnen Individuums nur zufällig) sollte zum Ansatzpunkt eine Sicherheitsstrategie gemacht werden, die eigentlich auf die Gesundheit der ganzen Bevölkerung zielte. ${ }^{495}$

492 Ebd.: S. cclxvf.

493 Vgl. Artikel 3: Westminster Medical Society, Final Dicussion on the Cholera, 28. April, 1832: in: The Lancet London, 1832: S. 148.

494 Greenwood: Late Proceedings at the Westminster Medical Society, The Lancet, 1. Mai, 1832: S. 150.

495 Es scheint mir im Zusammenhang mit den Theorien des Liberalismus angemessener, nicht von Bevölkerung, sondern eher von Gesellschaft zu sprechen. 


\section{Die Armen als die Schwachstelle der öffentlichen Gesundheit}

In vielen Städten wurden Suppenküchen eingerichtet und andere allgemeine Schritte unternommen, den Gesundheitszustand der Pauper und Armen angesichts der drohenden Epidemie anzuheben. ${ }^{496}$ Dies zeigt aber auch, wie verbreitet trotz der zu dieser Zeit sehr populären Annahme der Übertragbarkeit der Cholera, die Ansicht unter den Mitgliedern der verschiedenen local boards zirkulierte, die auch schon Annesley vertreten hatte. ${ }^{497}$ Nämlich, dass die Prävention der Cholera sich gegen die sog. predisposing causes richten musste. Sie unterstützten eine Politik der positiven Mobilisierung und Sicherung von »(Lebens-)Kräften«, indem sie sich auf die Beseitigung dieser $»$ predisposing and exciting causes « konzentrierten.

»Subscriptions were subsequently made for the establishment of a soup kitchen, and three hundred messes of excellent soup have, for the last fortnight, been distributed to the necessitous, three times a week. Wine has been allowed from the public funds, for the cases of Typhus, which has been prevailing among the families of the poor; the more filthy dwellings have been ordered to be lime-washed, and coals and blankets have been distributed, as necessity has pointed out. $\ll^{498}$

Die Beseitigung oder Milderung aller Einflüsse, die bekannt dafür waren, die Widerstandskräfte des Körper und die Lebenskraft eines Individuums zu schwächen - »to debilitate or fatigue the system; whatever lowers its vital energy « ${ }^{499}$ - Hunger, Kälte, Unhygiene - war es, worauf sich die präventiven Maßnahmen richteten und weshalb sie sich in so direkter und unkomplizierter Weise auf die Arbeiter und Armen konzentrierten, denen man aufgrund ihrer Lebensverhältnisse eine Schwächung ihrer Lebenskräfte unterstellte. ${ }^{500}$ Diese praktische Direktive dominierte nach dem Ausbre-

496 Vgl. Central Board of Health, Council Office: Instructions addressed by the Central Board of Health to the medical superintendents of the districts, for their guidance, with a view to the more effectual relief of those who are attaced by cholera: in: The Cholera Gazette, 1832: S. 180.

497 »Proceedings upon the doctrine that cholera originates in obscure epidemic causes, and appears to spread sometimes in that way alone but in certain circumstances not yet fully ascertained puts on a contagious character, - a doctrine which is maintained by, I believe, the whole medical members of the Edinburgh Board, with the exception of some of the East India members, who are not yet prepared to admit the existence of contagion in any circumstance, - the Board resolved, and have already had occasion to carry into effect the following preventive measures.«: Christinson, Robert: Art. XI. - Account of the Arrangements made by the Edinburgh Board of Health, preparatory to the arrival of Cholera in the City. 15th February 1832: in: Supplement on cholera: in: ESMJ, 38.1832, S. ccliv cclxxxviii: S. cclxvi.

498 Moir, D.M.: To the President of the central board of health [London, Musselburgh, Jan. 20th, 1832]: in: The Cholera Gazette, 1832: S. 67f.

499 Annesley: Sketches of the most prevalent diseases of India, 1829 [1825]: S. $244 f$.

500 Es ist nicht klar, ob sich diese Position aufgrund der Erfahrungen und des Diskurses über die Cholera herausgebildet hat. Allerdings hat sie sich später im 19. Jahrhundert als ein allgemeiner Grundsatz in der Gesundheitspolitik und der Seuchenbekämpfung im briti- 
chen der Cholera die Maßnahmen, die man in England und Schottland zur Eindämmung der Epidemie veranlasste.

»Means should be taken for improving considerably the conditions of the lower orders in respect of food, clothing, and cleanliness the moment the disease breaks out in a place. [...] [I]t appears to me the great advantage might be derived from raising the lower orders to even a higher state of comfort, in respect to the necessaries of life, for a short period after the breaking out of the epidemic, an object which can scarcely be attained without the aid and encouragement of Government. [...] [T]he disease in its various epidemic visitations has been for some length of time at first confined almost entirely to the lower orders: that its attacks have been in a great majority of cases referable to one or other of the exciting causes connected with privations of poverty; and that it has not affected to any material extent person exempt from privations till it has made some head among those who were subject to them. $\aleph^{501}$

Es gibt in den allgemeinen Beschreibungen der Eigenschaften der Cholera sehr viele Beteuerungen, dass die Cholera im Grunde jeden Menschen zur Strecke bringen könne. Im Grunde sei niemand vor der Cholera sicher: Alte wie Junge, Reiche wie Arme, in einer guten gesundheitliche Verfassung oder nicht, das spiele keine besondere Rolle. Aber ebenso häufig betonen die Berichte über die Choleraepidemien, dass es vor allem Angehörige der Arbeiterklasse und der armen Bevölkerungsschichten seien, die der Cholera als erstes zum Opfer fielen. Die Lebensweise und die Lebensumstände der Armen wurden daher als besonders begünstigend für die Erkrankung gesehen. »[T]hese attacks very often occur immediately after obvious exposure to various exciting causes, such as drunkenness, cold, wet, starvation, errors in diet, and other ills of poverty. $\ll^{502}$ Was eine z.B. arme Arbeiterin im Gegensatz zu einem reichen Bürger zur $>$ Risikogruppe ${ }^{503}$ zählen ließ, war kaum etwas, was mit ihrer persönlichen Diät oder Lebensweise zu tun hatte. Oder man könnte auch sagen, dass

schen Regierungsbereich durchgesetzt. So schrieb z.B. der in Bombay praktizierende Arzt Morehead, Professor für Medizin am Grant Medical College und Chefchirurg des Jemsetjee Jeleeboy Krankenhauses in Bombay 1867: »There can be no doubt that the causes of general bad health predispose and favour the action of all the ordinary and specific exciting causes of diseases, and that therefore the removal and or prevention of these causes of bad general health is most important and necessary to the maintenance of the public health, to the diminution of the susceptibility to disease, and of severity of its types, and thereby to the reduction of the general mortality. « Report on the questions, submitted by Dr. Farr to the Council, concerning the classification of epidemic disease: in: TES, 2.1867 S. 1 - 30: S. 23.

501 Christinson, Robert: Art. XI. - Account of the Arrangements made by the Edinburgh Board of Health, preparatory to the arrival of Cholera in the City. 15th February 1832: in: Supplement on cholera: in: ESMJ, 38.1832, S. ccliv - cclxxxviii: S. cclxxxiv.

502 Ebd.: S. cclxvii.

503 Diesen Begriff gab es zu dieser Zeit selbstverständlich noch nicht. Doch es wäre eine durchaus berechtigte Frage, ob die Rationalität der Regierung, die später für das Aufstreben des >Risikos < im späten 20. Jahrhundert verantwortlich ist, nicht bereits hier im Entstehen begriffen war. 
diese persönliche Lebensweise in der Betrachtung eine sehr geringe Rolle spielte. Die Zugehörigkeit zu einer Klasse mit meist gesundheitlich nachteiligen Lebensumständen allein, bedeuten die erhöhte statistische Wahrscheinlichkeit zu den ersten Cholerakranken eines Ortes zu gehören und zum Ausgangspunkt eines lokalen epidemischen Ausbruchs zu werden. Die gesamte Existenzweise, die Wohn- und Arbeitsorte, das Wasser und die Luft an diesen Orten ebenso wie die Ernährung wurde nicht als subjektive, sondern als objektive betrachtet. Das Problem war demnach nicht die Existenz der Arbeiterklasse an sich. Es ging nirgends darum, sie als Klasse zu problematisieren. Im Gegenteil, das Ziel musste sein, auf die Existenz dieser Klasse Einfluss zu nehmen, oder, wie es in dem Bericht des General Board of Health von 1854 heißt, ihre Leben gemäß den einfachen Regeln einer gesunden Existenz zu verbessern. In den Berichten während der ersten Epidemie wurden die Armen zur Schwachstelle einer ganzen Bevölkerung oder Stadt und damit zum Ansatzpunkt für die Maßnahmen gegen das Ausbrechen oder die Verbreitung der Cholera deklariert. Je schlechter der Zustand der arbeitenden und armen Klasse, desto größer die Gefahr, dass die Krankheit in einer Stadt Fuß fassen und sich auch auf die anderen Schichten ausweiten würde.

»This system [of soup kitchens], as well as the distribution of clothes and coals to the necessitous, must be continued on an enlarged scale, as affording the best probable means of confining the ravages of the disease among the poor within moderate bounds, on which may depend the safety of those who are in easy or affluent circumstances. $\ll^{504}$

Solange es gelang, die Cholera unter den Armen zu mildern, bestand die Chance, dass andere Teile der Bevölkerung, die unter besseren Bedingungen lebten, von ihr verschont blieben. In dieser Logik zeigte sich, dass auch die Praxis der seclusion eine Bedeutung zukam, die die der Isolation weit überstieg und sich sogar grundsätzlich von ihr unterschied. Während die Isolation einen negativen und repressiven Charakter hatte, der in der Funktion der Vermeidung von Kommunikation, Kontakt und Übertragung seine wesentlichen Eigenschaften hatte, bestand die Idee der seclusion eher in einer Beseitigung der Ursachen, die die Lebenskräfte schwächten und Menschen für die Cholera anfällig machten. Es ging also nicht um Repression der Kräfte der Krankheit, sondern um eine Stärkung der Gesundheit und der >Lebenskräfte<, indem man Menschen, die Anzeichen einer Art Vorerkrankung zeigten, zumindest für eine kurze Zeit, in andere Lebensumstände verfrachtete. Was auch immer die Quelle der Krankheit genau war, aus der sie die Kraft und Heftigkeit einer Epidemie zog, die liberale Rationalität tendierte dazu, die politischen Techniken gegen die Cholera in Richtung einer positiven auf die Gesundheit gerichteten Technologie zu verschieben.

»By removing [the poor] to an airy residence, feeding and clothing, and defending from cold, individuals who, whether from residence at a source of local miasma or from exposure to infection, have imbibed a tendency to the disease, there constitutions are brought into the best possi-

504 Cuninghame, W.G. [Sek. Board of Health Office: Adress issued by the Edinburgh board of Health on the appearance of the cholera in that city: in: The Cholera Gazette, 1832: S. $108 \mathrm{f}$. 
ble condition for resting that tendency for the short period during which it is apt to devolve itself, and are thus enable to throw off the lurking seeds of the malady. ${ }^{505}$

So wurden die Lebensbedingungen der Armen zum Hauptansatzpunkt der AntiCholerapolitik in Großbritannien - und das interessanterweise selbst in einer Phase relativer Anerkennung der Ansteckungsthese. ${ }^{506}$ Die Gründe für diese Konzentration auf die Armen und vor allem für die Entwicklung ganz spezifischer Techniken, die die Regierung im Rahmen ihrer gesundheitsbezogenen Politik in England und Schottland zur Anwendung brachte, lagen größtenteils außerhalb eines medizinischen Begründungszusammenhangs. Auch in anderen sicherheitspolitischen Bereichen, wie etwa in der Kriminalitäts- und Aufstandsbekämpfung, wurde die Gesundheit der Armen und der Arbeiterklasse zu einer wichtigen Stellschraube des allgemeinen Wohlstands. ${ }^{507}$

Der Bericht des Edinburgher Boards vom 14. Februar 1832 enthielt nicht nur eine besonders ausführliche Begründung seiner schließlich zur Ausführung gebrachten Maßnahmen, sondern außerdem eine relativ eindeutige Kritik am Central Board. Dieses habe seine Pflicht zur Unterstützung der Lokalen Boards vernachlässigt und den absurden und schädlichen Vorschlag zu Anwendung interner Quarantäne unterbreitet. Das Edinburgher Board konstatierte, es sei angesichts der Konzentration der Maßnahmen auf die Armen absolut notwendig, dass sich unter den Mitgliedern der Boards und vor allem des Central Boards Ärzte und Personen befänden, die über Kompetenzen und Wissen im Umgang mit den Armen verfügten. Überrascht habe man es in Edinburgh zur Kenntnis genommen, dass der Anteil der Mediziner im Central Board völlig einseitig besetzt worden sei durch Ärzte, die allesamt als »violent, if not unconditional contagionists« angesehen werden müssten. Eine Position, die von den wenigsten Ärzten in dieser Schärfe vertreten wurde. ${ }^{508}$ Noch größere Kritik äußerte der Bericht aus Edinburgh aber an dem Mangel an Erfahrungen über die Lebensbedingungen, Nöte und die Gewohnheiten der Armen unter den Mitgliedern des Central Boards.

»It has also been a matter of astonishment here, that the only medical members are all military surgeons [...] I may venture to say, that their experience is not exactly of the kind to impart a

505 Christinson, Robert: Art. XI. - Account of the Arrangements made by the Edinburgh Board of Health, preparatory to the arrival of Cholera in the City. 15th February 1832: in: Supplement on cholera: in: ESMJ, 38.1832, S. ccliv - cclxxxviii: S. cclxviif.

506 Vgl. Cuninghame, W.G. [Sek. Board of Health Office: Adress issued by the Edinburgh board of Health on the appearance of the cholera in that city: in: The Cholera Gazette, 1832: S. 109.

507 »These Acts of Parliament [sanitary legislation] have, speaking generally, been framed with the design of ameliorating the condition of considerable sections of the community, and through these, the entire population.«: Vgl. Edward, Joseph: A Brief Review of Recent Sanitary Legislation: in: TES.2s, 10.1890, S. $1-21$ : S. 2.

508 Vgl. Christinson, Robert: Art. XI. - Account of the Arrangements made by the Edinburgh Board of Health, preparatory to the arrival of Cholera in the City. 15th February 1832: in: Supplement on cholera: in: ESMJ, 38.1832, S. ccliv - cclxxxviii: S. cclxxxvf. 
minute acquaintance with the wants and habits of the poor in the civil ranks of life, whole interest in the present conjuncture are those most directly at stake. That a want of this knowledge may be discovered in the acts of the Central Board, I think will be admitted by any one who has been actively engaged in the preparatory transactions of any local Board of Health. $\ll^{509}$

Nichts habe der Arbeit des Boards in Edinburgh in einer Weise zum Erfolg verholfen, wie die Anwesenheit von Ärzten, die genau über dieses Wissen und diese Erfahrungen verfügten. ${ }^{510}$ Arme müssten anders regiert werden als die Bürger aus den gehobenen Schichten. Damit eine Regierung erfolgreich ist, müsse sie ihre Verhaltensweisen, ihre Bedürfnisse der Armen kennen und studieren.

Die britische Regierung hatte viel früher aufgrund der noch stärkeren Effekte ursprünglicher Akkumulation, der Ausweitung kapitalistischer Produktion, der Urbanisierung usw. das Phänomen einer sich herausbildenden Arbeiterklasse als Problem >erkannt< oder besser, zu einem Gegenstand der Regierung gemacht. Sie musste diese Klasse von Arbeitern als ökonomische aber daraufhin auch als politische und soziale Kraft begreifen, die langsam eigene Ansprüche auf Subjektivität und Machtbeteiligung erhob. Die britische Regierung reflektierte ihr Selbstverständnis in der Aufgabe der Regulierung eines Verhältnisses verschiedener Klassen und begann in diesem Kontext, Techniken an den Bedingungen der Aufrechterhaltung dieses Verhältnisses auszurichten. Es entstand die Nachfrage nach Wissen über diesen neuen komplexen Gegenstand des Lebens, der Bevölkerung und der Gesellschaft und über dieses komplexe heterogene Netz von Kräfteverhältnissen, von unterschiedlichen Schichtungen und Klassen, an denen sich die Gouvernementalität orientieren sollte. Ohne dieses Wissen würde auch die Cholerapolitik erfolglos bleiben. Das war in etwa das, was Christinson als Mitglied des Boards in Edinburgh konstatierte. ${ }^{511}$

Christinson brachte diese Kritik auch mit der Forderung einer stärkeren Dezentralisierung der Macht in Verbindung. Wenn der Erfolg der Institutionen von ihrem genauen Wissen über die lokalen und sozialen Umstände abhing, dann sollten diese auch die entsprechenden Kompetenzen erhalten, sich bei ihren Maßnahmen nach diesem Wissen und nicht nach zentralen Vorgaben richten zu müssen. ${ }^{512}$ Am 9. August 1832 richtete das Central Board einen weiteren Rundbrief ${ }^{513}$ an alle lokalen Boards und die lokalen Regierungen der von der Epidemie betroffenen Regionen in Großbritannien. Dieser Rundbrief war eine Reaktion auf eine Reihe von Kritiken, die u.a. von dem Board in Edinburgh an London und an die zentrale Regierung dort gerichtet

509 Ebd.: S. cclxv.

510 Vgl. ebd.: S. cclxxxvi.

511 Vgl ebd.: S.cclxxx.

512 Vgl. ebd.: S. cclxxxi. Eine Forderung, der nach dem Bericht von Sutherland (1854) über die Epidemie 1848/49 nachgekommen wurde: »New local authorities with adequate powers are requisite for the public safety«: Sutherland, J.: Report: in: Letter of the President of the General Board of Health 1854, 1855: S. 71.

513 Ähnliche Rundbriefe hatte das Board am 14. November, 13. Dezember 1831 und am 9. Mai 1832 verschickt: Vgl. The Cholera Gazette, 1832. 
worden war. ${ }^{514}$ Eine Veränderung betraf die Zusammensetzung der Lokal Boards, die einen stärkeren lokalen und > volksnäheren $<$ Charakter erhielten:

»[consisting] of one or more resident magistrates and clergymen, and parish authorities, a certain number of substantial householders, of one or more medical men, and an efficient secretary. [...] These Boards should appoint district inspectors to visit daily, and report upon such deficiencies as may be found to exist in the following primary elements of public health; viz. the food, clothing, and bedding of the poor, the ventilation of their dwellings, space, means of cleanliness, their habits as to temperance. $\ll^{515}$

Zur Verfügung gestellt werden sollen Kleidung, Nahrung und andere Mittel zur Verbesserung der Lebenssituation der Bedürftigen. ${ }^{516}$ Auch die Position zu interner Quarantäne und Maßnahmen von Zwangsisolierung wurden stärker und expliziter kritisiert, auch wenn auf den Begriff der Isolation gänzlich verzichtet wurde. ${ }^{517}$ Der Zweck der »separation of the sick from the healthy « wurde in erster Linie damit begründet, dass man ihn unter Bedingungen unterbringt - »placed under the most favourable conditions $\ll^{518}$-, die für seine eigene Gesundheit und die Wiederherstellung seiner Kräfte vorteilhaft seien und dass gerade auf diesem Wege und nicht durch die Vermeidung des Kontaktes mit den Gesunden, etwas für die Sicherung der allgemeinen Gesundheit getan werden könne: »both for the recovery of his own and the safety of the public health $\ll^{519}$. Was die Empfehlungen des Boards bezüglich der Diät betraf, so wurde eher allgemein davor gewarnt, größere Änderungen in der Ernährung vorzunehmen und schwer Verdauliches zu sich zu nehmen. ${ }^{520}$ Dazu wurden die Adressaten der Empfehlung relativ explizit unterschieden. Für die, die besser gestellt seien, wurde sogar eine ausführlichere Empfehlung für die Ernährung gegeben:

»If in easy circumstances, take for dinner a moderate quantity of roast meat in preference to boiled, with stale bread or good potato, two glasses of wine with water, or an equivalent of good spirits and water, or of sound porter or ale. Eat garden-stuff and fruit sparingly, and avoid fat luscious meats. In short, whilst under apprehension of cholera, use a dry, nutritive diet, sparing rather than abundant, observe great caution as to, eating suppers, for cholera most frequently attacks about midnight, or very early in the morning. $\ll^{521}$

Andererseits wurde auch noch einmal betont, dass besonders die Menschen, die unter ungünstigen Bedingungen leben, die größte Vorsicht walten lassen müssten: »neglect

514 Vgl. Pym, W.: Malignant Cholera. Sanitary regulations issued by the government Board of Health, in August, 1832. (Circular): in: The Lancet London: S. 652.

515 Ebd.: S. 652.

516 Vgl. ebd.: S. 652.

517 Vgl. ebd.: S. $652 \mathrm{f}$.

518 Ebd.: S. 653.

519 Ebd.

520 Vgl. ebd.: S. 653.

521 Ebd.: S. 654. 
would most assuredly dispose an individual living in an infected atmosphere to be attacked by that disease $\ll .{ }^{522}$

Die Berichte der lokalen Boards, die während der ersten Epidemie nach London und an verschiedene medizinischen Zeitschriften versandt und veröffentlicht wurden, enthielten aber auch noch eine ganze Reihe an Kritiken und ungelösten Problemen auf welche man nun im Laufe der Epidemie aufmerksam geworden war. Die Praxis der Choleraprävention, die über die Stärkung der Schwachstelle einer Gesellschaft die Armen - erfolgen sollte, führt im vom Liberalismus geprägten Großbritannien schließlich zu der Schlussfolgerung, diese Stärkung könne langfristig nicht durch das Verteilen von Lebensmitteln und Reinigen der Häuser der Arbeiterklasse erfolgen, sondern müsste durch die Arbeiter selbst erreicht werden. Der Schlüssel zu dieser Verbesserung ihrer Lebensbedingungen und Lebenskräfte lag langfristig nicht in der Wohltätigkeit, sondern darin, sie $\mathrm{zu}>$ wirklich freien< Lohnarbeitern zu machen. ${ }^{523}$ Damit verbunden war die Betonung des nationalen und allgemeinen Interesses bei der Bekämpfung der Epidemie »by such means as Government alone can command « für die gesamte Ökonomie Großbritanniens: »the total destruction of life throughout the county will be much less than if the infected districts are left to struggle against the disease in unassisted poverty. « ${ }^{524}$

In einem Artikel im Lancet im April 1832 wurde noch eine andere Strategie der Konzentration der Maßnahmen auf die Armen deutlich, die bisher noch nicht so sichtbar geworden ist: Die Anwendung von Maßnahmen zur Verhinderung eines Aufstands, vor dem man sich angesichts der Cholera und kurz nach den Ausschreitungen in Paris fürchtete. ${ }^{525}$ Gemäß der Argumentation des Artikels sei es legitim gewesen, während der Choleraepidemie in Großbritannien restriktive Maßnahmen anzuwenden und sogar Panik zu verbreiten, um die Massen gefügig zu machen. Im Gegensatz zu dem, was kritische französische und deutsche Ärzten 1832 zu bedenken gaben, behauptete die Redaktion des Lancet, die den Artikel verfasst hat, die Angst der Bevölkerung und das Abrufen einer alten restriktiven politischen Praxis hätten zur Aufrechterhaltung der Ordnung beigetragen. Selbst wenn diese Techniken aus wissenschaftlicher Sicht vielleicht nicht begründet seien, so seien sie doch wenigstens politisch gerechtfertigt gewesen. Der Presse sei in dieser Sache Verantwortung zugekommen, die Bevölkerung nicht durch anti-kontagionistische Argumentationen gegen die Maßnahmen aufzuwiegeln und damit die Glaubwürdigkeit der Regierung zu schwächen. ${ }^{526}$ Die Redaktion des Lancet hatte sich, zumindest in der Zeit als die lokalen Boards gegründet und die Cholerakrankenhäuser errichtet wurden, bedeckt gehalten, was ihre Position zur Frage der Kontagiosität betraf. Nach den Aufständen in Paris behauptete sie nun, die Positionierung der »mercenary, a trading press « und

522 Ebd.: S. 654.

523 Vgl. Christinson, Robert: Art. XI. - Account of the Arrangements made by the Edinburgh Board of Health, preparatory to the arrival of Cholera in the City. 15th February 1832: in: Supplement on cholera: in: ESMJ, 38.1832, S. ccliv - cclxxxviii: S. cclxv.

524 Ebd.: S. cclxxxvi.

525 Vgl. Harrison: Disease and the modern world: 1500 to the present day, 2004, S. 105.

526 Vgl. [Hrsg.]: The Cholera in England, 28 April 1832: in: The Lancet London, 1833: S. 122. 
liberaler Ärzte, die die Doktrin der Ansteckung und die Maßnahmen der Regierung öffentliche angegriffen hatten, sei angesichts solcher »stimulants to outrage« unverantwortlich gewesen.

»[W]e firmly believe that many a benevolent practitioner would have been sacrificed to the blind fury of the multitude, had not one influential medical journal dared to stem the torrent, powerfully aided in its exertions by the labours of the Roman Catholic clergy of the London diocese. $\aleph^{527}$

Ein weiteres Argument der Redaktion des Lancet bestand darin, dass sie behaupteten, die Doktrin wäre notwendig gewesen, um die >wohltätigen< Maßnahmen zu rechtfertigen, die man in Bezug auf die Armen durchgeführt hätte. Im Grunde genommen sei die »doctrine of contagion « selbst ein Instrument gewesen, um die von der Krankheit bedrohten Armen aus ihrer Lebensverhältnissen herauszuholen. Folglich sei es in dieser Hinsicht irrelevant, ob die Cholera wirklich ansteckend sei oder nicht. Denn der Zusammenhang zwischen den Lebensbedingungen der Armen, ihrer Anfälligkeit für die Cholera und damit der allgemeinen Gefahr für die öffentliche Gesundheit sei offensichtlich. ${ }^{528}$

Wie man sieht, bestand auch in Großbritannien die Angst, die Ablehnung der Doktrin könne die Handlungsfähigkeit der Regierung beschränken. Auch hier galt die Behauptung, dass die Kontagiosität ein wesentliches Element ihrer Souveränität ausmachen, dass ihr durch die Anti-Kontagionisten zu entgleiten drohe. Nun, da die Kontagiosität von immer mehr Medizinern und Journalen in Frage gestellt wurde, wäre die Bereitschaft, Maßnahmen gegen die Choleraepidemie zu akzeptieren, gesunken. ${ }^{529}$

\section{Liberalismus und anti-kontagionistische Doktrin}

Tatsächlich vollzog sich bald nach dem Ausbruch der Cholera in Großbritannien wieder eine Hinwendung zu dezidiert anti-kontagionistischen Positionen. Medizinisch-wissenschaftliche Gesellschaften und die Redaktionen einflussreicher Fachjournale wechselten von der kontagionistischen zur anti-kontagionistischen Seite. ${ }^{530}$ Auf den Sitzungen der Westminster Medical Society wurde der Positionswechsel der Journale von den Vertretern der anti-kontagionistischen Position als Argument dafür verwendet, dass die Boards und ihre Politik ihren Rückhalt in der Ärzteschaft und bei der medizinischen Wissenschaft ohnehin bereits verloren hätten und dass eine entsprechende Positionierung der Gesellschaft höchste Zeit sei. ${ }^{531}$ Tatsächlich hatte die Redaktion des Lancet in der gleichen Ausgabe im April 1832 zum ersten Mal deutli-

527 Ebd.: S. 122.

528 Vgl. ebd.: S. 126.

529 Vgl. ebd.

530 Vgl. Artikel 1: Westminster Medical Society, Discussion on the Cholera, Question of Contagion, 5. März, 1832: in: The Lancet London, 1832: S. 22.

531 Vgl. Artikel 3: Westminster Medical Society, Final Dicussion on the Cholera, 28 April, 1832: in: The Lancet London, 1832: S. 148. 
cher über ihren Positionswechsel Rechenschaft abgelegt. ${ }^{532}$ An der Entscheidung der Westminster Medical Society lässt sich allerdings auch sehr deutlich sehen, dass dieser Positionswechsel schwerlich etwas mit neuem Wissen oder Erkenntnissen der Medizin zu tun hatte. Eher stellten die Teilnehmer der Sitzungen nach und nach fest, dass man durch die Diskussion wissenschaftlicher Berichte nicht zu einer Einigung kommen würde und die Diskussion keine Fortschritte machte. »[T]he Cholera Discussion will lose its claims to eternity ${ }^{533}$, kommentierte ein Berichterstatter des Lancet. Die wissenschaftlichen Berichte und Beobachtungen lieferten nur vage und negative Belege gegen die Kontagiosität ohne sichere positive Gegenbeweise. Die Positionierung war somit mehr an politisch-strategische und moralische Bedingungen geknüpft als an die Wissenschaft. Man positionierte sich gegen die Boards of Health, die vorgegeben hatten, auf Basis wissenschaftlicher Erkenntnisse gehandelt zu haben. ${ }^{534}$

Die Anti-Kontagionisten innerhalb der Westminster Society stellt die Glaubwürdigkeit der Boards allgemein in Frage, indem sie der Regierung unterstellten, ihr Handeln sei rein politisch, oder noch schlimmer, von machtpolitischen Interessen geleitet gewesen, die sich mit den alten unliberalen Kräften und Praxen verbündet hätten. ${ }^{53}$ Der Arzt, Anti-Kontagionist und Herausgeber der Medico-surgical Review, James Johnson, analysierte 1832 einen großen Teil der zur Cholera veröffentlichten Bücher, Texte und Dokumente, auch die des Board in London, welcher u.a. folgendermaßen kommentierte:

»We puzzled our brains, in vain, to account for this revolution of opinion in the course of six short days, during which no new information was received. Did the great captain of quarantine throw his yellow standard into the scale, in imitation of a famous captain of antiquity, who threw his sword there, and thus made it kick the balance in favour of contagion? «36

Es erscheint mir hier besonders wichtig, die wechselseitigen Bedingungen und Verbindungen deutlich zu machen, die zwischen der Frage der Rationalität und Konsistenz der Äußerungen und der allgemeinen Moralität eines Subjekts sichtbar werden: Wenn sich Mitglieder der Regierung für die restriktiven Praktiken, die bereits aus Gründen der Humanität und Liberalität verurteilt wurden, entscheiden, müssten sie dies in besonderem Maße durch eine medizinische Begründung, durch das Argument einer medizinischen Notwendigkeit rechtfertigen. Durch Letzteres wäre ihre moralische Integrität nicht nur gerettet, sondern sogar der Ersteren gegenüber, die auf die Humanität verweist, erhöht. Ist diese Rechtfertigung aber nicht gegeben oder brüchig, fällt auch die moralische Integrität und Position, zu deren Absicherung der Ver-

532 Vgl. [Hrsg.]: The Cholera in England, 28 April 1832: in: The Lancet London, 1833: S. 124.

533 Artikel 2: Westminster Medical Society, Dicussion on the Cholera, 7. April, 1832: in: The Lancet London, 1832: S. 51.

534 Vgl. Artikel 1: Westminster Medical Society, Discussion on the Cholera, Question of Contagion, 5. März, 1832: in: The Lancet London, 1832: S. 22.

535 Vgl. ebd.

536 Johnson: [Medico-surgical Review - Epidemic Cholera], 1832: S. 179. 
weis auf die Wahrheit gedient hatte, hinter das Niveau einer weniger wissenschaftlich begründeten naiven moralischen Position zurück. Wenn die Regierung nicht auf Rationalität, Objektivität und Wissen begründet ist, muss sie automatisch das Gegenteil sein: willkürliche Machtausübung und subjektives Interesse. Im Umkehrschluss kann aber nun auch das grundsätzliche Interesse an der Wahrheit und die Bereitschaft, sich der mühevollen Arbeit der Erkenntnissuche hinzugeben und der wissenschaftlichen Kritik und Prüfung auszusetzen, die quasi die Voraussetzungen des Subjekts für die Teilnahme am wissenschaftlichen Diskurs sind und zu den Bedingungen einer wahren Aussage gehören, angezweifelt werden. Etwa in dieser Weise haben es die AntiKontagionisten während der Diskussion in der Westminster Medical Society und anderswo vermocht, die Ärzte David Barry und Willam Russell, die im Wesentlichen für die Arbeit und die Veröffentlichungen des London Board of Health verantwortlich gemacht wurden, erfolgreich zu diskreditieren. ${ }^{537}$ Des Weiteren haben die AntiKontagionisten die >Güte < ihrer Position untermauert, indem sie sich positiv auf eine Deklaration von Pariser Ärzten (»the declaration of the distinguished surgeons and physicians of the Hotel-Dieu $\ll^{538}$ ) bezogen. Diese hatten sich unter dem politischen Vorzeichen von Liberalität und Humanität und angesichts ihrer Erfahrungen mit der Epidemie gegen die Kontagiosität ausgesprochen. ${ }^{539}$

Anhand weitere Beispiele möchte ich die Haltung der Anti-Kontagionisten und wie sich ihre Kritik im Laufe der 1830er Jahre entwickelt hat, skizieren. An Texten dreier britischer, anti-kontagionistischer Autoren möchte ich im Folgenden zeigen, dass die gesundheitliche Regierung der Arbeiter - nicht als Individuen, sondern als soziale Gruppe und Klasse - aus einer liberalen Regierungslogik hervorging. Bei den drei Autoren handelt es sich George Hamilton Bell, Absolvent des College of Surgeons in Edinburgh und medizinischer Sekretär des dortigen Board of Health; Captain W. White, der selbst kein Mediziner war, und dem Arzt Joseph Ayre. Dabei kann ich bereits vorweg sagen, dass sich hier eine gewisse Ähnlichkeit zu dem diskursiven Subjekt der medizinischen Mittelschicht in der Diskussion um die medical reform zeigen wird, die ich weiter oben analysiert habe. Alle drei Autoren haben in ihren Texten eine gewisse Opposition zur zentralen Regierung in London und gegenüber mächtigen Institutionen, wie dem College of Physicians, eingenommen. Die betonte Distanz zu solchen Orten oder Zentren der Macht hatte natürlich auch die Funktion, die Wahrheit und Unabhängigkeit ihrer Aussagen zu belegen. ${ }^{540}$ Gleichzeitig wird noch zu einer anderen Macht Distanz aufgebaut, die man als die Macht der Straße, des Mobs oder auch der öffentlichen Meinung bezeichnen könnte. Diese Macht charakterisiert sich durch ihren Mangel an Rationellem, ihre Nähe zum Vorur-

537 Vgl. Artikel 1: Westminster Medical Society, Discussion on the Cholera, Question of Contagion, 5. März, 1832: in: The Lancet London, 1832: S. 22. Vgl. Artikel 2: Westminster Medical Society, Dicussion on the Cholera, 7. April, 1832: in: The Lancet London, 1832: S. 54.

538 Artikel 2: Westminster Medical Society, Dicussion on the Cholera, 7. April, 1832: in: The Lancet London, 1832: S. 51.

539 Vgl. ebd: S. 53.

540 Vgl. Johnsons Kommentar über die Schriften von Bell: Johnson: [Medico-surgical Review - Epidemic Cholera], 1832: S. 186f. 
teil und zum Aberglauben, sie ist tendenziell eruptiv und durch Leidenschaften gesteuert und aus Sicht der Autoren daher anfällig für die These der Kontagiosität. ${ }^{541}$ Ayre bedauerte, die Verbreitung der Doktrin der Kontagiosität durch die Instruktionen des Board of Health habe die Vorurteile und die Angst in der Bevölkerung geschürt. Nun müsse aktiv gegen diese Meinung vorgegangen werden, um den Behinderungen und Gefahren, die von ihr ausgehen, zu begegnen. ${ }^{542}$ White schrieb:

»Terrified and frightened to death themselves, while they were preaching up >common prejudice<, they became indiscreet beyond measure. They railed against unnecessary alarms but declared that the less intercourse man had with man the better. ${ }^{543}$

Allein die Tatsache, dass ein Militär wie White es sich herausnahm, über die Cholera, ihre Ursachen und Behandlung in der Weise zu schreiben, wie er es tat, ist bezeichnend. Galt die Zugehörigkeit einer Person zu einem medizinischen College oder einer wissenschaftlichen Gesellschaft doch als Beleg für die Wahrheit ihrer Aussagen und als Garant für die Qualität ihrer medizinisch-wissenschaftlichen wie ärztlichen Praxis, so wurde nun die praktische Erfahrung zum Attribut des Subjekts, das in der Cholera-Frage eine wahre Aussage machen kann. White begründet seine Position aus den langjährigen Erfahrungen, die er während seiner Aufenthalte in Indien mit der Cholera gesammelt hatte..$^{54}$

»I was induced to recommend it, as >no medical man had said a word as to any measure which might be resorted to as a probable means of prevention $<$. The grounds upon which I did so, although incomprehensible to the central Board of Health, have ever since been recognised by most of the first medical men in the world, contagionists and non-contagionists; and who have more scientifically and pathologically, then I could do, explained why and wherefore. « ${ }^{545}$

Wir haben es hier mit einer diskursiven Strategie zu tun, einer Art von >Diskursspiel<, welches Foucault als »Praxis des Wahrsprechens« in seiner Untersuchung der antiken parrhesia und in seinen Vorlesungen zur Regierung des Selbst und der anderen ausführlich analysiert hat. In diesem Spiel werden die Kriterien für Wahrheit an ein Verhältnis des Subjekts zur Macht gekoppelt, während die Moralität des Subjekts durch das Ausprechend der Wahrheit bestätigt wird. ${ }^{546}$ Diese Konstellation zwischen den Verfahren der Veridiktion und den Praktiken des Selbst wird durch eine be-

541 Vgl. Bell: Treatise on cholera Asphyxia, or epidemic cholera, as it appeared in Asia, and more recently in Europe, Edinburgh/London, 1832: S. vi.

542 Ayre: A Letter to Lord John Russell, M.P on the evil policy of those measures of quarantine, and restrictive police, which are employed for arresting the progress of the Asiatic Cholera, 1832: S. 38.

543 White: Treatise on cholera morbus; the method of treatment, and means of prevention, 1834: S. 33.

544 Vgl. ebd.: S. iii.

545 Ebd.: S. viii.

546 Vgl. Foucault: Die Regierung des Selbst und der anderen II, 2010 [1983 - 1984]: S. 15. 
stimmte Praxis des »Wahrsprechens « hergestellt. ${ }^{547}$ Die Wahrheit einer Aussage wird dadurch belegt, dass das Subjekt sie entgegen der Macht der Menge, oder eines mächtigen Gegenübers - eines Fürsten, Königs, oder Tyrannen - äußert. Der mutige gefährliche Akt des Wahrsprechens erhebt andererseits das Subjekt moralisch gegenüber den Trägern der Macht. Es handelt sich also bei diesem >Diskursspiel< selbst um eine Strategie der Macht, die mithilfe von Wahrheit und Rationalität herrscht. ${ }^{548}$

Bei Bell und Ayre sind vor allem ihre praktische Erfahrung Grundlage ihres >Wahrsprechens $<$, wie auch die damalige Rezeption ihrer Texte zeigt. ${ }^{549}$ Die Beurteilung von kontagionistischen Positionen als theoretisch spekulativ begründet, gegenüber der auf Grundlage von wirklichen Beobachtungen entstandenen Positionen der Anti-Kontagionisten, findet sich nicht nur bei den genannten Autoren. Über den Wandel des Arztes Reginald Orton vom Anti-Kontagionisten zum Kontagionisten urteilte etwa ein Mitglied der Westminster Society, dass seine ursprüngliche Positionierung als Anti-Kontagionist auf Erfahrungen in Indien beruht hätten, während seine Position für die These der Übertragbarkeit der Krankheit im stillen Kämmerlein in der Heimat entstanden wäre, also nur theoretisch begründet worden sei. ${ }^{550}$

Für Ayre waren Aussagen, die sich nur in einem wissenschaftlichen Disput eigneten (»fitted only to serve as a subject for medical disputation ${ }^{551}$ ), aber keinen praktischen Nutzen hervorbrachten, völlig nutzlos. Ein besonderes Wissen oder eine spezielle medizinische Ausbildung, konstatierte auch der Arzt, sei für die Beobachtung und Beurteilung der Fakten nicht erforderlich: »The question is not a mere professional one, and requiring professional knowledge to appreciate, but is one strictly of facts, and may be intelligible to all. ${ }^{552}$ Auch White begründet die Einbeziehung der Stimmen und der Erfahrungen von Nicht-Ärzten explizit damit, dass die Medizin und die wissenschaftliche Auseinandersetzung noch zu keinen praktischen Vorschlägen geführt haben. ${ }^{53}$ »For philosophical and scientific objects, the ascertaining the remote causes of Cholera Morbus is certainly very important; but for immediate purposes, the means of prevention, and method of cure, are far more so. «554

Die Anti-Kontagionisten sahen in dem Wissen aus Erfahrung - im Gegensatz zu spekulativen und theoretischen Überlegungen der Medizin - die Grundlage für lokale

547 Vgl. ebd.: S. 54.

548 Vgl. Foucault: Die Regierung des Selbst und der anderen I, 2009 [1982 - 1883]: S. 444.

549 Vgl. Johnson: [Medico-surgical Review- Epidemic Cholera], 1832: S. 187.

550 Vgl. Artikel 1: Westminster Medical Society, Discussion on the Cholera, Question of Contagion, 5. März, 1832: in: The Lancet London, 1832: S. 22. Vgl. auch: An Essay on the Epidemic Cholera of India. By Reginald Orton, Surgeon, late Majesty's Thiry-fourtg Regiment of Foot. Second Edition with Supplement, London, 1831 [...]: in: ESMJ, 37.1832 , S. $179-210$.

551 Ebd.: S. 4.

552 Ayre: A Letter to Lord John Russell, M.P on the evil policy of those measures of quarantine, and restrictive police, which are employed for arresting the progress of the Asiatic Cholera, 1832: S. 4.

553 Vgl. White: Treatise on cholera morbus; the method of treatment, and means of prevention, 1834: S. vii.

554 Ebd.: S. 13. 
und effektive Maßnahmen zur Bekämpfung der Choleraepidemie. ${ }^{555}$ Das Erfahrungswissen eignete sich wesentlich eher als die medizinische Doktrin dazu, die Handlungsfähigkeit und Macht der Regierung herzustellen und für die beteiligten Akteure eine machbare Praxis zu entwerfen. Alle Versuche in Europa eine Praxis auf der Grundlage einer solchen Doktrin, wie der der Kontagiosität einzuführen, konstatierte Bell, haben nur ihre Nutzlosigkeit bewiesen: »the practical application of the doctrine has been much worse than useless. ${ }^{556}$ Die Argumentation gegen die Doktrin und die Regierung, die sich auf diese berufen hatte, erfolgt bei den drei Autoren nach einem ähnlich Muster verknüpfter Kriterien für Wahrheit und der eines guten moralischen - in erster Line fortschrittlichen liberalen - und rationalen Subjekts. Subjekt und Wahrheit konstituierten in ihrem Verhältnis die Bedingungen der Akzeptierbarkeit der Ausübung von Gouvernementalität. So kam mit dem besonderen Gewicht, den die Autoren auf die praktische Effektivität der Regierung legten, auch die Destabilisierung der Subjektposition, der Wahrheit über die Ungültigmachung der Verfahren einer anderen Gouvernementalität ins Spiel. Wenn die Praxis der Regierung nutzlos für ihr Ziel war, die Gesundheit der Bevölkerung zu schützen, dann musste auch die gesamte sich in Subjektivität, Wahrheit und Macht bedingenden Konstellation hinfällig sein. Besteht die Möglichkeit, dass die Regierung sich nicht auf eine Wahrheit berufen hatte? Hatte sie die Verfahren der Veridiktion missachtet? Hatte sie dies absichtlich getan und hatte sich damit auch dieses Subjekt, welches vorgab, in guter Absicht regieren zu wollen, als unmoralisch, willkürlich oder machtversessen erwiesen?

White ging von beidem aus: Weder die Kriterien für Wahrheit, die an ein bestimmtes Verfahren der Veridiktion, einen bestimmten Modus der Produktion von Erkenntnissen gebunden ist, wurde erfüllt, noch wurde den Bedingungen eines Verfahrens zur Subjektivierung, zur Produktion eines moralischen, zum Wahrsprechen und zur guten Regierung fähigen Subjekts genügt. ${ }^{557}$ Besonders White machte deutlich, dass er in der Favorisierung der Doktrin durch das Government Board und der daraus abgeleiteten Anordnung der Quarantäne überhaupt keine wissenschaftliche Begründung sehen könne, sondern sogar eine bewusste Abweichung von der Vernunft, der Regierungsrationalität, die sich aus einer seiner Meinung nach so offensichtlichen und aufdringlichen Wahrheit gezeigt habe. In Folge bezeichnet er »the doctrine of contagion« nur noch als eine Dummheit (»folly«). ${ }^{558}$ Anstatt, wie später die Redaktion des Lancet, eine strategische Bezugnahme auf die Doktrin zu vermuten, brachte White diesen Widerspruch mit Irrationalität, mittelalterlichem Aberglauben und der völligen Entkoppelung von Wahrheit und Rationalität und Regierung in

$555 »[\mathrm{~B}]$ ut really such speculations are of little value, nor is there any theory of the disease which has led to important practical results, except that which traces its origin and spread to contagion alone.«: Bell: Treatise on cholera Asphyxia, or epidemic cholera, as it appeared in Asia, and more recently in Europe, 1832: S. 61.

556 Bell: Treatise on cholera Asphyxia, or epidemic cholera, as it appeared in Asia, and more recently in Europe, 1832: S. 130.

557 Vgl. White: Treatise on cholera morbus; the method of treatment, and means of prevention, 1834: S. 31.

558 Vgl. ebd.: S. 34. 
Zusammenhang. ${ }^{559}$ Er kritisierte die Maßnahmen, die die Boards of Health durch ihre Maßnahmen den Menschen zugemutet hätten: die Trennung von ihren Familien, die Beschwerden des Transports. All das sei völlig unnötig gewesen. ${ }^{560}$ Ebenso steht es laut ihm um die Quarantäneverordnung: »The Quarantine Laws have proved all over the world a source of misery to mankind, and perfectly inadequate for the purposes for which they were invented. $«^{561}$

Bell, White und Ayre kritisierten aber auch die Haltung der schlichten Ablehnung der Kontagiosität einiger Ärzte mit dem Verweis auf eine andere unbeeinflussbare Ursache der Cholera. Die Drei gingen alle über diese rein negative Aussage, die in dieser Weise vielleicht nur einen Machtverlust der Regierung herbeigeführt hätte, hinaus. Sie nennen nun aus der Position der Anti-Kontagionisten den Ansatzpunkt oder vielmehr ein ganzes Feld von Problemen, an denen die Regierung präventiv und vor allem sehr viel effektiver ansetzen kann, um gegen die Cholera vorzugehen. Worin bestand dieses Feld? Aus allem, was auch schon zuvor mit den sog. »predisposing causes « benannt wurde und welche in erster Linie in der Schwächung der Lebenskräfte der armen Bevölkerung durch deren Armut und Lebensverhältnissen liegen. ${ }^{562}$ Diese benannte Bell wie üblich: Schlechte Ernährung, mangelnder Schutz vor Kälte oder Wärme, Überanstrengung, Exzesse, Unruhe und Angst. ${ }^{563}$ Dem Studium und der Beseitigung dieser Ursachen hätten sich die Boards und die Untersuchungen der Kommissare der Regierung seiner Ansicht nach widmen sollen. Hier liegt das Wissen, das auch nach Whites Meinung vielerorts zu einer effektiven Praxis gegen die Cholera geführt hätte. ${ }^{564}$ Ayre, der seinen Brief an die Regierungskommissare Russle und Barry erst 1837 verfasste, fürchtete den erneuten Ausbruch der Cholera in Großbritannien, da diese seit 1835 in weiten Teilen Europas, bereits zum zweiten Mal in diesem Jahrzehnt grassierte. Sein Anliegen war es, die Regierung von einer, seiner Meinung nach weitaus günstigeren, auf die Armen und die sog. predisposing causes gerichteten Präventionspolitik zu überzeugen: »the poor of all countries are predisposed to be affected by the disease $\ll^{565}$

»[I]t would be easy to shew, that the sum to be expended in carrying into effect the measures I have proposed [distribution of meat to the destitute of the laboring poor], would not exceed what has so unprofitable spent to arrest it as an infection, and would fall greatly below the sum

559 Vgl. ebd.: S. 33.

560 Ebd.: S. 34.

561 Ebd.: S. 36.

562 Ayre: A Letter to Lord John Russell, M.P on the evil policy of those measures of quarantine, and restrictive police, which are employed for arresting the progress of the Asiatic Cholera, 1832: S. 37.

563 Vgl. Bell: Treatise on cholera Asphyxia, or epidemic cholera, as it appeared in Asia, and more recently in Europe, 1832: S. 133f.

564 Vgl. White: Treatise on cholera morbus; the method of treatment, and means of prevention, 1834 [1831]: S. 33.

565 Ayre: A Letter to Lord John Russell, M.P on the evil policy of those measures of quarantine, and restrictive police, which are employed for arresting the progress of the Asiatic Cholera, 1832: S. 6. 
which the country lost by the quarantine, through the interrupting and delay which it inflicted on trade. $\ll^{566}$

Das Interessante ist nun an der Position von Ayre, aber auch von den anderen beiden, dass sie eine enge Verbindung zwischen den negativen Folgen der Quarantäne für die nationale Ökonomie und Anfälligkeit und Empfänglichkeit der Bevölkerung für die Krankheit herstellen. Die Hauptursache für die epidemischen Ausbrüche der Cholera sei die Armut der arbeitenden Klasse. Wenn aber die Quarantäne den Handel und somit auch die Produktion hemme, so hätte diese notwendigerweise Entlassungen von Arbeitern zur Folge, die daraufhin erst recht von Armut bedroht seien. Also ist die Quarantäne eine Technik der Regierung, die nicht gegen die Cholera wirkt, sondern, im Gegenteil, das Risiko einer Epidemie sogar noch verstärkt:

»For it is a fact too notorious to be denied, and too nearly connected with this question to be overlooked, that the destitute of the labouring poor form, in every country, of those attacked by it, infinitely the greater number, and in our own nearly the only subjects of it; and therefore, that there is something in their physical condition, and allied to their poverty, which in some way predisposes them to its attacks. But the restrictions of quarantine, by interrupting the labours of the manufacturer and the merchant, and thus diminishing the demand for labour, go directly to diminish the resources of the poor, and thus, by increasing their poverty, increase their predisposition to the disease [...]. But if, on the contrary, it can be proved, that the disease is not infectious, and that the destitution of labouring poor is the very cause itself, by which, when it is present, they are especially subjected from it, then the quarantine, by its restrictions and regulations, and by the poverty, with its multiplied privations, which it creates and perpetuates, becomes a very purveyor to the complaint, feeling it with its victims, and so deserving to be ranked amongst the most pernicious expedients, which prejudice and folly have ever invented to increase the suffering of mankind. «567

Es wäre sicherlich zu einfach, diese Verknüpfung als den grundlegenden Gedanken der liberalen Anti-Kontagionisten zu verstehen. Aber sie ist Teil einer gesamten und veränderten Sichtweise, die sich an einer Vorstellung, oder besser gesagt, bestimmten ökonomischen Interpretation von >Realität< ausrichtete. Wenn man zuvor die Forderung an die Regierung gerichtet hatte, sich der Gesundheit der Bevölkerung anzunehmen, so geschah das in einer eher unspezifischen positiven Weise. Ein größeres Engagement des Staates in dieser Hinsicht bedeutete einen größeren positiven Effekt. Aber nun ergeht die Aufforderung an die Regierung, sich stärker an dem Gegenstand des Lebens und der Bevölkerung, genauer der Ökonomie und Zirkulation, die sie scheinbar am Leben hält, auszurichten. Die Regierung soll sich auf einen fragilen und selbstregulativen Bereich von unzählige Verknüpfungen und Kräften konzentrieren. Sie soll gleichzeitig akzeptieren, dass die Undurchschaubarkeit dieses Bereichs, die eine wirkliche, weniger juristische als praktische Begrenzung ihrer Macht darstellt. Ihre Begrenzung besteht nicht mehr in einer formal festgesetzten rechtlichen Beschränkung ihrer Souveränität, sondern vielmehr in einer begrenzten, aber durch 
Wissen verschiebbaren Reichweite ihrer Erkenntnis und Technik. Die Argumente für einen freien Markt und Handel werden als Bedingung für das Wohlergehen und die Gesundheit der Bevölkerung gesetzt. In jeder Hinsicht besteht die Frage, wie die Kräfte des Marktes und die Kräfte der arbeitenden Körper freigesetzt werden können, damit sie zu Reichtum und Wohlstand führen. Wie können die Kräfte des Körpers und des Marktes gefördert werden, um sich gegen die Gefahr der Krankheit zu wappnen? Die liberale Regierungslogik zielt auf die Steigerung und Freisetzung von Kräften, von denen man behauptet, dass sie gewissermaßen natürlich sind, möglicherweise unterdrückt werden und befreit werden müssen. In diesem Sinne sind beinahe alle ihre Vorschläge von der Idee der Aktivierung geprägt, restriktive Praxen werden als schädlich angesehen. Auch die Armen sollen möglichst nicht einfach Almosen erhalten, sondern sie sollen über die Mechanismen des Marktes in Lohn und Brot gebracht werden und dadurch aus dem Zustand ihrer sie für die Krankheit anfällig machenden Armut befreit werden usw. Selbst der Staat sollte besser Arbeit als Brot an die Armen verteilen, um zu verhindern, dass die Armen in eine >Abhängigkeit< geraten und eine für Lohnarbeiter schädliche Lebensweise zu ihrer Gewohnheit machen - ein Einschätzung Ayres, die grundlegenden liberalen Lösungsansätzen von Batham und auch Malthus völlig entsprach. ${ }^{568}$

Die Protagonisten der sanitären Reform in Großbritannien haben gegenüber dem, was Heinrich Heine über die Verbreitung von Diätwissen, festen Glauben und das Verteilen von Flanellbauchbinden erreichen wollte ${ }^{569}$, eine sehr gegensätzliche Regierung umsetzen wollen: Sie forderten eine Regierung, die sich im Ganzen über diese religiös geprägte Form der Selbstpraxis stellte. Ihnen schwebten andere Mechanismen zur Regierung und Entfaltung der Lebenskräfte vor, die sich für jeden Arbeiter aus seiner bloßen Existenz ergeben sollten. ${ }^{570}$ Die Unterschiede und die Ungleichheit werden als notwendig hingenommen, eine moralische Differenzierung der unterschiedlichen Subjekte und Gruppen und ihrer Selbstpraxis wird vollzogen, ohne dass die Regierung es auf die Verbesserung der Menschen durch Selbstpraxis angelegt hat. Sie betrachtet das Verhalten der Arbeiter nicht mehr in Form einer Kritik der Lebensweise, sondern als Realität und unter Gesichtspunkten der öffentlichen Gesundheit und Sicherheit. Sie tut dies, indem sie das Subjekt, das sie regiert, Konzeptionell vereinfacht und seine Aktivität und Existenz auf eine angeblich natürliche ökonomische Rationalität reduziert: In letzter Konsequenz will ein Subjekt, so konzeptioniert, nichts weiter, als seine materielle Existenz sichern. In dieser Reduktion ist jedes Individuum verallgemeinerbar, berechenbar und regierbar. Die Frage nach dem sozialen Fortschritt, der Verbesserung der Menschen und der Gesellschaft werden sie vom Sockel der moralisch-religiösen Selbstpraxis herunter heben und in eine ganz materielle, ökonomische Frage umwandeln. ${ }^{571}$ Entsprechend enthält z.B. der

568 Vgl. ebd.: S. 34.

569 Vgl. Heine: Artikel VI: in: Französischen Zustände, 1833 [1832]: S. $69 f$.

570 Harrison: Disease and the modern world: 1500 to the present day, 2004, S. 111.

571 »The question, indeed was denounced as a >profitless one<, and undeserving of serious consideration; jet of the decision of that most important, but neglected question, hinged all the efficiency of all the preventive measures, or well nigh all the evil that could be feared from the disease. (Ayre: A Letter to Lord John Russell, M.P on the evil policy of 
Text von White regelrechte Spotttiraden über die diätetischen u.ä. Ratschläge, die die Regierung im Vorfeld der ersten Epidemie der Bevölkerung empfohlen hatte und kritisiert diese geradezu als zynisch. ${ }^{572}$

\section{Der Bericht des General Board of Health und die Sanitaristen}

Entgegen der Befürchtungen des Arztes Joseph Ayre blieb Großbritannien von der zweiten Welle der ersten europäischen Choleraepidemie verschont. Erst die zweite europäische Epidemie, die 1848/49 ausbrach, erreichte im Herbst 1848 auch britische Häfen und breitete sich, wie auch während der ersten Epidemie, von Sunderland in Richtung Schottland und von dort aus bald über ganz Großbritannien aus. ${ }^{573}$ In Edinburgh wurden am 6. Oktober die ersten Cholerafälle gemeldet. Die Epidemie zeigte schon kurz nach ihrem Auftreten dieselben Eigenschaften, die auch bei der Epidemie 1832 zu beobachten gewesen waren. ${ }^{574}$

John Sutherland wurde 1848 vom Government Board of Health in London beauftragt, einen umfassenden Bericht über die Choleraepidemie anzufertigen. Im Unterschied zu den Sammlungen von einzelnen Berichten und Dokumenten erhoffte sich das Board gerade durch eine einheitliche Ordnung der verschiedenen Fakten und Berichte, durch Statistiken und durch verschiedenste Karten und Stadtplänen ${ }^{575}$, die es

those measures of quarantine, and restrictive police, which are employed for arresting the progress of the Asiatic Cholera, 1832: S. 32) »The question is not [...] as it has been presented to be, an idle and profitless one. Fitted only to serve as a subject for medical disputation; but is in truth one of preeminent importance, and involves in it, not merely the welfare, but the very existence of multitudes. « Ebd.: S. 4.

572 Vgl. White: Treatise on cholera morbus; the method of treatment, and means of prevention, 1834 [1831]: S. 33; 37.

573 »In a few days after the disease had struck the northern metropolis, it appeared in the neighbouring towns of Newhaven, Portobello, Loanhead, and a number of other localities, and reached the west of Scotland on the 11th November, when it attacked the city of Glasgow, and subsequently a large number of manufacturing towns and villages in Lanarkshire, Ayrshire, Dumfriesshire, and other counties in the south and west of Scotland. A few sporadic cases and local outbreaks of the disease occurred in England during the same period. The first stroke of the epidemic appeared to have subsided early in May, 1849 , although the disease still lingered in many parts of the country. It again assumed an epidemic form in the latter end of May, and during the summer and autumn nearly every large city and town in England was attacked, as well as several towns in Scotland, the last severe seizure being that of the inmates of Taunton Union workhouse, in the beginning of November.«: Vgl. Sutherland, J.: Report: in: Letter of the President of the General Board of Health, 1855 [1854]: S. 2.

574 Vgl. ebd.: S. 1.

575 Allerdings musste auf die aller umfangreichste Sammlung von Statistiken über die Epidemie 48/49 noch bis zum Frühjahr 1852 gewartet werden. Vgl. Baly: Report on the cause and diffusion of the epidemic cholera 1854: in: Baly/Gull: Reports on epidemic cholera drawn up at the desire of the Cholera Committee of the Royal College of Physicians, 1854: 7f. Vgl. Farr: Report on the Mortality of Cholera in England, 1848 - 49, 1852 . 
ermöglichten, die unterschiedlichen Daten zu vergleichen, eine größere Kenntnis über die Eigenschaften der Cholera zu gewinnen. Der Bericht war von dem Ehrgeiz beseelt, mit den Erfahrungen aus der zweiten Epidemie endlich eine bessere Grundlage für politische Maßnahmen und Techniken zu entwickeln. ${ }^{576}$ Die Frage der Kontagiosität spielte in dem Bericht so gut wie keine Rolle. Auch daran lässt sich vermuten, wie einflussreich die Macht der Anti-Kontagionisten auf die ganze Problematisierung der Cholera in dieser Zeit geworden sein muss. Dieser deutliche Umschwung wurde von dem Großteil der Mediziner und der medizinisch-wissenschaftlichen Gesellschaft, wie z.B. im Edinburgh Surgical and Medical Journal, entsprechend begrüßt.

»It affords us sincere pleasure to observe that this doctrine of the non-contagiousness of, cholera, which we showed in 1832 is the correct one, and the only one consistent with facts, has at length been recognized in this manner, and that it is recommended to be the basis of any practical measures, should that disease again visit the British dominions. $\ll^{577}$

Selbst das College of Physicians öffnete sich im Lauf der 40er und 50er Jahre für andere Erklärungen und Thesen über die Ursache und den Modus der Verbreitung der Cholera. ${ }^{578}$ Aber es war weniger nur diese andere Sicht auf die Cholera oder die Anerkennung einer neuen Wahrheit, als vielmehr eine Umformung und Anpassung der Regierung von Gesundheit an das Prinzip der Sicherung der Gesundheit (der Produktivität und Lebenskräfte einer Gesellschaft), die im Umgang mit der zweiten Epidemie deutlich wurde. Die Frage der Ursache trat deutlich in den Hintergrund. Auf diese Weise wurde die Cholera, die von der Medizin und der Bevölkerung als unerklärliche und rätselhafte Bedrohung angesehen worden war, zu einem nüchtern zu beobachtenden Phänomen, dessen Bedingungen und Auswirkungen auf das menschliche Leben bestimmten Regeln folgte, die einmal dokumentiert für die Regierung handlungsleitend werden konnten.

»Sufficient evidence will presently be advanced to show that cholera is by no means so capricious in its attacks as has been generally supposed, but that on the contrary it is propagated according to certain fixed laws, although the limits of these have not as yet been precisely defined. $\ll 79$

Das menschliche Leben, die Gesundheit einer ganzen Bevölkerung als ein bestimmten Gesetzen folgendes Spiel heterogener Kräfte und Einflüsse zu interpretieren und

576 Vgl. Sutherland, J.: Report: in: Letter of the President of the General Board of Health, 1855 [1854]: S. 3.

577 Metropolitan Sanitary Commission: The Report of the Metropolitan Sanatory Commissioners, \&c, contains several points deserving attention: in: EMSJ, 69.1848, S. 255 - 263: S. 255.

578 Vgl. Begbie, J. Warbubton: Art. VI.- On the Facts and Opinions recently recorded in regard to Asiatic Cholera: EMSJ, 81.1854, S. 502 - 523: S. 523.

579 Sutherland, J.: Report of the General Board of Health on the epidemic cholera of 1848 \& 1849, 1850: S. 3 f. 
die Politik auf die Sicherung der positiven Effekte dieses Spiels zu richten, war nun die Aufgabe der Regierung. In ähnlicher Weise wie Thomas Malthus diese »natürlichen Gesetze« über die Bevölkerung aufgestellt hatte, wurde der Entstehung und Verbreitung einer Epidemie und selbst der Art und Weise, wie sie menschliches Lebens auslöschte, eine Regelhaftigkeit und Ordnung zugerechnet, die es zu erkennen galt. Es erscheint wie ein Aufwachen in einer Wirklichkeit, einer Ordnung und Wahrheit, dass das Leben der Bevölkerungen schon immer in einer bestimmten Weise und nach einer Reihe von natürlichen Regeln der Existenz durch die Natur regiert wurde. Die Anerkennung dieser Ordnung, die Ausrichtung der Regierung an den ganz materiellen und natürlichen, bald wird man auch sagen können, biologischen Gesetzen, ist die Aufgabe jeder Regierung, des Selbst und der Anderen in gleichem Maße. So schrieb Sutherland in der Einleitung seines Berichts:

»It must now be considered and established truth in science, that the health, the well-being, and the duration of the life of man are intimately connected with the observance of the natural laws of the universe in which he dwells. The acknowledgement of this fact is not, however, sufficient to ensure obedience to those laws. Men must be taught individually and collectively to obey them; each man for himself; every family, in order to ensure its possession of that immunity from disease which the Great Creator obviously intended his creatures to possess; and all men acting in their social or corporate capacity for the protection of each other, and of the entire community. $\ll^{580}$

Der Mensch sei in Besitz der Kräfte, um es mit diesen multiplen Kräften, die gegen sein Leben wirken, aufzunehmen. Nicht indem er diese Kräfte besiege, sondern ihre Gesetze und ihre Rationalität zu seinen eigenen mache. Er besäße die Fähigkeit der Erkenntnis dieser natürlichen göttlichen Bedingungen seiner Existenz und er könne sie überleben. Kein Staat mit seinen Gesetzen und keine sozialen Sanktionen oder legitimer Zwang nötigen den Menschen mehr zu einem bestimmten Verhalten und zu einem bestimmten Leben, dass ihn gesund erhalten und ihm Wohlstand bescheren werde, als die (von Gott geschaffene) Natur selbst. Nur seine eigenen Erfahrungen und die Vernunft würden ihn zwingen, diese anzuerkennen.

Das ist mehr oder weniger die Logik, die sich auch in dem Bericht von Sutherland zeigt: Keine menschliche Macht sei in der Lage, gegen diese natürlichen Gesetze zu handeln. Eine vernünftige Regierung könne nur die sein, die diese natürlichen Gesetze, auf der die Ökonomie des Lebens und die Erhaltung der Gesundheit und der Lebenskräfte beruhen würden, zur Grundlage ihrer Rationalität erkläre. Ganz in der Tradition protestantischer Wissenschaftsphilosophie ging Sutherland in seinem Bericht davon aus, dass Epidemien bestimmten göttlichen, also logischen Gesetzen folgen müssten und es die Aufgabe der Wissenschaft sei, diese Gesetze zu erforschen: $\gg$ those special conditions attending the epidemic $\ll^{581}$. Die Freiheit des Menschen bestehe nun darin, keinem menschlichen anderen Gesetz mehr, das neben oder außerhalb dieser natürlichen Ordnung steht, folgen zu müssen. 
Im Grunde impliziert diese Rationalität der Regierung, dass es keine menschlichen Exekutiven mehr geben müsse, keine Polizei und keine Behörden, die für die Wirksamkeit dieser Gesetze garantieren. Die Natur habe ihre eigene Exekutive. Alles menschliche Regieren kann sich nur noch auf die Sicherheit und die Sicherung des Lebens vor dieser automatischen Exekutive der Natur beziehen. Aus dieser Position, aus diesem Konstrukt besteht die ganze Unschuld ihrer Macht, ihre Liberalität und ihre Humanität. Ihre Form entspricht der Grundidee der sozialen und religiösen Regierungspraxen, die sich in Großbritannien im 18. Jahrhundert herausgebildet haben. Eine Regierung der bürgerlichen religiösen Gemeinschaften (communities), die durch ihr Regime nur eine Art vorgeschaltetes System der Regulierung bedeutete, die das Ziel hatte, zu verhindern, dass die Mitglieder der Gemeinschaft der Macht des Staates und seinem erbarmungslosen Strafsystem zum Opfer fallen. ${ }^{52}$ Vor den Gesetzen der Natur gibt es kein Entkommen. Haben ihre Gesetze zu wirken begonnen, ist alle menschliche Macht nutzlos. Die Sicherung des Lebens vor dieser natürlichen Macht muss in einem vorbeugenden und präventiven Sinne ${ }^{583}$ erfolgen, um erfolgreich zu sein. Es bleibt also nur die Wahl, sich einer Sicherheitsregierung zu unterwerfen oder sich den Gesetzen der Natur auszusetzen, die wie ein übergeordnetes, unbeeinflussbares, erbarmungsloses und tödliches Strafsystem erscheinen. Es ist eine Macht, vergleichbar mit dem Strafsystem des englischen Staates des 17. und 18. Jahrhunderts, dessen Zugriff durch die vorbeugende Kontrolle und Regierung innerhalb der religiösen Gemeinschaften entkommen werden konnte.

»There is a free choice given. On the one hand there is obedience and health, with all the numberless blessings and privileges which go with it; on the other, there is neglect and its infallible consequences, which no human power can fully avert when they are entailed, and these are disease, death, pauperism, loss of property, ignorance, debasement, crime. ${ }{ }^{84}$

Das ist das, was Matthias Bohlender als »Geburt einer liberalen Biopolitik « bezeichnet hat. ${ }^{585}$ Aufgabe der Regierung ist, dafür zu sorgen, dass dieser positive Mechanismus, der durch das Zusammenwirken der verschiedenen positiven Kräfte in Gang gehalten wird, sich fortsetzen kann. Ihr Handeln muss auf die Aktivierung und Sicherung dieser Kräfte beruhen, da die Zerstörung oder Schwächung dieser positiven Kräfte die Gefahr einer umgekehrten negativen Kettenreaktion auf das gesamte Geflecht von Kräften nach sich ziehen könnte. In dieser Vorstellung ist die Sicherung der Gesundheit der Bevölkerung, die Sicherung ihrer lebendigen und produktiven Kräfte, die damit verbunden ist, zu einem absolut zentralen Problem dieser Regierung geworden.

582 Vgl. Foucault: Die Wahrheit und die juristischen Formen, 2003 [1974]: S. 88ff.

583 »[T]hrough various measures of a medical preventive nature carried out under the regulations of the General Board of Health«: Sutherland, J.: Report of the General Board of Health on the epidemic cholera of $1848 \& 1849,1850:$ S. 3.

584 Ebd.: S. 3.

585 Bohlender: Metamorphosen des liberalen Regierungsdenkens, 2007: S. 171. 
»The social evils of this neglect are at present ramified throughout the entire framework of society. A vast amount of property has grown up in all parts of the country, of which it is not too much to assert that it is as productive of misery to the people, as it is unproductive of legitimate revenue to the possessor. Large masses of population are congregated together without any attention to those conditions on which their healthy existence depends, and until very recently it was even denied that there were any special causes of disease which occasioned a greater mortality in towns than was the common lot of the human race. Melancholy experience has however proved that unless a very different view be taken of those new duties which devolve on all men, by the very act of their social union, and suitable means of protection adopted, our country will exhibit a progressive descent in the health and productive power of its people, and a corresponding degradation in their moral and social condition, of which, indeed, a low sanitary state must now be considered as an almost invariable exponent. $\aleph^{586}$

Vereinfacht gesagt, bezog sich die Angst vor den Folgen einer verheerenden Epidemie auf die Produktion. Man fürchtete einem massenhaften >Verlust< an Menschen, die der Produktion als Arbeitskraft dienten. Aber es ist auch sehr wichtig zu sehen, dass hierdurch ein völlig neuer, nun nahezu unbegrenzter Bereich für die Regierung eröffnet wurde, zu denen auch die neuen Techniken der public health (»various measures of a medical preventive nature $\ll^{587}$ ) zu zählen waren. Die Regierung akzeptierte neue Grenzen, wurde aber insgesamt in einem viel umfassenderen und effektiveren Sinne fähig zu regieren: »it is nevertheless of extreme importance to know that there are other laws, the modifying conditions of which can be to a great extent influenced. $\aleph^{588}$ Die Definition der Cholera, selbst der allgemeiner gefassten Epidemie, ließ sich reduzieren auf das Phänomen des Zusammentreffens verschiedener Kräfte und deren Wirkungen auf die Lebenskräfte der Menschen. ${ }^{589} \mathrm{Um}$ die These von diesen, die Lebenskräfte (»the resisting vital forces of individuals«) schwächenden Bedingungen noch näher zu charakterisieren, beschrieb Sutherland das Phänomen, dass häufig, bevor die Cholera an einem Ort ausbrach, Fälle von Diarrhö und MagenDarmbeschwerden auftraten. ${ }^{590}$ Obwohl Sutherland eingestand, dass bestimmte Verhaltensweisen einzelner Individuen »specific acts of intemperance in food or drink, over-fatigue, or perhaps sudden alarm $\ll^{591}$ ebenfalls in der Lage gewesen seien, diese Widerstandskräfte des Körpers zu zerstören, so lägen doch die wichtigsten Bedingungen in bestimmten lokalen Umständen. ${ }^{592}$ Es seien die viel mächtigeren und allgemeiner wirkenden epidemischen Bedingungen einer Lokalität und nicht die individuellen »predisposing causes«, die zum Ansatzpunkt für die präventiven Maßnahmen

586 Ebd.

587 Ebd.

588 Ebd.: S. 4.

589 Vgl. ebd.

590 Ebd.

591 Ebd.

592 »Epidemics invariably haunt the same localities. A few scattered drops of the storm may fall elsewhere, but its violence is spent where its purifying influence is most required. I shall presently describe and illustrate those conditions which cholera finds most congenial.«: Ebd.: S. 5. 
gegen die Epidemie gemacht werden müssten. Alle individuellen Maßnahmen können nur noch in Zusammenhang mit den lokalen Bedingungen gedacht werden. ${ }^{593}$

Der zuvor medizinisch definierte Zustand von Krankheit und Gesundheit wurde mit dem Bezug auf die Lebenskräfte des Körpers selbst zu einem Zusammenspiel permanenter heterogener Kräfte und Konflikte, die sich in einem Spielraum von verträglichen naturgemäßen Schwankungen befänden, bis sie einen kritischen Punkt erreichen und das flexible Gleichgewicht zerbreche. Sutherland meinte es sei nötig, die Gesundheit und die Lebenskräfte in einem Verhältnis zu den anderen um das Individuum herum bestehenden Einflüsse und Kräfte zu erkennen, genauer gesagt, die Gesetze zu erkennen, die dieses Verhältnis regierten. Der Blick auf diese Gesetzmäßigkeiten wird gerade durch die statistische Betrachtung der Epidemie erst möglich.

$\gg$ They [epidemics] are corrective rather than destructive, and one of their special objects seems that of arousing mankind, by signs which cannot be mistaken, to a sense of the necessity of recognising and obeying the laws of his physical existence. $\ll^{594}$

In den deutschen und französischen Ansichten, nach denen Angst und Leidenschaften, die Choleraepidemie ausgelöst hatten, stellten diese starken Gefühle eine Gefahr, oder sogar eine direkte Ursache der Epidemie dar und mussten unbedingt gemäßigt werden. In der Interpretation Sutherlands waren Angst und egoistische Triebe der Selbsterhaltung nichts Negatives. ${ }^{595}$ Emotionen wurden sogar zur direkten Quelle der Vernunft und zum Ausgangspunkt der Verbesserung der Lebensbedingungen und des Selbst.

»Under such circumstances men are most readily affected by the passion of fear, and the instinct of self-preservation leads them to inquiries and physical reforms which remove those material causes from which originates a debased state of health both of body and mind. «596

Im Gegensatz zu diesen, man könnte sagen, die Lebensgeister >aktivierenden « Gefühlen, würden von Lustlosigkeit, Müdigkeit, Hoffnungslosigkeit und jeder Art von Gleichgültigkeit eine lebensbedrohliche Gefahr ausgehen. ${ }^{597}$ Dieser »state of hopeless collapse « sei auch in vielen Fällen, bei denen die Cholera besonders schnell zum Tod geführt habe, zu beobachten gewesen. ${ }^{598}$ Diese vielen Ursachen lassen in ihrem Zusammenspiel die Gesetze der Wirkung der Epidemien sichtbar werden, auch wenn diese niemals eine Kausalität und einen absoluten Zusammenhang aufweisen. Die Epidemie, so stellte es Sutherland dar, diktiere der Regierung eine neue Aufgabe, ei-

593 »It is of great importance to keep in mind this distinction, because, in issuing instructions for the guidance of the population, as to diet, regimen, \&c., it would be manifestly insufficient to take the previous experience of any one locality as a foundation on which to rest those precautionary measures to be recommended for every other.«: Ebd.: S. 5.

594 Ebd.

595 Vgl. ebd.

596 Ebd.

597 Vgl. ebd.: S. 5f.

598 Vgl. ebd.: S. 6. 
ne Notwendigkeit, ihren Gegenstand, das Leben oder die Lebenskräfte der Bevölkerung, in einem weiteren nicht kausalen, sondern relativen, ökonomischen Zusammenhang als einer Vielzahl von Einflüssen und Kräften zu denken. Allerdings gaben die Epidemien der Regierung alles andere als klare Handlungsanweisungen. Die einzelnen Wissenschaften, die sich immer nur auf einzelne Probleme konzentrierten: Die Medizin, die Chemie die Meteorologie usw., könnten durch ihr spezifisches Wissen immer nur einen Teil der Umstände erhellen, welche die Epidemie als Phänomen hervorbrachten. Die Regierung könnte sich nicht auf eine oder zwei solcher Wissenschaften beschränken, sondern müsste tendenziell alles einbeziehen. Mit Blick auf die Gründung der public health science schrieb der Arzt und Präsident des General Board of Health, Benjamin Hall 1854 an den damaligen Innenminister Palmerston, der kurz darauf Premierminister wurde:

$»[\mathrm{P}]$ ublic confidence be acquired to this department, should the science of public health take its place among the matters with which statesmanship may properly concern itself, as I believe must sooner or later be the case, a wider field will be opened to this department and to the professional advisers whom it may be able to associate with it. The circumstances of this country, its wealth and poverty, its great cities with their social extremes of luxury and privation, its aggregation of individuals on the same spots, its multifarious industrial occupations, all point to the duty of studying the effects on life and health of trades, callings and processes, habitations, sites, water supply, sewerage, the adulteration of substances used for food, drink, and medicine, as matters vitally affecting the well-being of the nation. $\ll^{599}$

Die Gesetze der Epidemie seien keine absoluten, sondern statistische Gesetze, Regeln des Zusammenspiels verschiedener Einflüsse. Aus ihnen ergäben sich die Bedingungen und der Rahmen einer Regierung, die niemals mehr als nur einen relativen Erfolg zu erwarten hätte. ${ }^{600}$

Die Frage, die sich der Regierung nun stellte, war nicht mehr, worin die eine notwendige Ursache besteht, durch deren Beseitigung sich die gesamte Epidemie ausschalten lässt, sondern die Frage ist viel pragmatischer: An welchem Punkt kann eine Regierung möglichst erfolgreich und effizient ansetzen? Wo kann sie mit einem möglichst geringen Aufwand und möglichst ohne Schaden durch ihren Eingriff zu verursachen, einen möglichst hohen Erfolg erzielen? Auch in der Hinsicht spricht der Text von Sutherland eine sehr deutliche Sprache. Der Großteil der epidemischen Bedingungen sind sanitäre lokale Bedingungen, die relativ einfach durch menschliches Dazutun verändert werden können. ${ }^{601}$ Auf diese Weise wurde die Cholera zu einer Krankheit, die durch eine gute Regierung, zumindest in ihren fatalsten Erscheinungen, verhindert werden kann. Die Epidemie wurde im sanitären Sinne >managable< die Cholera zu eine >preventable disease $<$.

599 Hall, B.: 2. Letter, General Board of Health, 6. September 1854: in: Letter of the President of the General Board of Health, 1855 [1854]: S. 11.

600 Vgl. Sutherland, J.: Report of the General Board of Health on the epidemic cholera of 1848 \& 1849, 1850: S. 7.

601 Vgl. ebd.: S. 7. 
»[I]t is possible to prevent the localization of the epidemic, by removing the obvious topical causes which precede and accompany its attacks. [...] if from their magnitude or nature it be impossible to abate these causes, the same object may be attained by the removal and dispersion of the people. $\ll^{602}$

Neben der Bestätigung der Maßnahmen der Hausinspektionen, der Früherkennung und frühen Behandlung von Darmerkrankungen wie auch der kurzfristigen Maßnahmen zur Verbesserung der Sauberkeit und der sanitären Bedingungen, nannte Sutherland in seiner Schlussfolgerung die Übereinstimmung der epidemischen Eigenschaften der Cholera mit anderen epidemischen Krankheiten. ${ }^{603}$ Damit, konstatierte er, bestünde die Möglichkeit, durch bestimmte Maßnahmen nicht nur präventiv gegen die Cholera, sondern allgemein gegen Krankheiten, wie Typhus, Pocken und Scharlach, vorgehen zu können. ${ }^{604}$ Eine ganze Reihe von Maßnahmen hätten für die Prävention dagegen als nutzlos oder wenig effektiv erwiesen. Die politischen Maßnahmen hätten eher dem Management der Epidemie als dem Ziel, sie zu verhindern gedient:

»In the great majority of instances, these measures, which contain no efficient element of prevention, may be said to constitute the machinery at present in use for the management of epidemics.[...] A niggardly medical relief is provided, entailing enormous labour on the officers, and resulting in many fatal casualties from over fatigue and exposure in the affected districts; parties are vaccinated for whom application it made; hospital accommodation is generally afforded; additional parochial relief for the sick administered where necessary; and the dead are buried. $\ll^{605}$

Mit dem Verweis auf die natürlichen Gesetz- und Regelmäßigkeiten von Epidemien, die Sanitaristen wie Sutherland aus der Untersuchung der Cholera ableiteten, gelang es, eine andere Form von Universalisierung vorzunehmen. Trotz gleicher Herkunft leitete sie sich nicht mehr aus einer diätetischen Lehre über die Lebensweise des Einzelnen her, sondern konnte als Grundlage zur gesundheitlichen Regierung von Bevölkerung dienen. Sutherland macht in seiner Schlussfolgerung sehr deutlich, dass diese veränderte Interpretation der Cholera, als eine von vielen Epidemien, die klaren epidemischen Gesetzen folgt, eine neue und viel weitere Handlungsgrundlage für die Regierung schaffte. Die Utopie der Sanitaristen bestand - ähnlich wie in Rousseaus Reflexionen über die Hygiene als Tugendlehre - in einem Leben ohne Krankheit. Sutherland nannte vor allem die Notwendigkeit, diese ersten und grundsätzlich lokalen Bedingungen für Epidemien mit dauerhaften Verbesserungen der sanitären Situation dieser Orte entgegenzuwirken: »by permanent sanitary improvements and police regulations; [...] measures, to prevent the localization of cholera. $\ll^{606}$

Im Gegensatz zu Frankreich hat man in Großbritannien keine Schwierigkeiten, suggestiv Gesetze zu erlassen, die für die praktische Umsetzung dieser Politik erfor-

602 Ebd.: S. 41.

603 Vgl. ebd.: S. 147.

604 Vgl ebd.: S. 147f.

605 Ebd.: S. 147.

606 Ebd. 
derlich waren. Selbst wenn sie die privaten Rechte z.B. der Hauseigentümer und Fabrikbesitzer beschnitten. Dies zeigt u.a. die Ablösung des Contagious Diseases Prevention Act durch den Nuisances Removal and Diseases Prevention Act (1848) oder z.B. der Water Supply (Metropolis) Act $(1852)^{607}$ und den Public Health Act $(1852)^{608}$. Die Erfahrungen mit der Cholera waren bedeutend für die Durchsetzung der Gesetzte und das Verständnis der Epidemien, dass ihnen zugrunde gelegt wurde.

»However, recent sanitary legislation in this country had been dependent upon events which had occurred within the experience of the present generation - namely, the three outbreaks of cholera in 1831,1849 , and 1854 . The epidemic of 1831 thoroughly awakened the country to the necessity of sanitary reform. Parliamentary action was taken, and in 1848 was passed the great comprehensive measure of public health, which was the ground work of all sanitary legislation in this country, or in the world. The visitations of cholera in 1849 and 1854 further strengthened the opinion as to the necessity for sanitary reform, and several Acts were passed with that object in view. ${ }^{609}$

Die in dem Public Health Act umgesetzte Idee der sanitären Reform verband in ihrem totalisierenden Blick soziale mit hygienischen Reformen. Man ging von dem Grundsatz aus, dass alle epidemischen Krankheiten durch sanitäre Verbesserungen verhinderbar (preventable) seien, oder zumindest eingedämmt werden könnten. Jede soziale Reform, ob sie die Architektur von Häusern und Arbeiterwohnungen, StraBenreinigung und -befestigung oder das Abwassersystem betrafen, waren immer auch hygienische Maßnahmen, die Epidemien vorbeugen oder diesen entgegenwirken sollten. Sie repräsentierten, wie Johnson et al. schrieb, »social reform and public hygiene in a seamless whole $\ll{ }^{610}$ Die sanitären Reformer meinten, dass sie die Entstehung einer epidemischen Krankheit oder Krankheiten generell, überhaupt auf die Umwelt und die hygienischen sanitären Bedingungen eines bestimmten Ortes zurückführen könnten. Teilweise gaben sie atmosphärische Gründe an, andere vertraten die Miasma-Theorie, nach der sich vor allem aus stinkenden und faulenden Abfällen, Extrementen oder Kadavern pathogene Dämpfe entwickelten. Ebenso sollten erkrankte Körpern giftige oder krankheitserregende Ausdünstungen (»noxious effluvia«) absondern. Die Arbeiterklasse wurde aufgrund ihrer besonderen Empfänglichkeit und Empfindlichkeit für die Krankheiten weiterhin als Ansatzpunkt dieser allgemeinen Sicherheitstechnologien, die eigentlich auf den Schutz der Gesundheit der Bevölkerung zielten, gesehen.

607 Vgl. House of Commons, June 17, 1852: Metropolis Water Supply Bill: in: Hansard, Thomas Curson: Hansard's parliamentary debates, 1852: S. 840.

608 Vgl. Johanson/Brody/Paneth/Rachman/Rip: Cholera, Chloroform, and the Science of Medicine, 2003: S. 172.

609 [Hrsg.]/Nothern Corespondent: Hygiene and Public Health: MP, 1.1879, S. 435 - 436: S. 435 .

610 Johanson/Brody/Paneth/Rachman/Rip: Cholera, Chloroform, and the Science of Medicine, 2003: S. 172. 


\section{Verschiebung der Sicht auf die arbeitende Klasse}

Die Local Boards of Health leiteten auch während der 1849er Epidemie eine Reihe von Maßnahmen ein, um die Ausbreitung der Epidemie zu verhindern, bzw. diese abzuschwächen, die sich speziell auf die Hebung des Lebensstandards der Armen richteten. Die meisten Aktivitäten der lokalen Boards konzentrierten sich auf die frühe Behandlung der sog. Vorzeichen der Cholera, wie Diarrhö u.ä. Für die Armen wurde kostenlose permanente medizinische Versorgung angeboten. Dazu wurden konsequent Inspektionen in Häusern und bei Familien in den betroffenen Stadtteilen durchgeführt, um zu verhindern, dass Fälle von Cholera verheimlicht wurden, unbehandelt blieben und um andere Instruktionen zu geben. ${ }^{611}$ Des Weiteren wurde Kleidung, Nahrung und andere Dinge an die >Bedürftigen < ausgeteilt, um diese gegen die Krankheit zu rüsten. Diese Maßnahmen gerieten im Laufe der Epidemie 1848/1849 in die Kritik: Es wurde bemängelt, dass man die >unabhängigen < Arbeiter durch diese Maßnahmen in Abhängigkeit vom Staat brachte und nach den Begriffen der Liberalen sogar zur Unfreiheit zwang. Diese Kritik, die auch Sutherland in seinen Bericht über die Epidemie übernahm, entsprach der liberalen Kritik während der Diskussion um die Reform der Poor Laws, die sich ab den 1815 bis zur Verabschiedung des neuen Poor Law 1834 abgespielt hatte. Ausgangspunkt der Kritik war die These, dass die Maßnahmen zur Unterstützung der Armen und Arbeiter sich negativ auf ihre Subjektivität auswirken. Wie auch das alte Poor Law, so die Anfeindung, hätte die »parochial medical relief« während der Epidemie Ende der 1840er Jahre die freien Lohnarbeiter zu passiven Objekten der Wohlfahrt degradiert.

»Had the great majority of cases of cholera occurred among paupers, there would have been some show of reason for the parochial arrangement of relief being adopted; but it was very soon discovered that such was not the case, $[\ldots]$ the force of the epidemic fell not on the paupers, but on the working classes and small tradesmen. [...] three-fourths taking place among the independent working classes, who were thus thrown upon the parochial medical relief, with no other alternative than to take it as the law had provided, or run the risk of death. $\ll^{612}$

Das Problem, medizinische Versorgung für die ganze Arbeiterklasse zur Verfügung zu stellen, wurde in den meisten Fällen über das System und die Institutionen der Armenhilfe nur unzureichend gelöst ${ }^{613}$ : »giving working people so situated no other choice than to take refuge in a parish establishment $\ll{ }^{614}$ Dennoch sei diese Möglichkeit vielerorts die einzige gewesen, um überhaupt für die medizinische Versorgung der Arbeiterklasse zu sorgen, rechtfertigte Sutherland die Maßnahmen im Nachhinein. Auch hätten die Maßnahmen auf andere Weise einer Pauperisierung entgegengewirkt, die andernfalls durch die Epidemie selbst verursacht worden wäre:

611 Bspielsweise die Reinigung der Häuser, die Unterbringung der Kranken in Cholerakrankenhäuser usw. Vgl. ebd.: S. 78.

612 Ebd.: S. 79.

613 Siehe auch: [Hrsg]: Art. IV. - Cholera among the Pauper Children of Tooting: in: EMSJ, 71.1849, S. $310-336$.

614 Sutherland, J.: Report of the General Board of Health on the epidemic cholera of 1848 \& 1849, 1850: S. 138. 
»when the self-sustaining heads of families were being cut off «. ${ }^{615}$ Denn dann musste die Frage in erster Linie gewesen sein: »how the largest saving of productive human life could be effected $\aleph^{616}$ ?

Statt der Lösung des Pauper-Problems sahen die meisten liberalen Kritiker durch die gesundheitlichen Maßnahmen die Gefahr der Pauperisierung der Arbeiterklasse jedoch eher vergrößert. War es doch das Ziel, alles in den Arbeitern hervorzubringen, was sie dazu brachte, sich als freie Lohnarbeiter zu verdingen. Angestrebt wurde eine Klassen-Subjektivität, von $»$ respectable working people ${ }^{617}$, das sich als frei betrachtete und von sich behauptete, über die eigene Hände-Arbeit seine Existenz sichern zu können. Es lassen sich inhaltliche Parallelen zu dem aufmachen, was Foucault in Wahnsinn und Gesellschaft beschrieben hat: Dort zeigte er den Wandel des >Wahnsinns als etwas gegenüber der Vernunft Schweigendes, Negatives zum positiven Gegenstand des Wissens und der Wissenschaft. ${ }^{618}$ So ähnlich wurde im Laufe des 19. Jahrhunderts das Ideal einer >proletarischen Subjektivität< entdeckt und zum Adressaten verschiedener Politiken. Die Reform der Armengesetze 1834 wurde von dem Anliegen begleitet, die Armen und die Arbeiterklasse durch bestimmte Mechanismen genau zu dem Subjekt zu machen, welches die liberale Gouvernementalität als $>\operatorname{Re}-$ gierung der Wirklichkeit< und Materialität schlechthin als ihre Bedingung setzen muss. Zunächst einmal bedeutet die Umwandlung der Arbeiter oder der Armen als das Andere - als >Nicht-Subjekte< gegenüber der Subjektkonstruktion der bürgerliche Klasse - in einen eigenen positiven Gegenstand, die Ansammlung von Wissen und die Aufspaltung in unterschiedliche Formen, die nach dem Muster der wahren und der beschädigten proletarischen Subjektivität unterschieden werden konnten.

Nachdem das Armengesetz verändert wurde, schrieben die Poor Law Commissioners in ihren jährlichen Berichten über die Ergebnisse und die Verbesserungen im Verhalten der Arbeiter in Folge der Gesetzesänderung. ${ }^{619}$ Die Commissioners berichteten Chadwick von den >positiven Effekten $<$ auf die Moral, die Disziplin und die Arbeitswilligkeit der Arbeiterklasse: »the moral effect which has been developed by their operation upon the labouring classes ${ }^{620}$ und $»$ in favour of the rate-payers, by diminishing the burden of the poor-rates $\ll^{621}$.

Chadwick, der vor seiner Arbeit für die Poor Law Commission Sekretär von Jeremy Bentham gewesen war, bemerkte den Einfluss der sanitären Bedingungen und die Lebensbedingungen auf die Subjektivität der Arbeiter, ihre tatsächliche physische Leistungsfähigkeit und das Risiko der Pauperisierung erst, nachdem der Plan, der

\section{Ebd.}

616 Ebd., vgl. auch S. 140.

617 Ebd.: S. 138.

618 Vgl. Foucault: Wahnsinn und Gesellschaft, 1992 [1973]: S. 172.

$619 »$ The second class of paupers (namely, the able-bodied paupers)« Chadwick, E.: Suggestions as to the most eligible Modes of providing Out-door Employment for Able-bodied Paupers, in Cases where there is not an efficient Workhouse, and preparatory to the Establishment of the Workhouse System, 1836 [1835]: S. 46. Vgl. auch S. 45, 48.

620 Hawley [Assistant Poor Law Commissioner: Report as to the Operation and effects of the Poor Law Amendment Act, in the County of Sussex, 1836: S. 214.

621 Ebd.: S. 215. Vgl. auch S. 224, 226, 229. 
Pauperisierung durch die Reform der Poor Laws entgegenzuwirken, nur bedingt wirksam geworden war. ${ }^{622}$ In dem Bericht, den Chadwick 1842 verfasste und der den Anstoß für die Verabschiedung des Public Health Act gab, zeugt von dieser Verschiebung in Chadwicks Perspektive. Er stellt aber auch die Verbindung zwischen den Zielen einer liberalen Reform der Armengesetze, ein bestimmtes Subjekt des Arbeiters zu produzieren, und den etwas später einsetzenden, auf die Arbeiterklasse gerichteten gesundheitspolitischen Maßnahmen und sanitären Reformen her. Das Ziel der Verbesserung der gesundheitlichen Lebensbedingungen der Arbeiterklasse musste als Voraussetzung für die Herstellung einer bestimmten Klasse von Arbeiter gesehen werden und musste folglich technisch so umgesetzt werden, dass es diese gewünschte Subjektivierung ebenfalls befördern sollte oder zumindest ihr keinen Schaden zufügen würde. Nachdem Chadwick also in dem Report on the Sanitary Conditions of the Labouring Population of Great Britain alle lokalen und allgemeinen Gründe für die erhöhte Sterblichkeit in der Arbeiterklasse in Folge von Krankheiten und in bestimmten Distrikten aus den Berichten der Poor Law Commissioners extrahiert hatte ${ }^{623}$, enthielt der Bericht auch Informationen über die Verhaltens- und Lebensweisen der Arbeiter und deren Verbindung mit dem sanitären Zuständen in den Wohnungen und den Arbeitsstätten der Arbeiterklasse. ${ }^{624}$ Indem Chadwick u.a. auf das Problem der Chiffonniers, der Müllsammler von Paris verwies, behauptete er, eine Gesetzmäßigkeit zwischen der Ansammlung von Abfällen aufgrund von Nachlässigkeit bei der Beseitigung durch die Stadtverwaltung und Polizei und der Entstehung einer spezifischen unmoralischen und gefährlichen Klasse erkennen zu können. ${ }^{625}$

»These degraded creatures are also found amongst the inmates of the workhouses, and the close identity of their habits with those of the chiffonniers of Paris afford a striking proof of the simi-

622 »Edwin Chadwick, a barrister who had been secretary to the utilitarian philosopher Jeremy Bentham, was instrumental in designing the New Poor Law of 1834. His initial goal was efficiency, seeking both to centralize the response to poverty and to create systems that discouraged pauperism and to reduce the total state expenditures «: Johanson/Brody/ Paneth/Rachman/Rip: Cholera, Chloroform, and the Science of Medicine, 2003: S. 171.

$623 »[\mathrm{M}]$ ost powerfully influenced by the physical circumstances under which the population is placed - as the external and internal condition of their dwellings, drainage, and ventilation.« (Chadwick, E.: Report on the Sanitary Conditions of the Labouring Population of Great Britain, 1842: S. 1.) »[A]tmospheric impurity, [...], more or less sufficient drainage of houses, streets, roads, and land, combined with more or less sufficient means of cleansing and removing solid refuse and impurities, [...] overcrowding the places of work and dwellings, including the effects of the defective ventilation of dwelling-houses, and of places of work where there are fumes or dust produced.« Ebd.: S. 4.

624 Ebd.: S. $98 f f$.

625 Chadwick zitierte hierfür einen Augenzeugen: »The bone-pickers are the dirtiest of all the inmates of our workhouse; [...] I have not observed that these creatures were savage, but they were thoroughly debased. Often hardly human in appearance, they had neither human tastes nor sympathies, nor even human sensations, for they revelled in the filth which is grateful to dogs, and other lower animals, and which to our apprehension is redolent only of nausea and abomination «.«: Ebd.: S. 95. 
larity of the population produced by similarity of circumstances. [...] It is not these unfortunate creatures only who choose this centre of disease for their living-place who are affected; but the whole town is more or less deteriorated by its vicinity to this pestilential mass, where the generation of those elements of disease and death is constantly going on. $\ll^{626}$

Um zu verhindern, dass sich in einer Stadt eine solche in vielerlei Hinsicht >gefährliche< Klasse entwickelte, müsse also auf allgemeine Weise und mit Hilfe von Gesetzen für die Beseitigung von Abfällen und für Sauberkeit gesorgt werden. Kein Armengesetz könne in Abwesenheit von Gesetzen, die diesen Bedingungen entgegenwirken, erfolgreich sein. ${ }^{627}$ Ebenso könne, laut Chadwicks Untersuchungen, ein erheblicher ökonomischer und sozialer Gewinn aus anderen präventiven Gesundheitsmaßnahmen gezogen werden, wie er u.a. mit der folgenden Wirkungskette begründet:

»The frequency of cases of early deaths, and orphanage, and widowhood amongst one class of labourers, the journeymen tailors, led me to make some inquiries as to the causes affecting them; and I submit the following evidence for peculiar consideration, as an illustration of the operation of one predominant cause; - bad ventilation or overcrowding, and the consequences on the moral habits, the loss of healthful existence and happiness to the labourer, the loss of profit to the employer, and of produce to the community, and the loss in expenditure for the relief of the destitution, which original cause (the bad ventilation) we have high scientific authority for stating to be easily and economically controllable. « ${ }^{628}$

Immer wieder bekräftigte Chadwick in seinem Bericht, dass sanitäre Maßnahmen zur Prävention von Krankheiten und krankheitsbedingter Sterblichkeit unter den Arbeitern um ein vielfaches günstiger seien, als die Folgen der Krankheiten und die Entstehung von Weisen, Witwen und (non-able-bodied) Paupern abzufedern. Wie auch später in dem Bericht von Sutherland über die Choleraepidemie, betont er nachdrücklich, dass es sich hier um verhältnismäßig einfach zu behebende Probleme handelte. Im Rahmen dieses Diskurses sollten die politischen Techniken - die Sicherheitstechniken -, die von der Regierung im Bereich der Gesundheit und vor allem zum Schutz vor Epidemien eingesetzt wurden, ab den 1850er Jahren auch von einer deutlicheren Differenzierung zwischen armen Arbeitern und Paupern abhängen. In der Diskussion um die Prävention von Epidemien bildeten die Gewohnheiten und die Lebensweise der Arbeiterklasse den Exponenten der äußeren Faktoren, die gemeinsam die Entwicklung einer Epidemie und die Festsetzung der Cholera an einem Ort begünstigen. ${ }^{629}$ Die Regierung müsse sich also darauf konzentrieren, den Arbeitern beizubringen, welche der Umstände unter denen sie leben, welche ihrer Angewohnheiten und Lebensweisen gegen ihr persönliches Interesse, gesund zu sein oder auch nur zu

626 Ebd.: S. 95f.

627 Vgl. ebd.: S. 96.

628 Ebd.: S. 98.

629 Vgl. Baly: Report on the cause and diffusion of the epidemic cholera 1854: In: Baly/Gull: Reports on epidemic cholera drawn up a the desire of the Cholera Committee of the Royal College of Physicians, 1854: S. 11. 
überleben, verstoße. Allerdings stehe dem im Wege, dass die Bedingungen unter denen die Arbeiterklasse und die Armen gemeinhin lebten, bereits negativ auf deren Trieb und Willen zu überleben wirke. Anstatt sich also der Ruhe und Gelassenheit zu erfreuen, von der man in Frankreich und Deutschland teilweise sogar überzeugt war, dass sie ein Schutzmittel gegen die Cholera sei, ist die Teilnahmslosigkeit und Passivität, mit der die Arbeiter ihrem Schicksal entgegen sehen, in der Logik der liberalen Regierungspraxis ein absolutes Hindernis.

»It must further be borne in mind that the principal sufferers from epidemic cholera belong to a class whose habits of life are peculiarly calculated to render them unwilling to anticipate misfortune. They may, perhaps, be taught that the filth, intemperance, and wretchedness in the midst of which they so generally live, render them peculiarly susceptible to the worst forms of any prevalent pestilence; but unfortunately that which is the source of their danger is also the cause of their apathy. The trials which fill their thoughts are those of the day and of the hour. The pressing necessity of struggling with actual suffering begets generally a reckless indifference to merely contingent evils; and thus it has been found that even when cholera is raging in an overcrowded alley or filthy undrained court, the poor inhabitants, neglecting the commencement of the disease (which it must be recollected is without pain), rarely apply for medical aid until the disease has reached that stage when medicine is all but unavailing. « ${ }^{630}$

Ebenso, wie die Regierung von der Epidemie und aus der Beobachtung ihres Verhaltens die Gesetze erlernen soll, nach denen sie wirkt und entsprechende sanitäre Verbesserungen veranlassen muss, so muss auch jeder Einzelne lernen, von welchen natürlichen Gesetzen sein Überleben abhängt und beginnen, strategisch nach diesen zu handeln. Alle Freiheit, die man den Subjekten scheinbar oder auch in Wirklichkeit überließ, diente diesem Erkenntnisprozess. Deshalb hat man sich so viele Gedanken darum gemacht, welche Art von Präventionsmaßnahmen z.B. gegen die Cholera diese Art von Bewusstseinsbildung, diese Art von Selbstregierung bei den Arbeitern verderben könnte. Deshalb hat man bei der Regierung der Gesundheit der Bevölkerung einen großen Umweg ums Subjekt gemacht und dieses ganze Spektrum an Sicherheitstechniken entwickelt, die nur die Funktion einer allgemeinen Sicherung hatten und die der Schaffung von Rahmenbedingungen dienten, in denen die Menschen diese bestimmte Form von Subjektivität entfalten sollten. Denn der weit größte Teil der Maßnahmen bestand in allgemeinen Verbesserung der Häuser, Wohnungen und Straßen, der Abwassersysteme und der Trinkwasserversorgung.

\section{Die Folgen der sanitären Politik}

John Snow vertrat die Theorie einer Aufnahme des Cholerakeims über den Mund, v.a. durch verunreinigtes Wasser. Damit befand er sich 1848 in Großbritannien in Opposition zu der zu dieser Zeit gerade zur Durchsetzung gekommenen und von den Sanitaristen bevorzugten eher lokalistischen Doktrin. Angesichts dessen wagte Snow die Veröffentlichung seiner Thesen, mit denen er grundsätzlich den Ansätzen der

630 Hall, B.: Introduction to the local authorities on preventive measures in relation to epidemic cholera, under the Nuisance Removal Acts: in: Letter of the President of the General Board of Health, 1855 [1854]: S. 75f. 
Kontagionisten näher stand, vorerst nicht. Erst als ihm im August 1849 zwei lokale Ausbrüche der Cholera nahe der Themse mehr praktische Beweise für den Zusammenhang der Ausbrüche mit der dortigen Trinkwasserversorgung lieferten, schienen ihm seine Ergebnisse empirisch belegbar genug. ${ }^{631}$

Das Interessante an dieser Veröffentlichung ist, dass man in ihr eine gewisse Taktik Snows erkennen kann. Er versuchte seine Thesen so zu äußern, dass sie sich im Sinne der hegemonialen Regierungslogik verwenden lassen würden. Das Angebot, das Snow also machte, war zu sagen: >Die medizinischen Erkenntnisse über die Ursachen der Cholera stehen nicht gegen Eure politische Praxis, sondern untermauern sie noch viel mehr als die Theorien eines Miasmas oder über atmosphärische Ursachen der Krankheit. Meine Theorie wird eine Regierung, die das Ziel hat, die Gesundheit der Bevölkerung zu sichern, viel effektiver und handlungsfähiger machen.く

»Die Uebertragbarkeit der Cholera muss nicht in der Idee, ihre Kenntnis würde panischen Schrecken verursachen, oder Veranlassung zum Verlassen der Kranken geben, dem Volke verhehlt werden. [...] [D]ie Wahrheit aber, dass man die Cholera als eine übertragbare Krankheit ansehen müsse, der man durch wenige einfache Vorsichtsmaassregeln ausweichen könne, ist eine viel weniger entmutigende Lehre, als die, welche annimmt, sie hänge von irgendeinem mysteriösen Zustande der Atmosphäre ab, in die wir alle eingetaucht und die einzuathmen wir gezwungen sind. $\ll^{632}$

Im Unterschied zu den Kontagionisten favorisierte Snow als Mittel gegen die Verbreitung der Cholera keine Sperren, keine Isolation oder Quarantäne, sondern Versorgung mit sauberem Trinkwasser, Handhygiene und allgemeine Sauberkeit, ebenso wie es mehr oder weniger die Lokalisten und Anhänger der Miasma-Theorie vertraten. Sogar der Arzt David D. Cunningham, der entschieden gegen jede - auch gegen Snows - Theorie der Übertragbarkeit der Krankheit eintrat, hatte wenig Gründe dessen Theorie zu kritisieren. Im Gegenteil, strategisch musste er sie sogar befürworten, da sie zu der gleichen Konsequenz führte, nämlich sanitären Verbesserungen an Stelle von Quarantäne. ${ }^{63}$ Von Seiten des General Board of Health zeigte man sich dementsprechend gelassen und beinahe mit einer gewissen Gleichgültigkeit, die man gegenüber allen Auseinandersetzungen innerhalb der Medizin um die genauen Ursachen der Cholera entwickelt hatte. ${ }^{634}$ »But whether the one or the other channel is

631 Vgl. Johanson/Brody/Paneth/Rachman/Rip: Cholera, Chloroform, and the Science of Medicine, 2003: S. 202.

632 Snow, J.: Verbreitungsweise der Cholera, 1855 [1854] [Assmann, A.F.W. Übers. u. Hrsg. der deutschen Ausgabe], 1856: S. 128.

633 Cuningham, J.M.: Die Cholera. Was kann der Staat thun, sie zu verhüten?, 1885: S. 62ff.

634 Diese Haltung, sich nur noch in statistischer Hinsicht und nicht mehr in medizinischer den Ursachen der Krankheit zuzuwenden, wurde vom College of Physicians kritisiert. Vgl: Begbie, J.W.: Art. VI.- On the Facts and Opinions recently recorded in regard to Asiatic Cholera.: EMSJ, 81.1854, S. 502 - 523: S. 507. 
that by which the poisonous effects are produced, seemed thus far to be a question of little importance. $\ll 35$

Snow forderte exakte statistische Daten über die Trinkwasserversorgung der Distrikte und Haushalte in London. ${ }^{636}$ Überhaupt blieb er mit seiner Theorie und seinen Vorschlägen gegen die Cholera ganz in den Grenzen der dominierenden politischen Rationalität, die auf präventive, kostengünstige, effektive und relative Maßnahmen setzte, die weder den Verkehr und Handel noch die Individuen durch repressive Politiken in der Entwicklung einer entsprechenden unabhängigen Subjektivität einschränken sollte. Dies nahm auch William Baly in seinem Bericht zur Kenntnis. ${ }^{637}$ Die allgemeine epidemiologische Sichtweise der Regierung ermöglichte es, eine offene und grundsätzlich integrative Haltung im Hinblick auf neue Theorien und Erklärungen für die Cholera in ihre Praxis und ihre Rationalität aufzunehmen, ohne eine abschlieBende Entscheidung über deren Wahrheitsgehalt zu treffen. Im Grunde konnte jede Form des Wissens, jede Perspektive auf den Gegenstand, die auch nur in geringstem Maße eine Chance bot, nützliches Wissen zu dessen Regierung zur Verfügung zu stellen, ohne Probleme aufgenommen werden.

»This theory, as a whole, then, is untenable. It has, however, directed attention to circumstances which may be hereafter shown to bear a part in the production or increase of this as well as other epidemics; and the inquiries it suggests must not be neglected when the causes and mode of propagation of such diseases are again made the subject of investigation. « ${ }^{638}$

Mit den populärer gewordenen Thesen des britischen Arztes John Snow verschob sich der Fokus etwas mehr auf die Versorgung mit sauberem Trinkwasser und den Bau eines vom Trinkwasserzugang getrennten Abwassersystems. ${ }^{639}$ Zwar waren die Thesen von Snow zu diesem Zeitpunkt unter den Medizinern in Großbritannien noch höchst umstritten, aber die Einbeziehung seiner Erkenntnisse stellte für die Regierung und das Medical Council keine besonderen Schwierigkeiten dar:

635 Baly: Report on the cause and diffusion of the epidemic cholera 1854: In: Baly/Gull: Reports on epidemic cholera drawn up at the desire of the Cholera Committee of the Royal College of Physicians, 1854: S. 191.

636 Vgl. Johanson/Brody/Paneth/Rachman/Rip: Cholera, Chloroform, and the Science of Medicine, 2003: S. 210.

637 Vgl. Baly: Report on the cause and diffusion of the epidemic cholera 1854: In: Baly/Gull: Reports on epidemic cholera drawn up a the desire of the Cholera Committee of the Royal College of Physicians, 1854: S. 197.

638 Ebd.: S. 213.

$639 \mathrm{Vgl}$. »That a certain connexion exists between the use of impure water and the spread of pestilential disease is a circumstance that has been observed from the earliest times, and during the epidemic of 1848 - 49 it was found that the use of such water led in some instances to severe and fatal outbreaks of cholera. In the report of the General Board of Health on that epidemic a number of carefully observed cases of this kind are given.«: Sutherland, J.: Report: in: Letter of the President of the General Board of Health, 1855 [1854]: S. 39. 
»The matter in dispute is really of no great practical value, for if it be a fact that the use of impure water is dangerous to the public health, the manner of its action is of very secondary importance, at least for practical purposes. $\ll^{640}$

Trotz aller in der Medizin weiter fortschreitenden Uneinigkeiten und Auseinandersetzungen über die Cholera und ihre Ursachen, entwickelte sich im Bereich der Public Health ein gewisses Selbstbewusstsein. Kannte man auch nicht die genauen Ursachen, so doch die Bedingungen für das Auftreten der Cholera, wie der Epidemien allgemein. »The chief causes which have localized epidemic cholera during the late and previous epidemics are known and removable. ${ }^{641}$

Der Erfolg und die Handlungsfähigkeit der Regierung, die allgemeine Praktikabilität, Effektivität der Maßnahmen stand über dem Problem ihrer medizinischen Erklärung.

Mit dem Nuisances Removal and Diseases Prevention Act wurde nach 1849 den lokalen Boards mehr Handlungsfähigkeit verschafft, um sanitäre Maßnahmen umzusetzen. ${ }^{642}$ Ein Medical Council wurde in beratender Funktion eingesetzt, dass im Wesentlichen die Aufgabe hatte, die Regierung in wissenschaftlicher Hinsicht zu unterstützen und zu beraten. Seine Funktion, Wissen über den Gegenstand der Regierung zur Verfügung zu stellen, die sich im Sinne der Sanitaristen auf die Gesundheit der Bevölkerung richtete, erforderte notgedrungen eine wesentlich breitere Ausrichtung.

$»[\mathrm{~A}]$ wider field will be opened to this department and to the professional advisers [...]. The circumstances of this country, its wealth and poverty, its great cities with their social extremes of luxury and privation, its aggregation of individuals on the same spots, its multifarious industrial occupations, all point to the duty of studying the effects on life and health of trades, callings and processes, habitations, sites, water supply, sewerage, the adulteration of substances used for food, drink, and medicine, as matters vitally affecting the well-being of the nation. $\ll^{643}$

Unter Einbeziehung des Council veröffentlichte und versandte das General Board of Health Rundschreiben an die Local Boards, die Instruktionen über die Präventiven Maßnahmen enthielten. ${ }^{644}$

Die nächste und letzte Choleraepidemie ereignete sich in Großbritannien in den Jahren 1866/67. Danach erlebte Großbritannien im Gegensatz zu Deutschland und

640 Ebd.: S. 40.

641 Ebd.: S. 71.

642 Sutherland, J.: Report: in: Letter of the President of the General Board of Health, 1855 [1854]: S. 19.

643 Hall, B.: 2. Letter, General Board of Health, 6. September 1854: in: Letter of the President of the General Board of Health, 1855 [1854]: S. 11.

644 »The instructions here given contain ample information as to the manner in which the preventive measures in general, and the house-to-house visitation in particular, may be best conducted, and as to the machinery by which it may be most successfully worked.«: Hall, B.: Introduction to the local authorities on preventive measures in relation to epidemic cholera, under the Nuisance Removal Acts: in: Letter of the President of the General Board of Health, 1855 [1854]: S. 76. 
Frankreich nie wieder einen epidemischen Ausbruch der Cholera. ${ }^{645} \mathrm{Zu}$ dieser Zeit spielte es schon fast keine Rolle mehr, ob man an die Übertragung der Cholera durch den Menschen glaubte oder nicht. Die meisten Ärzte in Großbritannien folgten mehr oder weniger der These von Snow und anderer europäischer Ärzte, dass die Ausscheidungen (discharges) der Cholerakranken den Keim der Krankheit enthielten und dieser auf verschiedenen Wegen, u.a. über das Wasser, transportierte werden könnte. In dieser Weise wendeten sich die britischen Ärzte erneut von der indischen Ärzteschaft ab, die zum allergrößten Teil wieder oder weiterhin einen rein lokalistischen Standpunkt vertrat. Was sich allerdings nicht änderte, war die Überzeugung, dass das sicherste und vernünftigste Vorgehen gegen die Cholera in den allgemeinen sanitären Verbesserungen, dem Ausbau des Abwassersystems, der Trinkwasserversorgung usw. bestand. ${ }^{646}$ Die Möglichkeit dieser Trennung lag in einer sich allgemeiner vollziehenden Trennung von medizinischer, diätetischer und epidemiologischer Perspektive auf Krankheiten, sie bildete eine der wichtigsten Bedingungen des Public Health-Ansatzes der Regierung. Was die Berichte über die epidemische Cholera auszeichnete, waren nicht die medizinisch-pathologischen Beschreibungen. An die Stelle solcher Darstellungen und an die Stelle von Texten, die im Jargon des ärztlichen Rats geschrieben wurden, rückten Statistiken, Karten und Datensammlungen. Im Vordergrund der epidemiologischen und ätiologischen Perspektive, mit der man die Cholera zu begreifen versuchte, stand die Frage nach der Möglichkeit, sie mit möglichst einfachen und effektiven Techniken der Prävention in den Griff zu bekommen.

645 »Since 1866, cholera, though more than once brought to our shores - as during the European epidemics of $1871-74$ and $1884-87$ - has never succeeded in establishing itself in our midst, a result which is no doubt due to the steady removal from amongst the people of those insanitary conditions which are essential to its epidemic spread, and to the increasing security afforded by those measures of imperial and local sanitary administration by which it is sought to diminish sickness and mortality from all preventable diseases including cholera «: Thorne, Richard Thorne: On the Progress of Preventive Medicine During the Victorian Era. Inaugural Address of Session 1887 - 88, November 9th, 1887: in: TES.2s, 7.1889, S. 1 - 46: S. 44.

646 Vgl. Buchanan, George: Memorandum concerning the cholera, 4. Juli 1883: in: TES.2s, 2.1883, S. $99-102$. 



\section{Die Internationalen Gesundheitskonferenzen $1851-1903$}

Die Erfahrung mit der Cholera knüpfte an kollektive Erinnerungen und Interpretationen der Pest-Epidemien an, die noch bis ins 18. Jahrhundert hinein in Europa aufgetreten waren. Nur, dass die Cholera nun zu einem Zeitpunkt ausbrach, zu dem sich die (außen)politischen und wissenschaftlichen Bedingungen anders darstellten. Die fortschreitende Herausbildung neuer - gouvernementaler - Rationalitäten und Verfahren, durch welche sich die Regierung über ihre Sorge um das Leben (der Bevölkerung) zu definieren versuchte, machte das »Große Sterben $\aleph^{1}$ zu einem Katalysator für die Auseinandersetzung um vernünftiges Regieren in Europa. Es ist bemerkenswert, wie die Cholera sehr schnell als ein Problem behandelt wurde, das nicht anders als über nationale Grenzen und nationale Einflussbereiche hinweg behandelt werden könnte. Nach der Pest war sie vielleicht die erste Epidemie, die als globales politisches Problem wahrgenommen wurde, nur, dass die alten juridischen Bestimmungen für die internationale politische Praxis mit ihr deutlicher zur Disposition standen. Zwischen 1851 und 1903 fanden in Paris, Istanbul/Konstantinopel, Wien, Washington, Rom, Dresden und Venedig elf Internationale Gesundheitskonferenzen statt. Die Choleraepidemien in Europa waren sowohl Anlass für die Konferenzen, als auch zentrales Thema der Verhandlungen. Die Delegationen bestanden in der Regel aus Diplomaten und Wissenschaftlern, was eine absolute Neuheit war. Jahrhundertelang war die Diplomatie einer kleinen politischen Elite vorbehalten gewesen. Unter den Wissenschaftlern befanden sich die Köpfe der europäischen wissenschaftlichlichen, Hygiene, Sanitären Politik, Epidemiologie und Bakteriologie. Zu ihnen zählten u.a. John Sutherland, Max Pettenkofer, Antoine Fauvel, Adrian Proust und David Cunningham.

Abhängig von den Interessen des einladenenen Staates und dem speziellen Thema, wurden unterschiedliche Mächte eingeladen, Delegierte zu den Konferenzen zu entsenden. ${ }^{2}$ Ziel der Konferenzen sollte sein, verschiedene Regelungen an Grenzen,

1 Dies entsprach laut Max Pettekofer der Bezeichnung »mahämäri« für die Cholera im Sanskrit: Vgl. Pettenkofer: Die Verbreitungsart der Cholera in Indien, 1871: S. 8.

2 Ich habe mich dazu entschieden, keine Listen oder Tabellen der Delegierten und jeweiligen Staaten zu erstellen, die an den von mir analysierten ersten elf ISCs teilnahmen. Häufig nahmen Delegierte nicht an allen Sitzungen teil. Eine völlige Transparenz über die jeweili- 
Häfen und für den Handel in einem gemeinsamen Vertrag der teilnehmenden Mächte festzuhalten. Auf den Konferenzen 1851 und 1859 in Paris, 1866 in Konstantinopel, 1874 in Wien und 1881 in Washington entwarfen die Delegierten Vorschläge für ein solches Abkommen, dass dann von den Regierungen ratifiziert werden sollte, was jedoch nie geschah. Erst auf der 6. Konferenz 1885 besaßen die Delegierten ein politisches Mandat und waren zur Unterzeichnung eines Abkommens bereichtigt. ${ }^{3}$

In der derzeitigen Forschung $\mathrm{zu}$ den Internationalen Gesundheitskonferenzen werden aus diesem Grund die ersten sechs der insgesamt 14 Konferenzen zwischen 1851 und 1938 in der Regel als >erfolglos< angesehen. Das Scheitern der Konferenzen wird in der einschlägigen Forschungsliteratur damit erklärt, dass bis Anfang der 1880er Jahre keine Klarheit über die Ursachen der Cholera bestand und daher auch keine Einigung über geeignete Maßnahmen gegen die Cholera und andere epidemische Krankheiten getroffen werden konnten. Angeblich hätten sich die Teilnehmer der Konferenzen, gespalten in ein kontagionistisches und ein anti-kontagionistisches Lager, kaum einigen können. ${ }^{4}$

Ich möchte im Folgenden dagegen mit der These argumentieren, dass besonders die ersten sechs Konferenzen, mit Ausnahme der zweiten ${ }^{5}$, mit Blick auf die Schaffung einer gemeinsamen Rationalität und Identität von Regierung im Bereich Gesundheitspolitik und Seuchenbekämpfung als durchaus erfolgreich bewertet werden können. Die hier gemeinsam diskursiv produzierte Rationalität und die mit ihr verbundenen Bedingungen der Akzeptierbarkeit einer Regierung beförderten ein spezifisches und zunehmend geteiltes Selbstbewusstsein von guter Regierung. Dieser Prozess bildete schließlich die Grundlage der späteren Kommunikation und Einigung der Delegierten auf den darauf folgenden Konferenzen.

gen Teilnehmer der von mir untersuchten Diskussionen herzustellen, schien mir für meine Forschung zu unwichtig. Die Listen mit den Delegierten befinden sich auf den ersten Seiten der Protokollbände und noch einmal zu Beginn der einzelnen Sitzungsprotokolle. Diese sind über das Open Collection Program der Harvard Universität leicht online einzusehen. Vgl. Open Collections Program: Contagion, International Sanitary Conferences: http://ocp. hul.harvard.edu/contagion/sanitaryconferences.html (08. November 2016).

3 CSI-6, 1885, Protocole $\mathrm{N}^{\circ} 1$ : S. 5. Allerdings führte dies 1885 noch dazu, dass zum Ende der Konferenz die Sitzung für die Unterschriftengebung auf einen unbestimmten Zeitpunkt verschoben wurde. Die Delegierten meinten, sie bräuchten Zeit, um sich mit ihren Regierungen abzusprechen. Schließlich wurden die Unterschriften größtenteils überhaupt nicht mehr getätigt. Aber auf der Konferenz selbst wirkte das Mandat auf das politische Selbstbewusstsein der Delegierten und der ganzen Konferenz.

4 Vgl. Huber: The unification of the globe by disease?, 2006: S. 459. Baldwin: Contagion and the State in Europe 1830 - 1930, 1999: S. 190.

5 Die zweite Konferenz wurde einberufen, um schell einige Punkte zu klären, die angeblich auf der ersten Konferenz aufgrund zu langwieriger wissenschaftlicher Streitigkeiten nicht in einer sinnvollen Weise für die Entscheidungen der Regierungen vorbereitet werden konnten. Tatsächlich war die Konferenz aus meiner Sicht jedoch noch weniger produktiv, weil es nicht zu einer Stiftung gemeinsamer Identität und zu keiner Annährung in Fragen der Regierung der Cholera kam. Ich werde auf diesen Punkt später genauer eingehen. 
Die Subjektivität und ethische Existenz von Regierung wurden einerseits über das Verhältnis der Regierung zum Wissen und zur Wissenschaft und zum anderen über das Verhältnis zu den Regierten definiert. Die Aussagen, die sich auf dieses erste Verhältnis beziehen, erfüllten zwei unterschiedliche Funktionen: Erstens, die Funktion der Trennung des Wissens von der Macht und der Betonung der Unabhängigkeit des Wissens von der Macht. Damit soll belegt werden, dass eine Regierung, die sich auf dieses Wissen bezieht, eine äußere und nicht eine selbstgefällige Wahrheit zur Grundlage ihrer Rationalität bzw. ihrer Praxis macht. Für die Wissenschaft bedeutete dies andersherum, dass sie ihre Legitimität gerade dadurch erhält, dass sie es für eine Regierung möglich macht, sich auf sie zu beziehen - also, dass sie keine sog. >Elfenbeinturm-Wissenschaft< ist, sondern einen praktischen Nutzen und eine Anwendbarkeit ihrer Erkenntnisse für die Regierung ermöglicht. Zweitens, erfüllen die Aussagen die Funktion für die Regierung, sich über dieses Verhältnis zur Wissenschaft von einer >schlechten < Regierung abgrenzen zu können, die diesen Kriterien nicht gerecht wird, die also entweder willkürlich regiert, in erster Linie Machtinteressen verfolgt oder aus Unwissenheit und Ignoranz > ungerecht< und irrational agiert.

Bereits die Einstiegsdiskussionen der ersten Sitzungen der Konferenz von 1851/ $1852^{6}$ zeugen deutlich von einer Auseinandersetzung um diese gemeinsamen Bedingungen für >gutes< Regieren und das >richtiges< Verhältnis von Regierung und Wissenschaft.

Auch in den Protokollen der späteren Konferenzen finden sich immer wieder verstreute Aussagen, die der Vergewisserung dieses Verhältnisses dienen.

Die Aussagen, die sich auf dieses zweite Verhältnis, das Verhältnis von Regierung und Regierten beziehen, tauchen ebenfalls bereits in den Protokollen der ersten Konferenzen auf. ${ }^{7}$ Eine deutliche Häufung und Verdichtung dieser Aussagen findet sich allerdings ab der dritten Konferenz 1866. Die Aussagen erfüllen zwei Funktionen: Erstens die der Vergewisserung des Selbstverständnisses einer guten Regierung, die die Gouvernementalität der Bevölkerung ist. Ihr Gegenstand ist das Leben der Bevölkerung selbst. Ihre Techniken richten sich auf die Sicherung dieses Lebens in einem sehr allgemeinen Sinn: Leben beinhaltet alles, was die Existenz einer Bevölkerung beziehungsweise einer Gesellschaft auf ihrem >derzeitigen Stand der sozialen Entwicklung< umfasst. Zweitens dienen die Aussagen dazu, über die Betonung oder

6 Die erste und längste Conférence Sanitaire Internationale, zu der die französische Regierung eingeladen hatte und die am 23. Juli 1851 in Paris eröffnet wurde, dauerte über achtundvierzig Sitzungen und über einen Zeitraum von sieben Monaten. Die letzte Sitzung fand am 19. Januar 1852 statt. Nicht mehr als 12 Delegationen nahmen an der Konferenz teil. Alle Teilnehmenden »Mächte« (puissances) waren mehr oder weniger aufgrund ihrer Lage am Mittelmeer oder ihrer Stellung im Welthandel mit dem Problem der Quarantäne und der Verbreitung der Cholera über die Schifffahrt konfrontiert und damit an der Problemstellung der Konferenz zumindest potenziell interessiert: Ziel war es, sich auf ein gemeinsames »système de quarantaines et des lazarets dans la Méditerranée« zu einigen. CSI1, 1852 [1851], Séance $\mathrm{N}^{\circ} 1$ : S. 1.

7 Vgl. z.B. Rapport à la Conférence sur les questions du programme et leur solution, fait au nom d'une Commission composée de MM. Bô, Betti, Costo et Mêlier, médecins, et de MM. Lavison, Perrier et Segovia, consuls: Annexe: CSI-1, 1852 [1851], Séance Nำ: S. 2. 
Abgrenzung der Subjektivität von Regierten, Kriterien für gute Regierung zu formulieren.

Es wird ein Zusammenhang zwischen der Lebensweise, den Werten und dem Grad der >Zivilisiertheit< oder >Modernität< einer Bevölkerung und den Anforderungen für eine bestimmte entsprechende Regierung hergestellt. Etwa gelten unter diesen Umständen bestimmte Techniken, die die Freiheit oder das Leben der Bevölkerung beschränken, als inakzeptablen, während die gleichen Techniken angesichts einer als >traditional< oder > vormodern< angesehenen Bevölkerung, legitim sein können. Mit anderen Worten: Die Möglichkeiten einer praktischen Verwirklichung gouvernementaler Rationalität durch eine Regierung hängen von der Annahme oder Verinnerlichung dieser Rationalität durch die Regierten ab.

Im Gegensatz zu den oben erwähnten Forschungen zeige ich, wie stark die Diskussionen der Konferenzen auf Fragen der Nützlichkeit und Anwendbarkeit eingeengt wurden. Wissenschaftliche und politische Diskussionen sollten teilweise sogar gänzlich ausgeklammert werden. So wurde etwa auch die Frage, ob die Cholera kontagiös sei oder nicht, immer wieder aus den Debatten der Konferenz verbannt. Konflikte auf den Konferenzen lassen sich daher kaum auf den Streit zwischen Kontagionisten und Anti-Kontagionisten zurückführen.

Stattdessen hoffe ich anhand verschiedener Diskussionen auf den Konferenzen veranschaulichen zu können, dass hier verschiedene Strategien den Anforderungen moderner Regierung gerecht zu werden, miteinander konkurrierten. Von diesen spezifischeren Rationalitäten des Regierens setzte sich schließlich die vor allem in Großbritannien herausgebildete liberale Strategie durch.

\section{Das VerhältNis Von Wissen, Wissenschaft UND REGIERUNG}

Die erste und längste Conférence Sanitaire Internationale (CSI) zu der die französische Regierung eingeladen hatte und die am 23. Juli 1851 in Paris eröffnet wurde, hatte mehr als achtundvierzig Sitzungen und dauerte sieben Monate. Die letzte Sitzung fand am 19. Januar 1852 statt. Nicht mehr als 12 Delegationen nahmen an der Konferenz teil. Bereits die Diskussionen um >reineく Formalitäten, wie Stimmrecht, Abstimmungsverfahren etc., genauso wie die schwammig wirkenden Reden über die hohen Ziele der Konferenzen, die $1851 \mathrm{mehr}$ als drei ganze Sitzungen füllten, waren überaus bedeutend hinsichtlich der erwähnten Aussagefunktionen - also für die Klärung eines bestimmten Verhältnisses der Regierung zum Wissen und zur Wissenschaft. Dazu gehört etwa die Diskussion um die Frage, ob die Delegierten einer Regierung je eine Stimme haben, oder ob alle Personen, die an der Konferenz teilnahmen mit ihrer eigenen Stimme gezählt werden sollten. ${ }^{8} \mathrm{Um}$ die Bedeutung der Diskussion richtig zu erfassen, muss bedacht werden, dass sich die Delegationen in der Regel aus einem diplomatischen und einem wissenschaftlichen Vertreter zusammensetzten. Der spanische Delegierte, Segovia, vertrat z.B. die Meinung, die Delegierten seien nur in ihrer Funktion als Delegierte und Vertreter eines Staates anwesend, jede 
Delegation, also jeder Staat, solle also nur eine einzige Stimme zählen: »[I]l n’y a rien d'individuel dans la mission des délégués. « Der toskanische Delegierte, Betti, erwiderte darauf, dass die Regierungen alle Freiheit besäßen, die Ergebnisse der Konferenz abzulehnen. Die Freiheit der einzelnen Mitglieder, vor allem der Wissenschaftler, nach ihrer eigenen Vernunft zu urteilen würde, so Betti, würden den Ergebnissen der Konferenz einen größeren Wert geben. ${ }^{9}$ Der sardische Delegierte, Magnetto, konstatierte daraufhin, wie wichtig es sei, dass die Klärung wissenschaftlicher Fragen auf der Konferenz die größtmögliche Unabhängigkeit von staatlichen Interessen gegeben werde.

»[L]a science est quelquefois en opposition avec l'administration publique, et qu'il en résulte que le commerce se trouve souvent gêné par des restrictions funestes. Il y a des pays, ajoute-til, où l'administration, en vue de faciliter les transactions commerciales, incline à se relâcher sur les précautions sanitaires conseillées par la science. Il y a d'autre pays où l'administration, trop influencée par des préjugés nationaux, sacrifice le commerce à des précautions sanitaires en contradiction avec mêmes de la science. C'est précisément dans le but de mettre un terme à ces contradictions que nos gouvernements respectives ont envoyer ici un représentant de l'élément scientifique et un représentant de l'élément administratif: les lumières des unes, l'expérience des autres, en se développant dans cette réunion, provoqueront, sans doute, quelques décisions favorables à la réforme qu'on poursuit. Pour arriver à cet éclaircissement mutuel, il est donc nécessaire que chacun parle et vote selon sa conscience. $\ll^{10}$

Der griechische Delegierte und Arzt Costi äußerte die Befürchtung, die Ärzte würden auf diese Weise zu viel Macht erhalten. ${ }^{11}$ Dem britischen Delegierten Sutherland gelang es zu schlichten, indem er die Frage stellte, wie eine Regierung oder eine Administration sich wirklich in Opposition zur Wissenschaft stellen könne? Denn auch wenn diese beiden unterschiedlichen Elemente anwesend seien, so seien diese doch in einem Ziel vereint. ${ }^{12}$ Perrier, der ebenfalls der britischen Delegation angehörte, war zunächst der Meinung seines Kollegen und erklärte: »[Si] la raison même que les gouvernements ont toute confiance dans leurs délégués [...] alors le vote pourra parfaitement avoir lieu par puissance. »Aber was, wenn nicht «,(?) - gab der französische Delegierte zu bedenken. ${ }^{13}$ Was, wenn einige Regierungen voller Vorurteile seien oder doch von (Macht-)Interessen beeinflusst? Wäre es dann nicht besser, eine Trennung vorzunehmen, damit die Entscheidungen auf der Konferenz nicht durch die Macht und Willkür einzelner Regierungen verfälscht werde? Die einzige Möglichkeit, die Souveränität der Regierungen anzuerkennen und gleichzeitig die Freiheit der Wissenschaft zu bewahren, bestünde in dieser Trennung. Die Konferenz entschied sich also »à une grande majorité « für ein individuelles Stimmrecht. ${ }^{14}$

9 Vgl. ebd.

10 Magnetto: ebd.: S. 5.

11 Vgl. ebd.

12 Vgl. ebd.

13 Vgl. ebd.

14 Ebd.: S. 6. 
Einer ähnlichen Logik folgt die Diskussion um geheime Wahlen, die später abgelehnt wurden. Damit privilegierte die erste Konferenz aber nur auf den ersten Blick eine für die Wissenschaft übliche Praxis des Wahrsprechens gegenüber einer diplomatischen Praxis der Einigung. ${ }^{15}$ Dieser Gegensatz stellte keinen Widerspruch dar, sondern bildete eine Konstellation, ein Verhältnis oder besser, eine Bewegung der gegenseitigen Reproduktion von rationaler Regierung und nützlicher Wissenschaft. Die Praxis des Wahrsprechens erfüllte eine wichtige Funktion für das Verfahren einer rationalen und damit moralischen Gouvernementalität.

Ein weites Ereignis auf der ersten Konferenz, dem ich für die Klärung des Verhältnisses von Regierung und Wissenschaft eine wichtige Bedeutung beimesse, bestand in der Einigung auf bestimmte Prinzipien des Diskutierens: Um überhaupt eine gemeinsame Konvention zu entwerfen, sahen viele Delegierte auf der ersten Konferenz 1851 zunächst die Notwendigkeit, sich auf bestimmte Prinzipien zu einigen. ${ }^{16}$ Die ersten beiden Prinzipien, die, von einer gesonderten Kommission vorbereitet, die Arbeit und die Diskussionen der Konferenz erleichtern sollten, beruhten auf dem Ausschluss politischer und wissenschaftlich-theoretischer Fragen. Beide hätten nichts zu tun mit dem Ziel der Konferenz, welches ausschließlich das der Gesundheit sei.

$»$ Sur $\mathrm{n}^{\circ} 1$, relatif aux questions politiques qui auraient pu se présenter sur notre chemin, nulle discussion ne s'est élevée, la commission entendant [...] la politique et tout ce qui s'y rapporte doit être soigneusement et expressément écarté de nos délibérations. Les motifs en sont trop évident pour avoir besoin d'être énoncés. La santé seule est notre objet; la santé seule doit nous occuper. $\ll^{17}$

»Il en a été de même du n 2 , relatif aux discussions scientifiques. Par cela même que la Conférence, toute pratique et l'application, a beaucoup moins pour but la recherche, si difficile d'ailleurs, d'une vérité absolue, que d'établir entre les nations intervenantes et leurs pratiques sanitaires diverses une sorte de transaction amiable, il a été convenu que les questions de science pure et de théorie seraient, autant que possible, évitées: non pas, certes, que l'on veuille dore par là que la science et ses dictions, ses observations et leurs résultats, ne doivent pas être considérés comme le meilleur guide à suivre en toutes choses: ce serait, dans notre bouche surtout, une véritable hérésie; nous voulons dire seulement que nous entendons éviter des discussions qui ne sauraient être leur place dans une semblable réunion et que comportent seules les réunions académiques. $\ll^{18}$

>Die Konferenz ist keine Akademie. Ihr Verhältnis zur Wissenschaft ist ein anderes. Sie ist nicht interessiert an Forschung und an einer absoluten Wahrheit. Sie ist interessiert an Praxis und an Anwendbarkeit. < So lautete der Tenor der Delegierten. Eher als um einen Wissensaustausch sollte es um einen Austausch hinsichtlich der Tech-

15 Vgl. CSI-1, 1852 [1851], Séance N4: S. 2.

16 Vgl. Segovia, ebd.: S. 4.

17 Rapport à la Conférence sur les questions du programme et leur solution, fait au nom d'une Commission composée de MM. Bô, Betti, Costo et Mêlier, médecins, et de MM. Lavison, Perrier et Segovia, consuls: Annexe: CSI-1, 1852 [1851], Séance Nำ: S. 5.

18 Vgl. ebd.: S. 5f. 
niken und Praxen gehen, um die Gesundheit auf internationaler Ebene zu regieren. ${ }^{19}$ Mit anderen Worten: Man einigte sich auf ein Verfahren der Regierung. Das ist das, was die Kommission vorschlägt. Es ging bei den Zielen der Konferenz um die Frage der Möglichkeiten der Praxis, um ein relatives Ergebnis, dass eine Praxis ermöglicht und die Regierungen ermächtigt. Das sind die Gründe, warum man die Verfahren der Wissenschaft nicht ausschließen konnte, aber in einer bestimmten Weise in ihrer Funktion beschränkte. Die Konferenz sollte ein bestimmtes Verfahren der Veridiktion und Kriterien für Wahrheit aus den wissenschaftlichen Disziplinen ausschließen, die im Widerspruch stehen könnten zu einer gouvernementalen Vernunft. Weil die Disziplin in ihrem begrenzten Bereich, den sie behandelte, nur eine Wahrheit gelten lassen konnte, weil sie nicht akzeptieren konnte, sich in einem vagen Feld von Wahrscheinlichkeiten, praktischen Möglichkeiten, Risiken und Gefahren und heterogener Faktoren zu bewegen, mussten die Fragen der Regierung, die Verfahren der Gouvernementalität vor ihr abgeschirmt werden. Dies war also der praktische und wirkungsvolle Mechanismus der ersten Konferenz: Die Konstruktion und Bestätigung der Bedingungen für eine gute Regierung, die Festigung der Anerkennung bestimmter Verfahren der Gouvernementalität, die eine Regierung akzeptierbar machen sollte.

Ein anderes Beispiel, dass verdeutlicht, wie Kriterien für gute Regierung auf den Konferenzen an ihrem Verhältnis zur Wissenschaft geknüpft wurden, lässt sich den Protokollen der dritten Konferenz entnehmen, die 1866 in Konstantinopel tagte. Sie gab den Startschuss für eine vor allem von Frankreich ausgehenden Initiative und für eine neue Strategie zur Verhinderung der >Einschleppung< der Cholera aus dem Osten. Maßnahmen an den innereuropäischen Grenzen sollten gelockert werden. Stattdessen sollten rigorosere, rationalere und v.a. effektivere Maßnahmen an den Grenzen Europas, an den geographischen Berührungspunkten von Europa und >Orient $<$ am Mittelmeer, wie auch am Herkunftsort der >choléra asiatique< ansetzen. Frankreich hatte seit der ersten Konferenz seine Position hinsichtlich der These zu den sog. foyers $^{20}$ der Cholera geändert und war nun davon überzeugt, dass die Choleraepidemien in den 40er und 50er Jahren des 19. Jahrhunderts von Indien aus über den >Orient $<$ (v.a. durch die Mekka-Pilger) nach Europa gelangt sei. ${ }^{21}$ Der britische Delegierte Goodeve bestritt diese These und behauptete, es gäbe zumindest in Russland und im vorderen >Orient< Orte, an denen die Cholera mittlerweile heimisch geworden sei und

19 Vgl. ebd.: S. 5f.

$20 »[\mathrm{~L}] \mathrm{a}$ Commission à propos des foyers originels de choléra: ১Sans s'enquérir, dit-elle, si la permanence est dûe à des conditions naturelles du sol et du climat, ou à des conditions artificielles créées par l'homme lui même, à des causes de genèse nouvelle et continuelle, ou simplement à des transmissions suivies de la maladie, elle considère tout simplement comme foyer originel chaque localité dans laquelle le choléra s'est établi en permanence. Par cette déclaration la Commission exclut, comme on le voit, la recherche des causes de cette permanence, c'est à dire le point capital à résoudre.«: CSI-3, 1866, Séance $N^{\circ} 24$ : S. 8.

21 Auf der ersten Konferenz 1951 hatte die französische Delegation noch die Aussage gestützt, dass die Cholera in Europa heimisch geworden sei, ihre Ausbrüche auf lokale Bedingungen zurückzuführen seien und die Möglichkeit der Einschleppung der Cholera daher keine große Rolle mehr spielte. 
von wo aus sich Epidemien in Europa ausgebreitet hätten. Goodeve verweigerte seine Unterschrift unter die betreffenden Protokolle der 1866er Konferenz. ${ }^{22}$ Eine Kommission zur Ausarbeitung einer Konvention schlug unter Einfluss der französischen Delegation vor, dass die Konferenz eine internationale Kommission zur Untersuchung der Cholera in Indien, wo die Krankheit endemisch war, entsenden sollte, um diese dort, an ihrem vermeintlichen Herkunftsort, zu untersuchen. ${ }^{23}$ Eine Kommission, die einen ausgewiesenen und ausschließlich wissenschaftlichen Charakter haben sollte: »donné le caractère exclusivement scientifique «. ${ }^{24}$ Der französische Delegierte, Monlau, legte ein »procès-verbal« der ersten Konferenz vor, auf welcher die Delegierten, auch die britische Delegation, im Prinzip zugestimmt hätten, eine solche Untersuchung in Indien durchführen zu lassen. ${ }^{25}$ Monlau fügte außerdem hinzu, man wolle keinerlei Vorurteile gelten lassen. Aber es sei speziell an den Mächten wie Großbritannien und anderen, die Besitzungen (possessions) auf dem indischen Subkontinent besäßen, für eine solche Kommission zu stimmen und zur Durchführung einer solchen Forschung (»études qui intéressent l'humanité entière «) beizutragen. ${ }^{26}$ Die britischen Delegierten der Konferenz von 1866, Stuart und Goodeve, lehnte die Bildung einer internationalen Kommission jedoch konsequent ab und bezeichneten diese als eine Bedrohung der Souveränität der britisch-indischen Regierungen, die völlig in der Lage sei und deren eigene Aufgabe es sei, eine solche Untersuchung durchzuführen. ${ }^{27}$ Stuart schlug daraufhin vor, den Antrag der französischen Delegation abzuändern und in einen unverbindlichen Aufruf an die betreffenden Regierungen umzuwandeln, solche Untersuchungen selbst durchzuführen. ${ }^{28}$ Die anderen Delegierten, vor allem Segovia (Spanien) und Monlau protestierten gegen die Haltung des britischen Delegierten. Eine rein wissenschaftliche Kommission als Angriff auf die Unabhängigkeit einer Regierung zu sehen, sei geradezu lächerlich. Andererseits waren sie auch der Meinung, dass die divergierenden Haltungen der Mächte und die Position Großbritanniens eine eigenmächtige objektive Untersuchung kaum erwarten ließen. Eine internationale Kommission dagegen sei wesentlich glaubwürdiger. ${ }^{29} \mathrm{Da}-$ von könne letztlich auch die britische Regierung profitieren, argumentierte Monlau. ${ }^{30}$

22 »M. Goodeve a signé sous réserve, inscrite au procès-verbal de la séance du 5. juillet, qu'il n'y a pas de preuves que le choléra ait été importé dans le Hedjaz, en 1865, par les pèlerins venant des Indes.«: CSI-3, 1866, Séance N²3: S. 51.

23 Vgl. § XX. [des Entwurfs] Commission de recherches scientifiques sur l'origine et la genèse du choléra dans les lieux que l'on croit être le berceau de cette maladie.: Annexe CSI-3, 1866, Séance $\mathrm{N}^{\circ} 11$.

24 Vgl. CSI-3, 1866, Séance N¹1: S. 13.

25 Vgl. ebd.: S. 13.

26 Vgl. ebd.: S. 14.

27 Vgl. ebd.: S. 13.

28 »>Appeler l'attention des Gouvernements respectifs des pays que l'on croit être le berceau du choléra, sur l'utilité d'entreprendre ou de continuer des recherches locales rigoureuses sur l'origine et la propagation de la maladie. Énumérer les questions dont la solution, ou une connaissance plus profonde est démontrée nécessaire par la science<.«: Ebd.: S. 13.

29 Vgl. ebd.

30 Vgl. ebd.: S. 14. 
Der Delegierte Segovia bekräftigte mit seiner Rede die Aussage: Die wahre Wissenschaft und das, was sie hervorbringt, müsse der Macht fern sein. Wenn sie der Macht nicht fern sei, bestehe die Gefahr, dass sie verfälscht und verdreht wird durch die Macht. Nichts sei allerdings dagegen einzuwenden, wenn sich eine Regierung dann auf dieses machtferne Wissen, diese Wahrheiten beziehe. Im Gegenteil, eine Regierung müsse sich auf dieses Wissen beziehen. Je macht-ferner das Wissen sei, desto besser, desto mehr könne eine Regierung legitimerweise tun. Auch die britische Regierung müsse sich im Prinzip dieser Logik beugen. Auch sie müsse sich im Prinzip wünschen, von der Wahrheit einer solchen unabhängigen Kommission profitieren zu können. Nicht, weil sie anders nicht die Wahrheit über die Cholera erfahren könne, sondern weil sie erst dann wirklich mächtig sei und ihre Macht von allen anerkannt werden würde, wenn sie sich nicht auf eine nationale Untersuchung, möglicherweise durch ihre eigene Macht verfälschte Wahrheit beziehen müsse. Eine Kommission im Dienste der Wissenschaft könne also keine Gefahr für die Macht und Souveränität einer rationalen Regierung darstellen. Nichtsdestotrotz stimmte Großbritannien gegen eine solche internationale wissenschaftliche Kommission. ${ }^{31}$ Der portugiesische Delegierte, Gomez, griff schließlich die Argumentation, die Segovia eingeleitet hatte, wieder auf, um sie allerdings positiv und zur Verteidigung der britischen Delegierten und indischen Regierungen zu wenden. Es mache keinen Sinn, wenn eine andere als die britische Regierung in Indien Untersuchungen durchführe. Die britische Regierung habe durch die Maßnahmen, die sie in Indien angewendet habe, schließlich bereits mehr als jede andere Regierung bewiesen, dass sie im Sinne der angeführten Bedingungen als eine gute Regierung handele. Man müsse ihren Recherchen also einen großen Wahrheitsgehalt beimessen. ${ }^{32}$ Hier zeigt sich ein für die Konferenzen sehr häufig wiederholendes Muster. Großbritannien war im Grunde in der Lage, alles Mögliche zu fordern, sich aber selbst von Bedingungen und Regelungen auszunehmen, indem seine und andere Delegierte auf die praktischen Erfolge der britischen Regierung verwiesen.

Auf der 6. Konferenz 1885, um ein weiteres Beispiel zu nennen, unternahm man noch einen weiteren Versuch, der Trennung von Wissenschaft und Regierung - oder auch Politik - zumindest institutionell zu gewährleisten. Ausgangspunkt dafür war die Tatsache, dass die Delegierten der Konferenz zum ersten Mal ein politisches Mandat besitzen sollten. Sie sollten also die Macht haben, durch ihre Unterschrift die Zustimmung ihrer Regierung zu den auf der Konferenz beschlossenen Reglements zu besiegeln. ${ }^{33}$ Die Konferenz hatte sich zum Ziel gesetzt, sich über den Ursprung und die Ursachen von Krankheiten - vor allem der Cholera - zu verständigen. Entgegen

31 Stuart: »Ils s'opposent seulement au projet d'y envoyer une commission internationale.«: Vgl. CSI-3, 1866, Séance $\mathrm{N}^{\circ} 12$ : S. 14.

32 Vgl. ebd.: S. 17.

33 CSI-6, 1885, Protocole $N^{\circ} 1$ : S. 5. Allerdings führte dies 1885 noch dazu, dass zum Ende der Konferenz die Sitzung für die Unterschriftengebung auf einen unbestimmten Zeitpunkt verschoben wurde. Die Delegierten meinten, sie bräuchten Zeit um sich mit ihren Regierungen abzusprechen. Schließlich wurden die Unterschriften größtenteils überhaupt nicht mehr getätigt. Aber auf der Konferenz selbst wirkte das Mandat auf das politische Selbstbewusstsein der Delegierten und der ganzen Konferenz. 
der Behauptung von Norman Howard-Jones ${ }^{34}$ kam es auf der Konferenz jedoch nicht zu einer Einsicht aller Delegierten über die wahre Ätiologie der Krankheit, welche dann eine Einigung über die Maßnahmen ermöglicht hätte. Die Konferenz 1885 blieb trotz dieser scheinbar wissenschaftlichen Fragestellung, ihrem auf Erfahrung, Praxis und Machbarkeit ausgerichteten Charakter treu. Wie auch schon auf den vorangegangenen Konferenzen wurde betont, dass es für Fachdiskussionen und vor allem solche, die rein theoretischen Charakter hätten, keinen Raum auf der Konferenz geben solle. ${ }^{35}$

Nicht nur aufgrund des Programms der Konferenz, sondern auch durch das politische Mandat der Delegierten und damit den offiziell politischen Charakter der Konferenzen, entstand das Bedürfnis, diesen Bereich der Politik von dem der Fachdiskussionen, die notwendig seien würden, zu trennen. Zum ersten Mal setzten die Teilnehmer der Konferenz eine entsprechende Kommission ein, die den allergrößten Teil der Diskussionen, Protokolle und Sitzungen ausmachen würden. ${ }^{36}$ Diese technische Kommission bestand ausschließlich aus wissenschaftlichen Vertretern, Medizinern, Hygienikern usw. Darüber hinaus war es keine Kommission, die lediglich aus einer Gruppe auf der Konferenz ernannter Teilnehmern bestand, sondern alle wissenschaftlichen Vertreter aller Delegationen gehörten automatisch dieser Kommission an. ${ }^{37}$ Die Diskussionen im Rahmen der »commission technique«, lassen darauf schließen, dass es auch hier darum ging, zwei unterschiedliche Verfahren der Akzeptierbarkeit einer Aussage im Umgang mit einem Problem voneinander zu trennen: Erstens gab es ein wissenschaftliches Verfahren der Veridiktion bezüglich der Akzeptierbarkeit einer Aussage als wahr, und zweitens das Verfahren der Gouvernementalität bezüglich der Akzeptierbarkeit der Ausübung von Macht, von der die Souveränität der Regierung abhing. In dem einen Bereich der Konferenz sollte nur die Frage nach der Wahrheit einer Aussage gelten, die man gemäß den Verfahren der Veridiktion wissenschaftlicher Disziplinen vorbringen und prüfen würde. In der regulären Sitzung, den »séance plénière « solle dagegen ein anderes Verfahren angewendet werden, das einer modernen Gouvernementalität. Hier sollte es um Kriterien für eine Regierung gehen, die sich auf ein heterogenes Feld von Kräften beziehen muss, die zwischen den technischen, praktischen Möglichkeiten der Umsetzung einer Maßnahme, den Interessen der Ökonomie und des Handels, der Zumutbarkeit bestimmter Maßnahmen für die Bevölkerung und den Gefahren einer Epidemie berechnen und abwägen muss.

34 Vgl. Howard-Jones: The scientific background of the International Sanitary Conferences 1851 - 1938, 1975: S. 55.

35 Vgl. CSI-6, 1885, Protocole $\mathrm{N}^{\circ} 1$ : S. 5.

36 Diese Trennung und Aufteilung verschiedener Diskussionen, politischer und fachlicher Art, wurde auf allen späteren Konferenzen fortgesetzt.

37 Allemagne: Koch, Eckard; Autriche-Hongrie: Hoffann, Grosz; Brésil: d'Azambuja; Danemark: Lehmann; États-Unis de l'Amérique du Nord: Sternberg; France: Brouardel, Rochard; Grande-Bretagne: Hunter, Thorne Thorne; Inde: Fayer, Lewis; Italie: Baccelli, Moleschott, Semmola, Buonomo; Japon: Nagi; Mexique: Hijar y Haro; Pays-Bas: Ruysch; Portugal: da Silva Amado; Roumanie: Obédénare; Russie: Eck; Suède et Norvège: Bergman, Dahl; Suisse: Sonderegger, Reali; Turquie: Zoéros Pascha. Vgl. CSI-6, 1885, ProcèsVerbaux, Commission Technique, $N^{\circ} 1$ : S. 84. 
Man könnte meinen, dass das Problem der Plenarsitzung nun darin bestand, den Bereich der diplomatischen und politischen Verhandlungen und Verfahren von dem wissenschaftlichen zu befreien, dass man durch die Trennung versuchte, den Diplomaten die ausladenden medizinischen Fachdiskussionen zu ersparen. Die technische Kommission sollte etwas ausarbeiten, feststellen, was wahr sei, damit im politischen Bereich dann auf der Grundlage dieser Wahrheit mit dem Abwägen und Errechnen der praktischen Folgen bestimmter Politiken ungestört begonnen werden konnte. Ich bezweifle nicht, dass das das Anliegen war. Es stellte sich im Laufe der Arbeit der »commission technique« allerdings heraus, dass die Schwierigkeit eher darin bestand, die Fragen der Konferenz rein fachlich zu behandeln, wie es die Aufgabe der Kommission sein sollte. Die Diskussionen in der Kommission nahm zu keinem Zeitpunkt den Charakter einer wissenschaftlichen Fachdiskussion an. Ausschlaggebend blieb auch hier die Frage der politischen Praxis. Auf den Sitzungen der commissions techniques wurden also die Fragen zur Quarantäne und zu den Maßnahmen gegen die Cholera und anderen epidemischen, infektiösen Krankheiten diskutiert. Anstatt dass es hier, wie man denken könnte, zur vollen Entfaltung wissenschaftlich-theoretischer Debatten kam, mussten die Mitglieder sich eher immer wieder gegenseitig daran erinnern, dass sie sich nicht um die Fragen der Regierbarkeit, der Praxis und der Machbarkeit kümmern sollten. Der US-amerikanische Delegierte Sternberg proklamierte: »L'organisation des quarantaines de terre sont inexécutable et inutiles ${ }^{38}$ und selbst Robert Koch, der von der Theorie der Übertragbarkeit überzeugt war, meinte: »En théorie, l'isolement, les cordons sanitaires et les quarantaines sembleraient indiqués, mais en pratique ces moyens ne sont admissibles que dans un nombre très restreint de cas. $\ll^{39}$

Schließlich lautete die Empfehlung der Kommission an die Hauptsitzung, die alles andere als eine wissenschaftliche Begründung enthielt: »Les quarantaines de terre et les cordons sanitaires sont inutiles. $\aleph^{40}$ Eine zuvor vorgeschlagene Begründung, die sich auf die unzumutbaren Beschränkungen des Handels und der Kommunikation bezog, wurde ohne Ersatz gestrichen, nachdem der türkische Vertreter Zoéros Pascha darauf hingewiesen hatte:»les considérations commerciales ne doivent pas influer sur les délibérations d'une commission médicale. ${ }^{41}$ Oder später in der Diskussion um die Seequarantäne intervenierte der italienische Delegierte und Arzt, Buonomo, und erklärte:

»La Commission technique n'a pas le mandat pour discuter les moyens à adopter par les administrations sanitaires des différentes États dans le but de prévenir les invasions du choléra. Ce sera la tâche de la Conférence générale de discuter ces moyens et de les proposer aux Gouvernements. Nous n'avons qu'à présenter des criteriums médicaux. $^{42}$

38 CSI-6, 1885, Procès-Verbaux, Commission Technique, N²: S. 90.

39 Ebd.: S. 91.

40 Ebd.: S. 93.

41 Ebd.: S. 90.

42 Ebd.: S. 98. 
Es wurde auf den Konferenzen immer wieder gemahnt, dass man Fragen pragmatisch behandeln müsse, aber faktisch gab es niemanden, der gerne eine wissenschaftliche Diskussion führen wollte, auch nicht im Rahmen der »commission technique«. Die Aufteilung in diplomatische und technische Aufgaben fand trotz dieser formalen Trennung faktisch nicht statt. Es war nichts weiter als eine schon zuvor stattgefundene Arbeitsteilung, so wie es Decrais relativierend bei der Einführung der technischen Kommissionen geäußert hatte. ${ }^{43}$ Parallel zu dieser eher formalen Trennung wiederholten die Delegierten auch auf den Konferenzen der 1890er Jahre stetig, wie angewiesen die Politik auf die Wissenschaft sei. ${ }^{44}$ Das Leben zu sichern (»les règles protectrices de la vie«), resümierte der französische Delegierte Barrière auf der Konferenz 1894, sei der gemeinsame Gegenstand von Wissenschaft und Diplomatie: »1'œuvre commune de la science et de la diplomatie «. ${ }^{45}$ Auch auf der Konferenz 1897 definierte der französische Delegierte, Proust, die Aufgaben der beiden Bereiche der Konferenz in ähnlicher Weise als miteinander verbunden. ${ }^{46}$

Wie wichtig trotz des Ausschlusses aller wissenschaftlicher Diskussionen die Anwesenheit der Wissenschaftler und ihrer Stimme für die Produktion einer Identität von guter Regierung war, zeigt die zweite Konferenz. Auf der zweiten Konferenz 1859 wurden keine Ärzte eingeladen, sondern nur die Diplomaten der Mächte, die auch schon auf der Konferenz 1851/52 vertreten waren. Hierdurch erhofft man sich ein schnelleres Vorgehen. ${ }^{47}$ Die Diskussion, die sehr auf Einigung bedacht war, führte aber eher dazu, die Frage der Maßnahmen gegen die Cholera in der Konvention insgesamt aufzuweichen, es also letztlich den einzelnen Staaten zu überlassen, ob sie selbst unter bestimmten Bedingungen Quarantäne gegen bestimmte Schiffe anwenden wollten oder nicht. ${ }^{48}$ Bemerkenswert an der zweiten Konferenz ist vor allem, dass die zuvor so leidenschaftlich geführten Diskussionen und Reden der ersten Konferenz, die voller ethischer Bekundungen und Ermahnungen gewesen waren, hier ausblieben. Wenn es darum ging, abzuwägen, ob bestimmte Regelungen akzeptierbar seien, wurde nun öfter über die Frage der Gerechtigkeit diskutiert, als über die Frage der Praktikabilität. Aus der Analyse der Protokolle wage ich die These aufzustellen, dass diese Konferenz, in Abwesenheit der Mediziner und Hygieniker, auf der diskursiven Ebene am >erfolglosesten<war. Sie entfaltete keine eigene Machtdynamik, produzierte keine gemeinsame Rationalität und war damit weniger als die anderen Konferenzen an der Stiftung dieser für die Einigung der Staaten und Einzelpersonen auf der Konferenz schließlich essenziellen Grundlage beteiligt. Anders gesagt, die zweite Konferenz, auf der die Stimme der Wissenschaft, der Hygieniker und der Sanitaristen abwesend war, produzierte keine gemeinsame Identität, keine gemeinsamen Bedingungen für die Akzeptierbarkeit und Moralität von moderner Regierung. Die blieb im

43 Vgl. ebd.: S. 73.

44 Vgl. die Äußerung des italienischen Staatssekretärs für auswärtige Angelegenheiten, d'Arco: CSI-7, 1892, Protocole $\mathrm{N}^{\circ} 1$ : S. 5.

45 CSI-9, 1894, Procès-Verbaux, Séance $N^{\circ} 1$ : S. 11.

46 Vgl. CSI-10 1897, Procès-Verbaux, Séance N²: S. 42.

47 Vgl. CSI-2, 1859, Séance $\mathrm{N}^{\circ} 2$ : S. 2 - 11.

48 Vgl. CSI-2, 1859, Séance $N^{\circ} 3$ : S. 3. Vgl. CSI-2, 1859, Séance $N^{\circ} 13:$ S. 6. 
Modus der alten Regierung und Diplomatie verhaftet, der gänzlich ungeeignet war, um einen Gegenstand wie das Leben zu regieren. ${ }^{49}$

\section{Das Wissen der Hygiene}

Norman Howard-Jones schrieb in Bezug auf die ersten Konferenzen von 1851/52, 1859, 1866, 1874, 1881 und 1885: »[T] he etiology and mode of spread of plague and cholera were equally shrouded in mystery. ${ }^{50}$ Die Schwierigkeit der sog. CholeraFrage, die die Delegierten auf den frühen CSIs beschäftigte, ergab sich aber meiner Analyse zufolge nicht aus einem $>$ Mangel< oder einer noch nicht ausreichend fortgeschrittenen medizinischen Erkenntnis bzw. Forschungstechnik. Die Techniken und Methoden standen zum großen Teil zur Verfügung. John Snow vertrat bereits 1848 die Theorie einer Aufnahme des Cholerakeims über den Mund, v.a. durch verunreinigtes Wasser. Sein Wissen spielte eine Bedeutende Rolle im Erfolg der sanitären Politik in Großbritannien auch ohne die Kenntniss des Bakteriums, die aber - wenn man Pancinis Forschung berücksichtigt -, ebenfalls bereits existierten. Sie fügten sich in das breite Wissen dieser Zeit über die Cholera: ein weites reiches Feld an Wissen, das zu diesem Zeitpunkt nicht durch die Medizin, sondern durch die Rationalität der Hygiene dominiert wurde, die sich für die Praxis und die Zusammenhänge interessierte und nicht für die kausalen Ursachen oder die Absolutheit einer medizinischen Theorie. Die Hygiene und die Epidemiologie traten dabei weniger als Wissenschaften denn als Regierungs- und Praxiswissen in Erscheinung. Nicht die Medizin, sondern die Hygiene sollte den Regierungen die Mittel und das Wissen in die Hand geben, um diese Probleme zu bewältigen: »Le seul remède contre cette maladie vous est offert par l'hygiène. ${ }^{51}$ Weit wichtiger als die Wahrheit einer wissenschaftlichen Aussage war die Nützlichkeit des Wissens.

Bereits die Positionen der französischen und britischen Delegation auf der ersten Konferenz, aber auch der österreichischen und sardischen Delegationen, die sich ihnen anschlossen, zeigen, wie wenig man das Problem der Cholera überhaupt von einer medizinischen Seite betrachten wollte und wie sehr man es stattdessen in den Zusammenhang der sozialen Entwicklung stellte. ${ }^{52}$ Das Programm der Konferenz 1851 und der Entwurf für ein Reglement sahen nicht vor, die Cholera als ansteckende Krankheit zu behandeln. ${ }^{53}$ Die Diskussion auf der Konferenz drehte sich zunächst um

49 Eine Genealogie gouvernementaler Außenpolitik und die Transformation der Diplomatie unter dem Einfluss neue Anforderungen an Regierung in Europa ab dem 18. Jahrhundert zu schreiben, wären eine äußerst spannende Forschungsaufgabe. Aber hier ist kein Raum dafür.

50 Vgl. Howard-Jones: The scientific background of the International Sanitary Conferences 1851 - 1938, 1975: S. 9.

51 CSI-1, 1852 [1851], Séance $\mathrm{N}^{\circ} 12:$ S. 10; S. 15.

52 Vgl. ebd.: S. 10.

53 Ménis plädierte hinsichtlich des Entwurfs für ein Reglement: »[L]es mesures à prendre pour empêcher l'importation de maladies contagieuses, il n'est pas question du choléramorbus. Les maladies contre lesquelles on devra employer ces mesures se réunissent à la peste et à la fièvre jaune«: CSI-1, 1852 [1851], Séance N5: S. 6. 
die Frage, ob die Cholera überhaupt Gegenstand einer Verhandlung der CSI sein konnte: »Cette maladie sera-t-elle l'objet de mesures sanitaires? $«^{54}$

Fraktionen von Kontagionisten und Anti-Kontagionisten waren auf den Konferenzen zwar vertreten ${ }^{55}$. Allerdings traten diese, wenn überhaupt, eher als die Vertreter ungleicher politischer Strategien auf. Relevanter für die ganze Diskussion um die Cholera waren die Erfahrungen während der vergangenen Epidemien über Wirkungsweisen bestimmter politischer Techniken, die man unterschiedlichen politischen Rationalitäten zuordnete. Die Quarantäne gegen die Cholera zu Land und in den Häfen wurde auf der ersten Konferenz abgelehnt, nicht, weil sich die meisten Vertreter einig darüber waren, dass die Cholera nicht ansteckend sei - im Gegenteil: Der Großteil der Delegierten stand eher auf der Seite der Kontagionisten. Die Quarantäne wurde abgelehnt, weil sich die meisten Teilnehmenden darüber einig waren, dass diese Maßnahmen sich erfahrungsgemäß als unnütz erwiesen hatten. ${ }^{56}$ Auch die mit der Cholera-Frage auf der ersten Konferenz betraute Kommission begründete die Ablehnung der Kordons und der Quarantäne für die Cholera mit den Erfahrungen, die die Staaten aus den vorangegangenen Choleraepidemien gezogen hätten. ${ }^{57}$ »Il faut bien se rappeler que c'est sur l'expérience seule qu'on doit compter. $\ll^{58}$

Die Cholera-Frage war keine medizinisch-wissenschaftliche und schon gar nicht auf der Basis einer medizinischen Theorie zu klären. Die Frage war vielmehr: Wie sollen sich Menschen, Gesellschaften oder Staaten angesichts der Cholera verhalten? Oder besser: Wie kann man die Cholera (gut) regieren? Zur Beantwortung dieser Frage spielt die Art der Übertragbarkeit, die Bewegungs- und Verbreitungsart, das Verhalten und die Herkunft der Cholera eine große Rolle. Erst an zweiter Stelle stand die Frage nach dem Erreger oder der medizinischen Definition der Krankheit. Bedeutend sei, betonten die Delegierten immer wieder, vor allem die Erfahrung und die praktische Möglichkeit der Anwendung von Maßnahmen. Der englische Delegierte Sutherland nutzte immer wieder die Gelegenheit, um erneut darauf zu pochen, dass die einzig wahre Politik gegen die Cholera auf Basis der Hygiene erfolgen müsse. ${ }^{59}$ Diese Maßnahmen, die einen Bereich des Regierens berührten, der wohlgemerkt nicht innenpolitischer sein konnte, würden die Basis des sanitären Systems der Zukunft sein, prophezeite der britische Delegierte.

»L'hygiène, largement compris et bien entendue, doit être la véritable préservation des peuples contre les fléaux morbides qui les menacent. [...] Ces foyers sont la cause réelle véritablement puissante de la formation des maladies. [...] point de quarantaine contre le choléra, parce

54 Rapport à la Conférence sur les questions du programme et leur solution, fait au nom d'une Commission composée de MM. Bô, Betti, Costo et Mêlier, médecins, et de MM. Lavison, Perrier et Segovia, consuls: Annexe: CSI-1, 1852 [1851], Séance Nº : S. 10.

55 Vgl. CSI-1, 1852 [1851], Séance N`5: S. 6 und 9.

$56 \mathrm{Vgl}$. Rapport du M. Tardieu Adopté par le Comité consultatif d'hygiène publique dans sa sánce du 8 septembre 1851, Annexe: CSI-1, 1852 [1851], Séance Nº: S. 2. Vgl. auch CSI1, 1852 [1851], Séance $N^{\circ} 10$ : S. 3.

57 Vgl. ebd.: S. 3ff.

58 Ebd.: S. 12.

59 Vgl. CSI-1, 1852 [1851], Séance $\mathrm{N}^{\circ} 12$ : S. 25. 
qu'elles ne peuvent rien pour l'empêcher, on dit: Mesures d'hygiène et de propreté, mesures d'aération et de ventilation, dispersion des personnes et assainissement des bâtiments et des marchandises. Ce sont, comme on le sait, les vues et les pratiques de l'Angleterre dans ces matières, vues bien fondées, pratiques et parfaitement rationnelles, que le General Board of Health s'efforce de faire prévoir, et qui, il faut le croire, deviendront, dans un avenir prochain, la base de tout système sanitaire. $\ll^{60}$

Auch die Kommission hatte alternativ zu ihrer Ablehnung von Land- und Seequarantäne vorgeschlagen, die Staaten sollten stattdessen auf wirkungsvollere hygienische Maßnahmen gegen die Cholera umlenken. Man benötige ein »règlement à intervenir [qui] spécifierait avec soin et détail les mesures d'hygiène en question « ${ }^{61}$. Gleichzeitig war sich die Kommission bewusst, dass sie mit dieser Empfehlung einen Bereich berührte, der abgetrennt von dem der internationalen Politik bestand. Ihre Vorschläge könnten also nur fakultative Regelungen nach sich ziehen, da sie innenpolitische Angelegenheiten der Staaten beträfen ${ }^{62}$. Ein typischer Vorwurf, den man den Kritiker der Quarantäne und anderer restriktiver Maßnehmen gegen die Cholera gemacht hatte, bestand darin, zu sagen: >Ihr wollt keine Maßnahmen, ihr lehnt alles ab. Ihr wollt, dass wir, die Regierenden, machtlos gegen die Cholera sind. ${ }^{63}$ Daraufhin haben die Hygieniker und die Sanitaristen geantwortet: >Wir wollen alles andere, als die Regierung machtlos machen, wir wollen sie verbessern, wir wollen sie effektiver machen rationaler!< Es ist genau das Argument, dass Ménis, Mélier und Sutherland gegen die Kritik vorbrachten und im Kern ganz der sanitaristischen Ideologie entsprachen: >Man muss die Maßnahmen den natürlichen Gesetzen der Epidemien anpassen! ${ }^{64}$

»Les gouvernements sages savent bien comment il faut conduire les peuples et quels sont les moyens les plus efficaces à adopter afin que les timides soient encouragés, les préjugés bannis, les coutumes réformées et les vices corrigés, qui offrent au choléra ses victimes favorites. [...] Dans ce siècle de lumières, et sous l'influence des puissances les plus éclairées de l'Europe, [...] j'espère de même qu'il ne se passera pas longtemps sans qu'on voie établir parmi toutes les nations un système bien réglé d'hygiène, qui, par sa salutaire influence sur le physique et surtout sur le moral des peuples, détruira les éléments les plus favorables à l'extension du choléra. $\ll^{65}$

Die Erklärung Sutherlands war dagegen wesentlich weniger auf die Verbesserung der Moral und der Menschen als auf die Verbesserung der Lebensbedingungen und der hygienischen Zustände in den Städten gerichtet:

60 Rapport à la Conférence sur les questions du programme et leur solution, fait au nom d'une Commission composée de MM. Bô, Betti, Costo et Mêlier, médecins, et de MM. Lavison, Perrier et Segovia, consuls: Annexe: CSI-1, 1852 [1851], Séance Nº: S. 11.

61 Ebd.: S. 12.

62 Vgl. ebd.

63 Dies war in etwas die Argumentation des toskanischen Delegierten Cecconi auf der Konferenz. Vgl. CSI-1, 1852 [1851], Séance $\mathrm{N}^{\circ} 11$ : S. 26.

$64 \mathrm{Vgl}$. [Sutherland] ebd.: S. 26.

65 [Ménis] CSI-1, 1852 [1851], Séance $\mathrm{N}^{\circ} 12$ : S. 13f. 
»Il a été prouvé que le choléra ne décime jamais les populations qui vivent dans de bonnes conditions hygiéniques; mais, au contraire, qu'il éclate toujours dans les endroits où se trouvent des conditions favorables à sa propagation: telles que les grandes agglomérations d'hommes, les eaux de mauvaise qualité, la malpropreté des rues et des maisons, le manque d'égouts convenables pour dessécher le sol, l'humidité excessive du terrain, une atmosphère souillée par des matières organiques et d'autres conditions semblables. Il a été aussi prouvé que, par les améliorations des villes et des maisons, telles que je les ai indiquées, la population peut être protégée contre le choléra aussi bien que contre toutes les autres épidémies. « ${ }^{66}$

Man müsse die Maßnahmen rationalisieren, wirkungsvoller machen und dadurch im Grunde die Regierung verbessern. Das Wissen und die Theorien der Medizin hinsichtlich der Cholera waren umstritten und wurden immer wieder aus den Diskussionen auf den Konferenzen verbannt. Grundlage der Reflexion über einen guten Umgang mit der Cholera sollte das Wissen der Hygiene und der Epidemiologie allen voran aber die Erfahrungen der Regierungen mit den vergangenen Epidemien sein. Dies änderte sich allerdings auch nicht, nachdem das Wissen über einen mikrobiellen Erreger der Cholera bekannter wurde. Nachdem die Untersuchung der Cholera an dem als ihren Ursprung ausgemachten Ort, Indien, durch eine internationale wissenschaftliche Kommission auf den Konferenzen in den 1870er Jahren von Großbritannien abgelehnt worden war, hatten Deutschland und Frankreich 1883/84 nahezu zeitgleich ihre eigenen Forscherteams nach Ägypten geschickt, um dort den >Keim< der Krankheit zu untersuchen. Zu den jeweiligen Forschungsexpeditionen gehörten Louis Pasteur und Robert Koch. 1884 hatte Robert Koch die Ergebnisse seiner Forschungen und seine >Entdeckung< des »Kommabazillus« veröffentlicht. Im Bereich der medizinischen Theorie hatte es im Hinblick auf die Suche nach der primären Ursache der Cholera eine Veränderung gegeben. Nachdem über sechzig Jahre lang die wissenschaftliche Medizin gegenüber den allgemeinen und praktischen Ansätzen der Hygiene mehr oder weniger kapituliert hatte und die Mediziner nicht müde wurden, mit einer gewissen Scham zu verkünden, dass sie im Grunde nichts über die Cholera wüssten, konnten nun Mediziner behaupten, die wahre Ursache und den bakteriellen Erreger der Cholera gefunden zu haben. Aber änderte diese etwas an der dominierenden Position der Hygiene auf den Konferenzen? Im Prinzip nicht. Auch Koch, der von der Übertragbarkeit überzeugt war, erkannte die Aufgabe der Konferenz und ihre Verhandlung über praktische Regierungsweisen an. ${ }^{67}$ Je größer das politische Selbstbewusstsein und je fester die Bande der Regierungswissenschaften, Hygiene und Epidemiologie mit der politischen Rationalität zusammengeschmiedet wurden, desto ungefährlicher wurde ihr das Wissen der Medizin und desto weniger bestand die Gefahr, dass die Rationalität der Wissenschaft zu einem ungünstigen Diktat für die Regierung werden könnte und deren eigene Rationalität behinderte. Die Frage der politischen Maßnahmen gegen die Cholera hatte sich sozusagen in der Zeit der Verunsicherung der Medizin von der medizinischen Rationalität emanzipiert und konnte nun ganz unproblematisch wieder Bezug auf medizinisches Wissen nehmen. Auch nach der breiten Anerkennung des Wissens über den Cholera-Erreger blieb die Hygiene

66 Ebd.: S. 26.

67 Vgl. CSI-6, 1885, Procès-Verbaux, Commission Technique, N²: S. 92. 
und die Praxis der Sanitaristen gegenüber der Medizin und ihren Theorien überlegen. Auf der rein quantitativen Ebene der Bezüge ist dies sehr offensichtlich. Die Bezüge auf das bakteriologische Wissen waren auf den Konferenzen sehr selten. Was man aus der Bakteriologie für die Rationalisierung der Techniken und Maßnahmen verwenden konnte, wandte man an; was innerhalb der Rationalität der Regierung keinen Nutzen hatte, wie bestimmte Techniken der Isolation, wurde nicht verwendet. Auf der Konferenz von Wien 1892 resümiert Brouradel:

»La science a fait de grands progrès depuis la dernière Conférence. Actuellement nous connaissons le bacille du choléra. Nous savons qu'il réside dans les déjections du malade, dans les linges qui en sont souillés; que sa vitalité y est très prolongée; qu'après des mois il possède encore toute sa force; [...]. Notre situation est beaucoup plus favorable qu'en 1885, lorsque nous siégions à Rome. A cette époque, la découverte du bacille du choléra par le docteur R. Koch était chose récente, peu certaine. Aujourd'hui que tant d'observations l'ont confirmée, elle n'est plus discutée. [...] Si nous sommes, d'une part, des théoriciens, en ce sens que nous appuyons nos idées sur la science, nous sommes aussi des gens pratiques. Parmi les preuves que je puis fournir, j'en choisis une; je l'emprunte à la Grande-Bretagne. Ce que nous demandons c'est le système appliqué par le Local Government Board en Angleterre, système que est une gloire pour ses hygiénistes. $\ll^{68}$

\section{Die grenzenlose Regierung des Lebens}

Wie bereits zuvor in der britisch-indischen Diskussion um die Quarantäne wurde diese in den Debatten der Konferenz immer wieder als Beispiel für eine irrationale und illiberale Regierungsweise herangeführt. Das Ideal einer Regierung, deren Ziel die Sicherung des Lebens der Bevölkerung, ihrer Gesundheit, aber auch der ökonomischen Grundlagen dieses Lebens war, war hierbei grundlegend. Während seiner Eröffnungsrede rief der Präsident der ersten Konferenz, Céleste-Etienne David, die teilnehmenden Delegationen der Konferenz auf: »à rendre de si importants services au commerce et à la navigation de la Méditerranée, tout en sauvegardant la santé publique dans les différents États ${ }^{69}$. Die ökonomischen Interessen Frankreichs und Großbritanniens an einer Erleichterung des Handels verbanden sich mit der These der Irrationalität der Quarantäne. Der Ökonomie und der Freiheit des Handels wurde eine ebenso große Wichtigkeit für das Leben der Bevölkerungen beigemessen (»le commerce et la navigation, ces deux grands ressorts de la vie sociale $\ll^{70}$ ), wie dem Schutz der Bevölkerungen vor Epidemien. ${ }^{71}$ Die Diskussion um die Cholera wurde immer

68 CSI-7, 1892, Protocole N5: S. 227.

69 CSI-1, 1852 [1851], Séance Nº1: S. 2.

70 Rapport à la Conférence sur les questions du programme et leur solution, fait au nom d'une Commission composée de MM. Bô, Betti, Costo et Mêlier, médecins, et de MM. Lavison, Perrier et Segovia, consuls: Annexe: CSI-1, 1852 [1851], Séance Nº ${ }^{\circ}$ S. 1.

$71 »[\mathrm{~L}] \mathrm{a}$ liberté des communications, cet autre besoin des peuples, avec tout ce qui s'y rattache ou en découle, et cela à une époque de grande civilisation. [...] Le première, au nom de l'humanité, demande protection contre les dangers que la menacent; la seconde, au nom du commerce et des relations, cherche à s'affranchir des restrictions qu'on lui oppose. [...] 
wieder für die Vergewisserung dieser Kriterien moderner Gouvernementalität genutzt. Man wollte zunächst nicht über Politik diskutieren und nicht über wissenschaftliche Theorien, aber über Humanität: Ziel sollte es jeder Zeit sein, das Leben der europäischen >Völker $<$ zu schützen. Die alten Regelungen der Quarantäne wurden wiederholt als Beispiel einer alten illiberalen und rückschrittlichen Regierung angeführt, die auf der Grundlage von >Machtinteressen< agierte, statt als ihr oberstes Ziel die Sicherung des Lebens der Bevölkerung anzusehen. ${ }^{72}$ Die Quarantäne zu unterstützen, wurde im Kontext der Konferenz als Ansatzpunkt dafür gesehen, einem Staat oder einer Delegation entweder Willkür oder Unwissenheit und Ignoranz gegenüber den Fakten vorzuwerfen. Unter dem hieraus resultierenden Druck bekundeten auch die Delegierten Russlands und Österreichs, die, wie Erwin Ackerknecht gezeigt hat, als autokratische Mächte und Heimat der Verteidiger der kontagionistischen Doktrin bezeichnet wurden, auf der ersten Konferenz 1851 ihre Ablehnung gegen die Quarantäne und die Kordons zur Verteidigung gegen die Cholera. ${ }^{73}$ Sie gestanden ein, dass das Verhalten der russischen, preußischen und österreichischen Regierung Anfang der 1830er Jahre allein auf einem Mangel an Erfahrungen mit der Epidemie zu diesem Zeitpunkt zu erklären sei. ${ }^{74}$

Auf der Konferenz 1885 waren sich die Delegierten über die Fragen der Politik, mit der man eine ganz bestimmte Form der Politik, die sog. >Machtpolitik<, gemeint hatte und die man auf den ersten Konferenzen hatte beiseite lassen wollen, nicht mehr so sicher. Denn gab es nicht eine legitime Macht der Regierung, die sich nicht mehr auf den Erhalt des Staates richtete, sondern die ihre Legitimation gerade aus ihrem Verhältnis zum >Volk< und aus ihrer > wahren < Aufgabe - der Regierung des Lebens der Bevölkerung und seiner Sicherung - begründen sollte? Diese Regierungsmacht musste sich erst das Selbstbewusstsein schaffen, auf dessen Grundlage sie sich als eine legitime politische Macht erklären und ihren Gegenstand unter ihren eigenen Bedingungen als politisch deklarieren konnte.

»Bien plus que le prestige de la puissance et l'éclat des victoires, les services rendus à l'humanité et à la civilisation ont leur place marquée dans les annales du monde. Il sont, dans la vie des peuples leurs titres de noblesse le plus purs et les plus légitimes devant l'histoire. J'espère, et je souhaite qu'il en soit ainsi des résultats de la Conférence, dont j'ai en ce moment l'honneur d'inaugurer les travaux, et dont je déclare ouvert la première séance.«75

Die Regierungsmacht, die sich hier bestätigte und verallgemeinerte, hatte mit dem Widerspruch zu kämpfen, dass sie sich von alten Machtpolitiken dadurch abgrenzen und moralisch erhöhen wollte, dass sie die Souveränität der Staaten und zunehmend die Souveränität der >Völker und die Freiheit einer Regierung über ihre inneren An-

ce grand et difficile problème que vos Gouvernements, tous inspirés par une haute pensée de bien publique [...] combiner nos efforts et les associer aux nôtres.«: Ebd.: S. 2.

72 Ebd.: S. 5.

73 Vgl. Ackerknecht: Anticontagionism between 1821 and 1867, 2009 [1948]: S. 7.

74 Vgl. CSI-1, 1852 [1851], Séance N¹1: S. 6.

75 [Der italienische Außenminister Pasquale Mancini in seiner Eröffnungsrede]: CSI-6, 1885, Protocole $\mathrm{N}^{\circ} 1$ : S. 5 . 
gelegenheiten selbst zu bestimmen, anerkannte. Dennoch funktionierte die ganze Rechtfertigung der Regierung des Lebens der Bevölkerung über einen Gegenstand, der selbst keine territorialen Grenzen kannte. Die materielle und biologische Wirklichkeit dieses Lebens wurde durch die Epidemie und den Handel überdeutlich. Ab dem Moment, wo ihre Konstitution, ihre rein formale und rechtliche Legitimation als Regierung eines speziellen Volkes gelungen war, hing ihre Existenz von ihrer Praxis ab, von ihrem Funktionieren. Die Grenze der Macht der Regierung wurde von hier aus nicht mehr so sehr in ihrer formalen juristischen Beschränkung auf ein Territorium gesehen, sondern als Grenze ihrer eigenen Erkenntnisfähigkeit. Das heißt als Grenze der Fähigkeit, ihren Gegenstand zu kennen, alle Mechanismen des Lebens, der Bewegungen und Spiele von Kräften zu durchschauen und die Gesetze und Regeln des Lebens selbst.

Schon auf der ersten Konferenz hatte Sutherland quasi einen Vergleich zwischen Schmugglern, Tieren und der Cholera gezogen, gegen die sich bisherige allgemeine Grenzsperren als nutzlos erwiesen hätten. ${ }^{76}$

Die Grenzen mussten gegenüber dem Leben praktisch verwirklicht werden. Wie durchlässig müssen die Grenzen sein, damit das Leben, der Handel, die Ökonomie nicht beschädigt wird? Wie kontrolliert und gesichert müssen die Grenzen z.B. an den Pforten Europas sein, damit die europäischen Bevölkerungen vor den Seuchen und den Menschen aus dem >Orient< beschützt werden? Diese Kalkulationen stellte man auf den Konferenzen ununterbrochen an. Während der Handel und seine Ausdehnung eine aus europäischer Sicht notwendiges und sicherndes Element dieses zu regierenden Lebens darstellte, markierten Migrationsströme und Epidemien die negative und bedrohliche Eigenschaft der $\mathrm{zu}$ regierenden lebendigen und beweglichen Kräfte: »La maladie ne connaît, pas de frontières. ${ }^{77}$ Wenn der Handel das positive Beispiel für diese >Grenzenlosigkeit< demonstrierte, so war die Epidemie das negativste Beispiel der Beschaffenheit dessen, was die Regierung regulieren sollte. Der lebensnotwendigen Grenzenlosigkeit wurde ihre Gefahr als Pendant und gleichwertiges Problem der Regierung gegenübergestellt. Genau dies geschah auf den Konferenzen.

Aus der Perspektive einer Gouvernementalität, die sich auf diese komplexe Ökonomie des Lebens richtete, waren die Choleraepidemien ein vortreffliches Ereignis, um ihre Rationalisierung anhand der neuen Existenzbedingung voranzutreiben. Indem die Epidemien die >Grenzenlosigkeit< des Gegenstandes demonstrierten, waren sie ebenso wie die Ökonomie optimales Betätigungsfeld und Zentrum der Reproduktion und Rationalisierung einer spezifischen liberalen Gouvernementalität. Ein sich wiederholendes Muster der Diskussionen war, zunächst die Gefahr und die Bedrohung der Bevölkerung durch die Epidemien und Krankheiten zu betonen, folglich deren Sicherungen zu fordern und Maßnahmen hierfür vorzuschlagen, daraufhin aber diese Maßnahmen dafür zu kritisieren, dass sie das Leben der Bevölkerungen auf andere Weise gefährdeten, nämlich indem sie den Handel, den Kontakt und die Kommunikation behinderten. Schließlich folgte die Projektierung von Maßnahmen, die

76 Vgl. CSI-1, 1852 [1851], Séance N9: S. 3.

77 [Deucassé, französischer Außenminister bei der Eröffnungsrede der Konferenz von 1903] CSI-11 1903, Procès-Verbaux, Séance N¹: S. 14. 
einen doppelten Schutz gewährleisten sollten: »la défense commune contre les fléaux qui menacent à la fois la santé publique et la vie économique des peuples! « ${ }^{78}$ Fraglos war es ein Mechanismus der Rationalisierung einer Regierung unter kapitalistischen Verhältnissen, oder besser gesagt, nicht nur die Anpassung, sondern auch gleichzeitig die Ermöglichung bestimmter kapitalistischen Gesellschaften entsprechenden Formen der Regierung.

Besonders die Protokolle der Konferenzen von 1866, 1874 und 1894, auf denen immer wieder über den Ursprungsort der Cholera, mögliche Maßnahmen zur Verhinderung der Einschleppung der Cholera und schließlich die Möglichkeiten der Bekämpfung der Cholera am Ort ihrer angeblichen Entstehung diskutiert wurde, verdeutlichen das Bestreben, politische Techniken gemäß dem neu entdeckten grenzenlosen Gegenstand der Regierung weit über nationale Grenzen hinaus zum Einsatz zu bringen. Es galt der Krankheit zu folgen, ihre Regeln und ihre Natur zur Grundlage gesundheitspolitscher Maßnahmen zu machen:»Vous avez à poursuivre le choléra vers sa source ${ }^{79}$. Diese >natürlichen $<$ Gesetze der Krankheiten, der Ökonomie und des Lebens zu ergründen und sich nach ihnen zu richten und zu begrenzen, stand im Vordergrund. Das Problem der staatlichen und territorialen Grenzen war hiermit notwendigerweise etwas völlig anderes geworden. Keine imaginäre Linie mehr, keine vertraglich und gesetzlich verbriefte Trennlinie zweier Territorien, zweier Herrschaftsbereiche. Wenngleich diese Veränderung nicht zu einer Aufweichung von territorialen Grenzen, sondern zu ihrer Umdeutung und in Folge zu einer vermehrten Materialisierung und Sicherung dieser Grenzen führte. Vor allem gegenüber dem, was jetzt den Eigenschaften dieses >Lebens< entsprechend wenig Achtung vor Markierungen auf Landkarten zeigte, musste die Grenze erste >real gemacht<werden. Grenzen mussten von Grenzen, die Besitztümer und formale Herrschaft voneinander schieden, zu >realen< Grenzen für Menschen werden, die umherzogen, wanderten und migrierten. Sie musste zu einer realen Grenze für giftige Miasmen und schließlich Bakterien werden, die sich durch die Luft, durch das Wasser oder mit Hilfe von Verkehrsmitteln oder Transportgütern, durch Menschen oder Tieren verbreiteten. Der Widerspruch, der sich ergab, sobald man versuchte, die Regierung des Lebens auf ein Territorium zu begrenzen, forderte einen neuen Bereich von Aufgaben für die internationale Regierung. Aufgaben der Sicherung, Begrenzung, der Kontrolle mithilfe von Kriterien für die Ökonomie, einer Permeabilität von Grenzen, die völlig neuer Techniken bedurfte. Es stimmt zwar, dass im Gegensatz zur souveränen Macht eines Fürsten die Gouvernementalität quasi einer Enträumlichung der Macht gleichkam, aber gleichzeitig wurde das Problem dieser Auflösung zu einem Aufgabenfeld der Gouvernementalität. ${ }^{80}$

78 [Santoliquido, erster Delegierter Italiens] Ebd.: S. 16.

79 CSI-9, 1894, Procès-Verbaux, Séance $\mathrm{N}^{\circ} 1$ : S. 11.

80 Vgl. Foucault: Raum, Wissen und Macht, 2005 [1982]: S. 328. 


\section{Die Rationalisierung der Quarantäne}

Die 6. Konferenz, 1885, wurde in aller Eile und vor dem Hintergrund einer erneuten >Bedrohung< Europas durch die Cholera einberufen, da die Krankheit 1883 in Ägypten erneut ausgebrochen war. ${ }^{81}$ Ziel der Konferenz, vor allem dem Wunsch Frankreichs entsprechend, war es außerdem, sich weiterhin genauer über den Ursprung und die Ursachen von Krankheiten - vor allem der Cholera - zu verständigen. Auf dieser Konferenz in Rom wurde die Definition der Cholera als eine ansteckende Krankheit kaum noch bezweifelt. Die Frage, die man 1851 gestellt hatte, nämlich ob man die Cholera als eine >maladie pestilentielle < mit den hierfür bestehenden Maßnahmen in den Griff bekommen könne, stellte niemand mehr. Von den Erfahrungen ausgehend, versuchte man ein ganzes Repertoire von Maßnahmen zu entwickeln, die auf eine spezielle Situation angewendet, in der Lage sein würden, gegen die unterschiedlichen Risiken der Einschleppung der Cholera zu wirken und gleichzeitig Rücksicht auf Handel und die Freiheit der Kommunikation zu nehmen. Gerade aus dieser Denkbewegung heraus fragte man, was die Cholera genau sei, hier noch einmal in aller Deutlichkeit. Ziel war nich nicht, sich für eine Maßnahme zu ihrer Eindämmung zu entscheiden, sondern für jede spezifische Situation das beste Ensemble von Maßnahmen zusammenzustellen. Die Abschaffung der Quarantäne war kein Thema mehr. Eher stand zur Debatte, ob man Teile dieser variierenden Maßnahmen gegen die Cholera noch als Quarantäne bezeichnen könne. ${ }^{82}$ Ich möchte im Folgenden die Veränderung der Quarantäne, oder anders gesagt, die Rationalisierung ihrer Technik genauer erläutern.

Von dem »ancien système des quarantaines $\ll^{83}$ zum »neo-quarantenism $\ll^{84}$, wie Baldwin es nannte, und über die Diskussion darüber, ob man den Namen der Quarantäne ganz abschaffen müsse, findet sich ein reichhaltiges Feld von Aussagen darüber, wie eine Regierung sein muss, die die Quarantäne befürwortet, und welchen Charakter eine Regierung haben muss, die gegen sie ist. Es gibt Aussagen darüber, was eine politische Technik rational und akzeptierbar macht und was sie inakzeptabel macht, genauer noch, unter welchen Bedingungen eine Regierung und ihre Techniken als rational und akzeptabel gelten kann.

Die Diskussionen um die Quarantäne hatten teilweise eine >nationale< Vorgeschichte - vor allem in Großbritannien. Quarantäne avancierte hier in der ersten Hälfte des 19. Jahrhunderts zum Symbol für Willkürherrschaft, Unfreiheit und Unterdrückung, wie auch Harrison schrieb.

»[Q]uarantine had [...] come to be identified with tyranny. Free trade had long been associated with political liberty, and the growing influence of such doctrines in the Anglophone world led a number of writers to equate quarantine with authoritarian regimes. ${ }^{85}$

81 Vgl. CSI-6, 1885, Protocole $N^{\circ} 1$ : S. 5.

82 Vgl. CSI-6, 1885, Procès-Verbaux, Commission Technique, Nº: S. $191 \mathrm{f}$.

83 Vgl. CSI-6, 1885, Protocole $N^{\circ} 3$ : S. 101.

84 Baldwin: Contagion and the State in Europe 1830 - 1930, 1999: S. 165.

85 Harrison: Disease, diplomacy and international commerce, 2006: S. $214 \mathrm{ff}$. 
Bekannt wurde im Zusammenhang mit der britischen Kritik an der Quarantäne vor allem die Schrift von Charles Maclean über die britische und spanische Quarantänegesetzgebung. Er bezeichnete die »quarantine laws« und »sanitary laws« noch 1832 als »without exception, the most gigantic, extraordinary, and mischievous superstructure, that has ever been raised by man, upon a purely imaginary foundation ${ }^{86}$. Die Errichtung der Quarantäne wurde vor allem mit der Geschichte der Pest-Pandemien assoziiert und erst ab den 1840er Jahren stärker mit der Cholera in Verbindung gebracht. Auf den CSIs wurde die Kritik an der Quarantäne durch die Cholera-Frage belebt. Es war erst angesichts der geradezu periodischen Choleraepidemien und der relativen Hilflosigkeit der Regierungen möglich, Druck auf die Verhandlungen über die Quarantäne auszuüben und deren Liberalisierung und Rationalisierung voranzutreiben. Die Cholera funktionierte hier wie ein Katalysator.

\section{Die Kritik an der Quarantäne}

Ein Bericht von Auguste Ambroise Tardieu, der der Konferenz am 8. September 1851 als Material vorlag, dokumentiert aus der Sicht Frankreichs die Ungerechtigkeiten und Ungleichheiten der sanitären Maßnahmen im Mittelmeerraum. Insbesondere kritisierte Tardieu darin die Quarantäne, die aufgrund der Cholera in mehreren Häfen des Mittelmeers durchgeführt wurde. Er betonte in dem Bericht den Gegensatz der sanitären Maßnahmen und Gesetze Frankreichs - »prudents et libéraux « - zu anderen Staaten am Mittelmeer. ${ }^{87}$ Daran zeigt sich, wie stark Frankreich anfänglich für eine Lockerung der Quarantäne im Mittelmeerraum eingetreten war. ${ }^{88}$ Wenn man von dem zuerst durch Frankreich präsentierten Vorschlag für eine Konvention ausgeht, lässt sich aber feststellen, dass es in den ersten Jahrzehnten nach 1851, zumindest was die Ergebnisse der Konferenzen anging, nicht zu der gewünschten Liberalisierung und Lockerung der Quarantäne kam. Wie schon gezeigt, wurde die Cholera im Programm der ersten Konferenz noch nicht in die Quarantäneregelungen einbezogen. Der britische Vertreter Sutherland äußerte seine Ablehnung gegenüber jeglicher Quarantäne und bezeichnete sie als - »un système basé sur des théories surannées «. ${ }^{89}$ Sein Kollege, Perrier, nannte die Quarantäne und das System der Kordons: »les pratiques suivies sous l'influence de l'ignorance des siècles reculés. ${ }^{90}$ Hinsichtlich der Kordons und der Quarantänestationen entlang der Ländergrenzen setzte sich die kritische Position vor allem mit Hilfe des praktischen Arguments durch. Ohne zu einer gemeinsamen Einigung über die wissenschaftliche Fragwürdigkeit dieser Maßnah-

86 Maclean, C.: Remarks on the British quarantine laws, 1823: S. 2.

87 Rapport du M. Tardieu Adopté par le Comité consultatif d'hygiène publique dans sa sánce du 8 septembre 1851, Annexe: CSI-1, 1852 [1851], Séance N8: S. 2.

88 Frankreich und Großbritannien vertraten auf der ersten Konferenz ähnlich liberale Positionen. Laut Harrison wurden in den 1850er die britischen sanitären Reformen in Frankreich als besonders fortschrittlich gelobt. Vgl. Harrison: Disease and the modern world: 1500 to the present day, 2004: Polity, S. 114f.

89 »Au point de vue de la science, je ne plus conséquemment soutenir cette solution. Je ne crois pas que les mesures quarantenaires soient le meilleur moyen d'empêcher la marche de maladies réputées transmissibles. «: CSI-1, 1852 [1851], Séance N¹0: S. 2.

90 CSI-1, 1852 [1851], Séance N¹1: S. 24. 
men zu gelangen, entschieden die Delegierten mehrheitlich, dass sie schlicht nicht erfolgreich umzusetzen seien. ${ }^{91}$ Nach erheblichem Protest wurde schließlich auf der 14. Sitzung im Oktober 1851 doch noch eine Quarantäne für die Cholera vorgeschlagen, die für Frankreich und Großbritannien einen akzeptablen Kompromiss darstellte, aber von den Delegationen Spaniens (Segovia, Monlau) und des Kirchenstaats ${ }^{92}$ (Escalon, Cappello) unter Protest als unzureichend abgelehnt wurde. ${ }^{93}$ Die Berechnung der Dauer der Quarantäne für die Cholera, Gelbfieber und für die Pest wurde hauptsächlich aus verschiedenen medizinischen Indikatoren für die Inkubationszeit der Krankheiten berechnet. Im Vergleich zu späteren Formulierungen war die Praxis der Hygiene hier noch wenig ausformuliert und eher vage. ${ }^{94}$ Auf der zweiten Konferenz wurde in dem Bestreben der Einigung vorgeschlagen, die Quarantäne für die Pest auf 30 Tage, die für das Gelbfieber auf 20 Tage und für die Cholera auf 10 Tage festzulegen. Insgesamt wurde ein Minimum von 10 und ein Maximum von 40 Tagen Quarantäne vorgeschlagen. Zusätzlichen zu der Quarantäne sollten durch europäische Ärzte ausgestellte Zertifikate vergeben werden, die den hygienischen Zustand des Hafens und der Schiffe bei Abreise angeben sollten. Wie schon zuvor konnte die Quarantänedauer abhängig von der Zeit der vorangegangenen Passage gemacht werden. Verschiedenste Ausnahmen wurden für bestimmte Schiffe und Häfen festgelegt. ${ }^{95}$ Der Türkei wurde z.B. zugestanden, an ihren Häfen die bisherige restriktivere Praxis fortzusetzen, wenn sie es für nötig hielte.

Auch auf der dritten Konferenz 1866 stritt die osmanische Delegation gegen den Großteil der übrigen Delegierten um die Dauer und Härte der sanitären Maßnahmen am Suez-Kanal bezüglich der Mekka-Pilger. ${ }^{96}$ Die französische Delegation, bestehend aus Lallemand und Fauvel, unterbreitete einen Vorschlag, der zum Ziel hatte, eine effektive Quarantäne am Suez einzurichten. Dadurch sollte die Gefahr der >Einschleppung< der Cholera durch die von dort abreisenden Pilger verhindert werden. Die Verbreitung der Cholera auf dem Landweg hielt man dagegen für weniger gefährlich: »une longue marche par étapes dans le désert était, contre le choléra, la meilleure des quarantaines $\ll .{ }^{97}$

91 Vgl. ebd.: S. 29.

92 Nach dem Ende des Pariser Friedens und dem Wiener Kongress 1815 bestanden auf dem Gebiet des heutigen Italiens sechs kleinere Staaten. Einer davon, der Kirchenstaat, umfasste größtenteils bis 1860 (bis zum Risorgimento) und spätestens bis 1870 Gebiete unter der päpstlicher Regierung.

93 »[L]eur vote contre l'article soit inséré au procès-verbal, en spécifiant qu'ils ne votent pas contre le principe de la quarantaine, mais contre la nature et la durée, qui leur semblent- insuffisantes.«: CSI-1, 1852 [1851], Séance N4: S. 12.

94 Der toskanische Delegierte Betti äußerte etwa, für ihn sei die Isolation auch einen hygienische Maßnahme: Vgl. CSI-1, 1852 [1851], Séance $\mathrm{N}^{\circ} 10$ : S. 3.

95 Vgl. CSI-2, 1859, Séance N²: S. 2 - 11.

96 Vgl. CSI-5, 1866, Séance $N^{\circ} 3$ : S. 25.

97 Propposition: Sur les mesures à prendre dans le cas où le choléra se manifesterait cette année par/ni les Pèlerins réunis à La Mecque, présentée par les Délégués du Gouvernement français [A. de Lallemand und Fauvel: Annexé (1): CSI-3, 1866, Séance $N^{\circ} 1$ : S. 2. 
»Que reste-t-il donc à faire! Il reste, selon nous, à mettre en pratique la mesure la plus simple, la plus prompte, la plus facile à exécuter et la plus sûre, celle qui offre le moins d'inconvénients sous tous les rapports: elle consisterait, en cas de choléra parmi les pèlerins, à interrompre momentanément, c'est-à-dire pendant la durée de l'épidémie, toute communication maritime entre les ports arabiques et le littoral égyptien, en laissant ouverte aux hadjis, pour leur retour en Égypte, la route de terre suivie par la caravane. ${ }^{98}$

Die Delegation des Osmanischen Reiches reicht daraufhin einen noch weitergehenden Antrag ein, der die Pilger dazu zwingen sollte, ihre Rückkehr über den Landweg anzutreten. Ihre Begründung lautet, dass das Osmanische Reich von allen Staaten am stärksten von der Gefahr der Ausbreitung der Cholera betroffen sei. ${ }^{99}$ Wo soll die Quarantäne also eingerichtet werden? Ist es möglich, die Quarantäne außerhalb Europas in einer Weise zu gestalten, dass die Gefahr einer >Invasion< durch die Cholera verhindert werden kann?

Die Mehrheit der Delegierten betrachtete eine Quarantäne am Suez und des internationalen »Conseil sanitaire« in Konstantinopel als eine praktikable Lösung. Die Bedingungen der Akzeptierbarkeit der Quarantäne werden hier weniger im Zusammenhang mit dem Wissen über die Verbreitungsweisen der Krankheiten verhandelt als mit den sozialen und kulturellen Gegebenheiten eines Ortes. Wie müsse eine Gesellschaft aufgebaut sein, dass die Quarantäne, wie restriktiv sie auch sei, selbst an Land akzeptabel sei? Die europäischen Mächte kritisierten die Quarantäne u.a. deshalb, weil sie angesichts der Entwicklung des Handels und der Zunahme des Verkehrs der Menschen, auch über die Grenzen ihrer Regionen und Nationen hinweg, unmöglich geworden sei. Angesichts dieser Entwicklungen sei die Quarantäne zu einer inakzeptablen Beschränkung der Freiheit für die >zivilisierten< Bevölkerungen geworden. Wie sei es aber mit der Bevölkerung des Orients und Asiens? Was sei mit den Nomaden und den Pilgern, deren Lebensweise eine ganz andere sei? Die ein ganz anderes Gefühl für den Wert der Zeit hätten, usw.? Hier wurden auf den Konferenzen eine Reihe von rassistischen und moralischen Differenzierungen vorgenommen, die sich auf das Verhältnis von Regierung, legitimen Techniken und den Eigenschaften der Regierten bezogen.

Auch die vierte Konferenz 1874 in Wien setzte sich mit dem Zielen eines möglichen Ausschlusses der Cholera an den europäischen Grenzen auseinander. ${ }^{100}$ Die lange verworfene Frage der Landquarantäne wurde hier erneut aufgegriffen und erneut als nicht durchführbar deklariert: »l'organisation des quarantaines de terre est inexécutable et par conséquent inutile $\aleph^{101}$. Nur Griechenland protestierte und behauptete, die Landquarantäne könnte unter bestimmten geographischen Bedingungen durchaus hilfreich sein. Während das Diktum der Einheitlichkeit der Regelungen bisher auf den Konferenzen unumstritten war, stellt Griechenland die Frage, ob eine

98 Ebd.: S. 3.

99 Projet d'amendement concernant la proposition d'urgence de MM. Les Délégués du Gouvernement Français présenté par les Délégués de la Sublime-Porte. Annexé (3): Vgl.

CSI-3, 1866, Séance $\mathrm{N}^{\circ} 3$ : S. 1.

100 Vgl. CSI-4, 1874, Séance $\mathrm{N}^{\circ} 1: \mathrm{S} .1$.

101 CSI-4, 1874, Séance Nº6: S. 82. 
einheitliche Regelung für alle Staaten und Bedingungen angemessen sei. ${ }^{102}$ Dickson wies darauf hin, dass das wesentliche Kriterium nicht ein geographisches sei, sondern dass es sich um eine Frage der Entwicklung des Handels, der Dichte der Population und der Gesellschaften handele. Die Idee der Landquarantäne basiere auf der Theorie der Übertragbarkeit der Krankheiten durch den Menschen und sei daher gemacht, um deren Bewegung zu beschränken. Möglicherweise könne man also die Landquarantäne in einem Gebiet anwenden, das wenig bevölkert sei, oder wo die Kommunikation und der Handel eine geringere Rolle spielen würden z.B. im Orient: »où les populations marchent lentement et n'ont aucune idée de la valeur du temps, les quarantaines de terre ont pu fonctionner ${ }^{103}$.

»Toutefois en Europe, où les communications sont si nombreuses et si fréquentes, où les intérêts matériels sont d'une importance vitale, les quarantaines de terre deviennent tout-à-fait impossible, et il serait inutile d'en essayer l'introduction. Je m'oppose donc à tout mesure de quarantaine par terre; et je voterai dans ce sens. $\ll^{104}$

Auf diesen Beitrag Dicksens reagierte der persische Vertreter mit Empörung. Auch in Asien wäre es unmöglich, eine Landquarantäne durchzuführen. Zum Beispiel, weil umherziehende Nomaden mit ihren Vieherden ein solches Regime nicht akzeptieren und sich dieser Regierung entziehen würden. Daraufhin versicherte der britische Delegierte, dass er gegen die Landquarantäne plädiere, selbst im >Orient< und in Asien. ${ }^{105}$ Der russische Delegierte Lenz erinnerte daraufhin an die Ergebnisse der Konferenz von 1866, denen zufolge man nicht sehr überzeugt von der Wirksamkeit der militärischen Kordons gewesen sei. Man habe sich aus den genannten Gründen (dichte Bevölkerung, viel Verkehr und lebensnotwendigen Handel) gegen die Landquarantäne im zentralen Europa ausgesprochen, aber für die Landquarantäne im >Orient $<$ und in Asien, konstatiert er: »[L]es cordons sont non seulement possible, mais nécessaires «. ${ }^{106}$ Der Schweizer Vertreter, Zehnder, bekräftigte: »La quarantaine sur terre est impossible et restera ordinairement sans résultat en Europe, vu les relations commerciales et personnelles établies actuellement. «107 Der serbische Vertreter, Milossavlevitch, ergriff Partei für die griechische Delegation und bekräftigt, man müsse die Praktikabilität der Quarantäne nach den jeweiligen Möglichkeiten vor Ort entscheiden. Es sei nicht ausgeschlossen, dass die Bedingungen auch im zentralen Europa hier und da die Durchführung der Quarantäne ermöglichten. ${ }^{108}$

Die Diskussion über die Quarantäne auf der Konferenz von 1874 ist aus verschiedenen Gründen eine genauere Betrachtung wert. Zunächst, weil die Akteure, die sich an der Diskussion beteiligten, andere waren als auf den vorangegangenen Konferenzen. Die Französische Delegation war auf der Konferenz 1874 erst ab der 9. Sit-

102 Vgl. ebd.: S. 83.

103 Ebd.: S. 83f.

104 Ebd.: S. 84.

105 Ebd.: S. 84.

106 Vgl. ebd.: S. 85.

107 Ebd.: S. 89f.

108 Vgl. ebd.: S. 88f. 
zung anwesend. Die englische Delegation hielt sich in den ersten Sitzungen relativ stark zurück. Die wieder aufgegriffene Diskussion um die See-Quarantäne uferte für die meisten Delegierten unerwartet aus, nachdem die von den Deutschen und den Italienern dominierten Kommission in ihrem Programmentwurf vorschlug, die Quarantäne gegen die Cholera in den europäischen Häfen ganz abzuschaffen und nur in Su$\mathrm{ez}^{109}$ und Alexandria einzuführen ${ }^{110}$. Teilweise kann man sicherlich den Einfluss Max Pettenkofers auf die Kommission dafür verantwortlich machen, denn den Protokollen der Sitzungen zufolge dominierte er die Diskussion und nahm großen Einfluss auf die Formulierungen. Aber auch sein deutscher Kollege, die Russen und die Italiener unterstützten die radikale Initiative der Kommission. Es scheint so, als wollte sich, nachdem bisher immer Großbritannien und zumindest bis 1866, auch Frankreich und Sardinien die >liberale< Fraktion auf der Konferenz abgegeben hatten, nun eine neue Gruppe als Träger der Kritik an der Quarantäne profilieren. Der deutsche Delegierte Hirsch referierte auf der 6 . Sitzung:

»Une autre question qui doit nous préoccuper, est celle de connaître la proportion entre les avantages que nous offrent les cordons sanitaires et les quarantaines et les pertes qu'ils nous imposent au point de vue commercial. Vous me donnerez raison, Messieurs, si je déclare impossible aujourd'hui les premiers, et si j'ajoute que les quarantaines offrent de minces résultats, en présence des énormes sacrifices qu'elles imposent au mouvement commercial et des graves inconvénients qui en résultent pour les quarantenaires. [...] Je déclare que ces mesures d'isolement sont inutile et vexatoires, je dirais même barbares. Je dis inutiles, parce qu'aucun ne se flattera de pouvoir effectivement isoler un pays, et nuisibles, comme portant de sérieuses atteintes aux mouvements commerciaux. $\ll^{111}$

Interessant an der Kritik von Hirsch und Pettenkofer war auch, dass sie sich anders auf die genauere Praxis der Maßnahmen bezogen und daran gebunden eine andere Kategorisierung vornahmen. Demnach war die Quarantäne in erster Linie eine Praxis der Isolation. Hirsch erklärte diese Praxis und die Isolation für falsch, nicht die Quarantäne, deren Definition unklar sei. Er ging sogar so weit, die Delegierten der Konferenz von 1874 nach der genauen Bedeutung des Begriffs Quarantäne zu befragen: »il faut donc préciser tout le sens et la valeur du terme quarantaine ${ }^{112}$. Damit wurde auch deutlich, dass er die Quarantäne als ein altes System samt seiner Logik ablehnte, aber bereit war, über die Sinnhaftigkeit aller möglicher anderer Maßnahmen zu diskutieren, die, abgesehen von der Isolation, Teil der Quarantäne gewesen seien. Der spanische Delegierte Semola, der seine Argumentation für eine strengere Seequarantäne immer mit der speziellen Bedrohung Spaniens als Mittelmeerstaat verband, zeigte sich angesichts der deutschen und v.a. italienischen Position verwirrt. Selbstverständlich wolle auch er nicht die Quarantäne in ihrer alten Form erhalten,

109 Der Suez-Kanal war seit 1869 geöffnet Vgl. Vgl. Harrison: Disease, diplomacy and international commerce, 2006: S. 216.

110 Vgl. CSI-4, 1874, Séance $\mathrm{N}^{\circ}$ 5: S. 77.

111 CSI-4, 1874, Séance $\mathrm{N}^{\circ} 6$ : S. 91.

112 Ebd.: S. 90. 
konstatierte er. ${ }^{113}$ Semola unternahm einen Versuch, die Bedeutung des Begriffs der Quarantäne zu erklären. ${ }^{114}$ Er begründet die Quarantäne nur in der Hinsicht auf ihre, wenn auch geringe Fähigkeit, Menschen vor der Epidemie zu bewahren.

Die Quarantäne sei ein Mittel der Sicherung von Existenz, von Leben. Semola betrachtete das Leben in seiner Ausführung als biologisches Leben, als pure Existenz. Das war mehr oder weniger der Vorwurf, den man ihm auf der Konferenz entgegenhielt: >Die Regierung kann dieses Leben nicht nur als eine solche einfache Existenz betrachten. Die Quarantäne ist in Anbetracht der Komplexität des Lebens, auf das sich die Regierung richten muss, zu einseitig, zu oberflächlich. Wenn man nach Maßnahmen sucht, die diese Kriterien erfüllen, könnte man nicht nur fragen, ob Quarantäne durchgeführt werden sollte oder nicht.< Die Frage im Programm, ergänzte Hirsch, hätte so, wie sie dort steht, nicht beantwortet werden können. ${ }^{115}$ Während der portugiesische Delegierte, Sousa Martins, und Semola die Frage nach der Nützlichkeit der Quarantäne als eine wissenschaftliche Frage formulierten, die man nach einer Prüfung positiv oder negativ beantworten könne, ging das Urteil der liberalen Fraktion tatsächlich aus einer undefinierbaren und unklaren Menge an Faktoren hervor, die nicht alle erkennbar und beeinflussbar seien. ${ }^{116}$ Während für Semola das Leben nur das Gegenteil zum Tod sei, sei das Leben aus Sicht der liberalen Argumentation ein komplexes Phänomen in dem unterschiedliche Kräfte wirken würden und dass von einem schwer zu überschaubaren, geschweige denn steuerbaren Spiel dieser Kräfte abhinge.

Sousa Martin war ebenfalls der Meinung, dass man die Quarantäne verbessern müsse, wenn sie nicht nützlich sei, wenn sie das Leben der Menschen nicht schütze, aber er war absolut gegen die Schlussfolgerungen der Kommission, die Quarantäne abzuschaffen. ${ }^{117}$ Auch Dicksen war über den Einsatz der Kommission verwirrt. Vor allem aber deshalb, weil die Kommission die Frage der Nützlichkeit der Quarantäne als eine prinzipielle gestellt hatte, als eine politische und philosophische. Beinahe zynisch erklärte Dicksen, die Gründe für die Position Russlands, Deutschlands und Italiens wären nur die Folge innenpolitischer besonderer Zustände und Auseinandersetzungen, hätten also mit der allgemeinen Problematik der Quarantäne nichts zu tun. ${ }^{118}$

Es ist bemerkenswert, dass selbst Großbritannien, das sich bei den Diskussionen in Konstantinopel zurückgehalten und bei den Entscheidungen teilweise enthalten hatte, verwundert über die liberale Haltung Russlands, Österreichs und Deutschlands gegenüber der Quarantäne zeigte. Die drei Länder also, die nach der ersten europäi-

113 Vgl. CSI-4, 1874, Séance N8: S. 106.

114 Vgl. ebd.: S. 107f.

115 Vgl. ebd.: S. $112 \mathrm{f}$.

116 Vgl. CSI-4, 1874, Séance $\mathrm{N}^{\circ}$ 9: S. $119 f$.

117 Vgl. ebd.: S. 128f.

118 Harrison betont hingegen, dass auch die außenpolitischen Bedingungen nach der Gründung des Deutschen Reichs 1871 zu dieser Konstellation auf Konferenzen 1874 und 1885 beitrug. Das Bündnis zwischen Deutschland, Österreich und Italien, welches im Interesse eines Gegengewichts zu Frankreich geschlossen wurde, brachte die Staaten dazu, auf den Konferenzen eher die Position der Briten unterstützten. Vgl. Harrison: Disease, diplomacy and international commerce, 2006: S. 216. 
schen Choleraepidemie als autokratisch und illiberal in ihrer gesundheitspolitischen Praxis gegolten hatten, stellten sich plötzlich mit einer prinzipiellen Kritik an der Quarantäne gegen den bereits etablierten Pragmatismus. Der Standpunkt der russischen, deutschen und italienischen Delegierten war nicht direkt anti-kontagionistisch, da sie grundsätzlich anerkannten, dass die Cholera übertragbar sei. Vielmehr war ihre Haltung radikal im Sinne der Sozialmedizin, der Hygiene und der Sanitaristen, was die Praxis der Quarantäne betraf. Im Vergleich zu Großbritannien etwa, wo die Ablehnung der Quarantäne und die Befürwortung der sanitären Reformen eine etablierte Position darstellte und kaum mehr umkämpft war, verbanden sich zu dieser Zeit in Deutschland, Italien und Russland soziale und politische Auseinandersetzungen mit der Problematik der Hygiene und der öffentlichen Gesundheit. Die scharfe Kritik von Hirsch an der Desinfektion ${ }^{119}$ z.B. bezog sich auf einen deutschen Diskurs und wirkte auf der Konferenz deplatziert. In der weiteren Diskussion über die Quarantäne auf der Konferenz 1874 konzentrieren sich Frankreich und England eher darauf, den prinzipiellen Charakter der Frage der Kommission zu mildern. Auch Frankreich betonte in dieser Hinsicht, dass die unterschiedlichen Staaten unterschiedliche Interessen hätten. Aber die große Erkenntnis der vierten Konferenz war, dass die Nützlichkeit und Rationalität der Quarantäne keine Frage des Prinzips mehr sein könne. Ebenso, wie sie sich nicht prinzipiell aus der kontagiösen Eigenschaft einer Krankheit abgeleitet werden könne. ${ }^{120}$

Nachdem man wirklich begonnen hatte, die Quarantäne nicht als Prinzip, sondern als konkrete Praxis in Augenschein zu nehmen, zeigte sich ein großes und flexibel variierbares Feld an Techniken und Bedingungen, die im Einzelnen zu bewerten waren. Die Frage der Quarantäne und die Frage, wie man aus der Quarantäne oder auch ohne sie ein rationelles System der sanitären Sicherung vor der Cholera und anderen Epidemien entwicken könne, stellte sich als weitaus komplexer heraus. ${ }^{121}$ Das war die Erkenntnis der Konferenz von 1874, die den ersten Schritt zu einer ganz anderen Form der Rationalisierung der Quarantäne ermöglichte. Von welchen lokalen, sozialen, geographischen und klimatischen Bedingungen hing diese Rationalität jeweils ab? Oder anders gefragt, mithilfe welcher Rationalität war ein solches System der Sicherung rationalisierbar? Die Regierung entdeckte auch auf der internationalen Ebene erst nach und nach, wie viele unterschiedliche Ansätze und Stellschrauben ihr zur Erreichung ihrer Ziele zur Verfügung standen. ${ }^{122}$ Die hygienischen Maßnahmen wurde nicht zum Ersatzmittel für Sicherungstechniken und Maßnahmen an den Grenzen, sondern sie wurden einem expandierenden und rationalisierten Ensemble von Techniken hinzugefügt. Bekanntermaßen war Foucaults Ausgangspunkt bei der Untersuchung der Geschichte der Gouvernementalität im Rahmen seiner Vorlesungen am Collège de France sein Erstaunen über die Sicherheitstechniken oder »Sicherheitsdispositive « wie er sie zuerst nannte. ${ }^{123}$

119 Vgl. CSI-4, 1874, Séance Nº: S. 91.

120 Vgl. ebd.: S. 173.

121 Vgl. ebd.: S. 171.

122 Vgl. [Der ägyptische Delegierte Colucci Pascha]: Ebd.: S. 159.

123 Vgl. Foucault: Geschichte der Gouvernementalität I, 2004 [1977 - 1978]: S. 36; 39. 
»Die Disziplin arbeitet in einem leeren künstlichen Raum, der gänzlich konstruiert ist. Die Sicherheit ihrerseits stützt sich auf eine gewisse Anzahl materieller Gegebenheiten. Sie arbeitet selbstverständlich mit der Lage [...]. Sie bearbeitet etwas Gegebenes. [...] Es geht einfach darum, die positiven Elemente zu maximieren, so dass man auf bestmögliche Weise vorankommt, und im Gegensatz dazu Risiko und Missstand, wie den Diebstahl, Krankheiten usw. auf ein Mindestmaß zu beschränken, wobei man genau weiß, dass man sie niemals beseitigen wird. «24

Die moderne Gouvernementalität, konstatierte er in dem wohl meistzitierten Aufsatz zur Gouvernementalität ${ }^{125}$, ziehe ihr Wissen aus der Ökonomie, und ihre Techniken sind die Sicherheitstechniken. Die Regierung des Lebens überschreitet die biologische Grenze zur modernen Regierung, sie wird zur Agentin der Biopolitik. Ihr Prinzip ist es »leben zu machen « und »sterben zu lassen « ${ }^{126}$, anstatt ihre Macht darin $\mathrm{zu}$ artikulieren, dass sie entweder tötet, oder leben lässt. Die Techniken zu Sicherung des Lebens aber führen Foucault über die Anfänge der Biopolitik hinaus. Schließlich ertappte sich Foucault dabei, nicht die Geschichte der Biopolitik von den Sicherheitspolitiken her genealogisch aufzurollen, sondern eine Geschichte der liberalen Regierung aufzudecken. Die liberale Regierung ist, wie es sich auch für Foucault herausstellte, entgegen des hartnäckigen Images des Liberalismus, kein >Wenigerregieren $<$, sondern ein $>$ Mehr $<$. Es ist fragwürdig, ob das $>$ Mehr $<$ oder $>$ Weniger $<$ überhaupt der Ansatzpunkt der Kritik sein sollte. Was die liberale Regierung auszeichnet, ist eine unglaubliche Menge an neuen Techniken und gerade eine enorme Steigerung der Macht der Regierung durch ihre spezifische Form der Rationalisierung. Auf diese Weise erwies sich die liberale Kritik an der Quarantäne als ein Instrument, diese in ein vielfach effektiveres, komplexes und weitreichendes Repertoire von Techniken umzuformen, welches den einzelnen Regierungen zwar unmöglich machte, auf die alte Form der Quarantäne zurückzugreifen, ihr aber im Gegenzug ein sehr viel umfassenderes Instrument der Regierung bereitstellte.

Eine weitere Folge der Annahme dieser neuen liberalen, modernen Rationalität der Regierung auf den Konferenzen und in Bezug auf die Quarantäne war, dass ähnlich wie in dem von Großbritannien etablierten System - aus rigoroser Quarantäne hier und ihrer völligen Aufhebung dort, die restriktiven Maßnahmen, ob man sie nun Quarantäne nannte oder nicht, nicht mehr im Widerspruch zu dem System und den Techniken der hygienischen und sanitären Maßnahmen standen. Vielmehr befanden sie sich nun gemeinsam auf einer Skala unterschiedlich schwerer Eingriffe, die entsprechend der Möglichkeiten vor Ort und dem kalkulierten Risiko eingesetzt wurden. Es wurde daher unnötig, die hygienischen Maßnahmen als ein alternatives System im Rahmen eines Kampfes gegen die Quarantäne anzuführen, wie es Pettenkofer noch zu Beginn der Konferenz 1874 getan hatte. ${ }^{127}$ Ebenso wie man aufhören konnte, >Krieg< gegen die Quarantäne zu führen ${ }^{128}$, konnte man aufhören, die sanitären Maßnahmen als liberales Alternativprogramm zu dem System der Quarantäne zu

124 Ebd.: S. 38.

125 Vgl. Foucault: Die »Gouvernementalität«, 2000 [1978]: S. 64.

126 Foucault: In Verteidigung der Gesellschaft, 2001 [1975 - 76]: S. 284.

127 Vgl. CSI-4, 1874, Séance $\mathrm{N}^{\circ} 11$ : S. 188.

128 CSI-6, 1885, Procès-Verbaux, Commission Technique, Nº9: S. 219. 
propagieren. ${ }^{129}$ Die hygienischen Maßnahmen waren zwar auch schon auf den ersten Konferenzen und verstärkt auf der Konferenz von 1866 diskutiert worden, aber sie blieben bis 1885 schwer zu fassen. Sie waren der Trumpf der britischen Regierung, durch den diese sich immer wieder als fortschrittlicher gegenüber den anderen Mächten hatte profilieren können. Der Erfolg der sanitären Maßnahmen wurde anerkannt. Erfolg und Rationalität der Maßnahmen war bewundert und anerkannt worden. ${ }^{130}$ Das Argument der britischen Regierung, sich aufgrund ihres Programms an sanitären Maßnahmen von manchen internationalen Vereinbarungen der Quarantäne und anderen Beschlüssen auszunehmen, war jedoch nicht akzeptiert worden.

Auf der Konferenz 1866 wurde eine gesonderte Kommission eingesetzt, um sich mit den Möglichkeiten und den Grenzen der sanitären und hygienischen Maßnahmen $\mathrm{zu}$ befassen. Insgesamt lässt sich die Aussage des Berichts folgendermaßen zusammenfassen: Die Hygiene ist, wenn sie weit genug entwickelt sei, das rationellste und beste System der Abwehr von Krankheiten. Folglich sei die Hygiene das System der zivilisierten modernen Staaten und aufgeklärten Gesellschaften. Die Hygiene sei das System des Okzidents. ${ }^{131}$ Historisch befinde man sich gewissermaßen in der Situation, dass der Moment zwar nah sei, in dem die >zivilisierten $<$ Nationen in ein Stadion der Perfektion der Hygiene einträten, aber man habe diesen Moment noch nicht erreicht. ${ }^{132}$ Die >zivilisierten< Gesellschaften und ihre Regierungen würden ihr Wissen und ihre Techniken überall hin verbreiten und das System der Hygiene sogar bis in den >Orient< bringen. Wenn der Moment gekommen sei, würde man in der Lage sein, die Quarantäne gänzlich abzuschaffen. Man sei zuversichtlich, aber der Moment sei noch nicht da. Besonders die Cholera habe gezeigt, dass man vor allem im >Orient noch nicht so weit sei. Diese Tatsache stelle auch eine Gefahr für Europa dar. Allein aus diesem Grund sei man gezwungen, hinsichtlich der als eher rückschrittlich und weniger rational angesehenen Bevölkerungen bestimmter Regionen, die für Handel und für die Freiheit der modernen >Völker`so schädlichen Maßnahmen der Quarantäne, weiter anzuwenden. ${ }^{133}$

Die Teilnehmer der Konferenz 1866 versuchten noch, ohne die einzelnen Systeme der Quarantänemaßnahmen und der Hygiene zu verschmelzen, eine Aufteilung vorzunehmen: Erstens Quarantäne am Suez und an den Grenzen Europas, zweitens Hygiene innerhalb Europas und Abschaffung der Quarantäne an innereuropäischen Grenzen. ${ }^{134}$ Wobei über die Installation hygienischer Maßnahmen in Europa, die Sache jeder einzelnen Regierung blieb, kaum diskutiert wurde.

129 Vgl. Rapport: Sur les mesures d'hygiène à prendre pour la préservation contre le Choléra Asiatique; fait au nom d'une Commission composée de MM. Gomes, Goodeve, Lenz, Millingen, Monlau, Mühlig et Spadaro (médecins). et de MM. Keun, Malkom-Khan, Segovia et Vetsera (diplomates): Annexé (2): Vgl. CSI-3, 1866, Séance N²4: S. 1.

130 Vgl. ebd.: S. 3f.

131 Vgl. ebd.: S. 2.

132 Vgl. ebd.: S. 3f.

133 Vgl. ebd.: S. 4.

134 Vgl. »Lecture du Rapport sur les Mesures quarantenaires«: Vgl. CSI-3, 1866, Séance $\mathrm{N}^{\circ} 30$ : S. 5. 
Ein andere Streitpunkt des Berichts der Kommission, der später in der Hauptsitzung der Konferenz von 1866 zu Debatten führten, war die Frage, ob die hygienischen Maßnahmen aufgrund ihrer Relativität im Gegensatz zur Quarantäne nicht einer gewissen Gründlichkeit entbehrten. Der Gegenstand der öffentlichen Gesundheit könne von Natur aus weder perfekt noch vollständig sein. Sie sei grundsätzlich relativ und ihr Erfolg hinge stark vom historischen und sozialen Kontext ab, gab der französische Delegierte Fauvel zu. ${ }^{135}$ Die Hygiene sei weniger selbst eine Wissenschaft, als eine Kunst, die von verschiedenen Wissenschaften und dem Fortschritt und Wissen dieser Disziplinen abhänge, ergänzte sein französischer Kollege Monlau. ${ }^{136}$ Fauvel fügte später in der Diskussion noch hinzu, dass die Hygiene zwar universell anwendbar, aber nur dann effektiv sei, wenn sie an den lokalen Bedingungen des Klimas, des Boden und an der Bevölkerung eines Ortes ausgerichtet würde. Die Hygiene richte sich auf diese allgemeinen Faktoren und sei umso perfekter, desto mehr sie diese Faktoren und ein möglichst umfangreiches Wissen einbeziehe. ${ }^{137}$ Die Hygiene sei ein weiter Bereich an Maßnahmen, der eher eine allgemeine Funktion erfüllt, als dass er als sicheres spezifisches Mittel gegen eine Epidemie angesehen werden könne. Sie sei eine relative Methode zur Senkung der Sterblichkeit, zur allgemeinen Sicherung der Gesundheit und zur Abschwächung des Risikos für Krankheiten allgemein. ${ }^{138}$ Weiter legte die Kommission in ihrem Bericht den Regierungen nahe, ihr Gesundheitssystem nach dem Vorbild u.a. Großbritanniens und den local boards of health auszubauen. Außerdem empfahl sie, nach dem französischen Vorbild, Instruktionen an die Bevölkerung auszugeben, wie sich die einzelnen Menschen im Falle einer Epidemie verhalten sollten: »Instruction populaire contenant les préceptes principaux de la préservation individuelle«. Aber auch die Instruktionen müssten immer an den lokalen Bedingungen ausgerichtet werden - »écrites dans un langage à la portée du peuple et adaptées aux conditions locales. « ${ }^{139}$

Alle Elemente der strengsten Quarantäne werden sich in dem Repertoire der neuen hygienischen Techniken - »[1] es mesures s'inspiraient [...] de principes libéraux $\ll^{140}$ wiederfinden, wenn auch in einer $>$ rationalisierten $<$ Form. Als solche werden sie alles, was zuvor unspezifisch unter dem Begriff der Quarantäne gefasst wurde, ersetzen. ${ }^{141}$ Die Quarantäne, die als Technik einer Regierung bis dato der Gegensatz der Methoden der öffentlichen Hygiene gewesen ist, wird auf diesem Wege zu einer Maßnahme von vielen werden. Sie wird auf einer ganzen Bandbreite von möglichen Techniken ihren Platz einnehmen, bzw. selbst zu einer relativen Technik werden, die man den Gegebenheiten und den Möglichkeiten eines Ortes, einer Bevölkerung oder

135 Vgl.: S. 2, Vgl. auch CSI-3, 1866, Séance N²4: S. 6.

136 Vgl. CSI-3, 1866, Séance N²4: S. 7f.

137 Vgl. ebd.: S. 9. Zuspruch erhielt Fauvel vor allem von dem deutschen Delegierten Mühlig, dem Briten Goodeve und dem Italiener Bartoletti. Vgl. ebd.

138 »Après l'assainissement des ports, il faut s'occuper de l'assainissement des villes.«: Ebd.: S. 23; vgl. S. 25.

139 Ebd.: S. 37.

140 [Santoliquido, Delegierter Italiens] Vgl. CSI-11 1903, Procès-Verbaux, Séance $N^{\circ} 1$ : S. 29.

141 Vgl. [Proust] ebd.: S. 27. 
den Möglichkeiten einer Regierung anpassen muss und deren relative Effektivität man akzeptiert. ${ }^{142}$ Die Frage, ob eine Maßnahme nützlich und sinnvoll ist, wird also davon abhängen, ob eine Regierung, die sie eingesetzt hat, in der Lage ist, die entsprechenden Kalkulationen anzustellen. In diesen Rechnungen taucht das Wissen der Medizin über die Eigenschaften einer Krankheit nur als ein Faktor neben einer Reihe von anderen Faktoren auf, die sich eher auf den Ort oder die Bevölkerung und deren Eigenschaften und Lebensweise richten.

»Des facteurs nouveaux viennent s'y joindre et neutraliser jusqu'à un certain point les indications qui résultent de la doctrine scientifique. Ainsi la prophylaxie quarantenaire doit prendre en considération: $1^{\circ} 1^{\prime}$ 'élément sanitaire, c'est-à-dire la nécessité de protéger la santé publique, $2^{\circ} 1^{\prime}$ 'élément commercial, dont l'importance va sans cesse croissant, et $3^{\circ}$ la possibilité inapplication des moyens prophylactiques. ${ }^{143}$

Was bedeutet diese Art der Berechnung noch? Sie bedeutete, dass es nicht mehr um Gleichheit, übereinstimmende Regelungen und damit verbunden um eine Form der Gerechtigkeit in der Anwendung von Maßnahmen an Häfen oder gegen kontaminierte Schiffe etc. ging. Die Relativität der Maßnahmen bedeutete, dass die Festsetzung einheitlicher Regelungen gerade ungerecht und auch irrational sein müssen, weil sie die spezifischen Bedingungen eines Ortes oder Landes/Staates nicht berücksichtigen. Fauvel resümierte:

»Eh bien, Messieurs, dans l'état actuel de l'Europe, ces divers facteurs présent d'un poids trèsinégal dans la balance des intérêts engagés dans la question des quarantaines. Dans certains pays l'intérêt sanitaire est prédominant, soit parce que le climat, les habitudes hygiéniques, l'esprit des populations rendent les maladies contagieuses, et en particulier le choléra, plus redoutables; dans d'autres pays, au contraire, c'est l'élément commercial qui domine et qui vient faire obstacle à l'application rigoureuse des mesures de quarantaine. Il est donc tout naturel que l'utilité des quarantaines soit envisagée différemment, selon que l'un ou l'autre intérêt est dominant. $\ll^{144}$

Es war mehr die Frage nach der Nützlichkeit und dem Effekt, bzw. der Effektivität der Quarantäne angesichts multipler Faktoren, weniger als die nach ihrer Entsprechung mit einer medizinisch-wissenschaftlichen Wahrheit, die über die Cholera anerkannt war. Anstatt die Gleichheit und Einheit der sanitären Regelungen zu fordern, konnten Staaten mit Verweis auf eine besondere geographische Lage oder ein spezielles Klima in ihrem Land die Quarantäne aufrecht erhalten. Gleichzeitig wurde eine Differenz produziert und Ländern, die noch nicht bereit für die Abschaffung der Quarantäne waren, eine Identität aufgezwungen, die eine für sie nachteilige Ungleichbehandlung rechtfertigte. Dies war noch die Trennung und Aufteilung auf der Konferenz 1866.

142 Vgl. [Der ägyptische Delegierte Colucci Pascha]: Ebd.: S. 159.

143 Séance Nr. 10, 15 juillet 1874: in: CSI-4, 1874: Procès-Verbaux de la Conférence sanitaire internationale, ouvert à Vienne le 1 Juillet 1874, Wien, 1874: 172.

144 Ebd.: S. 172. 
Auf der vierten Konferenz 1874 gingen die Delegierten zu der Frage über, ob eine Rationalisierung der Quarantäne möglich sei. In diesem Zusammenhang wurde auch über eine Umbenennung der ihr zugehörigen Praktiken diskutiert. Aber war die Quarantäne nicht zu sehr assoziiert mit einer alten Praxis? Das erste Programm der Konferenz von 1885 sah eine erneute Diskussion der Quarantäne vor. Alle bereits auf anderen Konferenzen, in Konstantinopel und in Wien diskutierten Fragen der Quarantäne sollten erneut diskutiert und abgestimmt werden. ${ }^{145}$ Es ging darum, die bestehenden Beschlüsse einer Revision entlang des alten Programms der Konferenz von Wien (1874) zu unterziehen. ${ }^{146}$ In der Zwischenzeit hatte 1881 die Konferenz in Washington getagt. Der Modus der Rationalisierung internationaler sanitärer Politik hatte schnell auch die Praxis der Verhandlung verändert. Die Diskussion über die Maßnahmen, die die Quarantäne an Land betrafen, verlief erwartungsgemäß noch ohne größere Schwierigkeiten. ${ }^{147}$ Die Diskussion zur Seequarantäne zu Wasser und an den Flussmündungen gestaltete sich dagegen nicht so einfach. Schon nach wenigen Sitzungen der technischen Kommission wurde deutlich, dass es kaum eine Möglichkeit geben würde, wie noch auf der Konferenz von Wien 1874, über die Quarantäne zu diskutieren. ${ }^{148}$ Die Quarantäne und alles, was man sich früher darunter vorgestellt hatte, wurde von keinem der teilnehmenden Delegationen mehr als vernünftig angesehen. Auf der anderen Seite befürwortete keine Regierung, nicht einmal die Britische, eine völlige Abschaffung aller vorhandenen Quarantänepraktiken. ${ }^{149}$ Es war hierdurch einerseits unnötig und unmöglich geworden, die Irrationalität der alten Quarantäne immer wieder zu betonen. Vielmehr kümmerte man sich darum, die Quarantäne zu rationalisieren, in dem man sie durch eine ganze Reihe von Maßnahmen ergänzt. Der italienische Delegierte Baccelli kommentierte:

»On ne fait pas la guerre ici aux quarantaines par idée préconçue. Il s'agit simplement de les remplacer par des moyens de préservation raisonnables, inspirés par les progrès de la science et de l'expérience médicale. $\ll^{150}$

Eine völlige Abschaffung der Quarantäne komme nicht in Frage. Dies würde bedeuten, alle Techniken der Beschränkung und der Prüfung an den Grenzen oder ab bestimmten Passierstellen auszusetzen. ${ }^{151}$ Was wollte man der Quarantäne hinzufügen? »Renseignements sur l'état sanitaire des ports «, »désinfection à bord; »isolement des maladies « und »[m]esures d'assainissement au point de départ«, all diese detaillierten

145 »Projet de Question prealable: 1. Question sur les mesures de quarantaine en temps de choléra. 2. Question au sujet de l'institution d'une Commission internationale appelée à combattre les épidémies. 3. Question relative à des mesures de quarantaine à prendere contre des épidémies pouvant régner parmi les hommes et qui cont autres que le choléra. «: CSI-6, 1885, Protocole $\mathrm{N}^{\circ} 1$ : S. 6.

146 Ebd.: S. 5.

147 Ebd.: S. 56.

148 Vgl. CSI-6, 1885, Procès-Verbaux, Commission Technique, N4: S. 110.

149 CSI-6, 1885, Procès-Verbaux, Commission Technique, N³: S. 101.

150 CSI-6, 1885, Procès-Verbaux, Commission Technique, Nº ${ }^{\circ}$ S. 219.

151 Vgl. [Brouardel] Ebd.: S. 101. 
Techniken machten die Quarantäne zu etwas anderem als sie es früher war und auf diese Weise wurde sie akzeptierbar. ${ }^{152}$ Damit zeigt sich auch, dass die Quarantäne nicht mehr in erster Linie eine Praxis der Isolation oder der Verwahrung sein konnte. Sie wurde in dieser Bedeutung ausgehöhlt. Stück für Stück wurde ihre Bedeutung und Praxis transformiert von einer Praxis des Ausschlusses, der reinen Isolation und Verwahrung in eine Praxis der medizinischen, hygienischen Untersuchung und genaue Beobachtung. Sie wurde in eine Praxis der Reinigung, Desinfektion und Hygiene und Zertifikation verwandelt. Die Isolation war nicht mehr selbstverständlicher Teil der Quarantäne. Das war der Grund, warum die Isolation als eigene Praxis zum ersten Mal im Zusammenhang mit der Quarantäne separat erwähnt wurde. Weil die Quarantäne kein Synonym mehr für eine Praxis der Isolation war. Die Isolation konnte immer noch ein Teil von ihr sein, aber sie war zugleich etwas abgetrenntes, eigenes, das, wie die Desinfektion und die medizinische Inspektion, zu einem Baustein einer auf Ort und Risiko abgestimmten Quarantäne gehören konnte.

Die Diskussionen um die sanitären Maßnahmen, medizinischen Inspektionen von Schiffen und der Ausstellung von Zertifikaten, sog. »patentes« knüpfte an Diskussionen auf der Konferenz von Wien 1874, und der Diskussionen um die »bill of heath (»patente de santé«) der Konferenz von Washington 1881 an. ${ }^{153}$ Dort wurde das System einer bestimmten Regierung und Überwachung der Gesundheit einer Bevölkerung als Aufgabe der Innenpolitik immer öfter Thema. Diese Aufgabe der Regierung stand nicht mehr im Widerspruch oder wurde als Alternative zur Quarantäne empfohlen, sondern wurde als ein Teil der selben langfristigen Strategie betrachtet. ${ }^{154}$ Das neue System der Maßnahmen, welches sich aus der Annahme einer anderen Rationalität ergab, mobilisierte neue Bereiche des Wissens und fordert, eine ganze Reihe von neuen Differenzierungen deutlicher vorzunehmen, als dies bisher der Fall gewesen war. Wie schon erwähnt, blieb die Praxis der Isolation und Beobachtung neben der medizinischen Inspektion, der Desinfektion und allen möglichen Praktiken der Reinigung bestehen und fügte sich nun in ein ganzes, im Prinzip sich immer weiter ausdifferenzierendes Repertoire an Maßnahmen. So enstand ein Ensemble von Techniken, das auf die unterschiedlichsten Situationen und Bedingungen angepasst und eingesetzt werden sollte. Parallel hierzu erfolgte die genauere Ausdifferenzierung und Grenzziehung der Gegenstände, auf die sich diese Techniken beziehen sollten. Klarer und wichtiger und unter Aufbringung neuen Wissens wurde nun feiner unterschieden zwischen gefährlichen und unbedenklicheren Schiffen, Orten, Gegenständen und Menschengruppen, die zum Gegenstand der Maßnahmen gemacht werden sollten. Wie auch Valeska Huber bemerkte, blieb der Modus der Differenzierung und Identifikation besonderer Risiken auch auf den späteren Konferenzen zentral:

»The convention added some more categories to the list of suspect cholera transmitters: it prescribed special precautions against different groups of people, more specifically, >against gyp-

152 CSI-6, 1885, Procès-Verbaux, Commission Technique, N4: S. 110.

153 Vgl. CSI-6, 1885, Procès-Verbaux, Commission Technique, N5: S. 119f.

154 Vgl. [Brouardel] CSI-6, 1885, Procès-Verbaux, Commission Technique, Nº4: S. 114. 
sies and habitually itinerant people, against emigrants, against people who, to practice their job, have to wander back and forth across the border $<[\ldots] . \ll^{155}$

Auf der sechsten Konferenz 1885 schlug Koch im Namen der deutschen Delegation vor, eine Unterscheidung von Schiffen, die Waren transportierten, und Schiffen, die große Mengen von Menschen beförderten (»grandes masses de personnes, émigrants, coolies, pèlerins, troupes, etc.«) vorzunehmen. Letztere stellten seiner Meinung nach ein größeres Risiko für die Verbreitung von Krankheiten dar. ${ }^{156}$ Die Mekka-Pilger blieben auf der Grundlage einer ähnlichen Einschätzung, die bereits seit der Konferenz 1866 deutlich geworden war, zum Gegenstand rigoroser Quarantänepraktiken am Suez-Kanal. Auf der Konferenz 1885 betrachtete man die Pilger unter anderen Gruppen weiterhin als besonderes Risiko für die Einschleppung der Cholera nach Europa. Auf der siebten Sitzung der technischen Kommission am 29. Mai 1885 wurde eine weitere Kommission ernannt, die sich speziell mit dem Problem der Pilger aus Mekka beschäftigen sollte. Der französische Delegierte Rochard bekräftigte die Aufgabe der Subkommission:

»La question du pèlerinage de la Mecque intéresse tous les Etats européens au même degré. Ce pèlerinage est un des grands moyens d'expansion du choléra. C'est une menace constante pour l'Europe et ce ne sont pas seulement les puissances qui ont des possessions dans l'Inde qui doivent être appelées à résoudre cette question. «157

Wurden die undifferenzierten militärischen Grenzkordons auch weiterhin abgelehnt, so wurde die Kontrolle an den Grenzen doch insgesamt eher verbessert, als verringert. Dazu gehörte mehr noch als zuvor die Frage, wo der günstigste, der am wenigsten schädliche und effektivste Ansatzpunkt der Maßnahmen gegen die Verbreitung der Cholera sein würde. Das Projekt, die Quarantäne und andere Maßnahmen vor allem an den Grenzen Europas zu etablieren, oder genauer »aux points ordinaires d'entrée du choléra en Europe«, und dagegen die Quarantäne zwischen den europäischen Staaten aufzuheben, wurde weiter fortgesetzt. ${ }^{158}$ Der französische Delegierte, Proust, erinnerte auf der Konferenz 1885:

»[N]otre but a toujours été de diminuer la rigueur des mesures prises en Europe, là où elles perdent beaucoup de leur efficacité: mais nous demandons comme compensation que l'entrée du choléra soit absolument fermée dans la Mer Rouge, par un système de surveillance rationnel établi sur cette mer. $\ll^{159}$

155 Huber: The unification of the globe by disease?, 2006: S. 468.

156 Vgl. CSI-6, 1885, Procès-Verbaux, Commission Technique, ํ3: S. 96.

157 CSI-6, 1885, Procès-Verbaux, Commission Technique, Nº 7: S. 143.

158 [Semola]: »[L]es quarantaine maritimes dans les ports d'Europe, lorsqu'il existe déjà des foyers de choléra sur le continent, sont inutiles«: CSI-6, 1885, Procès-Verbaux, Commission Technique, $\mathrm{N}^{\circ} 3$ : S. 97.

159 CSI-6, 1885, Procès-Verbaux, Commission Technique, Nº8: S. 172. 
Aus dem Gegensatz der Systeme der Quarantäne und der Hygiene wurde auf diese Weise ein flexibles Ensemble von Techniken, dass sich der Rationalität der Hygiene und der Sanitaristen angepasst hatte und dass auf diese Weise jede noch so restriktive Praxis unter bestimmten Umständen in eine rationale Maßnahme verwandelte. Die öffentliche Hygiene, die, wie Foucault schrieb, Ende des 18. Jahrhunderts zunächst als eine $»$ raffinierte Variante der Quarantäne $\ll^{160}$ entstanden war, hat zum Ende des 19. Jahrhunderts die Quarantäne, nachdem sie sie ihrer Rationalität unterworfen hatte, als eine ihrer Techniken integriert. Auf diese Weise ist sie zu einer rationalen Regierungstechnik, die absolut nichts mit der hässlichen, überkommenen Praxis der Quarantäne mehr zu tun hatte, geworden.

Diese Rationalisierung der Quarantäne blieb nicht nur begrenzt auf Maßnahmen gegen die Cholera. Auch bezüglich der Pest beschloss die Konferenz 1897 eine Rationalisierung nach diesem Muster. Nach der Konferenz von 1885 wurden alle Bereiche, die die Konvention bis dahin umfasste, in dieser Hinsicht überarbeitet. Die Phase ab den 1890ern $(1892,1893,1897)$ und schließlich 1903 können als eine Phase der Anpassung der vorherigen Programme und Einigungen an diese Rationalität betrachtet werden.

\section{Von der AbgrenzUng ZUR RegIERUng DES >ORIENTS،}

Wie bereits erwähnt, spielte auch ein gewisses Verfahren der moralischen Differenzierung und damit einhergehend die Abgrenzung gegenüber einer >alten $<$, >illiberalen<, >despotischen< Form der Regierung für die Konstruktion einer >guten Regierung< eine wichtige Rolle. Die Differenzierung der verschiedenen Subjektivitäten bezog sich dabei nicht nur auf das Selbstbewusstsein der Regierung, sondern auch auf die unterschiedlichen Subjektivitäten der Regierten. Etwas vereinfacht lassen sich eine Reihe von Aussagen in dieser Funktion der Konstruktion und Unterscheidung von guten und schlechten Regierungen und unterschiedlich zu regierenden Bevölkerungen nachzeichnen. Es handelt sich um Aussagen über die Existenzweise von Menschen oder Bevölkerungen und daran geknüpfte Aussagen über legitime Techniken und Rationalitäten einer Regierung, die sie regiert. Immer wieder finden sich in den Konferenzprotokollen Formulierungen einer gemeinsamen Identität, die für gemeinsame Kriterien für moralische Subjektivität und gute Regierung stehen: >Wir sind die Regierungen der >zivilisierten Völker $<$; $>$ wir $<$ sind in der Lage die Regeln der Hygiene zu verstehen. $>$ Unsere $<>$ Völker $<$ sind moralisch, ihre Lebensführung ist moralisch. Aber sie sind auch rational. Sie brauchen Freiheit. Ihre Existenz hängt von der Freiheit, ihrer Kommunikation untereinander und von der Bewegung und der Freiheit des Handels ab. >Unsere Völker< sind fortschrittlich und aufgeklärt, sie akzeptieren keine Beschränkungen mehr, die irrational und willkürlich sind. Sie können keine nutzlose Zeit in der Quarantäne verbringen, weil Zeit für sie einen hohen Wert hat. Wie ist es aber z.B. mit den >Völkern < des >Orients $<$ ? Haben diese überhaupt ein Zeitgefühl? Einen Sinn für den Wert der Freiheit? Sind sie aufgeklärt? Wie muss man sie regieren? Wie ist es mit den unterschiedlichen Klasse in einer Gesellschaft, muss 
man sie nicht unterschiedlich regieren? Auf jeden Fall gibt es in den Konferenzprotokollen einen ganzen Bereich von Aussagen, die in dieser Weise funktionieren. Es ist zugleich die Verkündung einer neuen Zeit, einer grundlegenden Neubetrachtung, einer Erkenntnis über eine vernachlässigte Wahrheit der Regierung, des Verhältnisses zu ihren Regierten und des Verhältnisses zu anderen Regierungen.

Ich werde mich in dem folgenden Abschnitt allein auf die Differenzierung zwischen Europa und dem Orient konzentrieren. Die Differenzierung der Regierung unterschiedlicher Klassen ist ja auch bei der Betrachtung der einzelnen Länder in den vorrangegangenen Kapiteln immer wieder Thema gewesen.

Die Konferenz von 1866 zeichnete sich durch eine Stimmung der Panik und der absoluten Dringlichkeit aus. Die offensichtlichen Gründe hierfür waren, dass sich scheinbar eine weitere Cholerapandemie von Osten her in Richtung Europa ausbreitete und im Laufe des Jahres schließlich Ägypten, also die Küste des Mittelmeers erreichte. Auch im späteren Verlauf der Konferenz trafen immer wieder Telegramme ein, die von der Ausbreitung der Pandemie zeugten. Nicht alle Delegierten teilten die Einschätzung der französischen Delegation über die Dringlichkeit. Oder sie hielten es für schwierig in dieser Frage, die so viele gemeinsame Einsichten etwa über den Herkunftsort der Cholera erfordere, Druck auf die Delegierten auszuüben. Vor allem Frankreich war der Überzeugung, dass die muslimischen Pilger, die auf dem Weg nach Mekka, oder auf der Heimreise, angeblich bereits während der vergangenen Pandemie als ideales Vehikel für die Cholera gedient hatten, erneut zu einer »Gefahr für ganz Europa« werden könnten, sollte die Cholera in Mekka ausbrechen:

»Nous voulons parler des mesures à prendre pour le cas où le choléra se manifesterait cette année parmi les pèlerins réunis à La Mecque. Nous aimons à espérer que cette éventualité ne se réalisera pas; mais enfin rien ne nous le garantit, et il est de notre devoir, pour répondre dignement à la confiance placée en nous par nos Gouvernements respectifs, de nous prémunir contre ce danger. Voyez, en effet, Messieurs, quelle triste chose ce serait si, tandis que nous discuterions gravement sur l'origine et les moyens de prévenir l'importation du choléra, cette maladie faisait une nouvelle irruption à la suite des pèlerins! C'est donc une mesure de précaution en vue d'un péril prochain que nous venons soumettre d'urgence à vos délibérations. $^{161}$

Entsprechende Vorkehrungen zur Sicherung Europas sollten am Suez, am Roten Meer, an den Häfen Ägyptens und des Osmanischen Reiches getroffen werden. Auf der Konferenz in Konstantinopel waren Delegierte aus Ägypten und dem Osmanischen Reich vertreten. Nach dem Wortlaut der Französischen Delegation sollte die Umsetzung solcher Maßnahmen im Einverständnis der Regierung des Osmanischen Reichs und der ägyptischen Autoritäten stattfinden. Dennoch war das Verhältnis der Delegierten von Anfang an durch Asymmetrie geprägt, wie auch Valeska Huber feststellt. ${ }^{162}$ Von der »fraternité humaine « und ideellen Grundlagen der Einigung, die der

161 Propposition: Sur les mesures à prendre dans le cas où le choléra se manifesterait cette année par/ni les Pèlerins réunis à La Mecque, présentée par les Délégués du Gouvernement français [A. de Lallemand und Fauvel]: Annexé (1): CSI-3, 1866, Séance N 1 : S. 1.

162 Huber: The unification of the globe by disease?, 2006: S. $460 f$. 
ägyptische Vertreter A'Ali Pascha in seiner Eröffnungsrede beschwor, war in den späterem Diskussionen wenig zu spüren. ${ }^{163}$

»Contrary to this description of humanity as one big family, the conference was heavily biased towards Europe, as the list of members shows. [...] The proceedings are teeming with condescending Eurocentric expressions. More than once Europeans conceptualized the project of the conferences as a civilizing mission geared towards the >Orient $<$ under the aegis of hygiene and compared themselves either to the Roman Empire or to the Christian crusaders. «164

Der Antrag der Franzosen enthielt den Vorschlag der vollständigen Unterbrechung des gesamten Schiffsverkehrs im Mittelmeer zwischen den Häfen Arabiens und des Osmanischen Reichs und der Ägyptischen Küste. ${ }^{165}$ Nur eine Quarantäne am Suezkanal oder in Ägypten einzurichten, sei bereits zu riskant, hieß es. ${ }^{166}$

Da man die Verbreitung der Cholera auf dem Landweg für weniger gefährlich einschätzte, plädierten die französischen Delegierten in ihrem Vorschlag dafür, die Pilger zu einer Rückreise auf dem Landweg, das bedeutete zu einer Karawane durch die Wüste, zu bewegen: »[U]ne longue marche par étapes dans le désert était, contre le choléra, la meilleure des quarantaines ${ }^{167}$. Die türkischen Delegierten bezweifelten die Ansicht der Franzosen, dass der Landweg eine ausreichende >Quarantäne« darstelle: »[T]rès souvent il [le choléra] préfère suivre dans sa marche les grandes routes de terre. Plusieurs épidémies en font pleinement foi. « ${ }^{168}$ Abgesehen davon, wäre es schwierig den Schiffsverkehr mit kleineren Boten zu verhindern. Eine Schließung der Häfen würde gerade dazu führen, dass dieser unkontrollierbare Verkehr über das Rote Meer zunehmen würde. ${ }^{169}$ Als Konsequenz hieraus folgerten die osmanischen Delegierten, man müsse ein System der Einschiffung der Pilger entwickeln, »substituer à l'interdiction maritime absolue un système méthodique d'embarquement $\ll .{ }^{170}$ Die Einrichtung von Lazaretten, Camps und Baracken in den arabischen Häfen sei außerdem erforderlich. ${ }^{171}$ Der Antrag, unterzeichnet durch den osmanischen Delegierten

163 Vgl. CSI-3, 1866, Séance $\mathrm{N}^{\circ} 1:$ S. 3.

164 Huber: The unification of the globe by disease?, 2006: S. 460.

165 Vgl. ebd.: S. 6.

166 Vgl. Propposition: Sur les mesures à prendre dans le cas où le choléra se manifesterait cette année par/ni les Pèlerins réunis à La Mecque, présentée par les Délégués du Gouvernement français [A. de Lallemand und Fauvel]: Annexé (1): CSI-3, 1866, Séance $\mathrm{N}^{\circ} 1$ : S. 2 und 6.

167 Ebd.: S. 6.

168 Ebd.

169 Ebd.: S. 4.

170 Rapport de la Commission chargé d'examiner la proposion, résentée par MM. les Délégues du gouvernement français, sur les mesures à prendre dans le cas où le choléra se manifesterait cette année parmi les pèlerins réunis à La Mecque. Annexé (1): CSI-3, 1866, Séance $\mathrm{N}^{\circ} 3$ : S. 3.

171 Vgl. Projet d'amendement concernant la proposition d'urgence de MM. Les Délégués du Gouvernement Français présenté par les Délégués de la Sublime-Porte. Annexé (3): Vgl. CSI-3, 1866, Séance N³: S. 8. 
Bartoletti, begründete dessen Vorschlag auch damit, dass man strategischer verfahren müsse und das Verhalten und die Wahrnehmung der Maßnahmen durch die muslimischen Pilger berechnen müsse. ${ }^{172}$ Der Franzose Fauvel protestierte während der Diskussionen in der Kommission, die Umsetzung einer jeder der vorgeschlagenen Alternativen sei illusorisch: Sowohl ein organsiertes System der Verschiffung der Pilger als auch notdürftig eingerichteten Lazarette und Quarantänemaßnahmen in Ägypten böten keine ausreichende Sicherheit gegen die Einschleppung der Cholera nach Europa. ${ }^{173}$ Der persische Delegierte Sawas reichte einen Vorschlag ein, welcher einerseits auf das Problem der politischen Umsetzbarkeit des französischen Vorschlags abzielte, als auch auf die Gewohnheiten und Sitten der muslimischen Pilger, bzw. der Menschen Asiens und des Orients allgemein. ${ }^{174}$ Den muslimischen Pilgern eine Rückreise über das Meer zu verbieten und ihnen stattdessen einen beschwerlichen und gefährlichen langen Fußmarsch und Weg auf dem Landweg zuzumuten, sei für die Regierungen der muslimischen Bevölkerungen schwer zu vermitteln.

»[S] upprimer complètement le pèlerinage et forcer les pèlerins à rester tranquillement chez eux [...] leur interdire absolument la voi de mer, c'est à dire de les condamener, au nom de l'humanité, à périr de faim et de midère dans le désert.«: Rapport de la Commission chargé d'examiner la proposion, résentée par MM. les Délégues du gouvernement français, sur les mesures à prendre dans le cas où le choléra se manifesterait cette année parmi les pèlerins réunis à La Mecque. ${ }^{175}$

Abgesehen hiervon, sei es ebenso unmöglich die Pilger in Mekka festzuhalten, da es bald an Wasser und Lebensmitteln fehlen würde, vor allem aber sobald dort eine Epidemie ausgebrochen sei. ${ }^{176}$ Sawas Kollege, der persische Delegierte, Mirza-Malkom-Khan insistierte in der Diskussion der Kommission:

»[L]a proposition française, sans parler de sens autre inconvénients, aurait celui de soulever des tempêtes de haine dans le monde musilman et de créer les plus graves difficultés aux Gouvernements Orientaux. Les idées, les mœurs, les doctrines et la logique de l'Asie sont tellement différentes de celles de l'Europe que cette seule idées que les Souveraines Musulmans se sont entendues avec les Puissances Européennes pour réglementer la marche des pèlerins, suffirait pour changer complètement les rapports de ces Souverains avec leurs sujets et pour les mettre en but aux attaques d'un fanatisme d'autant plus violent que, dans ces derniers temps, tout a été fait pour le comprimer. [...] [L]a tâche des puissances Musulmanes est pleine de difficultés et

172 Projet d'amendement concernant la proposition d'urgence de MM. Les Délégués du Gouvernement Français présenté par les Délégués de la Sublime-Porte. Annexé (3): Vgl. CSI-3, 1866, Séance N³: S. 7f.

173 Vgl. ebd.: S. 4.

174 Vgl. ebd.: S. 3.

175 [Mirza-Malkom-Khan] Annexé (1): CSI-3, 1866, Séance N³: S. 7.

176 Vgl. Projet d'amendement concernant la proposition d'urgence de MM. Les Délégués du Gouvernement Français présenté par les Délégués de la Sublime-Porte. Annexé (3): Vgl. CSI-3, 1866, Séance N³: S. 5. 
de dangers, et qu'il n'est donné à aucun gouvernement, même dans les pays les plus civilisées, de détruire à son gré les préjugés de ses peuples. «177

Die Kommission wurde sich über die verschiedenen Vorschläge nicht einig und trat schließlich mit ihrem ergebnislosen Bericht vor die 4. Plenarsitzung. Aber auch dort drehte sich die Diskussion weiter im Kreis. Der Konflikt war zunächst relativ offensichtlich. Die französische Delegation, die größtenteils von den anderen europäischen Delegierten unterstützt wurde, wollte eine aus Sicht Europas einfache und eindeutige Vereinbarung mit der persischen und vor allem der osmanischen Regierung treffen, die die Unterbindung der Rückkehr der Pilger nach Ägypten auf dem Seeweg sicherstellen sollte. Ihr Fokus war völlig auf das Ziel der Sicherung Europas gerichtet. Die Umsetzung und die politischen Bedenken, die von Sawas und Bartoletti geäußert wurden, waren aus dieser Perspektive und für dieses Interesse relativ irrelevant. Die Vertreter des Osmanischen Reiches und Persiens unternahmen im Prinzip den Versuch, mit allen Mitteln und den auf der Konferenz anerkannten Strategien und Rationalitäten, Anerkennung für die Komplexität des Problems und die Schwierigkeit der Umsetzung durch ihre eigenen Regierungen zu erhalten. Indem sie diese Schwierigkeiten im Zusammenhang mit den Besonderheiten der Bevölkerung des Orients erklärten, bedienten sie sich der auf der Konferenz üblichen Modi der Differenzierung von zu regierenden Subjekten. Die häufig wiederholte Betonung der Besonderheiten der Sitten, Gewohnheiten und Schwierigkeiten, die es bedeutet, die Pilger zu regieren, wurde aber in der Argumentation der französischen Regierung anders aufgegriffen und bewertet. Diese Besonderheiten seien gerade der Grund dafür, dass statt den üblichen sanitären Maßnahmen eher auf eine absolute Unterbrechung des Schiffsverkehrs gesetzt werden müsse, erklärte Fauvel. In der 4. Plenarsitzung ging Fauvel auf das Problem ein, indem er der persischen Delegation in etwa Folgendes sagt: Ihr braucht uns nicht zu erzählen, wie >rückständig< ihr seid bzw. >unzivilisiert< eure Bevölkerungen sind, denn das wissen wir ja schon. Auch den Vorschlag der osmanischen Delegation wies Fauvel auf diese Weise zurück. ${ }^{178}$ Eine andere Bevölkerung, legitimierte für die Delegierten eine andere Regierung, genauer gesagt, eine andere Rationalität und ein anderes Verfahren der Gouvernementalität. Die muslimischen Pilger seien nicht regierbar, oder zumindest anders oder schwerer zu regieren, als die europäischen >Völker $<$ : »L'histoire nous apprend que les pèlerins ne sont pas les hommes les plus faciles à gouverner. ${ }^{179}$ Auf strategische politische Überlegungen, die auf den Grad der >Aufklärungく, die Vorurteile und Ängste der Bevölkerungen eingingen, waren durchaus akzeptierter Bestandteil der Diskussionen um die Regierung der Bevölkerungen in Europa. Für die muslimischen Bevölkerungen trafen aber diese Bedingungen nicht zu. Sie konnten nicht zur Bedingung der Regierung gemacht werden, da davon ausgegangen wurde, dass eine Regierung, die sich der Logik

177 Rapport de la Commission chargé d'examiner la proposion, résentée par MM. les Délégues du gouvernement français, sur les mesures à prendre dans le cas où le choléra se manifesterait cette année parmi les pèlerins réunis à La Mecque. Annexé (1): CSI-3, 1866, Séance N³: S. 7.

178 Vgl. CSI-3, 1866, Séance N4: S. 17f.

179 CSI-3, 1866, Séance N5: S. 14. 
dieser Bevölkerungen anpasste, allen übrigen Bedingungen einer fortschrittlichen und modernen Regierung nicht mehr entsprechen könne. Eine solche Regierung musste ihre Rationalität, einer Anerkennung durch eine irrational denkende Masse opfern. So wie die persische Regierung, bzw. die persischen Delegierten, welche laut Fauvel:

»[C]'est évident, n'ont eu qu'une seule préoccupation, - celle de sauver les apparences; - il suffit d'avoir l'air de secourir les pèlerins; - peu importe si les mesures qu'on propose sont de nature à aggraver leur situation. Périssent les pèlerins, périssent les populations européennes ravagées par le choléra, mais que les apparences soient sauvées! Messieurs, si de tels principes peuvent avoir cours en Orient, il n'en saurait être de même au sein de la Conférence. [I]l n'en est pas mois vrai qu'à leur insu, et par suit de cette logique asiatique sont il a été question, ils ont été amenés à des conséquences que, sans doute, ils ne prévoyaient pas. ${ }^{180}$

Die moderne Regierung müsse sich auf die Fakten beziehen. Man könne nicht, so Fauvel, die Fakten ignorieren aus Rücksicht auf die Sitten einer Bevölkerung. Ebenso sei es nicht akzeptabel, die europäischen >Völker $<$ zu gefährden, nur um den Schein einer Regierung im Orient aufrecht zu erhalten, die in Wirklichkeit nicht in der Lage sei, effektiv zu regieren. Die Konferenz verhandele nicht in diesem Modus der Politik! ${ }^{181}$ Sie sagten: >Verschont die Konferenz mit eurem Gejammer über die Schwierigkeiten, die euch eure irrationale Bevölkerung bei der Umsetzung rationaler Maßnahmen macht. Das ist nicht unser Problem.<

»Les questions sanitaires que nous avons à traiter ne sont pas, en effet, de celles qui se prêtent aux tempéraments, aux moyens de conciliation de la politique. On ne transige pas avec le choléra. Le choléra est un ennemi brutal, qui se joue de tous les ménagements, de toute les prévenances. [...] [N]e pas vous préoccuper des prétendus difficultés politiques qui pourraient résulter de notre projet. Ce n'est pas notre affaire. ${ }^{182}$

Nicht ohne Grund erinnerte Fauvel die Delegierten Persiens daran: »La Conférence a un but exclusivement humanitaire de lui d'étudier le choléra et de proposer les moyens de s'en préserver. ${ }^{183}$ Das einzige Argument, das bezüglich des Umgangs mit den Pilgern zählte, war das >humanitäre «. Man konnte die muslimischen Pilger nicht als Subjekte regieren - nicht aus Sicht einer rationalen Regierung, aber man konnte sie als Opfer, als Menschen, die Hilfe benötigen, regieren, denn die Subjektivität einer modernen Regierung bestand auch aus ihrer überlegenen Moralität. Sie konnte genau aus dieser moralisch überlegenen Position der rationellen Regierung die Pilger als Menschen betrachten, ohne sie als Subjekte zu sehen. Dies ist vermutlich das fatalste Erzeugnis des Humanismus: Die Anerkennung aller Menschen als Menschen bei einer gleichzeitigen Ausdifferenzierung ihrer Subjektivitäten nach ihrem Wert, ihres >Entwicklungsstands $<$, ihrer Moralität und Vernunft. Diese unter-

180 CSI-3, 1866, Séance N4: S. 19.

181 Vgl. ebd.

182 Ebd.: S. $19 f$.

183 Ebd.: S. 19. 
schiedlichen Subjektivitäten sind es schließlich, wonach sich die Regierung ins Verhältnis zu ihren Regierten setzt und bestimmt, welche Techniken anzuwenden sind. Die Reduktion von Menschen auf das Menschliche entbehrte, die Idee einmal bis zu Ende gedacht, gänzlich der Notwendigkeit, ihnen eine Subjektivität zuzuschreiben, die eine Regierung in einer Art intersubjektiven Verhältnis ernst zu nehmen hatte. Edward Said bemerkte hierzu:

»The point is that the very designation of something as Oriental involved an already pronounced evaluative judgment, and in the case of the peoples inhabiting the decayed Ottoman Empire, an implicit program of action. Since the Oriental was a member of a subject race, he had to be subjected: it was that simple. $\ll^{184}$

Auf der Konferenz 1866 kam diese Differenzierung von europäischen, bzw. okzidentalen und orientalischen >Völkern< und der Verschiedenheit der Regierungslogiken, mit denen man sich auf sie beziehen sollte, sehr deutlich zum Vorschein. Nach der Zurückweisung der Gegenvorschläge der persischen und osmanischen Regierungen änderte die persische Delegation ihre Strategie. In den folgenden Diskussionen fand die persische Delegation nur noch in dem Maße Gehör, wie es ihr gelang, die Vorschläge der französischen und osmanischen Delegation hinsichtlich ihrer inhumanen Umgangsweise mit den Pilgern, mit den Menschen, zu kritisieren. Es seien doch immer noch Menschen, die man dort in der Wüste verdursten und verhungern lassen würde! ${ }^{185}$ Vor allem die osmanische Delegation, die über die Situation und die Bedingungen in Hedjaz informiert sei, hätte wissen müssen, welches Unglück ihr Vorschlag für die Pilger bedeuten würde. ${ }^{186}$ Es sei egoistisch von den europäischen Mächten, nur ihre Interessen (»préoccupant que des intérêts de l'Europe) im Sinn zu haben und die Pilger buchstäblich in die Wüste zu schicken (» à les laisser sans ressources au milieu du désert ${ }^{187}$ ).

Fauvel, der sich gegen den Vorschlag und den Antrag von Bartoletti, also gegen die Einrichtung der Quarantäne am Suez und in den arabischen Häfen stellte, setzte der Kritik der osmanischen und persischen Delegierten entgegen, dass, wenn die Reise durch die Wüste nicht möglich sei, die jeweiligen Regierungen eben gewährleisten müssten, dass die Pilger so lange blieben, bis der Schiffsverkehr wieder ohne Gefahr für Europa aufgenommen werden könne. ${ }^{188}$ Allen Warnungen und Versuchen zum Trotz, setzte sich schließlich der Vorschlag der Franzosen mit Hilfe der Mehrheit der europäischen Delegierten ohne eine nennenswerte inhaltliche Änderung durch. Die Entscheidung zeigt, dass letztlich relativ wenig Interesse an der Bewahrung der Freiheit der Pilger, noch deren körperlicher Unversehrtheit bestand. Widerstand oder Zuwiderhandlung durch Pilger sollte in erster Linie mit Repressionen und Kontrollen entgegengewirkt werden. ${ }^{189}$

184 Said, E.: Orientalism, 1977: S. 208.

185 Vgl. [Mirza-Malkom-Khan] CSI-3, 1866, Séance ํ5: S. 4.

186 [Mirza-Malkom-Khan] Ebd.: S. 4.

187 Ebd.: S. 5.

188 Vgl. ebd.: S. 26.

189 Vgl. ebd.: S. 40, 44. 
Mit dem Beschluss des Vorschlags der Franzosen zur temporären Unterbrechung des Schiffsverkehrs war das Thema der Pilger aber nicht vom Tisch. Während der weiteren Diskussion auf der Konferenz wurde die Differenz des >Orients $<$ zu $>$ Europa immer wieder ins Zentrum der Entscheidungen um die Quarantäne und die grundlegende Differenzierung internationaler Maßnahmen gegen die Cholera gestellt. Sie war immer wieder Ausgangspunkt für die Differenzierung von Techniken, nicht nur einer $»$ Police sanitaire du pèlerinage ${ }^{190}$, sondern der Regierung des Orients bezüglich der Cholera im Allgemeinen und bei der Einstufung von Gefahren. Das Problem des Orients avancierte zu einem eigenen Problembereich. Er symbolisierte einen Ort, an dem die Regelungen für die Regierung gesondert betrachtet werden und nach anderen Verfahren der Gouvernementalität entschieden werden mussten: ${ }^{191}$

»Conformément à la nature du problème, vous avez décidé que le système de préservation comprendrait trois ordres de mesures; $1^{\circ}$ mesures hygiéniques; $2^{\circ}$ mesures quarantenaires; $3^{\circ}$ mesures spéciales pour l'Orient. ${ }^{192}$

Selbst wenn die Diskussionen darüber, welche Maßnahmen möglich und effektiv seien, verschiedene Positionen hervorbrachten, blieb das Muster dieser Gegenüberstellung und absoluten Differenzierung des >Orients< von Europa konstant. Beispielhaft dafür ist die Diskussion über die Quarantäne, der ich mich im vorrangegangenen Abschnitt gewidmet habe. Die Kritik der Quarantäne war zumindest auf den ersten Konferenzen tief verankert in einer Praxis der Subjektivierung der europäischen Mächte und ihrer Delegationen als liberal, aufgeklärt, rational und fortschrittlich. Auf der anderen Seite wurde die Quarantäne im 〉Osten`, selbst wenn sie der öffentlichen Gesundheit dienen sollte, als eine Tyrannei deklariert: ${ }^{193} »[\mathrm{C}]$ es cordons permanents et ces lazarets du moyen-âge qui séparaient systématiquement l'Orient de l'Occi-

190 Rapport: Fait a la Conférence Sanitaire Internationale, par une Commission, composée de M. Segovia, président, et de MM les Docteurs: Gomes, Goodeve, Monlau, Pelikan, Spadoro et Van Geuns, nommée pour rebiser les questions du 3me groupe (la Programme (Préservation)et proposer la méthode à suivre pour leur étude: Annexé (2): in: CSI-3, 1866, Séance $\mathrm{N}^{\circ} 9$ : S. 6.

191 »Y a-t-il lieu d'appliquer les mesures quarantenaires aux provenances des Indes Orientales en général; dans quelles circonstances et dans quelle mesure? Quelles mesures convient-il de prendre [...] à Djeddah, Yambo, Suez, Alexandrie, en Perse, etc.«: CSI-3, 1866, Séance $N^{\circ} 8$ : S. 6.

192 Rapport: Sur les mesures d'hygiène à prendre pour la préservation contre le Choléra Asiatique; fait au nom d'une Commission composée de MM. Gomes, Goodeve, Lenz, Millingen, Monlau, Mühlig et Spadaro (médecins). et de MM. Keun, Malkom-Khan, Segovia et Vetsera (diplomates): Annexé (2): Vgl. CSI-3, 1866, Séance N²4: S. 1.

193 »Dr John Bowring also told the House of Commons $1842[\ldots]>$ There was no doubt that political objects were sought for in the maintenance of quarantine in the east; and it was equally certain that political interests were promoted by them, and that these, and not the health of nations, were the principal motives for the great severity with which the regulations were enforced abroad.«: Harrison: Disease, diplomacy and international commerce, 2006: S. 214. 
dent. ${ }^{194}$ Dieses Verfahren der Subjektivität konnten Delegierte strategisch nutzen. So etwa bei der Feststellung, die Landquarantäne sei in Europa unzumutbar und schädlich, im >Orient< aber angemessen. ${ }^{195}$

Aus der Sicht der europäischen Delegierten bedeutete das Prinzip der Auflösung der Quarantäne zwischen den europäischen Mächten und dafür die Verschärfung der Quarantäne an den Grenzen Europas nichts weiter als eine Verschiebung innerhalb ihrer Logik der Prävention, ${ }^{196}$ die lautete: >Wenn wir die Cholera an den Grenzen Europas aufhalten, oder besser noch am vermeintlichen Ort ihres Entstehens, sind unsere Maßnahmen viel effektiver als wenn wir sie erst an unseren Landesgrenzen zu stoppen versuchen. ${ }^{197}$ Während der freie Handel und die Bewegung der Menschen als eine der Bedingung für das Leben betrachtet wurde, stellten die Epidemien, die Pilger, die umherziehenden Bettler und Vagabunden, die Schattenseite dieses schwierigen und schwer zu regierenden Gegenstandes dieser >Regierung des Lebens< dar. Wie der Markt Teil eines notwendig grenzenlosen und unübersichtlichen Problems der Regierung wurde, so wurden es auch die Epidemie, die Migrationsströme usw. All dies musste nach und nach in das Bewusstsein dieser neuen Gouvernementalität rücken und zu ihrer Aufgabe werden. Valeska Huber beschrieb in diesem Zusammenhang die Vorstellung zweier verschiedener Arten von Mobilität, die man dem >Orient $<$ und dem Okzident zurechnete:

»[G]roups such as transmigrants, gypsies, or itinerant people became increasingly targeted as potential contagion bearers. These ideas were in line with the modern states >sedentarization policies and the war on itinerant lifestyles both in Europe and in the colonies. They furthermore illustrate the distinction between different types of mobility [...]: while some types of mobility - connected with European expansion and trade - became a marker of modernity, other types came to be seen as symbol of the Orient and its lack of civilization. ${ }^{198}$

Die Quarantäne an den neu markierten Grenzen Europas funktionierte nicht nur als eine Barriere gegen die >exotischen< Krankheiten des Orients und seine potenziell >infizierten<Bevölkerungen als >Überträgerく, sondern markierten außerdem die Grenze zweier unterschiedlicher Rationalitäten des Regierens, die im Zusammenhang mit einer bestimmten Darstellung und Wahrnehmung der Regierungen und Bevölkerungen des Orients stand.

Auch in den Diskussionen bezüglich einer »passage en quarantaine « auf der sechsten und siebten Konferenz 1885 und 1892 nahmen die Delegierten immer wieder Bezug auf die grundsätzlichen Differenzen zwischen Europa und dem Orient. ${ }^{199}$

194 »Lecture du Rapport sur les Mesures quarantenaires«: Vgl. CSI-3, 1866, Séance N³0: S. 7.

195 Vgl. ebd.: S. 6; 10.

196 Vgl. Harrison: Disease and Modern World, 2004: S. 103.

197 Vgl. »Lecture du Rapport sur les Mesures quarantenaires«: Vgl. CSI-3, 1866, Séance No30: S. 7f.

198 Huber: The unification of the globe by disease?, 2006: S. 462.

199 Vgl. Huber: The unification of the globe by disease?, 2006: S. 466. 
Die Konferenz 1892 konzentrierte sich auf die Neuregelung der Quarantänemaßnahmen am Suezkanal, der seit 1869 unter britischer Kontrolle stand. In Verbindung mit der Ausweitung des gesamten Repertoires sanitärer Maßnahmen, der »inspection médicale«, der Desinfektion, der Überprüfung und Ausstellung von Zertifikaten, der Modernisierung der Lazarette usw., verlangten die europäischen Staaten einerseits eine Ausweitung ihrer Macht über sanitäre Maßnahmen auf ägyptischem und persischem Boden, wollten sich aber auf der anderen Seite wenig an der Finanzierung dieser Maßnahmen beteiligen. Die europäischen Delegierten nutzten abwechselnd verschiedene Argumentationen, mit denen sie einerseits die Intervention europäischer Mächte und den Bedarf der Anwesenheit und Kompetenz europäischer Ärzte und Experten mit der >Rückständigkeit $<$ Ägyptens rechtfertigten. Andererseits begründeten sie ihre Zurückhaltung bei der finanziellen Unterstützung mit der Souveränität und Rücksicht auf die inneren Angelegenheiten der ägyptischen Regierung. ${ }^{200}$

Die Konferenz 1894 in Paris fand im Zeichen des speziell von Frankreich erneut propagierten Plans einer Prävention der >Invasion« von Choleraepidemien nach Europa durch verstärkte Kontrollen und Maßnahmen an den am Mittelmeer gelegenen Toren Europas statt. ${ }^{201}$ In gewisser Weise sollte die Konferenz 1894 das Problem der Pilger nach der Logik der Prävention in einen noch größeren Abstand von Europas Grenzen bringen. Weithin ging man davon aus, dass die Pilger ein besonderes Risiko der Verbreitung der Cholera bedeuteten: $»$ un terrible terrain de culture. ${ }^{202}$ Der zweite französische Delegierte, Proust, fuhr fort mit einem historischen Abriss über die Geschichte der Kommunikation und des Handels zwischen Europa und dem >Orient< bzw. mit >den Muslimen<, die dort lebten. In seiner Darstellung war dieser Kontakt bereits in seinen Anfängen, die im Mittelalter von Venedig ausgingen, geprägt von der >Einschleppung<sog. exotischer Krankheiten, womit er vorrangig auf die Pest verwies. ${ }^{203} \gg$ La première maladie exotique dont l'importation ait été combattue par des mesures restrictives est la peste d'Orient. ${ }^{204}$ Seit dieser Zeit, referiert Proust weiter, hätten sich durch den Fortschritt der Medizin und Hygiene aber neue Möglichkeiten eröffnet, einen Schutz gegen das Eindringen von Seuchen aus dem >Orient< einzurichten, die auch für den ausgeweiteten und immer wichtiger werdenden Handel weniger schädlich seien. ${ }^{205}$

Die britischen Delegierten verfolgten auf der Konferenz 1894 bereits eine Strategie, die weniger auf Abgrenzung vom Orient zielte, als auf die europäische Einflussnahme auf das osmanische Reich, Ägypten und Persien. Der britisch-indische Delegierte, Cunningham, machte auf der Konferenz immer wieder deutlich, dass Indien das beste Beispiel dafür sei, dass die Regierungsmethoden und Praxen der öffentlichen Gesundheit in Europa unter der Autorität der britischen Regierung auch in Asi-

200 Vgl. CSI-7, 1892, Protocole $\mathrm{N}^{\circ} 14:$ S. 264.

201 Vgl. [Barrère] ebd.: S. 13.

202 Ebd.: S. 17.

203 Vgl. ebd.

204 [Proust] Ebd.: S. 18.

205 Vgl. ebd.: S. 19. 
en erfolgreich angewendet worden seien. ${ }^{206}$ Teilweise, mahnt er an, seien sie sogar erfolgreicher als in manchen Städten Europas umgesetzt worden. ${ }^{207}$ Cunningham vertrat hier eine typisch sanitaristisch-universalistische Position: Die Epidemien unterlägen gewissen Gesetzmäßigkeiten und Bedingungen. Diese könne man studieren und auf ihrer Grundlage sei man in der Lage, auf der ganzen Welt Maßnahmen gegen die Epidemien, die Cholera eingeschlossen, zu entwickeln. Die Differenzierung von $>$ Orient< und Okzident stellte, wie wir sehen, keinen Widerspruch zur universalistischen Logik der Sanitaristen dar. Gegen das Dilemma, das die früheren Konferenzen aufgeworfen hatten und das vor allem mit dem Ruf nach einer Abgrenzung und Absicherung Europas zum >nicht regierbaren<>Orient< geendet hatte, konnte aus Sicht der Sanitaristen pragmatisch gelöst werden. Nämlich, indem man die Unterschiede der Verhaltensweisen und Gewohnheiten der Bevölkerungen, des Klimas und des Budgets, sowie der Praxis der Regierungen des Orients als nichts weiter als eine Reihe weiterer von der Regierung zu kalkulieren Faktoren einbeziehen müsse. In gewisser Weise brachte die Logik der Sanitaristen ein viel effektiveres Rationalisierungskonzept interventionalistischer Regierungspraxen hervor, weil es unbegrenzt an die Möglichkeit seiner Übertragung glaubte und tatsächlich eine weit größere Anpassung seiner Techniken in Aussicht stellte.

Im Gegensatz zu einer Strategie der Abgrenzung Europas vom Orient, die u.a. vor allem der Stiftung einer europäischen Identität und Subjektivität von Regierten und Regierungen gedient hatte, stand der Ansatz der Sanitaristen eher im Zeichen einer Praxis der Vereinnahmung und des Nutzens. Die britischen Vertreter, ebenso wie Cunningham, verfolgten auf der Konferenz gegenüber den persischen und türkischen Vertretern offensichtlich eine andere Strategie als die Franzosen und die meisten anderen europäischen Mächte. Letztere versuchten politisch und moralisch Druck auf die Regierungen der Türkei und Persiens auszuüben, waren aber im Grunde immer noch vor allem daran interessiert, durch eine Abgrenzung zum >Orient<, die Legitimität und Moralität ihrer eigenen Regierungsrationalität zu bekräftigen. Indem man den Regierungen Ägyptens, Persiens und der Türkei den Vorwurf machte, sich nicht genug um die öffentliche Gesundheit und Menschheit zu sorgen, versuchte v.a. Frankreich deren Zustimmung zu den europäischen Vorschlägen zur Abschottung und Kontrolle an den Grenzen durchsetzen. Die Briten hingegen unterstützten Persien und die Türkei ein Stück weit in ihren Forderungen nach Unterstützung bei der Umsetzung der von Europa geforderten Maßnahmen. Aus Sicht der liberalen Gouvernementalität hing die Legitimität und Souveränität einer Regierung an ihrer faktischen Fähigkeit zu regieren und der praktischen Ausübung von Macht. Die immer wieder betonte Unfähigkeit, die geforderten Maßnahmen umzusetzen, nutzten die britischen Delegierten für die Legitimation europäischer Intervention. ${ }^{208}$

206 Vgl. auch Harrison, Mark (1994): Public Health in British India: Anglo-Indian Preventive Medicine 1859 - 1914: S. 109.

207 Vgl. CSI-9, 1894, Procès-Verbaux, Séance Nº6: S. 191f.

208 Vgl. CSI-8, 1893, Procès-Verbaux 1. Commission $N^{\circ} 1$ : S. 27. 


\section{VeraLlgemeinerung Liberaler Gouvernementalität UND RATIONALITÄT}

Ich möchte noch einmal auf das Problem der >Erfolglosigkeit< der ersten sechs und des Erfolges der späteren Konferenzen eingehen, das die meisten Forschungen zu den CSIs bis heute beschäftigt hat. Aus dem bisher Dargelegten ist deutlich geworden, dass sich die Schwierigkeiten und Ergebnisse, wie auch der Verlauf der unterschiedlichen Diskussionen auf den Konferenze weder durch den Mangel und die langsamen Erfolge und Erkenntnisse der medizinischen Forschung noch durch den politisch untermauerten Konflikt autokratisch-kontagionistischer und liberal-anti-kontagionistischer (Staaten-)Fraktionen erklären lässt. Die Analyse hat vielmehr einen konflikthaften Prozess um die Durchsetzung bestimmter Rationalitäten und die Rationalisierung der Techniken der internationalen Regierung von Gesundheit offen gelegt. Selbst die Bekanntmachung des Bakteriums als Erreger der Krankheit änderte wenig an dem Einfluss der sanitaristisch Logik und dem liberalen Muster dieser Rationalisierung. Diese >Entdeckung< erweiterte nur das Spektrum an Möglichkeiten zur Verbesserung und Ausweitung der sanitären Maßnahmen, niemals aber wichen diese Rationalisierung von der Logik der Hygiene und der von liberaler Regierungslogik durchsetzten sanitären Doktrin ab.

»[L]'expérience et les progrès de la science prophylactique depuis six ans permettent de modifier les règlements dans un sens libéral. [...] Le temps est passé où le médecin sanitaire était considéré par le commerce comme son pire ennemi; $[\ldots] . \ll^{209}$

Beinahe durchgängig wurde auf den Konferenzen darauf hingewiesen, dass man sich, statt auf medizinische Theorien, auf die Erfahrungen und statistisch abgebildeten Fakten berufen wolle. Man hatte in der Weise, wie die Ziele der Konferenzen formuliert waren, bereits zu Beginn verstanden, dass die öffentliche Gesundheit einen viel breiteren Blickwinkel einzunehmen hatte als die Medizin.

Die Konferenzprotokolle spiegeln die Durchsetzung einer bestimmten Rationalität und mit Hilfe dieser die Etablierung eines Mechanismus der Rationalisierung aller vorhandenen politischen Techniken zur Abwehr von Seuchen hin zu einem System der >rationellen< Sicherung wider. Einer liberalen Regierungsrationalität, die ihre Wahrheit in einer bestimmten Ökonomie und einem Spiel der Kräfte und des Lebens der Bevölkerungen erkannte. Deren Ziel nicht in die Zähmung oder Unterdrückung, sondern in der Ermöglichung und Sicherung und die Verteidigung der Freiheit dieses Spiels lag: ${ }^{210} »[\mathrm{~L}]$ a défense de [...] la vie économique des peuples! $\aleph^{211}$ Obwohl die gesamten, sich wiederholende Kritik und Reform der Konventionen auch vor 1893 diesem Muster der Rationalisierung folgten, gab es offenbar einen Moment, an dem man sich auf den Konferenzen so sehr annäherte, dass man von einem Modus des

209 [Barrère] CSI-11 1903, Procès-Verbaux, Séance N¹: S. 18.

210 [Proust] »[D]e faciliter la rapidité des communications«: CSI-11 1903, Procès-Verbaux, Séance $\mathrm{N}^{\circ} 1$ : S. 21.

211 [Santoliquido] Ebd.: S. 6. 
Konflikts und der Kritik in einen Modus der Übersetzung und damit der Umsetzung der allgemein angenommen Rationalität übergehen konnte.

Die Annahme einer bestimmten Rationalität hinsichtlich der Seuchenprävention und der Vorbeugung von Choleraepidemien hing neben den materiellen ökonomischtechnischen Bedingungen auch an der Erfindung und Entwicklung politischer Technologien und Organisations- und Übersetzungsformen. Zunächst zirkulierten zwischen den Staaten verschiedene Entwürfe und Strategien im Umgang mit den sich verallgemeinernden Anforderungen von Gouvernementalität als Regierung des Lebens. Eine ebenso wichtige Voraussetzung für eine gemeinsame Vernunft, für einen übereinstimmenden Modus der Kalkulation einer Regierung war also die Annäherung hinsichtlich bestimmter Bedingungen für Akzeptierbarkeit einer guten Regierung und damit die Konstruktion eins gemeinsamen Ideals von Identität und Souveränität einer modernen, europäischen und liberalen Regierung. Mit Blick auf die CSIs lässt sich die Entwicklung einer Basis für internationale Einigung, für die Annahme einer mehr oder weniger gemeinsamen Regierungsrationalität hinsichtlich der Seuchenprävention, die schließlich die Bedingung für den Eintritt in die Phase des >Erfolgs $<$ der Konferenzen darstellte, nur vor diesem Hintergrund verstehen.

Ich möchte im folgenden Abschnitt zeigen, wie sich immer wieder eine bestimmte liberale Gouvernementalität in den Diskussionen der Konferenzen gegenüber anderen Verfahren der Gouvernementalität durchsetzen konnte. Diese Verfahren sind vor allem daraufhin zu beleuchten, inwiefern sie einen Machtzuwachs oder eine Machtsicherung für Regierungen bedeuteten bzw. eine Entmachtung einer anderen Regierung nach sich ziehen konnten. Es handelte sich dabei um Machtmechanismen, die das Problem der Souveränität der Staaten, also die Begrenzung des Einflusses durch andere Staaten, was Zylberman als das >westfälische< System bezeichnete, zu umgehen halfen. ${ }^{212}$ Es sind zugleich Verfahren der Gouvernementalität, die auf andere Bedingungen des Regierens und der Akzeptanz der Souveränität von Regierungen verweisen. Diese Verfahren funktionierten, indem sie die > wahren $<$ oder >realen $<$ Kriterien für eine Regierung umkodierten und als allgemeine Bedingungen der Akzeptierbarkeit von Macht reproduzierten. Außerdem sollen die Beispiele, die ich zeigen werde, die bisher etwas zu kurz gekommenen Konferenzen und Themen in den Blick rücken.

$212 »[\mathrm{~T}]$ he history of governance of infectious disease threats from the mid-nineteenth century to the beginning of the twenty-first century evolved as a series of institutional arrangements: the International Health Regulations based on non-interference and disease control of the border; the WHO's vertical programs based on disease control or eradication at the source and expert guidance; and finally the fall of the classical system leading to a new, post-Westphalian regime standing beyond state centrism and national interest.« Zylberman: Civilizing the State: Borders, Weak States and International Health in Modern Europe, 2006: S. 34. 


\section{Information und Entscheidungsfreiheit}

Die fünfte Konferenz in Washington im Jahr 1881 unterschied sich von den vier vorherigen dadurch, dass sie einen sehr viel internationaleren Charakter hatte. Zum ersten Mal waren Delegationen auch aus Übersee-Staaten wie auch mehrere südamerikanische Länder, Japan und Liberia zugegen. Die Konferenzsprache war ausnahmsweise nicht Französisch, sondern Englisch. Obwohl zusätzlich alle Protokolle auch ins Französische übersetzt wurden, war dies angesichts der Gepflogenheiten der Diplomatie im 18. und 19. Jahrhundert eine Neuerung. Die USA waren Gastland und hatten ihre Einladungen in dem Interesse ausgesprochen, neben der Cholera auch die Verbreitung anderer Epidemien, wie etwa des Gelbfiebers, zu problematisieren. Das genaue Ziel der Konferenz sollte die Etablierung eines Benachrichtigungs- und Meldesystems für den Ausbruch von Seuchen in Staaten und Häfen werden. Durch dieses System sollte sowohl die Verbreitung der Seuchen, als auch unnötige Quarantäne und Zurückweisungen von Schiffen an Häfen auf Basis von Gerüchten oder Vorurteilen über deren mögliche Kontamination verhindert werden. ${ }^{213}$

Der Vorteil des Systems der Benachrichtigung sollte darin bestehen, es den Staaten zu ermöglichen, anstelle von generellen Maßnahmen an ihren Häfen zielgerichtet und an einem speziellen Risiko ausgerichtet, ihre selbst gewählten Vorkehrungen zu treffen. Auf diese Weise sollte es möglich werden, die Kosten für aufwendige Maßnahmen zur Abwehr von Epidemien zu reduzieren. Langfristig würde das System durch den Abbau von »unnecessary and burdensome restrictions upon commerce $\ll^{214}$ auch dem Handel zugutekommen, da weniger unnötige Maßnahmen, wie z.B. Quarantänen, durchgeführt würden. ${ }^{215}$ Häfen, Städte und Staaten sollten sich verpflichten, umgehend zu melden, wenn eine Epidemie ausgebrochen war und die Gefahr bestand, dass Schiffe, die ihre Häfen verließen, die Epidemien verbreiteten. Außerdem sollten allgemeine Informationen über die sanitären Zustände der Länder und Häfen in regelmäßigen Abständen über ein solches internationales System verbreitet werden. ${ }^{216}$ Während die Begründungen dafür, dass alle Staaten das Benachrichtigungssystem einrichten und anerkennen sollten, zu Beginn der Konferenz eher einen moralischen Anstrich hatten ${ }^{217}$, wurde im Laufe der Konferenz immer deutlicher, dass andere Mechanismen etabliert werden müssten, um die Funktionalität dieses Systems sicherzustellen. Anfangs war noch ein Widerspruch zwischen den ökonomischen Interessen und den moralischen Ansprüchen gesehen worden. ${ }^{218}$ Später entwickelten die Teilnehmer der Konferenz schließlich Pläne, die genau dieses ökonomische Interesse selbst zum Regulator und Instrument der Rationalisierung des Systems machen sollten. Einen Großteil der Zeit stritten und verhandelten die Teilnehmer auf der Konferenz über die genauen Bedingungen dieses Benachrichtigungs- und Informationssystems. Warum sollte ein Staat bekanntgeben, dass sein Hafen möglicherweise

213 Vgl. CSI-5, 1881, Protocol N²: S. 18.

214 Ebd.: S. 18.

215 Vgl. ebd.: S. 16.

216 Vgl. ebd.: S. 9.

$217 »[$ E]ach civilized nation would assume the responsibility of preventing the transmission of its epidemics into other countries«: Vgl. ebd.

218 Vgl. ebd.: S. 10. 
infiziert ist? Welche Autoritäten in der jeweiligen Hafenstadt hätten die nötige Unabhängigkeit und Glaubwürdigkeit für die anderen Staaten, die sich auf die Zertifikate, Informationen und Nachrichten verlassen mussten? Wie ließe sich ein System etablieren und ein Mechanismus einsetzen, damit eine gegenseitige Sicherheit gewährleistet wäre? Die europäischen Mächte und die USA forderten, dass alle Staaten, die an diesem System teilnehmen würden, in regelmäßigen, kurzen Abständen Statistiken und Berichte über den gesundheitlichen Zustand und über die Morbidität und Mortalität hinsichtlich bestimmter Krankheiten in ihren Häfen und größeren Städten abliefern sollten. ${ }^{219}$ Die Benachrichtigung über den gesundheitlichen Zustand der Bevölkerung in den größeren Städten und speziell den Hafenstädten musste, so insistierten u.a. die Delegationen Spaniens, Italiens, der USA und Deutschlands, außerdem bestimmten wissenschaftlichen Standards genügen. Die zusammengestellten Informationen müssten eine bestimmte einheitliche Form wahren und eine Anzahl von statistischen Entwicklungen der Sterblichkeit bezüglich bestimmter Krankheiten über einen längeren Zeitraum enthalten. ${ }^{220}$ Es wurde relativ schnell deutlich, dass zur Erbringung solcher Daten bestimmte Institutionen und Verwaltungsstrukturen erforderlich waren, die bei Weitem nicht alle Staaten aufweisen konnten. Auch grundsätzlich, stellten die Delegierten fest, mache es doch einen Unterschied, ob eine Epidemie in einem Staat mit einem gut ausgebauten sanitären System auftrete oder dort, wo die nötigen Maßnahmen zur Eindämmung der Krankheit überhaupt nicht getroffen werden konnten. ${ }^{221}$

Es ist sehr offensichtlich, wie neben der formalen Anerkennung der Souveränität und Gleichheit der Regierungen ein solches System der Differenzierung von Regierungen und Ländern Teil der Entscheidungen der Konferenzen wurde und die Staaten damit innerhalb der internationalen Ordnung nach einem völlig anderen und parallelen Muster der Hierarchisierung zu Ungleichen machte. Der kanadische Delegierte Taché äußerte ebenfalls die Ansicht, dass das System nur umgesetzt werden könnte, wenn eine einheitliche Organisation der öffentlichen Gesundheit gegeben wäre: »the organization of an universal sanitary service«. Regierungen sollten durch den Abschluss einer entsprechenden Vereinbarung dazu verpflichtet werden, sanitäre Einrichtungen und Ausgaben zu akzeptieren »which they believe useless or impracticable on their own account $\ll^{222}$.

Während den Regierungen auf Basis der Anerkennung eines konstitutionellen Rechts, möglicherweise eines natürlichen oder göttlichen Rechts, Gleichheit, Souveränität und Unabhängigkeit bei der Regelung ihre inneren Angelegenheiten zuerkannt wurde, stand im Gegensatz dazu die faktische und praktische Ungleichheit der Staaten in Bezug auf ihre >Regierungskompetenz $<$ außer Frage. Nun konstatierte der Delegierte Italiens, de Camporeale,

219 Vgl. CSI-5, 1881, Protocol N³: S. 24f.

220 Vgl. [Cervera, Delegierter Spaniens] »It is desirable the governments be bound mutually to give all the necessary communications to each other as soon as a disease makes its appearance and disappearance. $\ll$ : Vgl. CSI-5, 1881, Protocol N²4: S. 36, 40.

221 Vgl. CSI-5, 1881, Protocol N5: S. 32f.

222 Ebd.: S. 33. 
»[I]t is evident that no government would be willing to assume an obligation which would not be reciprocal. The principal object of the Government of the United States in calling together this Conference is to establish a uniform and compulsory system of sanitary information, but the governments, in order to be able to give exact and trustworthy information, must be possessed of it, and should therefore engage themselves to obtain the data which alone can enable them to notify with exactness the other governments of the sanitary condition of their own country. ${ }^{223}$

Hiermit wurde einerseits die Souveränität der Staaten bestätigt, andererseits konstatiert, sie seien ungleich. Als ungleich wurden sie auf der Ebene ihrer jeweiligen Regierung, der Rationalität ihrer Regierung, der Fähigkeit und des praktischen Erfolgs ihrer Regierung gesehen. Der Mangel ihrer Regierung machte sie praktisch zu Ungleichen und berechtigte zu einer Differenzierung und Abstufung des Rechts auf unabhängige Selbstregierung. ${ }^{224}$ Die Definitionsmacht war hier nicht gleich verteilt, sondern lag bei den Regierungen, die sich auf der praktischen und faktischen Ebene als >erfolgreicher p päsentierten. Ihnen blieb, aufgrund ihrer Stellung in dieser faktischen, materiellen und ökonomischen Asymmetrie, die Macht zu definieren, von welchem Risiko durch welches Land auszugehen sei. Es gab Länder in den Tropen, die aufgrund ihres bestimmten Klimas als verdächtiger und gefährlicher galten. Sie sollten vor allem die Orte sein, an denen Inspektionen durchgeführt wurden. ${ }^{225}$ Die von Anfang an vorhandene Aufteilung der Staaten auf der Konferenz in $>$ Regionen der Gefahr < und >Handelsnationen<, die mit ihnen Handel trieben, wurde hier erst in aller Deutlichkeit sichtbar. Vor diesem Hintergrund wurde auch die Erforschung von Krankheiten wie Gelbfieber in den Staaten am Golf von Mexiko durch europäische und nordamerikanische Wissenschaftler ohne Beanstandung hingenommen. ${ }^{226}$ Ein Eingriff, den, wie weiter oben erwähnt, Großbritannien, in der Frage der Entsendung einer wissenschaftlichen Untersuchungskommission in Indien, für eine untragbare Verletzung ihrer Souveränität erklärt hatte. Das Gleiche galt für die Erforschung der Pest im Nahen Osten und in der Türkei, die auch ohne Widerspruch akzeptiert wurden. ${ }^{227}$ Aber nicht nur das. Die als Gefahr für Europa und die Vereinigten Staaten betrachteten Länder sollten, um weniger als eine Gefahr gesehen zu werden, die politische Praxis der europäischen Länder im Bereich der Gesundheitspolitik übernehmen.

223 Ebd.: S. 37.

224 Hierzu hinterlässt (der britische Delegierte Archibald?), da er nicht anwesend sein kann, eine schriftliche Nachricht. Nachdem sich Großbritannien während der ganzen Konferenz relativ ruhig verhalten hat, reichte der britische Delegierte Archibald einen schriftlichen Kommentar ein: »I am willing, nevertheless, that it should be tried, experimentally, within certain geographical limits in those regions of the globe from whence there is the greatest danger of importing yellow fever or other dangerously contagious diseases. In the temperate zones the circumstances are exceptional and of rare occurrence, which would justify the burthens on commerce involved in the general application of the system, apart from the question of its efficiency. «: CSI-5, 1881, Protocol N7: S. 101.

$225 \mathrm{Vgl}$. [Der spanische Delegierte Jervera] ebd.: S. 110.

226 Vgl. CSI-5, 1881, Protocol N8: S. 140.

227 Vgl. CSI-5, 1881, Protocol N7: S. 115. 
Um von diesen Staaten als glaubwürdig und weniger gefährlich angesehen zu werden und den Handel mit diesen Staaten aufrecht erhalten zu können, blieb ihnen auch nichts anderes übrig, als genau dies zu tun. ${ }^{228}$ Die Differenzierung, die zwischen den Staaten vorgenommen wurde, war aber auch eine Warnung: >Wenn ihr eure Regierung nicht anpasst, rationalisiert und verbessert, werden wir Euch das Recht auf diese Regierung, diese Macht abnehmen müssen. Mehr noch, die Aberkennung dieser Freiheit und dieser Macht würde nicht einmal auf einer juristischen Ebene, etwa durch einer Deklaration oder einen Vertrag erfolgen, sondern durch die $>$ Macht der Dinge< selbst. Denn, wenn Ihr die sanitären Maßnahmen nicht anwendet, wenn Ihr unser Vertrauen in eure Maßnahmen und Zertifikate nicht gewinnt, dann werden sich die Schiffe, die von Euren Häfen zu uns kommen, zeitaufwändigen und kostspieligen Maßnahmen der Prävention unterziehen müssen. Die Passage wird für die Händler also zu teuer werden und Eure Staaten werden letztlich durch die ökonomischen Verluste einen höheren Preis bezahlen als durch die Einrichtung der von uns vorgeschlagenen sanitären Maßnahmen und Einrichtungen. Oder noch schlimmer, wir werden das Risiko mit Euch Handel zu treiben, insgesamt zu groß einschätzen und einstellen. Ihr seid also frei zu tun, was Ihr wollt. Kein Vertrag, kein Gesetz, keine militärische Macht wird Euch zwingen, nur die Dinge selbst, die Wirklichkeit wird Euch zwingen, Euch zu fügen.< Genau mit dieser Argumentation stellten Großbritannien, die USA und Frankreich sich gegen jede Verpflichtung, die die USA am Anfang der Konferenz von 1881 noch gefordert hatten. Die Ökonomie selbst, die Macht und die Gesetzte des Marktes allein sollten genügen. Damit wurde die Verbreitung einer bestimmten Gesundheitspolitik und Praxis der Kontrolle und Regulierung der Gesundheit der Bevölkerung über diesen ökonomischen Mechanismus eingeleitet. Der britische Delegierte Archibald konstatierte in seiner schriftlich der Konferenz zugereichten Notiz, dass die Beschlüsse der vorangegangenen Konferenzen, die ebenso hehren Zielen gefolgt seien, wenn überhaupt, dann nur von kaum mehr als einer Handvoll Staaten ratifiziert wurden. ${ }^{229}$ Er hielt daher die Durchsetzung eines solchen Systems, wie es die US-Amerikaner vorgeschlagen hatten, für unrealistisch. ${ }^{230}$ Archibald schlug vor, es bei einer Empfehlung zu belassen, was die Veröffentlichung der Berichte und Statistiken betraf. ${ }^{231}$ Er zweifelte an der Effektivität des angedachten Systems besonders an der praktischen Umsetzung der Inspektion und Begutachtung der Schiffe vor ihrer Abfahrt. ${ }^{232}$ Es könne erstens, so Archibald, wohl kaum ein so umfassendes Netz an Inspektoren zur Verfügung gestellt werden. Außerdem sei es, zweitens, zu teuer, die Inspektionen zu finanzieren. Beide Gründe hätten bereits bei

228 »At the International Hygienic Congress, Turin, September 7, 1880, Dr. Fauvel spoke as follows: >Each government, according to its convenience (in the East), following the example of the French Government, should create a corps of sanitary physicians whose members are to be sent to those countries from which pestilential diseases come, and the present supervision, increased in this manner, will give all the necessary guarantees of safety.«: Ebd.: S. 114.

229 Vgl. ebd.: S. 101f.

230 Der französische Delegierte Outrey stimmt ihm zu. Vgl. ebd.: S. 105.

231 Vgl. ebd.: S. 102.

232 Vgl. ebd. 
der Abstimmung zu einer ambivalenten Zustimmung geführt. Die Umsetzung sei also nicht unbedingt zu erwarten. Folglich müssten die einzelnen Staaten ohnehin, um sicher zu gehen, weiterhin ihre eigenen Maßnahmen zur Abwehr der Seuchen durchführen. ${ }^{233}$ Archibald empfahl stattdessen die Verbesserung der hygienischen Zustände von Grund auf. Dies war seiner Meinung nach die Bedingung für einen geringeren Aufwand für Schutzmaßnahmen und der richtige Ansatzpunkt für Präventionen gegen die Entstehung und Verbreitung von Epidemien. ${ }^{234}$ Man wolle anstelle der vertraglichen, rechtlichen Verpflichtungen auch keine moralischen Pflichten mehr, wie sie der türkische Delegierte Aristarchi Bey vorgeschlagen hatte. ${ }^{235}$

Man konnte auf die Moral verzichten, denn die liberale Regierungstechnik setze auf den realen Zwang selbstregulativen Effekt der Ökonomie, um eine Anpassung an eine bestimmte (Selbst-)Regierungspraxis zu akzeptieren. ${ }^{236}$ Die Frage war nur, wo ein geeigneter Ansatzpunkt für diesen Mechanismus sein sollte. Der Vorschlag des Briten war, den Kapitän als Träger der liberalen Rationalität, sozusagen als rationale Instanz, als >Interessensubjekt< einzusetzen, das in der Lage sein würde, auf Grundlage der Situation und der gegebenen Faktoren, eine möglichst rationelle Entscheidung zu treffen. Der Kapitän solle entscheiden, ob er sich ein Gutachten für sein Schiff erstellen lässt. Er könne das Risiko am Ankunftshafen abgewiesen oder unter Quarantäne gestellt zu werden mit dem Aufwand und den Kosten einer Inspektion und einer Zertifizierung abwägen. Er würde die Berechnungen durchführen unter Einbeziehung der hygienischen Zustände am Hafen bei seiner Abreise, ebenso wie dessen allgemeiner Ruf in dieser Hinsicht. Er würde die Auflagen und die Regelungen am Ankunftshafen, die Strenge der sanitären Regelungen dort einzuschätzen haben. Das eigene ökonomische Interesse sollte den Kapitän zum perfekten Relais der rationellsten aller Regelungen machen. Es handelt sich eben um dieses Subjekt, dass Foucault als ein Grundelement der liberalen Regierung identifiziert hat:

»Man wird also gewissermaßen am Kreuzpunkt zwischen dieser empirischen Konzeption des Interessenssubjekts und den Analysen der Ökonomen ein Subjekt definieren können, ein Subjekt, das Interessenssubjekt ist und dessen Handeln zugleich einen multiplikativen und vorteilhaften Wert durch die Intensivierung des Interesses haben wird, und das zeichnet den Homo oeconomicus aus. $\ll^{237}$

Der Kapitän eines Handelsschiffs, von dem man annahm, dass er ökonomisch-rationale Entscheidungen treffen würde, wurde als Mittel der Rationalisierung von Sicherheitstechniken eingesetzt, die, wenn pauschal und universell durch die Regierungen festgelegt, im Einzelfall entweder zu restriktiv oder zu wenig restriktiv durchgeführt würden. Dies ist die Logik liberaler Gouvernementalität par excellence: Eine

233 Vgl. ebd.: S. 103f.

234 Vgl. ebd.: S. 105.

$235 »$ On the other hand, if the matter were left optional, those governments will contract moral obligations, which will be of great weight not only with their own people, but to other nations also.«: CSI-5, 1881, Protocol N4: S. 39.

236 Vgl. CSI-5, 1881, Protocol N5: S. 49.

237 Foucault: Geschichte der Gouvernementalität II, 2004 [1978 - 1979]: S. 379. 
Regierung, die, wie Foucault schreibt, das »Prinzip der Rationalisierung der Regierungskunst auf das rationale Verhalten der Regierten « ${ }^{238}$ stützt. »Diese Rationalität der Regierten soll als Regelungsprinzip für die Rationalität der Regierung dienen. Das scheint mir die liberale Rationalität zu charakterisieren [...]. «239

Die liberale Gouvernementalität braucht kein spezifisch moralisches Subjekt. Im Gegenteil, sie braucht ein Subjekt, das möglichst nur nach seinen eigenen egoistischen Bedürfnissen handelt. Genau als ein solches Subjekt wird es nicht nur regierbar, sondern unter den Bedingungen kapitalistischer Ökonomie selbst zum Agenten, zum Überträger und Katalysator der liberalen Regierung. Die Macht der liberalen Regierung entfaltet sich gerade durch diese spezifische Freiheit, die sie schafft. Die Freiheit, der Staaten und der Kapitäne, sich keiner Vorschrift beugen zu müssen, wird durch den Markt als Technologie ein überaus effektives Mittel der Regulation werden.

»You must leave liberty of action to the captain, who is the best judge of his interest, and you must trust to him to put himself in accord with the authorities of the port where he wishes to go. These general observations apply with still more reason to those cases where the captain has only to consider the regulations of the country to which he is going. $\ll^{240}$

Alle Regularien und Gesetze werden dann in der Praxis effektiv und am wenigsten repressiv sein, wenn sie in der Lage sind, diesen Mechanismus in Gang zu setzten: Das ist die Idee der liberalen Regierung. Die Subjekte, den Zwängen von Ökonomie, den Bedingungen des Überlebens, der Wirklichkeit oder einer angeblichen >Natur auszusetzen und mittels der Macht dieser Zwänge, als ihre Techniken und durch die daraus resultierende Rationalität jede einzelne Person zu regieren, macht die liberale Gouvernementalität aus. Die Strategie, die die britische Regierung als erste entwickelte bzw. zu der sie als erste Regierung in der Lage war, sie, die Strategie, innerhalb ihrer Regierungspraxis zu installieren und die sie innerhalb ihrer Armenpolitik, in ihrer Gesundheitspolitik, bei der Regierung ihrer ganzen nationalen Ökonomie einsetzte, funktionierte in dieser Weise. Die britischen Delegierten konnten durch den Erfolg ihrer liberale Rationalität und Praxis des Regierens eine auf den Konferenzen und im Hinblick auf die Diskurse, eine deutliche Machtposition einnehmen.

Mit dem >Erfolg< einer Regierung meine ich hier ihre Fähigkeit, sich unter Berücksichtigung eine Reihe von historischen Vorbedingungen und angesichts neuer Existenzbedingungen für Regierung zu reproduzieren, ihre Rationalität und Praxis in Einklang zu setzen, sich möglicherweise durch eine Abgrenzung gegenüber einer anderen Regierung, einer anderen Rationalität etc. als fortgeschritten zu inszenieren usw.

238 Ebd.: S. 428.

239 Ebd.

240 CSI-5, 1881, Protocol N7: S. 106. 


\section{Hygiene und liberale Gouvernementalität auf den CSIs}

Die mächtige Rolle, die Großbritannien so gut wie über den gesamten Zeitraum der CSIs im 19. Jahrhundert einnahm, lässt sich meiner Ansicht nach nicht nur auf seine generelle ökonomische Stärke und seine spezielle Rolle als größte europäische Handelsmacht zurückführen, gegen die die schwachen Mittel des Internationalismus und die anderen Mächte auf den Konferenzen nichts ausrichten konnten, wie z.B. Valeska Huber vermutet. ${ }^{241}$ Alle Regierungen, nicht nur die britische, vertraten nationale und wirtschaftliche Interessen. Interessanter ist doch die Frage, welche Strategien die Staaten anwendeten, um die entsprechenden Bedingungen auf der Konferenz zu schaffen, durch die ihre Forderungen und Interessen akzeptierbar wurden. Oder die Frage: Auf welche vorhandenen Bedingungen und Rationalitäten ihre Strategien verweisen? Nicht nur, um die nationalen oder ökonomischen >Interessen< ihrer Regierung zu befriedigen, sondern auch, um als Teilnehmende der Konferenz und als Regierung Macht zu gewinnen bzw. diese nicht zu verlieren. Damit meine ich auch die Macht, die an ein moralisch-diskursives Subjekt gekoppelt war, oder eine Souveränität und Legitimität, die an eine bestimmte Rationalität, an einen bestimmten Diskurs des > vernünftigen< Regierens anknüpfte. Großbritannien war, meiner Meinung nach, aus verschiedenen Gründen in der Lage, eine Reihe solcher Diskurse zu beherrschen. Dies wurde auf den internationalen Gesundheitskonferenzen im 19. Jahrhundert mehr als deutlich.

Großbritannien nahm von Anfang an eine besondere Rolle auf den Konferenzen ein und präsentierte sich als große Fürsprecherin der hygienischen Maßnahmen, auch nachdem diese ihr Image als >liberales< Gegenmodell zur >despotischen< Quarantäne eingebüßt hatten. Der Einfluss der britischen Delegationen an der Rationalisierung der Quarantäne, ihrer Integration bis Auflösung in ein weiter gefasstes Repertoire sanitärer Techniken ist erheblich. Die Vertreter Großbritanniens wurden nie müde, die >Erfolge < ihrer Regierung auf diesem Gebiet in Form von Berichten und Statistiken den anderen Konferenzteilnehmer vorzulegen. ${ }^{242}$

»[L]'amélioration générale de l'état sanitaire a eu également pour conséquence d'amener une diminution dans le chiffre ordinaire de la mortalité, - de sorte que, d'après les calculs de M. Monod, le savant Directeur de l'Hygiène publique de France, nous sommes parvenus à sauver près de neuf cent mille personnes entre les années 1880 et $1889 . \ll^{243}$

Die Betrachtung einiger Diskussionen der späteren Konferenzen sollen im Folgenden dazu dienen, diese Rolle Großbritanniens zu veranschaulichen.

Die anderen Delegierten erkannten, wie schon gesagt an, dass Großbritannien herausragende >Erfolge $<$ durch seine sanitäre Politik erzielt hatte. Diese hatten es vor

$241 »[\mathrm{~T}]$ he European powers did not succeed in counterbalancing British dominance through the weak apparatus of internationalism. «Huber: The unification of the globe by disease?, 2006: S. 466.

242 »C'est surtout à l'application efficace des mesures sanitaires que nous attachons la plus haute importance.«: CSI-1, 1852 [1851], Séance $N^{\circ} 14:$ S. 290. Vgl. die vorgelegten Statistiken, »résultat des mesures d'assainissement prises aux Indes «: Ebd.: S. 291.

243 [Thorne, Thorne]: CSI-8, 1893, Protocole N4: S. 50. 
allem durch die gesenkte Sterblichkeitsrate und keinem einzigen epidemischen Cholera-Ausbruch nach 1866/67 in Großbritannien bewiesen. ${ }^{244}$ In den Konferenzen der 1890er Jahre wurde aber, neben der Anerkennung, unter den anderen Konferenzteilnehmern auch eine gewisse Resignation gegenüber dieser permanenten Inszenierung der Briten sichtbar. Die Konferenzteilnehmer appellierten an Großbritannien, seine ablehnende Haltung gegenüber strikteren sanitären Maßnahmen an europäischen Häfen und am Suez zu lockern. Sie verlangten dies von Großbritannien gewissermaßen aus Rücksichtnahme auf die Staaten, die es mit ihren sanitären Verbesserungen noch nicht so weit gebracht hatten. Großbritannien konnte sich kompromissbereit zeigen, forderte auf der anderen Seite aber Sonderrechte für seine aus Indien kommenden Schiffe und Ausnahmeregelungen, wie etwa die freie Passage des Suezkanals ihrer mit Cholera infizierten Schiffe. Freie Passage bedeutete: Durchfahrt ohne jegliche sanitäre Inspektion und Maßnahme. Passage en quarantaine nannte man es, wenn die Schiffe ohne Halt das Mittelmeer durchqueren und nirgendwo Kontakt mit anderen Schiffen oder Häfen haben sollten, bis sie einen Hafen auf den britischen Inseln erreichten. Dass die Dauer der Fahrt selbst als eine Art der Quarantäne angesehen werden konnte, war dabei nicht neu, aber auch nur eine von vielen Begründungen, die die britischen Delegierten zur Durchsetzung dieser Sonderregelung anführten. Eine andere war, dass die Lazarette am Suez und in Ägypten so schlecht ausgestattet seien, dass ein Versuch, die Kranken dorthin zu bringen, die Gefahr einer Verbreitung der Krankheit in Ägypten oder unter den Passagieren anderer Schiffe vergrößern würde. In Großbritannien angekommen, sah man sich in der Lage, sollte die Cholera immer noch an Bord des Schiffes grassieren, ihr durch sanitäre Maßnahmen, eigene Lazarette etc. Herr zu werden. ${ }^{245}$ Auf den Vorwurf, eine Sonderregelung für britische Schiffe zu deklarieren, antworteten die britischen Delegierten, jedes Land könne das gleiche Recht für seine Schiffe in Anspruch nehmen, wenn es in der Lage sei und beweisen könne, bei Ankunft infizierter Schiffe an ihren Häfen eine Epidemie sicher vermeiden zu können. ${ }^{246}$ Tatsächlich wurde die passage en quarantaine in den folgenden Jahren von immer mehr Staaten entgegen der Beschlüsse der Konferenz von 1885, deren Teilnehmende sich in dieser Sache noch mehrheitlich gegen Großbritannien gestellt hatten, angewendet. So stellte der österreichische Delegierte 1892 fest: »le passage en quarantaine est devenu la règle $\ll{ }^{247}$. Österreich-Ungarn und Großbritannien schlossen im Juli 1891 sogar ein bilaterales Abkommen, das sog. Protocole Anglo-Austro-Hongrois über dieses Vorgehen am Suez ab, das schließlich als ultimativer Auslöser für die Einberufung der Konferenz von 1892 in Wien gesehen werden kann. Der österreichische Delegierte Kuefstein, schlug dort vor, das Protocole AngloAustro-Hongrois, angesichts der realen Anwendung der (»passage en quarantaine [...] à l'état de choses actuel $\ll^{248}$ ), zur Grundlage einer internationalen Übereinkunft zu machen. ${ }^{249}$ Es sei schlicht ein Fakt, dass es seit 1868 keine Cholera-Epidemie

244 Ebd.: S. 49.

245 CSI-6, 1885, Procès-Verbaux, Commission Technique, Nº8: S. 171.

246 Vgl. [Proust rückblickend auf die Konferenz 1885] CSI-7, 1892, Protocole Nº2: S. 22.

247 Vgl. [Kuefstein] CSI-7, 1892, Protocole N4: S. 111.

248 Ebd.: S. 111.

249 Vgl. ebd.: S. 110. 
mehr in Großbritannien gegeben habe. Kein Schiff, das seitdem die britischen Inseln ansteuerte, habe die Cholera dorthin gebracht: »[p]armi les bateaux à destination de l'Angleterre aucun n'a apporté le choléra en Angleterre. ${ }^{250}$ Der britische Delegierte Lowther bestätigte:»Nous sommes prêts à donner toute sécurité, à prendre toutes les précautions, et nous disons que, dans ces conditions, le passage, même des navires infectés, n'est nullement dangereux. ${ }^{251}$ Lowther antwortete auf den Protest der Franzosen, die eine einheitliche Regelung der Inspektion am Suez verlangten:

»Le Gouvernement français avait parfaitement le droit de prendre les mesures qu'il a adoptées. Le Gouvernement anglais revendique même ce droit pour tous les Gouvernements. Il nous suffit que les bâtiments passent le canal. Ensuite que chacun, chez soi, fasse ce que bon lui semble. $\ll^{252}$

Trotz des Protests, vor allem der französischen Delegation, setzte sich Großbritannien erneut durch.

Auch als auf der Konferenz zwei Jahre später, 1894, über die Frage diskutiert wurde, ob Indien zu den >gefährlichen< Staaten gezählt werden solle, löste dies eine heftige Abwehrreaktion der Briten aus. Auf der einen Seite in diesem Streit befanden sich vor allem die Vertreter Britisch-Indiens und Großbritanniens. Auf der anderen Seite befand sich vor allem Frankreich und an seiner Seite noch eine Reihe anderer Mittelmeer-Anreinerstaaten. ${ }^{253}$ Die britische Delegation hatte 1885 die Kategorisierung Indiens als Ort des Ursprungs (foyer) der Cholera zurückgewiesen und zum großen Ärger der französischen Delegation gefordert, für ihre aus Indien kommenden Schiffe grundsätzlich die Zertifizierung des »patent nette« (rein), welches die freie Passage erlaubte, zu erhalten. ${ }^{254}$ Immer wieder verwiesen die britischen Delegierten auf die Fortschritte der Assanierung, die man in Indien durch sanitäre Maßnahmen erzielt habe und die strenge hygienische Aufsicht auf den Schiffen sowie in den indischen Häfen, die sie zu dieser Forderung berechtigten. ${ }^{255}$ Auch hier begründete Großbritannien seine Sonderrolle mit den praktischen Erfolgen, die sie durch sanitäre Maßnahmen erzielt hätten. ${ }^{256}$ Die anderen Delegierten hatten faktisch keine bessere Begründungen zur Hand, um Großbritannien unter den gegebenen Bedingungen der Akzeptierbarkeit von Regierung und Macht zu schwächen. Ihr Verweis auf die Notwendigkeit bestimmter restriktiverer Maßnahmen zur Sicherung der öffentlichen Gesundheit in Europa unterlag angesichts der britischen Bezeugungen, seit den 40er Jahren trotz reger Handelskontakte mit Indien und Übersee jegliche Quarantäne in Großbritannien abgeschafft zu haben.

250 Ebd.: S. 112.

251 CSI-7, 1892, Protocole Nº: S. 169.

252 CSI-7, 1892, Protocole N $4:$ S. 116.

253 Der Konflikt zog sich ab 1866 über mehrere Konferenzen bis 1894 hin: Vgl. CSI-9, 1894, Procès-Verbaux, Séance Nº: S. 195.

254 Vgl. CSI-6, 1885, Procès-Verbaux, Commission Technique, Nº8: S. 170f.

255 Diese Position wurde von Indien und Großbritannien auch auf weiteren Konferenzen nicht ablegt. Vgl. z.B. [Cunningham] CSI-9, 1894, Procès-Verbaux, Séance ํ2: S. 53.

256 Vgl. CSI-6, 1885, Procès-Verbaux, Commission Technique, №14: S. $293 \mathrm{f}$ 
»)Les bâtiments anglais à destination d'un port du Royaume-Uni, infectés ou non, seront libres de passer le canal de Suez en quarantaine «. De sorte qu'il semble qu'il ne s'agit que des intérêts du commerce. $\ll^{257}$

Auch der gelegentlich gemachte Vorwurf, die Briten würden ökonomische Interessen denen der öffentlichen Gesundheit vorziehen, konnten angesichts der praktischen Erfolge der britischen Regierung und ihrer Überlegenheit, die gerade darin bestand, den Widerspruch von ökonomischen und gesundheitspolitischen Interessen scheinbar >aufgehoben< zu haben, nur wenig Wirkung entfalten. ${ }^{258}$ Schon Sutherland, der im Auftrag des Government Board of Health 1848 einen umfassenden Bericht über die Choleraepidemie anfertigte, hatte sein sanitäres Regierungsprogramm nicht als eine Art Kompromiss zwischen den Interessen der Ökonomie und öffentlichen Gesundheit präsentiert, sondern als die schlicht beste Regierung der Gesundheit. ${ }^{259}$ Auch Peter Baldwin bemerkt, dass Großbritannien seine sanitäre Politik und seinen positiven Bezug auf Hygiene nicht einfach nur vorschob, um gemäß ihren rein ökonomischen Interessen die Quarantäne zu lockern. Sanitäre Politik war integraler Bestandteil ihrer liberalen Regierungspraxis und nichts dem Entgegengesetztes. ${ }^{260}$ Außerdem fordert Großbritannien nie ein wirkliches Sonderrecht, sondern lediglich die Anerkennung des >Faktischen< und die Freiheit, entsprechend dieser unterschiedlichen Bedingungen und Möglichkeiten ihrer Regierung agieren zu können. ${ }^{261}$ Das bedeutet, dass Großbritannien sich nach dem Scheitern seiner Forderungen auf der Konferenz 1885 einfach entzog, was nur eine andere Form der Demonstration von Macht entsprach. ${ }^{262}$ Bemerkenswert ist aber nicht nur, dass Großbritannien als Agentin der hygienischen Maßnahmen und der sanitaristischen Doktrin zu derartigen Machtäußerungen fähig war, sondern dass der Bezug auf Hygiene selbst zu einer allgemeineren Bedingung von Macht und Regierung wurde. Denn der Verweis auf die Überlegenheit einer Regierung, die nach den Maßgaben der Hygiene handelte, wurde erstens von allen Delegierten anerkannt und zweitens bei weitem nicht nur auf Großbritannien bezogen. Der Erfolg im Bereich sanitärer Maßnahmen in den Städten, der Assanierung und der Versorgung der Bevölkerung mit sauberem Trinkwasser verschaffte jeder Regierung, nicht nur der Britischen, auf den Konferenzen eine Position moralischer und politischer Überlegenheit. Diese Position bedeutete, was die Äußerungen, Forderungen, sowie was die Möglichkeiten des Entzugs der Kooperationsbereitschaft auf den Konferenzen betraf, einen realen Machtgewinn. Großbritannien entzog sich regelmäßig nicht nur den Abstimmungen, sondern teilweise auch den Diskussionen und nahm gleichzeitig eine wartende und erwartende Haltung ein. Als hielte man sich zurück

257 [Proust] CSI-7, 1892, Protocole N²: S. 22.

258 Siehe z.B. die Argumentation von Semmola. Vgl. CSI-6, 1885, Procès-Verbaux, Commission Technique, $\mathrm{N}^{\circ} 8$ : S. 173.

259 Vgl. [Sutherland] CSI-1, 1852 [1851], Séance Nº: S. 3.

260 Vgl. Baldwin: Contagion and the State in Europe 1830 - 1930, 1999: S. 209.

261 Vgl. z.B. CSI-6, 1885, Procès-Verbaux, Commission Technique, Nº8: S. 181.

262 »More decisive than the question of who had the power to voice their interests at these conferences was therefore that of who had the power simply to refuse to cooperate. $\ll: \mathrm{Hu}$ ber: The unification of the globe by disease?, 2006: S. 466. 
und wartete bis die anderen Delegierten endlich eine andere >fortschrittlichere< Überlegung und Erkenntnis als Grundlage der Debatte anerkennen würden. ${ }^{263}$

\section{Die ganze Welt - Der internationalistische Traum der Sanitaristen}

Die Doktrin der sanitaristischen Epidemiologie richtete sich auf eine universelle Weise auf die Fragen: >Wie regieren?<, >Wie regulieren?< Die ganze Aufmerksamkeit der Sanitaristen zielte auf Probleme der Regierung von Gesundheit in einem ökonomisch geordneten sozialen Raum. Verfahren und Kriterien für die Rationalität der Regierung richteten sich an dem Ziel einer möglichst effektiven und funktionalen Regulierung der Gesundheit in einem solchen Raum aus. Nach der sanitaristischen Logik musste eine Regierung nichts weiter tun, als sich an der Wirklichkeit und den natürlichen oder ökonomischen Bedingungen der Existenz einer Gesellschaft oder auch einer Epidemie ausrichten. Auf diese Weise beanspruchten die Sanitaristen Universalität für die Techniken ihrer Regierung: »[E]n hygiène tous les moyens ont un certain caractère d'universalité. «264 Was im disziplinär-medizinischen Sinne der Wahrheit entsprach, war sekundär. Das Wissen der Sanitaristen ging zunächst einmal, genau wie das Wissen der Hygiene, nicht in die Tiefe, drang nicht wie der ärztliche Blick in den Körper des Kranken ein, sondern akkumulierte Wissen über alle möglichen Bedingungen und Faktoren mit Einfluss auf das menschliche Leben, an der Oberfläche des Sichtbaren und Zählbaren. Ihr Gebiet war die Ökonomie, die Architektur ebenso wie die Meteorologie, die Biologie und die Medizin. Die Konzentration der Hygiene in Frankreich auf die Umwelt und die Herstellung des Zusammenhangs sozialer Verhältnisse und Gesundheit einer Bevölkerung wie bei der Sozialmedizin in Deutschland und der »médecin social « in Frankreich: All das bildete den gleichen Ausgangspunkt für die Überführung der alten Lehre und der Praxis der Hygiene in die Rationalität einer modernen Regierung des Lebens und der Gesundheit der Bevölkerung, wenn möglich sogar einer Weltbevölkerung. In Frankreich fehlte es bei weitem nicht an einer ausgeprägten Entwicklung der Hygiene als Wissenschaft. Kaum in einem anderen Land wurde so viel und so umfangreich über das Problem der Hygiene und die Notwendigkeit entsprechender Maßnahmen publiziert. Der Rechtsmediziner Paul Brouardel beschäftigte sich mit der Ätiologie von Krankheiten und Epidemien zur Verbesserung der Maßnahmen der hygiène publique. Adrien Proust arbeitete sogar an dem Konzept einer »police sanitaire extérieure «. ${ }^{265}$ Was immer auch die rechtlichen Beschränkungen in Frankreich oder die Schwächen dieser einzelnen Konzepte waren, bis Ende des 19. Jahrhunderts ließen die Umsetzun-

263 Vgl. z.B. CSI-6, 1885, Procès-Verbaux, Commission Technique, №14: S. $293 f$.

264 Rapport: Sur les mesures d'hygiène à prendre pour la préservation contre le Choléra Asiatique; fait au nom d'une Commission composée de MM. Gomes, Goodeve, Lenz, Millingen, Monlau, Mühlig et Spadaro (médecins). et de MM. Keun, Malkom-Khan, Segovia et Vetsera (diplomates): Annexé (2): Vgl. CSI-3, 1866, Séance N²4: S. 2.

265 Vgl. Martin, A.-J.: Rapport sur l'Exposition d'hygiène urbaine: in: SMP, 9.1886, S. 220 225: S. 221. Vgl. auch: Ministère de l'agriculture et du commerce: Services sanitaires extérieurs, 1881. Vgl. Proust: L'Orientation nouvelle de la politique sanitaire, 1896. 
gen auf sich warten. ${ }^{266}$ Das Vorweisen einer funktionierenden Praxis hatte auf den Konferenzen, der Rationalität der Hygiene und der liberalen Logik zufolge, weit gröBere Bedeutung als wissenschaftliche und politische Theorien.

Aus Gründen, die ich in den vorangegangenen Kapiteln versucht habe deutlich zu machen, waren die Bedingungen in Großbritannien vor dem Hintergrund der Geschichte protestantischer Selbstpraxis, realistischer, utilitaristischer und materialistischer Strömungen der Philosophie, dem Einfluss der Liberalen und Nationalökonomen, der fortgeschrittenen Industrialisierung und einem dezentralen Regierungssystem begünstigend für die Herausbildung der sanitären Bewegung und die relativ schnelle praktische und rechtliche Umsetzung einer Reihe von Reformen und sanitären Maßnahmen. Vor diesem Hintergrund gelang es der britischen Regierung der Rationalität moderner Regierung neue Kriterien aufzuerlegen. In Abgrenzung von Polizeipraktiken des kontinentalen Europas und in Ablehnung von >spekulativer $<$ politischer Philosophie und wissenschaftlicher Theorie, gründete sie die Verfahren der Gouvernementalität nicht auf eine >theoretische Wahrheit<. Strenger - im Sinne der Tradition der Hygiene -, wurde die Rationalität der Regierung an der Erfahrung und im praktischen Erfolg ihrer Maßnahmen deutlich. Die Verknüpfung von Effektivität, Rationalität und Freiheit bedeutete im Umkehrschluss, dass die Ineffektivität einer Regierung Zeichen ihrer Irrationalität und damit auf alte illegitime, despotische Herrschaftspraxis hinwies. Die liberale Regierung trägt dieses Moment der Abgrenzung bis heute in sich. Die Inszenierung der britischen Regierung als wirklich >liberal< und $>$ rational< hat ihre Wirkung auf den Konferenzen nicht verfehlt. Die offene Kalkulation der liberalen Regierung, unter Einbeziehung immer neuer Faktoren, neuem Wissen und neuer Kenntnisse und damit die Ausweitung ihrer Regierung, demonstrierte paradoxerweise die Anerkennung ihrer eigenen Grenzen als Grenzen der Erkenntnis und damit ihre Liberalität als das Gegenmodell zu einer willkürlichen Herrschaft. Ihre Begrenzung bestand nicht gegenüber der Freiheit der Individuen. Sie zeigte sich stattdessen einerseits in ihrer Fähigkeit zur umfassenden Kenntnis einer unendlich komplexen nach natürlichen Gesetzmäßigkeiten regulierten Interaktionen von Kräften und andererseits begrenzt durch die Grenze eines Nutzens und der Effizienz, die sie durch ihre Maßnahmen erwirken konnte. Die Konsequenz aus dieser Begrenztheit bedeutet für die liberale Regierung jedoch nicht ein >Weniger-regieren $<$, sondern ein $>$ Besser-regieren $<$. Im Grunde genommen ist es sogar ein >Mehr $<$ an Regierung, denn jede einzelne Maßnahme wird mit größter Wirksamkeit durchgeführt. Überall dort, wo die Regierung nicht eingreift, ist die Regierung doch völlig darüber im Bilde, wie sie mit einem gezielten und effektiven Handgriff alle Bewegungen stoppen und alle Kräfte ersticken kann, die sie zuvor mit Hilfe des Marktes und anderer Techniken in Gang gehalten und als Freiheiten vollzogen hat. Diese Eigenschaft der liberalen Gouvernementalität hat auch Foucault ausdrücklich betont. ${ }^{267}$

Die liberale Regierung muss, um ihre Regierung zu rationalisieren, um effektiver zu sein und nicht >unnötig zu regieren, eine Unmenge an Differenzierungen nach

266 »En France, ce qui manque le plus à un tel pont de vue, c'est assurément l'application des découvertes et des enseignements de nos hygiénistes.« Martin, A.-J.: Rapport sur l'Exposition d'hygiène urbaine: in: SMP, 9.1886, S. 220 - 225: S. 221.

267 Vgl. Foucault: Geschichte der Gouvernementalität I, 2004 [1977 - 1978]: S. 98. 
dem Kriterium der optimalen Regierbarkeit des jeweiligen Problems und der für jedes Problem geeignetsten Techniken vornehmen. Darin besteht das Potenzial, auf das sie ihre Universalität begründet. Sie kann theoretisch alles regieren, weil sie sich nach den jeweiligen Eigenschaften der Regierbarkeit von verschiedenen Menschen, Krankheiten, Regionen etc., die sie sorgfältig unterscheidet, richtet. Sie regiert mehr, indem sie mit einem unendlichen Repertoire völlig unterschiedlicher Techniken aufwartet, dem sich wirklich kaum noch etwas entziehen kann. Aus diesem Grund interessieren sich die Sanitaristen nicht für die medizinischen Klassifizierungen, sondern konzentrieren sich auf Kategorien, wie epidemische, ansteckende, heilbare und vermeidbare Krankheiten.

Die Ungleichheit stellt für diese Regierung kein >Problem< dar. Die Unterschiede zwischen den zu regierenden Bevölkerungen der einzelnen europäischen Länder hatte Sutherland 1851 ohne Protest hingenommen. ${ }^{268}$ Auch gegenüber den $>$ Besonderheiten « der >orientalischen Bevölkerungen< nahmen die britischen Delegierten eine akzeptierende Haltung ein. Die Sanitaristen stellten die Frage nach der Differenz zu den europäischen Bevölkerungen in einer Weise, die über die Abgrenzung zu Europa und europäischen Regierungsformen weit hinausging. Ihre Unterscheidung geschah auf die Frage aller möglichen Regierbarkeit hin. Die Besonderheit an dem Charakter der Universalität der von den Sanitaristen propagierten liberalen Regierungsrationalität bestand, wie schon eben bemerkt, darin, vom Prinzip her allgemein und in der Praxis aber an die spezifischen Eigenschaften eines Ortes, einer Krankheit, einer Bevölkerung angepasst zu sein. Ihre Liberalität lag nicht in einer grundsätzlichen Verringerung des Einsatzes von Repression, sondern der Anwendung einer bestimmten Rationalität zur Unterscheidung wann und wo die Freiheit eingeschränkt oder aufgehoben und wann und wo sie abgesichert und hergestellt werden müsste. Es war also auch ein Widerspruch für die britische Regierung, wenn sie teilweise und an manchen Orten sehr rigide und repressive Maßnahmen anwandte. ${ }^{269}$

Die Universalität des Ansatzes der Sanitaristen bestand nicht darin, auf dem Wege eines vereinheitlichten Wissens, oder einer medizinischen ermittelten Wahrheit der Cholera die Grundlage für eine gemeinsame, gleiche und dadurch gerechte Regelung zu schaffen. Diese Art des Zusammenhangs, wie er unter anderem in der anfänglichen Rechtfertigung der Quarantäne über die Inkubationszeit der jeweiligen Krankheit bestand, wurde von den Sanitaristen abgelehnt. Er sei zu eng und nehme zu wenig Rücksicht auf andere Faktoren und Bedingungen. Der Universalitätsanspruch der liberalen Regierung, die ich als Basis der sanitären Bewegung in Großbritannien verstehe, beruhte auf ihren Verfahren, Wissen zu verarbeiten und zu erfordern, auf ihren Modus der Kalkulationen über das Maß, den Zeitpunkt und den Ort restriktiver und stimulierender Techniken anzustellen, um eine möglichst effektive Regierung zu gewährleisten. Woran anders, als durch Statistiken, sollte diese `Effektivität< gemessen werden? Aus diesem Grund war das Verhältnis der Sanitaristen zu den Konventionen und Beschlüssen, als auch zu dem Streben nach Einheitlichkeit auf den internationalen Konferenzen gespalten. Sie befürworteten die Verallgemeine-

268 Vgl. CSI-1, 1852 [1851], Séance $N^{\circ} 11:$ S. 5.

269 Vgl. [Vingard] Société de Médecine: Discussion sur police sanitaire internationale: in: SMP, 12.1889, S. 9 - 27: S. 21: S. 21. 
rung einer auf die Praxis gerichteten liberalen Rationalität, aber stellten sich gegen die Verallgemeinerung von konkreten Maßnahmen, Techniken, politischen Programmen oder der Theorien auf denen diese gründeten. 


\section{Schluss}

Eine grundlegende These, die die Vorüberlegungen meiner Analyse der Geschichte der Regierung von Gesundheit beeinflusste, bestand in der Vermutung, dass es eine Herausbildung und Durchsetzung einer spezifisch liberalen Form moderner Gouvernementalität von Gesundheit im 18. und 19. Jahrhundert gegeben hat. Diese These hat sich im Laufe der von mir vorgenommenen Analyse in vieler Hinsicht bestätigt. Die Herausbildung liberaler Rationalität war, so hat sich ebenfalls gezeigt, begleitet von einem Prozess stetiger Gouvernementalisierung des Politischen. Die vorangegangene historische Untersuchung zeichnet allerdings lediglich Fragmente der Entstehungs- und Verbreitungsgeschichte einer liberalen Regierungsrationalität bei der Regierung von Gesundheit nach. Die Bruchstücke dieser Geschichte konterkarieren die Erzählung einer kontinuierlichen, linearen oder gar abgeschlossenen Entwicklung hin zu heute (wieder) wirkmächtigen Rationalitäten und Technologien der Regierung von Gesundheit.

Die moderne Regierung von Gesundheit, oder anders ausgedrückt: die Gouvernementalität der Gesundheit, war durch die Zeit ihrer Entstehung hindurch stets ein fragiles Kondensat wechselnder und sich wandelnder Kräfteverhältnisse, unzähliger kleinteiliger, kontingenter Veränderungen von Praxen und Ordnungen der Diskurse, bzw. der Konflikte und Krisen, die sich aus diesen Transformationen für Bedingungen der Regierung von Menschen und der Souveränität politischer Herrschaft ergaben. Ihre Entwicklung basierte auf einer andauernden Rationalisierung der Verfahren, durch die die Menschen zu einem bestimmten gesundheitsbezogenen Verhalten angeleitet und Regierungen zu bestimmten gesundheitspolitischen Strategien motiviert und für diese legitimiert wurden.

Aus heutiger Perspektive kann die liberale Regierung als eine äußerst >erfolgreiche< Strategie der Macht oder der Regierungen angesehen werden. Ihrer »liberalen politische[n] Rationalität, [...] in de[r] das Prinzip der Freiheit nichts der Macht, der Herrschaft oder dem Staat Äußerliches darstellt $\ll^{1}$, ist bis heute kein wirklicher $>\mathrm{Ge}$ gendiskurs $<$ gegenübergestellt worden. Kein wirklich bedrohlicher Angriff ist seitdem unternommen worden, der tatsächlich auf die Rationalität dieser Form der Herrschaft gezielt hätte, von der heutzutage selbst die meisten (neo)liberalismuskritischen Gegeninitiativen geprägt sind.

1 Bohlender: Metamorphosen des liberalen Regierungsdenkens, 2007: S. 18. 
Im Folgenden möchte ich noch einmal Revue passieren lassen, welche Fragmente einer Herausbildung liberaler Gouvernementalität von Gesundheit in Europa sich nachzeichnen lassen, welche alten und neuen, sie stützenden und ihr widersprechenden Verfahren der Gouvernementalität und welche Diskurse und Ereignisse sie durch das 19. Jahrhundert hindurch geformt haben. Zu diesen Fragmenten gehören die bürgerlichen diätetischen Praxen der Hygiene ebenso, wie auch die Gründung eines $\mathrm{Bu}$ reau sanitaire International. Sie schließt die Konstruktion neuer humanistischer Universalitäten und unterschiedlicher Vorschläge der Verfahren moralischer Subjektivität ein, die zugleich auch eine Geschichte unzähliger Verfahren der Differenzierung von Subjekten und Problemen, der (Neu)Verteilung von Macht und der Erfindung neuer Regierungstechnologien ist. Sie kann ebenso als Geschichte von Kämpfen, wie als eine von Aneignungen und Ausschließungen von Macht gelesen werden: Eine Geschichte, die von der Entdeckung des Menschen, seines (gesunden) Körpers und seiner Arbeits- und Lebenskraft als Quelle des Reichtums und Grundlage der Produktion geprägt ist und die vom Aufstieg einer auf Gesundheit gerichtetem Selbstpraxis bis hin zur gesundheitspolitischen Technologie einer Regierung der Bevölkerung erzählt.

\section{GouvernementalisierUng UND LIBERALE RegIERUNG}

Im ausgehenden 18. Jahrhundert entwickelten sich in den deutschen Staaten, Frankreich und im Vereinigten Königreich Bewegungen >progressiver die es sich zum Ziel machten, die ländliche und ärmere Bevölkerung gesundheitlich aufzuklären oder sogar zu versorgen. Sie unternahmen Versuche, den Staat in eine v.a. vom Bürgertum geführte Auseinandersetzung um das Problem der >guten $<$ gesundheitlichen Verhaltensführung und Versorgung, also der Regierung von Gesundheit, stärker einzubeziehen und produzierten so neue Anforderungen für die Regierung der Gesundheit der Bevölkerung.

In vielen deutschen Staaten unternahmen Ärzte im Anschluss an die hippokratische Lehre den Versuch, moralische Kriterien für gute Ärzte aber auch für die staatlichen Maßnahmen zur Steuerung der Gesundheit der Bevölkerung zu formulieren. Sie forderten eine Verbesserung und Reformierung der Polizeiwissenschaft nach dem Vorbild hygienischer Lehren, gewissermaßen als »Diätetik des Staates«.

Die Redaktion der Gazette de Santé propagierte solche Ziele in Verbindung mit Forderungen der Umstrukturierung der wissenschaftlichen Ausbildung von Medizinern. Der vor 1789 bereits etablierte >revolutionäre Diskurs< hatte die Auseinandersetzungen um Hygiene und >gute< Lebensführung und die Kritik an der Medizin mit Utopien der republikanischen Gesellschaft und einer Gesellschaft ohne Krankheit und folglich ohne Ärzte verbunden. In Frankreich hatte sich, wie in den deutschen Staaten, von Seiten hippokratischer Ärzte eine Kritik an der Polizei herausgebildet. Der Versuch, diese nach der Logik der Hygiene zu reformieren bzw. zu rationalisieren, wurden durch die Umbrüche der Französischen Revolution quasi über Nacht zum Regierungsprogramm. Nach der französischen Revolution wollte man die Polizei in zweierlei Hinsicht reformieren. Man forderte erstens ihre wissenschaftliche Rationalisierung mithilfe einer medizinisch-hygienischen Wissenschaft und zweitens 
auch eine enge personelle und institutionelle Verzahnung mit dieser erweiterten Medizin, ihrer Ethik, ihrer Institutionen und Gesellschaften und der medizinischen Wissenschaft. Der Vorschlag der Reform, den noch die alte Société royale de médecine 1790 der Nationalversammlung vorlegte, sah eine Vereinigung aller medizinischen Professionen zur art de guérir und aller medizinisch tätigen Personen als officiers de santé, sowie eine Verschmelzung von medizinischem und polizeilichem Personal unter dem Banner der Hygiene und mit dem Ziel der Abschaffung aller allgemeinen Ursachen für Krankheiten vor. Der >revolutionäre Diskurs\& versprach die Erneuerung der Gesellschaft und die Beseitigung der Krankheiten, die nun als Ausdruck eines >krankhaften<Gesellschaftszustandes interpretierbar waren. Die Ärzte sollten ganz im Sinne der Rolle, die ihnen im Rahmen der beschriebenen bürgerlich-hygienischen Auseinandersetzung zu- und gleich wieder abgesprochen wurde, zu den Diätlehrern der Menschen (hygiène privé) und des Staates (hygiène publique) werden. Es handelte sich, wie Foucault schrieb, um den »Mythos eines ärztlichen Berufsstandes, der in der Art des Klerus organisiert ist und der auf der Ebene der Gesundheit und des Körpers mit ähnlichen Vollmachten ausgestattet« werden sollte »wie jener im Hinblick auf die Seelen $\aleph^{2}$. De facto führten die revolutionären Umwälzungen zunächst einmal $\mathrm{zu}$ einem Zusammenbruch polizeilicher und medizinischer Organisationen, die nur langsam ersetzt oder wieder aufgebaut wurden. Man konzentrierte sich eher auf die Wissenschaft und ihre Aufgabe, die Bedingungen und allgemeinen Ursachen von Krankheiten zu erforschen. Die Medizin sollte paradoxerweise herausfinden, unter welchen Bedingungen man sie abschaffen könnte. In diesem Zusammenhang bildete sich die klinische Medizin heraus. Der ärztliche Blick veränderte sich, wie auch Foucault in seiner Studie zur Geburt der Klinik herausarbeitet hat.

Die bürgerlichen hippokratischen Bestrebungen in Deutschland und auch der liberalere Teil der Ärzte blieb wesentlich zurückhaltender, was ihre Forderungen bezüglich der Reformierung der gesundheitsbezogenen staatlichen Politiken anging. Paradoxerweise führte gerade die Erfahrung der Französischen Revolution dazu, dass die Ärzte noch stärker als vor 1789 auf eine langsame Reform der Medizinalverfassungen und der medizinischen Polizeien der einzelnen deutschen Staaten setzten. Die sprogressiven< hippokratischen Ärzte visionierten Ende des 18. Jahrhunderts in Deutschland eine ganz andere Utopie als die in Frankreich. Ihre Utopie bestand grob gesagt in der Idee der Konstruktion einer guten, aufgeklärt-absolutistischen Regierung von Gesundheit und von einem guten Fürsten, welche als Vorbild und übertragbares Modell der Regierung für die deutschen Staaten und sogar für die anderen europäischen Staaten gelten sollte. Diese Perspektive war mit der für Deutschland spezifischen >Überproblematisierung < der Polizeiwissenschaft verknüpft, die sich mit dem Ziel der Herstellung eines europäischen Gleichgewichts verbunden hatte. Dieses sollte ja, wie auch Foucault schrieb, dadurch erreicht werden, dass alle Staaten über eine gute Polizei, und damit über eine gute Kontrolle und Mechanismen zur Steigerung der Kräfte verfügen sollten. ${ }^{3}$ Wie in Frankreich versuchten die Ärzte auch in Deutschland, während sie die Kritik an Polizei und am Medizinalwesen formulierten, der Arzneiwissenschaft und der Ärzteschaft eine größere politische Bedeutung zu

2 Foucault: Die Geburt der Klinik, 2008 [1963]: S. 48.

3 Vgl. Foucault: Geschichte der Gouvernementalität I, 2004 [1977 - 1978]: S. $453 f$. 
verschaffen. Entgegen den - wenn auch schwächer als in Frankreich - vorhandenen Anfeindungen des Bürgertums, stellten sich die > guten< >rationalen< Ärzte selbst an die Spitze einer moralischen, hippokratischen und vor allem rationellen Reformierung der Regierung von Gesundheit. So beanspruchte die Arzneiwissenschaft in einigen deutschen Staaten, zumindest eine Zeit lang, nicht nur das Wissen, sondern sogar eine bestimmte Rationalität der Regierung, eine Auffassung von dem Gegenstand und einem aus ihm hervorgehenden Existenzgrund der Regierung beizusteuern. Die Ärzte gerieten über einen bestimmten Bereich, der mit der ärztlichen diätischen Praxis der Verhaltensführung verbunden war und dem Charakter nach eine gewisse Regierungsrationalität besaß, selbst in eine Diskussion über ihre Subjektivität, ihre Kunst und die moralischen, universellen Aufgaben ihres Regierens und des Regierens der Gesundheit überhaupt. Sie richteten sich an die Fürsten, indem sie sagten: >Wir sind machtlos und können nur hoffen, dass der Regent gegenüber unserem Urteil, zu dem wir uns in der Lage oder sogar berufen fühlen, nicht rücksichtslos ist.< Es ging also genau um diese Unterscheidung, die einerseits das Wissen als Mittel der Regierung - der Polizeiwissenschaft als »Werkzeug der Staatskunst $\aleph^{4}-$ bestimmt hatte und andererseits die Vernunft bzw. Rationalität, die den Existenzgrund der Regierung ausmachen sollte. Die Ärzte eröffneten der Regierung hierdurch nicht nur die Aussicht auf eine gute moralische Existenz, sondern boten ihr an, sich eine Geschichte der guten Regierungen anzueignen, ebenso wie sie der Arzneiwissenschaft auftrugen, sich selbst als Regierungskunst zu erkennen und sich für die Regierung nützlich zu machen. Auch unter dem Einfluss der transzendentalen Philosophie, namentlich der von Kant, blieb dieser Traum der Arzneiwissenschaftler und Diätlehrer jedoch auf einen innerärztlichen Diskurs beschränkt und von marginaler politischer Bedeutung. Kant sprach der Philosophie die Rolle zu, über die Rationalität der Regierung zu reflektieren und der Medizin, deren Gegenstand die Physik und nicht die Metaphysik war, ihren Beitrag zur Philosophie ab.

In Frankreich wurde die Macht der Ärzte als Regierende hinsichtlich der Regierung der Gesundheit der Bevölkerung aus anderen Gründen als in Deutschland dauerhaft beschränkt. Die Rolle, die man den Ärzten in Frankreich hier zunächst eingeräumt hatte, führte zu einer zu direkten Übertragung der diätischen bürgerlichen und moralischen Praxis auf die staatliche Regierung der Gesundheit. Für Frankreich spezifisch war, dass die Regierung zunächst die Selbstführung im Sinne der hygiène pri$v e ́$, die sich an diesem bürgerlichen Diskurs entwickelt hatte, als ihre eigene Bedingung setzte. Es bestand die Vorstellung der Zentralisierung und Vereinheitlichung, bzw. der Harmonisierung der Verhältnisse von privater und öffentlicher Hygiene, bürgerlichem Subjekt und einem politischen und sozialen System, von Medizin und Hygiene und der Praxis der $\gg$ Regierung des Selbst und der Regierung der anderen $\aleph^{5}$. Heterogenität, wie sie schon durch die Klassenverhältnisse und unterschiedliche Lebensweisen und Subjektivitäten in der französischen Gesellschaft bestanden, stellte in dieser Regierungslogik ein wirkliches Hindernis dar. Die französische Regierung war während der ersten und zweiten Republik ebenso wie während der Julimonarchie

4 Vgl. Justi: Grundsätze der Policey-Wissenschaft, 1756: Vorrede [Ohne Seitennummerierung, S. 4].

5 Foucault: Die Regierung des Selbst und der anderen I, 2009 [1982 - 1883]: S. 53. 
auf die Konstituierung ihrer Beziehung zu den Bürger-Subjekten konzentriert. Dies machte es grundsätzlich schwerer, einen praktischen Begriff von öffentlicher Hygiene zu entwickeln, der den neuen gesundheitspolitischen Anforderungen Industrialisierung und sozialer Polarisierung gewachsen war. Die hygiène publique, die man der hygiène privée als ihr Pendant gegenübergestellte, entwickelte sich vor allem als eine Wissenschaft und nicht als eine Technologie oder Praxis der Regierung. In Frankreich entfaltete sich, mehr als in jedem anderen europäischen Staat, die Hygiene als eine Wissenschaft von den für die Gesundheit relevanten Umwelteinflüssen. In dem Bestreben, die Ursachen für Krankheit zu ergründen, konzentrierte sich die Hygiene auf die Beobachtung und Analyse der Umwelt, der Luft, des Wassers und des Milieus - vor allem auf die Stadt bezogen. Die Choleraepidemie machte die Schwächen dieser Regierung nur deutlicher. Der Mangel an eigener praktischer Rationalität hatte die Regierung während der ersten Epidemie in ein noch engeres Abhängigkeitsverhältnis zur Medizin und wissenschaftlichen Hygiene, wie auch zur bürgerlichen privaten hygienischen Praxis und deren moralische Begründungen gedrängt. Die Art, wie man die mit der Hygiene verschmolzene »Medizin mit dem Schicksal des Staates verbunden $\ll^{6}$ hatte, führte zu einem sehr lang andauernden Konflikt, der schließlich zu einer erneuten Trennung der beiden Wissenschaften (Medizin und Hygiene) führte. Dies erfolgte auf der einen Seite, indem sich die Medizin von der Hygiene und damit von einer direkten Koppelung an die Rationalität der Regierung löste, auf der anderen Seite durch eine Abtrennung der Hygiene von der Medizin und damit von den Verfahren der wissenschaftlichen Veridiktion. Die Medizin strebte mit ihrer Nosologie, ihren Klassifikationen der Krankheiten nach der Vereinheitlichung ihrer Episteme, der Perfektionierung ihrer Regeln und Wahrheiten innerhalb der Disziplin. Diese typische Bewegung der Disziplin, sich selbst zu begrenzen und sich zu vertiefen, um innerhalb bestimmter Regeln und Kriterien Wahrheit über einen bestimmten Bereich zu akkumulieren, engte die Hygiene, deren Grundproblem eine Frage der Praxis des Umgangs und der Regierung war, zu sehr ein. Was die beiden ungleichen Logiken der Medizin und der Hygiene für diese kurze Zeit zusammengeschweißt hatte, war die utopischen Idee der Regierung von Gesundheit als die eines >revolutionären Diskurses<. Die medizinischen Reformen in Frankreich fanden zur Zeit des Übergangs vom 18. zum 19. Jahrhunderts vor dem Hintergrund eines revolutionären Mythos statt. Besonders die dauerhafte Neubegründung der Regierungen in der ersten Hälfte des 19. Jahrhunderts verlangte die ständige Wiedergeburt von Regierungsdiskursen, die die Regierung historisch, formal und juristisch begründete. Eine praktische Begründung und materialistische Diskurse waren diesen Diskursen nachgeordnet. Die juridische Identität und Logik der Regierung stellte eine reale Begrenzung ihrer Macht gegenüber den Rechten der Individuen her. Die Einheit der individualisierenden und totalisierenden Maßnahmen, die man in Frankreich auf die hygiène privée und hygiène publique verteilte, war nur im Bereich der Theorie und Wissenschaft, nicht aber als Praxis möglich. Die Handlungsfähigkeit der Polizei blieb hierdurch beschränkt, was Foucault als das »problème de la propriété privée, principe sacré $\ll^{7}$ bezeichnete. In Folge entstand im 19. Jahrhundert ein dauerhafter

6 Vgl. Foucault: Die Geburt der Klinik, 2008 [1963]: S. 51.

7 Vgl. Foucault: La naissance de la médecine social, 1994 [1974]: S. 223. 
kritischer Diskurs, der die Ineffektivität der französischen hygiène publique in der Praxis betonte. Spätestens die Choleraepidemie wirkte wie ein Schock. Nach 1832 war deutlich geworden, dass sowohl die vereinte Wissenschaft der Hygiene und Medizin, die vereinten Mediziner und Ärzte in ihrer Rolle als Ratgeber, Seelsorger und Gesetzesgeber der Gesundheit in einem, als auch schließlich die Bürger in ihrer Fähigkeit zu Selbstregierung mehr oder weniger als Ensemble der Regierung der Gesundheit versagt hatten. Daraufhin griff die Regierung schließlich wieder stärker auf die vorwiegend auf die Stadt gerichteten Techniken der alten - wenn auch auf Basis der Hygiene rationalisierten - Polizei zurück. Der Rückzug auf die Polizei war also nicht nur ein erneuter Bezug auf alte staatliche Techniken, sondern auch die Rückübertragung von Macht auf einen mehr und mehr rationalisierten und gouvernementalisierten Staat.

Anfang des 19. Jahrhunderts waren es vorwiegend in England und Schottland die Angehörigen einer ärztlichen Mittelschicht, die surgeons und apothecaries, die eine staatlich kontrollierte Neustrukturierung und gleiche Anerkennung aller ärztlichen Berufe im Rahmen einer medical reform forderten. Auch sie richteten sich an die Regierung, indem sie darauf aufmerksam machten, dass die medizinische Versorgung des Großteils der Bevölkerung, vor allem der Landbevölkerung, von ihnen geleistet wurde, während die Absolventen des elitären College of Physicians nur über ihre Lizenzen in den großen Städten wachten und lediglich einer wohlhabenden kleinen Schicht der Bevölkerung zur Verfügung standen. Die surgeons und apothecaries erklärten der Regierung gegenüber, dass sie in Wahrheit bereits eine Rolle bei der gesundheitlichen Regierung der Bevölkerung eingenommen hatten. Praktisch gesehen waren diese englischen und schottischen Wundärzte und Apotheker also die wahren Allgemeinmediziner: die general practitioners. Damit bezogen sie sich keineswegs mehr nur auf einen hippokratischen Diskurs der > wahren Medizin $<$, sondern stützten sich auf eine protestantische moralische Pflicht gegenüber der Gemeinschaft. Sie waren es, die sich nicht nur um die einzelnen Patienten kümmerten, sondern sich mit der Krankheit und den Epidemien in ihrer Verbindung zu einem größeren sozialen und ökonomischen Problem beschäftigten. Die Frage nach der guten Regierung stellt sich von diesem Diskurs, angeregt auch in einem bestimmten Rahmen für den Staat, anders.

Während des 17. und 18. Jahrhunderts war es bereits zur Entstehung und schrittweisen Medikalisierung einer privaten oder besser gesagt familiären, kommunitären Praxis der gegenseitigen und auf sich selbst bezogenen Krankenversorgung gekommen, die mit der Entwicklung einer protestantischen und gleichzeitig hippokratischen Ethik im Zusammenhang stand. Foucault schrieb, dass sich in »England eine Reihe von Mechanismen zur Kontrolle der Bevölkerung, zur permanenten Kontrolle der Menschen « herausbildete, »um eine Reihe von Bedürfnissen zu befriedigen ${ }^{8}$. Diese »gewannen dann immer größere Bedeutung, bis sie sich in der gesamten Gesellschaft ausbreiteten und in die strafrechtliche Praxis Eingang fanden « ${ }^{9}$. Foucault meinte hiermit bestimmte Kontrollmechanismen, die zunächst auf relativ niedriger Ebene der sozialen Hierarchie mit dem Ziel, eine gewisse soziale Ordnung aufrecht zu er-

8 Foucault: Die Wahrheit und die juristischen Formen, 2003 [1974]: S. 87.

9 Ebd.: S. 87. 
halten, entstanden waren und dort bestimmte Mittel und Techniken zur Sicherung der Ordnung hervorgebracht hatten. ${ }^{10} \mathrm{Ihr}$ Ziel war es, ganz im Sinne der sich, laut Weber, etablierenden protestantischen Ethik, alles zu bekämpfen »worin sich eine Verachtung Gottes zeigte ${ }^{11}{ }^{11}$ und zu fördern, was der Verehrung Gottes dienlich war - allem voran die Arbeit. Laut Foucault waren diese Techniken zunächst Teil einer Strategie um das soziale Umfeld der Macht des »bedrohlichen und blutigen Justizapparats ${ }^{12}$ in Großbritannien zu entziehen, bevor man gegen Ende des 18. Jahrhunderts begann, aus völlig anderen Motiven und von einer bürgerlichen, besitzenden Schicht ausgehend, eine Institutionalisierung und >Verstaatlichung < dieser Kontrollmechanismen umzusetzen. ${ }^{13}$ Während diese >praktischen Verhaltensänderungen< im Kontext protestantischer sozialer Mechanismen der Regierung entstanden, entwickelte sich daraus parallel eine bestimme moralische Philosophie und ein Diskurs über moralische und gute Lebensweise. Dieser nahm seinerseits Einfluss auf die Auseinandersetzung der Liberalen um Regierung und den Diskurs der Politischen Ökonomie. Von hier aus übertrug sich liberale, ökonomische Rationalität des Regierens zurück auf die Selbstpraxis und zwar als Diskurs der >Befreiung< von >willkürlichen< sozialen Kontrollmechanismen durch deren Verrechtlichung und Verstaatlichung. Etwa in diesem Kontext ist auch die Diskussion um die medical reform zu sehen, die zum Ziel hatte, einen Teil dieser nicht-staatlichen und nicht-professionellen medizinischen Praxis zu schwächen. Die Gesellschaften, die sich hier gründeten, waren nicht anti-staatlich ausgerichtet, sondern begannen eher eine bestimmte positive Praxis der Förderung und Beeinflussung der Gesundheit der Bevölkerung auf die Rolle der Gesetze und die Regierung zu übertragen. Die Argumentation, mit der man schließlich forderte, Gesetze zu erlassen, musste mit der Behauptung einhergehen, dass die sozialen Kontrollmechanismen versagten, bzw. die Rationalität und Moral der public opinion der einfachen Leute, zu verkommen, zu schwach oder angesichts der sozialen Umbrüche verkümmert sei, um die Regierung der Gesundheit ihren Wahlentscheidungen zu überlassen. ${ }^{14}$ Die Mittelschicht der britischen Ärzte kritisierten die Aufteilung und Hierarchisierung der medizinischen Professionen durch eine Reihe von Problematisierungen der >wahren Medizin<, die spezifisch für Großbritannien war. Die protestantische Ausprägung eines Berufsethos und die Konstruktion des guten und wahren Arztes zeichnete sich nicht nur durch die $>$ wissenschaftliche< Rationalität der Medizin, sondern durch die Hingabe zur mühsamen Arbeit für die Gemeinschaft aus.

Die utilitaristischen, materialistischen Ansätze und liberalen Theorien der Politischen Ökonomie nahmen Einfluss auf die medizinische Wissenschaftsphilosophie. Sie prägten einen wissenschaftlichen Realismus und eine realistische Methodologie in der Medizin, in der Praxis der Ärzte, aber auch in der Organisation der gesundheitlichen Versorgung der Bevölkerung. Bereits während der Diskussion um die medical reform hatten die Reformer gefordert, quasi >naturwüchsige<, an die gesellschaftli-

10 Vgl. ebd.: S. 88.

11 Ebd.: S. 89.

12 Ebd.: S. 91.

13 Vgl. ebd.: S. 92.

14 Vgl. S.M.: [A Letter on the suppression of Quack Medicine] To the Editors of the Medical and Physical Journal: in: MPJ, 2.1799, S. 150 - 152: S. 152. 
chen Strukturen angepasste Aufteilungen der medizinischen Professionen nicht wie in Frankreich einer künstlichen Vereinigung zu unterziehen. ${ }^{15}$ Eine gute Regierung müsse die $>$ Realität< der Dinge anerkennen und die Wissenschaft müsse sich auf die reine Beobachtung des Gegebenen stützen. Im Gegensatz zu Frankreich und Deutschland, wo die Medizin zwar auch als Erfahrungswissenschaft galt, aber die Empiriker unter den Medizinern um 1900 einen eher schlechten Ruf hatten, war es in Großbritannien legitim, auf der Grundlage dieses Erfahrungswissens zu praktizieren und zu regieren. Auf diese Weise blieb das Verfahren dieser Regierung offen und unverpflichtbar gegenüber einer bestimmten moralisch oder politisch relevanten Philosophie oder wissenschaftlichen Theorie. Die Abgrenzung der britischen wissenschaftlichen, also wahren Mediziner gegenüber den sog. quacks erfolgte nicht, z.B. wie in Deutschland, über die Differenz von Theorie bzw. Philosophie und Empirie, sondern über die Methode der Untersuchung - also über bestimmte Kriterien für Evidenzproduktion.

Die Anhänger der sanitären Bewegung in Großbritannien im 19. Jahrhundert ordneten die Hygienelehre, die sich nach der französischen Interpretation der hippokratischen Lehren auf das Verhältnis des Subjekts zu sich selbst und zu seiner Umwelt beziehen sollte, um. Sie machten aus ihr eine Lehre von den sozialen und ökonomischen Funktionsgesetzen und Existenzbedingungen. Diese Transformation bestand im Wesentlichen in der Ablösung von einer bestimmten asketischen oder auf Meditation beruhenden Selbstpraxis und einer entsprechenden Regierung, die von den Subjekten eine gewisse Beherrschung ihrer Lust und ihrer Bedürfnisse einforderte. Die liberalen Theoretiker und Moralphilosophen wendeten dagegen ein, dass hierdurch die >natürlichen< Kräfte des Lebens gehemmt würden, die doch gerade wichtig auch in der Abwehr und Immunität gegen Krankheit seien. Die Verknüpfung der Gesundheit mit dem Problem der Lebens- und vor allem der Arbeitskraft ${ }^{16}$ hing im Kern mit einer bestimmten >Entdeckung zusammen, die die Liberalen und überhaupt die Nationalökonomen im Ausgang des 18. Jahrhunderts gemacht hatten: Die 〉Entdeckung <, dass weder das Land noch die Rohstoffe, sondern die menschliche Arbeitskraft und die (freien) Lohnarbeiter die eigentliche Quelle des Reichtums einer Nation waren. In Großbritannien vollzog man als erstes, gestützt durch die protestantische Form der »innerweltlichen Askese ${ }^{17}$ einen deutlichen Bruch zu bestimmten Traditionen der Lebensführung, z.B. innerhalb der priesterlichen Sorge um die Seele, und begann dieser eine wirkliche Alternative der >Führung< entgegenzusetzen. Man entkoppelte die Frage der Lebensführung von einem moralischen Diskurs und ging ganz materialistisch davon aus, dass die ökonomische Rationalität ein direktes Resultat aus dem >natürlichen< menschlichen Streben nach Existenz angesichts einer Reihe von natürlichen gegebenen Bedingungen sei. Aus dieser Perspektive war weder ein individueller Prozess der Selbsterkenntnis - wie bei Kant - oder der asketischen, meditativen

15 [Hrsg.]: An attempt to develop the Fundamental Principles which should guide the Legislature in regulating the Profession of Physic: in: ESMJ, 14.1818, S. 1 - 26: S. 8.

16 Vgl. Foucault: Krise der Medizin oder Krise der Antimedizin, 2003 [1976]: S. 72. Vgl. Foucault: Die Geburt der Sozialmedizin (Vortrag), 2003 [1974]: S. 292f.

17 Vgl. Weber: Die protestantische Ethik und der Geist des Kapitalismus, 1995 [1904/04]: S. $80 \mathrm{f}$. 
Praxis des Selbst - wie in der christlichen oder europäischen antiken Tradition - erforderlich, damit ein Subjekt die Notwendigkeit einer Regierung und einer basalen Selbstregierung (der Gesundheit) anerkennen könne. Die Regierung musste nach dieser Logik nur diese einfache Rationalität berücksichtigen, sich nach ihr richten und einen Rahmen für sie schaffen, in dem sich diese entfalten könne. Sie sollten regieren, indem sie gerade die sinnliche Wahrnehmung von Schmerz und Lust und die Bedürfnisse als Antriebsfaktoren der Lebenskräfte beförderte und in bestimmte Bahnen lenkte. Die britische Regierung der Gesundheit war eine Regierung, die sich auf das Ziel der Förderung der Produktivität und auf den Arbeitskörper als Quelle des Reichtums ausrichtete. Dies beinhaltete auch die Verknüpfung einer spezifischen Form der Freiheit mit Gesundheit. Eine Regierung musste sich nun auf die Regulierung dieses heterogenen Zusammenwirkens von unterschiedlichen, sich teilweise widerstrebenden und konkurrierenden Kräften kümmern, indem sie gewissermaßen das Spiel dieser Kräfte in einer Weise förderte, so dass sich diese Kräfte möglichst gegenseitig nicht behindern sollten.

Die >Entdeckung<, dass Krankheiten und Epidemien von dem komplexen Zusammenwirken verschiedener Faktoren und Bedingungen abhingen, war nicht besonders neu. Ihr Grundgedanke war bereits in der modernen Systematisierung der hygienischen Lehre, von den sog. sex res non-naturals, auf die sich die hygienische Wissenschaft auch in Frankreich bezog, angelegt. Das Neue im Denken der britischen Sanitaristen (Anhänger des sanitary movement) war, das Prinzip der Erhaltung von Gesundheit in einem viel allgemeineren politischen Rahmen der Sicherung und Förderung bestimmter Kräfte zu übertragen. Die Sanitaristen formulierten Gesundheit als eine Bedingung der Sicherung einer Gesellschaft, ihres Lebens, ihrer Kräfte, ihrer Bewegung und des Spiels dieser Kräfte, in einen allgemeineren Bereich, auf den sich liberale Gouvernementalität richteten sollte. Dort agierte die Regierung mithilfe einer ökonomischen Rationalität, die alles, was sie zu ihrem Gegenstand machte, nach seiner Wirkung auf eine Ökonomie der Kräfte hin ordnete. In dem Maße, wie das Problem der Gesundheit zu einem Gegenstand moderner liberaler Gouvernementalität wurde, konnte es in einem viel weiter gefassten Bereich von möglichen Ansatzpunkten der Regierung betrachtet werden. Die Techniken und die Rationalität der liberalen Gouvernementalität lieferten die spezifische Antwort der Liberalen auf die Krise der alten Staatsräson. ${ }^{18}$

Die simple Rationalität, die man den Subjekten unterstellt hatte, wurde ab dem 19. Jahrhundert aber auch zu einem Problem der liberalen Gouvernementalität. Sie stellte fest, dass sie neben den Freiheiten, die sie einräumen wollte, einen ganzen Apparat an Techniken benötigte, um die Subjekte im Sinne ihrer Rationalität herzustellen und die Mechanismen der Ökonomie, des Marktes usw. in zumindest einigermaßen >rationale< Techniken zu verwandeln. Die Regierung entdeckte das Problem des Pauperismus. Es herrschte die Angst vor der Gefahr vor Epidemien, Revolu-

18 »Die liberale politische Rationalität steht vor der Beantwortung der Frage nach den Funktionsgesetzen des sozialen Raums und der veränderten aber gleichwohl notwendigen Rolle des Staates zu den Gesetzmäßigkeiten. Das heißt Smith muß nach seiner harschen Kritik an der bisherigen Staatsvernunft die Rationalität einer >ökonomischen Regierung< ausarbeiten.«: Bohlender: Metamorphosen des liberalen Regierungsdenkens, 2007: S. 86. 
tionen und Aufständen durch die arbeitende arme Bevölkerung. Die Regierung reagierte mit der Aufteilung und Ausdifferenzierung von Techniken und Gegenständen bzw. Problemen, auf die sich diese Techniken beziehen sollten. Die Spaltungen der Arbeitenden einerseits in (diseased) pauper und labouring poor und andererseits in able-bodied workers, ähnlich wie Unterteilungen curable und uncurable diseases, preventable diseases und not preventable diseases, waren das Ergebnis einer solchen Aufteilung und Abspaltung. Die Konzentration auf die Armen und die Arbeiter ist als Reaktionen einer Regierung zu sehen, die feststellt, dass ihre allgemeinen Regeln, Rationalitäten und Technologien Bereiche geschaffen hatten, die durch diese nicht erfasst, also nicht regiert werden können, obwohl sie ihren Gesetzen der Ökonomie anscheinend völlig inhärent waren. Die Auseinandersetzung um die Verbesserung der öffentlichen Gesundheit arbeitete sich in Großbritannien im 19. Jahrhundert und bis ins 20. Jahrhundert hinein in weiten Teilen an den Fragen ab, ob genügend und ausreichend effektive Gesetze existieren, um für die öffentliche Gesundheit gefährliches Verhalten zu bestrafen. Es existierte Anfang des 20. Jahrhunderts schließlich ein sehr dichtes Netz aus verschiedenen Gesetzen und Regelungen, die in Folge eines konkreten Problems, einer Gefahr, die man zu einem bestimmten Zeitpunkt festgestellt hatte, direkt oder indirekt zum Schutz der öffentlichen Gesundheit geschaffen worden waren. Die health and security laws sind hierfür exemplarisch und Teil einer Regierungstechnologie, die man mit Foucaults Worten als Sicherheitstechniken bezeichnen kann.

Spätestens ab Mitte des 19. Jahrhunderts kann man bezüglich der liberalen Gouvernementalität nicht mehr nur von einer spezifisch britischen Regierungsweise sprechen. Die Analyse der Protokolle der Internationalen Gesundheitskonferenzen des 19. Jahrhunderts und vom Anfang des 20. Jahrhunderts haben u.a. gezeigt, wie sich eine solche transnationale >Gouvernementalisierung < vollzogen hat, die vielleicht im Bereich der Gesundheit besonders einfach und eindeutiger als in anderen Bereichen der Regierung nachvollzogen werden kann.

Eine besondere Rolle spielten hier die Erfahrungen verschiedener Epidemien in Europa. Zunächst wurden bestimmte Krankheiten, wie die Pocken, der Typhus und schließlich vor allem die Cholera zum Ausgangspunkt für eine verselbstständigte staatliche Regierung der Gesundheit. Die Regierungen begannen gegenüber einer bürgerlichen hygienischen Selbstpraxis nun, ihre eigenen Techniken zu entwickeln. Gerade weil die Pocken und die Cholera nicht nur als eine Krankheit im medizinischen oder hygienischen Sinne, sondern als ein ökonomisches und bevölkerungspolitisches Problem bewertet wurden, konnten sie von der gouvernementalen Regierung der Bevölkerung und des Lebens völlig vereinnahmt werden. Die alte diätetische Betrachtung der Cholera wurde angesichts des Ausmaßes der Epidemien bald als unzureichend angesehen. Die moralischen und diätetischen Vorsichtsmaßnahmen, die man überall, aber vor allem in Frankreich noch als Instruktionen an die Bevölkerung verteilt hatte, führten kaum zu einer nennenswerten Senkung der Cholerasterblichkeit, noch verhinderten sie die Ausbreitung der Epidemie. Neben den eher >privaten< hygienischen Praxen, die sich auf die Cholera bezogen, gerieten die alten staatlichen Techniken, die noch aus den Erfahrungen mit der Pest abgeleitet worden waren, angesichts der Cholera in verstärktem Maße in die Kritik, irrational und ineffektiv zu sein. Vor allem in Großbritannien war die Kritik an der Quarantäne und verschiedenen Techniken der Isolation zur Verhinderung der Verbreitung > vorgeblich< anste- 
ckender Krankheiten bereits Ende des 18. Jahrhunderts vielfach laut geworden. Nach den Ausbrüchen der epidemischen Cholera in Europa 1829 setzte sich eine bestimmte Gegenüberstellung von >fortschrittlichen< liberalen und rationalen sanitären Praktiken der öffentlichen Gesundheit gegenüber willkürlichen, illiberalen und irrationalen Praktiken der Quarantäne weiter durch. Im Gegensatz zu Deutschland, wo die anti-kontagionistischen Positionen für die Regierungen und ihr limitiertes Repertoire von Techniken der Isolation, Quarantäne und Desinfektion, eine Gefahr der Entmachtung bedeutet hatte, gelang es der orleanischen französischen Regierung Anfang der 30er Jahren des 19. Jahrhunderts aus der Verknüpfung von Kritik an der Quarantäne und der Selbstprofilierung als moderne, humanistische und freiheitliche Regierung, als Gegenmodell zu absolutistischen und >willkürlichen< Regierungen, Gewinn zu schlagen. ${ }^{19}$ Die Quarantäne wurde zum Erkennungsmerkmal einer als rückschrittlich angesehene Regierungspraxis. Häufig war die Ablehnung der Quarantäne verbunden mit verschiedenen anti-kontagionistischen Positionen. Ebenso wie die Quarantäne anfänglich an das Kategorisieren einer Krankheit als >pestartig< geknüpft wurde, bekannten sich die Gegner der Quarantäne und meistens auch Vertreter einer eher liberalen >modernen< und >fortschrittlichen< Regierungspraxis zu Theorien und Ansätzen, die die Krankheiten eher als Ergebnis atmosphärischer, lokaler hygienischer, diätetischer und klimatischer Einflüsse erklärten. Oder sie gingen von einer miasmatischen Verbreitungsart der Krankheiten, z.B. der Cholera über Miasmen (pathogene Gase und Gerüche) in der Luft aus, anstatt eine Übertragung von Mensch zu Mensch oder über Gegenstände, die mit Kranken in Berührung gekommen waren, zu akzeptieren. Man muss allerdings dazu sagen, dass diese Anti-Kontagionisten in Europa zu heterogen waren, um sie in eine Gruppe einzugliedern. In Deutschland bedeutete eine anti-kontagionistische Position zu vertreten, keinesfalls eine grundsätzliche liberale Kritik am absolutistischen Staat und an der Regierungspraxis der Fürsten $\mathrm{zu}$ formulieren. In Großbritannien gingen Bestrebungen zu generellen sanitären Verbesserungen von einer liberalen bürgerlichen Bewegung aus. Diese bestand nicht unbedingt nur aus Anti Kontagionisten und sie richtet ihre Techniken nicht auf die Bürger, sondern speziell auf die arme und arbeitende Bevölkerung - anders als in Frankreich.

Die Sanitaristen waren es, die der >Epidemie< eine neue Bedeutung verschafften. Obwohl die kausalen Ursachen für die Entstehung der Cholera weitgehend unbekannt waren, errechneten sie aus Statistiken bestimmte Gesetzmäßigkeiten für das Auftreten und die epidemische Ausbreitung der Krankheit. Diese Gesetzmäßigkeiten wurden zum Ausgangspunkt konkreter gesundheitspolitisches Regierungsprogramme. Sie machten die Cholera, die quasi als unbeherrschbar galt, zu einer durch hygienische Maßnahmen effektiv vermeidbaren Krankheit. Auf diese Weise entwickelten die Epidemiologen in Großbritannien im 19. Jahrhundert eine ganze Reihe einfacher Techniken zur Verminderung der Sterblichkeit durch verschiedene epidemische Krankheiten, ohne um deren genaue Verbreitungsart und die spezifische pathogene Ursache zu wissen. Auch in Frankreich und Deutschland unterstütze die seuropäi-

19 Vgl. Conseil de Salubrité/Comité Consultatif d'Hygiène Publique/l'Académie Nationale de Médecine: Instructions sanitaires sur les moyens préservatifs du choléra-morbus, Précédées d'une notice sur l'assainissement de Paris, 1849: S. 27f. 
sche $<$ Erfahrung mit der Cholera eine Verschiebung von einem bevorzugten medizinisch-klinischen Blick hin zu einem epidemiologischen Blick auf die Krankheit. Die Sichtweise förderte außerdem einen enormen Ausbau von Methoden der statistischen Erfassung und Sammlung von Daten über alle möglichen Faktoren im Leben der Bevölkerung, die man mit der Cholera-Morbidität und Mortalität eines Ortes zu korrelieren begann.

Die Frage nach dem praktischen Erfolg oder Misserfolg einer Regierung moderierte ab hier auch die internationalen Diskussionen darüber, ob eine Krankheit richtig kategorisiert sei. Man fragte, ob ihre Kategorisierung ihrer Regierbarkeit und der Wirksamkeit der damit verbundenen Techniken nachweislich entsprach. Infolge dessen spielte das medizinische Wissen über die Cholera für die Frage der richtigen Cholerapolitik und die Regelung auf den Internationalen Gesundheitskonferenzen im 19. Jahrhundert eine geringe Rolle. Selbstverständlich war die Kritik an der Quarantäne nicht völlig isoliert von den medizinischen >Erkenntnissen< über die Cholera. Aber die Entscheidung, ob die Quarantäne eine sinnvolle Praxis der Regierung sein konnte, fand in erster Linie unabhängig von diesem Wissen statt. Sie war eher abhängig von der Frage, ob diese Praxis erfolgreich war, oder nicht.

Die vielfältigen Bezüge auf die Hygiene und die Logik der Sanitaristen auf den Konferenzen spielten eine wichtige Rolle bei der Durchsetzung und Übertragung von liberaler Gouvernementalität. Die ersten CSIs, die zwischen 1851 und 1885 stattfanden und die allgemein als die erfolglosesten Konferenzen gelten, scheiterten zwar an ihrem Vorhaben, eine ratifizierbare Konventionen anzufertigen, sie waren aber enorm wichtig, um eine gemeinsame Identität von Regierung, oder besser, eine bestimmte europäische Subjektivität und eine ethische Existenz von Regierung zu stiften. Auf diesen ersten Konferenzen wurde die Grundlage der späteren >erfolgreichen< Kooperation in Form gemeinsamer Kriterien für Rationalität und Moralität des Regierens geschaffen. Die ganzen Entwicklungen, die ich beschrieben habe, die Abgrenzung von >Orient<, die >sanitäre Rationalisierung< der Quarantäne, die vielfältigen Aufspaltungen von Problemen und entsprechenden neuen Aufteilungen von Techniken: All das kann als ein Prozess der Übertragung einer größtenteils in Großbritannien entstandenen liberalen Gouvernementalität der Gesundheit gesehen werden, die die europäische und schließlich auch die globale Praxis und Rationalisierung der Regierung von Gesundheit nachhaltig geprägt hat. Und nicht nur das: Meiner Ansicht nach spielte dieser Ansatz der britischen Sanitaristen und der public health eine extrem wichtige Rolle in der Legitimation und Festigung einer von Ungleichheit und Ausbeutung geprägten internationalen Ordnung. Sie war das besonders effektive Element eines Diskurses, aus dem die >Überlegenheit $<$ und $>$ Fortschrittlichkeit $<$ europäischer Regierungspraxis behauptet werden konnte und durch welches neue Formen der Herrschaft in eine koloniale und vor allem auch postkoloniale Ordnung einfließen konnte. $^{20}$

Am Ende dieses Prozesses stand eine Herrschaft, die auf einer Rationalität und Subjektivität von Regierungen aufbaut, die sich zuvor und dauerhaft aus einer spezifisch europäischen Entstehungsgeschichte moralischer Selbstpraxen entwickelt hatte

20 Vgl. Williams: International Development and Global Politics, 2012: S. 3; 6. 
und der die Behauptung einer >überlegenen< moralischeren und vernünftigeren Existenz(weise) zugeordnet zu sein, völlig inhärent war.

Darüber hinaus hat die Analyse der Herausbildung liberaler Gouvernementalität von Gesundheit deutlich werden lassen, dass es weder das Ziel noch die tatsächliche Eigenschaft der liberalen Regierung ist weniger zu regieren. Eher, so hat sich gezeigt, handelt es sich bei der liberalen Regierung um eine besonders effektive Form der Regierung und Praxis der Anpassung und Rationalisierung der Regierung. Foucault hat in dem bekannten Gespräch mit Ducio Trombadori konstatiert, es gäbe »eine gewisse Tendenz, ein bestimmtes politisches Regime im Namen der Prinzipien, von denen es sich leiten lässt, von allem freizusprechen, was es zu tun imstande ist. ${ }^{21}$ Weiter erklärte Foucault »ein bestimmter, im neunzehnten Jahrhundert entstandener Liberalismus hat Techniken extremen Zwangs entwickelt, die gewissermaßen das Gegengewicht zu der ansonsten eingeräumten ökonomischen und sozialen Freiheit bildeten $\ll^{22}$. Was ich an dieser Stelle sagen möchte, ist, dass die liberale Regierung nie aufgehört hat, Mechanismen und Techniken weiter zu entwickeln, die dazu da sind, das genaue Gegenteil von dem zu tun, was ihr eigentliches und permanentes Ziel sein soll: Die Freiheit zu vollziehen und herzustellen. Die Frage nach der Reichweite und Wirkmächtigkeit liberaler Gouvernementalität lässt sich nicht in der Gegenüberstellung von einem liberalen und autokratischen oder paternalistischen Staatsverständnis beantworten, oder indem der Gegensatz von Staat und Zivilgesellschaft reproduziert wird. Letzterer wurde, wie Foucault konstatierte, selbst Ende des 18. Jahrhunderts von liberalen Ökonomen erst vorgeschlagen, um »in einem gegebenen Kontext [...] einer genau bestimmten Intention zu entsprechen ${ }^{23}$, nämlich die liberale Regierung mit dem Image eines generellen >Weniger` an Regierung zu verknüpfen.

Das >Mehr-Regieren< der liberalen Regierung lässt sich nur losgelöst von dieser automatischen Gegenüberstellung erkennen. Es besteht in ihrem Potenzial, einen enormen Bereich von Freiheiten zu beschränken, sobald die Macht oder Freiheit als außerhalb der sehr spezifischen und beschränkten Formen von Freiheit, die durch sie gefördert werden sollen, angesehen wird. Wer die sechs Bände von Johann Peter Frank über sein »Vollständiges System der medizinischen Polizei« in den Händen hält, mag diesen Text als das Programm einer absoluten, alles durchdringenden Regierung ansehen, als den beunruhigenden Plan einer wirklich alles umfassenden gouvernementalen Regierungsmacht. Fakt ist aber, dass eine medizinische Polizei dieses Umfangs nicht nur zu teuer, sondern, bei dem Versuch sie umzusetzen - trotz der sechs Bände -, sich als viel zu starr und viel zu allgemein formuliert erweist, um >erfolgreich< zu sein. Das haben die Liberalen Anfang des 19. Jahrhunderts kritisiert und das ist mit ein Grund, warum sie sich zu einem ganz anderen Projekt der Rationalisierung der alten Regierungstechniken berufen fühlten. Sie erklärten nicht, die re-

21 Foucault: Gespräch mit Ducio Trombadori, 2005 [1978]: S. 111.

22 Ebd.

23 »Das war quasi ein Kampfbegriff, der den administrativen Optionen der Staaten jeder Zeit entgegengesetzt wurde, um einem bestimmten Liberalismus zum Triumph zu verhelfen.«: Foucault: Ein endliches System angesichts einer unendlichen Nachfrage, 2005 [1983]: S. $449 f$. 
pressiven Maßnahmen der Isolation, die die Quarantäne beinhaltete, seien allgemein nichts wert, sondern sie seien in dieser allgemeinen Anwendung ineffizient. Der Modus ihrer Rationalisierung geht deshalb, wie schon gesagt, mit einer permanenten Differenzierung einher. Die liberale Regierung darf, um effektiver zu sein, vor allem nicht unnötig regieren. Dafür ist eine Unmenge an Differenzierungen nach dem Kriterium der optimalen Regierbarkeit des jeweiligen Problems und der für jedes Problem geeignetsten Techniken vorzunehmen. Es ist leicht $\mathrm{zu}$ sehen, dass die liberale Regierung eine unglaubliche Menge an neuen Techniken und eine unglaubliche Ausdehnung der Macht der Regierung durch diese Form der Rationalisierung herbeiführen konnte. Das Ideal der liberalen Regierung besteht nicht in einem >Wenigerregieren< wie oft angenommen wird, sondern darin, Mechanismen einzusetzen, die es für jedes Individuum zum persönlichen Nachteil machen, ihrer Rationalität zuwider $\mathrm{zu}$ handeln. Überall dort, wo die Regierung nicht eingreift, ist sie sich idealerweise doch völlig darüber im Bilde, wie sie mit einem gezielten und effektiven Handgriff alle Bewegungen stoppen und alle Kräfte zum Erliegen bringen kann, die sie zuvor mit Hilfe des Marktes und anderer Techniken in Gang gehalten und als Freiheiten vollzogen hat. »Mit einer Hand muß die Freiheit hergestellt werden, aber dieselbe Handlung impliziert, daß man mit der anderen Einschränkungen, Kontrolle, Zwänge, auf Drohungen gestützte Verpflichtungen usw. einführt. « ${ }^{24}$

Die liberale Regierung ist heute vielleicht die umfassendste, durchdringendste und vor allem effektivste Regierung, die die Welt seit dem Anbruch des von Foucault benannten »Zeitalters der Verhaltensführung « gesehen hat. Dies gilt nicht nur für den Bereich der Gesundheit. Die liberale Gouvernementalität ist mehr als jede Regierung vor ihr in der Lage, die Freiheit, die sie lässt, wo es ihr notwendig scheint, wieder zu nehmen.

\section{Ausblick}

Die Analyse der Entstehung liberaler Gouvernementalität von Gesundheit hat einige Funktionsweisen und die Rationalität der liberalen Regierung deutlicher werden lassen und Anknüpfungspunkte an Foucaults Thesen und Analysen in diesem Bereich bestätigt.

In Anlehnung an Foucaults weiterführende Analyse liberaler Gouvernementalität im 20. Jahrhundert, erscheint es mir vor dem Hintergrund meiner Ergebnisse nicht sinnvoll, eine epochale Unterteilung vorzunehmen, nach der die liberale Regierung nach 1945 und ca. bis in die 1970er nur noch weniger präsent war. Laut Foucault entsteht der Neoliberalismus eher ab 1930 oder in Europa ab 1945. ${ }^{25}$ Das soll nicht heißen, dass die Phänomene, die ab den 1970ern für den Neoliberalismus bezeichnend sind und die auf eine Veränderung in den letzten 40 Jahren verweisen, nicht analysiert und ernst genommen werden sollen. Möglichweise macht es jedoch eher Sinn, Transformationen der liberalen Gouvernementalität zu untersuchen: Folgte auf den Neoliberalismus möglicherweise ein »Hyperliberalismus« wie Benjamin Opratko bei

24 Foucault: Geschichte der Gouvernementalität II, 2004 [1978 - 1979]: S. 98.

25 Vgl. ebd.: S. 303. 
seiner Analyse aktueller globaler Herrschaftsformen im Anschluss an Robert Cox und Gramsci schrieb?26 Aktuelle Studien zu Gesundheit und Neoliberalismus stellen auch in Europa wieder eine steigende Ungleichheit fest, was den Zugang zu gesundheitlicher Versorgung angeht. Die oft behauptete völlig neue Qualität oder Rationalität dieser (neo)liberale Reformen und Umstrukturierungen jüngster Zeit im Bereich der Gesundheitsversorgung oder Regierung von Gesundheit, lässt sich in einem gröBeren historischen Kontext betrachtet, nicht bestätigen. Die Anfänge liegen weit zurück, wie Foucault Mitte der 1970er Jahre gegenüber der Kritik, einer Zunahme ökonomischer Rationalität in der Medizin äußerte.

»Wir erleben eine durch bestimmte Tatsachen zum kritischen Höhepunkt getriebene Situation. Die Tatsachen sind im Grunde dieselben über die gesamte medizinische Entwicklung des Systems hinweg seit dem 18. Jahrhundert, als eine politische Ökonomie der Gesundheit entstand, und als Prozess einer verallgemeinerten Medizinisierung und die Mechanismen einer BioGeschichte auftauchten. $\ll^{27}$

Man könnte hier die Frage stellen, ob es sich bei den momentanen Tendenzen, der Rücknahme sozial-staatlicher Verantwortung im Bereich der Gesundheitsversorgung, der $\gg$ Privatisierung der Risikovorsorge $\ll^{28}$ und einer wieder stärkeren Anrufung der Subjekte, sich selbst um ihre Gesundheit zu sorgen, nicht eher um eine wieder eingesetzte Strategie liberaler Regierung handelt. Eine Strategie, die in Zeiten zugespitzter kapitalistischer Krisen stückweise zum Einsatz gekommen ist, die vielleicht aber diese Regierung als Option immer parat hatte. Vor dem Hintergrund meiner Analyse lassen sich Phänomen einer wieder stärkeren Einbeziehung von Subjekten hinsichtlich der Regierung von Gesundheit zumindest nicht mehr als neues Phänomen des Neoliberalismus begreifen. Stattdessen könnte an meine Untersuchung anknüpfend, danach gefragt werden, mit welchen Praktiken des Selbst im Unterschied zum 18. und 19. Jahrhundert gesundheitsbezogenes Verhalten moralisch, rational, oder schlicht als >gut< im Hinblick auf die Reproduktion eines Subjekts angesehen wird. Auf diese Weise wäre es möglich, diese Veränderungen als eine Verschiebung innerhalb eines Spektrums von Selbst- und Sicherheitstechniken zu begreifen, die mehr oder weniger der gleichen ökonomischen Rationalität unterworfen sind. Meine Untersuchungen haben auch offengelegt, inwiefern solche auf die Lebensweise bezogenen Diskurse um moralische und vernünftige Verhaltensweisen, Ausgangspunkt einer Kritik an Bestehendem, an festgefahrenen Vorschriften und Normen für Verhaltensweisen, als auch an politischer Herrschaft sein konnten. Es hat sich aber auch gezeigt, dass gerade die moderne und liberale Regierung von Gesundheit, seit ihrer Entstehung darauf angelegt wurde, mit solchen Diskursen zu korrespondieren. Das heißt, dass sie ihr als Referenzpunkt und permanenter Ort der Rationalisierung dienen konnten. Sollte die Strategie der Regierung, heute im >Neoliberalismus< oder »Hyperliberalismus« oder wie auch immer man diese Zeit betitelt, aufgehen, sodass

26 Vgl. Opratko: Hegemonie: Politische Theorie nach Antonio Gramsci, 2012: S. 88f.

27 Foucault: Krise der Medizin oder Krise der Antimedizin, 2003 [1976]: S. 75.

28 Vereinigung zur Kritik der Politischen Ökonomie/Altvater: Editorial: Gesundheit im Neoliberalismus, 2003: S. 361. 
die Subjekte sich heute, was ihre Gesundheit angeht, besser selbst regieren oder zumindest, dass man die Regierung der Gesundheit effektiver machen kann, indem man den Individuen mehr $\gg$ Wahlentscheidungen in Sachen Gesundheit ${ }^{29}$ eröffnet, so würde dies weniger von der Freiheit der Subjekte oder Verantwortungslosigkeit einer Regierung zeugen, als etwas darüber aussagen, wie ausreichend die Subjekte, also wir, heute dressiert sind. Vielleicht sind wir erst heute ausreichend »Interessenssubjekt « und »Homo oeconomicus $\aleph^{30}$, um als Mittler und Relais einer liberalen Regierung von Gesundheit optimal zu funktionieren. Oder vielleicht stellt sich heraus, dass sich eine solche Praxis der Selbstregierung doch wieder nur innerhalb bestimmter sozialer Gruppen >effizient< umsetzten lässt. Denn es ist wie Foucault für den Liberalismus konstatierte: »Natürlich konnte man die Individuen nicht befreien ohne sie zu dressieren. ${ }^{31}$ War es denn nicht schon im 18. Jahrhundert der Traum der Liberalen, dass sich die Regierung irgendwann - wenn die Subjekte ausreichend >befreit< und heute müsste man vielleicht sagen, auch ausreichend informiert sind, einmal völlig auf deren >Rationalität< verlassen kann? Denn schließlich charakterisiert die liberale Regierung ja gerade - und das macht sie so schwer zu fassen und zu kritisieren, dass sie die »Rationalität der Regierten [...] als Regelungsprinzip für die Rationalität der Regierung « ${ }^{32}$ einsetzt.

29 Foucault: Ein endliches System angesichts einer unendlichen Nachfrage, 2005 [1983]: S. 456.

30 Foucault: Geschichte der Gouvernementalität II, 2004 [1978 - 1979]: S. 379.

31 Foucault: Gespräch mit Ducio Trombadori, 2005 [1978]: S. 111.

32 Foucault: Geschichte der Gouvernementalität II, 2004 [1978 - 1979]: S. 428. 


\section{Quellen und Literatur}

\section{QUELLEN}

\section{Zeitschriften Serien}

\section{Deutsche Zeitschriften/Serien}

\section{BS Serie}

Berlinische Sammlungen zur Beförderung der Arzneywissenschaft, der Naturgeschichte, der Haushaltungskunst, Cameralwissenschaft und der dahin einschlagenden Litteratur. Martini, F. H. W. (Hrsg.), Berlin, Bd. 1.1768 - 10.1779.

\section{JNA Serie}

Journal der Erfindungen, Theorien und Widersprüche in der Natur- und Arzneiwissenschaft. Freunden d. Wahrheit u. Freimüthigkeit (Hrsg.), Gotha, 1.St. 1.1792/ 93 - 16. St. 6.1797.

Neues Journal der Erfindungen, Theorien und Widersprüche in der gesammten Medicin. Freunden d. Wahrheit u. Freimüthigkeit (Hrsg.), Gotha, 17.St. 7.1798 - 44. St. 11.1804 .

\section{JPA Serie}

Journal der practischen Arzneykunde und Wundarzneykunst. Hufeland, Christoph Wilhelm (Hrsg.), Berlin, 1.1795 - 7.1799.

Neues Journal der practischen Arzneykunde und Wundarzneykunst. Hufeland, Christoph Wilhelm (Hrsg.), Berlin, 8=1.1799 $-11=3.1801$.

Neues Journal der practischen Heilkunde. Hufeland, Christoph Wilhelm (Hrsg.), Berlin, $12=4.1801-27=20.1808$.

Journal der practischen Heilkunde. Hufeland, Christoph Wilhelm, [Zeitweilig gemeinsam mit Himly, K./Harles, J.Ch. F./Osann, Emil.] (Hrsg.), Berlin, $28=21$. $1809-83=76.1836$.

\section{MTKS Serie}

Magazin für specielle Therapie, Klinik und Staatsarzneikunde. Marcus, Adalbert Friedrich (Hrsg.), Jena, 1.1802/03 - 2.1805/06. 


\section{VöG Serie}

Deutsche Vierteljahrsschrift für öffentliche Gesundheitspflege. Deutscher Verein für Öffentliche Gesundheitspflege (Hrsg.), Braunschweig, 1.1869 - 47.1915.

\section{Französische Zeitschriften/Serien}

\section{GS Serie}

Gazette de Sante, contenant les nouvelles découvertes sur les moyens de se bien porter, et de se guèrir quand on est malade. Gardane, Joseph Jacques (Hrsg.), Paris, $1.1773-52.1775$.

Gazette de santé, contenant les découvertes utiles, faites en médecine, chirurgie, pharmacie, physique, chymie, botanique, histoire naturelle, \&c. Gardane, Joseph Jacques (Hrsg.), Paris, 1.1776 - 31.1776.

Gazette de santé, par une Société de médecin. Dies. (Hrsg.), Paris, 32.1776 52.1784 .

Gazette de Santé ou Analyse de livres ou défaits nouveaux relatifs aux diverses branches des sciences naturelles telles que la Chymie, la Botanique, la Médecine, la Chirurgie \&c. Société de médecine (Hrsg.), Paris, 1.1785 - 52.1786.

Gazette de Santé. Société de médecine (Hrsg.), Paris, 1.1787 - 52.1789.

Gazette de Santé, ou journal analitique de tout ce que l'art offre de plus avantageux en théorie et en pratique pour prévenir ou guérir les maladies. Société de médecine de Paris (Hrsg.), Paris, 1.1804 - 52.1818.

Gazette de Santé, ou recueil général et périodique de tout ce que l'art offre de plus avantageux en théorie et en pratique pour prévenir ou guérir les maladies. Société de médecine de Paris (Hrsg.), Paris, 1.1819 - 52.1821.

Gazette de Santé, Journal de médecine et des sciences assessoires. Med. Dr. Miguel, Autoine (Hrsg.), Paris, 1.1822 - 36.1829.

\section{RP-Serie}

[Römische Zahlen entsprechen dem Revolutionskalender: V= 5. Jahr der Republik usw.]

Recueil périodique de la Société de médecine de Paris. Société de Santé de Paris, Sédillot, Jean (Hrsg.), Paris, 1.V [1796]

Recueil périodique de la Société de médecine de Paris. Société de médecine, Sédillot, Jean (Hrsg.) Paris, 2.V [1797] - 14.VI [1798]

Journal général de médecine, de chirurgie et de pharmacie, ou Recueil périodique de la Société de médecine de Paris, Sédillot, Jean (Hrsg.), Paris, 15.VII [1799] 72.X [1802]

\section{JGM Serie}

Journal général de médecine, de chirurgie et de pharmacie françaises et étrangeres, ou, Recueil périodique de la Société de médecine de Paris. Société de médecine de Paris (Hrsg.), Paris, 15.1802 - 17.1803

Journal général de médecine, de chirurgie et de pharmacie. Société de médecine de Paris, Sédillot, Jean (Hrsg.), Paris, 15.1802 - 111.1830. 


\section{SMP - Serie}

Bulletin de la Société de médecine publique et d'hygiène professionnelle (enthalten: séances de la Société de médecine publique et d'hygiène professionelle). Société de médecine publique et d'hygiène professionnelle (Hrsg.), Paris: 1.1877 23.1900 .

\section{Englische Zeitschriften/Serien}

\section{LMJ Serie}

London Medical Journal. Society of Physicians (Hrsg.), London, 1.1780 - 11.1790.

\section{Serie}

Medical and philosophical commentaries by a Society of physicians in Edinburgh. Society of physicians in Edinburgh (Hrsg.), Edinburgh, 1.1773 - 6 1779, 2. Aufl. $1.1774-3.1784$.

Medical commentaries: exhibiting a concise view of the latest and most important discoveries in medicine and medical philosophy. Duncan, Andrew (Hrsg.), London, 1780 - 1795, 2. Aufl. 1783 - 1787.

\section{MPJ Serie}

The Medical and physical journal containing the earliest information on subjects of medicine, surgery, pharmacy, chemistry, and natural history, and a critical analysis of all new books in those departments of literature, London, 1.1799-6.1802.

The Medical and physical journal, London, 7.1803 - 32.1814.

\section{ESMJ Serie}

The Edinburgh medical and surgical journal, exhibiting a concise view of the latest and most important discoveries in medicine, surgery, and pharmacy, Edinburgh, $1.1805-4.1805$.

The Edinburgh medical and surgical journal, Edinburgh, 5.1806 - 82.1855.

Supplement, containing official reports and analyses of other recent publications on malignant cholera: The Edinburgh medical and surgical journal, Edinburgh, 38. 1832.

\section{MP Serie}

Medical Press and Circular, (2 Bd. pro Jahr) 1.1838 - 2.1946.

\section{TES Serie}

Transactions of the Epidemiological Society of London - The journal of public health and sanitary review. Epidemiological Society of London (Hrsg.), London, 1. $1859-60-4.1882$.

Tansactions of the Epidemiological Society of London. Epidemiological Society of London (Hrsg.), London [Neue Serie], 1.1881 - 82 - 26.1907. 


\section{Einzelne Artikel aus Zeitschriften}

Häufig wurden Artikel und Editorials von den Herausgebern der Zeitschriften verfasst. In diesem Fall habe ich in den Fußnoten und im Literaturverzeichnis [Hrsg.] anstelle des Autors gesetzt.

\section{The Lancet London}

[Hrsg.]: The Cholera in England, 28. April 1832: in: Elsevier (Hrsg.): The Lancet London. A journal of British and foreign medicine, surgery, obstetrics, physiology, chemistry, pharmacology, public health and news, 1831 - 1832 in zwei Bänden, Band 2, London, 1832, 121 - 126.

[Anonym]: On The poor-law and workhouse-test: in: The Lancet, 1840 - 1841, 2 von 2 Bd., London, 3.4.1841, 50 - 53.

Artikel 1: Westminster Medical Society, Discussion on the Cholera, Question of Contagion, 5. März, 1832: in: Elsevier (Hrsg.): The Lancet London. A journal of British and foreign medicine, surgery, obstetrics, physiology, chemistry, pharmacology, public health and news, London, 1831 - 1832 in zwei Bänden, 2. Bd., $21-24$.

Artikel 2: Westminster Medical Society, Dicussion on the Cholera, 7. April, 1832: in: Elsevier (Hrsg.): The Lancet London. A journal of British and foreign medicine, surgery, obstetrics, physiology, chemistry, pharmacology, public health and news, London, 1831 - 1832 in zwei Bänden, 2. Bd., 51 - 54.

Artikel 3: Westminster Medical Society, Final Dicussion on the Cholera, 28. April, 1832: in: Elsevier (Hrsg.): The Lancet London. A journal of British and foreign medicine, surgery, obstetrics, physiology, chemistry, pharmacology, public health and news, London, 1831 - 1832 in zwei Bänden, 2. Bd., 146 - 149.

Greenwood, James: Late Proceedings at the Westminster Medical Society, 1. Mai 1832: in: Elsevier (Hrsg.): The Lancet London. A journal of British and foreign medicine, surgery, obstetrics, physiology, chemistry, pharmacology, public health and news, Nr. 18, 1832, 150.

Pym, William: Malignant Cholera. Sanitary regulations issued by the government Board of Health, in August, 1832. (Circular): in: Elsevier (Hrsg.): The Lancet London. A journal of British and foreign medicine, surgery, obstetrics, physiology, chemistry, pharmacology, public health and news, London, $1831-1832$ in zwei Bänden, 2. Bd., $652-655$.

\section{Journal de médecine et de chirurgie pratiques}

[Hrsg.]: Considérations pratiques sur le choléra-morbus de Paris, son invasion, sa marche, ses symptômes, son traitement, et les précautions prises par l'autorité pour en prévenir le développement ou arrêter ses progrès: in: Lucas-Championnière, Just (Hrsg.): Journal de médecine et de chirurgie pratiques: à l'usage des Médecins Praticiens, Paris, 3.1832, 129 - 137.

\section{Medical facts and observations}

[Hrsg]: Are tropical fiever contagious?: in: Simmons, Samuel Foart (Hrsg.): Medical facts and observations, Nr. 7, Band 4, London, 1799, 6- 20. 


\section{Münchener Medicinische Wochenschrift}

Pettenkofer, Max von: Ueber Cholera, mit Berücksichtigung der jüngsten Choleraepidemie in Hamburg. Münchener Medizinische Abhandlungen. Fünfte Reihe. Arbeiten aus dem hygienischen Institute. Herausgegeben von Geheimrath Professor Dr. Max von Pettenkofer, 39. Heft, 5. Reihe, 4. Heft. Sonderdruck aus der Münchener Medicinische Wochenschrift 1892 Nr. 46, München, 1892.

\section{Zeitschrift für Staatsarzneikunde}

Braun, K.: Ueber die Behandlung der ostindischen Cholera von Seiten des Staates: in: Henke, Adolpf (Hrsg.) Zeitschrift für Staatsarzneikunde, Band 22, 11. Jahrgang, 3. Heft, Erlangen, 1831, 195 - 206.

\section{Protokolle der CSIs}

Protokolle der internationalen Gesundheitskonferenzen

CSI-1: Procès-Verbaux de la Conférence Sanitaire Internationale Ouverte à Paris le 27 juillet 1851. Tome I. und II, Imprimerie nationale, Paris, 1852.

CSI-2: Protocoles de la Conférence Sanitaire Internationale, ouverte à Paris le 9 avril 1859, Avril - Août 1859, Imprimerie imperiale, Paris, 1859.

CSI-3: Procès-Verbaux de la Conférence Sanitaire Internationale, ouverte a Constantinople le 13 février 1866, Imprimerie centrale, Konstantinopel, 1866.

CSI-4: Procès-Verbaux de la Conférence Sanitaire Internationale, ouvert à Vienne le 1 Juillet 1874, Imprimerie Impériale et Royale, Wien, 1874.

CSI-5: Proceedings of the International Sanitary Conference: Provided for by Joint Resolution of the Senate and House of Representatives in the Early Part of 1881, Government Printing Office, Washington, 1881.

CSI-6: Protocoles et Procès-Verbaux de la Conférence Sanitaire Internationale de Rome, Inaugurée le 20 mai 1885, Imprimerie du Ministère des Affaires Étrangères, Rom, 1885.

CSI-7: Protocoles et Procès-verbaux de la Conférence Sanitaire Internationale de Venise, Inaugurée le 5 janvier 1892, Imprimerie Nationale de J. Bertero, Rom, 1892.

CSI-8: Procès-Verbaux de la Conférence Sanitaire Internationale de de Dresde, 11 mars - 15 avril 1893, Imprimerie B.G. Teubner, Dresden, 1893.

CSI-9: Conférence Sanitaire Internationale de Paris, 7 février - 3 avril 1894, ProcèsVerbaux, Imprimerie Nationale, Paris, 1894.

CSI-10: Conférence Sanitaire Internationale de Venise, 16 février - 19 mars 1897, Procès-Verbaux, Forzani et Cie, Imprimeurs du Sénat, Rom, 1897.

CSI-11: Conférence sanitaire internationale de Paris, 10 octobre - 3 décembre 1903, Procès-Verbaux, Imprimerie Nationale, Paris, 1904.

\section{Weitere Quellen}

Académie de Médecine: Rapport sur l'épidemie cholérique de 1854: in: Revue Hebdomadaire, Nr.19, Paris, 8. Mai 1869.

Académie de Médecine: Sur le rapport de la nouvelle commission du choléra morbus: in: Gazette Médicale de Santé, Clinique des Hopitaux de Paris, et Journal spécial du Choléra-Morbus, réunis, Bruxelles, Avril 1832, 318 - 321. 
Académie de Sciences: Traveaux des Académies, Académie de Sciences: in: Gazette Médicale de Santé, Chlinique des Hospitaux de Paris, et Journal spécial du Choléra-Morbus, réunis, Bruxelles, Avril 1832, 19 - 20.

Academie Royale de Médecine: Rapport sur le choléra-morbus lu à l'Academie Royale de Médecine, en Séance Générale, les 26 et 30 Juillet 1831, Première Partie, Paris, 1831.

Allibert, Casimir/Boudard/Dalmas/Dubled/Sandras: Rapport lu à l'Académie Royale de Médecine, et remis à M. le Ministre du Commerce et des Travaux publies en décembre 1831, membres de la commission envoyée en Pologne par le gouvernement pour étudier le choléra-morbus, Paris, 1932.

Annesley, James [Surgeon of the Madras Hospital]: Sketches of the most prevalent diseases of India. Comprising a treatise on the epidemic cholera of the East, 2. Aufl., London, 1829 [1825].

Aristoteles: Über die Seele [384 v.Chr. - 322 v.Chr.], 8. Aufl., Berlin, 2006.

Ayre, Joseph: A Letter to Lord John Russell, M.P on the evil policy of those measures of quarantine, and restrictive police, which are employed for arresting the progress of the Asiatic Cholera [...], London, 1832.

Bacon, Francis: Maxims of the Law: in: The works of Francis Bacon, 2 Bde., Midwinter, D./Innys, W./Browne, D./Davi, C./Tonson, J. and R./Millar, A./Ward, J. (Hrsg.), London, 1753 [1597].

Bacon, Francis: The Works of Francis Bacon, 1. Bd., Containing De Augmentis Scientiarum, London, 1815 [1723].

Baly, William: Report on the cause and diffusion of the epidemic cholera 1854: in: Baly, William/Gull, William W.: Reports on epidemic cholera drawn up at the desire of the Cholera Committee of the Royal College of Physicians, London, 1854.

Bantham, Jeremy: An Introduction to the Principles of Morals and Legislation, 1. von 2. Pickering, W. (Hrsg.), London, 1823 [1798].

Behr, Otto: Die Cholera in Deutschland. Populaire Belehrungen über das Auftreten und die Bekämpfung dieser Seuche, Leipzig, 1848.

Bell, George Hamilton [Fellow of the College of Surgeons Edinburgh, joint medical secretary to the Edinburgh Board of Health]: Treatise on cholera Asphyxia, or epidemic cholera, as it appeared in Asia, and more recently in Europe, Edinburgh/London, 1832.

Bernier, Jean: Histoire chronologique de la medecine, et des medecins, où il est traité de l'origine, du progrés, \& de tout ce qui apartient à cette science, Paris, 1695.

Bidart, Eugène: Commentaire législatif de la loi du 15 novembre 1867 sur les expropriations pour cause d'utilité publique, Brussel, 1868.

Board of Health (Hrsg.): Papers relative to the disease calles Cholera spasmodica in India now prevailing in the north of Europe, printed by authority of the lords of his Mahesty's most honourable privy council, London, 1831, v - vi.

Board of Health, Gateshead: Resolutions respecting the Treatment of the Preliminary Diarrhoea: in: The Cholera gazette, consisting of documents communicated by the Central Board of Health, with intelligence relative to the disease, derived from other authentic sources, 2. Aufl., London, 1832, $47-51$.

Boyle, James, Surgeon: Treatise on the epidemic cholera of India, London, 1821. 
Braun, K.: Mitteilungen des Neusten und Wissenswürdigsten über die Asiatische Cholera. Radius, Justus, in Verbindung mit mehreren in- und ausländischen Gelehrten (Hrsg.), Nr. 2, 3, Leipzig, September 1831.

Braun, K.: Ueber die Behandlung der ostindischen Cholera von Seiten des Staates: siehe im Quellenverzeichnis unter Einzelne Artikel aus Zeitschriften: Zeitschrift für Staatsarzneikunde.

Brefeld, Franz, Königl. Preuss. Regierungs- und Medizinal-Rath etc. zu Breslau: Die endliche Austilgung der asiatischen Cholera, Breslau, 1854.

Browne, Thomas: Religio Medici. 8. Aufl., Scot, R./Basset, T./Wright, J./Chiswell, R. (Hrsg.), London, 1682 [1643].

Burdach, R.: »Uber den Einfluß der Gemütsbewegungen auf die Entstehung der Cholera: in: Cholera-Zeitung, herausgegeben von den Aerzten Königsbergs, Königsberg, $1832,84-88$.

Cabanis, Pierre-Jean-Georges: Révolutions et réforme de la médecine. Euvres complètes de Cabanis, 1. Bd., Paris, 1823 [1806].

Cabanis, Pierre-Jean-Georges: Rapport sur l'organisation des écoles de médecine, fait au conseil des cinq-cents, Séance du 29 brumiere an VII in: Euvres complètes de Cabanis, 1. Bd., Paris, 1823 [1799].

Cabanis, Pierre-Jean-Georges: Quelques considérations sur l'organisation sociale en général, et particulièrement sur la nouvelle constitution, Imprinterie nationale, $\mathrm{Pa}$ ris, 1800 [1799].

Cabanis, Pierre-Jean-Georges: Coup d'oeil sur les révolutions et sur la réforme de la médecine, Crapart, Caille et Ravier, Paris, 1804.

Central Board of Health: The Cholera gazette, consisting of documents communicated by the Central Board of Health, with intelligence relative to the disease, derived from other authentic sources, 2. Aufl., London/Edinburgh/Dublin, 1832.

Central Board of Health Council Office: Form of handbills recommended for circulation in the infected districts: in: The Cholera gazette, consisting of documents communicated by the Central Board of Health, with intelligence relative to the disease, derived from other authentic sources, 2. Aufl., London, 1832, 50.

Central Board of Health Council Office: Quarantine, 4th January 1832 at Whitehall: in: The Cholera gazette, consisting of documents communicated by the Central Board of Health, with intelligence relative to the disease, derived from other authentic sources, 2. Aufl., London, 1832, $1-7$.

Central Board of Health, Council Office: Instructions addressed by the Central Board of Health to the medical superintendents of the districts, for their guidance, with a view to the more effectual relief of those who are attaced by cholera: in: The Cholera gazette, consisting of documents communicated by the Central Board of Health, with intelligence relative to the disease, derived from other authentic sources, 2. Aufl., London, 1832, 179 - 181.

Central Board of Health: »Looseness of the bowels is the beginning of Cholera.«: in: The Cholera gazette, consisting of documents communicated by the Central Board of Health, with intelligence relative to the disease, derived from other authentic sources, 2. Aufl., London, 1832, 50.

Central Board of Health: Notice of a Letter in the Times: in: The Cholera gazette, consisting of documents communicated by the Central Board of Health, with in- 
telligence relative to the disease, derived from other authentic sources, 2. Aufl., London, 1832, 134.

Quarantine cholera reports. Details of cases of Cholera which have occurred on board coasting vessels, from ports infected in England, from 11th November, 1831, to 31st January, 1832: in: The Cholera gazette, consisting of documents communicated by the Central Board of Health, with intelligence relative to the disease, derived from other authentic sources, 2. Aufl., London, 1832, 93 - 103

Central Board of Health: Quarantine cholera reports. 11th February 1832: in: The Cholera gazette, consisting of documents communicated by the Central Board of Health, with intelligence relative to the disease, derived from other authentic sources, 2. Aufl., London, 1832, 115 - 116.

Central Board of Health: Notice of a Letter in the Times: in: The Cholera gazette, consisting of documents communicated by the Central Board of Health, with intelligence relative to the disease, derived from other authentic sources, 2. Aufl., London, 1832, 134.

Chadwick, Edwin [Secretary, Poor Law Commission Office London]: Suggestions as to the most eligible Modes of providing Out-door Employment for Able-bodied Paupers, in Cases where there is not an efficient Workhouse, and preparatory to the Establishment of the Workhouse System. 21. September 1835: Document issued by the Central Board, No. 1: in: Poor Law Commissioners for England and Wales, London, 1836, 45 - 48.

Chadwick, Edwin: Report on the Sanitary Conditions of the Labouring Population of Great Britain: in: Report to Her Majesty's principal secretary of state for the Home Department from the Poor Law Commissioners on an Inquiry into the Sanitary Conditions of the Labouring Population of Great Britain, with Appendices. Presented to the House of Pariament, by Command of Her Majesty, London, Juli 1842.

Commission Centrale de Salubrité, Département de la Seine: Instructions populaires sur les principaux moyens à employer pour se garantir du choléra morbus. Et sur la conduite à tenir lorsque cette maladie se déclare. Commission Centrale de Salubrité, Département de la Seine, Paris, November 1831.

Conseil de Salubrité/Comité Consultatif d'Hygiène Publique/l'Académie Nationale de Médecine: Instructions sanitaires sur les moyens préservatifs du choléramorbus, Précédées d'une notice sur l'assainissement de Paris, Paris, 1849.

Cuningham, James McNabb [Generalarzt im indischen Medicinaldepartement und Medicinalreferent bei der indischen Regierung]: Die Cholera. Was kann der Staat thun, sie zu verhüten? Mit einem Vorwort von Dr. Max von Pettenkofer, Braunschweig, 1885.

Cuninghame, W. G. [Sek. Board of Health Office]: Adress issued by the Edinburgh board of Health on the appearance of the cholera in that city: in: The Cholera gazette, consisting of documents communicated by the Central Board of Health, with intelligence relative to the disease, derived from other authentic sources, 2. Aufl., London, 1832, 108 - 110.

DeLamare, Nicolas: Traité de la police, où l'on trouvera l'histoire de son établissement toutes les loix et tous les règlemens qui la concernent, 1. Bd., Paris, 1729.

Diderot, Denis/D’Alembert, Jean-Baptiste le Rond: Encyclopédie Méthodique, Par Une Société De Médecins, Paris, 1824. 
Dubreuil, Joseph-Marie/Rech, Hypolite [Commissaires de la la Faculté de Médecine de Montpellier]: Rapport sur le choléra-morbus asiatique qui a régné dans le midi de la France en 1835, présenté à Messieurs les Ministres du Commerce et de l'Instruction publique, Montpellier, 1836.

Farr, William: Report on the Mortality of Cholera in England, 1848 - 49, London, 1852.

Frank, Johann Peter: System einer vollständigen medicinischen Polizey, Erster Band: Von Fortpflanzung der Menschen und Eheanstalten, von Erhaltung und Pflege schwangerer Mütter, ihrer Leibesfrucht und der Kind-Bettnerinnen in jedem Gemeinwesen, 2. Aufl., Frankenthal, 1791.

Frank, Johann Peter: System einer vollständigen medicinischen Polizey, Zweiter Band: Von der außereheligen Zeugung, dem geflissentlichen Mißgebähren und andern Mißhandlungen der uneheligen Kinder, von der physischen Erziehung des Neugebohrnen bis zum erwachsenen Bürger, Mannheim, 1804.

Frank, Johann Peter: System einer vollständigen medicinischen Polizey, Dritter Band: Von Speise, Trank und Gefäßen. Von Mäßigkeitsgesetzen, ungesunder Kleidertracht, Volksergözlichkeiten. Von bester Anlage, Bauart und nöthigen Reinlichkeit menschlicher Wohnungen, Mannheim, 1783.

Frank, Johann Peter: System einer vollständigen medicinischen Polizey, Vierter Band: Von Sicherheits-Anstalten, in so weit sie das Gesundheitswesen angehen. Mit einigen Zusätzen von F. August v. Wasserberg (Dritte verbesserte Auflage), Wien, 1790.

Frank, Johann Peter: System einer vollständigen medicinischen Polizey, Fünfter Band. Von Sicherheits-Anstalten, in so weit sie das Gesundheitswesen angehen, und von Beerdigung der Todten, Tübingen, 1813.

Frank, Johann Peter: System einer vollständigen medicinischen Polizey, Sechster Band, Teil I: Von den medicinischen Lehranstalten im Allgemeinen (Neue Auflage), Wien, 1817.

Frank, Johann Peter: System einer vollständigen medicinischen Polizey, Sechster Band, Teil II: Von den medicinischen Lehranstalten ins Besondere, Wien, 1817.

Frank, Johann Peter: System einer vollständigen medicinischen Polizey, Sechster Band, Teil III: Von der Vieharzneykunde; von der Prüfung und Bestätigung der Heilkünstler, Wien 1819.

Gérardin, Auguste/Gaimard, Paul, Membres et commissaires de l'Académie Royale de Médécine, envoyé en Russie par le gouvernement Français, pour étudier le choléra: Lettres adressées à M. le comte d'Argout, - Du choléra morbus en Russie, en Prusse et en Autriche pendant les années 1831 et 1832, Paris, 1832.

Gillkrest, James: Letter VII: in: Letters on the Cholera Morbus. Containg ample evidence that this disease, under whatever name known, cannot be transmitted from the person of those labouring under it to other individuals, by contact through the medium of inanimate substances or through the medium of the atmosphere; and that all restrictions, by cordons and quarantine regulations, are, as far as it regards this disease, not merely useless, but highly injourious to the community, London, $1831,44-48$.

Greenwood: siehe im Quellenverzeichnis unter Einzelne Artikel aus Zeitschriften: The Lancet London. 
Grimm, Dr. Johann Friedrich Karl Werke von Hippocrates, aus dem griechischen übersetzt, und mit Erläuterungen, Bd. 1, Altenburg, 1781.

Gruner, Christian Gottfried: Gedanken von der Arzneiwissenschaft und den Ärzten, Beslau, 1772.

Halford, Henry [Präsident des Board of Health]: Preliminary steps advised to be taken on the first appearance of the Disease: in: dies. (Hrsg.): Papers relative to the disease calles Cholera spasmodica in India now prevailing in the north of Europe, printed by authority of the lords of his Mahesty's most hinourable privy council, London, 1831, $36-38$.

Halford, Henry [Präsident des Board of Health]: Report: in: dies. (Hrsg.): Papers relative to the disease calles Cholera spasmodica in India now prevailing in the north of Europe, printed by authority of the lords of his Mahesty's most hinourable privy council, London, 1831, $1-17$.

Hall, Benjamin: 2. Letter, General Board of Health, 6. September 1854: in: Letter of the President of the General Board of Health, London, 1855 [1854].

Hall, Benjamin: Introduction to the local authorities on preventive measures in relation to epidemic cholera, under the Nuisance Removal Acts: in: Letter of the President of the General Board of Health, to right honourable the Viscount Palmerston, Secretary of state for the home departement, according a Report Dr. Sutherland on Epidemic Cholera in the Metropolis in 1854, London, 1855, 75 - 76.

Hallé, Jean Noël/Tourtelle, Étienne: Traité d'hygiène, 4. Aufl., Paris, [1798] 1855.

Harleß, Christian Friedrich: Die Indische Cholera nach allen ihren Beziehungen, geschichtlich, pathologisch, diagnostisch, therapeutisch und als Gegenstand der Staats- und Sanitäts-Polizei, Braunschweig, 1831.

Hawley, William Henry Toovay [Assistant Poor Law Commissioner]: Report as to the Operation and effects of the Poor Law Amendment Act, in the County of Sussex, 16, Juni 1836: in: Poor Law Commissioners for England and Wales, London, 1836, $214-240$.

Hecker, August Friedrich: Allgemeine Geschichte der Arzneikunde, Leipzig, 1793.

Hecker, August Friedrich: Die Heilkunst auf ihren Wegen zur Gewissheit, oder die Theorien, Systeme und Heilmethoden der Ärzte seit Hippokrates bis auf unsere Zeiten, Erfurt, 1802.

Heine, Heinrich: Artikel VI: in: Französischen Zustände, Berichte für die Augsburger Allgemeine Zeitung 1831/32, 1833 [1832], Hamburg, 139 - 175.

House of Commons: Metropolis Water Supply Bill: in: Hansard, Thomas Curson: Hansard's parliamentary debates, third series, Band 122, 4. Juni bis 1. Juli 1852, London, 1852.

Hufelands Vorwort: in: Kant: Von der Macht des Gemüths durch den bloßen Vorsatz seiner krankhaften Gefühle Meister zu sein, Leipzig, 1824 [1797].

Hume, David: A treatise of human nature. Being an attempt to intriduce the experimental method of reasoning into Morla Subjekts. Bd. 2 von 2, London, 1817 [1739/1740].

Hume, David: An Enquiry concerning Human understanding: in: Essays and treatises on several subjects, in Bd. 2 von 2, Edinburgh, 1809 [1748], 3 - 185.

Hume, David: An Enquiry Concerning the Principles of Morals, 1751, London.

Hume, David: Of the idea of necessary connexion [1748]: in: The Philosophical Works of David Hume, in 1 von 4 Bänden, Edinburgh, 1826. 
Huszty, Zacharias Gottlieb: Diskurs über die medizinische Polizei, 1. Bd., Preßburg und Leipzig, 1786.

Instruction populaire sur le choléra asiatique, Imprimé aux frais du Gouvernement, Lausanne, 1831.

Johnson, James: [Medico-surgical Review - Epidemic Cholera] We are now arrived at the point where defensive measures were taken up by our own Government [etc.]: The Medico-chirurgical review and Journal of Practical Medicine, Neue Serie, Band 20, London, 1832, 177 - 224.

Justi, Johann Heinrich Gottlobs von: Grundsätze der Policey-Wissenschaft in einer vernünftigen, auf den Endzweck der Policey gegründeten, Zusammenhange und zum Gebrauch Academischer Vorlesungen abgefasst, Göttingen, 1756.

Kant, Immanuel: Beantwortung der Frage: Was ist Aufklärung?: in: Berlinische Monatsschrift. Dezember-Heft, Berlin, 1784, 481 - 494.

Kant, Immanuel: Der Streit der Fakultäten in drei Abschnitten: Brandt, D. Horst/ Giordanetti, Piero (Hrsg.): Mit Einleitung, Bibliographie und Anmerkung von Piero Giordanetti, Hamburg, 2005 [1789].

Kant, Immanuel: in: Sömmering, Th.: Über das Organ der Seele, Königsberg, 1796.

Kant, Immanuel: Kritik der praktischen Vernunft: in: Weischedel, Wilhelm (Hrsg.): Werke, Bd. 7/12, Frankfurt am Main, 2000 [1788].

Kant, Immanuel: Kritik der reinen Vernunft 1: in: Weischedel, Wilhelm (Hrsg.): Werke, Bd. 3/12, Frankfurt am Main, 1974 [1. Aufl. 1781, 2. Aufl.1787].

Kant, Immanuel: Kritik der reinen Vernunft 2: in: Weischedel, Wilhelm (Hrsg.): Werke, Bd. 4/12, Frankfurt am Main, 1974 [1. Aufl. 1781, 2. Aufl.1787].

Kant, Immanuel: Von der Macht des Gemüths durch den bloßen Vorsatz seiner krankhaften Gefühle Meister zu sein. Hufeland, C.W. (Hrsg.), Leipzig, 1824 [1797].

Keir: Extract from the Report on the Epidemic Disease called Cholera Morbus, which prevailed in the City of Moscow, and in other parts of Russia, in Autumn 1830, and Winter 1831: in: Board of Health (Hrsg.): Papers relative to the disease calles Cholera spasmodica in India now prevailing in the north of Europe, printed by authority of the lords of his Mahesty's most hinourable privy council, London, $1831,18-27$.

Koch, Dr. C. F: Die Cholera-Epidemie des Regierungsbezirks Merseburg im Jahre 1866. Nach amtlichen Ermittelungen: in: Engel, Ernst (Hrsg.): Zeitschrift des Königlich Preussischen Statistischen Bureaus, 8. Jahrgang, Nr. 1/2/3, Berlin, $1868,1-20$.

Kühn, Johann Friedrich: Vorwort: in: Ackermann, Johann Christian Gottlieb: Polizeylich-medizinische Miszellen, Posen/Leipzig, 1806, vii - xii.

Lalleau, Charles de: Traité de l'expropriation pour cause d'utilité publique, 1. Bd., 4. Aufl., Paris, 1845.

Lanthenas, François Xavier (Ex-Membre de la Convention Nationale et du Corps Législatif): Religion civile proposée aux républiques pour lien des gouvernements représentatifs, Paris, 1795.

Learmonth, John: Extracts from the second report of the Edinbugh board of health: in: The Cholera gazette, consisting of documents communicated by the Central Board of Health, with intelligence relative to the disease, derived from other authentic sources, 2. Aufl., London, 1832, $110-112$. 
Leibniz, Gottfried Wilhelm: Monadologie, Deutsch, mit einer Abhandlung über Leibniz' und Herbart's Theorieen des wirklichen Geschehens. Zimmermann, Norbert (Hrsg. deut. Ausgabe), Wien, 1847 [franz. 1. Ausg. 1714].

Les préfètes de la Seine et de police [Hrsg.]: Rapport sur la marche et les effets du choléra-morbus dans Paris et les communes rurales du département de la seine, par la Commission nommée, avec l'approbation de M. le ministre du commerce et des traveaux publics, année 1832, Paris, 1834.

Lincke, C. G.: Versuch das Wesen der pandemischen Cholera zu erklären, Halle, 1833.

Luce, Johann Wilhelm Ludwig von: Versuch ueber Hypochondrie und Hysterie, ein praktisches Handbuch fuer angehende Aerzte. Gerstenberg u. Dittmar, Gotha, 1797.

Macdonald: Sanitary Measures adopted at the bottle works company, Sunderland. Board of Health, Sunderland, 3d January, 1832: in: The Cholera gazette, consisting of documents communicated by the Central Board of Health, with intelligence relative to the disease, derived from other authentic sources, 2. Aufl., London, 1832, 8 - 9 .

Mackenzie, James: The history of health and the art of preserving it, 3. Aufl., Gordon, William (Hrsg.), Edinburgh, [1760]: [Nachdruck] USA, 1979.

Maclean, Charles: Remarks on the British quarantine laws: And the so-called sanitary laws of the continental nations of Europe, especially those of Spain, London, 1823.

Maclean, W. [Central Board of Health Council Office]: Important sanitary Recommendations: in: The Cholera gazette, consisting of documents communicated by the Central Board of Health, with intelligence relative to the disease, derived from other authentic sources, 2. Aufl., London, 1832, $19-35$.

Maclean, W. [Central Board of Health Council Office]: Queries issued by the central board of health: in: The Cholera gazette, consisting of documents communicated by the Central Board of Health, with intelligence relative to the disease, derived from other authentic sources, 2. Aufl., London, 1832, $45-47$.

Macnamara, Nokidge Charles: A history of asiatic cholera, London, 1876.

Magendie, M. François: Leçons sur le choléra-morbus, Paris, 1832.

Mahon, Pierre-Augustin-Olivier: Médecine légale, et police médicale, 3. Bd., Paris, 1811.

Malthus, Thomas: An Essay on the Principle of Population, as it Affects the Future Improvement of Society, with Remarks on the Speculations of Mr. Godwin, M. Condorcet, and Other Writers. Johnson, J. (Hrsg.), London, 1798.

Marcus, Adalbert Friedrich: Beyträge zur Erkenntniß und Behandlung des gelben Fiebers, Jena, 1805.

Mecklenburg, ... [Königl. Preuss. Kreis -Physikus in Deutsch-Crone]:Was mag die Sanitäts-Polizei gegen die Cholera? Nach einigen Erfahrungen beantwortet, Berlin, 1854.

Metzger, Johann Daniel: Handbuch der Staatsarzeneykunde enthaltend die medicinische Policey und die gerichtliche Arzneywissenschaft, Züllichau, 1787.

Mill, John Stuart: On Liberty, Kitchener/Kanada, 2001 [1859]. 
Ministère de l'agriculture et du commerce: Services sanitaires extérieurs: in: Recueil des travaux du comité consultatif d'hygiène de France et des actes officiels de l'administration sanitaire, 2. Band, Paris, 1881.

Ministre de l'agriculture et du commerce et des travaux publique (Hrsg.): Comité consultatif d'hygiène publique, Instruction relative à une enquête dur la marche et les effets du choléra épidémique en France: in: Documents statistiques et administratifs concernant l'épidémie de choléra de 1854, comparée aux précédentes épidémies cholériques qui ont sévi en France, publié par ordre et sous les auspices de son excellence le ministre de l'agriculture du commerce et des travaux publics, Paris, 1962.

Ministre de l'agriculture et du commerce et des travaux publique (Hrsg.): Documents statistiques et administratifs concernant l'épidémie de choléra de 1854, comparée aux précédentes épidémies cholériques qui ont sévi en France, publié par ordre et sous les auspices de son excellence le ministre de l'agriculture du commerce et des travaux publics, Paris, 1962.

Ministre de l'agriculture et du commerce et des travaux publique (Hrsg.): Instructions sur les mesures à prendre en vue de la réapparition du choléra: in: Documents statistiques et administratifs concernant l'épidémie de choléra de 1854, comparée aux précédentes épidémies cholériques qui ont sévi en France, publié par ordre et sous les auspices de son excellence le ministre de l'agriculture du commerce et des travaux publics, Paris, 1962.

Moir, D. M.: To the President of the central board of health [London, Musselburgh, Jan. 20th, 1832]: in: The Cholera gazette, consisting of documents communicated by the Central Board of Health, with intelligence relative to the disease, derived from other authentic sources, 2. Aufl., London, 1832, $67-68$.

Monod, Henri [Directeur de l'Assistance et de l'Hygiène publique, ancien Préfet du Finistère: Le Choléra. Histoire d'une Épidémie, Finistère, Paris, 1885 - 1886, 1892.

Montaigne, Michel: De l'institution des enfants: in: Essais de Montaigne, Paris, 1834 [1580].

Müller, E.H. (Geheimer Medicinal- und Regierungsrath): Cholera-Epidemie zu Berlin im Jahre 1873, Amtlicher Bericht, Berlin, 1874.

Muralt, Johann von: Hippocrates Helveticus, oder der Eydgenössische Stadt-, Landund Hauss-Artzt, Basel, 1692.

Musset-Pathay: Avis de l'éditeur: in: Rousseau, Jean Jacques: Émile, Oeuvres complètes de J.J. Rousseau, Nouvelle Édition, Bd. 1, Brüssel, 1827.

Nasse, Christian Friedrich: Von der Stellung der Aerzte im Staate, Leipzig, 1823.

Nouveau Plan de constitution pour la médicine en france, présenté à l'Assemblée Nationale par la Société royale de Médicine, Paris, 1790.

Orton, Reginald [Surgeon]: An essay on the epidemic cholera of India, with a Supplement, 2. Aufl., London, 1831 [Madras, 1820].

Osterhausen, Johann Karl : Ueber medicinische Aufklärung, Bd. 1 - 2, Zürich, 1798.

Ottawa-Charta zur Gesundheitsförderung, 1986 [Ottawa Charter for Health Promotion, 1986, Erste Internationale Konferenz über Gesundheitsförderung, Ottawa, Kanada, 17.-21. November 1986], WHO-autorisierte Übersetzung: Hildebrandt/ Kickbusch auf der Basis von Entwürfen aus der DDR und von Badura sowie 
Milz. 02.12.2014, http://www.euro.who.int/de/publications/policy-documents/ ottawa-charter-for-health-promotion,-1986 (25.10.2016).

Pettenkofer, Max: Die Verbreitungsart der Cholera in Indien. Ergebnisse der neuesten aetiologischen Untersuchungen in Indien, München, 1871.

Pettenkofer, Max von: Ueber Cholera, mit Berücksichtigung der jüngsten Choleraepidemie in Hamburg. Münchener Medizinische Abhandlungen: siehe im Quellenverzeichnis unter Einzelne Artikel aus Zeitschriften: Münchener Medizinische Wochenschrift.

Pettenkofer, Max: Ueber Cholera: mit Berücksichtigung der jüngsten Choleraepidemie in Hamburg, München, 1892.

Préfet de Police [Hrsg.]: Journal des Commissions sanitaires établies dans le département de la Seine, contenant les travaux de ces commissions, les actes décisions et instructions de l'administration qui leur sont relatifs (hebdomadaire), publié sous les auspices de M. le Préfet de Police, Paris, 3.12. 1831 bis August 1832.

Proust, Adrien [Hrsg.]: L'Orientation nouvelle de la politique sanitaire. Conférences sanitaires internationales (Venise-Dresde-Paris). Règlement de police sanitaire maritime de 1895, Paris, 1896.

Proust, Adrien [Hrsg.]: Le choléra. Étiologie et Prophylaxie. Ouvrage accompagné d'une carte représentant la marche des épidémies et suivi de l'instruction populaire sur les précautions d'hygiène à prendre en cas d'épidémie, Paris, 1883.

Pruner-Bey, Franz Ignaz: Die Weltseuche Cholera oder die Polizei der Natur, Erlangen, 1851.

Pym: siehe im Quellenverzeichnis unter Einzelne Artikel aus Zeitschriften: The Lancet London.

Raisson, Horace: Histoire de la Police de Paris, Paris, 1844.

Réveillé-Parisé, Joseph Henri Gabriel: Physiologie et Hygiène des Hommes livrés aux travaux de l'esprit, ou Recherches sur le Physique et le Moral, les Habitudes, les Maladies et le Régime des Gens de Lettres, Artistes, Savants, Homme d'État, Jurisconsultes, Administrateurs, etc., 1. Bd., Paris, 1834.

Richter [Pseudonym für Dr. Carl Westphal]: Vollständiges Handbuch der Diätetik, oder die Kunst Leben und Gesundheit zu erhalten. Ein allgemeines Tischbuch, welches die Beschaffenheit und Verdaulichkeit aller Speisen und Nahrungsmitteln angiebt. Ein rathender Arzt bei fast allen Krankheits-Vorfällen usw. Verlag der rnstlichen Buchhandlung, Quedlinburg und Leipzig, [ca. um 1820], 81 - 82.

Roberton, John, M. D.: A Treatise on Medical Police, and on Diet, Regimen, \&c. In which the permanent and regularly recur. Ring causes of disease in general, and those of Edinburgh and London in particular, are described; with a general plan of medical police to obviate them, and a particular one adapted to the local circumstances of these cities. 2 Bde., London, 1809.

Rousseau, Jean Jachques: Emil oder über die Erziehung I.-IV.: deutsche Fassung von: Esterhues, Josef (Hrsg.), Paderborn, 1958 [1762].

Rousseau, Jean Jacques: Émile Euvres complètes. Musset-Pathay (Hrsg.), Bd. 1, Brüssel, 1827 [1762].

Russell, Barry: Extract from the joint Report, St. Petersburgh, July, 1831: in: Board of Health (Hrsg.): Papers relative to the disease calles Cholera spasmodica in India now prevailing in the north of Europe, printed by authority of the lords of his Mahesty's most hinourable privy council, London, 1831, 28 - 35 . 
Sachs, Albert: Tagebuch über das Verhalten der bösartigen Cholera in Berlin. Eine Sammlung von Aufsätzen phatologisch-therapeutischen, gesundheits-polizeilichen und populär-medicinischen Inhalts in Bezug auf den Verlauf der Epidemie, Berlin, 1831.

Sandras, Stanislas (Professeur agrégé à la faculté de médecine de Paris, membres de la Commission envoyée en Pologne par le gouvernement pour étudier le choléra morbus): Du choléra épidémique observé en Pologne, en Allemagne et en France, avec quelque remarques sur les mesures prises par l'administration, et quelque conseilles à l'autorité, aux gens du monde et aux médecins, Paris, 1832.

Schelling, Friedrich W. J.: Entwurf eines Systems der Naturphilosophie. Oder: Ueber den Begriff der speculativen Physik und die innere Organisation eines Systems dieser Wissenschaft, Leipzig/Jena, 1799.

Smith, Adam: An Inquiry into the Nature and Causes of the Wealth of Nations. Soares, S. M. (Hrsg.). MetaLibri Digital Library, 2007 [1776] www.ibiblio.org/ml/ libri/s/SmithA_WealthNations_p.pdf (18.06.2012).

Snow, John: Verbreitungsweise der Cholera, zweite vermehrte Ausgabe, London, 1855 [1854]. Aus dem Englischen übertragen von Dr. A.F.W. Assmann, Quedlinburg, 1856.

Société Royale de Médecine: Nouveau plan de constitution pour la médecine en France: présenté à l'Assemblée Nationale, Paris, 1790.

Société Royale der Médecine: Histoire de la Société Royale de Médecine, Année 1776, Avec les Mémoires de Médecine \& de Physique Médicale, pour la même Année, Tirés des Registres de cette Société, Paris, 1779.

Stephenson, Geo. [Sek., Board of Health, Sunderland]: Treatment of Vagrants and Removal of Paupers: in: The Cholera gazette, consisting of documents communicated by the Central Board of Health, with intelligence relative to the disease, derived from other authentic sources, 2. Aufl., London, 1832, 70 - 71.

Steuart, James: An Inquiry into the Principles of Political Economy, being an Essay on the Science of Domestic Policy in Free Nations in which are particularly considered Population, Agriculture, Trade, Industry, Money, Coin, Interest, Circulation, Banks, Exchange, Public Credit, and Taxes, in 1/2 Bd., London, 1767.

Sutherland, J.: Report: in: Letter of the President of the General Board of Health, to right honourable the Viscount Palmerston, Secretary of state for the home departement, according a Report Dr. Sutherland on Epidemic Cholera in the Metropolis in 1854, London, 1855, $19-71$.

Sutherland, John: Report of the General Board of Health on the epidemic cholera of 1848 \& 1849, Presented to both Houses of Parliament by Command of Her Majesty, London, 1850.

Sydenham, Thomas [1670]: Of the Cholera Morbus of the Year 1669: in: Robinson, G. G. J. and J. (Hrsg.): The works of Thomas Sydenham, on acute and chronic diseases; wherein their histories and modes of cure, as recited by him, are delivered with accuracy and perspicuity. To which are subjoined notes, corrective and explanatory, from the most eminent medical writers; adapting the whole to the present improved state of physic, and shewing under what classes, orders, and genera, most of the complaints treated of are arranged by nosologists: with a variety of annotations, 1. Bd., London, 1788, $218-224$.

Tissot, Samuel Auguste André David: Avis au peuple sur sa santé, Lyon, 1876. 
Tissot, Samuel Auguste André David: L'Onanisme: dissertation sur les maladies produites par la masturbation, Paris, 1810.

Vicq-d'Azyr, Félix: Exposé des moyens curatifs et préservatifs contre les maladies pestilentielles des bêtes à cornes. Publié par ordre du Roi, chez Mérigot l'aîné, Paris, 1776.

White, W.: Treatise on cholera morbus; the method of treatment, and means of prevention. Dedicated to his Imperial Majesty, the Emperor of Russia, 2. Aufl., London, 1834 [1831].

Wurtz, Adolphe/Bouley/Brouardel/Du Mesnil/Durand-Claye/Ch. Girard/Grancher/ Koechlin-Schwartz/Lereboullet/Levraud/Liouville/Martin/Napias/Pabst/Pozzi/ Proust/Rochard/Siredey/Thévenot/Émile Trélat/Vidal/Walther/Vallin: Instruction populaire sur les précautions d'hygiène privée et les mesures d'hygiène à prender en cas d'épidémie de choléra, au nom d'une Commission composée de [...]: in: Proust, Adrien [Hrsg]: Le choléra. Étiologie et Prophylaxie. Ouvrage accompagné d'une carte représentant la marche des épidémies et suivi de l'instruction populaire sur les précautions d'hygiène à prendre en cas d'épidémie, Paris, 1883.

\section{LITERATUR}

Ackerknecht Erwin H. (2009 [1948]): Anticontagionism between 1821 and 1867 [The Fielding H. Garrison Lecture]: in: Bulletin of the History of Medicine Nr. 22, 1948, 562 - 593. Abridged and with portions translated. Reprinted with permission by: International Journal of Epidemiology, 7 - 21 .

Aisenberg, Andrew R. (1999): Contagion. Disease, Governemet, and the »Social Question « in Nineteenth-Century France, Standfort, California.

Arendt, Hannah (2010 [1958]): Vita Activa oder Vom tätigen Leben, Zürich u. München.

Baldwin, Peter (1999): Contagion and the State in Europe 1830 - 1930, New York.

Bauman, Zygmunt (2003): Flüchtige Moderne, 1. Aufl., Frankfurt am Main.

Beck-Gernsheim, Elisabeth (1994): Gesundheit und Verantwortung im Zeitalter der Gentechnologie, in: Beck, Ulrich/Beck-Gernsheim, Elisabeth (Hrsg.), Riskante Freiheiten: Individualisierung in modernen Gesellschaften, 1. Aufl., Frankfurt am Main, 316 - 335.

Beck, Ulrich/Beck-Gernsheim, Elisabeth (Hrsg.) (1994): Riskante Freiheiten: Individualisierung in modernen Gesellschaften, 1. Aufl., Frankfurt am Main.

Bohlender, Matthias (2007): Metamorphosen des liberalen Regierungsdenkens, Mannheim.

Bourdelais, Patrice/Raulot, Jean-Yvres (1987): Une Peur Bleue: Histoire du Choléra en France 1832 - 1854, Paris.

Brown, Theodore M./Fee, Elizabeth (2004): Editorials. A Role for Public Health History: in: American Journal of Public Health, Band 94: Nr. 11, November 2004, 1851 - 1853.

Bröckling, Ulrich/Lemke, Thomas/Krasmann, Susanne (2000): Gouvernementalität, Neoliberalismus und Selbsttechnologien: in: dies. (Hrsg.): Gouvernementalität der Gegenwart. Studien zur Ökonomisierung des Sozialen, Frankfurt am Main, 7 -40 . 
Bynum, William F.(1993): Policing Hearts of Darkness: Aspects of the International Sanitary Conferences: in: History and Philosophy of the Life Sciences, Band 15: Nr. 3, 1993, $421-434$.

Carroll, Patrick E. (2002): Medical Police and the History of Public Health: in: Medical History, Band 46: Nr. 4, Oktober 2002, $461-494$.

Chevalier, Louis (2002 [1958]): Classes laborieuses et classes dangereuses à Paris pendant la première Moitié du XIXe siècle, Paris.

De Montbas, Hugues: La Police Parisienne Sous Louis XVI, 1949, Paris.

Delaunay, Dr. Paul (1933) (Membre de la Société Français d'histoire de la médecine): Le Corps Médical et le Choléra en 1832, Paris.

Dettke, Barbara (1995): Die asiatische Hydra. Die Cholera von 1830/31 in Berlin und den preußischen Provinzen, Posen, Preußen und Schlesien, Berlin/New York.

Dietz, Bernhard/Neumaier, Christopher/Rödder, Andreas (2014): Gab es den Wertewandel?: Neue Forschungen zum gesellschaftlich-kulturellen Wandel seit den 1960er Jahren, München.

Doering-Manteuffel, Anselm/Raphael, Lutz (2008): Nach dem Boom: Perspektiven auf die Zeitgeschichte seit 1970, Göttingen.

Duden, Barbara (1990): Körpergeschichte. Reihe Tandem-Kultur- und Sozialgeschichte, 1, Wolfenbüttel.

Fee, Elizabeth (1993): Introduction - Public Health, Past and Present: A Shared Social Vision: in: George Rosen (Hrsg.): A History of Public Health - Expended Edition, The John Hopkins University Press, Baltimore u. London, ix - lxvii.

Filippini, Nadia Maria (2002): Die »erste Geburt« Eine neue Vorstellung vom Fötus und vom Mutterleib (Italien, 18. Jahrhundert): in: Duden, Barbara/Schlumbohm, Jürgen (Hrsg.): Geschichte des Ungeborenen. Zur Erfahrungs- und Wissenschaftsgeschichte der Schwangerschaft, 17. - 20. Jahrhundert, Berlin, 99 - 127.

Foucault, Michel (1988 [1976]): Archäologie des Wissens, übers. von Köppen, Ulrich, Frankfurt am Main.

Foucault, Michel (1992 [1967]): Andere Räume: in: Barck, Karlheinz u.a. (Hrsg.): Aisthesis. Wahrnehmung heute oder Perspektiven einer anderen Ästhetik, Leipzig, $34-46$.

Foucault, Michel (1992 [1973]): Wahnsinn und Gesellschaft, übers. von Köppen, Ulrich, Frankfurt am Main.

Foucault, Michel (1994 [1974]): La naissance de la médecine social: in: ders.: Dits et Écrits II, Paris, 207 - 228.

Foucault, Michel (1997 [1976]): Der Wille zum Wissen. Sexualität und Wahrheit I, übers. von Raulff, Ulrich/Walter, Seitter, Frankfurt am Main.

Foucault, Michel (1998 [1984]): Der Gebrauch der Lüste. Sexualität und Wahrheit II, übers. von Raulff, Ulrich/Seitter, Walter, Frankfurt am Main.

Foucault, Michel (2000 [1978]): Die »Gouvernementalität«, übers. von Gondek, Hans-Dieter: in: Bröckling, Ulrich/Lemke, Thomas/Krasmann, Susanne (Hrsg.): Gouvernementalität der Gegenwart. Studien zur Ökonomisierung des Sozialen, Frankfurt am Main, $41-68$.

Foucault, Michel (2001 [1968]): Ärzte, Richter und Hexer im 17. Jahrhundert, übers. von Bischoff, Michael: in: ders.: Schriften in vier Bänden. Dits et Ecrits, Bd. I: 1954 - 1969, Frankfurt am Main, 958 - 973. 
Foucault, Michel (2001 [1968]): Religiöse Abweichung und medizinisches Wissen [übers. von Bischoff, Michael]: in: ders.: Schriften in vier Bänden. Dits et Ecrits, Bd. I: 1954 - 1969, Frankfurt am Main, 798 - 811.

Foucault, Michel (2001 [1970]): Die Ordnung des Diskurses, übers. von Seitter, Walter, Frankfurt am Main.

Foucault, Michel (2001 [1975 - 76]): In Verteidigung der Gesellschaft. Vorlesungen am Collège de France, übers. von Ott, Michaela, Frankfurt am Main.

Foucault, Michel (2001 [1978]): La »gouvernementalité«: in: ders.: Dits et Écrits II, Paris, $635-657$.

Foucault, Michel (2001 [1978]): La philosophie analytique de la politique: in: ders.: Dits et Écrits II, Paris, 534 - 551.

Foucault, Michel (2001 [1978]): La scène de la philosophie: in: ders.: Dits et Écrits II, Paris, $571-595$.

Foucault, Michel (2001[1980]): La poussière et le nuage: in: ders.: Dits et Écrits II, Paris, $829-838$.

Foucault, Michel (2002 [1971]): Nietzsche, die Genealogie, die Historie, übers. von Bischoff, Michael: in: ders: Schriften in vier Bänden. Dits et Ecrits, Bd. II: 1970 - 1975, Frankfurt am Main, 166 - 191.

Foucault, Michel (2002 [1972]): Die wesentlichen Funktionen der Medizin in unserer Gesellschaft, übers. von Gondek, Hans-Dieter: in: ders.: Schriften in vier Bänden. Dits et Ecrits, Bd. II: 1970 - 1975, Frankfurt am Main, 474 - 476.

Foucault, Michel (2003 [1974]): Die Geburt der Sozialmedizin (Vortrag), übers. von Gondek, Hans-Dieter: in: ders.: Schriften in vier Bänden. Dits et Ecrits, Bd. III: 1976 - 1979, Frankfurt am Main, 272 - 298.

Foucault, Michel (2003 [1974]): Die Wahrheit und die juristischen Formen, übers. von Bischoff, Michael, Frankfurt am Main.

Foucault, Michel (2003 [1979]): Krise der Medizin oder Krise der Antimedizin?, übers. von Gondek, Hans-Dieter: in: Michel Foucault: Schriften in vier Bänden. Dits et Ecrits, Bd. III: 1976 - 1979, Frankfurt am Main, 54 - 76.

Foucault, Michel (2004 [1977 - 1978]): Geschichte der Gouvernementalität I. Sicherheit Territorium, Bevölkerung. Vorlesung am Collège de France. Hrsg. von Sennelart, Michel, übers. von Brede-Konersmann, Claudia/Schröder, Jürgen, Frankfurt am Main.

Foucault, Michel (2004 [1978 - 1979]): Geschichte der Gouvernementalität II. Die Geburt der Biopolitik. Vorlesung am Collège de France 1977 - 1978, Sennelart, Michel (Hrsg.), übers. von Schröder, Jürgen, Frankfurt am Main.

Foucault, Michel (2005 [1979]): »Omnes et singulatim« Zu einer Kritik der politischen Vernunft, übers. von Schröder, Jürge: in: ders.: Schriften in vier Bänden. Dits et Ecrits, Bd. IV: 1980 - 1988, Frankfurt am Main, 165 - 198.

Foucault, Michel (2005 [1980]): Gespräch mit Ducio Trombadori, übers. von Brühmann, Horst: in: Michel Foucault: Schriften in vier Bänden. Dits et Ecrits, Bd. IV: 1980 - 1988, Frankfurt am Main, $51-119$.

Foucault, Michel (2005 [1981]): Die Maschen der Macht, übers. von Bischoff, Michael: in: ders.: Schriften in vier Bänden. Dits et Ecrits, Bd. IV: 1980 - 1988. Frankfurt am Main, $224-244$. 
Foucault, Michel (2005 [1982]): Die politische Technologie der Individuen, übers. von Bischoff, Michael: in: ders.: Schriften in vier Bänden. Dits et Ecrits, Bd. IV: 1980 - 1988, Frankfurt am Main, 999 - 1015.

Foucault, Michel: (2005 [1983]): Ein endliches System angesichts einer unendlichen Nachfrage, in: ders: Schriften in vier Bänden. Dits et Ecrits, Bd. IV: 1980 - 1988, Frankfurt am Main, 440 - 461.

Foucault, Michel (2005 [1982]): Raum, Wissen und Macht, übers. von Bischoff, Michael: in: ders: Schriften in vier Bänden. Dits et Ecrits, Bd. IV: 1980 - 1988. Frankfurt am Main, 324 - 341 .

Foucault, Michel (2005 [1982]): Subjekt und Macht, übers. von Bischoff, Michael: in: ders: Schriften in vier Bänden. Dits et Ecrits, Bd. IV: 1980 - 1988, Frankfurt am Main, 269 - 294.

Foucault, Michel (2005 [1983]): Zur Genealogie der Ethik. Ein Überblick über die laufende Arbeit [übers. von Gondek, Hans-Dieter]: in: ders.: Schriften in vier Bänden. Dits et Ecrits, Bd. IV: 1980 - 1988, Frankfurt am Main, 461 - 498.

Foucault, Michel (2005 [1984]): Die Rückkehr der Moral, übers. von Gondek, HansDieter: in: Michel Foucault: Schriften in vier Bänden. Dits et Ecrits, Bd. IV: 1980 - 1988, Frankfurt am Main, 859 - 873.

Foucault, Michel (2005 [1984]): Was ist Aufklärung?, übers. von Gondek, HansDieter: in: Michel Foucault: Schriften in vier Bänden. Dits et Ecrits, Bd. IV: 1980 - 1988, Frankfurt am Main, 687 - 707.

Foucault, Michel (2008 [1963]): Die Geburt der Klinik, übers. von Seitter, München.

Foucault, Michel (2009 [1982 - 1983]): Die Regierung des Selbst und der anderen I. Vorlesungen am Collège de France, übers. von Schröder, Jürgen, Frankfurt am Main.

Foucault, Michel (2010 [1983 - 1984]): Der Mut zur Wahrheit - Die Regierung des Selbst und der Anderen II. Vorlesungen am Collège de France, übers. von Schröder, Jürgen, Berlin.

Gehring, Petra (2004): Die Philosophie im Archiv, Frankfurt am Main.

Gehring, Petra (2006): Was ist Biomacht? Vom zweifelhaften Mehrwert des Lebens, Frankfurt am Main.

Giordanetti, Piero (2005): Einleitung: in: Kant, Immanuel [1789]: Brandt, D. Horst/ Giordanetti, Piero (Hrsg.): Der Streit der Fakultäten in drei Abschnitten. Mit Einleitung, Bibliographie und Anmerkung von Piero Giordanetti, Hamburg.

Greco, Monica (2000): Homo Vacuus. Alexithymie und das neoliberale Gebot des Selbstseins: in: Lemke, Thomas/Krasmann, Susanne. (Hg.): Gouvernementalität der Gegenwart. Studien zur Ökonomisierung des Sozialen, Frankfurt am Main, $265-287$.

Harrison, Mark (1994): Public Health in British India: Anglo-Indian Preventive Medicine 1859 - 1914, Cambridge.

Harrison, Mark (2004): Disease and Modern World. 1500 to the Present Day, Cambridge [u.a.].

Harrison, Mark (2006): Disease, diplomacy and international commerce: the origins of international sanitary regulation in the nineteenth century: in: Journal of Global History, Nr. 1, 2006, London School of Economics and Political Science (Hrsg.), London, $197-217$. 
Harrison, Mark (2010): Medicine in an Age of Commerce and Empire. Britain ans its Tropical Colonies, 1660 - 1830, Oxford/New York.

Howard-Jones, Norman (1975): The scientific background of the International Sanitary Conferences 1851 - 1938. History of international Public Health, Nr. 1, 1975, World Health Organization (Hrsg.), Genf.

Huber, Valeska (2006): The unification of the globe by disease? The international sanitary conferences on cholera, 1851 - 1894: in: The Historical Journal, Band 49, Nr. 2, 2006, Cambridge, 453 - 476.

Hurrelmann, Klaus/Razum, Oliver (2012): Handbuch Gesundheitswissenschaften. 5., vollständig überarbeitete Aufl., Weinheim.

Johanson, Peter Vinten/Brody, Howard/Paneth, Nigel/Rachman, Stephen/Rip, Michael (2003): Cholera, Chloroform, and the Science of Medicine. A life of John Snow, New York.

Jorland, Gérard (2010): Une société à soigner: Hygiène et salubrité publiques en France au XIXe siècle, Paris.

Kerchner, Brigitte (2006): Wirklich Gegendenken. Politik analysieren mit Michel Foucault: in: Dies./Schneider, Silke (Hrsg.) Foucault: Diskursanalyse der Politik. Eine Einführung, Wiesbaden, 145 - 164.

Kickbusch, Ilona (2007): Health Governance: The Health Society: in: McQueen, David V./Abel, Thomas/Balbo, Laura/Kickbusch, Ilona/Pelikan, Jürgen M./Potvin, Louise (Hrsg.), Health and Modernity: The Role of Theory in Health Promotion, New York, $144-161$.

Koppelin, Frauke/Müller, Rainer (2010): Gesundheit und Krankheit in »biopolitischen Zeiten«: in: Paul, Bettina/Schmidt-Semisch, Henning (Hrsg.), Risiko Gesundheit, Wiesbaden, 73-87.

Krasmann, Susanne (2003): Die Kriminalität der Gesellschaft. Zur Gouvernementalität der Gegenwart, Konstanz.

Kudlick, Catherine J. (1996): Cholera in Post-Revolutionary Paris, a Cultural History, Berkeley.

Labisch, Alfons (1992): Homo Hygienicus - Gesundheit und Medizin in der Neuzeit, Frankfurt am Main/New York.

Landwehr, Achim: Rezension zu: Sarasin, Philipp: Geschichtswissenschaft und Diskursanalyse. Frankfurt am Main 2003, in: H-Soz-u-Kult, 21.10.2003, <http://hsoz kult.geschichte.hu-berlin.de/rezensionen/2003-4-041> (06.01.2013).

Latour, Bruno (2002): Die Hoffnung der Pandora, übers. Roßler, Gustav, Frankfurt am Main.

Lemke, Thomas (2000): Die Regierung von Risiken. Von Eugenik zur genetischen Gouvernementalität: in: Bröckling, Ulrich/Lemke, Thomas/Krasmann, Susanne. (Hrsg.): Gouvernementalität der Gegenwart. Studien zur Ökonomisierung des Sozialen, Frankfurt am Main, 227 - 264.

Lindemann, Gesa (1993): Das paradoxe Geschlecht. Transsexualität im Spannungsfeld von Körper, Leib und Gefühl, Frankfurt an Main.

Lindemann, Mary (2010): Medicine and Society in Early Modern Europe, 2. Aufl., Cambridge.

Loudon, Irvine (1992): Medical practitioners 1750 - 1850 and the period of medical reform in Britain: in: Wear, Andrew (Hrsg.): Medicine in Society, Historical Essays, Cambridge. 
Manigon, Carmen M. (2011): >Give them practical lessons <: Catholic women religious and the transmission of nursing knowledge in late nineteenth-century England: in: Dinges, Martin/Jütte, Robert: The transmission of health practices (c. 1500 to 2000), Institut für Geschichte der Medizin, Stuttgart, 89 - 104.

Maset, Michael (2002): Diskurs, Macht und Geschichte. Foucaults Analysetechniken und historische Forschung, Frankfurt am Main.

McLean, David (2006): Public Health and Politics in the Age of Reform. Cholera, the State and the Royal Navy in Victorian Britain. International Library of Historical Studies 33, London/New York.

McQueen, David V./Kickbusch, Ilona (2007): Introduction. Health Promotion: The Origins of the Third Public Health Revolution Leading to a New Public Health: in: McQueen, David V./Abel, Thomas/Balbo, Laura/Kickbusch, Ilona/Pelikan, Jürgen M./Potvin, Louise (Hrsg.), Health and Modernity: The Role of Theory in Health Promotion, New York.

Merson, Michael H./Black, Robert E./Mills, Anne J. (2001): Introduktion: in: dies. (Hrsg.): International Public Health - Diseases, Programs, Systems, and Policies, Gaithersburg.

MEW - Marx, Karl/Engels, Friedrich (1974): Werke, 7. unveränderte Aufl., Berlin.

Mortimer, Ian (2009): The dying and the doctors. The medical revolution in seventeenth century England, The Royal Historical Society (Hrsg.), London.

Open Collections Program: Contagion, International Sanitary Conferences: http:// ocp.hul.harvard.edu/contagion/sanitaryconferences.html (03. Januar 2013).

Opratko, Benjamin (2012): Hegemonie: Politische Theorie nach Antonio Gramsci, Münster.

Palfner, Sonja (2006): Werkzeug Aussage - Ein politikwissenschaftlicher Versuch: in: Kerchner, Brigitte/Schneider, Silke (Hrsg.) Foucault: Diskursanalyse der Politik. Eine Einführung, Wiesbaden, 210 - 230.

Pender, Stephen (2010): Subventing Disease: Anger, Passions, and the Non-Naturals: in: Vaught, Jennifer C. (Hrsg.): Rhetorics of Bodily Disease and Health in Medieval and Early Modern England, Farnham/Burlington, 193 - 218.

Porter, Dorothy (1994): Introduction: in: dies. (Hrsg.): The History of Public Health and the Modern State, Amsterdam, $1-44$.

Porter, Dorothy (1994) (Hrsg.): The History of Public Health and the Modern State, Amsterdam.

Porter, Dorothy (1999): Health, Civilization, and the State: A History of Public Health from Ancient to Modern Times, London/New York.

Porter, Roy (1992): The patient in England, c. 1660 - c. 1800: in: Wear, Andrew (Hrsg.): Medicine in Society, Historical Essays, Cambridge, $91-118$.

Porter, Roy (Hrsg.) (2001): The popularization of medicine: 1650 - 1850. Reprint, London [u.a.].

Prokla-Redaktion (2003): Editorial: Gesundheit im Neoliberalismus. Prokla, Zeitschrift für kritische Sozialwissenschaft, Heft 132 - 33. Jahrgang 2003, Nr. 3.

Ramsey, Matthew (1988): Professional and popular medicine in France, 1770 1840, the social world of medical practice, Cambridge.

Ramsey, Matthew (1994): Public Health in France: in: Porter, Dorothy (Hrsg.): The History of Public Health and the Modern State, Amsterdam, 45 - 118. 
Ramsey, Matthew (2001): The popularization of medicine in France, 1650 - 1900: in: Porter, Roy (Hrsg.), The popularization of medicine: 1650 - 1850 (Reprint), London, 97 - 133.

Rosen, George (1993 [1958]): A History of Public Health. Expanded Edition, Baltimore.

Sablowski, Thomas (2011): Die jüngste Weltwirtschaftskrise und die Krisentheorien: in: VielfachKrise, Hamburg, 29 - 44.

Said, Edward (1977): Orientalism, London.

Sarasin, Philipp (2001): Reizbare Maschinen. Eine Geschichte des Körpers 1765 1914, Frankfurt am Main.

Sarasin, Philipp (2003): Geschichtswissenschaft und Diskursanalyse, Frankfurt am Main.

Sarasin, Philipp (2005): Michel Foucault zur Einführung, Hamburg.

Sarasin, Philipp/Berger, Silvia/Hänseler, Marianne/Spörri, Myriam (Hrsg.) (2007): Bakteriologie und Moderne: Studien zur Politik des Unsichtbaren, Frankfurt am Main.

Sarasin, Philipp (2009): Darwin und Foucault, Frankfurt am Main.

Schmidt, Rainer (2002): Klopstock, Friedrich Gottlieb: Werke und Briefe. Band 2 Apparat/Kommentar. Anhang, Berlin u. Boston.

Schmidt-Semisch, Henning (2000): Selber schuld - Skizzen versicherungsmathematischer Gerechtigkeit: in: Lemke, Thomas/Krasmann, Susanne. (Hrsg.): Gouvernementalität der Gegenwart. Studien zur Ökonomisierung des Sozialen, Frankfurt am Main, 168 - 193.

Schmidt-Semisch, Henning/Paul, Bettina (2010): Risiko Gesundheit. Eine Einführung: in: Paul, Bettina/Schmidt-Semisch, Henning (Hrsg.), Risiko Gesundheit: Über Risiken und Nebenwirkungen der Gesundheitsgesellschaft, Wiesbaden, 721.

Stern, Alexandra Minna/Markel, Howard (2009): Commentary: Disease etiology and political ideology: revisiting Erwin H Ackerknecht's Classic 1948 Essay, >Anticontagionism between 1821 and 1867 <, International Journal of Epidemiology, Band 38, Nr. 1, 2. Januar: S. 31 - 33.

Stolberg-Wernigerode, Otto zu (2001): Neue deutsche Biographie, Bd.: 20, Berlin.

Strube, Julian (2016): Sozialismus, Katholizismus und Okkultismus im Frankreich des 19. Jahrhunderts, Berlin u. Boston.

Stuckler, David/Basu, Sanjay (2014): Sparprogramme töten - Die Ökonomisierung der Gesundheit. 1. Aufl., Berlin.

Trojan, Alf/Legewie, Heiner (2000): Nachhaltige Gesundheit und Entwicklung Leitbilder, Politik und Praxis der Gestaltung gesundheitsförderlicher Umweltund Lebensbedingungen. Verlag für Akademische Schriften, Frankfurt am Main.

Vereinigung zur Kritik der Politischen Ökonomie/Altvater, Elmar (2003): Gesundheit im Neoliberalismus. Prokla, Zeitschrift für kritische Sozialwissenschaft, Heft 132 - 33. Jahrgang 2003, Nr. 3, Münster.

Weber, Max (1995 [1904]): Die protestantische Ethik und der Geist des Kapitalismus, Erfstadt.

Weindling, Paul (1994): Public Health in Germany: in: Porter, Dorothy (Hrsg.): The History of Public Health and the Modern State, Amsterdam, 119 - 131. 
Weindling, Paul (1995): Introduction: constructing international health between the wars: in: Der. (Hrsg.) International health organisations and movements, 1981 1939, Cambridge, $1-3$.

Weiner, Dora B. (1993): The Citizen-Patient in Revolutionary and Imperial Paris, Baltimore.

Whaley, Russell F./Hashim, Talal J. (1995): Textbook on world health: a practical guide to global health care, New York u. London.

White, B. M. (1983): Medical police. Politics and police: the fate of John Roberton: in: Medical History, 27 (4), 407 - 422.

Wiesing, Urban: Immanuel Kant, seine Philosophie und die Medizin: in: Gerhard, Volker/Meyer, Thomas (Hrsg.): Kant im Streit der Fakultäten. 2005, Berlin u. New York, $84-116$.

Williams, David (2012): International Developement and Global Politcs. History and Practice, London.

Ziai, Aram (2003): Foucault in der Entwicklungstheorie, in: Peripherie. Zeitschrift für Politik und Ökonomie in der Dritten Welt, Band 23, Nr. 92: Gouvernementalität, $406-429$.

Zylberman, Patrick (2006): Civilizing the State: Borders, Weak States and International Health in Modern Europe: in: Bashford, Alison (Hrsg.): Medecine and at the Border. Diesease, Globalization and Security, 1850 to the Present, New York. 


\section{Politikwissenschaft}
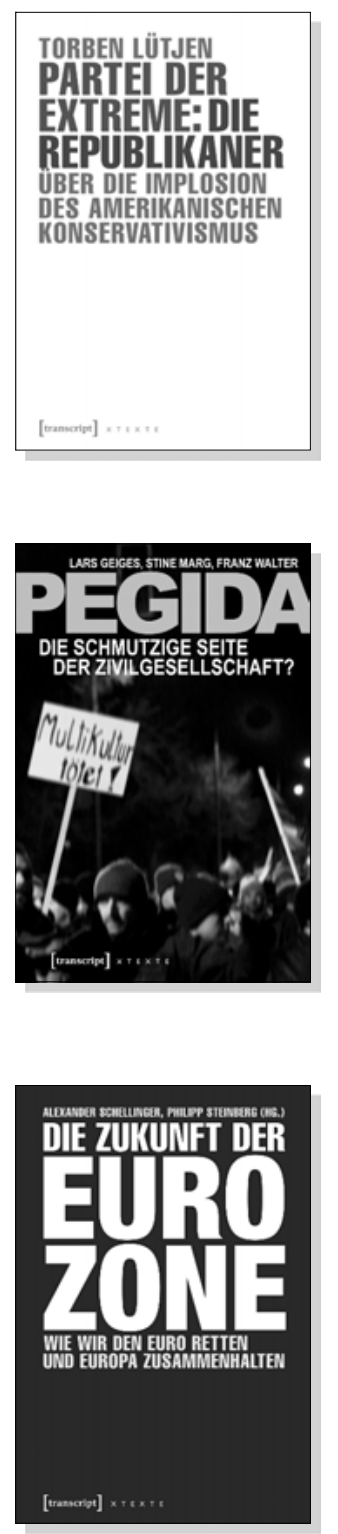

\section{Torben Lütjen}

Partei der Extreme: Die Republikaner

Über die Implosion

des amerikanischen Konservativismus

Oktober 2016, 148 S., kart., 14,99 $€(D E)$,

ISBN 978-3-8376-3609-3

E-Book: 12,99 € (DE), ISBN 978-3-8394-3609-7

EPUB: $12,99 €(\mathrm{DE})$, ISBN 978-3-7328-3609-3

Lars Geiges, Stine Marg, Franz Walter

Pegida

Die schmutzige Seite der Zivilgesellschaft?

2015, 208 S., kart., farb. Abb., 19,99€ (DE),

ISBN 978-3-8376-3192-0

E-Book: $14,99 €(D E)$, ISBN 978-3-8394-3192-4

EPUB: $14,99 €(D E)$, ISBN 978-3-7328-3192-0

Alexander Schellinger, Philipp Steinberg (Hg.)

Die Zukunft der Eurozone

Wie wir den Euro retten

und Europa zusammenhalten

Oktober 2016, 222 S., kart., 19,99 $€(D E)$,

ISBN 978-3-8376-3636-9

E-Book: $17,99 €(\mathrm{DE})$, ISBN 978-3-8394-3636-3

EPUB: $17,99 €(D E)$, ISBN 978-3-7328-3636-9 


\section{Politikwissenschaft}

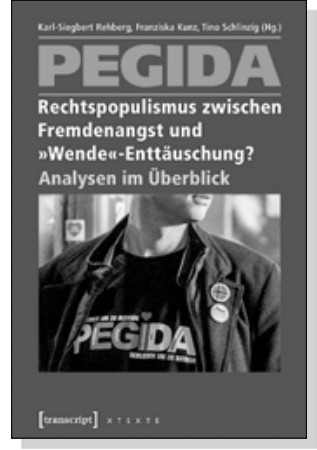

Karl-Siegbert Rehberg, Franziska Kunz,

Tino Schlinzig (Hg.)

PEGIDA - Rechtspopulismus zwischen

Fremdenangst und »Wende«-Enttäuschung?

Analysen im Überblick

September 2016, 384 S., kart., 29,99 $€(D E)$, ISBN 978-3-8376-3658-1

E-Book: 26,99 € (DE), ISBN 978-3-8394-3658-5

EPUB: $26,99 €(D E)$, ISBN 978-3-7328-3658-1

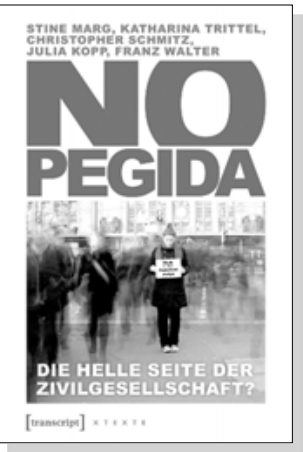

Stine Marg, Katharina Trittel, Christopher Schmitz, Julia Kopp, Franz Walter

NoPegida

Die helle Seite der Zivilgesellschaft?

März 2016, 168 S., kart., 19,99€ (DE),

ISBN 978-3-8376-3506-5

E-Book: $17,99 €(D E)$, ISBN 978-3-8394-3506-9

EPUB: $17,99 €(\mathrm{DE})$, ISBN 978-3-7328-3506-5

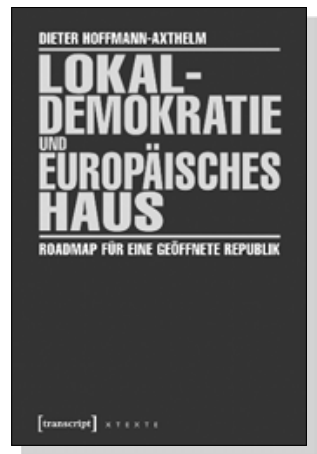

Dieter Hoffmann-Axthelm

Lokaldemokratie und Europäisches Haus

Roadmap für eine geöffnete Republik

Oktober 2016, 114 S., kart., 17,99 € (DE),

ISBN 978-3-8376-3642-0

E-Book: $15,99 €(\mathrm{DE})$, ISBN 978-3-8394-3642-4 
